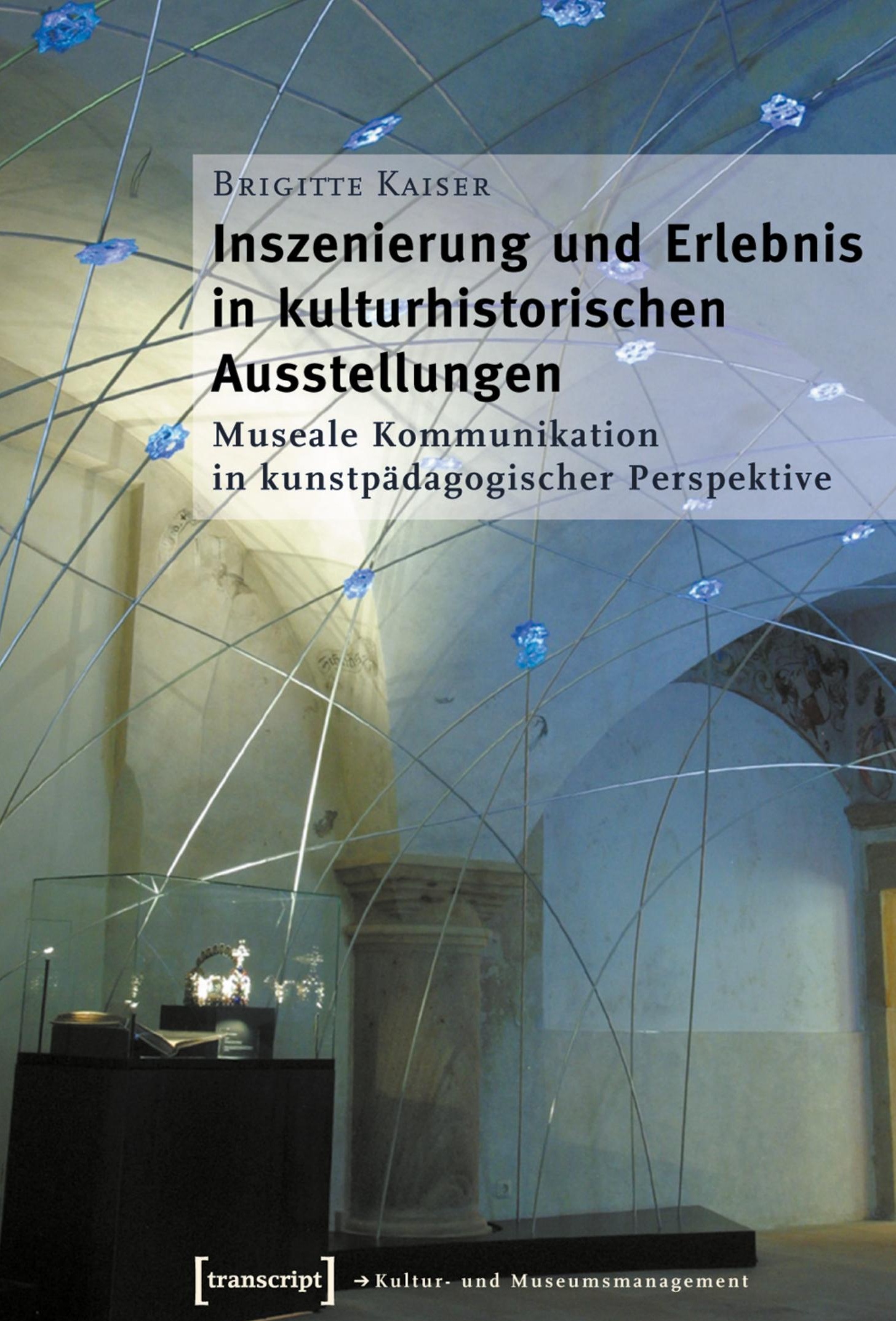


BRIGITTE KAISER

Inszenierung und Erlebnis in kulturhistorischen Ausstellungen Museale Kommunikation in kunstpädagogischer Perspektive 
Für Thomas Witter

Brigitte Kaiser (Dr. phil.) war Leiterin des Stadtmuseums in Neuötting und arbeitet jetzt freiberuflich im Bereich Ausstellungswesen und Kulturvermittlung. 
BrigitTe KaIser

\section{Inszenierung und Erlebnis in kulturhistorischen Ausstellungen}

Museale Kommunikation in

kunstpädagogischer Perspektive 
Diese Arbeit wurde im Jahr 2005 als Dissertation an der Fakultät 9 Geschichtsund Kunstwissenschaften an der Ludwig-Maximilians-Universität München angenommen.

\section{Bibliografische Information der Deutschen Bibliothek}

Die Deutsche Bibliothek verzeichnet diese Publikation in der Deutschen Nationalbibliografie; detaillierte bibliografische Daten sind im Internet über http://dnb.ddb.de abrufbar.

(C) 2006 transcript Verlag, Bielefeld

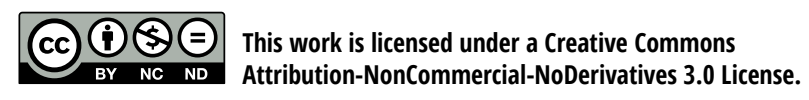

Umschlaggestaltung \& Innenlayout: Kordula Röckenhaus, Bielefeld Umschlagabbildung: Rauminstallation »Der Kaiser« in der Landesausstellung »Heinrich II. 1002-1024" in Bamberg im Jahr 2002. Foto: Christiane Kappes, München

Lektorat: Piroschka Pongratz, Weilheim

Satz: Brigitte Kaiser, München

Druck: Majuskel Medienproduktion GmbH, Wetzlar

ISBN 3-89942-452-2

Gedruckt auf alterungsbeständigem Papier mit chlorfrei gebleichtem Zellstoff.

Besuchen Sie uns im Internet: $h t t p: / / w w w . t r a n s c r i p t-v e r l a g . d e$

Bitte fordern Sie unser Gesamtverzeichnis und andere Broschüren an unter: info@transcript-verlag.de 


\section{INHAL T}

$\begin{array}{ll}\text { Dank } & 9\end{array}$

$\begin{array}{ll}\text { Einleitung } & 11\end{array}$

1 Die Ausstellung als Raumbild und die Besucher als Orte der inneren Bilder

1.1 Arbeitsdefinition Inszenierung 29

Rekonstruktive Raumbilder $\quad 40$

Abstrahierende Raumbilder $\quad 46$

1.2 Arbeitsdefinition Erlebnis 51

Erlebnisse als subjektive Bedeutungskonstruktion $\quad 52$

Besucherforschung und Ausstellungserlebnisse 54

2 Pädagogische Perspektiven musealer Kommunikation 61

2.1 Historische Erfahrung 65

Geschichtsbewusstsein 66

Historische Imagination $\quad 69$

2.2 Ästhetische Erfahrung $\quad 74$

Ästhetik und Anästhetik $\quad 75$

Ästhetische Erfahrung der Differenz $\quad 78$

2.3 Historische Erfahrung versus Ästhetische Erfahrung 81

2.4 Museale Orte als Stätten der Differenzerfahrung und Reflexion 93 
3.1 Die Gestalter der Botschaft - das Ausstellungsteam 100 Die diffuse Rolle der Museumspädagogen im Ausstellungsteam

3.2 Dimensionen kommunikativer Strategien 111 Anschaulichkeit - Verdichtung der Aussage mittels Gestaltung 112 Handlungsorientierung - die Besucherinteressen und Erfahren mit allen Sinnen

Ganzheit - Ausstellungsumwelten und ganzheitliche

Erlebnisse

Differenzierung - die Offenheit der Interpretation und die Heterogenität des Publikums

3.3 Strategien besucherorientierter Präsentationen

Narrativer Ansatz

Künstlerischer Ansatz 150

Partizipativer Ansatz

Emotionalisierung und die Rhetorik einer Ausstellung 186

Präsentation, Museumspädagogik und Ideologie

4.2 Die ökonomische Dimension

4.3 Gegenüberstellung musealer und kommerzieller Strategien

Differenzierender Kontext: Akzentuierung - Offenheit Irritation 
5 Bilder vom Mittelalter in kommerziellen und musealen Formen

5.1 Reflexionen zur Rezeption des Mittelalters 233

Das „entzweite Mittelalter“ 234

Mittelalter in zeitgenössischen, kommerziellen Präsentationen 242

5.2 Bildungstheoretische Überlegungen 250

Die Aktualität des Mittelalters 253

Mittelalterbilder in der Rezeption 255

5.3 Mittelalter in musealen Ausstellungen 260

Nostalgie - das romantische Bild 262

Schatzkammer - die Auratisierung der Objekte 268

Theatralik - die dramaturgische Inszenierung 275

6 Kunstpädagogische Analyse der Ausstellung „Kaiser Heinrich II. 1002-1024““

6.1 Darstellung der Ausstellungsanalyse 284

Das kunstpädagogische Analysekonzept 285

Die Besucherbefragung 287

6.2 Die Ausstellung „Kaiser Heinrich II. 1002-1024“ 291

Das Haus der Bayerischen Geschichte und sein

Ausstellungsteam 294

Ziele und Inhalte der Ausstellung 300

Das Präsentations- und Vermittlungskonzept 312

6.3 Analyse unter den Dimensionen kommunikativer Strategien 316 Anschaulichkeit $\quad 316$

Handlungsorientierung $\quad 329$

Ganzheit 340

Differenzierung 346 
6.4 Analyse unter den Dimensionen metakommunikativer Aspekte

Die politische Dimension

Die ökonomische Dimension

6.5 Zusammenfassung

Schlussbetrachtung

\section{Anhang}

Literaturverzeichnis

Internetquellen

Interviewleitfaden der Besucherbefragung

Abbildungsverzeichnis

Abbildungen 


\section{DANK}

Meist formt sich die Idee zu einem Dissertationsthema in einem längeren Entstehungsprozess. So war dies auch bei der Studie der Fall. Ohne die großartige Unterstützung und Hilfe Dritter hätte ich dieses Projekt nicht verwirklichen können und deshalb möchte ich allen Beteiligten hiermit meinen Dank aussprechen.

Das vorliegende Buch hat seine Wurzeln in der Stadt Neuötting und deren Stadtmuseum. Im Rahmen meiner Tätigkeit als Museumsleiterin hatte der Erste Bürgermeister Frank Springer großes Vertrauen in meine Arbeit und lies mir weitgehend freie Hand bei der Realisierung auch von manch unkonventionellem Projekt. Zu jeder Zeit Unterstützung hierbei fand ich beim Geschäftsleiter Erich Nachreiner. Bei der Verwirklichung von Konzepten halfen mir während dieser Zeit temporär sehr viele. Zahlreiche gedanklichen Auseinandersetzungen insbesondere mit Nezaket Ekici, Angie Walther und Tanja Antonini, Klaus Loichinger, Michael Naumann und Robert Graf finden sich in der Studie wieder. Kritisch reflektierte Gespräche basierend auf eigenen Erfahrungen mit der Gestaltung und Konzipierung von Ausstellungen führte ich mit Edwin Hamberger.

Einen museologischen sowie praktischen Einblick in das Thema „exhibition design" ermöglichte mir der Aufenthalt an der Reinwardt Academy in Amsterdam. Anregende, auch zum Teil kontroverse Standpunkte vertraten Han Meeter, Peter van Mensch und Wendy Westerhof, die zu weiterführendem Nachfragen anspornten.

Da das Thema Ausstellungsgestaltung bis dato in Deutschland noch wenig wissenschaftlich erforscht ist, dienten Experteninterviews dazu, neben dem Literaturstudium einen weiteren Fokus auf das zu bearbeitende Feld zu werfen. In diesem Rahmen fanden Gespräche mit Vertretern der Fachwissenschaft, der Gestaltung, der Museumspädagogik sowie der Besucherforschung statt. Besonders nennen möchte ich Prof. Dr. Diethard Herles vom Institut für Kunstwissenschaft und Bildende Kunst an der Universität Koblenz-Landau, die Mitarbeiter des Hauses der Bayerischen Geschichte mit Dr. Josef Kirmeier, Dr. Christian Lankes, Dr. Wolfgang Jahn, die Direktorin der Museen der Stadt Bamberg Dr. Regi- 
na Hanemann, den Direktor der Staatsbibliothek Bamberg Prof. Dr. Bernhard Schemmel, die Konservatorin für den Bereich „Mittelalter, Skulptur, Textil“" am Badischen Landesmuseum Karlsruhe Dr. Brigitte Herrbach-Schmidt, die Referentin für Medien- und Redaktionsarbeit am Reiss-Engelhorn-Museum in Mannheim Luisa Reiblich, das Gestaltungsbüro Gruppe Gut aus Bozen mit Alfons Demetz und Uli Prugger, das Büro Ranger Design in Stuttgart mit Kurt Ranger, die Künstlerin und Museumspädagogin Rosemarie Zacher, die Museumspädagogin Heidi Fischer, Prof. Dr. Hans-Joachim Klein vom Institut für Soziologie an der Universität Karlsruhe, die Mitarbeiter der Landesstelle für die nichtstaatlichen Museen in Bayern mit Dr. Hannelore Kunz-Ott, Dr. Albrecht A. Gribl und Georg Waldemer sowie den Leiter des MPZ München Prof. Dr. Manfred Treml.

Während der langen Phase der Entwicklung unterstützte mich mein Doktorvater Prof. Dr. Wolfgang Kehr jederzeit und gab zur passenden Gelegenheit die richtigen Impulse. Hervorheben möchte ich auch die wertvollen Diskussionen im Examens- und Doktorandenkolloquium bei meinem Zweitgutachter Prof. Dr. Ernst Rebel.

Die Hanns-Seidel-Stiftung gewährte mir durch ein Promotionsstipendium aus Mitteln des Bundesministeriums für Bildung und Forschung sowohl ideelle wie auch finanzielle Unterstützung.

Einen wichtigen Teil zur fotographischen Dokumentation der Heinrichsausstellung in Bamberg trug Christiane Kappes bei. Während der intensiven Zeit des Schreibens und des Korrigierens war mir Piroschka Pongratz eine immens große Hilfe, die trotz eigener beruflicher, anstrengender Aufgaben nicht aufhörte mich zu motivieren. Sie hat die gesamte Arbeit präzise kommentiert und korrekturgelesen. In der Schlussphase halfen mir zusätzlich Alexa Maly-Motta sowie Kathrin Hamburger. Auch meine Eltern sowie Schwestern Angelika und Christiana standen mir immer ermunternd und hilfsbereit zur Seite. Meine Töchter AnnaMaria und Marlene bewiesen Geduld, wenn sie viele Stunden auf mich verzichteten. Gleichzeitig spornten sie mich an, die Dissertation konsequent zu Ende zu führen. Sowohl im Hinblick auf alle praktischen Fragen in Bezug auf Medien- und Computerprobleme wie auch als kritischer und unnachgiebiger Diskussionspartner erwies sich mein Mann Thomas Witter als unentbehrlich. Jedoch allein in Worten lässt sich nicht sagen, wie facettenreich, hochgeschätzt und liebevoll die Hilfe von seiner Seite war.

Bei allen Genannten, wie auch bei vielen, die ich nun nicht erwähnen konnte, möchte ich mich von Herzen bedanken. 


\section{EINLEITUNG}

Die Bedeutung von Geschichte im kulturellen Leben hat seit den 1980er Jahren deutlich zugenommen. Die Gründung zahlreicher Museen, bedeutende kulturhistorische Ausstellungen und die Präsenz historischer Themen in den Medien zeugen davon. ${ }^{1}$ Der Erfolg von Großausstellungen wird durch eine enorme Besucherresonanz belegt. ${ }^{2}$ Dieses große Interesse an kulturhistorischen Ausstellungen kann auf mehrere Faktoren zurückgeführt werden. Ein wichtiger Aspekt besteht darin, dass neue Formen der Ausstellungspräsentation Themen auch für den Laien auf eine unterhaltsame Art präsentieren.

Unterstützt wird diese Neuorientierung in der Ausstellungsgestaltung zunehmend auch durch den finanziellen Druck. Dies bedeutet, dass sich Museen nicht mehr allein den fach- und wissenschaftsbezogenen Aufgaben widmen können, sondern sich auch vermehrt Fragen des Marketings und des ökonomischen, gewinnorientierten Handelns stellen müssen. ${ }^{3}$

1 Allein in Bayern sind innerhalb der vergangenen fünf Jahre 150 Neueröffnungen von Museen zu verzeichnen. Dementsprechend ist Bayern mit etwa 1150 Museen nun das museumsreichste Bundesland. Landesstelle für die nichtstaatlichen Museen in Bayern (Hrsg.): Museen in Bayern. München/Berlin, 2000. In Hinsicht auf die enorme Präsenz historischer Themen siehe auch: Füßmann, Klaus/Grütter, Heinrich Theodor/Rüsen, Jörn (Hrsg.): Historische Faszination - Geschichtskultur heute. Köln/Weimar/ Wien 1994.

2 Zahlreiche positive Pressemeldungen belegen den enormen Zuspruch in der Bevölkerung. So wurde zum Beispiel die Landesausstellung „Die Römer zwischen Alpen und Nordmeer" mit 250.000 Besuchern als voller Erfolg gewertet. Angemerkt wurde auch, dass erstmals ein Gewinn erwirtschaftet werden konnte. Krill, Hannes: Römer bereichern Rosenheim. In: Süddeutsche Zeitung vom 8. November 2000.

3 „Kultureller Konsum als Wachstumsbranche“, „Handel mit Museen“ sind Schlagworte, die in diesem Zusammenhang genannt werden können. ICOM widmete der steigenden betriebswirtschaftlichen Orientierung der Museen ein spezielles Symposium. Treff, Hans-Albert: Museen unter Rentabilitätsdruck. Engpässe - Sackgassen - Auswege. Bericht über ein internationales Symposium vom 29. Mai bis 31. Mai 1997 am Bodensee, 
Dies führt zu einer gesteigerten Orientierung an den Bedürfnissen des Besuchers. Das Vermitteln von Erlebnissen ist hier ein zentrales Element und kann dazu führen, dass die Ausstellung auf möglichst spektakuläre Weise präsentiert wird. Hier zeigt sich bereits ein erster Problemkreis. Kritiker befürchten eine Annäherung an kommerzielle Themenparks, die rein dem Konsumbedürfnis der Besucher entsprechen. ${ }^{4}$ Die Disneysierung stehe dem „Anliegen der Museen im Wege, das mit seinen Objekten dazu beitragen will, die Welt und unsere Kultur zu begreifen und Gegenwärtiges aus Vergangenem zu verstehen [...]. ${ }^{\text {5 }}$ Eine völlige Ablehnung einer neuen Präsentationsästhetik kann jedoch keine Antwort auf die veränderten Rahmenbedingungen sein. Museen müssen sich dieser Herausforderung stellen. Unter der Besinnung auf ihre Bildungsfunktion sind Ausstellungen in einer Form zu gestalten, die sowohl den Ansprüchen der Besucher als auch der Museen gerecht werden.

Will man heute Besucher erreichen, so sollten auch die veränderten Wahrnehmungsbedingungen berücksichtigt werden. Das sich langsam durchsetzende Verständnis von musealer Kommunikation beinhaltet auch, dass der Besucher mit einem Museumsbesuch positive Gefühle verbinden sollte. Auch die Besucherforschung bestätigt inzwischen, dass das Publikum in Museen freizeitorientiertes Verhalten zeigt. ${ }^{6}$ Ein weiterer Aspekt, der verändernd auf die Ausstellungspräsentation wirkt, ist die technologische Entwicklung der Neuen Medien. Dies stellt gleichzeitig eine neue Herausforderung für die Museen dar. ${ }^{7}$ Inwieweit sich dies verändernd auf die Präsentationsmöglichkeiten auswirkt und worin die Chancen und Möglichkeiten, aber auch die Schwierigkeiten liegen, kann

veranstaltet von der ICOM-Nationalkomitees Deutschlands, Österreich und der Schweiz. München 1997.

4 Herles, Diethard: Das Museum und die Dinge. Wissenschaft - Präsentation - Pädagogik. Frankfurt a. Main/New York 1996, S. 119.

5 Vgl. Vieregg, Hildegard: Kein Museum in Disneyland. Museumspädagogik in neuer Sicht - Erwachsenenbildung im Museum. Band I, Grundlagen - Museumstypen - Museologie. Baltmannsweiler 1994, S. 300.

6 Treiner, Heiner: Besucherforschung und Vermittlungsstrategien in kulturhistorischen Ausstellungen. In: Haus der Bayerischen Geschichte (Hrsg.): Kolloquiumsbericht zu den Ergebnissen der Ausstellung „Geschichte und Kultur der Juden in Bayern“. München 1991.

7 Klein, Hans-Joachim: Mediendämmerung. Die unaufhaltsame Computerisierung der Museen. Karlsruhe 1995. In diesem Buch, das im Rahmen der Karlsruher Schriften zur Besucherforschung erschienen ist, zeigen die Autoren verschiedene Forschungsperspektiven auf. 
auf breiter Basis untersucht werden. Dies eröffnet ein umfangreiches Forschungsfeld.

Eine wichtiges Bezugssystem bilden die erkenntnistheoretischen Thesen des Konstruktivismus. ${ }^{8}$ Eine Grundannahme des so genannten Radikalen Konstruktivismus, die von der Biologie über die Linguistik, Psychologie, Pädagogik bis zu den Wirtschaftswissenschaften zur Klärung ihrer jeweiligen Grundlagen herangezogen wird, ist, dass nicht entschieden werden kann, ob das, was wir wahrnehmen, einer objektiven Wirklichkeit entspricht. Geschichte zeigt sich dabei nicht als die Geschichte, vielmehr kann man eine Vielfalt der Sichtweisen auf die Vergangenheit, verschiedenste Formen der Erinnerung und differente Wahrnehmungen der Bedeutung und des Sinns von Geschichte konstatieren.

„Die großen Interpretationslinien wie ,Klasse‘; ,Geschlecht" oder ,Sozialgeschichte', die in den siebziger Jahren noch eine ungebrochene interpretative Kraft ausstrahlten, sind in ihrer Wirkung geschwächt. An ihre Stelle ist ein Patchwork von Interpretationen, Sichtweisen und divergenten Bedeutungszuschreibungen getreten, die allesamt eines eint: Relationalität.“ (Beier 2000, S. 14)

Das Interpretationsmonopol der historischen Wissenschaften wird somit relativiert und auch andere Formen der Interpretation erhalten Legitimität. Diese erkenntnistheoretischen Thesen bilden das Fundament für das Plädoyer dieser Studie, nicht nur die historische Herangehensweise zu verfolgen, sondern den Blick zu weiten und auch andere Perspektiven zuzulassen. Diese Öffnung zielt darauf, zum Beispiel auch dem Laienoder Künstlerblick Bedeutung zuzumessen.

Die Keimzelle der Idee zum Thema dieser Dissertation liegt in Neuötting und dessen Stadtmuseum. Nach meinem Staatsexamen übernahm ich dort die Leitung des historischen Museums. Ein Aufgabenschwerpunkt

8 Der Konstruktivismus ist eine Erkenntnistheorie mit einer langen erkenntnistheoretischen Tradition. Sie ist keine Wissenschaftsdisziplin, sondern ein inter- und transdisziplinäres Paradigma, das sich vor allem von ontologischen und metaphysischen Wahrheiten distanziert. Der kleinste gemeinsame Nenner in der Diskussion ist die Feststellung, dass Wirklichkeit beobachterabhängig ist. Einen Überblick über die verschiedenen Disziplinen und Positionen sowie eine Bilanz der Konstruktivismusdiskussion für die Bildungspraxis siehe: Siebert, Horst: Pädagogischer Konstruktivismus. Neuwied/Kriftel 1999. 
lag in der Konzipierung von Ausstellungen. Dieser Ort eröffnete mir wegen fehlender Hierarchien und eines aufgeschlossenen Umfeldes die Möglichkeit, experimentell zu arbeiten und unkonventionelle Wege der Ausstellungsgestaltung zu beschreiten. Aufgrund meines kunstpädagogischen Hintergrundes standen bei der Erstellung von Ausstellungskonzepten weniger historische, sondern vielmehr kunstpädagogische Fragen im Vordergrund. Ein wichtiges Anliegen bestand darin, das $\mathrm{Mu}-$ seum als anregenden Ort zu erfahren, in dem die Bildungsarbeit in Auseinandersetzung mit den Objekten in lustvoller Form erlebt wird. ${ }^{9}$ Die Herangehensweise des learning by doing erweckte jedoch den Wunsch, die Kompetenz auf diesem Gebiet durch das Studium von Fachliteratur zu erweitern. Dabei stellte ich jedoch fest, dass dies in Deutschland ein noch wenig wissenschaftlich bearbeitetes Forschungsfeld darstellt.

\section{Forschungsstand}

Die Studien im Bereich Museumskommunikation und Ausstellungssprache zählen zu den jungen Forschungsgebieten der Museologie. Obwohl Ausstellungen zu den wichtigen Foren der Vermittlung von Kultur zählen, haben bislang weder Fach- noch öffentliche Diskurse adäquate Instrumente entwickelt, um Ausstellungen als Medien zu verstehen, zu analysieren und zu kritisieren. Eine Forschungslücke besteht nach wie vor in einer differenzierten Analyse der Ausstellungssprache. Publikationen zur Theorie der Ausstellungsgestaltung stammen aus verschiedensten Fachbereichen und verfolgen dementsprechend unterschiedliche Akzentuierungen. Wichtige Publikationen und Theoretiker, die Eckpunkte der Theoriebildung markieren, seien im Folgenden kurz vorgestellt.

9 Wie sich dies in der Praxis manifestierte, lässt sich an der Ausstellung „Artefakte des Vergangenen“ aufzeigen. Zwei konzeptionelle Leitgedanken standen dabei im Vordergrund. Zum einen sollte die Bevölkerung in den Entstehungsprozess einer Ausstellung eingebunden werden und somit eine aktive Rolle bekommen. Zum anderen ging es um einen ästhetischen Umgang mit den Objekten. Eine ausführlichere Beschreibung dieses Projekts siehe: Kaiser, Brigitte: Aktivitäten zur Belebung eines kleinen Stadtmuseums - Das Beispiel Neuötting. In: Museum heute, Fakten Tendenzen - Hilfen. (1999) Heft 18. S. 20-30. 
Grundlegende theoretische Reflexionen zur musealen Kommunikation erörtert Maroević. ${ }^{10}$ Vor einem historischen Hintergrund entfaltet er eine auf verschiedene Ansätze der Kommunikations- und Medienwissenschaften sowie der Semiotik aufbauende Theorie der Museologie, die er auf den traditionellen musealen Aufgabenkanon - Sammeln, Bewahren, Forschen, Präsentieren - überträgt. Aspekte der praktischen Museumsarbeit, wie zum Beispiel des Museumsmanagements, bleiben dabei jedoch ausgespart. Maroevićs Konzeption versteht sich als zentrale wissenschaftliche Disziplin, deren Erkenntnisse für einen sinnvollen und zielgerichteten musealen Umgang jedoch unerlässlich sind. Als Grundlagenwerk zählt auch die Dissertation von Peter van Mensch. ${ }^{11}$ In dem Kapitel „Communication - the language of exhibitons“ diskutiert er ausführlich unterschiedliche Formen der Klassifizierung von Ausstellungen. ${ }^{12}$

Ein Standardwerk im deutschsprachigen Raum „Handbuch der Allgemeinen Museologie“ wurde von Friedrich Waidacher vorgelegt. ${ }^{13}$ Es enthält Abschnitte über die theoretischen Grundlagen und sämtliche Anwendungsbereiche des Musealwesens. Aufgrund der bedeutenden Rolle des Emotionalen in der musealen Ausstellung räumt Waidacher der unmittelbar auf die Wahrnehmung zielenden ästhetischen Komponente höchste Bedeutung ein (Waidacher 1999, S. 261). Für ihn sind künstlerisch gestaltete Ausstellungen kulturelle Schöpfungen im strengen Sinne, die nicht nur durch ihren wissenschaftlichen Inhalt, sondern

10 Maroević, Ivo: Introduction to Museology - the European Approach. München 1998.

11 Mensch, van Peter: Towards a methodology of museology, PhD theses at the University of Zagreb. 1992, http://www.xs4all.nl/ rwa/contents.htm (letzter Zugriff: 29.12.01, Link existiert heute nicht mehr).

12 Auch auf Verbandsebene wird das Thema musealer Kommunikation diskutiert. So fand im Jahr 1991 ein Symposium des ICOFOM (International Committee for Museology) statt, in der ausführlich das Thema ,exhibition language“ diskutiert und Analysefelder aufgezeigt wurden. Sofka, Vinos (Hrsg.): ICOFOM '91 Symposium: The language of exhibitions. ICOFOM Study Series, Vevey 1990.

13 Waidacher, Friedrich: Handbuch der Allgemeinen Museologie. Wien 1999. Friedrich Waidacher studierte Musik, Volkskunde, Kunstgeschichte und Philosophie und war von 1977 bis 1994 Direktor des Steiermärkischen Landesmuseums in Graz. Er ist Mitglied internationaler wissenschaftlicher Gesellschaften und Redaktionen und Gründungsmitglied der Union of Museologists. 
vor allem durch ihre ästhetische Überzeugungskraft wirken (ebd.). Nicht das Sammlungsobjekt, sondern das Erlebnis, das es in uns hervorruft, soll Ziel aller musealen Arbeit sein. ${ }^{14}$ Ebenfalls auf die hohe Bedeutung der ästhetischen Komponente verwies immer wieder Korff in seinen Publikationen. Bereits in den achtziger Jahren stellte er fest, dass Ausstellungen im Unterschied zu anderen historischen Darstellungsformen unweigerlich als ästhetische Präsentationsform definiert sind und als solche verstanden werden müssen.

„Ästhetik, das ist die Tatsache, dass sie [die Ausstellungen, Anm. d. V.] den Augensinn, die Motorik und den Intellekt des Betrachters gleichermaßen bedienen. Eine Ausstellung ist eine Installation einer historisch bedeutungsvollen Merkwelt in einem dreidimensionalen Raum, in der sich der Betrachter in toto, mit Leib und Seele bewegt.“ (ebd. S. 334)

Der Sammelband „Museumsdinge, deponieren - exponieren“ vereint erstmals Texte des Kulturwissenschaftlers Gottfried Korff zur Geschichte und Theorie der Kulturmuseen aus den drei vergangenen Jahrzehnten. ${ }^{15}$ Korffs Sicht verbindet zwei Perspektiven: die des Ausstellungsmachers, dem an der Entwicklung von Präsentationsästhetiken und an den Möglichkeiten der Vermittlung kulturhistorischer Themen und Zusammenhänge gelegen ist und die des Theoretikers, dem es um die Sichtung der Ideen, Strategien und Funktionen des Museums geht. Er wendet sich gegen die für ihn fragwürdige Allianz von Didaktik und Design als Zwei-D-Präsentationen und spricht sich für sinnlich inszenierte Bildwelten als Mittel der Interpretation und Deutung aus (Korff 2002, S. 330).

Demgegenüber ist Boockmann ein vehementer Vertreter einer ablehnenden Haltung gegenüber abstrahierenden Formen von Inszenierun-

14 Waidacher, Friedrich: Museen lernen: Lange Geschichte einer Verweigerung oder Warum Museen manchmal so gründlich daneben stehen. http://www.vl-museen.de/m-online/99/99-2.htm (letzter Zugriff: 01.05. $04)$.

15 Korff, Gottfried: Museumsdinge: Deponieren - Exponieren. Köln/ Weimar/Wien 2002. Gottfried Korff ist Professor am Ludwig-UhlandInstitut für Empirische Kulturwissenschaft der Eberhard-Karls-Universität in Tübingen. An wegweisenden Ausstellungsprojekten, wie zum Beispiel die Ausstellung „Preußen - Versuch einer Bilanz“ (1981) und „Berlin, Berlin - Bilder einer Ausstellung“ (1987), war Korff maßgeblich beteiligt. 
gen. ${ }^{16}$ Für Boockmann sind dies Formen von Disneyland, bei denen es nicht so sehr um Aufklärung des Publikums, sondern vielmehr um dessen „Überwältigung mit der Technik von Kaufhaus-Dekorateuren“ geht (Boockmann 2000, S. 310). ${ }^{17}$ Obgleich Boockmann in einer Geschichtsausstellung als überdimensioniertem Lehrbuch einen Weg in die verkehrte Richtung sieht, könne man seiner Ansicht nach mit den Protagonisten dieses kognitiven, lernzielorientierten Ansatzes immerhin noch diskutieren. Im Gegensatz dazu würde sich jedoch der Dialog mit Verfechtern szenographischer Konzepte verbieten, denn hier würden „nicht nur Wege zurück in das Museum des 19. Jahrhunderts, zurück in eine Art dreidimensionale Höhlenmalerei beschritten“, sondern mit grundsätzlich anderen Kategorien gearbeitet werden, die keine Basis für Auseinandersetzungen ermöglichen (ebd. S. 312). Ebenfalls zu den Kritikern des modernen Ausstellungswesens, insbesondere der historischen Großausstellungen, zählt Ekkehard Mai. ${ }^{18}$ Sein Vorwurf richtet sich vor allem an den Verlust des Quellenwerts zu Gunsten eines ästhetischen Gestaltungswertes. Ausstellungen fungieren vorrangig als „moderner Mummenschanz der Freizeitindustrie, als Dekoration der Ungeschichtlichkeit, die mit schnellen Impressionen Geschichtsverständnis und -interesse simulier[en] und dabei doch nur vordergründig an Geist und Sinne apellier[en].“ (ebd. S. 66)

Diese gegensätzlichen Positionen zeigen, dass sich die Ausstellungskritiker im Wesentlichen in zwei Lager teilen. Wie ein roter Faden durchzieht dies die deutsche Diskussion zwischen dem auf die Geschichte verpflichteten Museum und dem Kunstmuseum und seiner Rezeptionsform der vorbedingungslosen, unmittelbaren Anschauung des

16 Eine Beschreibung abstrahierender Raumbilder siehe Kap. 1.1: Abstrahierende Raumbilder.

17 Boockmann, Hartmut: Wege ins Mittelalter. Beck 2000. Boockmann studierte Geschichte, Germanistik und klassische Philologie. Nach der Habilitation 1974 war er Professor für Mittlere und Neuere Geschichte in Kiel, Göttingen und Berlin. Er starb am 15.6.1998. Sein Forschungsschwerpunkt bildete die Geschichte des Mittelalters. Dabei bezog er sich auch auf konkret vorhandenes Bildmaterial, eine von Historikern oft unterschätzte Quelle. Folgerichtig führte ihn der Weg von der Anschauung der materiellen Hinterlassenschaften zu programmatischen Aussagen über die angemessene Präsentation von Geschichte in Museen. Von Anfang an begleitete er das Deutsche Historische Museum in Berlin.

18 Mai, Ekkehard: Expositionen. Geschichte und Kritik des Ausstellungswesens. München 1981. 
autonomen Werks. Die einen sehen das Kunstwerk als einen Gegenstand, dessen äußere Schönheit Anlass zu Freude und Erlebnis des Publikums ist, für die anderen wird das Werk erst mit Hilfe zusätzlicher Information und durch die dadurch ermöglichte, eingehendere Betrachtung des Kunstgegenstandes erlebbar und zum Erlebnis. Den Ersteren erscheint die vermeintliche Informationsschau als gleichsam unmoralischer Verstoß gegen die Aura des Kunstwerks und die Belehrung des Publikums als unzumutbare Bevormundung. Demgegenüber wirft die andere Gruppe in ihrer ablehnenden Haltung der so genannten Schatzkammern den Ausstellungsmachern vor, mit der Informationsverweigerung den Betrachter in geradezu undemokratischer Weise zu entmündigen, indem man ihm bewusst lediglich rezeptives Verhalten in Form eines idealisierten Kunsterlebens zugesteht und ermöglicht. ${ }^{19}$

Ungeachtet der Tatsache, dass in dieser Polarität keine Annäherung der Parteien zu Gunsten des Museumspublikums möglich ist, scheint dennoch sicher festgestellt werden zu können, dass durch bloßes Sehen, Sich-versenken und Freuen primär äußerliche Kriterien wahrgenommen werden können. Das Fehlen einer gemeinsamen Theoriebildung von Pädagogik, Ästhetik und Geschichtswissenschaft führte zu einer Pauschalverurteilung programmatisch inszenierter Ausstellungen als populistische Ausflüge in die Welt der Amüsierbetriebe. Dabei wird auch die Tatsache negiert, dass Ausstellungen von Geschichte in Museen immer auch in Zusammenhang mit ästhetischer Erfahrung stehen und diese auch bei der Gestaltung von Ausstellung berücksichtigt werden muss. Das Buch „Geschichte sehen“ markiert ein verändertes Bewusstsein, in welchem der ästhetischen Erfahrung eine eigene Sinnbildungskompetenz zugesprochen wird. ${ }^{20}$ Auch spiegeln historische Ausstellungen oft mehr die Gegenwart und Haltung derer wider, die sie produzieren, als die vergangenen Kulturen, von denen sie handeln. ${ }^{21}$ Mit diesem gesellschaftli-

19 In diesem Zusammenhang werden oft die Schlagwörter „Lernort contra Musentempel“" zitiert, die auch den Titel für die Tagungsdokumentation des Ulmer Vereins „Verband für Kunst- und Kulturwissenschaften“ im Jahr 1975 bildeten. Spickernagel, Ellen/Walbe, Brigitte (Hrsg.): Das Museum - Lernort contra Musentempel. Gießen 1976.

20 Rüsen, Jörn/Ernst, Wolfgang/Grütter, Heinrich Theodor: Geschichte sehen. Beiträge zur Ästhetik historischer Museen. Pfaffenweiler 1988.

21 Im Hinblick auf eine kritische Selbstbefragung durch die Museen, inwieweit die Museen selbst kulturelle Zuschreibungen und Bewertungen beeinflussen, wird die Diskussion der Interpretation und Präsentationsästhetik in Amerika intensiv geführt. Stellvertretend seien hier zwei Titel genannt. 
chen und politischen Zusammenhang der Präsentationsästhetik setzt sich zum Beispiel Schober in ihrem Buch „Montierte Geschichten“ auseinander. $^{22}$

Die These, dass Vergangenheit in musealen Ausstellungen nicht abgebildet, sondern nur gedeutet und konstruiert werden kann, bildet die Grundlage für den Sammelband „Geschichtskultur in der Zweiten Moderne", in dem konstruktivistische Ansätze der Darstellung von Geschichte vorgestellt und erläutert werden. ${ }^{23}$ Dieser Sammelband gibt einen guten Einblick in den aktuellen Diskussionsstand mit seinen unterschiedlichen Facetten. So geht es zum Beispiel um die Frage, welche Rolle die Erinnerung innerhalb der Konstruktion einer Gemeinschaft einnimmt.

Das steigende Selbstbewusstsein gepaart mit der zunehmenden Bedeutung der Rolle der Gestalter im Ausstellungsteam spiegelt sich in dem Handbuch „Museografie und Ausstellungsgestaltung“, welches von den Ausstellungsgestaltern Schwarz und Teufel herausgegeben wurde, wider. $^{24}$ Umfangreiches Fotomaterial, anregende Handskizzen und Computergraphiken sowie die Vorstellung unterschiedlicher Ausstellungsprojekte geben Einblick aus der Perspektive der Macher in die gegenwärtige Ausstellungspraxis.

Bereits 1977 stellte Rohmeder in seinem Buch „Methoden und Medien der Museumsarbeit" fest, dass zwar Fachwissenschaftler die sachlich-faktische Richtigkeit der Museumsarbeit gewährleisten, jedoch für die Vermittlung der Inhalte an die Besucher sich eine andere Zuständigkeit ergibt, die bei den Kommunikationswissenschaften liegt. ${ }^{25}$ Daraus ergibt sich die Forderung, dass Ausstellungen im Team entwickelt werden sollten, welches idealerweise aus den drei Kompetenzen der Fachwissenschaft, der Gestaltung und der Pädagogik besteht. Diese vor

Karp, Ivan/Lavine, Steven D.: Exhibiting Cultures - The Poetics and Politics of Museums Display. Washington/London 1991. Henderson, Amy/ Kaeppler, Adrienne L.: Exhibiting Dilemmas. Issues of Representation at the Smithsonian Washington D.C. 1997.

22 Schober, Anna: Montierte Geschichten. Programmatisch inszenierte historische Ausstellungen. Wien 1994.

23 Beier, Rosemarie (Hrsg.): Geschichtskultur in der Zweiten Moderne. Frankfurt am Main/New York 2000.

24 Schwarz, Ulrich/Teufel, Philipp: Handbuch - Museografie und Ausstellungsgestaltung. Ludwigsburg 2001.

25 Rohmeder, Jürgen: Methoden und Medien der Museumsarbeit. Pädagogische Betreuung der Einzelbesucher im Museum. Köln 1977, S. 12. 
knapp dreißig Jahren formulierte Feststellung der Notwendigkeit der Integration von Museumspädagogen in das Ausstellungsteam ist bis heute nur in wenigen Ausnahmefällen realisiert. ${ }^{26}$ Im Bibliographie-Report des Jahres 1993 zur museumspädagogischen Literatur unterscheidet Noschka-Roos zwischen Museumspädagogik als personeller Vermittlungsarbeit und Museumsdidaktik bezogen auf Ausstellungsgestaltung. ${ }^{27} \mathrm{Ob}$ wohl diese begriffliche Abgrenzung zwischen Didaktik und Pädagogik als überholt kritisiert wird ${ }^{28}$ markiert sie doch eine wichtige Unterscheidung. Die Mitarbeit in einem Ausstellungsteam verlangt vom Museumspädagogen ein spezielles Know-How, das sich trotz vorhandener Gemeinsamkeiten von der personellen Vermittlung unterscheidet. Speziell die Frage, wie sich Museumspädagogik bereits in die Ausstellungsgestaltung einbringen kann, ist bis heute in Deutschland wenig wissenschaftlich diskutiert worden. Noschka-Roos erörtert in ihrem Buch „Besucherforschung und Didaktik" allgemeindidaktische Argumente für eine systematische Begründung einer Ausstellungsdidaktik. ${ }^{29}$ Im praktischen Teil konzentriert sie sich auf die Bedingungen der Textrezeption und versucht zu klären, wie und auf welche Weise mit diesem wichtigen Medium die Vermittlung verbessert werden kann.

Ein Plädoyer zu Gunsten einer pädagogisch reflektierten, ambitionierten und wissenschaftlich begründeten Museumsdidaktik formuliert Herles in seiner Dissertation. Da sich der Vermittlungsauftrag der Museen im Wesentlichen nicht in der personalen Betreuung, sondern im Prä-

26 Als Musterbeispiel hierfür wird in der Literatur immer wieder das „Haus der Geschichte“ in Bonn angeführt. Seit 2002 gibt es in Deutschland ein weiteres berühmtes Beispiel dafür: auch bei der Neueinrichtung des Jüdischen Museums in Berlin bildete das potentielle Publikum eine entscheidende Einflussgröße.

27 Noschka-Roos, Annette: Bibliographie - Report 1993 zu Museologie, Museumspädagogik, Museumsdidaktik und Besucherforschung. Berlin 1993.

28 Dazu sowie ein Überblick zum Stand der aktuellen Museumspädagogik siehe Kindler, Gabriele/Liebelt, Udo: Bildung und Kommunikation. Museumspädagogik im Konzert der Museumsarbeit. In: Landesstelle für die nichtstaatl. Museen in Bayern (Hrsg.): Im Dialog - Museumspädagogik für alle Besucher, Tagungsdokumentation zum 11. Bayerischen Museumstag in Bayreuth. München 2002, S. 20.

29 Zur Entstehungsgeschichte des Begriffs Ausstellungsdidaktik und einen Überblick zur Diskussion beginnend in den siebziger Jahren, vgl. Noschka-Roos, Annette: Besucherforschung und Didaktik. Opladen 1994; S. $76 \mathrm{ff}$. 
sentationsbereich verwirkliche, sei eine Koalition von Fachdisziplin und Pädagogik gefragt (Herles 1990, S. 235).

Die Studie „Von der Gesinnungsbildung zur Erlebnisorientierung“ von Urban unternimmt den Versuch, die Bildungsarbeit in den Geschichtsmuseen auf die Rezeptionsfähigkeit und die Interessen der Besucher auszurichten sowie auf den Erkenntnissen der modernen Geschichtsdidaktik aufzubauen. ${ }^{30}$ Zwei Aspekte erscheinen ihm dabei für die Museumspädagogik von besonderer Bedeutung: Das auf „die Bildung des Geschmacks und des Verstandes abzielende historische Lernen im Museum gewinnt seine eigentliche Qualität durch die sinnliche Erfahrbarkeit der Überlieferung" (ebd., S. 243). Zweitens betont er für eine rezipientengerechte Geschichtsvermittlung die Notwendigkeit der „Berücksichtigung der subjektiven Einbildungskräfte der Besucher beim historischen Lernen“, welche bis heute weitgehend vernachlässigt werden (ebd.).

Seit den siebziger Jahren hat sich der Blickwinkel verändert. Standen zu Beginn der Diskussion um Demokratisierung von Bildung inhaltliche Fragen im Zentrum, rückt gegenwärtig zunehmend der Besucher mit seinen Wünschen und Bedürfnissen in den Vordergrund. Auch kristallisiert sich heraus, dass Abstand davon genommen wird, einem fiktiven Besucher etwas vermitteln zu wollen. Die Integration der potentiellen Besucher und deren Interessen stellen relevante Größen für die Entwicklung von Ausstellungskonzepten dar. Aus diesem Grund erweist sich der Begriff Vermittlung als nicht mehr adäquat. Stattdessen wird der Begriff seale Kommunikation bevorzugt.

Insbesondere die Literatur des angloamerikanischen Raumes spiegelt diese veränderte Perspektive wider. Falk/Dierking stellen in das Zentrum ihres Buches das Museumserlebnis und entwickeln „A Professional's Guide to the Museums Experience. ${ }^{* 31}$ Wie Erwachsene und Kinder bei meist kurzen Ausstellungsbesuchen dennoch etwas lernen können, diskutiert Hein in seinem Buch „Learning in the Museum“. ${ }^{32}$ Unter anderem zeigt er, wie Besucherforschung und Erziehungswissenschaft gemeinsam pädagogische Erfahrungen beeinflussen können und welche

30 Urban, Andreas: Von der Gesinnungsbildung zur Erlebnisorientierung. Geschichtsvermittlung in einem kommunalen historischen Museum im 20. Jahrhundert. Schwalbach 1999.

31 Falk H. John/Dierking, Lynn D.: The museums experience. Washington D.C. 1992.

32 Hein, George E.: Learning in the museum. London 1998. 
aktuellen Lerntheorien relevant für das Museum sind. Hooper-Greenhill geht in ihrem Buch „Museum and the Interpretation of Visual Culture“ der Frage nach, wie Besucher Sammlungen interpretieren und wie dieser Vorgang von der Pädagogik des Museums beeinflusst wird. ${ }^{33}$

Das zum Teil konsequente Umsetzen von Besucherorientierung in amerikanischen Museen steht in Zusammenhang mit dem wirtschaftlichen Zwang, über Eintrittsgelder finanzielle Ressourcen zu erschließen. Besucherorientierung ist somit nicht nur eine ideelle Verpflichtung, sondern kann zur Überlebensstrategie werden. Betriebswirte übernehmen zur Sicherung der Einnahmen die Museumsleitung und Marketingabteilungen werden eingerichtet. Inwiefern sich diese amerikanischen Managementstrategien und auch damit einhergehende Konsequenzen auf Deutschland übertragen lassen, analysiert Dauschek in ihrer Dissertation „Museumsmanagement“. ${ }^{34}$

Darüber hinaus gibt es noch Einzelstudien, die ebenfalls Fragen der Gestaltung anhand eines Museums oder einer museologischen Persönlichkeit diskutieren. Stellvertretend sei hier auf zwei Werke verwiesen. Von Plato erörtert mit Blick auf die französische Geschichtskultur, speziell Pariser Museen und Weltausstellungen im 19. Jahrhundert, die Frage, wie sich Geschichte verändert, wenn sie statt einer gebildeten Elite einem Massenpublikum präsentiert wird. ${ }^{35}$ Gorgus widmet sich in ihrer Dissertation „Der Zauberer der Vitrinen“ dem Museologen Georges Henri Rivières. ${ }^{36}$ Diese in Deutschland kaum wahrgenommene Persönlichkeit entwickelte bahnbrechende Konzepte zum musealen Umgang mit der Alltags- und Gegenwartskultur. Mit seiner Idee des Écomusée lancierte Rivières ein folgenreiches Konzept für das kulturhistorische Museum der Alltagskultur.

33 Hooper-Greenhill, Eilean: Museums and the Interpretation of Visual Culture. London/New York 2000.

34 Dauschek, Anja: Museumsmanagement. Amerikanische Strategien in der deutschen Diskussion. Ehestorf 2001.

35 Plato von Alice: Präsentierte Geschichte. Ausstellungskultur und Massenpublikum im Frankreich des 19. Jahrhunderts. Frankfurt/New York 2001.

36 Gorgus, Nina: Der Zauberer der Vitrinen. Zur Museologie Georges Henri Rivières. Münster 1999. 


\section{Aufbau der Studie}

Die Studie befasst sich mit Geschichtsbildern zeitgenössischer kulturhistorischer Ausstellungen und steht somit im Spannungsfeld zwischen Historik, Ästhetik und Pädagogik. Ich beziehe mich dabei auf den Doppelsinn des Bildbegriffs, der sowohl technisch-mediale wie auch mentale Bilder meint. Dabei betrachte ich sowohl die im dreidimensionalen Raum vorhandenen Bilder inszenierter Ausstellungen als auch den Besucher als Ort der inneren Bilder. In den ersten vier Kapiteln erfolgen grundsätzliche museologische Überlegungen. Diese werden im fünften Kapitel anhand der Rezeption des Mittelalters konkretisiert. Die bis dahin erfolgten Reflexionen erfahren im sechsten Kapitel eine weitere $\mathrm{Zu}$ spitzung, indem anhand einer Ausstellungsanalyse die theoretischen Erörterungen auf die Praxis bezogen werden.

Bei meiner Untersuchung konzentriere ich mich auf die Betrachtung kulturhistorischer Ausstellungen und grenze diese damit von der klassischen Kunstausstellung ab. Trotz dieser Eingrenzung zeigt sich, dass auch dieser Bereich äußerst vielfältig ist. Hierzu zählen, um nur einige zu nennen, kleine Regionalmuseen, kulturgeschichtliche Spezialsammlungen wie Alpinmuseen, Feuerwehrmuseen etc. sowie auch große Landesausstellungen. ${ }^{37}$ Der Deutsche Museumsbund untergliedert die Museenlandschaft in unterschiedliche Fachgruppen, in der es auch einen Bereich der kulturgeschichtlichen Museen und Kunstmuseen gibt. Eine allgemein verbindliche Definition liefert der Verband jedoch nicht. ${ }^{38}$ Die

37 Als eine Besonderheit in der Bundesrepublik Deutschland entwickelte sich die historische Großausstellung, besonders im letzten Viertel des 20. Jahrhunderts entstanden zahlreiche und äußerst vielfältige Ausstellungsprojekte. Thematisch orientierten sich diese dabei an Jubiläen bzw. Jahrestagen. Eine umfangreiche Aufzählung der in Deutschland stattgefundenen Ausstellungen siehe Korff 2002, S. 24-48. Der leitende Direktor der Magdeburger Museen Dr. Puhle stellt fest, dass Museumskollegen von einem spezifisch deutschen Ausstellungstyp sprechen und damit die monumentale historische Sonderausstellung, die einer Epoche oder einer historischen Persönlichkeit gewidmet ist, meinen. Puhle, Matthias: Historische Großausstellungen und ihre kulturhistorische Bedeutung. In: Ministerium für Wirtschaft und Arbeit des Landes Sachsen-Anhalt, Kulturhistorisches Museums Magdeburg (Hrsg.): Otto der Große, Magdeburg und Europa. Magdeburg 2002, S. 8.

38 Im Hinblick auf die Nutzanwendung der Kulturgeschichte auf das Museum spricht Kramer von einem Verlegenheitsbegriff. Die Bezeichnung wird 
Hinwendung zur Alltags- und Sozialgeschichte der historischen Wissenschaften bedeutete auch für das Museums- und Ausstellungswesen, dass nicht nur Kunstwerke, sondern auch Objekte der Alltagsgeschichte gesammelt und ausgestellt wurden. Die kulturhistorische Ausstellung nimmt somit eine Art Zwitterstellung zwischen Kunst- und Geschichtsausstellung ein. Während sich das Kunstmuseum auf Meisterwerke stützt, verwendet das historische, ähnlich wie das volkskundliche Museum, seine Exponate als Sachzeugnisse und als Belegstücke für Geschichtsinterpretationen.

Dieses Charakteristikum der Zwitterstellung ist von tragender Bedeutung, da dies zu einer Konkurrenzsituation in der Wahrnehmung führen kann. Der ästhetische Genuss der Objekte kann in Konkurrenz mit dem Anliegen der Geschichtsvermittlung treten. Eine Kunstausstellung ermöglicht ästhetische Erfahrung, diese hat Priorität vor historischer Erfahrung. Eine kulturhistorische Ausstellung will jedoch beiden Ansprüchen gerecht werden.

Den zentralen Bezugspunkt der Überlegungen bilden die musealen Objekte und die Frage nach unterschiedlichen Formen von Kontextualisierung und Interpretation sowie deren Funktionen im Rahmen der musealen Kommunikation. Folglich beziehe ich mich bei meinem Untersuchungsmaterial auf Ausstellungen, die nach wie vor museale Objekte als zentrale Figuren betrachten. Auf thematische Ausstellungskonzepte ohne museale Objekte gehe ich nur dann ein, wenn dies der Verdeutlichung eines Sachverhaltes dienlich ist.

Da sowohl die Begriffe Inszenierung als auch Erlebnis sehr unterschiedlich interpretiert werden, geht es im ersten Kapitel darum, diese Begriffe im Hinblick auf meine Fragestellung zu beleuchten. Bei der Ausstellungsinszenierung differenziere ich zwischen rekonstruktiven und abstrahierenden Raumbildern. Diese stellen einen Teil der Geschichtserfahrung dar, die die Erinnerungsbilder der Besucher prägen. Erlebnisse können nicht eindimensional betrachtet werden, da diese immer in Abhängigkeit von der subjektiven Persönlichkeitsstruktur entstehen. Neuere Formen der Besucherforschung vor allem im angloamerika-

zwar verwendet, jedoch wird nicht erklärt, was darunter zu verstehen ist. Ein summativer, weiter Kulturbegriff wird benutzt, dieser geht aber in der Beschreibung der Aufgaben kulturgeschichtlicher Museen nicht über das objektfixierte und nicht an kulturellen Prozessen orientierte Sammeln und Präsentieren hinaus. Vgl. Kramer, Dieter: Kulturgeschichtstheorie und kulturgeschichtlich-volkskundliche Museen und Sammlungen. In: Spickernagel/Walbe 1976, S. 21. 
nischen Raum stellen die Besucher und ihre Erlebnisse ins Zentrum der Betrachtung. Bessere Kenntnisse über die Art und Weise der Verarbeitung ermöglichen eine Verbesserung des begleitenden Angebots in der Ausstellungsumwelt.

Obgleich Besucherforschungen nur einen geringen effektiven Lernzuwachs nach einem Ausstellungsbesuch konstatieren, haben dennoch museale Präsentationen eine unersetzbare gesellschaftliche Funktion, deren Nutzen sich jedoch nicht nach ökonomischen Kategorien berechnen lässt, sondern im Bereich der ideellen Werte liegt. Worin speziell das pädagogische Potential kulturhistorischer Ausstellungen, insbesondere in Abgrenzung zu kommerziellen Erlebniswelten, liegt, thematisiere ich im zweiten Kapitel. Historische und ästhetische Erfahrungen bilden dabei die Bezugspunkte. Diese pädagogische Dimension stellt auch das fundamentale Element dar, wenn es um die Frage geht, wie sich Museumspädagogen im Ausstellungsteam positionieren können.

Im dritten Kapitel stehen Überlegungen zur musealen Kommunikation im Zentrum der Betrachtung. Da Ausstellungen von den subjektiven Interpretationen der Macher geprägt werden, beleuchte ich zunächst die personelle Komponente. Insbesondere interessiert dabei die Frage, welche Rolle Museumspädagogen dabei spielen und durch welche Kompetenzen sich Museumspädagogen auszeichnen sollten. Dabei können kommunikative Strategien angewendet werden. Ich betrachte diese unter den Dimensionen Anschaulichkeit, Handlungsorientierung, Differenzierung und Ganzheit. Aus diesen Überlegungen entwickle ich analytische Fragen, die dann im Praxisteil die Grundlage für die Ausstellungsanalyse bilden. Zunächst jedoch stelle ich drei Präsentationsformen vor, wie sie in der Gegenwart angewendet werden und die somit typische Formen besucherorientierter Konzepte darstellen.

Metakommunikative Aspekte, insbesondere die politische und ökonomische Dimension der musealen Kommunikation, bilden den Fokus des vierten Kapitels. Inhaltliche Interpretation stellt eine Schlüsselaufgabe für die Ausstellungsmacher dar. Diese Aufgabe liegt nicht nur bei den fachwissenschaftliche Kuratoren, sondern zählt auch zum Verantwortungsbereich der Museumspädagogen. Bereits in der inhaltlichen Aufbereitung sollten pädagogische und kommunikative Aspekte einfließen. In der Realität der musealen Ausstellungswelt jedoch ist dies nur mit wenigen Ausnahmefällen der Fall. Im Gegenteil wird der Museumspädagogik sogar von einzelnen Kritikern vorgeworfen, dass diese dazu beitragen würde, der zunehmenden Kommerzialisierung Vorschub zu leisten. So fürchten zum Beispiel Gegner erlebnisorientierter Ausstellungen, dass 
diese ausschließlich dem Besucherbedürfnis nach Konsum antworten und eine intensive Begegnung und Auseinandersetzung mit Inhalt und Objekt verschwimmen. Auch hat Museumspädagogik in historischer Betrachtung mit einem schweren Erbe zu leben. In der Zeit des Nationalsozialismus wurde didaktische Gestaltung in Propagandaausstellungen usurpiert und zu manipulativen Zwecken missbraucht.

Im fünften Kapitel erfolgt eine thematische Eingrenzung auf die Betrachtung der Rezeption des Mittelalters. Die Vermittlung dieser Zeit stellt eine besondere Herausforderung an Ausstellungsmacher dar. Die Vorstellungsbilder dieser Epoche sind einerseits von romantischen und klischeehaften Gedanken geprägt, andererseits stammen die Überreste dieser Zeit aus einer generell anderen Erfahrungswelt. Da ein oft formulierter Vorwurf an inszenierte Ausstellungen darin liegt, diese würden sich zu sehr den kommerziellen Freizeitparks annähern, gehe ich detaillierter auf historische Erlebnisparks ein, die speziell mit mittelalterlichem Spektakel werben.

Anhand der Ausstellung „Kaiser Heinrich II. 1002 - 1024“ in Bamberg im Jahr 2002, die vom Haus der Bayerischen Geschichte konzipiert worden ist, analysiere ich in Kapitel sechs das Vermittlungs- und Gestaltungskonzept. Diese Ausstellung bot sich für eine Untersuchung an, da zwei gegensätzliche Präsentationsstrategien - ein Inszenierungskonzept sowie eine objektorientierte Präsentation - nebeneinander verwirklicht wurden. Bei der Analyse beziehe ich mich auf die im dritten und vierten Kapitel entwickelten Fragestellungen der kommunikativen und metakommunikativen Dimensionen. Ergänzend dazu geben zwei Besucherbefragungen Aufschluss darüber, wie die verschiedenen Präsentationen bewertet wurden.

Im abschließenden Kapitel soll nochmals das Spannungsfeld zwischen Kommerzialisierung und Besucherorientierung inszenierter Ausstellungen betrachtet werden. Dabei interessiert insbesondere, wo und wie sich museumspädagogische Gesichtspunkte innerhalb der Konzeptentwicklung von Ausstellungen verwirklichen lassen. 


\section{Die Ausstellung als Raumbild und die BESUCHER ALS ORTE DER INNEREN BILDER}

Bei der Arbeit mit inszenatorischen Mitteln wird versucht, die musealen Objekte nicht als singuläre Schätze zu präsentieren, sondern diese in einen Kontext einzubinden und in einen inhaltlichen oder assoziativen $\mathrm{Zu}$ sammenhang mit dem Ziel eines Gesamteindrucks zu stellen. Korff vertritt die These: „Das Museum bebildert nicht; es ist Bild.“1 Er pointiert damit seine Überlegung, dass das Museum als Ort der Sammlung und Bewahrung anschaubarer Objektwelten eine Institution der sinnlichästhetischen Wahrnehmung sei. Das originale Objekt fordere die Inszenierung als erklärende Darstellung schon allein deshalb, weil es nicht nur Dokument sei, sondern ebenso über eine sinnliche Qualität verfüge. ${ }^{2}$ Aus diesem Grund scheinen für Korff die „Re-Dimensionierung“ und „ReKontextualisierung" von Dingen mit den Mitteln der bildhaften Inszenierung angemessen und legitim. Unter Re-Kontextualisierung versteht Korff die Notwendigkeit, die authentisch überlieferten Objekte, die jedoch wie andere Quellengruppen nur bruchstückhaft vorhanden sind, zu erklären und zu deuten. Dies bedeutet eine klare Abwendung von einer scheinbar neutralen Präsentation. ${ }^{3}$ In konsequenter Weiterführung der These von der Notwendigkeit bildhafter Präsentation stellt Fehr fest, dass „der Historiker als Ausstellungsmacher zu einem Bildproduzenten [wird] - und sich damit nolens volens der Kritik aus einem Bereich aus[setzt], den gerade Historiker traditionell gerne meiden: den Bereich der Kunstwissenschaft und Kunstgeschichte.“ (Fehr 2000, S. 149)

1 Korff zitiert in Fehr, Michael: Das Museum als Ort der Beobachtung. Einige Überlegungen zur Zukunft des Museums. In: Beier 2000, S. 149.

2 Korff, Gottfried: Bildwelt Ausstellung - Die Darstellung von Geschichte im Museum. In: Borsdorf, Ulrich/Grütter, Heinrich Theodor (Hrsg.): Orte der Erinnerung. Frankfurt/New York 1999, S. 331.

3 Korff, Gottfried/Roth, Martin (Hrsg.): Das historische Museum - Labor, Schaubühne, Identitätsfabrik. Frankfurt/New York 1990, S. 18. 
Die Feststellung der Notwendigkeit der Re-Kontextualisierung und ReDimensionierung als Formen der Inszenierung und als Mittel der visuellen Rhetorik besagen jedoch noch nichts über ihre jeweils konkrete Realisierung und die möglichen Darstellungsformen. ${ }^{4}$ Eine Bildwissenschaft, die beispielsweise allgemeine Kriterien für die zahlreichen verschiedenen Arten der Bilder und deren Analysen aufstellt, hat sich bisher noch kaum ausgebildet. ${ }^{5}$ Die Gründe hierfür sind vielfältig. Ein wesentlicher Aspekt ergibt sich aus der Heterogenität der Phänomene, die wir mit dem Ausdruck Bild bezeichnen. Man spricht von Weltbildern, Menschenbildern und Leit- oder Idealbildern ebenso wie von Spiegelbildern, Sprachbildern und mentalen Bildern. ${ }^{6}$

Zunächst kann eine Hauptunterscheidung zwischen materiellen und mentalen Bildern getroffen werden. Nach Belting rechtfertigt sich der Bildbegriff nur als anthropologischer Begriff, der sich von dem Doppelsinn nicht trennen lässt, den wir ihm geben, wenn wir von mentalen Bildern sowie von den Artefakten der künstlerischen und technischen Bildproduktion sprechen.

„Der Doppelsinn innerer und äußerer Bilder ist vom Bildbegriff nicht zu trennen und verrät gerade dadurch dessen anthropologische Fundierung. Ein Bild ist mehr als ein Produkt der Wahrnehmung. Es entsteht als das Resultat einer persönlichen und kollektiven Symbolisierung. Alles, was in den Blick oder

4 Grütter, Heinrich Theodor: Die Präsentation der Vergangenheit. Zur Darstellung von Geschichte in historischen Museen und Ausstellungen. In: Füßmann 1994, S. 182.

5 Obwohl eine fächerübergreifende Bildwissenschaft noch nicht existiert, ist innerhalb der Geisteswissenschaft, insbesondere unter Kunst- und Medienhistorikern eine rege Debatte darüber entstanden, wie sie aussehen könnte und welche Themen vorrangig behandelt werden sollten. Unter dem Schlagwort „Iconic Turn“, der den Wandel von der textbasierten Kommunikationsgesellschaft hin zum bildmedialen Zeitalter fokussiert, fand eine interdisziplinäre Vorlesungsreihe an der Ludwig-MaximiliansUniversität München statt, in der internationale Experten aus verschiedensten Perspektiven zu diesem Thema referierten. Die Vorträge sind nun in einem Sammelband publiziert. Maar, Christa/Burda, Hubert: Iconic Turn. Die neue Macht der Bilder. Köln 2004. Siehe auch: http://www. iconic-turn.de (letzter Zugriff: 04.01.05).

6 Sachs, Hombach, Klaus/Rehkämper, Klaus (Hrsg.): Bild - Bildwahrnehmung - Bildverarbeitung. Interdisziplinäre Beiträge zur Bildwissenschaft. Wiesbaden 1998, S. 9. 
vor das innere Auge tritt, läßt sich auf diese Weise zu einem Bild klären oder in ein Bild verwandeln." ${ }^{47}$

In Bezug auf meine Untersuchung sind beide Aspekte relevant. Mit der Visualisierung von historischen Ereignissen werden sowohl materielle als auch mentale Geschichts- und Erinnerungsbilder erzeugt. Die materiellen Bilder entstehen durch die konkrete, im Raum vorhandene dreidimensionale Situation. Sie beziehen sich also nicht nur auf das klassisch zweidimensionale Bild, sondern im Sinne eines Bühnenbildes auf das Arrangement der einzelnen bildkonstituierenden Elemente im Raum. Diese materiellen Bilder stehen jedoch in direktem Zusammenhang mit den mentalen Bildern. Bei der Frage um die mentalen Bilder geht es um die Qualität der transportierten Inhalte und welche Vorstellungsbilder kreiert werden.

\subsection{Arbeitsdefinition Inszenierung}

Bereits Shakespeare stellte fest, dass die ganze Welt eine Bühne sei. Doch erst in der Moderne ist Inszenierung zu einem Leitbegriff unserer Gesellschaft geworden. Seit Mitte der achtziger Jahre scheint das gesellschaftliche Phänomen der Inszenierung allgegenwärtig zu sein.

„Wohin man sich auch dreht und wendet, zu den Künsten oder zu den Wissenschaften, zur Politik, zur Populärkultur oder zum Sport, zur Religion, zur Natur oder schlicht zur Alltagssphäre, nahezu überall drängt sich der Faktor Inszenierung auf. Sie scheint so allgegenwärtig wie die Hintergrundmusik im Kaufhaus, der bunt flimmernde Bildschirm und die sogenannten neuen Medien." ${ }^{8}$

Gegenwärtig wird Inszenierung auch für das In-Szene-Setzen verschiedener anderer Bereiche verwendet, beispielsweise für die Werbung, ebenso bei Medienspektakeln sowie für Architektur. Die Raffinesse der Zusammenstellung von Dingen und die Aura der Inszenierung trivialer bis wertvoller Gegenstände in Ausstellungen haben eine lange kultur-

7 Belting, Hans: Bild-Anthropologie - Entwürfe für eine Bildwissenschaft. München 2001, S. 11.

8 Früchtl, Josef/Zimmermann, Jörg: Ästhetik der Inszenierung. Dimensionen eines gesellschaftlichen, individuellen und kulturellen Phänomens. In: Früchtl, Josef/Zimmermann, Jörg (Hrsg.): Ästhetik der Inszenierung. Frankfurt am Main 2001, S. 9. 
historische Tradition. Das Zurschaustellen von Artefakten aller Art Gemälde, Skulpturen, Preziosen, bibliophile und naturwissenschaftliche Sammlungen, Archivalien und Kuriosa - blieb bis zum Beginn des 19. Jahrhunderts ein Privileg des Adels und des Patriziats. Mit Beginn der Weltausstellungen veränderte sich das Zielpublikum. Nicht nur eine gebildete Elite, sondern auch ein breites Massenpublikum sollte angesprochen werden. ${ }^{9}$

Die Präsentationsformen der Museen und somit auch die Inszenierungen in Ausstellungen sind in der museumsgeschichtlichen Literatur bisher wenig behandelt worden. Dies bestätigt, was Jörn Rüsen in Bezug auf das historische Museum angemerkt hat. Er stellt fest, dass das historische Museum im Allgemeinen unter den Aspekten Politik und Wissenschaft betrachtet werde, dass aber die Dritte im Bunde, die spezifische Eigenart der Darstellung - er nennt es Ästhetik - unbeachtet bleibt. Dabei bezieht gerade das historische Museum hieraus seine öffentliche Wirkung und nicht daraus, dass es wissenschaftlich fundiert oder politisch instrumentalisierbar erscheint (Rüsen 1988, S. 11). Matthias Götz vom Museum für Gestaltung in Basel formuliert die für ihn hohe Bedeutung des Ausstellens eindeutig: „Das Ausstellen ist nicht eine Unterabteilung des Museums und des musealen Triviums Sammelnbewahrenvermitteln, sondern viel mehr ist das Museum eine dem Ausstellen untergeordnete Institution." (Götz zitiert in Schwarz 2001, S. 11)

Inszenierungen in Ausstellungen können keineswegs als zeitgenössische Phänomene betrachtet werden. Gegenwärtig werden zum Teil ähnliche Themen besprochen, die bereits vor hundert Jahren diskutiert wurden. Boockmann verweist darauf, dass bei Diskussionen um Ausstellungspräsentationen auch eine Betrachtung der historischen Entwicklung aufschlussreich sein kann. Selbst wenn dies keine Lösung für gegenwärtige Gestaltungsfragen liefert, so bietet der historische Blick vielleicht die Chance, ,[...] Irrtümer nicht noch einmal zu begehen und in längst ausgeschrittenen Sackgassen nicht wiederum herumzuirren.“ (Boockmann 1987, S. 7)

9 Das Ansprechen eines großen Massenpublikums zählte zu den großen Herausforderungen und auch Errungenschaften der internationalen Weltausstellungen. Es mussten andere Präsentationsformen entwickelt werden, um den gestellten kommerziellen publikumsbezogenen Ansprüchen gerecht zu werden. Damit wurde Neuland in der musealen Welt beschritten. Vgl. dazu Plato 2001, S. 101. 
Die malerische Präsentationsweise ist ein Begriff, der bereits im 19. Jahrhundert verwendet wurde, ohne inhaltlich präzise bestimmt worden zu sein. Gemeint ist damit eine Aufstellung von Objekten fern jeder chronologischen, typologischen, material- oder funktionsbezogenen Systematik, die darauf zielt, möglichst alles zu zeigen und einen malerischen Gesamteindruck hervorzurufen. ${ }^{10}$ Von einer der großen Industrieund Gewerbeausstellungen (Düsseldorf 1880), die auch die Museumseinrichtungen beeinflussten, ist folgende Schilderung überliefert, die die Besonderheiten der Präsentation gut vermittelt:

„Wie Geisterodem weht es uns beim Eintritt in die von farbengedämpftem Licht erfüllten Räume entgegen, unwillkürlich hemmen wir, von dem Totaleindruck gefesselt, den Schritt: Die Wände sind bedeckt mit kostbaren Gobelins und alterthümlichen Waffen, zwischen den Möbeln und Glasschränken, aus denen uns Kleinodien von unschätzbarem Werth, kunstvoll gearbeiteten Broncen und Prozellane entgegenblicken, stehen, eisengepanzerten Rittern gleich, schwere Rüstungen, Zeugnis gebend von der hohen Blüte des mittelalterlichen Kunstgewerbes und - der Körperkraft unserer Altvordern. [...] Wir sehen die Culturentfaltung eines klassischen Volkes von der formvollendeten Broncefigur in Lebensgröße, das Steinbeil und den reich verzierten Musqueton aus der Zeit seiner ersten Herstellung. Köstliche Erzeugnisse der Vorzeit sind hier aufgestapelt." ${ }^{11}$

Die scheinbare Einheit der überlieferten Relikte und der für das Museum hergestellten Kopien mit dem Museumsbau selbst war auch im Bayerischen Nationalmuseum in München zu finden. An vielen Orten wurde die Architektur den auszustellenden Gegenständen angepasst, kirchenbauartige Architekturelemente für die Kirchenkunst und burgähnliche Architektur-Attrappen für die laikale Kunst des Mittelalters geschaffen. Verbindungslinien zwischen Museum und Theater gab es in mehrfacher Hinsicht. Auch wenn man im Hinblick auf Museumsräume von Inszenierungen damals nicht sprach: Diese Räume sahen den Bühnenbildern, in denen zur selben Zeit Historien-Dramen aufgeführt wurden, sehr ähnlich.

10 Foerster, Cornelia: Zwischen malerischer Präsentation und historischer Dokumentation. Darbietungsformen in Geschichtsmuseen des 20. Jahrhunderts. In: Museumskunde 60. (1995) S. 88.

11 Westfälischer Anzeiger Nr. 76, 29.6.1880. So zitiert nach Foerster 1995, S. 89. 


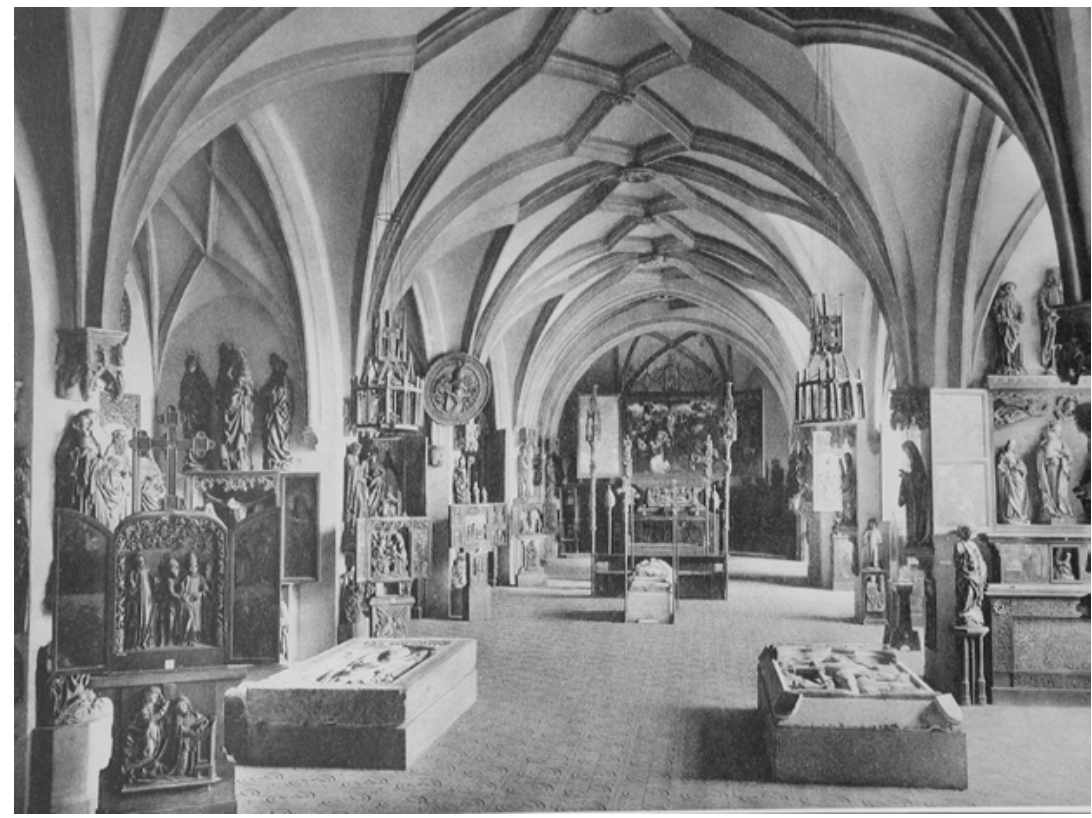

Abbildung 1: Blick in den Kirchensaal des Bayerischen Nationalmuseums im Jahr 1900.

Die Ähnlichkeit lag auch darin, dass hier wie dort der Gesamteindruck wichtig war. Was heute meist als selbstverständlich gilt, nämlich dass jeder Museumsgegenstand mit Hilfe eines Schildchens kurz bezeichnet wird, verstand sich damals keineswegs von selbst. In Nürnberg konnten die Besucher die einzelnen Stücke erst seit dem Jahre 1893 mit Hilfe von Anschriften identifizieren. Die Einbettung der Exponate in einen inszenierenden architektonischen Rahmen resultierte in den ersten, für die Allgemeinheit eingerichteten, fürstlichen wie bürgerlichen Museen aus dem Streben um Repräsentation und aus didaktischer Intention. Sowohl die Absicht des Fürsten, seinem Mäzenatentum ein eindrucksvolles Denkmal zu setzen, wie auch der Versuch, ein Ambiente zu schaffen, das die Kunstwerke erläutert, ließ die Museen zu eigenen Kunstwerken geraten (Herles 1996, S. 110).

Das Gesamtbild war ein wesentliches Ziel der malerischen Präsentation. Es ging um die Gesamtheit der kulturellen Äußerungen einer Epoche. Ein vorgestelltes Lebensgefühl etwa der Renaissance war das geistige Band, das die Anordnung der Objekte miteinander verknüpfte. Die 
Objekte sollten einen Blick für das Leben, Fühlen und Denken der Menschen eröffnen. In malerischer Präsentation konnten sowohl Ensembles als auch Einzelobjekte gezeigt werden. Entscheidend war die intuitive Vermittlung. Der Geist der Epoche sollte in sinnlicher Darbietung erlebt werden. Die dingliche Überlieferung wurde dabei nicht so sehr als Quelle betrachtet, die wissenschaftlich zu erschließen war, sondern als bedeutsamer Zeuge der Vergangenheit und als Reliquie, die Geschichte unmittelbar verkörperte.

Gegen Ende des 19. Jahrhunderts entstand eine neue Form von $\mathrm{Mu}-$ seen, die sogenannten Hygiene- und Sozialmuseen. Sie bewahrten nicht in erster Linie das kulturelle Erbe der Vergangenheit, sondern versuchten, für aktuelle Probleme praktikable Lösungen zu propagieren. Sie zeigten konkretes Anschauungsmaterial, waren aber vor allem bestrebt, mit modernster Technik ihre Botschaften zu vermitteln und eine Verhaltensänderung zu bewirken. Diese Museen waren ausdrücklich informativ, lehrhaft und handlungsorientiert, sie waren nicht auf stille Betrachtung angelegt. Dies bedeutete jedoch nicht, dass hier ein rationales Studium als angemessene Rezeptionsform gewünscht war. Vielmehr wirkten gerade die neuen Medien mit starker Suggestivkraft. Film, Ton und Licht sowie graphische Mittel waren geeignet, eine gewünschte Aussage plakativ hervorzuheben. ${ }^{12}$ Der volkspädagogische, letztlich demokratische Anspruch dieser Darbietungsformen erfuhr allerdings in der Folgezeit eine inhaltliche Verkehrung. Die neuen Möglichkeiten und Methoden der Darstellung wurden von der nationalistischen Propaganda für ihre Zwecke vereinnahmt. ${ }^{13}$ In Deutschland kam es nach dem Zweiten Weltkrieg zu einer Zäsur bei der Inszenierungspraxis. Dies ist wohl auf den ideologischen Missbrauch durch den Nationalsozialismus und deren Propagandamaschinerie zurückzuführen. ${ }^{14}$

$12 \mathrm{Zu}$ diesen Präsentationsformen siehe ausführlich: Roth, Martin: Heimatmuseum. Zur Geschichte einer deutschen Institution, Berlin 1990, S. 191242.

13 Zum Thema dramaturgisch inszenierter Propagandaausstellungen siehe Kapitel 4, S. 187ff.

14 Bei einem vergleichenden Blick mit den USA lässt sich feststellen, dass dort kein derartig klarer Einschnitt zu erkennen ist, sondern dass sich die Inszenierungspraxis kontinuierlich mit verschiedensten Ausprägungen entwickelte. Vgl. Kulik, Gary: Designing the Past: History-Museum Exhibitions from Past to the Present. In: Leon, Warren/Rosenzweig, Roy: 
In den fünfziger und sechziger Jahren waren die Präsentationen von einer wissenschaftlichen Nüchternheit und Konzentration auf das reine Objekt geprägt. Nach der Text- und Lesewelle der siebziger Jahre veränderten sich in den achtziger Jahren die Gestaltungen musealer Darbietungsformen, für die dann die Bezeichnung Inszenierung verwendet wurde. Obwohl im 19. Jahrhundert in Museen inszeniert wurde, gab es dafür noch nicht diese Bezeichnung. Seit wann Inszenierung und Inszenieren für die Tätigkeit des Zur-Schau-stellens in Ausstellungen genau verwendet werden, ist nicht ganz klar. Es dürfte sich dabei aber um eine relativ neue Wortübernahme handeln. Im Jahr 1972 fand dieser Begriff in der Praxis von historischen Museen und Ausstellungen noch keine Anwendung (Schober 1994, S. 9ff.). Ein Wiederaufgreifen der Praxis des Inszenierens im großen Stil einer kulturhistorischen Ausstellung fand in Deutschland im Jahr 1981 mit der Berliner Ausstellung „Preußen Versuch einer Bilanz" statt (Boockmann 2000, S. 310). ${ }^{15}$

Die Abkehr von der nüchternen Vitrinenpräsentation hin zu inszenierten Räumen erwächst aus der Forderung, den Besucher wieder mehr ins Blickfeld zu nehmen. Dies bedeutet einen Perspektivenwechsel von der Objektorientierung hin zu besucherorientierten Ausstellungen. Die zwei wichtigen Argumente, die diese Entwicklung förderten, waren zum einen, dass die Museen im Sinne der Demokratisierung ihren Bildungsauftrag stärken sollten. Zum anderen bedeutete es eine Abkehr vom elitären Musentempel für hauptsächlich akademisches Fachpublikum. In der wachsenden Erlebnisgesellschaft sollten auch in Museen Bildung für breite Bevölkerungsschichten sowie Spaß und Unterhaltung möglich sein. Einzelobjekte sollten nicht mehr isoliert in Vitrinen gezeigt werden. Dies kann zwar den Nicht-Wissenschaftler ästhetisch beeindrucken, jedoch ohne Hintergrundinformationen sind für einen Großteil der Besucher die historischen Zusammenhänge kaum zu erschließen: die Objekte bleiben stumm. Schuck-Wersig formulierte ein Plädoyer für eine neue Sehkultur und stellte die rhetorischen Frage mit ihrem Buch „Die Lust am Schauen oder müssen Museen langweilig sein?“16

History Museums in the United States. A critical assessment. Urbana/Chicago 1989, S. 3-37.

15 Eine Ausstellung der Berliner Festspiele GmbH im Martin-Gropius Bau in Berlin, 15. August bis 15. November 1981.

16 Schuck-Wersig, Petra: Die Lust am Schauen oder müssen Museen langweilig sein? Plädoyer für eine neue Sehkultur. Berlin 1986. 
Unter dem Begriff Inszenierung lässt sich vieles subsumieren. Fasst man den Begriff sehr weit, so ist jegliche intentionale Platzierung, Zusammenstellung mit anderen Objekten, jeder Einsatz von Licht, Farben, Sockeln usw. bereits ein In-Szene-setzen. Das Spektrum von Präsentationsmitteln ist dabei sehr breit. Mit künstlerischem Selbstverständnis geschaffene Rauminstallationen, ebenso wie Rekonstruktionen historischer Räumlichkeiten und Situationen oder schlicht die Hervorhebung eines bestimmten Exponats durch Beleuchtung oder besondere Umgebung werden dann als Inszenierung begriffen.

Fasst man den Terminus Inszenierung jedoch so weit, dass er jede Platzierung und Konfiguration mit anderen Objekten und jeden Einsatz von Licht, Farbe und Sockel beinhaltet, wird der Begriff überdehnt und sein Informationsgehalt sinkt. Das Konzept Inszenierung, das programmatische Inszenieren in Ausstellungen, das den Untersuchungsgegenstand dieser Arbeit darstellt, muss somit deutlich enger gefasst und charakterisiert werden. Semantisch ist festzuhalten, dass der Begriff der Inszenierung dem Umfeld des Theaterbegriffs angehört. Sucht man im Brockhaus unter dem Begriff Inszenierung, findet man eine Definition, die sich ausschließlich auf Theater bezieht:

„französisch: die, darstellende Kunst: 1) die der Aufführung eines Bühnenstücks oder der Umsetzung eines Drehbuchs dienende Vorbereitung, Bearbeitung und künstlerische Gestaltung (Regie); 2) die Aufführung als Ergebnis dieser Vorgänge“ (Bibliographisches Institut \& F. A. Brockhaus AG, 2001)

Die Tätigkeit des Inszenierens im Theater umfasst alle Verrichtungen, die damit zusammenhängen, ein Stück auf die Bühne zu bringen: das technische und künstlerische Vorbereiten, Gestalten und Leiten von Aufführungen und Dreharbeiten. Inszenieren bedeutet damit, etwas - im Theater einen Text - zu visualisieren und für die Bühne umzusetzen. Die Umsetzung eines Stoffes - seine Inszenierung - geschieht immer aus einer bestimmten Perspektive. Bei jeder neuen Aufführung wird der ursprüngliche Text neu bearbeitet. Inszenieren enthält damit immer auch ein visualisierendes Deuten und Interpretieren (Schober 1994, S. 9). An dieser Stelle berühren sich die Absichten von Theater und Museum. Ähnlich ist dabei vor allem die Bedeutung, die den visuellen Gestaltungsmitteln zukommt, wobei das Interesse des Museums an Inszenierungen vor allem von den Ideen inspiriert wird, die das Theater bei der Gestaltung von Bühnenbild und -raum sowie Requisiten entfaltet. 
So weit gefasst wie der Inszenierungs-Begriff ist, kann er aus verschiedenen Perspektiven definiert werden. Um die Vielschichtigkeit des Begriffes aufzuzeigen, sollen hier stellvertretend zwei Definitionen angeführt werden, die den Vorgang der Inszenierung aus den Perspektiven der Pädagogik und Philosophie schlaglichtartig beleuchten. Die Arbeitsgruppe für Empirische Bildungsforschung betont die Tatsache, dass jede Form der Präsentation eine Interpretation der Inhalte darstellt. ${ }^{17}$

„Als Inszenierung verstehen wir solche Präsentationsformen, die mit anschaulichen Mitteln deuten. Dabei soll ausdrücklich mehr und anderes geschaffen werden, als eindimensionale Erklärungszusammenhänge von Objekt und Text. Inszenierungen sollen vielmehr durch das absichtsvolle Arrangement von Original und Medien und anderen Ausstellungsmitteln Kontexte schaffen, die auf die Vermittlung vernetzter Bezüge und Wechselwirkungen hin angelegt sind.“ (ebd., S. 8)

Mittels Inszenierung wird bewusst der Versuch unternommen, keine eindimensionalen Erklärungen zu geben, sondern Kontexte zu schaffen, die es dem Besucher ermöglichen, Inhalte im Zusammenhang kennen zulernen und somit auch Wechselwirkungen kritisch hinterfragen $\mathrm{zu}$ können. Der Bildung wird dabei ein besonderer Stellenwert eingeräumt.

Aus dem Blickwinkel der Philosophie sind für Martin Seel Inszenierungen absichtsvoll eingeleitete oder ausgeführte sinnliche Prozesse, die vor einem Publikum dargeboten werden, so dass sich eine auffällige, spatiale und temporale Anordnung von Elementen ergibt, die auch ganz anders hätte ausfallen können. ${ }^{18}$ Jede Inszenierung ist nach Seel eine Inszenierung der Gegenwart. Sie will etwas in seiner augenblicklichen Besonderheit hervortreten lassen. Diese Begegnung ist als solche weder

17 Die Arbeitsgruppe für empirische Bildungsforschung e.V. beschäftigte sich von 1987 bis 1989 im Rahmen eines vom Bundesministerium für Bildung und Forschung geförderten Projekts mit dem Thema „Weiterbildung von Museumspersonal für Vermittlungsaufgaben“. Unter besonderer Berücksichtigung eines Bildungsverständnisses für Inszenierung analysierte die Arbeitsgruppe zwei Ausstellungen als Fallstudien. Die daraus resultierenden Ergebnisse wurden in einer Dokumentation festgehalten. Paatsch, Ulrich: Konzept Inszenierung: Inszenierte Ausstellungen - einer neuer Zugang für Bildung im Museum? Ein Leitfaden. Heidelberg 1990.

18 Seel formuliert zunächst eine formale Bestimmung, die er jedoch im weiteren Verlauf seiner Thesen zu gehaltvollen Aussagen führt. Vgl. Seel, Martin: Inszenieren als Erscheinenlassen. Thesen über die Reichweite eines Begriffs. In: Früchtl/Zimmermann 2001, S. 49. 
ästhetisch noch ästhetisch inszeniert. Ästhetische Inszenierungen erzeugen vielmehr eine Gegenwart, die als solche auffällig wird. Sie machen Gegenwart bemerkbar: Das ist ihre primäre Leistung. Inszenierung, stellt Seel fest, ist die öffentliche Herstellung eines vorübergehenden räumlichen Arrangements von Ereignissen, die in ihrer besonderen Gegenwärtigkeit auffällig werden (ebd., S. 54ff.).

„Inszenierungen sind freilich nicht einfach Phänomene des Erscheinens, sie stellen etwas in seinem Erscheinen heraus, markieren es, um es für eine gewisse Dauer in einem öffentlichen Raum spürbar zu machen. Sie zielen darauf, das Geschehen, das sie ausmacht, in ihren momentanen und simultanen Bezügen zum Vorschein und damit zu einer vorübergehenden auffälligen Gegenwart kommen zu lassen." (ebd., S. 57)

Aktuell wird für inszenierte Ausstellungen auch der Begriff Szenographie verwendet, der primär von Seiten der Gestalter eingeführt und geprägt wurde. ${ }^{19}$ Insbesondere die Verantwortlichen für den Themenpark der Expo 2000 bedienten sich des aus dem Französischen entlehnten Begriffs. Pointierte, sinnlich aufgeladene Bilder sollen Aussagen verdichten und ein weites Assoziationsfeld eröffnen. Der Begriff Szenographie meint die künstlerische Interpretation und szenische Umsetzung von Inhalten, die durch gestalterische Mittel deutlicher und prägnanter in ihrer Wirkung und damit in ihrer intendierten Aussage sind. Dies ähnelt durchaus dem Anspruch eines Inszenierungskonzeptes. Während Inszenierungen jedoch primär von architektonischen und bühnenbildnerischen Maßnahmen geprägt sind, betont und praktiziert die Szenographie zudem die Integration von Tanz und Film, Techniksimulation und Musik, Choreographie und Kunst unter Einbeziehung sämtlicher technischer Möglichkeiten. ${ }^{20}$ Durch die Entwicklung der Eventkultur verlässt das Medium Ausstellung immer mehr das Museum, und umgekehrt hält die Szenographie Einzug in das Museum. Die Hochschule für Gestaltung in Karlsruhe, die seit Beginn der neunziger Jahre einen Lehr-

19 Bewusst verwende ich den aktuell modischen Begriff Szenographie nicht, da dieser meiner Ansicht nach zu sehr auf Technisierung, Mediatisierung und Environment setzt und dem musealen Objekt eine untergeordnete Bedeutung zumisst.

20 Drescher, Bettina: Im Westen nichts Neues? Themenpark und Sieben Hügel. Präsentationsästhetiken im Vergleich. 2000, S. 1, www.ulmerverein.de/drescher.html (letzter Zugriff: 03.07.01). 
stuhl für Szenographie eingerichtet hat, definiert ihr Lehrgebiet folgendermaßen:

„Interdisziplinäres Arbeiten ist das Ziel der Ausbildung mit dem Schwerpunkt der Szenografie an der HFG. Vor allem das Berufsbild des Bühnenbildners, auf den sich die Ausbildung bezieht, ist derzeit im Wandel begriffen. Der Weg zeigt weg von der klassischen Theaterbühne hin zum medienorientierten Arbeiten bei Film, Fernsehen und Eventagenturen, und zur Vernetzung mit dem Ausstellungs- und Lichtdesign unter Einbeziehung neuer Technologien.“21

Deutlich wird in dieser Formulierung, wie sehr sich die Grenzen zwischen den einzelnen Sparten auflösen und vermischen. Szenografen stehen an den Schnittstellen von Projekten zwischen Performance, Aktionskunst, Theater, Ausstellung, Media Plays, Scenic Environment und Multimedia Events.

Wie bereits der Inszenierungsbegriff sehr weit und unterschiedlich aufgefasst werden kann, so gibt es auch in Bezug auf konkretere Bestimmungen eine Vielzahl von Bezeichnungen, die jeweils aus verschiedenen Perspektiven interpretiert werden. Im Hinblick auf die strukturelle Gliederung der Ausstellungsexponate unterscheiden Schuck-Wersig/Wersig zwischen Ensemble und Konfiguration. Der Begriff Ensemble bezieht sich in diesem Fall auf rekonstruktive Bildräume, in denen Objekte zur Rekonstruktion eines ursprünglichen Bezugs zusammengeführt werden. Der Begriff Konfiguration verweist auf Inszenierungen, in denen sich Objekte und Informationen gegenseitig erläutern und eine Idee ausdrücken wollen (Schuck-Wersig 1986, S. 156).

Klein/Wüsthoff-Schäfer unterscheiden zwischen dem rekonstruktiven, dekorativen und symbolisierenden Typus. Die dritte Gruppe beschreibt alle Zusammenstellungen von Museumsgegenständen oder anderen Medien, um eine Idee zu vermitteln. Dekorative Ausstellungen betonen den Einsatz dramaturgischer Mittel wie Licht, Farbe und Materialien für vorwiegend ästhetische Zwecke und zur Erzeugung einer stimmigen Atmosphäre. ${ }^{22}$ In Bezug auf meine Einteilung fasse ich den dekorativen sowie symbolischen Typus zusammen und bezeichne diese als abstrahierende Raumbilder. Die Bezeichnung dekorativ erscheint mir nicht treffend gewählt, da mit Dekoration lediglich auf schmückendes

21 Studienleitführer der Hochschule für Gestaltung HFG Karlsruhe 2001.

22 Klein, Hans-Joachim/Wüsthoff-Schäfer, Barbara: Inszenierung an Museen und ihre Wirkung auf Besucher. Berlin 1990, S. 21. 
Beiwerk verwiesen wird. Dies deutet auf ästhetische Beliebigkeit hin. Gerade darin liegen die Ziele der Inszenierung nicht, die vielmehr in der bewussten Interpretation der Artefakte liegen.

Ausgehend von diesen Überlegungen unternehme ich den Versuch, Inszenierungen nach formalästhetischen Kriterien zu kategorisieren. Im Folgenden werde ich deshalb auch von Raumbildern sprechen. In Anlehnung an Stilkriterien der bildenden Kunst vollziehe ich eine Einteilung in zwei Hauptkategorien: rekonstruktive und abstrahierende Raumbilder. ${ }^{23}$ Diese Einteilung bezieht sich auf den Gesamteindruck der Inszenierungseinheit und der beabsichtigten Aussage. So kann zum Beispiel im Hinblick auf die inhaltliche Aussage unterschieden werden, ob ein Bezug zu einem speziellen historischen Sachverhalt hergestellt werden oder eine Idee vermittelt werden soll. Diese Einteilung in zwei Hauptkategorien dient als Mittel der Typologisierung. Einschränkend möchte ich betonen, dass diese in der Ausstellungsrealität nicht scharf voneinander abgegrenzt werden können. Die Gesamtinszenierung einer Ausstellung kann sich sowohl rekonstruktiver als auch abstrahierender Stilelemente bedienen. Diese stellen zwei Gegenpole dar, innerhalb deren Bandbreite eine unendliche Vielzahl von Variationen möglich sind.

23 Im Blick auf die angloamerikanische Bezeichnungen trifft Peart eine Unterscheidung zwischen abstract und concrete exhibits. Hier bezieht sich das Einteilungskriterium darauf, ob museale Objekte in die Ausstellung integriert sind. Abstract exhibits verzichten völlig auf museale Objekte und beschränken sich auf inhaltliche Vermittlung, im Gegensatz zu concrete exhibits, die primär das dreidimensionale, haptisch fassbare museale Objekt in den Mittelpunkt stellen. Vgl. Mensch, Peter van: Characteristics of exhibitions. Amsterdam 2001, S. 11. 


\section{Rekonstruktive Raumbilder}

$\mathrm{Zu}$ den rekonstruktiven Raumbildern zählen all die Inszenierungen, die zum Ziel haben, eine bestimmte historische Begebenheit zu rekonstruieren oder an historische Situationen zu erinnern. Zu dieser Kategorie gehören Freilichtmuseen, historische Häuser und Räume sowie historisch rekonstruktive Ausstellungen. ${ }^{24}$ Im weitesten Sinne zählen dazu auch die kommerziellen historischen Erlebnis- und Themenparks.

Wesentliches Unterscheidungskriterium zwischen musealen Ausstellungsgestaltungen und kommerziellen Erlebnisparks stellt die Art des Umgangs mit der Historie dar. Bei historischen Ausstellungen gilt der Grundsatz der wissenschaftlichen Korrektheit. Im Gegensatz dazu bilden für Themenparks historische Ereignisse lediglich einen Anknüpfungspunkt für eine phantasievolle und erfindungsreiche Erzählung mit dem übergeordneten Ziel, daraus unternehmerischen Gewinn zu erwirtschaften. Aus diesem Grund grenze ich bei meinen Ausführungen die rekonstruktiven Raumbilder auf wissenschaftlicher Basis von den kommerziellen Erlebnisparks mit historischen Themen ab. Dazwischen steht die dritte Gruppe der historischen Erlebnisorte. Diese orientieren sich an

24 Die englischsprachige Literatur entwickelte ebenfalls eine Reihe von Begriffen. Für die Einrichtung historischer Örtlichkeiten werden die Begriffe Period room sowie Period Setting verwendet. Fleming (1972) unternahm als erster den Versuch, diese zu klassifizieren. Sein Hauptkriterium für die Unterscheidung ist die Frage nach der historischen Authentizität. Im Hinblick darauf unterscheidet er zwischen Period rooms und Period settings. Bei der Gestaltung eines Period room wird versucht, die Gesamtheit eines Raumes und seiner Ausstattung nach dem ursprünglichen Zustand und Nutzen der jeweiligen Zeit zu rekonstruierten. Diese Rekonstruktion soll sich dem ursprünglichen Zustand möglichst annähern. Die Gegenstände werden nicht nur zusammengestellt, sondern auch deren ursprünglicher Gebrauchszusammenhang wird angedeutet. Das Period setting hingegen schafft mittels Architektur und dekorativen Elementen wie Boden, Wänden, Kaminen einen Prototyp eines authentischen Interieurs, während jedoch der Raum selbst als Ausstellungsraum für beispielsweise Möbel oder andere dekorative Elemente genutzt wird. Das Period setting fügt zusammengehörende Objekte, zum Beispiel aus der Renaissancezeit, zusammen. Es wird jedoch nicht der Versuch unternommen, detailliert das Leben nachzuvollziehen, es wird stilisiert angedeutet und kann sich auf einen Teilaspekt beschränken. Vgl. Mensch 1992, Kapitel 22, Communication. 
historischen Begebenheiten, jedoch auch das Gesamterlebnis der Besucher fließt in das Gestaltungskonzept ein. ${ }^{25}$

Die Inhalte und Botschaften rekonstruktiver Raumbilder bestehen darin, möglichst klar das historische Ambiente zu vermitteln. Die Klarheit der Gestaltung eines gesamtheitlichen, historischen Eindrucks mit weitgehender Ausklammerung verfremdender oder irritierender Elemente gewährleistet mit größerer Wahrscheinlichkeit, dass der Besucher diese Darstellungen nicht missverständlich interpretiert. Wie dies bestmöglich umgesetzt werden kann, darüber existieren wiederum verschiedenste Auffassungen und Meinungen. Ein wesentlicher Aspekt besteht darin, inwiefern sich die Ausstellungsmacher der historischen Fundierung verpflichtet fühlen. Das Ziel kann darin liegen, ein Maximum an Authentizität zu entwickeln. Problematisch jedoch ist, dass diese Art ebenfalls nur eine Form der Interpretation darstellt, die dem jeweiligen Zeitgeschmack und aktuellen Vorstellungen unterliegt. Ganzheitliche historische Erlebnisorte sind unter Wissenschaftlern sehr umstritten, da sie vorgeben, Vergangenheit rekonstruieren zu können, was letztlich aber nicht möglich sein kann. Die historische Betrachtung ist immer eine Heraushebung wesentlicher Elemente aus dem umgreifenden Lebenszusammenhang für das jeweilige Thema unter Vernachlässigung anderer Faktoren. Es entsteht ein neues Gebilde, das nicht als Spiegelbild des realen Lebenszusammenhangs aufgefasst werden kann. ${ }^{26}$

\section{Rekonstruktive Raumbilder auf der Basis wissenschaftlicher Forschung}

Die Gruppe der gegenständlichen Raumbilder ist wiederum in ihren Erscheinungen sehr unterschiedlich ausgestaltet. Historische Ortschaften und Häuser werden nach der Terminologie von Schuck-Wersig/Wersig als Ensembles (Schuck-Wersig/Wersig 1986, S. 156) und nach Klein \& Wüsthoff-Schäfer als Inszenierungen rekonstruktiven Typus' bezeichnet

25 In der angloamerikanischen Literatur findet man dafür die Bezeichnung immersion setting. In der wörtlichen Übersetzung bedeutet immersion Versenkung, Versunkenheit. Im Ausstellungswesen wurde der Begriff zuerst im Zusammenhang mit einem neuen Typus zoologischer Gärten verwendet, bei denen Besucher den Eindruck gewinnen, sich gemeinsam mit den Tieren in einer völlig natürlichen Landschaft zu bewegen (Klein 1998, S. 116).

26 Dies verweist auch auf die erkenntnistheoretischen Thesen des Konstruktivismus und der Grundannahme, dass es keine objektive Wirklichkeit gibt. 
(Klein/Wüsthoff-Schäfer 1990, S. 21). Diese können sich noch in ihrer ursprünglichen, natürlichen Umgebung befinden oder in der künstlichen Umgebung eines museologischen Umfeldes. Eine weitere Differenzierung kann zwischen authentischem und nicht authentischem Ensemble getroffen werden. Unter Ersterem wird die Anordnung ursprünglich wirklich zusammengehöriger Gegenstände verstanden, zum Beispiel das Mobiliar eines Wohnraumes oder Geräte und Maschinen einer Werkstatt, und zwar in der Weise, dass die Aufstellung im Museum genau den Verhältnissen der ursprünglichen Situation entspricht. Das nicht authentische Ensemble dagegen besteht aus zusammengestellten Gegenständen etwa aus einer bestimmten historischen Zeitspanne, zum Beispiel werden Möbel zu einem Biedermeierzimmer gruppiert, die ursprünglich nicht zusammengehörten. Auch eine entsprechende Zusammenstellung, in der Originale gemeinsam mit Nachbauten oder einem Großfoto gezeigt werden, kann gemeint sein. Es wird nicht naturgetreu nachgebildet, sondern es werden aus sachlich zusammengehörigen Originalgegenständen, aus Tonbandinterviews mit Zeitgenossen, aus historischen Fotographien und vielen anderen Bedeutungsträgern Bild-Räume aufgebaut. Auch die Vitrinen sind nach diesem Prinzip der Erzählung gestaltet. Kein Gegenstand der Ausstellung steht nur für sich selbst; alle sind in den Zusammenhang solcher erzählender historischer Ensembles und Räume eingebunden.

Als Beispiel für ein rekonstruktives Szenenkonzept sei auf die Ausstellung des Landesmuseums Karlsruhe „1848/49: Revolution der deutschen Demokraten in Baden“ verwiesen. Das Anliegen bestand darin, die komplexe Geschichte dieser Revolution in klar verständlichen, anschaulichen Bildern zu erzählen. Eine Szene zeigte zum Beispiel die überraschende Flucht eines Großherzogs. Die Dynamik des Geschehens sollte verdeutlicht werden (siehe Abb. 2).

,[...] stehengelassene Gepäckstücke einer geplanten, dann aber doch überstürzten Abreise, aufgerissene Schubladen, verstreute Dokumente [...]. Eine Säulengalerie, Waffen der badischen Armee enthaltend, gerät Säule für Säule immer stärker ins Kippen und fällt in den hoheitlichen Lebensraum hinein.“27

Die meisten Szenenbilder waren quasi eingefrorene Augenblicke, Momentaufnahmen, die so oder ähnlich stattgefunden haben könnten, als hätten die historischen Akteure gerade die Räumlichkeiten verlassen und

27 Ranger Kurt: Anschaulich ausstellen. Bilder erzählen Geschichten. In: Badisches Landesmuseum Karlsruhe (Hrsg.): Inszenierte Geschichte(n). Baden-Baden 1999, S. 15. 
könnten jeden Moment zurückkommen. Die Szenenbilder waren überwiegend konkret in ihrer Handlung und Erzählung und verzichteten weitgehend auf einen abstrakten symbolischen Gehalt, der erst unter Kenntnis eines Codes dechiffriert werden müsste, um ihn zu verstehen.

Die Rolle des Gestalters ist dementsprechend abhängig von der Forderung nach wissenschaftlicher Genauigkeit im Hinblick auf die historische Forschung und Quellenlage. Bei wissenschaftlich fundierten Ausstellungen ist die Freiheit des Gestalters nur insofern möglich, wie sie dem Ziel der Illustrierung des historischen Ereignisses dienlich ist.

„Was produziert wird, ist allerdings kein literarischer Text, sondern ein Text aus Bildern, Objekten, aus Vitrinen, Ensembles und festgelegten Wegen. Diese Inszenierung ist jedoch nicht beliebig. Auch die Darstellung von Geschichte in Ausstellungen und Museen erfolgt auf der Basis von Quellen, hier der Objekte, und ihrer Integration und darf der Quellenlage nicht zuwiderlaufen, wenn die Aussage verständlichen Sinn machen und die Sinnhaftigkeit eine Geschichte in sich hohe Erkenntnis umsetzen soll.“ (Grütter 1994, S. 182)

Dramaturgische Mittel wie Licht, Material und Farbe werden primär in einer Art und Weise eingesetzt, wie sie das Verständnis der historischen Darstellung fördern. Dies kann aber auch dazu führen, dass der Besucher zwischen Kopie und Original nicht mehr unterscheiden kann.

\section{Historische Erlebnisorte}

Eine Steigerung des rekonstruktiven Ansatzes stellen illusionistische Umwelten dar, von denen der Besucher mit allen Sinneseindrücken eingenommen wird, also etwa begehbare Räume, die quasi-authentische Erlebnisse eines Dort-Seins vermitteln. Als frühe Beispiele können die Freilichtmuseen angeführt werden. ${ }^{28}$ Zur Vervollkommnung des Gesamteindrucks im Sinne eines lebendigen Museums wird auch kostümiertes Personal eingesetzt, das im historischen Umfeld das Leben der Vergangenheit nachspielt. Besucher können die Schauspieler beim Arbeiten mit historischem Werkzeug beobachten.

In der Abgrenzung von kulturhistorischen Museen und Ausstellungen, die sich der wissenschaftlichen Genauigkeit verpflichtet fühlen, erhalten bei der Konzipierung von historischen Erlebnisorten Gestalter ei-

28 Bereits 1881 wurde das erste lebendige Freilichtmuseum Skansen in Schweden von Artur Hazelius gegründet. 
ne vergleichsweise gesteigerte Bedeutung. Hier unterliegt er nicht mehr so sehr den streng wissenschaftlichen Vorgaben. Der erlebnisorientierte Gesamteindruck dient als oberstes Entscheidungskriterium. Jedoch findet nach wie vor eine Orientierung am historischen Material statt, wie dieses Zitat der Macher der Ausstellung „The story of Berlin“ illustriert:

„Geschichte nicht als trockener Unterricht, als schier endlose Kette von Jahreszahlen, sondern spannend aufbereitet wie ein fesselnder Kriminalroman, wie ein guter Film. Ja, wir haben ausgewählt, aus dem großen Archiv der Jahrhunderte. Mit Hilfe der Gestalter haben wir Szenenbilder entstehen lassen, die emotionale Erfahrung mit sachlichen Informationen verbinden.“ ${ }^{29}$

\section{Kommerzielle Erlebnisparks mit historischen Themen}

Diese Erlebnisorte nähern sich den historischen Themenparks an. Auf eine wissenschaftliche Fundierung bei der Konzeptionierung kommerzieller Freizeiträume wird jedoch oft völlig verzichtet. Damit spielen Historiker in diesen Konzepten keine Rolle. Demgegenüber sind die Designer von sehr hoher Bedeutung, da diese maßgeblich das Erscheinungsbild bestimmen. Sie sind die prägenden Figuren, die ein phantasievolles Ambiente entwerfen. Das historische Thema stellt lediglich einen Ausgangspunkt dar und liefert gestalterische Impulse. Phantasievolle Verfremdungen sind legitim. Bei der gestalterischen Umsetzung besteht keinerlei Anspruch, Vergangenheit authentisch zu rekonstruieren. Vielmehr geht es darum, diese zu verbessern und negative Elemente zu eliminieren. Aus der Beschreibung des Arbeitsprozesse der Disney imagineer $^{30}$ geht dies sehr deutlich hervor: „What we create is a Disney Realism, sort of Utopian in nature, where we carefully program out all the negative, unwanted elements and program in the positive elements. “31

Den Urtypus eines Themenparks entwickelte Walt Disney in den fünfziger Jahren. In Zusammenarbeit mit Architekten und Animateuren entwickelte er die berühmten Ikonen der Disney-Themenparks mit Burg, Hauptstraße und Einteilung in verschiedene Themenbereiche. Diese zu-

29 Nishen, Dirk: The story of Berlin. Geschichten einer Metropole - Berlin schaut in den Spiegel. Berlin 1999, S. 5.

30 Dies ist die selbstgewählte Berufsbezeichnung der Gestalter der Disneyländer.

31 Wallace, Michael: Mickey Mouse History: Portraying the Past at Disney World. In: Warren, Leon/Rosenzweig, Roy: History Museums in the United States. Illinois 1989, S. 161. 
nächst nur in Amerika existierenden Parks gibt es mittlerweile in zahlreichen Ausformungen auch in Deutschland. Einen speziellen Typus dieser Erlebnisparks bilden jene Formen, die mit historischen Mythen und Klischees arbeiten. Deutschlands größter Freizeitpark, der Europa Park in Rust, wirbt mit den Kulturen Europas und zeigt nachgebaute Architektur aus elf europäischen Themenbereichen. In der Ritterburg „Castillo Alcazar" wird man in die Zeit der Ritter und Burgfräulein entführt. Im Prospekt steht zu lesen:

„Mächtig und gewaltig zeigt sich die altspanische Ritterburg Castillo Alcazar. [...] Die Möbel sowie die Gestaltung der 120 Zimmer sind in mittelalterlicher Schlichtheit gehalten, jedoch mit soviel modernem Luxus gepaart, dass keine Annehmlichkeit fehlt." (siehe Abb. 3) ${ }^{32}$

Es besteht bei den Verantwortlichen des Parks keinerlei Interesse, die Einfachheit und Kargheit der damaligen Lebenswelt zu vermitteln, wie zum Beispiel die Kälte in mittelalterlichen Burgen. Dies würde den romantischen Vorstellungen der Besucher nicht entsprechen und somit auch nicht den ökonomischen Zielen dienlich sein.

32 Beschreibung aus dem Prospekt des Europa-Parks in Rust aus dem Jahr 2001. 


\section{Abstrahierende Raumbilder}

$\mathrm{Zu}$ den abstrahierenden Raumbildern zählen jene Formen der Inszenierung, die über eine historisch bestimmbare Situation hinausweisen. Die Gestaltung tritt in den Vordergrund, der Designer oder Künstler bringt sich mit seinem künstlerischem Ausdruck ein. Bei einer Unterscheidung zwischen Ausstellungsdesigner und Ausstellungskünstler orientiert sich der Designer an den kulturhistorischen und geschichtlichen Vorgaben. Er begreift sich als Vermittler, der seine Aufgabe in der Visualisierung bestimmter Themen und Ideen sieht, dazu aber auch mit abstrakten, gestalterischen Formelementen in der Ausstellungssprache arbeitet. Der Ausstellungskünstler hingegen entwickelt eine expressivere Ausstellungssprache. Seine subjektive Interpretation tritt in den Vordergrund. Gleichzeitig bedeutet dies ein Zurückdrängen der historisch wissenschaftlichen Sichtweise. Dies kann bis hin zu einer freien Interpretation gehen, die die Objekte in völlig unerwartete Kontexte stellt. Bei dieser Arbeitsweise nähern sich die kulturhistorischen Ausstellungen den Kunstausstellungen an. ${ }^{33}$

Der Besucher wird mit seinen subjektiven Empfindungen und Dispositionen bei der Konzeptentwicklung als wesentliche Einflussgröße betrachtet. Es geht um die Frage, wie die Objekte zum Betrachter in Bezug gesetzt werden können. Die Aufmerksamkeit wird nicht mehr so sehr dem ausgestellten Objekt gewidmet, sondern einer allumfassenden Idee, bei der das Objekt nur noch eine komplementäre Aufgabe erfüllt. Ein Hauptanliegen besteht darin, ein Verständnis beim Betrachter zu erreichen. Es geht nicht ausschließlich darum, dem Betrachter Sachinformation zu liefern und etwas zu zeigen, sondern ihn an Erfahrungen teilhaben zu lassen. Speziell die emotionale Ebene des Betrachters soll zusätzlich angesprochen werden. Man möchte ihm dafür weitere Impulse anbieten. Dies soll den Besucher dabei unterstützen, den Grundgedanken dessen, was ausgestellt wird, auf mehreren Ebenen zu erfassen, zu beurteilen und schließlich zu verstehen. Mit anderen Worten: Das Ziel dieser Arbeitsweise ist in erster Linie die Auseinandersetzung mit Ideen und weniger die Ausstellung von Objekten. Der Rezipient soll an der Aktion beteiligt werden, die in diesen Ideen Gestalt annehmen. Diese Strömung ist deutlich von den Kunstbewegungen der sechziger Jahre mit ihren Installationen und Performances beeinflusst. Sie findet ihren Ausdruck

33 Eine ausführliche Beschreibung des künstlerischen Ansatzes siehe Kapitel 3.3: Künstlerischer Ansatz. 
unter anderem sehr deutlich in den Arbeiten von Hans Hollein. ${ }^{34}$ Das ganzheitliche Erleben war bereits auch in der malerischen Präsentation wichtig, doch bezieht sich hier das Erleben auf die historische Situation. Neu ist in der Entwicklung, die zeitlich ab den sechziger Jahren zu beobachten ist, dass zum Beispiel auch subjektive Gefühlszustände thematisiert werden. So geht es zum Beispiel dem Ausstellungsarchitekten Schaal „nicht um Ausstellungsdesign, sondern darum, die Welt des Staunens wiederzuentdecken. “35

Die Wahrnehmung und Decodierung kann im Vergleich zu den rekonstruktiven Raumbildern schwieriger sein, da die Wirkung beiläufiger, indirekter und zum Teil auch bewusst subtiler ausfällt. So kann dies auch dazu führen, dass Inszenierungseinheiten als solche nicht wahrgenommen oder missverständlich interpretiert werden.

Die Frage der Inhalte und Botschaften einer Ausstellung bilden grundlegende Faktoren für die gestalterische Umsetzung. Nach wie vor kann der Inhalt Bezug zu einem historischem Sachverhalt nehmen. Doch die primäre Intention liegt nicht in der Illustrierung eines historischen Ereignisses, sondern in dessen Abstrahierung. Dies kann die Thematisierung eines abstrakten Begriffes oder Visualisierung mittels Symbolen bedeuten. Beispielsweise demonstrierte der Ausstellungsarchitekt Schaal in seiner Arbeit konsequent, dass archäologische Fiktionen, verschüttete Erinnerungen, Träume, Mythen und Obsessionen stets aufs Neue thematisiert werden müssen, um aus immer komplexer werdenden, historischen Raum- und Zeitverflechtungen überhaupt noch einen kritischen Überblick oder einen alternativen poetischen Weltentwurf liefern zu können (ebd., S. 31). So war beispielsweise bei der Ausstellung „Berlin - Berlin“, gestaltet von Hans Dieter Schaal, der zentrale Raum ,die Metropole der 20er Jahre bei Nacht" als großes, begehbares Modell konzipiert. Gestaltet als „Phantasieraum mit Zitaten“ sollte dies die zwanziger Jahre vergegenwärtigen und gleichzeitig mittels Übertreibung Assoziationsräume schaffen.

34 Azara, Pedro/Harth, Carlos G.: Bühnen- und Ausstellungsarchitektur. Stuttgart/München 2000, S. 34.

35 Werner, Frank R.: Raum-Zeiten und Zeit-Räume: Ephemere Architektur im Spiegel der Geschichte. In: Werner, Frank R.: Hans Dieter Schaal. InBetween - Ausstellungsarchitektur. Stuttgart/London 1999, S. 29. 
„Im Mittelpunkt steht der einmalige Höhepunkt, urbaner Glanzraum der Welt: die Stadt Berlin in den 20er Jahren. Nachts: Lichter spiegeln sich im Asphalt. Die Wände stürzen, die Fenster tanzen, ein Geflecht auch sich kreuzenden heftigen Sehnsuchtswegen. Baustelle, Filmstudio, Labor. Im Entstehen und im Verfall. Kaum aufgerichtet, schon zum Skelett zur Ruine verfallen. Transparenz. Gläserne Momente der Geschichte." (Werner 1999, S. 65)

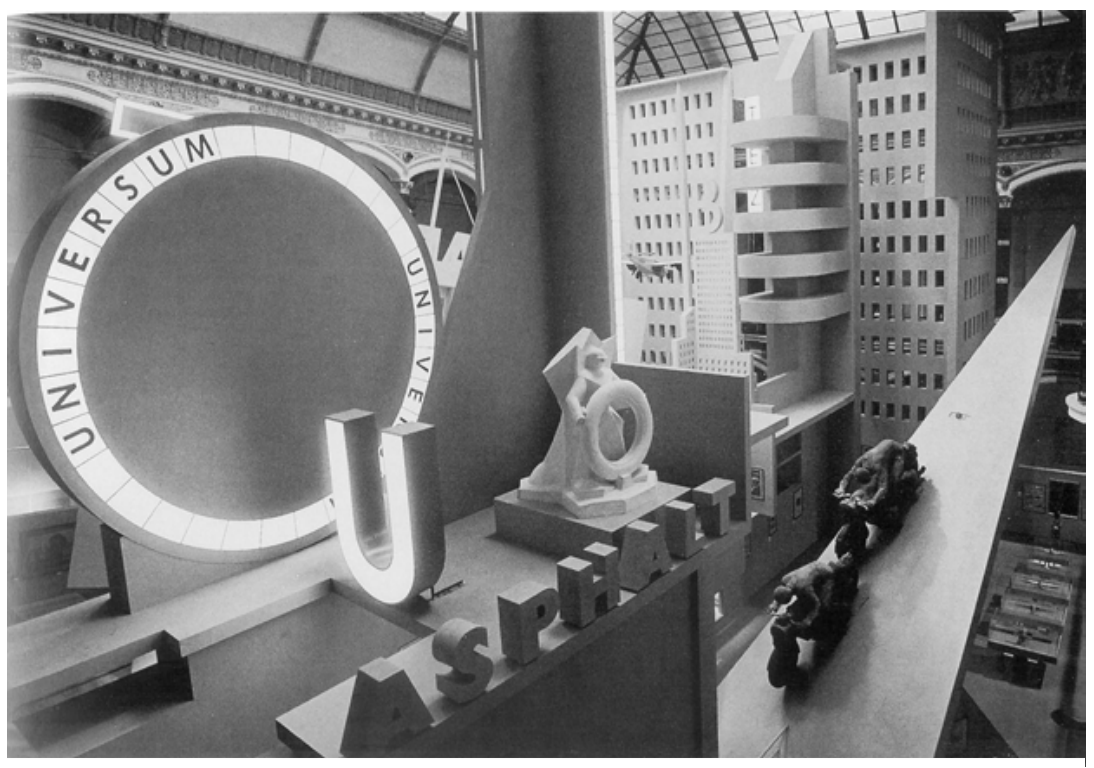

Abbildung 4: Der zentrale Raum „Die Metropole der 20er Jahre bei Nacht“ der Ausstellung „Berlin-Berlin“ im Martin-Gropius-Bau.

Dies bedeutet, dass Inhalte in der Ausstellungsdramaturgie nicht mehr nach fachwissenschaftlichen Kriterien gegliedert werden. Damit nimmt der Grad der subjektiven Interpretation zu. Im Falle der künstlerischen Interpretation kann dies zu höchst ungewöhnlichen Zusammenstellungen und somit zu einer völlig neuartigen Sichtweise führen. ${ }^{36}$ Im Hinblick

36 Im großen Stil wurde dieser Ansatz bei der Milleniums-Ausstellung „Sieben Hügel. Bilder und Zeichen des 21. Jahrhunderts“ im Martin-GropiusBau vom 14.05.-29.10.2000 in Berlin umgesetzt. „Tatsächlich nahmen die Raumarrangements mitunter die Gestalt von Allegorien an, der Andeutung von Begriffen durch Bilder, worin die einzelnen historischen Objekte, Kunstwerke, Installationen zu Attributen, ja Ornamenten zu werden schie- 
auf die Gestaltung arbeitet man unter Zuhilfenahme aller dramaturgischen Mittel wie Licht, Farbe und Materialien mit der Absicht zu verdichten, akzentuieren oder zu untermalen. Dies kann zum Beispiel durch Vergrößerungen, Verkleinerungen, Einbau von Irritationen, Einsatz von Licht- und Farbdramaturgie oder Variation mit Architekturelementen geschehen. Eine derartige Auffassung richtet sich explizit gegen bemüht wertneutrale Objektpräsentationen oder rekonstruktive Ansätze. Sie steht auch im Gegensatz zu ,postmodernen Ausstellungsprojekten der Vergangenheit, welche nach Gründerzeitmanier die Wirkung der Dinge durch verkünstelte Drapierungen, populistische Disneylandeffekte erstickt haben.“ (ebd., S. 29)

In welcher Form und Prägnanz die gestalterische Handschrift in den Vordergrund tritt, ist wesentlich vom Selbstverständnis des Ausstellungsgestalters abhängig. Durch die Wahl des Gestalters erfolgt eine zentrale Weichenstellung im Planungsprozess. Im Mittelpunkt aller Überlegungen steht die Frage, welchem gestalterischen Ansatz, welcher Gestaltungsphilosophie sich der Ausstellungsarchitekt oder -gestalter verpflichtet fühlt. Des Weiteren muss geklärt werden, ob und inwieweit er das Medium Ausstellung als eigenständige Ausdrucksform der visuellen Kommunikation begreift und es als selbstverständlich betrachtet, „den Primat des Objekts anzuerkennen, so wie man als Bühnentechniker anerkennen muß, daß es letztlich nur um die Schauspieler geht.“37 Meist stehen die Ausstellungsdesigner im Hintergrund und bleiben, abgesehen von den Protagonisten des Bauhauses und einiger weniger Stardesigner und -architekten, anonym. Da diese sich in der Regel als Teil eines Teams, vor allem in der Zusammenarbeit mit den Wissenschaftlern, begreifen, ist dies für die Gestalter auch legitim.

Ergänzend zur textlichen Vermittlung in der Ausstellung soll die Gestaltung die sinnliche Wahrnehmung der Objekte sowie des Ortes unterstützen. Das Zusammenspiel aller Ebenen - Exponate, Texte, audiovisuelle Medien, architektonische und graphische Gestaltung - erschließt den Besuchern den Inhalt der Ausstellung, jedoch ohne ein rea-

nen, deren Auswahl von ihrem dekorativen Wert nicht weniger als von einer wissenschaftlichen Beweisführung her definiert war." Vgl. Baumunk 2001, S. 184.

37 Der Berliner Architekt Jürg Steiner zitiert in John, Hartmut: Spielen wir noch in der Champions-League? oder: Plädoyer für professionelle Ausstellungsplanung im Museum. In: Schwarz 2001, S. 51. 
listisches Abbild der Vergangenheit zu zeichnen. Im Hinblick auf die Art und Weise der Entwicklung von Gestaltungsideen gibt es je nach Ausstellungsteam unterschiedliche Vorgehensweisen. In der Regel werden vom Gestalter einer Ausstellung Ideen erwartet. Als eine Möglichkeit der kreativen Umsetzung schlägt Schwarz vor, Metaphern zu finden. ${ }^{38}$ Durch die Gestaltung mit Metaphern kann der Bedeutungsraum erweitert werden, sie werden wegen ihrer stilistischen, poetischen Wirkung eingesetzt. Folgendes Beispiel verdeutlicht diese Gestaltungsidee:

„In einer Ausstellung galt es darzustellen, daß die Bauern am Rhein von der Landwirtschaft allein nicht leben konnten und sich deshalb in der Industrie verpflichten mussten. Es stellte sich die Frage, durch welches Bild oder durch welche Objekte dies am besten darstellbar wäre. Erst nach eingehender Recherche begreift man, was es bedeutete, kurz nach vier Uhr morgens aufzustehen, eine Stunde zu Fuß zum Bahnhof zu gehen, mit dem Zug in die Fabrik nach Karlsruhe zu fahren und abends wieder zurück. Die Metapher ist, daß diese Bauern ihr Dorf nur bei Nacht gesehen haben, und genau dies kann dann in der Ausstellung visuell umgesetzt werden, durch eine raumgreifende Illustration, als Exponate Uhrzeiger, die auf kurz nach vier stehen, davor genagelte Schuhe auf einem Podest.“ (ebd., S. 26)

Als weitere Möglichkeit schlägt Schwarz vor, Symbole zu schaffen. Symbole sind Zeichen, die für etwas nicht Wahrnehmbares stehen. Sie sind Bedeutungsträger und sollen einen bestimmten Sinngehalt darstellen. So symbolisiert die Gipsfigurine eines beleibten Mannes in kurzen Hosen vor einem Großfoto einer intakten Auenlandschaft die Bedrohung der Natur durch den Tourismus (ebd.).

38 Die Metapher beruht auf der Übertragung von Bedeutung. Sprachlich wird das eigentlich gemeinte Wort durch ein anderes ersetzt, das zumindest bildlich dieselbe Bedeutung hat. 


\subsection{Arbeitsdefinition Erlebnis}

Seit den achtziger Jahren avancierten die Begriffe Erlebnis und Event ${ }^{39}$ zu viel genutzten Modeworten. Die Geistes- und Sozialwissenschaften befassen sich mit dem Phänomen der Erlebnisorientierung unserer Gesellschaft. Die Marketingindustrie entdeckte dieses Schlagwort und entwickelte daraus verkaufsfördernde Konzepte. Auch in den Bereichen des Museums- und Ausstellungswesens findet eine Hinwendung zu Erlebnis und Event statt.

„Im New Metropolis Museum in Amsterdam kann der Besucher in einem nachgestellten OP-Saal eigenhändig ein Herz verpflanzen; in der Neuen Berliner Nationalgalerie konnte man entlang der Werke von Max Ernst, Arnold Böcklin oder Giorgio de Chirico mittels Hörer eine Reise ins Ungewisse unternehmen. “40

Diese ausufernde Anwendung führt zu einer Überstrapazierung des Begriffs. Nichtsdestotrotz erscheint eine Auseinandersetzung mit diesem Phänomen sinnvoll, da es an Aktualität und Bedeutung nichts eingebüßt hat. Auffallend ist, dass der nahezu inflationären Verwendung des Wortes eine bescheidene Aufarbeitung gegenübersteht. Der Begriff Erlebnis weist darauf hin, dass bei der Entwicklung von inszenierten Ausstellungskonzepten nicht nur die musealen Objekte und das Thema relevant sind, sondern auch die Besucherperspektive eine bedeutende Stellung einnimmt. In den siebziger und achtziger Jahren war der Großteil der Ausstellungen geprägt von Versachlichung, klarer Übersichtlichkeit durch Ordnung und Anordnung und kühler Präsentationsästhetik. Nach diesen Jahrzehnten des Designs und einem ,tendenziell klinischen Umgang sowohl mit dem Exponat als auch dem Besucher traten die Auch-

39 Event ist ein weiterer Begriff, der sich im Zusammenhang mit der Freizeitgesellschaft entwickelte. Events nehmen an Zahl und Bedeutung zu. Sie versprechen das Erlebnis des Außergewöhnlichen und prägen die Gesellschaft. Eine Annäherung an dieses Phänomen aus unterschiedlichen Perspektive siehe: Gebhard, Winfried/Hitzler, Ronald/Pfadenhauer, Michaele (Hrsg.): Events - Soziologie des Außergewöhnlichen. Opladen, 2000 oder Kemper, Peter (Hrsg.): Der Trend zum Event. Frankfurt am Main 2001.

40 Gribl, Albrecht A.: Der Besucher in der Ausstellung - ratlos? Zur Sprache heutiger Konzeption. In: Landesstelle für nichtstaatl. Museen in Bayern 2000, S. 30. 
Eigenschaften des Besuchers als fühlender, empfindender, erlebnisfähiger Mensch wieder verstärkt ins Gesichtsfeld der Macher“ (ebd., S. 32).

\section{Erlebnisse als subjektive Bedeutungskonstruktion}

Weit gefasst bezieht sich der Begriff Erlebnis auf jeden im Bewusstsein ablaufenden Vorgang. Nach der Aufklärung entwickelte sich im 18. Jahrhundert der Erlebnisbegriff als emotionaler Grundbegriff gegen die zunehmende kognitive Rationalität. ${ }^{41}$ Beim Prozess der Informationsverarbeitung handelt es sich immer um ein Zusammenwirken kognitiver und emotionaler Prozesse. Die Auswirkungen von Emotionen auf kognitive Leistungen können fördernd oder auch beeinträchtigend sein. Die Ergebnisse der emotionspsychologischen und neurobiologischen Forschung in den vergangenen zwei Jahrzehnten zeigen deutlich, dass Emotionen einerseits für unsere Aufmerksamkeit gegenüber uns begegnenden Sachverhalten unmittelbar bedeutsam sind. Andererseits ist die Stabilität der gedächtnismäßigen Abspeicherung und somit die Möglichkeit des Wiederabrufs von Gedächtnisinhalten in hohem Maße an die emotionale Bedeutsamkeit der Inhalte gebunden. ${ }^{42}$ Es gibt kein Verhalten, das allein kognitiv, also ohne Emotionen oder ausschließlich emotional ohne kognitive Elemente auftritt. Daher müssen Emotion und Kognition in einem wechselseitigen Beziehungsverhältnis als zwei Aspekte eines Phänomens, nämlich des menschlichen Handelns verstanden werden.

Die erkenntnistheoretische Einsicht, dass die Wirklichkeit, wie sie wirklich ist, verschlossenen bleibt, bedeutet, dass das Gehirn nicht die Welt abbildet oder einfach nur widerspiegelt, wie sie objektiv ist, son-

41 Von Wilhelm Dilthey (Philosoph, geb. 1833, gest. 1911) wurde das Erlebnis als Grundbegriff der Geisteswissenschaften eingeführt. Dilthey ist Begründer der Erkenntnistheorie der Geisteswissenschaften und einer der Hauptvertreter der hermeneutischen Wissenschaften (historische Schule). Im Unterschied zu den Naturwissenschaften, in denen unabhängig vom menschlichen Handeln gegebene Ereignisse durch theoretische Entwürfe systematisiert werden, muss der Geisteswissenschaftler seinen Gegenstandsbereich, dessen Teil er selbst ist, durch Nachvollziehen dieser Lebensäußerungen verstehen. Vgl. Bibliographisches Institut \& F.A. Brockhaus AG, 2001.

42 Standop, Jutta: Emotionen und ihr Einfluss auf das kognitive Lernen. In: Nahrstedt, Wolfgang (Hrsg.): Lernen in Erlebniswelten. Bielefeld 2002, S. 75 . 
dern dass Menschen eigene Wirklichkeiten konstruieren. Siebert stellt fest, ,dass unsere Welt aus unseren Bildern besteht - aus Selbst, Fremdund Weltbildern." ${ }^{43}$ Die Art und Weise, wie Menschen ihre Welt konstruieren, hängt von der Sozialisation, der Lerngeschichte, den Lebensverhältnissen und den Zukunftsperspektiven ab. Auch Erlebnisse können deshalb nicht eindimensional betrachtet werden, sondern sind von der Persönlichkeitsstruktur jedes einzelnen abhängig. Sie entstehen subjektbestimmt, reflexiv und unwillkürlich. „Sie sind psychophysische Konstruktionen, die sich nicht durch Gegenstände substituieren oder an Dienstleistungsunternehmen delegieren lassen.“" ${ }^{44}$ Dies bedeutet zum Beispiel, dass identische Situationen völlig unterschiedlich bewertet werden können. Empfindet der eine musikalische Untermalung als angenehmes Begleitprogramm, bewertet ein anderer dies als störende Berieselung.

„Was wir sehen, ist eher eine Vorhersage - unsere eigene persönliche Konstruktion, die dazu bestimmt ist, uns den besten Weg zu zeigen, um unsere Handlungsziele durchzuführen. Wir wählen diese Wege auf der Grundlage unserer vorherigen Erfahrungen.“ ${ }^{45}$

Erlebnisorientierung als die unmittelbarste Form der Suche nach Glück kennzeichnet die gegenwärtige Art zu leben und ist im historischen Vergleich etwas Neuartiges. Die kultursoziologische Untersuchung mit dem Titel „Die Erlebnisgesellschaft“ des Soziologieprofessors Gerhard Schulze zeigte eindrücklich auf, dass sich sowohl Individuum als auch Gesellschaft durch das Motiv der Erlebnisorientierung verändern. Während noch bis in die sechziger Jahre Werte wie materielles Wohlergehen und physische Sicherheit in der Einschätzung der Menschen im Vordergrund standen, zeichnete sich von den siebziger Jahren an deutlich ab, dass zunehmend Lebensqualität wichtig wurde. Die Suche nach dem Glück trat an Stelle des Strebens nach einem zufriedenstellenden Lebensstandard. Entsprechend wurde Freizeit mindestens so hoch oder gar höher bewertet wie etwa die Zufriedenheit mit der Berufstätigkeit. Die

43 Siebert, Horst: Der Konstruktivismus als pädagogische Weltanschauung Entwurf einer konstruktivistischen Didaktik. Frankfurt am Main 2002, S. 11.

44 Schulze, Gerhard: Die Erlebnisgesellschaft - Kultursoziologie der Gegenwart. Frankfurt am Main/New York 2000, S. 14.

45 Izard, Carroll E.: Die Emotionen des Menschen - Eine Einführung in die Grundlagen der Emotionspsychologie. Weinheim 1994, S. 168. 
soziale Stellung der Menschen in heutigen westlichen Gesellschaften lässt sich nicht mehr allein nach überwiegend objektiven Maßstäben wie Einkommen, Besitz oder Bildung bestimmen, sondern vor dem Hintergrund wachsender Konsum- und Freizeitmöglichkeiten. Erlebnis ist zu einer zentralen Kategorie in unserer Gesellschaft geworden. Für den Menschen wird die Erlebnisorientierung zur grundsätzlichen Motivation sozialen Handelns.

Die zunehmende Verschiedenartigkeit der Menschen ist Indiz für eine neue grundlegende Gemeinsamkeit der Erlebnisgesellschaft. Innenorientierte Lebensauffassungen, die das Subjekt selbst ins Zentrum des Denkens und Handelns stellen, haben außenorientierte Lebensauffassungen verdrängt (Schulze 2000, S. 35). Die zunehmende Individualisierung lässt verschiedenartige Ansprüche entstehen. Die theoretischen Überlegungen zur Erlebnisgesellschaft spiegeln sich in der Praxis der Ausstellungsgestaltung wider. Wie ein Ausstellungsgestalter der Gruppe Gut feststellt, änderte sich die Sensibilität der Wahrnehmung in den vergangenen Jahrzehnten:

„In der Gegenwart lebt jeder nach seiner Norm, führt ein individuelles Leben. Dadurch entwickeln sich völlig andere Aufnahmefähigkeiten. Der eine will mehr, der andere weniger. Der eine will es schnell, der andere will es langsam. [...] Früher gab es keinen Rhythmus, jetzt muss man einen Rhythmus reinbringen, weil die große Masse mittlerweile daran gewöhnt ist.“"46

Dies erschwert die Arbeit der Gestalter, da sich viele Menschen aus verschiedensten Motiven durch die Ausstellung bewegen. Dies bedeutet für die Ausstellungsgestalter, dass sie die unterschiedlichen Bedürfnisse bei der Gestaltung berücksichtigen sollten. Auch erwartet der erlebnisverwöhnte Mensch, Informationen spannend aufbereitet konsumieren $\mathrm{zu}$ können.

\section{Besucherforschung und Ausstellungserlebnisse}

„Visitors are the heart of the museum experience.“47 Dieser erste Satz von McLean im Vorwort des Buches über Planung von Ausstellungen

46 Interview mit Herrn Alfons Demetz und Herrn Uli Prugger/Gestaltungsbüro Gruppe Gut in Bozen, am 4. Juli 2002.

47 McLean, Kathleen: Planning for People in Museums Exhibitions. Washington D.C. 1993 S. V. 
signalisiert, welch hohen Stellenwert dem Besuchserlebnis im angloamerikanischen Raum eingeräumt wird. Neuere Besucherforschungen stellen das Besuchserlebnis mit seinen psychologischen, physiologischen oder architektonischen Bedingungsfaktoren ins Zentrum der Betrachtung, denn differenziertes Wissen darüber, wie Besucher Ausstellungen erleben, ermöglicht profundere Aussagen und Empfehlungen zur Entwicklung von Ausstellungen und Programmen.

Im Vergleich zu Deutschland ist der Theoriestand der Besucherforschung im angloamerikanischen Raum weiter entwickelt und die Evaluation als Planungsinstrument für die unterschiedlichen Entwicklungsstadien einer Ausstellung besser ausgebaut. ${ }^{48}$ Besucherforschung mit all ihren Varianten ist inzwischen aus der Museumsreformdiskussion nicht mehr wegzudenken. Vielmehr scheint es fast so, als hätte sie in Umfang und Gewicht die historische Museumsforschung überholt und wäre unter allen museumsbezogenen Forschungsrichtungen zu einer Art Leitdisziplin avanciert. Dabei verfolgt sie unterschiedliche Ziele und Fragestellungen. So geht es zum Beispiel darum, mittels genauer Besucherstatistiken Aufschluss über das so genannte Besucherprofil zu erhalten, welches die Häufigkeit und Verteilung von Besuchermerkmalen wie Alter, Geschlecht, soziale Herkunft, Bildungsniveau und Besuchsmotive darstellt. Einen weiteren Schwerpunkt bilden Evaluationen, die durch Interviews und Verhaltensbeobachtung die Besucher in die Ausstellungsplanung und -gestaltung mit einbeziehen. Man hofft, auf diese Weise die Verständlichkeit und Attraktivität des Angebots erhöhen zu können. ${ }^{49}$

Mit dem Ziel, die Vermittlungsarbeit zu verbessern, stellen die Museumswissenschaftler Falk/Dierking das Museumserlebnis in das Zentrum ihrer Forschungen. Den Rahmen dafür bildet „The Interactive Expe-

48 Vom fortgeschrittenen Konstituierungsprozess der Besucherforschung zeugt zum Beispiel die Zeitschrift ,Visitor Behaviour“.

49 In Deutschland informierten über Besucherforschung, über deren Ansprüche und Aufträge, die Verfahrensweisen und Resultate in den vergangenen Jahren vor allem das Institut für Museumskunde in Berlin (Bernhard Graf). Auch das Institut für Soziologie (Prof. Dr. Hans-Joachim Klein) mit den Karlsruher Schriften zur Besucherforschung trug wesentlich zur Theoriebildung bei. Einen sehr guten Einblick in die Wirklichkeit der gegenwärtigen Besucherforschung, die nicht nur an der Objektivität der Ausstellung, sondern an der Subjektivität ihrer Besucher interessiert ist, gibt der Band von Noschka-Roos (Hrsg.): Besucherforschung im Museum. Instrumentarien zur Verbesserung der Ausstellungskommunikation. München 2003. 
rience Model ${ }^{\text {“50 }}$. Anhand dieses Modells beschreiben sie den dynamischen Vorgang des Museumserlebnisses, der sich zwischen drei sich überlappenden Bereichen des persönlichen, sozialen und physischen Umfeldes abspielt. Jeder Kontext beeinflusst das Museumserlebnis und die Lernerfahrung. Mit dem personellen Umfeld beziehen sich die Autoren auf die Vorstellungen und Erwartungen, die jede Person unterschiedlich bei einem Museumsbesuch mitbringt. Das soziale Umfeld bedeutet, dass Besucher in Museen mit anderen Menschen in Kontakt treten. Dies können Begleitpersonen, das Museumspersonal und auch andere Besucher sein. Mit dem physischen Umfeld verweisen Falk/Dierking auf die Ausstellungsumwelt, so zum Beispiel die Architektur des Hauses oder das Ausstellungsdesign. Dieses weit gefasste Modell lenkt den Blick auf eine ganzheitliche Betrachtung des Ausstellungserlebnisses. Da Lernen im Museum hauptsächlich eine soziale Aktivität darstellt, fordern Falk/ Dierking, dass dem gesellschaftlichen Umfeld bei weitem mehr Aufmerksamkeit zukommen und dementsprechend Besucherforschung auf diesem Gebiet intensiviert werden sollte.

Die persönlichen Gründe für Ausstellungsbesuche sind ebenso heterogen, wie es die Museumsbesucher selbst sind. Nahezu alle Untersuchungen zu Besucherfrequenz und Besucherverhalten bestätigen, dass es den typischen Museumsmenschen oder Normalbesucher nicht gibt. ${ }^{51}$ Die Palette ist so weit, wie es unterschiedliche soziale Situationen, Fähigkeiten und Neigungen gibt. Miles stellte in seinen Untersuchungen fest, dass Museumsbesucher Ausstellungen aus den gleichen Gründen besuchen, wie sie andere Medien nutzen: "for information, for personal identity and reinforcement of personal values, for social interaction (to connect with family, friends and society) and for entertainment and relaxation." (Miles zitiert in McLean 1993, S. 5)

Diese Beweggründe existieren jedoch nicht isoliert voneinander, sondern ergänzen sich gegenseitig. Das Interesse an Information bildet nicht unbedingt die wichtigste Motivation für einen Ausstellungsbesuch,

50 Falk H. John/Dierking Lynn D.: The Museum Experience. Washington D.C. 1992. In einer späteren Publikation veränderten Falk/Dierking diese Bezeichnung und nennen das Modell „The Contextual Model of Learning“, ohne jedoch dabei die zugrunde liegenden Kategorien aufzugeben. vgl. Falk, John H./Dierking, Lynn D.: Learning from Museums - Visitors Experiences and the Making of Meaning. Walnut Creek/Lanham/New York/Oxford 2000.

51 Treinen, Heiner: Was sucht der Besucher im Museum? In: Fliedl, Gottfried (Hrsg.): Museum als soziales Gedächtnis? Klagenfurt 1988, S. 27. 
sondern stellt lediglich einen Beweggrund neben anderen Motiven dar. Unterhaltung und Interesse an geselligem Zusammensein spielen eine nicht minder bedeutende Rolle. Graf/Treinen stellten fest, dass im Museum Verhaltensdispositionen wirksam werden, die nicht auf das Lernen im traditionellen Sinne ausgerichtet sind, sondern der zweckfreien Anschauung mit dem Wunsch nach unmittelbarer Gratifikation verbunden sind. ${ }^{52}$ Dies gleicht einem freizeitorientiertem Verhalten. Die überwiegende Mehrzahl der Besucher sucht eher Abwechslung als Systematik, eher Unterhaltung als Wissensvermehrung. Daueranregung und Neugiersättigung sind für die Besucher wichtiger als logisch-rationales Nachvollziehen von Exponatreihungen oder kontemplativ-sensitivierendes Betrachten von Objekten (ebd., S. 145). Im angelsächsischen Sprachund Kulturraum hat sich für das flanierende Verhalten vor Schaufenstern in Geschäftsstraßen der treffende Ausdruck window-shopping gefunden. Diesen übertrugen Graf/Treinen auf die museale Welt als Etikett für typisches Verhalten in Ausstellungen. Sie bezeichnen dies als kulturelles window-shopping. Kritisch anzumerken ist, dass Graf/Treinen einerseits einschränken, dass es den typischen Normalbesucher nicht gibt, andererseits jedoch dann wiederum als Ergebnis festhalten, dass wohl der Großteil der Besucher flanierend durch das Museum wandelt, ohne tiefer gehende Interessen zu entwickeln.

Demgegenüber wird im angloamerikanischen Raum basierend auf lerntheoretischen Überlegungen versucht, ein differenziertes Bild vom Museumsbesucher zu schaffen. Anhand von Lerntheorien werden die verschiedenen Lernstile beschrieben. Die Heterogenität der Museumsbesucher äußert sich in der Unterschiedlichkeit der Informationsaufnahme. „Some people like to read and some don't. Some people like to interact with others, and some prefer a solitary experience. Some people are primarily visually oriented, others are oriented verbally or physically." (McLean 1993, S. 9)

In Ausstellungen wird Information in der Regel in einer monotonen Form ohne Rücksicht auf unterschiedliche Interessen oder Lernstile präsentiert. Im folgenden stelle ich zwei Modelle, die jeweils einen Versuch darstellen, die Vielschichtigkeit unterschiedlicher Lernstrategien zu klassifizieren, kurz vor. Beide entwickelten Anweisungen, wie Ausstellungen besuchergerecht gestaltet werden können. Bernice McCarthy entwi-

52 Graf, Bernhard/Treinen, Heiner: Besucher im Technischen Museum. Berlin 1983, S. 161. 
ckelte das lerntheoretische Modell „4MAT“533, von Howard Gardner stammt die Theorie der multiplen Intelligenzen. ${ }^{54}$

Im Modell von McCarthy werden bestimmte Charakteristika der Informationsaufnahme und -verarbeitung als Unterscheidungskriterien herausgestellt. McCarthy differenziert zwischen vier Lerntypen: imaginative, analytic, common sense und dynamic.

Imaginative learners suchen nach Bedeutung und Zusammenhängen. Die leitende Frage lautet „Warum?“. Gelernt wird durch Zuhören und Erörterung von Problemen; sehr hilfreich für diesen Typus ist es, sich auf direkte Erfahrungen beziehen zu können. Lebensnahe, gegenwartsbezogene Ausstellungen mit Möglichkeiten zur Interaktion entsprechen am besten diesem Typus. Analytic Learners sind primär an der Frage nach dem „Was?“ interessiert. Detaillierte Informationen, Fakten- und Expertenwissen wird von diesem Typ gewünscht. Diese Besuchergruppe ist an langen Ausstellungstexten mit ausführlichen Hintergrundinformationen interessiert. Common Sense Learners aktiviert die Frage „Wie funktioniert dies?". Dieser Typus will Probleme lösen und kann am besten durch eigene Aktivitäten neue Informationen verarbeiten und in das vorhandene Vorwissen integrieren. Diesem Typus entsprechen interaktive Ausstellungen. Die vierte Gruppe bilden die Dynamic Learners, die durch die Frage „Was ist, wenn?“ motiviert werden. Diese lernen am besten durch Versuch und Irrtum sowie Selbstentdeckung.

Wenn diese Theorie in der Ausstellungspraxis angewandt wird, so bedeutet dies, dass versucht wird, den Lerntypen ein unterschiedliches Angebot zu geben. So wird zum Beispiel ein Thema aus verschiedenen Betrachtungswinkeln beleuchtet. Das persönlich-menschlich Ansprechende, kenntnisreiche Detailinformation, Veranschaulichung und Einsatz interaktiver Techniken stehen in einem ausgewogenen Verhältnis.

Die Studie des Psychologen Gardner stellt eine weitere Annäherung zur Beschreibung von Lernstilen dar. Er wendet sich gegen die Verkürzung des Intelligenzbegriffes auf mathematisch-logisches Denken. Demgegenüber vertritt er die These, dass mindestens sieben unterschiedliche Formen von Intelligenz existieren. Jede für sich bildet einen Schlüssel zum Weltverständnis. Er unterschiedet zwischen linguistischer, musikalischer, logisch-mathematischer, räumlicher, körperlich-kinästhetischer,

53 Cassels, Richard: Learning Styles. In: Durbin Gail: Developing Museums exhibitions. London 1996, S. 38-45.

54 Gardner, Howard: Abschied vom IQ. Die Rahmen-Theorie der vielfachen Intelligenzen. Stuttgart 1991. 
interpersonaler und intrapersoneller Intelligenz. Diese existieren gleichwertig nebeneinander, ohne einer bestimmten Intelligenzform einen Vorrang einzuräumen. Als kognitive Prozesse ermöglichen jede für sich, Phänomene zu interpretieren und zu verarbeiten. Jedes Individuum besitzt die gesamte Palette unterschiedlicher Intelligenzen, jedoch mit den jeweiligen ungleichen Ausprägungen.

Im Hinblick auf die pädagogische Praxis fordert auch diese Theorie, wie bereits das vorherige Modell, zu Methodenvielfalt auf. Deutlich wendet sie sich gegen das einseitige Ansprechen der logischmathematischen Fähigkeiten. Folglich sollten bei der Konzipierung von Ausstellungen die verschiedenen Kanäle des Publikums berücksichtigt und unterschiedliche Sinne angesprochen werden. Dies spricht dafür, Informationen nicht nur über die traditionelle Form von Text, sondern auch über Medien zum Hören, interaktive PC-Stationen oder auch mittels theatralischer Elemente personell zu vermitteln.

Obgleich Lerntheorien dazu beitragen, die Aufnahme der Informationen durch den Besucher zu unterstützen, wäre es dennoch eine Illusion anzunehmen, dass umfangreiches, komplexes Wissen einfach und umfassend vermittelt werden kann. Denn ein Grundirrtum liegt in der Annahme, das Besucherinteresse an kulturhistorischen Objekten fände seine Entsprechung in intensiver Objektbetrachtung (Treinen 1991, S. 11).

Die museale Bildungsfunktion unterscheidet sich grundlegend von allen anderen Bildungsformen. In Ausstellungen vollziehen sich qualitativ andere Lernprozesse als dies vergleichsweise im klassischen Lernort Schule der Fall ist. Der schulische Lernprozess baut zum Beispiel auf methodischen Maßnahmen des Übens, Wiederholens und Prüfens auf. Diese auf langfristige Lern- und Abschlussprozesse hin organisierten Formen finden in Ausstellungen in der Regel keine Anwendung. ${ }^{55}$ Lernvorgänge sind langwierige und zögerliche Prozesse, die sich nicht ohne Anstrengung vollziehen lassen. Clifford Stoff, Mitbegründer des Internets, spricht von der Utopie des mühelosen Lernens und bezeichnet das Edutainment als pädagogische Illusion, da Lernen nicht ohne Mühen möglich ist. ${ }^{56}$ Der Annäherungsprozess vollzieht sich in langwierigen

55 Dies schließt im Gegenzug jedoch nicht aus, dass mit Hilfe musealer Sammlungen schulische Lernziele im Rahmen von Unterricht erarbeitet werden können.

56 Wechsler, Ulrich: Erst laufen, dann Rad fahren. Nicht die Nutzung der Medien macht den Grad unserer Bildung aus, sondern der Grad unserer Bildung bestimmt, wie sinnvoll die Nutzung der Medien ist. In: Süddeutsche Zeitung vom 06./07.04.02. 
Schritten, abhängig von individuellen Bedingtheiten, auch bedroht von Störungen der Situation und menschlichen Regungen ${ }^{57}$ Rumpf sieht in der konsumistischen Spielart der Kulturaneignung, wie sie derzeit mit Edutainment-Konzepten verwirklicht werden, Gemeinsamkeiten mit der Lerntechnologie der siebziger Jahre. Beide gingen von der Annahme aus, die schwierige, langsame und nicht berechnende, imaginative Vergegenwärtigung der Sache ersparen zu können. Bei dem Versuch, den Lerngegenstand so zu präzisieren, dass er möglichst anschaulich wird, um dadurch eine klare innere Repräsentation zu gewährleisten, sieht Rumpf die Gefahr, die Menschen zu einer Aneignung zu verführen, die bloßer Schein bleibt.

Zusammenfassend lässt sich feststellen, dass auch in musealen Ausstellungen „Schlaraffenlernen“ (ebd.) nicht angeboten werden kann. Kritikern inszenierter Ausstellungen könnte damit ein Argument für die Ablehnung kommunikativer Formen der Präsentation an die Hand gegeben werden. Jedoch wäre es ebenso irrig, als Schlussfolgerungen aus derartigen Befunden dem Museumswesen mangelnde Ausstrahlungskraft, Einflusslosigkeit auf Besucher und darüber hinaus ein gewisses Desinteresse an musealisierten Inhalten zu attestieren (Treinen 1991, S. 11). Die Dimensionen des Erlebnispotentials von musealen Ausstellungen können nicht auf empirisch verifizierbare Formeln des Wissenszuwachses reduziert werden, sondern sie liegen im Bereich der Erfahrungen. Gleichsam als Bausteine können sie den gesamten persönlichen Entwicklungsprozess befruchten. Dieses wiederum steht sehr wohl in Zusammenhang mit der Gestaltung der Ausstellungsumwelt, die zum Beispiel durch Akzentuierung den Blick steuert und dadurch eine vertiefende Betrachtung ermöglicht. Worin das spezifische museale Erfahrungs- und Erlebnispotential liegt, soll im folgenden Kapitel thematisiert werden.

57 Rumpf, Horst: Spielarten der Kulturaneignung. In: Staudte, Adelheid (Hrsg.): Ästhetisches Lernen auf neuen Wegen. Weinheim/Basel 1993, S. 20 . 


\section{Pädagogische Perspektive musealer KOMMUNIKATION}

Museale Ausstellungen sind Erlebnisorte, die sich durch eine bestimmte Erfahrungsqualität auszeichnen. In diesem Zusammenhang stellt sich auch die Frage nach dem Selbstverständnis der Museen.

„Wer sind wir überhaupt? Bildungsstätte, wie Alfred Lichtwark sagte, Volksmuseum, wie Gustav Pauli forderte, Lernort, wie man 1968 meinte? Hort der langsamen Bilder wider die schnellen in den Medien, Zuflucht der wirklichen Bilder im Ansturm der virtuellen? Eine Stätte der Ruhe und Konzentration aufs Geistige? Oder mittlerweile doch ein Ort der Massen und der Events?“"1

Bedeutsam erscheint die Frage, was die besondere Qualität des musealen Ausstellungserlebnisses auszeichnet. Auch aufgrund der zunehmenden Konkurrenz mit anderen Anbietern auf dem Freizeitsektor, „wächst sich bei der Institution Museum die Sinn- zur Überlebensfrage aus “"2. Im Folgenden erörtere ich die Frage, worin das besondere Potential im Hinblick auf den Bildungsgedanken des Museums liegt oder liegen sollte. Die Erörterung dieser Frage ist auch deshalb wichtig, da sich hier abzeichnet, in welcher Form sich museale Ausstellungswelten von kommerziellen Erlebniswelten abgrenzen.

Die Frage nach der besonderen Qualität der Erlebnisse im Museum führt zu den fünf Säulen der Museumsarbeit. Museen dienen der Sammlung, Bewahrung, Erforschung und Wiederherstellung von Kulturgut, vor allem aber dessen sinnvoller Vermittlung. Das International Council of Museums ${ }^{3}$ hat den Bildungsgedanken in seine Museumsdefi-

1 Schneede, Uwe (Hrsg.): Museum 2000 - Erlebnispark oder Bildungsstätte. Köln 2000, S. 9.

2 Rauterberg, Hanno: Musealisiert die Museen! Über den Wert und die Werte einer großen Institution. In: Museumskunde. 67. (2002) Heft 2. S. 35 .

3 Das International Council of Museums (ICOM) versteht sich als internationale, nicht-regierungsamtliche Organisation zur Förderung der Ziele der 
nition aufgenommen. In Artikel zwei seiner Statuten wird als elementare Aufgabe die bildungspolitische und gesellschaftliche Funktion des Museums definiert, die weiterentwickelt werden und ein immer breiteres Publikum aus allen Bereichen der Gesellschaft ansprechen soll. Den Dauer- und Sonderausstellungen wird dabei besondere Bedeutung zugesprochen.

„Die wichtigste Aufgabe des Museums ist es, seine Sammlung für die Zukunft zu bewahren und sie mit Hilfe von Forschung, Bildungsarbeit, Dauer- und Sonderausstellungen sowie Sonderveranstaltungen für die Entwicklung und Verbreitung von Wissen zu nutzen. “4

Diese sehr offen formulierte Regel liefert keine genauere Bestimmung der Bildungsfunktion. Im Hinblick auf den gesellschaftlichen Wandel muss diese Aufgabe immer wieder neu gestellt und reflektiert werden. Auch zum Umgang mit gewinnorientierten Aktivitäten von Museen geben die Statuten eine Richtlinie vor. Zur Erzielung von Einkünften sind kommerzielle Angebote legitim, doch soll klar zwischen erkenntnisorientierten und gewinnorientierten Vorhaben unterschieden werden. Nachbildungen, Reproduktionen oder Kopien müssen „die Echtheit des Originals respektieren und immer als Faksimile gekennzeichnet sein.“ (ebd., S. 8)

Wie bereits festgestellt und von der Besucherforschung bestätigt, kann die Vermittlung von komplexen historischen Inhalten mittels einer Ausstellung nicht oder zumindest nur bedingt geleistet werden. Die Aufgabe der Popularisierung von Wissen wird von anderen Medien ebenfalls, zum Teil sogar besser, geleistet. Eine steigende Zahl der Sach- und Fachbücher, populäre Geschichtsromane, durchdachte CD-ROMs, aufwendig produzierte Fernsehdokumentationen und ausführliche Internetseiten bieten sowohl dem interessierten Laien als auch dem forschenden Fachwissenschaftler in mannigfaltiger Form Auskunft. Diese Überlegungen führen $\mathrm{zu}$ der Frage, weshalb das Interesse an Ausstellungen nicht erlahmt, worin also die besondere Anziehungskraft und auch der Nutzen musealer Ausstellungen liegen. Sowohl im Hinblick auf effektiven Lernzuwachs als auch in Bezug auf finanziellen Nutzen können mu-

Museumskunde. Der Verband ist offizieller Berater der UNESCO im Bereich des Museumswesens.

4 ICOM-Deutschland/ICOM-Österreich/ICOM-Schweiz: ICOM Ethische Richtlinien für Museen (Code of Ethics for Museums). Berlin/Wien/ Zürich 2003, S. 7. 
seale Ausstellungen meist keine positive Bilanz ziehen. Außer Zweifel steht, dass auch Museen in irgendeiner Weise rentabel sein müssen, da sie von einer Gesellschaft für eine Gesellschaft erhalten werden. Die Rentabilität wird jedoch nicht in den wirtschaftlichen Kategorien von Gewinn und Verlust bemessen. „Gemäß der Besonderheit der Museen müssen Museen moralisch rentabel sein." ${ }^{5}$ Der Wert von musealen Ausstellungen, deren Wirkungen sich gesamtgesellschaftlich und langfristig bemerkbar machen, liegt somit weniger auf dem direkten Nutzen, sondern im immateriellen Bereich. Edson sieht im Museum eine gemeinnützige Organisation, die subjektive Nützlichkeit, emotionale Erfüllung und kulturelle Bereicherung bietet. Diese Werte sind nicht messbar, dennoch besitzen sie eine unschätzbare Bedeutung. Insbesondere in unserer gegenwärtigen, unübersichtlichen Umwelt ist das humanisierende Wirken von Museen und anderen gemeinnützigen Einrichtungen notwendiger als je zuvor.

„Die Menschheit hat aus der Leistung nicht gewinnbringender Organisationen Nutzen gezogen und tut dies weiterhin. Neue Ideen, Pläne, Projekte und unzählige publikumsorientierte Initiativen sind von dort gekommen." (Edson zitiert in Waidacher, ebd., S. 8)

Obwohl der effektiv abrufbare Wissenszuwachs nach Ausstellungsbesuchen als gering eingestuft werden muss, bedeutet dies auf der anderen Seite nicht, dass der Besuch keine Wirkung zeigt. Vieles bei einem Ausstellungsbesuch wird implizit gelernt und manches wird nicht als unmittelbares Lernergebnis sichtbar werden. Es handelt sich dabei um heuristische Richtziele. ${ }^{6}$ Diese besagen, dass Lerneffekte nicht bereits im aktuellen Zusammenhang eintreten, sondern hinsichtlich weiterführender Verknüpfungen von Belang sind. Die subjektinterne Verarbeitung bewirkt Effekte, die gerade aus ihrer Verlängerung und weiteren Verknüpfung bestehen und nicht an irgendeinem Punkt als fixes Resultat verstan-

5 Waidacher, Friedrich: Museum lernen: Lange Geschichte einer Verweigerung oder Warum Museen manchmal so gründlich daneben stehen. 1999, http://vl-museen.de/m-online/99/99-2.htm (letzter Zugriff: 01.05.04), S. 14.

6 Schulz, Wolfgang: Unterrichtsplanung. München/Wien/Baltimore 1980, S. 83. 
den werden können. ${ }^{7}$ Dies gilt auch für die Entwicklung von Geschichtsbewusstsein. $^{8}$

„In einem differenzierten, reichen Geschichtsbewußtsein und in einem lebendigen Verhältnis zur Geschichte sind immer auch Momente enthalten, die durch planbare Lernprozesse nicht zu erreichen sind, sondern jenseits des Lernens liegen.“9

Siebert unterscheidet auf heuristischer Ebene drei Intensitätsstufen des Lernens. Die erste Stufe des Lernens erfolgt als Informationsverarbeitung und als Erwerb von Kenntnissen. In der zweiten Ebene bedeutet Lernen Verstehen als Assimilation neuen Wissens in bereits vorhandene Wissensnetze. Dies schließt die Fähigkeit ein, Begriffe mit eigenen Worten erklären zu können. Erst auf der dritten Ebene findet Lernen als Aneignung, als horizont- und identitätserweiternde, konstruktive Erzeugung von Wirklichkeiten statt. Dieses bezeichnet Siebert als „Bildungslernen, eine Verinnerlichung wertvoller Erfahrungen.“ (Siebert 2002, S. 67)

Die zwei Spezifika des musealen Erlebnisses sind historische und ästhetische Erfahrungen. Aus diesem Grund betrachte ich diese zwei Formen näher und erörtere auch, inwiefern diese in Konkurrenz treten, um dann pädagogische Perspektiven musealer Kommunikation aufzeigen zu können. ${ }^{10}$

7 Die Annahme, dass Unterrichtsziele vorausbestimmbar, zu definierten Zeitpunkten kurzfristig erreichbar und überprüfbar seien, war der bis heute folgenreiche Fehlschluss der Lernzieleuphorie der siebziger Jahre.

8 Geschichtsbewusstsein als komplexes Phänomen lässt sich nicht auf Lernziele verkürzen. Die Verkürzung auf überprüfbare Lernziele zeigt sich auch vergleichsweise problematisch bei der Bewertung der Bedeutung des Geschichtsunterrichts. Das Unterrichtsfach Geschichte hat seit Jahrzehnten seinen führenden Platz eingebüßt. Es stellt sich die Frage, ob das jahrelange Einüben von Quellenarbeit, Textvergleichen und Begriffserklärungen, mit denen der wissenschaftliche Umgang mit Geschichte realisiert wird, nicht ins Leere läuft.

9 Schörken, Rolf: Historische Imagination und Geschichtsdidaktik. Paderborn/München/Wien/Zürich 1994, S. 13.

10 Ausstellungen sind auch Foren für Kommunikation und soziale Erfahrungen. Interaktion und Kommunikation zwischen Individuen innerhalb einer Gruppe definieren soziale Beziehungen. Diese Erfahrung steht nur indirekt in Zusammenhang mit musealen Exponaten und zählt aus diesem Grund 


\subsection{Historische Erfahrung}

Museen sind Orte, die historische Erfahrung ermöglichen. In nahezu allen Museumstypen, und nicht nur in den historischen Museen, kommt Geschichte vor, das heißt also auch in den Museen der Kunst, Technik, Natur, Völkerkunde usw. Die Besonderheit der historischen Erfahrung in einer Ausstellung basiert auf der für diese Kultureinrichtung charakteristischen Möglichkeit, der Geschichte mit allen Sinnen nicht nur kognitivdiskursiv, sondern auch über Emotionen und Affekte zu begegnen. ${ }^{11}$

„Was macht historische Erinnerung eingängig, was verleiht ihr Lebendigkeit, mit der sie die Abständigkeit und Unwirklichkeit der Vergangenheit in die überwältigende Wirklichkeit der Gegenwart hinein vermittelt? Diese Frage ist ohne einen Hinweis auf die ästhetische Qualität historischer Präsentationen der Vergangenheit nicht beantwortbar." ${ }^{12}$

Insbesondere in der Authentizität des historischen Relikts liegt die eigentümliche Qualität der Geschichtsdarbietung. Diese bietet einen Ausgangspunkt für besondere Formen von Geschichtserfahrung, die eben nicht nur auf kognitivem, intellektuellem und diskursivem Wege gewonnen wird, sondern die vor allem auf dem Prinzip der sinnlichen Anmutung und des sinnlichen Reizes aufbaut. Grund für dieses „Authentizitätsvermögen“" ist die Ambivalenz, die dem historischen Relikt eigen ist. Das Originalobjekt rückt Vergangenheit einerseits nah an die Betrachter heran, dennoch bleibt dieses ein Gegenstand aus längst vergangenen Zeiten. Diese eigenartige Fremdheit ist authentischen Dingen inkorporiert. Aber gerade diese Eigenheit zeichnet sie für historische Erkenntnisse aus (Korff 2002, S. 120).

nicht zu den spezifisch musealen Erfahrungen. Auch andere Einrichtungen, so zum Beispiel kommerzielle Erlebnisorte, besitzen dieses Potential und sehen hierin einen besonderen Qualitätsfaktor. Dieses Reservoir an Möglichkeiten wird bisher von musealen Ausstellungen im Vergleich zu Erlebniswelten kaum ausgeschöpft.

11 Die Geschichtsvermittlung in historischen Ausstellungen gewährt somit auch die Erlebbarkeit von Geschichte. Sie begegnet damit dem im Unterricht vielfach beklagten Mangel an erfahrbaren Geschehnissen. Vgl. Kuhn 1978, S. 7.

12 Rüsen, Jörn: Was ist Geschichtskultur? Überlegungen zu einer neuen Art über Geschichte nachzudenken. In: Füßmann 1994, S. 13. 


\section{Geschichtsbewusstsein}

Ausstellungen sind Elemente der Geschichtskultur. ${ }^{13}$ Geschichtskultur bezeichnet den Gesamtbereich der Aktivitäten des Geschichtsbewusstseins. Dieser lässt sich als eigener Bereich der Kultur mit einer spezifischen Weise des Erfahrens und Deutens der Welt beschreiben. Mit ihm rückt die Geschichtsdidaktik ihren spezifischen Gegenstand, das historische Lernen, in eine umfassende Perspektive, die den vorherrschenden Blick auf das Geschichtsbewusstsein und seine kognitive Seite erheblich erweitert. Die ganze Spielbreite des Geschichtsbewusstseins, seine emotionalen, ästhetischen, politischen, kognitiven, religiösen und weltanschaulichen Dimensionen geraten in den Blick. ${ }^{14}$ In den ästhetischen Bereich fallen u.a. Denkmäler, Museen und Ausstellungen. Dabei geht es um eine spezifische Wahrnehmungsqualität der Vergangenheit, also um die Imagination vergangener Lebenswelten. Die Wissenschaftsfrage der Didaktik der Geschichte ist darauf gerichtet, wie sich unter historisch gewordenen und gegebenen gesellschaftlichen Verhältnissen in der Auseinandersetzung mit der Vergangenheit Geschichtsbewusstsein bildet und gebildet wird. Mehr als bloßes Wissen an der Geschichte umgreift Geschichtsbewusstsein den Zusammenhang von Vergangenheitsdeutung, Gegenwartsverständnis und Zukunftsperspektive.

„Geschichtsbewußtsein meint die ständige Gegenwärtigkeit des Wissens, daß der Mensch und alle von ihm geschaffenen Einrichtungen und Formen seines Zusammenlebens in der Zeit existieren, also eine Herkunft und eine Zukunft

13 Jörn Rüsen hat Ende der neunziger Jahre den Begriff Geschichtskultur als Bezeichnung für den Denk- und Forschungsbereich der Geschichtsdidaktik geprägt. Der Begriff Geschichtskultur beschreibt die vielfältige Art und Weise des Umgangs von Individuen und Kollektiven mit Vergangenheit und Geschichte - in den Medien und Multimedien, in den Schulen, in Museen, Ausstellungen und historischen Gedenkorten. Auch verweist er auf das Phänomen, dass Geschichte einen völlig neuen Stellenwert im öffentlichen Bewusstsein und im Grenzbereich zwischen Politik, Wissenschaft und Ästhetik erhält. Vgl. Rüsen, Jörn: Was ist Geschichtskultur? Überlegungen zu einer neuen Art über Geschichte nachzudenken. In: Füßmann 1994, S. 3-26.

14 Rüsen, Jörn: Geschichtskultur. In: Bergmann, Klaus u.a. (Hrsg.): Handbuch der Geschichtsdidaktik. Seelze-Velber 1997, S. 38. 
haben, daß sie nicht darstellen, was stabil, unveränderlich und ohne Voraussetzung ist.“ ${ }^{\prime 15}$

Geschichtsbewusstsein setzt das Wissen voraus, dass die Rekonstruktion von Vergangenheit notwendig an die Erkenntnismöglichkeiten, die Deutungswünsche und die lebensweltlichen Fragestellungen einer Gegenwart gebunden ist. Diese Bestimmung setzt das Geschichtsbewusstsein ab vom Geschichtsbild, in dem Vergangenheitsverständnis zum gültigen Abbild der Geschichte erstarrt. Prinzipiell kann zwischen einem naiven und einem wissenschaftlich begründeten Geschichtsbild unterschieden werden. ${ }^{16}$

„Geschichtsbewußtsein läßt solche Geschichtsbilder als Ausdruck eines in den Erfahrungen und Bedürfnissen einer historischen Gemeinschaft wurzelnden Vergangenheitsdeutung erkennen und in ihrer Partialität wie Historizität begreifen." (Jeismann 1997, S. 42)

In dem Maße, wie sich seit Ende der sechziger Jahre Ziele und Methoden des Geschichtsunterrichts wandelten, die Offenheit und Mehrdeutigkeit der Geschichte in den Vordergrund traten und die apodiktische Behauptung, jeder Mensch brauche ein geschlossenes Geschichtsbild, in Zweifel gezogen wurde, rückt man mehr und mehr davon ab, den Schülern ein verbindliches Geschichtsbild vermitteln zu wollen (Schneider 1997, S. 292). Auch Ausstellungsmacher sind nicht nur Interpreten und Vermittler von historischen Bildern, sondern sie produzieren selbst fortlaufend Bilder von Vergangenheit in ihrer Gegenwart. Auch hier stellt sich das Problem einer adäquaten und zukunftsorientierten Sinnvermittlung.

Zur Bestimmung des Geschichtsbewusstseins gehört außerdem neben der Rationalität des Umgangs mit den historischen Zeugnissen die auf sich selbst zurückgewendete Aufmerksamkeit, die Reflexibilität. Geschichtsbewusstsein bringt die Reichweite und die Grenzen der eigenen

15 Schneider zitiert in Jeismann, Karl-E.: Geschichtsbewußtsein - Theorie. In: Bergmann 1997, S. 42.

16 Je nach Reichweite ideologischer Zielsetzung oder unter Zugrundelegung anderer Prämissen lassen sich folgende, bis in die Gegenwart hinein neben- oder nacheinander existierende, teilweise miteinander konkurrierende Geschichtsbilder feststellen: christlich-abendländisches, marxistischleninistisches, rassisch-biologisches, heroisches, idealistisches, germanozentrisches, europäisches, universales u.a. Geschichtsbild. Vgl. Schneider, Gerhard: Geschichtsbild. In: Bergmann 1997, S. 291. 
Deutungen in den Blick und ermöglicht die Abwägung des relativen Rechtes anderer Deutungen der gleichen Vergangenheit. Jeisman betont, dass der Singular des Begriffs Geschichtsbewusstsein nicht zu der Ansicht verführen dürfe, hinter den verschiedenen Rekonstruktionen von Vergangenheit verberge sich ein „wahres“ Geschichtsbewusstsein. Nicht an einer gültigen Geschichtsvorstellung, sondern am Bemühen um abwägende Urteilsbildung und Reflexion der Wertungen und Perspektiven ist Geschichtsbewusstsein zu erkennen (ebd., S. 43).

Die Begegnung mit den Objekten der Vergangenheit ermöglicht historische Erfahrung und trägt zur Entwicklung von Geschichtsbewusstsein bei. Die besondere Qualität dieser Erfahrung ist jedoch auch von der Gestaltung der Ausstellungsorte abhängig. Mit Ausstellungen werden ebenfalls Bilder zur Vergangenheit entworfen; diese können ein geschlossenes Geschichtsbild konstruieren, wie dieses bei den konsequent durchgestylten Erlebniswelten der Fall ist. Sie bergen jedoch auch im Speziellen diese Offenheit der Interpretation, die das Fragmentarische der Geschichtsrekonstruktion deutlich macht. Insbesondere die Anordnung der Objekte im dreidimensionalen Raum, der je nach Standort und Perspektive unterschiedliche Sichtweisen und Kombinationen zulässt, garantiert die Mehrdeutigkeit und unterschiedliche Lesbarkeit der Exponate, die nicht nur in dem spezifisch gesetzten Zusammenhang interpretiert werden, sondern zudem jedem Objekt einen Sinnüberschuss verleihen, der in einem anderen Kontext völlig anders interpretiert werden kann. ${ }^{17}$ Eine moderne visuelle Rhetorik des Historischen versucht, die Bilder und Zeichen der Vergangenheit bewusst mit der Gegenwart zu konfrontieren, um damit auf Kontinuitäten wie Diskontinuitäten hinzuweisen. Kennzeichnend für diese Art der Geschichtsdarstellung ist, dass sie die Vergangenheit nicht in die jeweilige Zeit verbannt, sondern mit den gegenwärtigen Bedürfnissen konfrontiert. Dies bedeutet auch, dass Vergangenheit weder realistisch noch naturalistisch dargestellt wird. Grütter propagiert das Mittel der ironischen Verfremdung als deutlich erkennbaren Hinweis, dass diese Vergangenheit nur als Konstrukt existiert. $^{18}$

17 Grütter, Heinrich Theodor: Geschichte im Museum. In: Bergmann 1997, S. 711.

18 Grütter, Heinrich Theodor: Warum fasziniert die Vergangenheit? Perspektiven einer neuen Geschichtskultur. In: Füßmann 1994, S. 55. 


\section{Historische Imagination}

Einen weiteren Aspekt, der in Zusammenhang mit Visualierung, Vorstellungsvermögen und Geschichtsbildern steht, stellen die Überlegungen zur historischen Imagination ${ }^{19}$ dar. Jede Beschäftigung mit Geschichte wird von einem Strom innerer Vorstellungen begleitet. Auch für das Verstehen und Erklären von geschichtlichen Zusammenhängen und Bedeutungen sind innere Bilder wichtig. Sie gehören zur intrasubjektiven Seite des Verstehensprozesses. Vergleichbar den Wörtern sprechen auch Bilder - Zeichen, die wir mit den Augen sehen - innere Bilder der Phantasie an. Äußere Bilder schreiben sich vor allem dann dem Gedächtnis ein, wenn sie mit bereits vorhandenen inneren Bildern korrespondieren. Historische Imagination stellt eine grundlegende Kategorie dar, ohne deren Vorhandensein Geschichte nicht funktionieren könnte. Schörken stellt die These auf: „Ohne Imaginationskraft keine Historie.“ (Schörken 1994, S. 18) Auch Geschichtsschreibung schafft eine Welt der Rekonstruktion als Konstruktion.

Schörken entwickelte seine theoretischen Überlegungen anhand der Erzählung im Geschichtsunterricht. Im Geschichtsunterricht des 19. und der ersten Hälfte des 20. Jahrhunderts wurde die methodische Form der Geschichtserzählung umfangreich angewandt. In den siebziger Jahren erfuhr die Geschichtserzählung scharfe Kritik. Abgelehnt wurde unter anderem die Naivität der Darstellung, das auf bloße Emotionalität bedachte, das Unkritische, die stille Parteinahme für die Großen in der Geschichte und das vom Schüler erwartete Lauschen. Auch wurde in der Geschichtserzählung ein Instrument gesehen, welches die unbewusste Übernahme von Gesinnung förderte (ebd. S. 122). Gegen diese vehemente Ablehnung regte sich Widerspruch. Es gibt keinen unlösbaren $\mathrm{Zu}-$ sammenhang zwischen der Geschichtserzählung und der Orientierung an großen Männern. Auch wurde argumentiert, durch einseitige Bevorzugung von Strukturen und Quantitäten die Geschichte in einer Weise zu entleeren, dass Menschen nur noch als Exponenten ökonomischer Pro-

19 Die Bezeichnung historische Imagination ist neu in der Geschichtsdidaktik. Das Wort kommt von lat. imago = Bild. Die Imagination hat es mit der Hervorbringung von inneren Bildern, also von Vorstellungen zu tun. Die geschichtsdidaktische Forschung ist aktuell noch weit entfernt, die Einsichten in Formen und Funktion der historischen Imagination zu systematischen Begriffen und Theorien zu fügen und Schlussfolgerungen für die Pragmatik des Gebrauchs von Geschichte in Schule und Öffentlichkeit zu ziehen. 
zesse aufträten und Geschichte zum Traum des Statistikers würde (ebd. S. 121).

Dennoch steht der Historiker der dem Erzählen innewohnenden Illusionswirkung sehr misstrauisch gegenüber. Es besteht der Argwohn, dass die Aneignung von Geschichte zu leicht gemacht werden würde, zumal die Vergegenwärtigung der Vergangenheit einen Vorgang darstellt, der nicht ohne Anstrengung zu bewältigen ist (ebd., S. 16). Ein weiterer Einwand des Historikers gegenüber dem historischen Roman bezieht sich auf die Verwendung fiktiver Mittel.

Der Vorwurf, dass die Erzählung und mit daraus resultierend die historische Imagination zu leichte Zugänge zur Vergangenheit schaffen würde, darf nach Ansicht Schörkens nicht generell zu einer grundsätzlichen Ablehnung dieser Methode führen, da sie eine wichtige Brückenfunktion zwischen Vergangenheit und Gegenwart erfüllt. Ein zentraler Punkt besteht darin, dass Vergangenheit nicht mehr habhaft ist und von ihr in der Gegenwart lediglich noch Spuren aufzufinden sind. Dem Vorgang der Vergegenwärtigung der Vergangenheit muss deshalb besondere Aufmerksamkeit geschenkt werden. „Die erste Aufgabe eines Habhaftwerdens der Vergangenheit liegt darin, dieser den Stachel der zeitlichen Distanz zu nehmen, also eine Dedistanzierung als Identifikation mit dem, was einst war.“ (ebd., S. 18)

Ein historisches Fundstück bedeutet noch keine historische Wirklichkeit, sondern verweist auf eine Spur zu einer nicht mehr vorhandenen Wirklichkeit. Das Identifizieren einer Spur, so zum Beispiel eines archäologischen Artefakts setzt sich aus kausalen Schlussfolgerungen und Interpretationen zusammen, die den Bedeutungscharakter der Spur betreffen. Dies bedeutet auch, dass Geschichte immer interpretierte Geschichte ist. Schörken bringt folgendes Beispiel:

„Der aufgefundene Teil einer Waffe kann z.B. auf Grund bestimmter Kausalschlüsse identifiziert werden: etwa die ovale Form einer Speerspitze, die Art des Metalls, die Anlage der Schneiden, die Befestigungsmöglichkeit für den Schaft. Was sie für die Aufhellung der Vergangenheit bedeutet, ist eine Sache der Interpretation.“ (ebd., S. 17)

Die Klärung der historischen Zusammenhänge stellt einen Interpretationsakt dar. Die Kausalschlüsse und Interpretationen der Historiker können sich nur dann entwickeln, wenn diese sich die Begebenheiten in ihrer Phantasie vorstellen können. Dieses Sich-Vorstellen bildet eine Basis für die Arbeit des Historikers. 
„Eine Waffe ist nur dann als Waffe zu identifizieren, wenn man sich vorstellen kann, wozu sie gebraucht und wie sie gehandhabt wurde." (ebd.)

Diese phantasiegebundene Arbeit des Archäologen hat nach Ansicht Schörkens mit der fiktionalen Welt des Schriftstellers ebensoviel zu tun, wie mit der des streng realistischen Empirikers. Je unbekannter das Objekt und je schwieriger seine Identifikation ist, umso größer ist auch der Anteil der Imagination. Phantasiemomente im Sinne von Sich-einevergangene-Welt-vorstellen spielen nicht erst in der narrativen Wiedergabe der Geschichte, sondern schon in der Rekonstruktionsarbeit des Historikers eine wichtige Rolle.

Ähnlich ergeht es Besuchern einer Ausstellung. Auch diese benötigen für die Interpretation der Objekte Vorstellungsvermögen. Archäologische Artefakte, so zum Beispiel Pfeilspitzen, erscheinen dem Laien lediglich als Steine, deren äußere Formen er betrachten kann. Mittels Methoden der experimentellen Archäologie können neolithische Waffen und Handwerkszeuge rekonstruiert und somit als dreidimensionale Gebrauchsobjekte gezeigt werden. Dies bietet dem Betrachter einen Anknüpfungspunkt, um sich die ursprüngliche Funktion dieser Artefakte vorstellen zu können.

Die Vorstellungsfähigkeit schafft Raum für Geschichte, indem sie die Alltagswelt partiell beiseite schiebt und einen Vorstellungsraum mit Menschen, Örtlichkeiten und Geschehen erfüllt. Die Vorstellungskraft fungiert als Brücke in die zweite Wirklichkeit. Wäre die Vergangenheit noch vollkommen sinnlich erfahrbar, brauchte man keine Imaginationskraft aufzuwenden. Die Imagination schafft das heran, was man nicht sehen, hören und fühlen kann, was man aber braucht, um eine vergangene Welt geistig aufbauen zu können (ebd. S. 135). Wenn der Prozess des Vergegenwärtigens der Vergangenheit nicht von der Seite des schreibenden und konstruierenden Historikers, sondern von der Seite des Laien erfolgt, so stellt sich die Frage, wie die Brücke zur Vergangenheit beschaffen sein kann. Die historische Erzählung bildet eine Möglichkeit, die historische Imagination zu wecken und damit die Kluft zur Vergangenheit zu überschreiten.

Vorstellungsbilder sind keine Abbildungen, sondern kreative Hervorbringungen des Geistes unterhalb der Reflexionsschwelle. Man sieht etwas, ohne es wirklich zu sehen. Das Vorstellungsbild setzt die faktische Abwesenheit voraus, was in den Bildern zur Anschauung gelangt. Vorstellungsbilder brauchen zu ihrer Entstehung Entfaltungsfreiheit. 
„Der sprachliche Anstoß tut bessere Dienste für die Aktivierung der Imaginationskraft als die Vollständigkeit der Beschreibung, welche die Imagination erdrücken kann.“ (ebd., S. 40)

Im Vergleich hierzu muss der Betrachter eines Films meist keine eigenen Vorstellungsbilder entwickeln. Das Bild wird fertig bis in die letzte Einzelheit geliefert. $^{20}$ Der Zuschauer ist damit beschäftigt, den Bildwechsel, das heißt, die Veränderungen des Dargestellten zu verfolgen und ist in der Regel innerlich damit ausgefüllt. Eine eigene Imaginationsfähigkeit wird nicht gebraucht, sie ist durch die ununterbrochene Lieferung fertiger Bilder entlastet, meistens sogar außer Kraft gesetzt, weil den Bildern nichts mehr hinzugefügt werden kann. „Sie haben in der Regel nicht das, was Roman Ingarden Leerstelle genannt hat: sie lassen keinen Raum für die Imagination." (ebd., S. 49)

Für die Praxis der Erzählung bedeutet dies, dass zwischen unterschiedlichen Formen des Erzählens differenziert werden muss. Nicht jede Art der Darstellung ist zu befürworten. Für den harmonisierenden, betulichen Gebrauch des Erzählens, wie dies zu Beginn des 20. Jahrhunderts der Fall gewesen ist, finden sich in der gegenwärtigen didaktischen Diskussion keine Befürworter. Die Kunstmittel des älteren historischen Erzählens - Illusion, Suggestion, Einstimmung, Geschlossenheit einer erzählten Welt - wurden zu Recht aufgegeben. Seit Anfang des Jahrhunderts gab es jedoch parallel in der erzählenden Literatur modernere Formen, die die einfache Erzählung zu Gunsten einer gebrochenen, verfremdeten und distanzierenden Erzählform mit den Stilmitteln von Montage, Verfremdung, Spiegelungen, Perspektivenwechsel, Handlungsdurchbrechungen, Reflexionen und dem Spiel mit Zitaten aufgaben (Schörken 1994, S. 119). ${ }^{21}$

Im Hinblick auf den Geschichtsunterricht können historische Imagination und Geschichtserzählung nur einer von vielen Bestandteilen eines multiperspektivischen und multimedialen Geschichtsunterrichts sein. Doch als eine Kategorie dürfen sie nicht übergangen werden. Die von

20 Einschränkend sei angemerkt, dass dies jedoch nicht für alle Filme gilt. Als ein Beispiel dafür sei auf die Kriminalfilme von Alfred Hitchcock verwiesen. Die Andeutung von Szenen ohne Zeigen der konkreten Handlung bildet ein typisches dramaturgisches Element seiner Filme.

21 Nur auf wenige literarisch revolutionäre Autoren, die Vertreter eines gebrochenen Wirklichkeitsverständnisses sind, sei in diesem Zusammenhang verwiesen: Gide, Proust, Joyce, Musil, Kafka, Woolf. 
Schörken aufgestellten Thesen zur Geschichtserzählung lassen sich auf die Thesen zur Ausstellungsgestaltung übertragen.

Gestaltung sollte einen Anstoß zur Aktivierung der Imaginationskraft bilden, jedoch dabei kein starres Bild entwerfen, sondern Offenheit mit Leerstellen zum Weiterdenken bewahren. Für meine Studie liefern die Überlegungen Schörkens zur Weckung der historischen Imagination eine Bestätigung der Tatsache, dass Ausstellungen eine Brückenfunktion darstellen, die Interesse für tiefer gehende Beschäftigung initiieren können. Historische Imagination anhand von Ausstellungen soll jedoch nicht in vorgefertigte klischeehafte Bilder münden. Diesem Risiko sind Ausstellungen ausgesetzt, wenn sie inszenatorische, multimediale Angebote integrieren. Der Rezensent einer Ausstellung über das Nibelungenlied hebt genau diese Problematik hervor.

„Wie nebenbei erblickt man die Totenmaske einer Dame, dreißig oder vierzig Jahre alt, unbeabsichtigt entstanden, als man die Leiche in Kalk legte, ein einzigartiger Fund. Jetzt in Gips ausgegossen gewährt sie den Blick auf einen Menschen des Mittelalters, wie ihn die zeichenhafte damalige Kunst niemals abgebildet hat. Und dazu hört man den Kommentar: 'Schauen Sie sich dieses Gesicht an! Ist es nicht von erstaunlicher Plastizität?' So ist es, und doch hört man es mit einigem Widerwillen. Aber das Erlebnis präformiert, erwürgt die Phantasie.“22

Der Gratwanderung zwischen Anregung der Vorstellungsfähigkeit und Festschreiben von Bildern muss mit höchster Sensibilität begegnet werden. Die Phantasietätigkeit benötigt Freiraum, aber andererseits muss genauso die Imaginationskraft angeregt werden, um sich entwickeln zu können.

22 Müller, Burkhard: Die Heimkehr des harmlosen Lindwurms. Bunte Fläche des Dazumal: Die Karlsruher Ausstellung über das Nibelungenlied bringt ihren Gegenstand zum Verschwinden. In: Süddeutsche Zeitung vom 28.01 .04 . 


\section{2 Ästhetische Erfahrung}

Wie Geschichte sind auch Ästhetik und Gegenständlichkeit im Museum präsente Phänomene. Die Begegnung mit historischen Relikten und musealen Exponaten bildet das charakteristische Element der ästhetischen Erfahrung in Ausstellungen. ${ }^{23}$ Darin besteht die spezifische Besonderheit. Generell finden ästhetische Erfahrungen jedoch überall statt. Der weitaus größte Anteil ästhetischer Beeinflussung und Bildung geschieht nicht durch pädagogische, schulische und außerschulische Intervention, sondern durch vielfältige Instanzen wie zum Beispiel mittels Werbung, Design oder auch kommerzieller Erlebniswelten. ${ }^{24}$ Prinzipiell wendet sich ästhetisches Genießen gegen Zweckorientierung. Ästhetische Erfahrung grenzt sich vom praktischen Zwang der Arbeit und den natürlichen Bedürfnissen der Alltagswelt ab. ${ }^{25}$ Ästhetisch genießendes Verhalten, in welchem sich das imaginierende Bewusstsein aus dem Zwang der Gewohnheit und der Interessen löst, ermöglicht eben dadurch, den in seinem alltäglichen Tun befangenen Menschen für andere Erfahrungen zu öffnen. Die Distanz zur alltäglichen Welt setzt die Möglichkeit frei, diese wieder anders wahrzunehmen. Sie stellt Freiräume für Reflexion zur Verfügung, die sich dann wiederum auf das eigene Leben auswirken können.

In der weitesten Bedeutung bezeichnet Ästhetik, abgeleitet von dem griechischen aisthesis als sinnliche Wahrnehmung, die Lehre von der Wahrnehmung, der Sinnlichkeit, der Rezeptivität. Sie wird als solche, so zum Beispiel bei Baumgarten, Kant und Schleiermacher der Logik gegenübergestellt (Lehnerer 1993, S. 38). Dieser weite Ästhetikbegriff enthält eine wichtige Unterscheidung:

23 Ästhetische Erfahrungen lassen sich sowohl rezeptiv als auch produktiv machen, d.h. sowohl in der Wahrnehmung ästhetischer Objekte und Phänomene als auch im eigenen Gestalten, sei es bildnerisch, musikalisch, dichterisch oder darstellerisch. Da die ästhetischen Erfahrungen in Ausstellungen meist rezeptiver Art sind, werde ich mich bei meinen Ausführung auf die erstgenannte Form beziehen.

24 Lehnerer, Thomas: Ästhetische Bildung. In: Staudte, Adelheid (Hrsg.): Ästhetisches Lernen auf neuen Wegen. Weinheim/Basel 1993, S. 40.

25 Jauß, Hans Robert: Kleine Apologie der ästhetischen Erfahrung. In: Stöhr, Jürgen (Hrsg.): Ästhetische Erfahrung heute. Köln 1996, S. 20. 
„(1) Als ästhetisch gilt die sinnliche Beziehung zu Gegenständen, objektiv, die Wahrnehmung, zugleich aber auch (2) unsere sinnliche Beziehung zu uns selbst, subjektiv das Gefühl.“ (ebd.)

In einem engeren Sinne meint Ästhetik die Philosophie der Kunst, hierzu kann nach weiterer Auffassung die gesamte Welt der Kunst, der Medien, des Designs, der Umweltgestaltung zählen. Im alltäglichen Sprachgebrauch ist der Begriff Ästhetik mit der Vorstellung einer spezifischen Wertung verbunden und bezieht sich auf etwas ganz besonders und wertvoll Sinnliches. Ästhetik in diesem engen Sinn meint Vollkommenheit, Anmut, Harmonie, Schönheit (ebd. S. 39). In der gegenwärtigen philosophischen Ästhetikdiskussion wird versucht, die Verengung der Ästhetik auf die Kunst oder nur auf das Schöne rückgängig zu machen. Ästhetik wird wieder in ihrem ursprünglichen Sinne als eine Theorie der sinnlichen Erkenntnis verstanden, ,als Thematisierung von Wahrnehmung aller Art, sinnenhaften ebenso wie geistigen, alltäglichen wie sublimen, lebensweltlichen wie künstlerischen.“26

\section{Ästhetik und Anästhetik}

Eine genauere Betrachtung des Ästhetikbegriffs ist elementar, denn er wird nicht nur im allgemeinen Sprachgebrauch, sondern auch in der Literatur, so zum Beispiel im wirtschaftswissenschaftlichen Bereich, sehr unterschiedlich gedeutet und verwendet. Pine/Gilmore27, zwei amerikanische Erlebnis-Managementberater, sehen in der ästhetischen Erfahrung

26 Welsch, Wolfgang: Ästhetisches Denken. Stuttgart 1993, S. 9.

27 B. Joseph Pine ist einer der führenden Wirtschaftsautoren und Managementberater der USA. Er lehrt u. a. an der Universität in Kalifornien (UCLA) und an der MIT Sloan School of Management. James H. Gilmore startete seine Karriere bei Procter \& Gamble und war danach bei führenden US-Unternehmensberatungen tätig. Die Schaffung von eindrucksvollen Erlebnissen steht im Zentrum ihrer Überlegungen. Unternehmen, die lediglich auf der Basis von niedrigen Preisen konkurrieren, erzeugen nur Massenware. Stattdessen argumentieren die Wissenschaftler für den Erlebniskauf. Jedes Geschäft sollte sich in eine Bühne verwandeln und einprägsame Erlebnisse inszenieren, für die die Kunden auch hohe Preise bezahlen wollen. Vgl.: Pine Joseph B./Gilmore James H.: Erlebniskauf: Konsum als Ereignis, Business als Bühne, Arbeit als Theater. München 2000 . 
einen Zustand, dessen wesentliches Charakteristikum die Passivität darstellt.

„Bei der ästhetischen Erfahrung taucht ein Mensch in ein Ereignis oder eine Umgebung ein, ohne selbst Einfluss darauf nehmen zu können. Eine ästhetische Erfahrung macht, wer am Rand des Grand Canyon steht, eine Kunstgalerie oder ein Museum besucht oder im Café Florian in Venedig sitzt. Ein Tribünenplatz beim Kentucky Derby gehört ebenfalls hierher." (Pine/Gilmore 2000, S. 59)

Für Pine/Gilmore gibt es keine künstlichen Erlebnisse, ihrer Ansicht nach ist jedes in einem Menschen hervorgerufene Erleben echt, seien die Reize natürlich oder simuliert. Unabhängig davon, ob man durch einen im Wesentlichen von Menschenhand geschaffenen Nationalpark wandert oder in einem Rainforest Café isst. Gemäß dieser Argumentation lassen sich problemlos Fälschungen, Repliken und Rekonstruktionen rechtfertigen. Das einzige außer Frage stehende Kriterium besteht darin, dass eine ästhetische Erfahrung auf die Gäste echt wirken muss (ebd., S. 63). Das Betrachten von Oberflächenreizen, die der Befriedigung der Schau- und Augenlust dienen, wird mit ästhetischer Erfahrung gleichgesetzt. Eine eigene Erkenntnisqualität wird ihr nicht zugerechnet.

„Während die Teilnehmer an einer Bildungserfahrung lernen, die Protagonisten einer Realitätsflucht handeln und die Teilnehmer an einem Unterhaltungserlebnis - nun, das beste Wort wäre wahrscheinlich empfinden wollen, geht es jenen, die eine ästhetische Erfahrung machen, darum, einfach dort zu sein.“ (ebd., S. 59)

Jedoch genau hierin sieht Welsch aus philosophischer Perspektive eine verkürzte Auffassung von ästhetischer Erfahrung, die nämlich zu dem genauen Gegenteil, nämlich einer Anästhetisierung führt. Welsch verwendet Anästhetik als Gegenbegriff zu Ästhetik und meint jenen Zustand, in dem die Elementarbedingungen des Ästhetischen - die Empfindungsfähigkeit - aufgehoben ist (Welsch 1993, S. 10). Während die Ästhetik das Empfinden verstärkt, thematisiert Anästhetik die Empfindungslosigkeit im Sinn eines Verlusts. Sensibilität wird unterbunden oder unmöglich gemacht. Dies kann auf unterschiedlichen Ebenen von physischer Stumpfheit bis zur geistigen Blindheit stattfinden (ebd.). Zur Verdeutlichung zieht Welsch einen Vergleich mit der Medizin. Hier wird durch Anästhesie die Empfindungsfähigkeit ausgeschaltet, und der Wegfall des höheren, des erkenntnishaften Wahrnehmens erweist sich als 
Folge davon. Anästhetik problematisiert folglich die elementaren Schichten des Ästhetischen, seine Bedingungen und Grenzen. Ästhetisierungsprozesse finden in der gesamten Umwelt statt, die jedoch dann wie Welsch feststellt - in eine gigantische Anästhetisierung münden.

„Betrachten Sie nur einmal das postmoderne Facelifting unserer bundesrepublikanischen Großstädte, insbesondere ihrer Einkaufzonen. Hier erfolgt zweifellos eine immense Ästhetisierung - eine den Konsum ankurbelnde Ästhetisierung. Aber am Ende entsteht bei aller chicen Aufgeregtheit und gekonnten Inszenierung doch wieder nur Eintönigkeit.“ (ebd., S. 13)

Bei szenographischen Konzepten multimedialer Inszenierung war in der Vergangenheit Kritik in diese Richtung zu hören. Das in Deutschland bedeutendste und kostenintensivste Ereignis des Jahres 2000 war der Themenpark der Expo 2000 in Hannover. In der Gesamtschau erhielt dieses Projekt wenig positive Resonanz und wurde als „großes, aufgeblasenes Nichts“ abqualifiziert, „ein klassischer Fall von viel Verpackung und kein Inhalt"“. ${ }^{28}$

Für Welsch sind dies Beispiele für Anästhetisierung, da viele der „konsum-inszenatorischen Dekorationsbauten“ bei Betrachtung im Detail sich ,als ausgesprochen leer, zombiehaft und für ein verweilendes Anschauen unerträglich erweisen." Bei der Wahrnehmung von Oberflächenformen und Details findet eine systematische Desensibilisierung statt. Die gestalterischen Elemente sollen lediglich eine Stimmungslage bewirken, ,in der sie als Spotlights einer aufgedrehten Atmosphäre der Stimulation zu schönem Leben und Konsum wirken." (ebd. S. 13). Die ästhetischen Werte sind reduziert auf Animationswerte. Zur Desensibilisierung für die ästhetischen Fakten kommt weiterhin eine Anästhetisierung auf psychischer Ebene hinzu. Die Stimulation zielt auf immer wieder neue Effekte durch Kleinereignisse. Diese führen jedoch in eine leerlaufende Euphorie und einen trancehaften Zustand der Gleichgültigkeit.

Nicht nur von philosophischer Seite wird diese Entwicklung mit Argwohn betrachtet, auch von der Seite der Freizeitforscher sind kritische Stimmen zu vernehmen. Opaschowski ${ }^{29}$ kritisiert nicht Erlebnisan-

28 Interview mit Herrn Kurt Ranger, Büro Kurt Ranger Design in Stuttgart, am 20. März 2002.

29 Univ.-Prof. Dr. Horst W. Opaschowski zählt zu den führenden Freizeitforschern in Deutschland. Er lehrt seit 1975 an der Universität Hamburg und leitet seit 1979 das B.A.T Freizeit-Forschungsinstitut. Opaschowski hat 
gebote, sondern die damit verbundenen, unerfüllbaren Glücksversprechen, die Anmaßung und die Tendenz zum Größenwahn, die für Bescheidenheit oder gar Demut keinen Raum lassen. Seiner Ansicht nach agiert „in den Kathedralen des 21. Jahrhunderts“ eine professionelle Priesterschaft, „die vom Dogma des käuflichen Glücks beseelt ist und mit geradezu messianischem Drang schwunghaften Handel mit Lebensfreude betreibt. “30 Opaschowski sieht die Gefahr, dass die Angst vor (Sinn-)Leere die Gier nach Sensationen kontinuierlich steigert und das menschliche Gefühl für Normalität und Mittelmaß verloren geht. Die Menschen stehen dann unter dem Zwang, ständig pausenlos Glück erleben zu müssen. Die Frage nach verantwortungsvollem Handeln mit Blick auf die Zukunft stellt sich für die Unterhaltungsindustrie jedoch nicht. „Für die Zukunft ist absehbar: Die weitere Aufrüstung der Erlebnisindustrie wird die Frage, Was kommt danach? unbeantwortet lassen.“ (ebd.)

\section{Ästhetische Erfahrung der Differenz}

Vor diesem skizzierten Hintergrund wird deutlich, dass mit ästhetischer Erfahrung nicht nur das Erleben von Sinnesreizen und Gemütvollem gemeint sein kann. Eine Reduzierung darauf bedeutet eine Befreiung der Ästhetik von der Moral (Rauterberg 2002, S. 37). Es geht also nicht nur um Gefallen, sondern um vielschichtige Dimensionen der Erfahrungen, die auch Beunruhigung und Irritation erzeugen, verbunden mit einer Intensität des Erlebens sowie gesteigerter Aufmerksamkeit.

Bei dem Versuch der Charakterisierung der besonderen Qualität ästhetischer Erfahrung beziehe ich mich auf Maset und seine Theorie der ästhetischen Bildung der Differenz als „Werkzeug zur Entfaltung der Potentiale differierender Subjekte. ${ }^{\text {“31 }}$ Für Maset kommt im Begriff Mannigfaltigkeit die Vorstellung der Vielheit in Verbindung mit Faltung vor. Das Gegebene wird hiermit in der Art beschrieben, dass jedes Objekt

sich im In- und Ausland als Zukunftsforscher und Politikberater einen Namen gemacht. Für die Weltausstellung EXPO 2000 war er als Jury- und Kuratoriumsmitglied tätig.

30 Opaschowski, Horst W.: Kathedralen und Ikonen des 21. Jahrhunderts: Zur Faszination von Erlebniswelten. In: Steinecke, Albrecht (Hrsg.): Erlebnis- und Kosumwelten. München/Wien 2000, S. 53.

31 Maset, Pierangelo: Ästhetische Bildung der Differenz. Kunst und Pädagogik im technischen Zeitalter. Stuttgart 1995, S. 122. 
ebenso wie jede Vorstellung als Einzelding aus Vielheiten zusammengesetzt ist. Das bedeutet, dass Objekte Schichten aufweisen, die über-, neben-, unter- oder aufeinanderliegen oder auch ineinander verwoben sind. Das Einzelding wird unter dem mikroskopischen Blick zu einem aus Vielheiten komponierten Einzelnen. Das Mannigfaltige muss in der Wahrnehmung hergestellt werden. Die Entfaltung als pädagogische Aufgabe besteht gerade in dieser Freilegung und Herstellung. Um dies zu verdeutlichen, zieht Maset einen Vergleich mit den ästhetischen Manifestationen im kulturellen Bereich. Hier erweist sich die Integration als Sog, der die Differenzen zugunsten der Einheit der Kultur einebnet. Am Beispiel der Kategorie Folklore wird dies deutlich. Sinnentleerter Talmi an einem Touristenstrand angeboten, wird ebenso darunter subsumiert wie die Werke der australischen Aborigines, die im Jahr 1994 von den Austellungsmachern der Art Cologne nicht als Kunst bewertet wurden (ebd., S. 120).

Die undifferenzierte Wahrnehmung im Sog der Gleichmachung findet sich auch im musealen Bereich. Korff sieht die Nähe zwischen Museum und Folklorismus in mehrerer Hinsicht gegeben. Zum Ersten hat die Folklorisierung die Musealisierung von Objektwelten und Sachaggregaten zum Ziel. Dazu gehört sowohl die ,ästhetisierende Orts- und Landschaftspflege“ als auch die „historische Re-Mobilmachung“ veralteter Transportsysteme wie Postkutschenrouten, Dampfeisenbahnen oder Dampfschifflinien. Diese Aktivitäten haben oft die Einrichtung derartiger Spezialmuseen zur Folge. Zum Zweiten sind damit oft „,folkloristische Schau-Offerten“ verbunden, wie zum Beispiel Spinnen, Weben, Buttern, Töpfern usw., die von Museen organisiert werden und somit auch touristische Interessen bedienen (Korff 2002, S. 132). Diese Art der Folklorisierung hat nach Ansicht von Korff einen wesentlichen Anteil an der Erzeugung eines Klimas, in der „Dingnostalgie“ und „Altwarenfetischismus" gedeihen. Diese Verklärungsmaschinerie hat ihren institutionalisierten Stützpunkt im Museum (ebd., S. 133). Auch kann in inszenierten Ausstellungen eine Unterscheidung zwischen Original und Replik erschwert werden und ist manchmal nur dem geschulten Auge möglich.

„Wer einmal das Libeskindsche Labyrinth ${ }^{32}$ durchwandert hat, weiß am Ende nicht mehr, was Fotografie, was Fotokopie ist, was nachgeformt und was nachgestellt wurde, was Original ist und was nicht." (Rauterberg 2002, S. 39)

32 Diese Bezeichnung bezieht sich auf das Jüdische Museum in Berlin. 
Dieses Beispiele illustrieren, wie wenig differentiell die Urteilsbildung bei Wahrnehmungsphänomenen operiert. Dagegen kann die Differenz des anderen bzw. fremden kulturellen Ausdrucks nur über eine „bildende Wahrnehmung" wahrgenommen werden, die das Differierende nicht integriert, sondern es expliziert. Hier zeigt sich eine Dimension des Differenzdenkens, die den Blick auf die Andersheit und Fremdheit des Anderen richtet (Maset 1995, S. 122).

„Die Differenz konstituiert das, was sowohl an der Fremdheit als fremd als auch an der Andersartigkeit als andersartig wahrgenommen werden kann und was diese erst hervorbringt. Sie bringt Fremdes und Anderes hervor, und das Ästhetische konstituiert sich aus der Mannigfaltigkeit der Differenzen." (ebd., S. 122)

Ästhetisches Bewusstsein integriert das Bewusstsein von Relativität. Es fordert keine fest verbindlichen Inhalte ein, die gleichermaßen für alle gesellschaftlich oder traditionell legitimiert sein können. Vielmehr spürt es auch hier Differenzen auf. Es wendet sich auch dem Verdrängten, den Leerzonen, den Zwischenräumen zu. ${ }^{33}$ Ästhetische Erfahrungen können als Erfahrungen der Diskontinuität und der Differenz zu bisher Erlebtem gelten. Ästhetische Bildung der Differenz müsste dahingehend konkretisiert werden, dass sie sich auf Differenzierung gründet, ihrerseits aber in Bewegung bleibt. „Diesseits von Kunstferne und Ikonoklasmus geht es darum, für Bildungsprozesse einen Zustand zwischen den Bildern (Barthes) zu finden." (ebd., S. 73) Übertragen auf die Arbeit der Ausstellungsmacher heißt dies, Offenheit zu bewahren und den eigenen Standpunkt zu relativieren. Es gibt nicht nur eine mögliche Form der Interpretation, sondern in Abhängigkeit der spezifischen Gegebenheiten gilt es immer wieder neu zu entscheiden, welche Fragen gestellt werden und was die adäquate Form der Realisierung ist. Für Hochreiter ist entscheidend, dass in der musealen Präsentation Ehrlichkeit gewahrt ist. Eine Sammlung entsteht durch eine Mischung aus Zufall und sozialer Auswahl, und ebenso wird eine Ausstellung unter bestimmten Prinzipien und Fragestellungen geordnet und organisiert. Dies muss auch gegenüber dem Besucher eingestanden und transparent gemacht werden.

33 Schuhmacher, Doris: Ästhetische Bildung und Hochschulausbildung nach der Moderne. Alphabetisierung - Nivellierung - Differenzierung. In: Essener Unikate (1997) Heft 9. S. 65. 
„Nur eine Museumsarbeit, die zur Selbstthematisierung von Sammeln, Forschen und Ausstellen und damit zur Relativierung ihrer Darstellungsmöglichkeiten gegenüber dem Publikum bereit ist, vermeidet den weihevollen Charakter der bereits konstatierten Abgeschlossenheit und Selbstevidenz ihrer Ausstellungen. “34

\subsection{Historische Erfahrung versus Ästhetische Erfahrung}

Kulturhistorische Ausstellungen reihen sich in das weite Feld von Geschichts- und Kunstausstellungen ein. In der Einleitung habe ich dies als Zwitterstellung bezeichnet, da nicht nur das ästhetische Erleben von Kunstwerken, sondern darüber hinaus auch historische Erfahrungen intendiert sind. Dies kann zu einem Spannungsverhältnis führen. In Abhängigkeit davon, welcher Erfahrungsform der Vorzug gegeben wird, spiegelt sich dies in den Präsentationsformen wider. Ein Blick auf die Geschichte der Entwicklung der kulturhistorischen Ausstellung zeigt, dass unterschiedliche Überzeugungen zu veränderten Darstellungsweisen führten. Dies pendelt zwischen Kontextualisierung im Sinne eines Geschichtsmuseums einerseits sowie Ästhetisierung der Objekte im Stile der Kunstmuseen andererseits. Im 19. Jahrhundert gruppierte man die Ausstellungsobjekte im dekorativen Stile der malerischen Präsentationsweise. $^{35}$ Im 20. Jahrhundert veränderte sich die Art der Präsentation vom historischen Museum zum Kunstmuseum. ${ }^{36}$ Ziel war nicht mehr das geschlossene Gesamtbild, sondern die nach wissenschaftlichen Gesichtspunkten geordnete Reihe von Einzelstücken. Man begann, zwei Gruppen von Ausstellungsgegenständen zu unterscheiden. Der einen waren ästhetisch hochstehende Stücke zugeordnet, während die andere aus solchen bestand, die nur ein historisches oder kulturgeschichtliches Interesse fanden. Die ersten wurden aus den bisherigen Ensembles gelöst und im Stile eines Kunstmuseums gezeigt. Die anderen wanderten zum größten Teil ins Depot.

34 Hochreiter, Walter: Vom Musentempel zum Lernort. Zur Sozialgeschichte deutscher Museen 1800 - 1914. Darmstadt 1994, S. 222.

35 Eine Beschreibung der malerischen Präsentationsweise siehe Kapitel 1, S. $31 \mathrm{ff}$.

36 Boockmann, Hartmut: Geschichte im Museum? Zu den Problemen und Aufgaben eines Deutschen Historischen Museums. München, 1987, S. 17. 
In den Nachkriegsjahren bis hinein in die siebziger Jahre prägten Kunsthistoriker nicht nur das Kunst-, sondern auch weitgehend das Geschichtsmuseum. Neben Archäologen, Vor- und Frühgeschichtlern sowie Völkerkundlern galten diese als die einzigen, die aufgrund ihrer Ausbildung mit Realien umzugehen verstanden. ${ }^{37}$ Aktuell dominiert in den musealen Ausstellungen immer noch das an Kunst- und Kunstgewerbemuseum angelehnte Prinzip. ${ }^{38} \mathrm{Im}$ Bereich der Sonderausstellungen werden auch zunehmend andere Präsentationsstrategien umgesetzt, so dass objektorientierte wie auch kontextualisierte Formen der Präsentation nebeneinander existieren. ${ }^{39}$

Auch gegenwärtig spiegeln sich diese unterschiedlichen Überzeugungen in der Präsentationsästhetik wider, wie sich anhand zweier Beispiele zeigen lässt. Bei der Ausstellung „Otto der Große - Magdeburg und Europa “40 entschieden sich die Ausstellungsmacher für eine objektorientierte Präsentation im Sinne von Kunstausstellungen. Nur Originale und keinesfalls Repliken oder Rekonstruktion sollten gezeigt werden.

37 Hoffmann, Detlef: Künstler und Wissenschaftler als Produzenten kulturhistorischer Ausstellungen? In: Rüsen, Jörn (Hrsg.): Geschichte sehen. Pfaffenweiler 1988, S. 138.

38 Dies steht im Gegensatz zu den angelsächsischen und skandinavischen Ländern und deren historischen Museen mit umfangreich inszenierten Dauerausstellungen.

39 Die Unterscheidung zwischen Dauerausstellung und Sonderausstellung ist auch deshalb von Bedeutung, da dies Einfluss auf die Art der Konzipierung der Ausstellung hat. Die temporäre Begrenzung erleichtert es den Entscheidungsträgern, in der Präsentationssprache unkonventionellere Wege zu gehen und experimentierfreudiger als die Museen neue Ideen umzusetzen. So lieferten in der Vergangenheit Sonderausstellungen innovative Impulse für neue Darstellungsformen. Frühe Beispiele dafür sind die Gewerbe- und Weltausstellungen ab Mitte des 19. Jahrhunderts. Obwohl sie in erster Linie der Wirtschaftsförderung dienten, hatten sie mit ihren modernen Ausstellungstechniken nachhaltigen Einfluss auf die museale Darstellung, wie es etwa in dem Stubenprinzip oder in der originalgetreuen Nachbildung von Häusern und der Vorführung von Dorfleben im Freilichtmuseum praktiziert wurde. Auch lässt sich bei Sonderausstellungen eine spezifische Objektauswahl treffen, die sich in den thematischen Kontext einfügen lässt. Das Museum ist je nach Sammlungskonzept wesentlich stärker als die Sonderausstellung durch seinen Bestand an historischen Objekten bestimmt.

40 Europaratsausstellung in Magdeburg im kulturhistorischen Museum vom 27.08.01-02.12.01. 
„Eine grundsätzliche Entscheidung war es, ausschließlich Originale zu zeigen und auf jegliche Kopien zu verzichten. Die Ausstellungsarchitektur mit wenigen, würdigen Inszenierungen und keinen flackernden Bildschirmen wahrte die Würde des Originalobjekts des 10. Jahrhunderts, in großen Teilen verehrte oder liturgisch verwendete Denkmale christlicher Kultur." ${ }^{4}$

Vorrangiges Ziel der Ausstellung war, wie dies im Kurzführer zur Ausstellung formuliert wurde, die historische Bedeutung Ottos des Großen für die deutsche und europäische Geschichte hervorzuheben. „Leihgaben aus ganz Europa zeichnen das Bild einer herausragenden Herrscherpersönlichkeit in einer Zeit des Umbruchs und der Erneuerung. "42 Die Illustrierung dieser historischen Herrscherfigur war demnach ein deutlich definiertes Ziel dieser Ausstellung. Demgegenüber vermied die Gestaltung jedoch weitgehend inszenatorische Kontextualisierungen der Objekte. Vielmehr sollte eine sachliche und zurückhaltende Ausstellungsarchitektur gewährleisten, dass die Objekte ihre Wirkung entfalten konnten. Kostbare Handschriften, Elfenbeinarbeiten, Werke aus Gold, Silber und Edelsteinen wurden ausschließlich in Vitrinen gezeigt, begleitende Objektbeschriftungen gaben kunsthistorische Detailinformationen. Die historische Wissensvermittlung erfolgte über Raumtexte. Sie bestanden aus einer Kombination aus Kapitel- und Thementexten (ebd.). ${ }^{43}$ Diese Art der Präsentation führte dazu, dass primär die Bewunderung der Kunstwerke durch den Besucher im Vordergrund stand, was durchaus auch der Absicht der Ausstellungsgestalter entsprach. „Indem die Räume

41 Hasse, Claus-Peter: „Einfach atemberaubend und beeindruckend“ - Zur Durchführung und Resonanz der 27. Ausstellung des Europarates und Landesausstellung Sachsen-Anhalt. In: Ministerium für Wirtschaft und Arbeit des Landes Sachsen-Anhalt, Kulturhistorisches Museum Magdeburg (Hrsg.): Otto der Große, Magdeburg und Europa. Auf den Spuren Ottos des Großen in Sachsen Anhalt. Magdeburg 2002. S. 23.

42 Puhle, Matthias (Hrsg.): Otto der Große, Magdeburg und Europa, Kurzführer. Main am Rhein 2001.

43 Eine darüber hinausgehende Vermittlung der Inhalte wurde vom Ausstellungsareal mit ihren Originalobjekten abgegrenzt. Als Ergänzung gab es einen museumspädagogischen Bereich, einen Computer-Visualistik-Raum sowie ein Medienkunstprojekt. Diese Angebot konnte der Besucher als Informationsinseln benutzen. Eine Verknüpfung mit den Ausstellungsobjekten erfolgte nicht. 
durch die Alabaster und die Vitrinen diffus beleuchtet wurden, betonte die Lichtregie die ästhetische Inszenierung der Exponate.“44

In Konzeption und Gestaltung bediente sich die Ausstellung somit der gängigen Präsentationsform eines Kunstmuseums. Das Ziel der Ausstellung, nämlich die Vermittlung der historischen Herrscherpersönlichkeit, wurde durch die Art der Präsentation, die auf den ästhetischen Genuss abzielte, nicht unterstützt. Die ästhetische Bewunderung von Kunstwerken dominierte das Anliegen der Geschichtsvermittlung, historische Fragestellungen spielten eine untergeordnete Rolle. Ein inhaltlicher Anknüpfungspunkt zwischen Gegenwart und der tausend Jahre alten Geschichte wäre zum Beispiel die historiographische Rezeptionsgeschichte, die im wissenschaftlichen Katalog von dem Frankfurter Historiker Johannes Fried dokumentiert ist. ${ }^{45}$ Hier wird deutlich, dass die Rezeption abhängig vom Kontext der jeweiligen Zeit ist und aus heutiger Sicht nicht immer unkommentiert hingenommen werden kann. Dies betrifft zum Beispiel die Funktionalisierung des Herrschers im Dienste nationalsozialistischer Ideologien.

„Die Zahl derer, die hier zusammenzucken und sich an die Ostforscher Albert Brackmann und Hermann Aubin erinnern, die um 1940 Kaiser Otto als deutschen Kulturbringer unter den kulturunfähigen Völkerschaften des späteren Polen priesen, dürfte gering sein.“ ${ }^{46}$

Seibt kritisiert die Ausklammerung dieser Thematik im Ausstellungsrundgang, wäre dies doch eine Möglichkeit gewesen, „eine Brücke über den Abgrund von tausend Jahren bauen zu können.“ (ebd.) Trotz erläuternder Schautafeln ist eine explizit historische Verortung des Gesehenen kaum möglich. Das Sehen erschöpft sich im wiedererkennenden Sehen oder in der Identifikation des Objekts mit Hilfe der Beschriftung. ${ }^{47}$

44 Köster, Gabriele/Pöppelmann, Heike: Otto der Große, Magdeburg und Europa - Texte und Bilder einer Ausstellung. In: Ministerium für Wirtschaft und Arbeit des Landes Sachsen-Anhalt, Kulturhistorisches Museum Magdeburg 2002, S. 29.

45 Fried, Johannes: Otto der Große, sein Reich und Europa - Vergangenheitsbilder eines Jahrtausends. In Puhle, Matthias (Hrsg.): Otto der Große, Magdeburg und Europa. Mainz 2001. S. 537-562.

46 Seibt, Gustav: Das Reich der Nationen, Magdeburgs große Ausstellung über Kaiser Otto den Großen. In: Die Zeit vom 30.07.01.

47 Godau, Sigrid: Inszenierung oder Rekonstruktion? Zur Darstellung von Geschichte im Museum. In: Fehr, Michael/Grohé, Stefan (Hrsg.): Geschichte - Bild - Museum. Köln 1989, S. 201. 
Ein zweites Beispiel beschreibt die gegenteilige Situation. Bei der bayerischen Landesausstellung in Aschaffenburg „Das Rätsel Grünewald“48 integrierten die Ausstellungsmacher die Kunstobjekte in ein Gesamtensemble, in dem das historische Gliederungsprinzip maßgebend war. Die Hängung hebt die überaus hochrangigen Kunstwerke von den weniger bedeutenden Archivalien nicht ab.

„Die Ausstellungsmacher wären der Ehre weiterer Originalstücke auch gar nicht gewachsen gewesen. Sie haben die Zeugnisse des Außergewöhnlichen, [...], seltsam lieblos in die viel zu dichte Folge banaler historischer Beweisstücke eingereiht. ““49

Auch berücksichtigten die Ausstellungsmacher nicht, dass Kunstwerke Raum zum Verweilen und Betrachten benötigen.

„Vor Grünewalds Grisaillen vom Heller-Altar, die eine geradezu soghafte Tiefe entwickeln, [...], ist kaum Platz zum Stehen. Die ,Beweinung' in ihrem Klimasarg hat man direkt neben einen heftig frequentierten Durchgang geklemmt."(ebd.)

Die gleichwertige Präsentation der hochrangigen Kunstwerke neben Archivalien erschwerte das Betrachten der Objekte und schränkte den ästhetischen Genuss ein. Dies wurde den hochwertigen Kunstwerken in ihrer kunsthistorischen Bedeutung nicht gerecht. Die Wirkung der Aura der Objekte konnte sich durch die aneinanderreihende Präsentation nicht entfalten. Der nur schwer lösbare Konflikt zwischen historischer und ästhetischer Erfahrung führt zu der Frage, welche davon die wertvollere ist. Eine Lösung dieser Frage könnte folglich Antworten geben, in welcher Form Präsentationskonzepte zu entwickeln sind. Für die Gegenwart stellt Stierle fest, dass historisches Bewusstsein im Vergleich zu ästhetischer Erfahrung wesentlich höher bewertet wird.

„Daß das historische Bewußtsein die höchste Form des Bewußtseins, ja die gegenwärtig einzig noch legitime Form des Bewußtseins sei, darf in den Geisteswissenschaften weithin und in den philologischen Disziplinen insbe-

48 Landesausstellung konzipiert vom Haus der Bayerischen Geschichte in Aschaffenburg, Schloss Johannisburg vom 30.11.-28.02.03.

49 Knapp, Gottfried: Der Mann, von dem man nichts wusste - Wie die Bayerische Landesausstellung in Aschaffenburg „Das Rätsel Grünewald“ zu lösen versucht. In: Süddeutsche Zeitung vom 30.11./1.12.02. 
sondere als ein Grundkonsens bei allen sonstigen Divergenzen der Meinungen und Methoden angesehen werden. .50

Für den Umgang mit den Werken der Kunst hat dies weitreichende Konsequenzen. Das wissenschaftliche Interesse der Kunstinterpretation ist gegenwärtig immer noch in erster Linie darauf gerichtet, das Werk als eine Form des historischen Bewusstseins zu begreifen und dieser erneut mit historischem Bewusstsein zu begegnen. Das Werk erscheint als Ort, von dem vielfältige Wege in die Geschichte weisen. Es steht in einem Zusammenhang und in einer Tradition von Themen und Inhalten, die sich zu überdauernden, immer neu aufgenommenen Topoi verdichten können (ebd.). Stierle wendet sich in seiner Argumentation gegen die Vorstellung der Einheit von historischem und ästhetischem Bewusstsein. Er ist überzeugt von einem unaufhebbaren Konflikt zwischen historischer und ästhetischer Erfahrung. Dieser Konflikt bedeutet jedoch nicht, jede historische Besinnung für das Kunstwerk als irrelevant abzuweisen, aber die Bedeutung des Historischen erscheint unter der Voraussetzung dieser Trennung in einem anderen Licht. Stierle hält die Affirmationen, die sich geschichtlich aus dem Kunstwerk gewinnen lassen, für trügerisch, da sie nicht selten als in das Werk hinein projizierte Wünschbarkeiten erscheinen. „In jedem Fall heißt Historisierung des Werks seine Integration in eine der möglichen historiographischen Diskurse und damit zugleich seine Reduktion als Werk.“ (ebd., S. 59)

Jedoch ist damit das Spannungsverhältnis nicht erschöpft. Ästhetische Erfahrung ist gerade bei Werken der Vergangenheit ohne historisches Wissen undenkbar. So ist zum Beispiel dem Laien das Entschlüsseln der Symbolik mittelalterlicher Tafelmalerei nicht möglich, wenn er nicht mit der christlichen Ikonographie vertraut ist. Diese fremde Bildsprache bedarf einer Übersetzung als Zugang zu dem Werk. Dennoch darf solches historisches Wissen als Fundierungsbedingung der ästhetischen Erfahrung nicht mit dem Fundierten, der ästhetischen Erfahrung selbst, verwechselt werden (ebd., S. 60).

Die ästhetische Komponente eines Ausstellungsumfeldes erzeugt eine eigene Dynamik mit Bedeutungszuschreibungen, die auch konträr zu den inhaltlich beabsichtigen Aussagen der Ausstellungsmacher wirken können. Rüsen weist darauf hin, in der ästhetischen Qualität der visuellen Kommunikation nicht nur eine sekundäre Größe zu sehen, wie dies

50 Stierle, Karlheinz: Ästhetische Rationalität - Kunstwerk und Werkbegriff. München 1996, S. 42. 
von Seiten der Wissenschaftler zum Teil der Fall ist, sondern er fordert, dem Eigenleben der Ästhetik besondere Aufmerksamkeit zu widmen.

„Das Medium der sinnlichen Anschauung kann selber zur Botschaft von Geschichte werden, es kann sich gegenüber den wissenschaftlichen und politisch vorgegebenen Inhalten verselbständigen und sich als Darstellungsform selber inszenieren. Die ästhetische Form selbst kann zum historischen Inhalt werden, und dann wird die politisch-praktische und wissenschaftlich-kognitive Seite geschichtlicher Darstellung sekundär, ja wesenslos.."51

Anstatt jedoch über die „Widerborstigkeit des Ästhetischen im Namen rationaler Strenge und politischer Eindeutigkeit historischer Botschaften zu klagen“ (ebd.), fordert Rüsen, Wissenschaft und Politik sollten sich im interpretierenden Umgang mit der historischen Erfahrung so verhalten, dass deren ästhetische Dimension in ihrem Eigengewicht anerkannt werde. Dies bedeutet, dass die Aufmerksamkeit sich nicht nur auf die ausgewählten Inhalte der Ausstellung richtet, sondern auch Sensibilität dahin gehend entwickelt wird, wie das Gesamtarrangement von Exponaten, Innenarchitektur und Texten wirkt.

„Perhaps more attention could be paid to the educational possibilities of installing objects rather than communicating ideas about them. Free viewers, in other words, and make less intimidated about looking. One way of doing this is to pay as much attention to the possibilities of installing as to the information about what is being installed." 52

Herles spricht von der Verklärung von Objekten als pädagogischem Problem (Herles 1996, S. 74). Wenn Objekte immer unter einem bestimmten Aspekt präsentiert und behandelt werden, so bleiben andere Inhalte und Bedeutungen der Dinge möglicherweise nicht nur ausgeklammert, sondern werden überlagert und geraten aus dem Gesichtsfeld (ebd., S. 88). Dies kann dann auch dazu führen, dass durch die Form der Präsentation eine „Unbewußtmachung“ erfolgt und Einsichten verhindert werden. In Fachsammlungen kann es geschehen, dass sie den Blick auf ihre Objekte auf den der ihnen zugrunde liegenden Wissenschaft einengen. In einer Ausstellung, die unter dem vorherrschenden Gesichtspunkt

51 Rüsen, Jörn: Für eine Didaktik historischer Museen. In: Rüsen/Ernst/ Grütter 1988, S. 13.

52 Alpers, Svetlana: The Museum as a Way of Seeing. In: Karp/Lavine 1991, S. 31. 
der technischen Entwicklung steht, werden dann beispielsweise Kriegsgeräte als „Meisterwerke der Ingenieurkunst“ vorgeführt (ebd., S. 89).

Politisch diffiziler gestaltet sich dies, wenn es sich bei den Exponaten um Ausstellungsobjekte des Nationalsozialismus handelt. Die objektorientierte Präsentation militaristischer Gegenstände, die deren problematische Geschichte verschweigt, erregt lediglich im museologischen Diskurs Widerspruch. Im Gegensatz hierzu ist der gegenwärtige Umgang mit den Objekten des Nationalsozialismus bei weitem schwieriger und emotional aufgeladen. Aktuell zeigte sich dies in dem Eklat zur Eröffnung der Dauerausstellung im Münchener Stadtmuseum, ${ }^{53}$ die von Münchens Oberbürgermeister als „folkloristische SA-Lederhosen-Schau“ bezeichnet wurde. ${ }^{54}$ Sein hauptsächlicher Kritikpunkt bestand darin, dass die Exponate nicht ausreichend in den Kontext eingebunden waren und so verharmlosend gezeigt wurden. Die Hinweise auf den Terror und das nahe KZ waren für Ude nicht ausreichend gegeben. Durch die Abwesenheit von Bildern der Gewalt, des Terrors und des Krieges in Gegenüberstellung zu den NS-Objekten wurde befürchtet, dass dies bei Besuchern unter Umständen zu nicht gewünschten Reaktionen, vielleicht sogar zu Bewunderung führen könnte. Bierkrüge, Kerzenständer oder Figuren von BDM-Mädchen in Trachten wurden in der SS-Manufaktur von Häftlingen aus dem Konzentrationslager in Dachau gefertigt. Das Exponat symbolisiert die doppelte Geschichte von Kitsch und Terror des Dritten Reiches. Auf den ersten Blick jedoch visualisiert es nur die ästhetische, banale Seite des Nationalsozialismus.

Wenn die grausamen Seiten des nationalsozialistischen Regimes in einer Ausstellung nicht vordringlich thematisiert werden und die NSObjekte mit ihrer Aura wirken können, stellt dies ein gewagtes Unterfangen dar, denn ohne das Wissen des historischen Hintergrundes erscheinen die Objekte zumindest äußerlich harmlos.

53 Im Sommer 2002 sollte im Münchener Stadtmuseum eine Dauerausstellung mit dem Titel „Nationalsozialismus in München - Chiffren der Erinnerung" eröffnet werden. Oberbürgermeister Christian Ude weigerte sich nach einer ersten Besichtigung trotz des Hinweises, dass Sichtachsen und Beschriftungen noch aufgebaut werden sollten, diese zu eröffnen. Erst nach einer Überarbeitung wurde diese Ausstellung ein Jahr später für das Publikum geöffnet.

54 Zekri, Sonja: Unter der SA-Lederhose wird gejodelt. Düsteres Menetekel oder blinkende Puppenstube: München streitet um eine Ausstellung zur NS-Geschichte im Stadtmuseum. In: Süddeutsche Zeitung vom 09.08.02. 


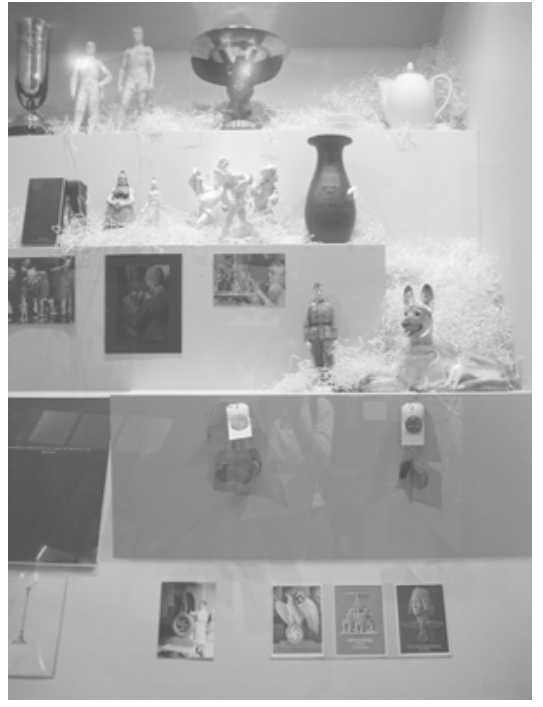

Abbildung 5: Blick in eine Vitrine mit Objekten, hergestellt in der Porzellanmanufaktur Allach in der Dauerausstellung „Chiffren der Erinnerung" im Stadtmuseum München.

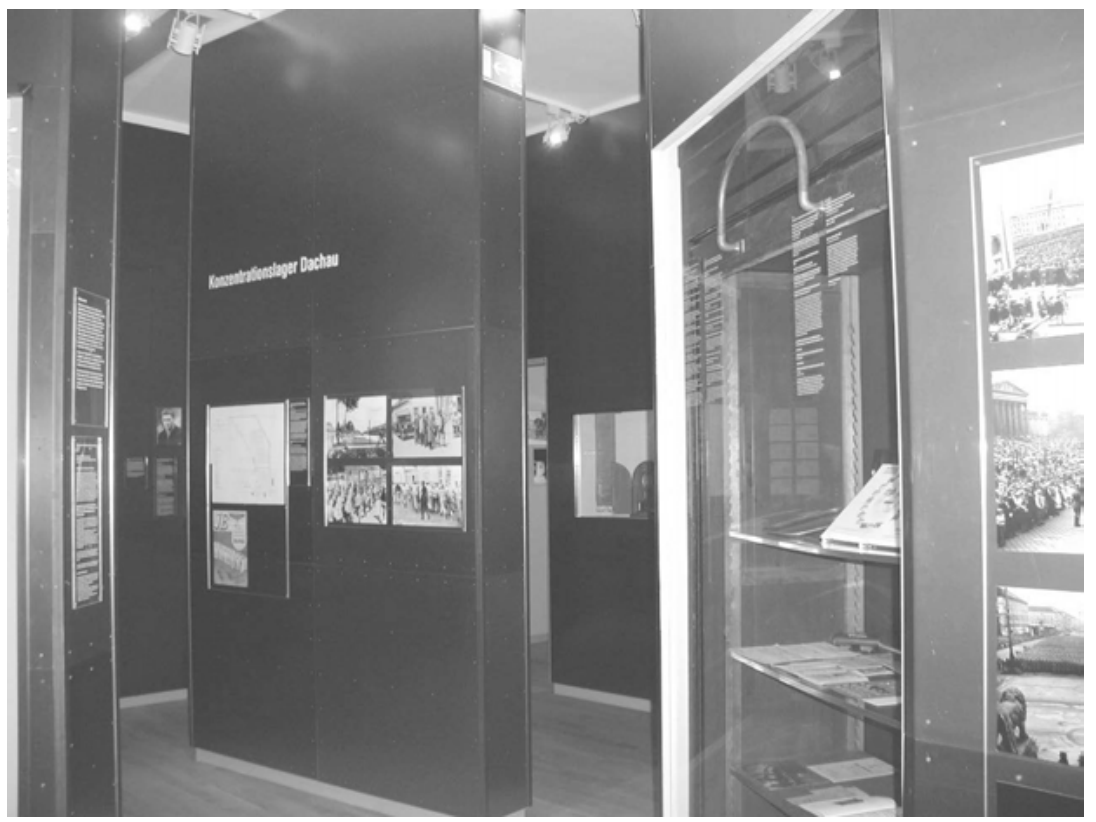

Abbildung 6: Sichtachse zum Bereich „Konzentrationslager Dachau“ in der Dauerausstellung „Chiffren der Erinnerung “ im Stadtmuseum München. 
Gerade die Musealisierung kann Nichtigkeiten, wie zum Beispiel den Porzellanfiguren in einer Vitrine, eine auratische Wirkung verleihen. So könnte mit einer derartigen Präsentation ein Weg der Bagatellisierung oder auch Sakralisierung beschritten werden. Auch stellt sich die Frage, ob nicht jeder Ausstellungsmacher, der den Originalen diese Wirkung erlaubt, die „Lügen der Nazis vom schönen Sein fortschreibt.“55 Aus diesem Grund gilt bei der Darstellung von NS-Geschichte als Mindeststandard eine strikte Kontextualisierung, die automatisch die verführerische oder verharmlosende Wirkung von Objekten durch Texte und Bilder des Schreckens auffängt. Trotz dieser aufgezeigten Problematik ist zu fragen, ob dies tatsächlich die einzig kanonisierte Art der Präsentation bleiben muss. Zekri äußert die Vermutung, ob es nicht vielleicht sogar lehrreicher wäre, wenn eine NS-Ausstellung ihre Besucher der Verführungskraft, der Verharmlosung vorübergehend aussetzt, ohne sie auf den ersten Blick durch die Bilder des Schreckens zu immunisieren.

„Möglicherweise lässt sich so erfahren, was über historische Fakten, den Konsens der Ablehnung und Empathie mit den Opfern hinausgeht: as uns von jener Zeit und jenen Menschen trennt, wie verführbar, wie leicht zu blenden jeder einzelne ist." (ebd., S. 63)

Im Vergleich hierzu erfährt der Besucher im Dokumentationszentrum auf dem Reichsparteitagsgelände in Nürnberg zahlreiche Facetten lokaler Geschichte. Über Videos, Hörbeispiele, wandgroße Fotographien und Zeitzeugenberichte kann sich das Publikum über den Aufstieg der NSDAP oder die Organisation der Reichsparteitage informieren. Das brisante und zentrale Thema dieses Ortes, welches an Aktualität bis heute nichts eingebüßt hat, die Manipulierbarkeit jedes Einzelnen, berührt die Nürnberger Ausstellung primär auf kognitiver Ebene. An diesem konfliktgeladenen Thema zeigt sich das Spannungsverhältnis von ästhetischer und historischer Erfahrung. Die historische Erfahrung in öffentlichen Präsentationen zielt durch die Darstellung des Schreckens des Dritten Reiches auf Mitgefühl für die Opfer. Andere Erfahrungshorizonte, beispielsweise wie subtile Strategien der Manipulation wirkten, werden nicht eröffnet.

55 Zekri, Sonja: München - Hauptstadt der Verdrängung. In: Museumskunde. 68. (2003) Heft 1. S. 59-63. 
„Sie als angebliche Devotionalien aus dem Museum zu verbannen, heißt ein Schlagwort an die Stelle der Kenntnisse vom Funktionieren der NS-Propagandamaschinerie zu setzen. Auch ist es das Gegenteil einer Verharmlosung des NS-Regimes, wenn darüber aufgeklärt wird, mit welchen Mitteln es sich selbst verharmlost."

Die Fokussierung auf die Opfer des Regimes hemmt einen mehrdimensionalen, objektbezogenen Zugang zum Thema, wie dies in der wissenschaftlichen Zeitgeschichte üblich und notwendig ist. ${ }^{57}$ Vergleichsweise wird es in einer Gedenkstätte kaum möglich sein, die Verführungs- und Integrationsfähigkeit eines totalitären Regimes nachvollziehbar darzustellen, ohne die Grenzen der Pietät zu überschreiten. Alle dokumentarischen, wissenschaftlichen und didaktischen Aktivitäten sind subtil von der Opfergeschichte geprägt und damit auf die Verfolgungsperspektive konzentriert. Insofern würde sich gerade an einem neutralen Ort, wie zum Beispiel in einem Stadtmuseum, die Möglichkeit ergeben, in der Thematisierung der ästhetischen Wirkung von Alltagsobjekten und deren manipulativer Strahlkraft neue Dimensionen des Zugangs zu eröffnen. ${ }^{58}$

56 Till, Wolfgang: Das Stadtmuseum im Netzwerk der Münchener Erinnerungskultur. In: Kulturreferat der Landeshauptstadt München/Bayerische Landeszentrale für politische Bildungsarbeit (Hrsg.): Ein NS-Dokumentationszentrum für München. Ein Symposium in zwei Teilen, Tagungsband. München 2003, S. 275.

57 Aufgrund der unterschiedlichen pädagogischen Möglichkeiten authentischer Orte des Nationalsozialismus wird zwischen Opfer- und Täterorten unterschieden, da diese unterschiedliche Affekte und Emotionen wecken. Opferorte sprechen das Mitgefühl an und fordern Pietät. An Täterorten stehen die Akteure im Zentrum des Interesses. Durch die Andersartigkeit und historische Authentizität ist Dahm überzeugt, dass zusätzliche Neugier und Wissensdrang der Menschen geweckt werden können. Für die historisch-politische Bildung bedeutet dies die Chance, auch Menschen anzusprechen zu können, die Gedenkstätten bisher nicht besuchten. Vgl. Dahm, Volker: Projekt eines NS-Dokumentationszentrums in München. Gutachten des Instituts für Zeitgeschichte, München - Berlin, erstellt im Auftrag der Bayerischen Landeszentrale für politische Bildungsarbeit. München 2002, S. 3.

58 Wie sehr die Ästhetisierung zeitgeschichtlich schwieriger Themen in der Öffentlichkeit gefürchtet wird, wurde auch an der Diskussion um die Kunstausstellung mit dem Arbeitstitel „Mythos RAF“ deutlich. Siehe Kapitel 3.3, S. 168ff. Bewusst auf die ästhetische Wirkung schockierender Bilder setzte zum Beispiel auch die Ausstellung „Vernichtungskrieg Verbrechen der Wehrmacht 1941 bis 1944“, siehe Kapitel 4, S. $191 \mathrm{ff}$. 
In der vorangegangenen Thesenstellung habe ich die Frage formuliert, ob die ästhetische oder die historische Erfahrung die wertvollere bildet. ${ }^{59}$ Eine pauschale Antwort kann es nicht geben. Diese Frage muss immer wieder neu gestellt und bewertet werden, in Abhängigkeit der jeweiligen Situation, der Exponatlage, des Inhalts und des gesellschaftlichen Hintergrunds.

„Entscheidend für die ästhetische Dimension der Geschichtskultur ist es vielmehr, daß ihnen eine (relative) Eigenständigkeit in der Sinnbildung des Geschichtsbewußtseins selber zukommt. Es gibt eine genuin und spezifische ästhetische Erinnerungsleistung des Geschichtsbewußtseins, die ihren eigenen Regulativen folgt und nicht unter die kognitive und politische Ausprägung der historischen Erinnerung subsummierbar ist." (Rüsen 1994, S. 13)

Die Frage, worin genau die spezifische historische Sinnbildungskraft des Ästhetischen besteht, wurde bislang nur wenig diskutiert. Das lag auch daran, dass in der traditionellen Ästhetik und in den Fachdisziplinen, die sich mit Kunst und Geschichte beschäftigt haben, das Ästhetische und das Historische zumeist als Gegensätze angesehen wurden. Die Konkurrenz zwischen ästhetischer und historischer Erfahrung wird sich tatsächlich nicht aufheben lassen. Sie können sich jedoch gegenseitig bereichern, wenn sie nicht als unvereinbare Gegensätze betrachtet werden, denn „das vernunftlose Erschauern vor der Aura der Kunstwerke ist den Museen ebenso unbekömmlich wie die Austrocknung zum sinnenfeindlichen Dokumentationszentrum." ${ }^{60}$ Eine kulturhistorische Ausstellung enthält eben nicht nur kognitive Elemente, sondern in bedeutend höherem Anteil als eine literarische Geschichtsverarbeitung auch emotionale Anteile, die die ästhetische Gestaltung der Ausstellung und die Auswahl der symbolischen Artefakte erforderlich machen (Hochreiter 1994, S. 220).

Die Sinne brauchen die Vermittlung der Inhalte durch ein symbolisches Zeichensystem, wenn diese bildungsrelevant sein sollen. Diesen Vorgang bezeichnet Stierle als ,ästhetischen Zirkel“, in dem das Werk zugleich die erste und die letzte Instanz der ästhetischen Erfahrung bildet (Stierle 1996, S. 62). Die Frage, was die Werke sagen, ist nach Ansicht von Stierle legitim, doch sie entspringt nicht primär ästhetischer Erfah-

59 Siehe Kapitel 2, S. 85.

60 Sauerländer zitiert in Glaser, Hermann: Zukunft braucht Herkunft. Über die ästhetische Erziehung des Menschen und den gesellschaftlichen Sinngehalt des Musealen. In: Museumskunde. 67. (2002) Heft 2. S. 29. 
rung, sondern überschreitet gerade diese. Sie trifft nicht das Werk als Werk, sondern eine in ihm aufbewahrte Aussage, Antwort, Einsicht, Gefühlslage oder ein sonstiges Äquivalent. Geschichtliche wie lebenspraktische Aneignung des Kunstwerks sind Formen der Überschreitung des im eigentlichen Sinne ästhetischen Bereichs. Beide aber haben in unterschiedlicher Weise Anteil an jener Form der werküberschreitenden Aneignung, die man kognitive Aneignung nennen könnte. Stierle argumentiert, dass die diskursive Auseinandersetzung in schreibender oder sprechender Form zu einer Vertiefung der ästhetischen Erfahrung führt, jedoch selbst keine ästhetische Erfahrung ist. Dies führt zunächst zu einer partikulierten Betrachtung, die auf besondere Aspekte verweisen kann. Eine Kontextualisierung in einer Ausstellung bedeutet, dass die Objekte unter einer bestimmten Perspektive betrachtet werden. Dies führt zu Eingrenzung, gleichzeitig jedoch bedeutet dies andererseits, dass die Objekte dadurch wieder Sprachfähigkeit gewinnen.

\subsection{Museale Orte als Stätten der Differenzerfahrung und Reflexion}

Obgleich sich der Gegensatz zwischen historischer und ästhetischer Erfahrung nicht auflösen lässt und dies zu Konflikten in der Wahrnehmung führen kann, lassen sich dennoch Gemeinsamkeiten finden, die sowohl für eine qualitativ hochwertige historische wie ästhetische Erfahrung relevant sind. Weder bei der ästhetischen noch bei der historischen Erfahrung geht es um Eindimensionalität, beiden gleich ist die Sensibilisierung für die Vielschichtigkeit sowohl von Historie, Artefakten und auch gegenwärtigen Erscheinungen. Die Steigerung des Bewusstseins in Bezug auf diese Mannigfaltigkeit kristallisiert sich als zentraler Punkt heraus. Der Auftrag musealer Ausstellungen liegt nicht nur in einer wie auch immer gearteten regulären, formalen Bildung. Gefordert ist vielmehr eine Qualität des Angebots und eine damit verbundene Ermunterung zur schöpferischen Auseinandersetzung. Als eine der elementaren Aufgaben von musealen Ausstellungen kann formuliert werden, dass diese als Stätten der Selbstbildung, als Orte der Reflexion und somit auch der Bildung von Bewusstsein fungieren sollen.

Versuchen Ausstellungen lediglich Vergangenheit mit dem Ziel einer „kompensatorischen Vergangenheitsvergegenwärtigung“ zu rekonstruieren, so lassen sie nicht nur einen Teil der Möglichkeiten ungenutzt, son- 
dern sie werden ihrem Auftrag nicht gerecht. ${ }^{61}$ Die Intention des Museums besteht zwar auch darin, die Zeit aufzuheben und sich gegen das Verschwinden zu stellen, also zu verlängern, was ansonsten unwiederbringlich vorbei ist. Darin darf jedoch nicht die alleinige Funktion bestehen. Es geht auch darum, bewusst Fragen zu stellen, Sehgewohnheiten zu stören oder Fremdheitserfahrungen zu inszenieren.

„Gebraucht werden die Museen als Stätten der Selbstreflexion. Von diesen gibt es nur wenige und es kann von diesen gar nicht genug geben. Dies könnte eine zentrale Aufgabe, ein Ziel, ein Wert des Museums sein: immer wieder an das Denken im Konjunktiv appellieren. Geschichte darf nicht nur lustvolle Kompensation einer grundstürzenden Gegenwart sein, nicht lauschige Dekoration einer kargen Jetzt Zeit.“ (Rauterberg 2002, S. 39)

Bildwerke und andere Schöpfungen der Vergangenheit können Anlass und Hinweis zur Reflexion historischer und auch gegenwärtiger Wirklichkeiten sein. Die Aufgabe der Museumspädagogik besteht darin, das pädagogische Potential der Objekte zu verstärken (Herles 1990, S. 229). Museale Ausstellungen ermöglichen die Begegnung mit Fremdem im Sinne von zeitlich, räumlich geistig Entferntem. Die Vermittlung des Museums zielt darauf ab, dieses Fremde ein Stück weit zu beleuchten, so dass es zum geistigen Besitz seiner Besucher werden kann. Die grundsätzliche pädagogische Funktion des Museums kann deshalb als Weckung oder Verständnis von Offenheit und Verständnis für historisch und/oder kulturell Fremdes definiert werden. Dies schließt auch Toleranz gegenüber geistig fremden Standorten ein. Herles betont, dass dies vor dem aktuellen Hintergrund pluralistischer Gesellschaften und notwendiger völkerverbindender Verständigungsprozesse ein zeitgemäßes und zunehmend bedeutsames Erziehungsziel sei (ebd. S. 229).

Eine weitere gesellschaftliche Funktion musealer Ausstellungen sollte auch darin bestehen, die Gegenwart zu hinterfragen und für kritische Belange Sensibilität zu wecken. In musealen Ausstellungen geht es nicht nur um die Entwicklung von Verständnis und Wertschätzung, sondern auch um die Fähigkeit zu Kritik an Erscheinungen der eigenen Epoche und Kultur. Im Hinblick auf die inhaltliche Themenwahl bedeutet dies, nicht zeitaktuellen Trends zu folgen, sondern auch hier das gesamte Potential der Möglichkeiten auszuschöpfen und zum Beispiel auch

61 Lübbe zitiert in Parmentier, Michael: Zwischen Schule und Freizeitpark. Das Museum als Stätte der Selbstbildung. In: Standbein Spielbein (1997) Heft 49. S. 13. 
gesellschaftliche Tabus zu thematisieren oder den Blick auf Randgruppen zu werfen. „Denn nur dann sollten Ausstellungen nach Trends fragen oder gesellschaftspolitische Ereignisse kommentieren, wenn sie zugleich tiefen Zweifel säen.“ (Rauterberg 2002, S. 40)

Ein weiteres Aufgabenspektrum eröffnet sich im Hinblick auf die Sensibilisierung der Sinne, im Speziellen kann auch Sehen lernen als Ziel formuliert werden. Der Regisseur Peter Greenaway ${ }^{62}$ kritisiert, dass unsere Bildung fast ausschließlich auf Text ausgerichtet ist. Konträr zu gegenwärtigen gesellschaftlichen Entwicklungen, die zunehmend vom Visuellen geprägt werden, fehlt in der Schule das Lernen der visuellen Sprache. Der Umgang mit Bildern wird wenig gefördert.

„Es bereitet mir große Sorge, dass unsere Bildung dermaßen auf Texte ausgerichtet ist. Wir verwenden viel Zeit darauf, um den Umgang mit einem Text zu erlernen, aber zu wenig, um zu lernen, wie wir dies mit Bildern tun müssen. [...] Kinder lernen das Alphabet, die Wörter, wir reihen Sätze aneinander, sprechen ständig, also sind wir sehr geschickt im Umgang mit Texten, aber sehr schlecht im Umgang mit Bildern. Dass man Augen besitzt, bedeutet nicht, dass man auch sehen kann. Um das Sehen und Formen von Bildern zu schulen, bedarf es der gleichen Verfeinerung wie bei Texten." ${ }^{\text {63 }}$

Auch Glaser plädiert dafür, dem „sensiblen, bildenden, zusammenfassenden Sehen" durch die sinnliche Erschließung von komplexen Gedanken- und Gefühlsräumen Raum zu geben (Glaser 2002, S. 29). Im Gegensatz zur visuellen Überfrachtung der alltäglichen Umwelt bildet das Museum ein letztes Refugium, in dem Menschen erfahren können, dass es nicht nur werbendes und zerstreuendes Sehen gibt. Glaser tritt für eine Korrektur des eskalierenden einseitigen Zeitverständnisses ein, das in einer Beschleunigungssucht jedes Gleichgewicht verloren hat. Museale Ausstellungen würden dann auch wieder „Orte der visuellen Stille und Nachdenklichkeit" werden (ebd.). Die Aufgabe musealer Ausstellungen liegt nicht in der Zerstreuung und Ablenkung. Dieser Bereich der Flüchtigkeit und Oberflächlichkeit gehört in die Domäne der Unterhaltungsindustrie mit Freizeitwelten und Themenparks.

62 Peter Greenaway ist ein bedeutender Experimentalkünstler, Filmemacher der Gegenwart. Seit 1991 arbeitet er auch als Ausstellungsmacher. Siehe Kapitel 5, S. 279ff.

63 Greenaway zitiert in Kolsteren, Steven: Einblick in den Geist des Mittelalters. Die Mission von Peter Greenaway. In: Deutsche Ausgabe der Groninger Museumskrant. (2001) Heft 1. S. 3. 
Wie diese unterschiedlichen Erfahrungsqualitäten ermöglicht werden und welche Strategien dabei zur Anwendung kommen können, soll im folgenden Kapitel diskutiert werden. 


\section{Die museale Kommunikation}

Mit der zunehmenden Bedeutung von Bildung in Ausstellungen definieren sich Museen nicht nur als Ort der Aufbewahrung, sondern auch als Orte der Kommunikation. Die Vermittlung von Botschaften findet in Ausstellungen auf mehreren Ebenen und in mehrere Richtungen statt. Grundlegende Punkte skizziere ich im Folgenden.

Museale Kommunikation bildet eine Form der Massenkommunikation. Sie ist ein Prozess der Vermittlung von Botschaften und Informationen. Bei einer elementaren Betrachtung des Kommunikationsprozesses steht auf der einen Seite der Absender und auf der anderen Seite der Empfänger der Botschaft. Die Grundform der musealen Kommunikation besteht im Ausstellen von interpretierten Objekten und dem Anleiten der Besucher, die abgesendete zusammengesetzte Botschaft aufzunehmen. ${ }^{1}$ Darüber hinaus kann die museale Kommunikation auch durch andere Medien stattfinden, durch alle Arten von Publikationen, durch Videound Audiomaterial, sowie durch Vorträge oder organisierte Veranstaltungen im Museum. Diese Arten der Kommunikation sind nicht ausschließlich an den Museumsraum gebunden. Die Entwicklung des virtuellen Museums, welches als Ergebnis der Entwicklung von Computertechnologie und Datenvernetzung immer aktueller wird, schuf weitere Formen der Kommunikation. $^{2}$

1 Maroević, Ivo: Museumsausstellungen - Museologische Herausforderung. (unveröffentl. Skript) Zagreb 2001, S. 3.

2 Das Medium baut traditionell auf die Authentizität und Materialität seiner Objekte. Seit einigen Jahren werden zunehmend digitale Medien, die im Gegensatz dazu auf dem Prinzip der Simulation basieren, in Ausstellungen eingesetzt. Damit eröffnen sich zahlreiche Fragen. An erster Stelle wird diskutiert, ob die Neuen Medien das Museum bereichern oder gefährden. Einen sehr ergiebigen Beitrag zu dieser Diskussion lieferte Anja Wohlfromm in ihrer Diplomarbeit, in der sie sich in einem Kapitel speziell mit Museen und „Hypermedien“ befasst und dabei auch auf „Virtuelle Museen" eingeht. Wohlfromm, Anja: Museum als Medium. Neue Medien in Museen. Überlegungen zu Strategien kultureller Repräsentation und ihre Beeinflussung durch digitale Medien. Köln 2002. 
Da meist ein Partner im musealen Kommunikationsprozess abwesend ist, ergibt sich die Schwierigkeit festzustellen, ob der Kommunikationsprozess funktioniert und die Botschaften die Empfänger erreichen und diese sie auch verstehen können. Oft entspricht die Ebene, auf der sich Ausstellungen mitteilen, nicht der Ebene der Empfänger. Ein wesentlicher Grund hierfür liegt darin, dass die für Gestaltung und Formulierung der Kommunikationsinhalte Verantwortlichen sich in der Sprache und mit dem Präzisionsanspruch der Fachwissenschaften ausdrücken und damit das Ziel, den Laien anzusprechen, verfehlen können.

In den späten sechziger Jahren unternahm Cameron den Versuch, kommunikationstheoretische Überlegungen auf die museale Kommunikation zu übertragen. Damit entfachte er eine lebhafte Diskussion, die bis heute andauert. ${ }^{3}$ In der Folgezeit wurden unterschiedliche Modelle entwickelt. ${ }^{4} \mathrm{Im}$ Wesentlichen kristallisierten sich zwei Hauptkritikpunkte am einfachen Absender - Empfänger - Kommunikationsmodell heraus.

Zum einen wurde kritisiert, dass die Empfänger, also die Ausstellungsbesucher, lediglich eine passive Rolle einnehmen. Außerdem vernachlässigte dieses einfache Modell die Verschiedenartigkeit der Empfänger und die Tatsache, dass das Publikum aktiv die Botschaften in Abhängigkeit von sozialer Herkunft und Bildungshintergrund interpretiert. Als Antwort auf diese Kritik integrieren modifizierte Modelle eine Feedback-Schleife, die dem Besucher die Möglichkeit gibt, auf die Gestaltung der Botschaften Einfluss zu nehmen.

Der zweite wesentliche Kritikpunkt am einfachen Kommunikationsmodell bestand darin, dass der Kommunikationsprozess innerhalb des Ausstellungsteams ebenfalls linear verläuft. Dies spiegelt sich darin wider, dass die verschiedenen Aufgabenbereiche isoliert voneinander arbeiten. Im linearen Modell übernimmt der Kurator die alleinige Aufgabe der Formulierung der Ausstellungsinhalte. Dies geschieht meist ausschließlich im Hinblick auf wissenschaftliche Fragestellungen ohne Berücksichtigung anderer Aspekte, so zum Beispiel gestalterische oder museumspädagogische Belange. Die Vernachlässigung der Besucherper-

3 Cameron, Duncan F.: A Viewpoint: The Museum as a Communications System and Implications for Museums Education. In: Curator. 11. (1968) Heft 1. S. 33-40.

4 Einen guten Überblick zu kommunikationstheoretischen Überlegungen und deren Übertragbarkeit auf Museen siehe Hooper-Greenhill, Eilean: Communication in Theory and Practice. In: Hooper-Greenhill, Eilean (Hrsg.): The Educational Role of the Museum. London 1994, S. 28-43. 
spektive geht zwangsläufig damit einher. Von den Gestaltern wird erwartet, die Ideen des Kurators gut zu verpacken. Dies reduziert deren Aufgabe auf technische und funktionale Aspekte. Ähnliches gilt für die Arbeit der Museumspädagogen. Ohne die Möglichkeit zur gestalterischen sowie inhaltlichen Einflussnahme auf das Konzept wird diesen nach Fertigstellung der Ausstellung die Aufgabe übertragen, ein Vermittlungskonzept zu entwickeln.

„The educator is brought into the process at far too late a stage to contribute to planing, and is forced into a remedial role, making the best of a bad job once the exhibition has opened, (re)interpreting it for those people who take part in events or activities." (Hooper-Greenhill 1994, S. 38)

Unter Berücksichtigung dieser Kritikpunkte schlägt der Besucherforscher Miles ${ }^{5}$ ein flexibles Modell für die Produktion von Ausstellungen vor, welches in allen Entwicklungsstadien Besucherforschung integriert. Unterschieden werden kann zwischen drei Phasen der Ausstellungsevaluation. ${ }^{6}$ Am Anfang stehen die Vorab-Evaluationen, die bereits vor Konzipierung einer Ausstellung beginnen. ${ }^{7}$ Dabei versucht man, sehr frühzeitig im Planungs- und Zielfindungsprozess relevante Informationen von und über Zielgruppen zu gewinnen, zum Beispiel über deren Vorstellungsbild von Thema und Inhalt einer Ausstellung. Dieses Wissen über Vorkenntnisse, Besuchsabsichten und Präferenzen bildet eine Basis zur Entwicklung alternativer Gestaltungsmöglichkeiten. Formative Evaluationen begleiten den Entwicklungsprozess einer Ausstellung.

5 Roger Miles, geb. 1937, kam nach seinem naturwissenschaftlichem Studium und diverser Museumserfahrungen 1968 zum British Museum in London, welches sich unter seiner Mitwirkung zu einem Publikumsmagneten entwickelte. Konsequent nutzte er die Möglichkeiten der Besucherforschung und setzte dies in den Ausstellungen um. In Theorie und Praxis setzte er Maßstäbe. Diese Ergebnisse hielt er in zahlreichen Veröffentlichungen fest, darunter das bedeutende Buch „The Design of Educational Exhibits“ (London, 1982).

6 Eine zusammenfassende Beschreibung mit gutem Überblick siehe Grewcock, Duncan: Before, During and After: Front-end, Formative and Summative Evaluation. In: Lord, Barry/Lord, Gail D. (Hrsg.): The Manual of Museum Exhibitions. Walnut Creek/Lanham/New York/Oxford 2002, S. 44-53.

7 Eine ausführliche Darstellung und Diskussion dieser Methode siehe Klein, Hans-Joachim (Hrsg.): Front-End Evaluation - ein nichtssagender Name für eine vielsagende Methode. Karlsruhe 1993. 
Ausgewählte Zielgruppen prüfen Ausstellungskomponenten. Anhand dieser Prototypen kann zum Beispiel kontrolliert werden, wie diese benutzt werden oder ob Texte verständlich sind. Die daraus resultierenden Ergebnisse können zu Verbesserungen führen. Die summative Evaluation erfolgt nach Eröffnung einer Ausstellung. Neben demographischen Angaben zu den Besuchern nach Alter, Geschlecht, Wohnort und Ausbildungsstand fragt sie meist nach Besuchsmotivation und Erwartungen sowie nach einer Bewertung bestimmter Ausstellungseinheiten oder Serviceleistungen im Ausstellungsumfeld. Außerdem dient sie zur Ermittlung der Wirkung von öffentlichkeitswirksamen Maßnahmen. Besucherorientierung und Besucherforschung sind somit zwei sich bedingende Variablen. Wird Besucherorientierung als Ziel formuliert, muss zugleich der Besucherforschung ein dementsprechend hoher Stellenwert eingeräumt werden.

Kapitel drei und vier dieser Arbeit $^{8}$ bilden die wissenschaftliche Fundierung für die Ausstellungsanalyse in Kapitel sechs. Da die theoretischen Überlegungen nicht losgelöst von der Praxis der Ausstellungsgestaltung formuliert werden sollen, entwickle ich im Anschluss an die Erörterung kommunikativer Strategien als eine Art reflektorische Zusammenfassung einen Fragenkatalog zur Ausstellungsanalyse. Anhand kommunikativer Strategien stelle ich einzelne Komponenten vor, die in den Gestaltungsprozess einfließen und für jede Form der Präsentation relevant sein können, unabhängig davon, ob diese einen narrativen, künstlerischen oder partizipativen Ansatz verfolgen. Diese genannten Präsentationsstrategien stelle ich vor und zeige, wie in unterschiedlicher Gewichtung kommunikative Strategien in eine Gesamtdramaturgie eingebunden werden können.

\subsection{Die Gestalter der Botschaft - das Ausstellungsteam}

\section{Die diffuse Rolle der Museumspädagogik im Ausstellungsteam}

Ausstellungen werden von Menschen gemacht, insofern sind sie von deren Handschrift, Absichten und Überzeugungen geprägt. Idealerweise werden Ausstellungen in einem Team entwickelt, welches sich aus meh-

8 In Kapitel vier werde ich mich der Frage der Interpretation widmen, die immer Teil von Ausstellungen ist. 
reren Kompetenzen zusammensetzt. Die klassische Variante eines Teams bildet sich aus Vertretern der jeweiligen Fachwissenschaft, der Gestaltung und der Pädagogik. ${ }^{9}$ Seit den siebziger Jahren, in denen sich die Museumspädagogik vor allem der Entwicklung des außerschulischen Lernorts Museum widmete, hat sich das Spektrum museumspädagogischer Aufgaben wesentlich erweitert. Trotzdem ist die Integration von Museumspädagogen in das Ausstellungsteam bis heute eine Ausnahme geblieben, anstatt selbstverständlich zu sein.

Im Jahr 1971 wurde mit dem ausstellungsdidaktischen Experiment „Dürer-Studio“ die Diskussion eingeleitet. ${ }^{10}$ Dieses mit großer Breitenwirkung durchgeführte Projekt bestätigte die Meinung der Verantwortlichen, dass „Ausstellungsdidaktik heute zu den wesentlichen Arbeitsbereichen der Museumspädagogik gehört. “11 Dreißig Jahre später, im Jahr 2001, stand das Thema während einer Fachtagung des Bundesverbandes Museumspädagogik erneut im Zentrum der Diskussion. Von Seiten der Museumspädagogen war aufgrund der mangelnden Integration bei Ausstellungsgestaltungen eine große Unzufriedenheit zu spüren. Abermals wurde festgestellt:

„Voraussetzung für eine objektbezogene, museale Kommunikation ist die uneingeschränkte interdisziplinäre Zusammenarbeit von Kuratoren und allen, die mit der Gestaltung beschäftigt sind: Besucherforschung und Marketing, Personal, Pädagogen, Techniker und Multimedia-Spezialisten, Lichtgestalter, usw. Offenheit und Kooperation zwischen den Kompetenzen muß vorhanden sein. “12

9 In Abhängigkeit von der Größe der Ausstellung kann es sein, dass bei sehr kleinen Ausstellungen diese Kompetenzen eine Person in Personalunion übernehmen muss. Bei großen Ausstellungen erweitert sich dieses Kernteam um weiteres Fachpersonal, so arbeiten temporär im Entstehungsprozess einer Ausstellung zum Beispiel auch Restauratoren, Techniker, Schreiner, Schlosser etc. mit.

10 Das „Dürer-Studio“ war eine didaktische Ausstellung als Ergänzung zur Dürer-Ausstellung „1471 Albrecht Dürer 1971“ im Germanischen Nationalmuseum anlässlich des Dürer-Jahres 1971.

11 Kunstpädagogisches Zentrum im Germanischen Nationalmuseum (Hrsg.): Zum Beispiel Dürer-Studio. Dokumentation und Kritik eines ausstellungsdidaktischen Experiments. Ravensburg 1972, S. 7.

12 Lindner, Ulrike: Bericht zur Fachtagung des Bundesverbandes Museumspädagogik e.V. vom 04.-07.10.01 in Berlin: Zeitzeichen - Leitzeichen Kommunikation im Museum. In: Landesarbeitskreis für Museumspädagogik Bayern e.V. 23. Mitgliederrundschreiben. (2001), S. 3. 
Einhellige Meinung herrschte darüber, dass Didaktik als wissenschaftliche Grundlage unverzichtbar sei und die stummen Exponate durch die Regie des Präsentierens und Inszenierens zum Sprechen zu bringen seien. Ebenso ungeteilte Zustimmung erhielt die Forderung nach einer professionell arbeitenden Museumspädagogik, die eng mit dem Ausstellungsmanagement kooperiert. Die Aktualität des bereits vor drei Jahrzehnten vorgebrachten Anliegens ist offensichtlich, dennoch stehen diesem eine sehr geringe Anzahl an realisierten Ausstellungsprojekten unter Mitwirkung von Museumspädagogen gegenüber. So scheint es nahe liegend zu ergründen, worin die Ursachen liegen, dass Museumspädagogen nach wie vor eher eine Randposition im Bereich der Ausstellungsgestaltung einnehmen.

Die Art und Weise, wie sich Museumspädagogen ins Team einbringen können, pendelt zwischen zwei Polen. Der eine Pol besteht darin, dass der Museumspädagogik die Leitungsfunktion übertragen wird. Inhaltliche Gliederung sowie Objektauswahl unterliegen ihrer Entscheidungsbefugnis und ihrem Verantwortungsbereich. Der Fokus auf die Besucher sowie kommunikative Elemente können so in den Vordergrund treten. ${ }^{13}$ Halbertsma ${ }^{14}$ sieht optimistisch eine unverkennbar wachsende Beteiligung von Museumspädagogen am Entwicklungsprozess von Ausstellungen. Er registriert, dass in vielen Fällen bei einer Kooperation von Konservator, Entwerfer und Museumspädagogen in einem Ausstellungsteam „dem pädagogischen Mitarbeiter nach einiger Zeit die Koordination der Ausstellungsprojekte übertragen wird!“15 Das andere Extrem ist, dass die museumspädagogischen Mitarbeiter nur am Rande an der Planung beteiligt werden. Museumspädagogen dürfen nach Fertigstellung des Ausstellungskonzeptes dieses mit einem Vermittlungskonzept bespielen, ohne jedoch noch auf Inhalt, Gliederung oder Objektauswahl Einfluss nehmen zu können. Beispielsweise fungiert die museumspädagogische Abteilung als Textwerkstatt, der die Objekttexte zur

13 Wie sich dieses dann in der Praxis darstellt, siehe Kapitel 3.3: Partizipativer Ansatz.

14 Nico Halbertsma ist Dozent an der Reinwardt Akademie, eine Fachhochschule für Museologie in Amsterdam. Er unterrichtet das Fach Museumskommunikation.

15 Halbertsma, Nico: Museumspädagogik - zwischen allen Stühlen ?!. In: Standbein Spielbein. (1998) Heft 50. S. 21. 
Überarbeitung vorgelegt werden, um diese für den Laien verständlich zu machen. Der Konservator aber bleibt der Endverantwortliche. ${ }^{16}$

Während eines Gespräches mit einer Mitarbeiterin bei der Ausstellung „Europas Mitte um 1000“17 kam letztere Praktizierweise sehr deutlich zum Ausdruck. Der Einflussnahme der Museumspädagogen auf gestalterische Aspekte in der Ausstellung selbst wurde deutlich eine Absage erteilt, basierend auf der Annahme, dass sich die Wünsche der Museumspädagogen mit denen der Kuratoren decken würden, da beide die Vermittlung im Auge hätten. Dass dies auch auf anderen Wegen erreicht werden kann, scheint nicht im Bereich des Denkbaren.

16 Dies ist auch die typische Form, wie es nach wie vor in Deutschland praktiziert wird. Diese eher konservative Haltung wird an manchen Orten durch die universitäre Ausbildung weiter gepflegt, so zum Beispiel am Institut für Kunstgeschichte in München, das von 2001 bis 2003 einen dreisemestrigen Aufbaustudiengang „Museums- und Ausstellungswesen“ anbot. Obwohl „Vermittlung“ auch als Ziel des Studienschwerpunktes aufgelistet war, lag der Hauptakzent im konservatorischen Bereich. Kommunikative Aspekte und Besucherorientierung in der Gestaltung fanden wenig Berücksichtigung, wie sich dieses dann auch in dem von den Studenten erarbeiteten Ausstellungsprojekt „Großer Auftritt - Piloty und die Historienmalerei“ in der Neuen Pinakothek im Jahr 2003 zeigte. Gegliedert nach kunsthistorischen Kriterien basierte die Präsentation auf einem traditionellem Konzept. Interpretationen durch gestalterische Akzentuierungen wurden vermieden, obwohl Gegenwartsbezüge und Aktualität des Historienmalers Piloty sich geradezu angeboten hätten. Die im Vorwort des Ausstellungskatalogs entwickelte spannende These, dass es eine ungebrochene Tradition des Erzählens von Geschichten in Bildern gebe und somit Piloty ein Vorläufer der Historienfilme sei, spiegelte sich nicht im Ausstellungskonzept wider. Dies hätte zum Beispiel als roter Faden in der Gestaltung dienen können und ein großes Potential an Möglichkeiten eröffnet. Mit der Integration des Mediums „Film“ hätten sich die Verbindungslinien zwischen der Gestaltungsdramaturgie des Malers Piloty und zeitgenössischen Filmregisseuren über die vergleichende Betrachtung als kunsthistorische Methode aufzeigen lassen. Vgl. Baumstark, Reinhold/Büttner, Frank: Großer Auftritt. Piloty und die Historienmalerei. München/Köln 2003.

17 Die Ausstellung „Europas Mitte um 1000“ vom 7.10.01-27.01.02 im Reiss-Museum in Mannheim war die dritte Station der 27. Ausstellung des Europarats, die als deutsch - polnisch - slowakisch - tschechisch - ungarisches Gemeinschaftsprojekt an sechs verschiedenen Ausstellungsorten gezeigt wurde. 
„Für die Museumspädagogik wurde Platz gelassen. Da wir verschiedene Teams sind, hieß es, das sind die Möglichkeiten. Sie bekamen frühzeitig die Pläne und sollten überlegen, wie man dies ergänzt. Von vornherein war in der Mitte der Ausstellung ein Aktionsraum geplant mit verschiedenen Möglichkeiten, wie zum Beispiel sich mittelalterlich anzuziehen oder ein Spiel zu machen. [...] Die Museumspädagogen können natürlich nicht sagen, dieses Objekt finden wir an dieser Stelle unpassend, wir hätten es lieber in einer anderen Ecke. Dies geht natürlich nicht. Es ist so, dass ganz bestimmte Vorstellungen von Möglichkeiten der Darstellung existieren. Diese decken sich mit dem, was wir sowieso wollen. “ 18

Der Grund für die Reduzierung der Einflussnahme der Museumspädagogen ist auch in Zusammenhang mit Machtkonstellationen innerhalb eines Teams zu sehen, denn je mehr die Vermittlung an Bedeutung gewinnt, desto deutlicher ergibt sich daraus logischerweise eine Begrenzung der fachwissenschaftlichen und konservatorischen Interessen. Die Umverteilung von Verantwortung und die damit verbundene Notwendigkeit zur Zusammenarbeit auf allen Ebenen gestaltet sich als schwierig, wie ein vergleichender Blick nach Amerika offensichtlich macht, wo besucherorientierte Konzepte in größerem Stil bereits umgesetzt wurden.

Anhand ausgewählter Fallstudien an amerikanischen Museen zeigte Dauschek auf, dass Umstrukturierungsmaßnahmen auf Widerstand gestoßen sind. Dieser regte sich vor allem von Seiten der Kuratoren, deren Position in der Hierarchie der Aufgaben geschwächt wurde (Dauschek 2001, S. 182). Die zentrale Mission der untersuchten Museen lautet Vermittlung und wird allen anderen Aufgaben übergeordnet. Dies unterscheidet sich von einer additiven Aneinanderreihung des Aufgabenspektrums von Sammeln, Bewahren, Forschen, Präsentieren und Vermitteln, wie dies in Deutschland der Fall ist (ebd.). Mit dem vermittlungs- und außenorientierten Schwerpunkt der Missions werden die klassischen Museumsaufgaben des Sammelns und Forschens von eigenständigen zu unterstützenden Aufgaben. In thematischen Ausstellungen stehen die Objekte nicht mehr zwingend im Mittelpunkt, und die sammlungsbezogenen Fachkenntnisse der Kuratoren sind weniger maßgeblich für Ausstellungen. Auch konservatorische Belange der Objekte stehen manchmal gegen die besucherorientierten Aktivitäten der Museumspädagogen und Marketing-Verantwortlichen. Mit der zentralen Rolle der Vermittlung im Aufgabenkanon der Museen verändert sich auch das Selbstverständnis der Fachwissenschaftler. Viele Museen wenden sich von der an

18 Interview mit Frau Luisa Reiblich M.A., Reiss-Engelhorn-Museum in Mannheim, am 20. März 2002. 
einem akademischen Publikum ausgerichteten Geschichtsforschung ab und begreifen ihre Arbeit im Sinne der Public History als Beitrag zum öffentlichen Geschichtsverständnis (ebd. S. 184).

In allen von Dauschek untersuchten Museen konnten sich die Kuratoren und Fachwissenschaftler nur schwer in ihren neuen Rollen und Positionen zurechtfinden. Neben einem „berufsinhärenten Konservatismus“ trägt die niedrige Fluktuation in fachwissenschaftlichen Stellen zum Problem bei (ebd.). Auch die Orientierung an wirtschaftlichen Gesichtspunkten und die Auseinandersetzung mit Managementstrategien erwies sich für einen Teil der Fachwissenschaftler als problematisch. Der Konkurrenzkampf zwischen den verschiedenen Berufsgruppen der Fachwissenschaft, des Marketings und der Pädagogik wird zudem durch die Angst vor Prestige- und Arbeitsplatzverlust genährt. Diese Befürchtung mancher Fachwissenschaftler erwies sich als berechtigt. Einige Museen sprachen Kündigungen als einzige Möglichkeit für erfolgreiche Reorganisation aus. Dennoch bildet weiterhin die Sammlung und die fachwissenschaftliche Erschließung die Basis für die Vermittlungsarbeit.

„When you are a collection based organisation and you are not involving your curators, that will be a problem at some point. The institutions that have succeeded well are the ones that were able to get the curators on board with the change." $" 19$

Aktive Personalentwicklung im fachwissenschaftlichen Bereich, die Kommunikationsfähigkeit und Methoden der Teamarbeit schult, wird angesichts dieser Schwierigkeiten nötig, um die bisher isolierten Aufgabengebieten zu integrieren und zur inhaltlichen Kooperation zu befähigen (ebd.).

Neben der psychologischen Komponente des Verdrängungswettbewerbs besteht ein zweiter entscheidender Gesichtspunkt für die fehlende Integration in Ausstellungsteams darin, dass Unklarheit darüber herrscht, mit welchen Kompetenzen sich Museumspädagogen in ein Ausstellungsteam einbringen können.

„As newcomers to exhibit development, educators have found that their role on the team has remained the murkiest. It has not always been clear just what

19 Interview mit Maureen Rolla, Museum Management Institute, zitiert in Dauschek 2001, S. 185. 
they expected to do: and in some cases their responsibilities seemed to overlap those of other team members.“ ${ }^{20}$

Befindet sich die „Museumspädagogik - zwischen allen Stühlen?!“ Diese Frage und zugleich Feststellung trifft Halbertsma. Er sieht in der Museumspädagogik kein definiertes, festumrissenes Fach. (Halbertsma 1998, S. 21) Als Grund dafür kann die fehlende Institutionalisierung der Museumspädagogik angeführt werden. Eine spezielle Ausbildung zum Museumspädagogen gibt es hierzulande nicht. ${ }^{21}$ Das Angebot an Fortbildungsprogrammen ist jedoch groß und vielfältig. ${ }^{22}$ Dementsprechend unterschiedlich sind Museumspädagogen qualifiziert. Auch resultiert daraus ein sehr facettenreiches Bild über das Tätigkeitsfeld der Museumspädagogik, während die Arbeit am beruflichen Selbstverständnis sich kontinuierlich fortsetzt. Dies zeigt sich daran, dass auf Tagungen immer wieder eine Standortbestimmung der deutschen Museumspädagogik diskutiert wird. ${ }^{23}$ Um dem Defizit des diffusen Berufsbildes der

20 Roberts, Lisa C.: Educators on Exhibit Teams: a New Role, a New Era. In: Hirsch, Joanne S./Silverman, Lois H. (Hrsg.): Transforming Practice. Washington D.C. 2000, S. 90.

21 Die Qualifizierung von Museumsmitarbeitern gestaltet sich ebenfalls sehr heterogen. Neben dem klassischen Volontariat an größeren Häusern gibt es mittlerweile universitäre Studienangebote begleitend zum fachwissenschaftlichen Studium (z.B. Universität Hamburg „Museumsmanagement"). Daneben gibt es Aufbaustudiengänge zum Museums- und Ausstellungswesen (z.B. in München, Stuttgart und Oldenburg). Eine vierjährige museologische Fachhochschulausbildung „Museumskunde“ gibt es in Berlin und Leipzig.

22 Stellvertretend sei die Bundesakademie für kulturelle Bildung Wolfenbüttel genannt. Seit mehreren Jahren bietet sie in Kooperation mit dem Bundesverband Museumspädagogik e.V. ein sogenanntes QuAM-Programm an, ein Projekt zur Qualifizierung von Mitarbeitern in kommunikativen Arbeitsfeldern der Museen. Vgl. http://www.bundesakademie.de (letzter Zugriff: 10.02.05).

23 Zuletzt auf einer Fachtagung des AsKI (Arbeitskreis selbständiger Kulturinstitute e.V.) im Museumszentrum Lorsch am 25./26. April 2002. Als Ergebnis konnte auch hier keine klare Definition des diffusen Berufsbildes Museumspädagogik geliefert werden. In einer weit gefassten Beschreibung umfasst das Berufsbild ein wissenschaftliches Studium mit fachlichen Kompetenzen, didaktische und pädagogische Grundkenntnisse sowie manuelles Geschick. Vgl.: Jung, Sabine/AsKI: Neue Wege der Museums- 
Museumspädagogik entgegenzutreten, entwickelte der Verein für Museumspädagogik Baden-Württemberg ein Positionspapier, welches den Auftrag, das Tätigkeits- und Anforderungsprofil der festangestellten museumspädagogischen Mitarbeiter beschreibt. In dieser Stellungnahme wird der Auftrag der verständlichen und vertiefenden Vermittlung musealer Inhalte für alle Bevölkerungsgruppen als erste These genannt und auf die beratende Funktion bei der Ausstellungsgestaltung hingewiesen:

„Die Museumspädagogin/der Museumspädagoge ist an der Schnittstelle zwischen Fachwissenschaft und Öffentlichkeit tätig, im Team der wissenschaftlichen Mitarbeiter eines Hauses leistet sie/er die ausstellungsdidaktische Beratung.“24

Trotz eines Plädoyers für Teamarbeit behält der Ausstellungsleiter weiterhin die tragende Funktion, der sich die jeweiligen Fähigkeiten und Talente des Teams zu Nutze macht. Teamorientierung bedarf gleichzeitig einer souveränen und entscheidungsfähigen Führungsfigur, denn, wenn alle mitreden, jedoch keiner entscheidet, kann dies dazu führen, dass Teamorientierung ein „,schönes Konstrukt auf dem Papier ist“ ${ }^{\star 25}$, jedoch unter Termindruck in der Hektik der Ausstellungsrealität sich dies als äußerst unpraktisch entpuppt. An der Spitze eines Teams, betont Brehm, muss ein Verantwortungsträger stehen, der einerseits „die ideale Ausstellung vor Augen hat" (ebd.) und andererseits gegenüber der Öffentlichkeit, der Politik und der Fachwissenschaft die Entscheidungen vertreten kann. Zusammenfassend bedeutet dies für die Museumspädagogen, dass eine elementare Voraussetzung für eine gelungene Integration darin besteht, dass die Ausstellungsleitung der Museumspädagogik aufgeschlossen gegenüber steht. ${ }^{26}$

pädagogik. Publikation zu einer internationalen Fachtagung des AsKI im Museumszentrum Lorsch. Bonn 2003.

24 Stephan, Ralph/Theune-Großkopf, Barbara: Das Berufsbild der Museumspädagogik. Positionspapier des Vereins für Museumspädagogik BadenWürttemberg. In: Standbein Spielbein. (2003), Heft 66. S. 60-61.

25 Telefonat mit Dr. Thomas Brehm, Leiter des Kunst- und Kulturpädagogischen Zentrums in Nürnberg, am 04.08.03.

26 Rese, Bernd: Didaktik im Museum. Systematisierung und Standortbestimmung. Bonn 1995, S. 119. 


\section{Ausstellungskompetenz als Kernkompetenz}

In der Reflexion über das Personalwesen stellt sich die Frage nach den Kernkompetenzen von Mitarbeitern einer Ausstellung. Dauschek beobachtete in amerikanischen Museen, dass die wissenschaftlichen Kompetenzen im Sinne einer dauerhaften Bereitstellung spezifischer Wissensbestände weniger wichtig geworden sind. Dagegen steigt die Bedeutung von Kommunikation, Gestaltung und Präsentation. Diese Kernkompetenzen fasst Dauschek unter der Bezeichnung Ausstellungskompetenz zusammen (Dauschek 2001, S. 224). Diese Ausstellungskompetenz stellt besondere Anforderungen an jeden Mitarbeiter im Ausstellungsteam.

Aufgrund der Komplexität von Ausstellungen ist eine Zusammenarbeit von mehreren Personen, die aus völlig unterschiedlichen Bereichen, zum Beispiel Mediendramaturgie, Technik oder Wissenschaft kommen, zwangsläufig. Diese haben völlig unterschiedliche Arbeitsweisen und eine gänzlich andere Sprache. Auch die Vorstellungen darüber, was in einer Ausstellung dargestellt werden soll, kann sehr divergierend sein. Im Blick auf die gegenwärtige Realität der Zusammenarbeit innerhalb eines Teams stellt Landsmann pragmatisch fest, dass an der Verbesserung des wechselseitigen Verständnisses noch zu arbeiten sein wird. ${ }^{27}$ Eine gute Kommunikation innerhalb des Teams während der Entwicklung einer Ausstellung bildet jedoch eine wesentliche Basis für ein gelungenes Ausstellungsprojekt und zählt damit zu den Kernkompetenzen.

„Eine Ausstellung kann immer nur so gut sein wie das Team. Ein kreativer Designer, aber ein träges Wissenschaftlerteam werden keine hervorragende Ausstellung schaffen. Ebenso wenig werden ein aufgeschlossenes Wissenschaftsteam und ein unsensibler Designer keine wirklich gelungene Ausstellung verwirklichen können. “28

Ausstellungsteams sehen sich mit vielen Problemen konfrontiert. Diese beginnen mit der Setzung von Prioritäten und setzen sich im kontinuierlichen Prozess der Einigung und Kompromissfindung fort. Veränderungen geschehen laufend und bedürfen einer Be- und Einarbeitung. Ein

27 Landsmann, Hannah: „Objekt versus Computer“. Symposium zu einem unter Museumsfachleuten heiß diskutierten Thema. In: Newsletter Jüdisches Museum Wien. (2001) Heft 32. S. 7.

28 Interview mit Herrn Kurt Ranger, Büro Kurt Ranger Design in Stuttgart, am 20. März 2002. 
wesentliches Problem liegt in der schon zuvor angesprochenen Einwegkommunikation. ${ }^{29}$ Die Forderung nach Integration in das Team der Ausstellung besteht nicht nur von Seiten der Museumspädagogen, sondern auch die Fachleute für Neue Medien betonen, dass durch eine frühzeitige Integration in den Entwicklungsprozess das Potential der technischen Möglichkeiten umfassender ausgeschöpft werden kann.

„Nachdem die Ideen von den Kuratoren ausgebrütet wurden, wird die Umsetzung der Ideen eingefordert. [...] Das bringt uns in ganz große Schwierigkeiten, weil die sogenannten Techniker dann oft nur Dinge umsetzen können und umgekehrt oft auch Kuratoren die Möglichkeit, die in den neuen Medien stecken, nicht einschätzen können. “30

Die Konturen der jeweiligen Fachrichtung brechen auf. Mit dem Ziel der Besucherorientierung nehmen zum Beispiel auch Gestalter vermittelnde Aufgaben wahr. Dies überschneidet sich mit dem Arbeitsfeld der Museumspädagogen.

„Ich sage immer, ich besorge das Geschäft des Museumspädagogen mit. [...] Ich denke ähnlich wie Pädagogen im Sinne von Vermittlung und zielgruppenorientierter Ansprache. “31

Die Anforderungen an Fachwissenschaftler verändern sich. Nicht nur der Spezialist für einen speziellen Sammlungsbereich oder eine Fachrichtung ist gefragt, sondern ein flexibler Wissenschaftler, der auf einer akademischen Ausbildung aufbauend Querschnittsfunktionen übernehmen kann. Diese Aufgaben sind nicht durch inhaltliches Fachwissen charakterisiert, sondern gehen in die Breite und richten sich an das allgemeine Publikum des Museums (Dauschek 2001, S. 228). Auch die Gestalter sollten nicht nur in den engen Grenzen eines Designkonzeptes denken, damit dieses sich nicht selbst inszeniert, sondern die dienende Funktion bewahrt. Für Gestalter kann dies bedeuten, dass sie manchmal schmerzlich Abstriche in der Stringenz eines Designkonzepts machen müssen. Hinweise und Objektbeschriftungen sollten primär ihrer Funktion gemäß

29 Zur Kritik am linearen Kommunikationsprozess siehe Kapitel 3, S. 98.

30 Gisinger zitiert in Landsmann, Hannah (Hrsg.): Objekt versus Computer?! Sinn und Unsinn Neuer Medien im Museums- und Ausstellungswesen, 12. Juni 2001, Jüdisches Museum Wien, Protokoll des Symposiums. (unveröffentl. Skript) Wien 2001, S. 19.

31 Interview mit Herrn Kurt Ranger, Büro Kurt Ranger Design in Stuttgart, am 20. März 2002. 
ohne Schwierigkeiten lesbar sein, typographische Experimente dienen nicht immer diesem Ziel.

Die Qualität einer Ausstellung hängt von einer gelungenen ganzheitlichen Kombination sinnlicher, kognitiver, ästhetischer, sozialer, symbolischer und innenarchitektonischer Elemente ab. Dies fordert dementsprechend von den Mitwirkenden eine ganzheitliche Sichtweise, Aufgeschlossenheit, Kommunikation und interdisziplinäre Fähigkeiten.

„Exhibit professionals need to be multilingual, or fluent in the languages of communication, environmental psychology, learning theory, conceptual and spatial design, interpretation and visitor studies. They must be able to sort information, apply a variety of problem-solving techniques, model and evaluate a variety of elements, and guide the development process." (McLean 1993, S. 37)

Wer sind diese Allrounder? Diese können sowohl von Seiten der Fachwissenschaft, des Designs, der Pädagogik oder auch aus einem gänzlich anderem Bereich kommen. ${ }^{32}$ Die optimale Voraussetzung besteht darin, ein Generalist zu sein, der die wichtige Bedeutung der richtigen inhaltlichen und fachlichen Belange kennt, ein Gespür für die Dynamik der dreidimensionalen Ausstellungsumwelt und Sensibilität für die Erwartungen und Interessen unterschiedlicher Zielgruppen hat. Ausstellungen machen erfordert eben nicht nur fachliche Kompetenzen, sondern darüber hinaus auch Offenheit, Neugier, Begeisterungsfähigkeit und ein Gespür dafür, welche Fragen für die Besucher interessant sein könnten und sich im dreidimensionalen Raum verwirklichen lassen. Das noch nicht Vorhandene muss entwickelt werden und verlangt Kreativität. Gerade das Vereinen dieser unterschiedlichen Fähigkeiten mit Blick auf den Besucher kann als Charakteristikum museumspädagogischer Qualifikation bezeichnet werden.

„Die Museumspädagogik als Kompetenz besteht aus einem Bündel an Kompetenzen. Ich verstehe Museumspädagogik nicht als rein pädagogische Aufgabe, sondern ich sehe einen großen Anteil künstlerischer Momente und einen Anteil, der werbewirksam und zielgruppenorientiert ist. Mehrere Punkte fließen zusammen und dieses Bündel lässt einen hier und dort mitreden.“33

32 Ein sehr erfolgreicher Ausstellungsmacher ist zum Beispiel der Jurist Christoph Vitali, ehemaliger Direktor des Hauses der Kunst, München.

33 Interview mit Frau Rosemarie Zacher M.A., Künstlerin und Museumspädagogin in München, am 30. Juli 2002. 
Das traditionelle Aufgabenfeld der Museumspädagogen liegt in der personellen Vermittlung. Bedacht werden muss jedoch, dass neben personellen Vermittlungskompetenzen auch visuelles Vorstellungsvermögen und Teamfähigkeit gefordert sind, welche bei der Mitarbeit bei Ausstellungsprojekten elementar sind. Die Rolle der Museumspädagogik innerhalb des Entwicklungsprozesses einer Ausstellung ist bis heute nicht genau definiert und erschwert dadurch auch die Mitwirkung innerhalb eines Teams. Überspitzt formuliert heißt dies:

„Jemand mit genau einer Kompetenz, kann diese Kompetenz linear massiv vertreten. Der Gestalter hat die Kompetenz der alleinigen Ästhetik, und für die kämpft er unabhängig von Inhalt und Exponaten.“(ebd.)

Zum Aufgabenfeld der Museumspädagogen als Sprecher für die Besucher gehört auch, darauf zu achten, ob die Kommunikation mit den Besuchern funktioniert. Dies bedeutet zum Beispiel, dass sie Vertreter der Interessen der unterschiedlichen Personengruppen sind, Lerntheorien und deren Anwendung in der Ausstellungsgestaltung kennen oder auch Besucherforschung betreiben. Aufgrund der Bündelung der Verschiedenartigkeit der Fähigkeiten erscheint eine klare Abgrenzung der Museumspädagogik von anderen Aufgabenbereichen äußerst schwierig. Dennoch soll im Folgenden der Versuch unternommen werden, die Konturen der kommunikativen Strategien klarer aufzuzeigen. Diese stellen eine Basis für die spezifischen museumspädagogischen Kompetenzen dar. Sie gelten zwar genauso für alle anderen Beteiligten im Team, bilden jedoch nicht deren Kernbereich.

\subsection{Dimensionen kommunikativer Strategien}

Überlegungen, die eine gezielte Vermittlungsabsicht für eine Ausstellung zum Inhalt haben, führen in den Bereich der Ausstellungsdidaktik. Dieser häufig verwendete Begriff wird in der Museumswelt sehr unterschiedlich interpretiert. ${ }^{34}$ Die Anwendung des Wortes Didaktik für Aus-

34 Eine Darstellung der zum Teil widersprüchlichen Systematiken der Begriffe Didaktik im Museum/Museumsdidaktik aus erziehungswissenschaftlicher Sicht siehe Noschka-Roos 1994, S. 80ff. Welche Unklarheiten und unterschiedlichen Vorstellungen über eine didaktische Ausstellung existieren, zeigte eine Umfrage der museumspädagogischen Zeitung Standbein Spielbein. Unter anderem sollte der Begriff didaktische Ausstellung defi- 
stellungen hält Frau Noschka-Roos für gerechtfertigt. In aktuellen Publikationen findet sich statt Didaktik vermehrt der Begriff Kommunikation. In meiner Studie verwende ich den Begriff Kommunikation, da dies implizit darauf hinweist, dass zunehmend der Besucher nicht mehr nur als Passiv-Konsumierender betrachtet wird, sondern dieser sich als AktivWahrnehmender in das Geschehen einbringt.

Neutrale Präsentationen gibt es per definitionem nicht. Allerdings existieren unterschiedliche Qualitäten der Formulierung der Interpretation. Allein die Tatsache, Exponate chronologisch zu präsentieren oder nach unterschiedlichen Sachgruppen zu sortieren, genügt dem Anspruch einer besucherorientierten Ausstellung nicht. Hilgers bezeichnet es als vordergründige Didaktik, wenn eine Ausstellung zwar einen illustrativen Titel trägt, aber dennoch lediglich oberflächlich ausgewählte Bilder aneinander reiht. (Hilgers zitiert in Noschka-Roos, 1994, S. 78). Grundsätzlich kann festgestellt werden, dass Objekte sich nicht von allein erklären. „Sie erzählen weder ihre Geschichte noch ihre Bezüge. Haben der Kurator oder das Ausstellungsteam eine Aussage im Sinn, müssen sie sich kommunikativer Strategien bemühen." (Wohlfromm 2002, S. 33).

In Anlehnung an die erziehungswissenschaftliche Theoriebildung zur Didaktik unterscheide ich zwischen den vier kommunikativen Strategien der Anschaulichkeit, Handlungsorientierung, Ganzheit und Differenzierung.

\section{Anschaulichkeit - Verdichtung der Aussage mittels Gestaltung}

Die haptische Gegenwart der Objekte in ihrer Materialität, Proportion, Farbe und Gestalt ermöglicht eine direkte sinnliche Begegnung und Anschauung. Schon allein aufgrund dieser Tatsache sind Ausstellungen Orte der Anschaulichkeit. Insbesondere in einer technisierten Welt mit einer fortschreitenden Immaterialisierung von Information, in der Erlebnisse zunehmend nicht mehr direkt erfolgen, können sich Ausstellungen als Gegenorte positionieren, indem die Museumsexponate im Mittelpunkt stehen und eine intensive Begegnung ermöglichen. Angesichts der

niert werden. Als Ergebnis stellte die Redaktion fest, dass trotz variierender Antworten fast alle den Besucher in den Mittelpunkt rückten. Heinje, Sylvia: Ausstellen. Was sich herausstellt. In: Standbein Spielbein. (1989) Heft 25. S. 8. 
Flüchtigkeit medialer Speicher- und Bildwelten spricht der Medienwissenschaftler Ernst vom Museum als „Reservat der Überschaubarkeit““. ${ }^{35}$ Sollen sich über diese unmittelbare Erfahrung hinaus Erkenntnisse vollziehen, bedarf es der Entwicklung von kontextualisierenden Strategien. Historisches Verständnis entsteht weder durch die bloße Zurschaustellung einzelner Objekte noch allein durch erläuternde Texte, sondern entsteht aus dem Erlebnis des gesamten sinnlichen Beziehungsgeflechtes, in das die Exponate eingebunden sind. Diese ästhetische Dimension der Präsentation von Geschichte meint mehr als Ausstellungsarchitektur und Vitrinenbau.

„Es ist vielmehr der Versuch, die Objekte visuell, sinnvoll-sinnlich ästhetisch $\mathrm{zu}$ ordnen und zu präsentieren, sie neu zu dimensionieren, (Durch-)Blicke freizugeben, Sichtweisen zu eröffnen, die auch ohne Worte Zusammenhänge ergeben, Bedeutungen in ihrer möglichen Vielfalt ahnen lassen. “36

Ausstellungen sind räumliche und graphische Organisationen in einem vorgegebenen Gebäude und stellen in besonderem Maße Anforderungen an die gestalterische Umsetzung der Thematik, wobei vor allem dem konsequenten Einsatz inszenatorischer Mittel Bedeutung zukommt. Diese haben nicht nur die Aufgabe, den eigentlichen Exponaten einen adäquaten Rahmen zu bieten, sondern die komplexen Inhalte anschaulich und begreifbar zu machen, die Bedeutung der Originale zu verstärken und damit die wissenschaftlich erarbeiteten Aussagen der Ausstellung zu vermitteln. Ergänzend zur textlichen Vermittlung in der Ausstellung lässt die Gestaltung sie zu einem Ort der sinnlichen Wahrnehmung werden.

Anschaulichkeit besagt, dass ein Gegenstand oder eine Situation unmittelbar oder mittelbar über Medien der sinnlichen Wahrnehmung oder Vorstellung zugänglich ist. ${ }^{37}$ Bereits Pestalozzi verwies auf die elemen-

35 Ernst, Wolfgang: Museale Authentizität in einer Welt der virtuellen Kommunikation? In: Standbein Spielbein. (2002) Heft 63. S. 25.

36 Borsdorf, Ulrich/Grütter, Heinrich Theodor: Überdachte Fragmentarik. Die Ausstellung, Vergessene Zeiten. Mittelalter im Ruhrgebiet‘. In: Fröhlich, Klaus: Geschichtskultur. Paffenweiler, 1992 S. 181.

37 Als spezifisches Kennzeichen des Lehrens ist Anschaulichkeit vor allem im vorschulischen Bildungsbereich und in der Grundschule gefordert. Es sei in diesem Zusammenhang jedoch daran erinnert, dass auch der zur Abstraktion fähige Erwachsene durch anschauliche Praxisbeispiele sein Vorstellungsvermögen unterstützen kann. Verwiesen sei hier stellvertre- 
tare Bedeutung der Anschauung, da sie das Fundament aller Erkenntnis bildet. Das heißt, Vorstellungsbilder und Begriffe werden durch die unmittelbar sinnliche Wahrnehmung eines Sachverhalts aufgebaut. Denken als Reflexion des Wahrgenommenen kann ohne diese Vorstellung nicht gelingen. ${ }^{38}$ Und gerade zur Erfüllung des Bildungscharakters von Ausstellungen erscheint mir dieses reflektierte Denken als überaus wichtig. Nicht umsonst zählt das Prinzip der Veranschaulichung zu den ältesten Unterrichtsprinzipien. Die Aufforderung von Comenius „Unterrichte anschaulich!“ ist nach wie vor als didaktisch-methodische Anweisung zu verstehen, die jeder Form der denkenden Auseinandersetzung dienen soll. ${ }^{39}$

Nicht die Menge der Anschauungsmittel ist entscheidend, sondern die Qualität des Einsatzes. Als Handlungskonsequenz in der Praxis kann dies bedeuten, dass es besser ist, nur ein Beispiel, ein Modell oder ein Diapositiv mit hohem Informationsgehalt und Erklärungswert zu verwenden als viele Beispiele mit Randinformationen und ergänzungsbedürftigem Erklärungswert. So ist die Anschauung der Wirklichkeit notwendig gekoppelt mit einer Darstellung, durch die wesentliche Züge herausgehoben werden, so dass sie besser zu erkennen sind, als es die komplexe Wirklichkeit erlaubt. Anschaulichkeit in der Darstellung ist eng mit einer Steigerung der Wahrnehmungsfähigkeit des Menschen verbunden.

Die kritischen Momente liegen vor allem in dem durch Medien bedingten Gebrauch von Informationsträgern, die zu einer Sachverfälschung, Sachverzerrung oder sinnentstellenden Vereinfachung führen können. Angesichts der Komplexität historischer Ereignisse stellt sich die Kernfrage, wie Veranschaulichung von Geschichte überhaupt methodisch umgesetzt werden kann.

tend auf eine neue Form des Gedächtnistrainings, des Mind Mappings, bei der speziell mit visuellen Elementen gearbeitet wird. Vgl. Hertlein, Margit: Mind Mapping - Die kreative Arbeitstechnik. Spielerisch lernen und organisieren. Hamburg 1997.

38 Köck, Peter/Ott, Hanns: Wörterbuch für Erziehung und Unterricht. Donauwörth 2002, S. 35.

39 In der heutigen Pädagogik und Didaktik spielt der Begriff Anschaulichkeit eine untergeordnete Rolle. Lenzen stellt fest, dass durch diese Bezeichnung lediglich Leerstellen markiert werden. Mit Verweis auf das Problem Anschaulichkeit wird aktuell auf ein Defizit heutiger Erziehungswissenschaft hingewiesen. Vgl. Lenzen, Dieter: Pädagogische Grundbegriffe, Reinbeck b. Hamburg 1989, S. 65. 
Berechtigterweise wurde scharfe Kritik an der Tendenz geübt, historische Ausstellungen mit Informationsmaterial zu überschütten, um Geschichtsobjekte zu rekontextualisieren. Als ein Weg in die verkehrte Richtung der Methode der Veranschaulichung stellten sich die als Lesetapeten bezeichneten Präsentationen heraus. Diese Lernausstellungen mit lehrbuchartiger Aufbereitung der Stoffe betonten einerseits die kognitive Komponenten ohne Berücksichtigung der sinnlichen Ebene. ${ }^{40}$ Korff spricht in diesem Zusammenhang von einem Zwei-D-Prinzip und meint damit die Zweidimensionalität der Flachware. Didaktik und Design dominieren die Gestaltung, vergessen jedoch wird dabei das gesamte Beziehungsgeflecht ganzheitlicher Raumerlebnisse.

„Zwei-D: Didaktik und Design. Diese Kombination rückt die museale Geschichtspräsentation in aller Regel in die Nähe zu einer Ästhetik, die den Charme eines Dentallabors hat, doch von der faszinierenden Fremdheit und Anmutungsqualität der historisch-authentischen Bildwelten nichts verspüren läßt.“" (Korff 2002, S. 330)

Das Konzept der Lernausstellung basierte auf Theorien der empirischen Erziehungswissenschaften der siebziger Jahre. Diese waren prägnante Beispiele für technizistisches Zweck-Mittel-Denken im methodischen Ansatz. Der Lehr-Lernzusammenhang wird kurzgeschlossen und so die damit verbundenen Vermittlungsprobleme ignoriert (Noschka-Roos 1994, S. 124). Ein zweiter Kritikpunkt dieser curricular aufbereiteten Präsentationen lag in der fehlenden Offenheit der Interpretation. Die festgeschriebenen Lernziele verengten den Blick und entmündigten die Besucher, indem diese die Objekte nur in einer bestimmten Form interpretieren sollten.

„Lange Schrifttafeln, Tonbandgeräte und audiovisuelle Apparate hämmern ihnen unbarmherzig und ohne einen Widerspruch oder auch nur eine Frage zu akzeptieren ein, daß sie die ausgewählten Objekte so und nicht anders verstehen müßten und daß es vor allem auf die von sogenannten MuseumsDidaktikern ersonnenen Aussagen ankomme, [...].“(Boockmann 2000, S. 304)

40 Im Jahr 1973 stellte Martin Scharfe auf einer Frankfurter Tagung erstmals sein Konzept der Lernausstellung als curricular geplantes, durchdachtes, kontrolliertes Ausstellungskonzept mit dezidierter Lernzielformulierung vor. Ausstellungspräsentationen, die in diesem Zeitraum und Umfeld entstanden, wurden intensiv diskutiert, waren jedoch nicht wegweisend. Als der Klassiker für ein textorientiertes Ausstellungskonzept wird in der Literatur oft auf das Historische Museum in Frankfurt verwiesen. 
Das Konzept der Lernausstellung definierte Bildung als kritisch-aufklärerische Praxis. Die bisherige Ausstellungstätigkeit der Museen wurde als systemstabilisierend gewertet und abgelehnt. Dadurch ergab sich eine selbstkritische Ironie, in der fraglich war, wer über die neuen Ziele und die Aufklärungsinhalte herrschaftskritisch bestimmen dürfte.

Aufgrund dieser kurz aufgezeigten Problematik, die mit Methoden der Veranschaulichung einhergehen, stellt sich umso mehr die Frage nach der Qualität und der Art und Weise der methodischen Umsetzung. Als Konsequenz auf Veranschaulichungsmethoden zu verzichten, bildet keine Lösung, da der Vergangenheit „,der Stachel der zeitlichen Distanz“ genommen werden sollte. ${ }^{41}$ Je stärker die Phantasie und Neugier geweckt wird, desto mehr wächst die Bereitschaft, sich auf die Geschichten einzulassen.

Als eine Möglichkeit der analytischen Betrachtung der Sprache von Ausstellungen verweist Waidacher auf Methoden der Semiotik. ${ }^{42}$ Die Erkenntnisse der Sprachwissenschaft können als Modell für die Betrachtung der Aussprache herangezogen werden. Waidacher schränkt zwar ein, dass Kommunikation im Museum nach eigenen Regeln funktioniere und Analogisierungen wegen der völlig unterschiedlichen Artikulation enge Grenzen gesetzt seien. Dies soll jedoch nicht heißen, dass es nicht notwendig und nutzbringend ist, die Erkenntnisse der Sprachwissenschaft auf andere Ausdrucksformen zu übertragen (Waidacher 1999, S. 249ff.). ${ }^{43}$

Ausstellungen sind Ausdrucksformen einer spezifischen Mitteilungsweise, nämlich der musealen Aussage durch Präsentation. Diese Mitteilung bedient sich visueller Zeichen, die in ihrer Gesamtheit die Ausstellungssprache bilden. So wie es im Film die Grundsätze bewegter

41 Zum Thema der Notwendigkeit der Vergegenwärtigung der Vergangenheit siehe auch Kapitel 2, S. 70.

42 Semiotik ist die Lehre von den Zeichen. Die Schwerpunkte semiotischer Forschung liegen bei der Philosophie und Sprachwissenschaft; im Allgemeinen wird die Semiotik gegliedert in Syntaktik (die Beziehungen der Zeichen untereinander), Semantik (die Beziehungen zwischen Bezeichnetem und Zeichen) und Pragmatik (die Beziehungen zwischen Bezeichnetem, Zeichen und Benutzer). Vgl. Bibliographisches Institut \& F. A. Brockhaus AG, 2001.

43 Eine kurze Zusammenfassung wichtiger Aspekte der Museums-Semiotik siehe Horta, Maria de Lourdes: Museum Language and Exhibitions Speeches ... a ,chicken and egg discussion. In: Sofka, Vinos (Hrsg.): The language of exhibitions. Stockholm 1995, S. 55-60. 
zweidimensionaler Formen sind, so sind es im Fall von musealen Ausstellungen die Prinzipien statischer dreidimensionaler Ausdrucksweisen. Die visuelle Sprache enthält die gestalterischen Grundelemente von Raum, Form und Farbe mit einer Fülle von visuellen Variablen. Hierzu zählen Plastizität, Farbpolarität, Gefüge, Ausmaß oder Menge, Stellung in der Fläche und im Raum. Da das Objekt eine Art visuelle Kurzschrift ist, muss seine jeweils angestrebte Aussage durch den Kontext unterstützt werden, in den es gestellt wird. Dieser ist nicht multivalent, sondern trägt auch entsprechend seinem Einsatz verschiedene Bedeutungen (Waidacher 1999, S. 255).

In der Kombination gestalterischer Elemente der visuellen Sprache bildet die museale Ausstellung eine Metapher, bildhafte Veranschaulichung von Geistigem, Substitut für Assoziationen. „Dabei werden die Objekte entweder als Metonymie (Umbenennung) oder als Synekdoche (Mitverstehen des Ganzen durch Präsentation von Teilen) eingesetzt und vertreten somit als repräsentative Elemente die Realität." (ebd., S. 251) In die Ausstellungssprache können Erkenntnisse der antiken Rhetorik im Sinne von visuellen Redefiguren in die Ausstellungssprache einfließen.

„Antithese (Gegensatz), Oxymoron (widersprüchlicher Gegensatz), Hyperbel (Übertreibung), Iteration (Wiederholung), Ellipse (Auslassung), Klimax und Antiklimax (Aufreihung mit Wertsteigerung oder -minderung) sind nur einige Beispiele für die Aufnahme dieser allgemein akzeptierten Kodes in die Kontextgestaltung von musealen Ausstellungen." (ebd.)

Waidacher weist einschränkend jedoch darauf hin, dass auch bei einer semiotischen Betrachtung der Ausstellungssprache nicht vergessen werden darf, dass zwischen der beabsichtigten Bedeutung einer Botschaft und dem Sinn, den ihr der Empfänger verleiht, oft erhebliche Unterschiede bestehen (Waidacher 1999, S. 251). 


\section{Fragen an die Ausstellung - Anschaulichkeit}

\section{Ästhetische Dimension}

- Wie wird die ästhetische Dimension von Ausstellungen generell berücksichtigt?

- Wie wirken Raumarchitektur und Gestaltung zusammen?

- Wie ist der Einsatz von innenarchitektonischen Elementen wie Material, Farbe und Licht?

- Welche Inszenierungsformen werden eingesetzt?

- In welchem Verhältnis stehen Original und sekundäres Museumsmaterial? Ist eine Unterscheidung zwischen Original/Replik möglich?

- Wie werden die Objekte präsentiert? Welche Objekte gibt es, wie ansprechend sind diese Objekte? Befinden sich diese Objekte in Vitrinen, wenn ja, in welchen Vitrinen?

- Welche Art von Graphiken werden eingesetzt? Zu welchem Zweck werden diese eingesetzt? Treten sie in Konkurrenz zum Objekt?

- Welche Arten von Typographie und Text werden eingesetzt?

- Welche rhetorischen Mittel werden wie eingesetzt, wie zum Beispiel Übertreibung, Wiederholung, Humor, Brechung, Irritation?

- Dominiert das Design die Objekte?

\section{Inhaltlich - historische Dimension}

- Wie wird der Besucher mit dem raumbestimmenden Thema vertraut gemacht? Werden Thema und Unterthema durch Raumbeschriftungen gegliedert? Wie ist das Grundschema der Informationsvermittlung angelegt?

- Raumtitel: Gibt es diese generell, wo sind diese angebracht? Wie umfangreich sind die Raumtexte? Wie umfangreich sind die Objekttexte? Wie werden die Texte mit den Objekten kombiniert? Wie ist das Verhältnis Objekt - Text, Inszenierung - Text, Inszenierung Exponat?

- Wie trägt die Inszenierung zur Veranschaulichung des Inhalts bei? Kann der Besucher inszenatorische Elemente decodieren?

- Führt die Inszenierung zu einer sinnentstellenden Verkürzung? 


\section{Handlungsorientierung - die Besucherinteressen und Erfahren mit allen Sinnen}

„Erkläre mir und ich vergesse. Zeige mir und ich erinnere, lass es mich tun und ich verstehe. “44 Dieses Zitat des chinesischen Philosophen Laotse drückt eine alte Weisheit aus, die in der pädagogischen Diskussion immer wieder aufgegriffen wurde. Der Grundgedanke besagt, dass sich durch eigenes Tun eine Intensivierung der Erfahrung vollzieht. In der Pädagogik wurde diese alte Idee erneut unter dem Begriff Handlungsorientierung in die Diskussion eingebracht. Dies wirkte sich verändernd auf Präsentationsformen in Museen aus. Lag der Schwerpunkt früher nur auf dem reinen Betrachten, gibt es nun vor allem in den technisch orientierten Museen verstärkt Exponate, die ein Anfassen und Ausprobieren nicht nur gestatten, sondern ausdrücklich wünschen. Langsam öffnen sich auch kunst- und kulturhistorische Museen und integrieren interaktive Elemente in die Ausstellungsparcours von Dauer- und Sonderausstellungen. ${ }^{45}$

In der pädagogischen Literatur wird unter dem Begriff Handlungsorientierung jedoch nicht nur auf den Vorgang der Aktivierung und das Lernen mit allen Sinnen verwiesen, sondern weitere Kriterien sind damit verbunden. Dieses ist die Beteiligung der Lernenden bei der Planung und Anknüpfung an deren Interessenslagen, ebenso bedeutet dies einen Gegenwarts-, Lebens- und Situationsbezug der Themen- und Fachinhalte. ${ }^{46}$

Einen Hauptgrund für die Langeweile historischer Museen sieht Parmentier in ihrer Unaktualität. „Das Vergangene erscheint nur noch als

44 Mittlerweile kann dieses Zitat auch empirisch belegt werden: Witzenbacher untersuchte in einer Studie der American Audiovisual Society menschliche Behaltensleistungen: Danach behalten wir zwanzig Prozent von dem, was wir hören, dreißig Prozent von dem, was wir sehen, achtzig Prozent von dem was, wir selber formulieren können und neunzig Prozent von dem, was wir selbst tun. Witzenbacher zitiert in Gudjons, Herbert: Handlungsorientiert lehren und lernen. Schüleraktivierung - Selbsttätigkeit - Projektarbeit. Bad Heilbrunn 1997, S. 19.

45 Aktuelle Beispiele dafür sind die im Jahr 2001 wieder eröffneten British Galleries des Victoria \& Albert Museums in London, die archäologische Abteilung im Landesmuseum in Karlsruhe oder das neu eröffnete Rheinische Landesmuseum in Bonn.

46 Schaub, Horst/Zenke, Karl G.: Wörterbuch Pädagogik. München 2000, S. 252. Siehe auch Gudjons 1997, S. 40ff. 
Vergangenes: Ausrangiert, abgelegt, übriggeblieben.“" ${ }^{47}$ Trotz aller Beteuerungen wird die Bedeutung der Vergangenheit für die Gegenwart nicht sichtbar. Ein Grund dafür liegt nach Vermutung von Parmentier in der anhaltenden Weigerung der Museumsmacher, die Ausstellung als ein weiträumiges Vergleichstableau zwischen dem Geschehenen und dem Aktuellen zu inszenieren (ebd.). ${ }^{48}$

Die Begründung für die Integration des Prinzips Handlungsorientierung basiert auf erkenntnistheoretischen Grundlagen und der Tatsache, dass sich jeder Mensch sein Wissen selbst konstruiert (Gudjons 1997, S. 49). Fehlt der Zusammenhang von Lernen und Handeln, von Wissen und Anwendung, kommt es - wie neuere Forschungen zum Wissenserwerb betonen - zu „trägem Wissen“. Gemeint ist damit ein Wissen, welches nicht zur Anwendung kommt und daher auch nicht in ein bestehendes Vorwissen integriert und vernetzt wird. Dadurch bleibt es zusammenhangslos (ebd., S. 50). In der konstruktivistischen Didaktik, jene Richtung, die die Selbstkonstruktion allen Wissens durch den Lernenden betont, wird auf diesen Sachverhalt ausdrücklich verwiesen. Zur Vermeidung des Problems trägen Wissens sollten sich Lernende nicht als passive Rezipienten von Fakten, sondern als aktive, selbst steuernde Lernende verstehen. Lehrende sollten sich weniger als Vermittler oder Präsentatoren von Wissen verstehen, sondern mehr als Mitgestalter von Lernumgebungen und Unterstützer von Lernprozessen. Gudjons folgert daraus für die Vermittlung, dass sich diese an lebensnahen Bereichen orientieren sollte. Lernen ist als aktiver Prozess zu verstehen: Vorhandenes Wissen verändert sich kontinuierlich durch neue Erfahrungen und konstruiert sich immer wieder neu. Für die Lehrinhalte sind somit Vorerfahrungen und Interesse wichtig. Das Neue und Fremde bedeutet eine

47 Parmentier, Michael: History is bunk. Gibt es eine Alternative zur Chronologie in historischen Museen? In: Standbein Spielbein. (2003) Heft 67. S. $4 \mathrm{ff}$.

48 Als positives Beispiel für die konsequente Orientierung an gegenwartsbezogenen Fragestellungen und das Aufzeigen ihrer historischen Bedingtheit ist das Haus der Geschichte Baden-Württemberg nennen. Dieser Ansatz manifestiert sich bereits in der Architektur des Hauses. Öffnungen im Boden ermöglichen dem Besucher Durchblicke von der Ebene des gegenwartsbezogenen Themenparks auf die darunter liegende Ebene der historischen Chronologie. Vgl. Lutum-Lenger, Paula: Die Gegenwärtigkeit der Geschichte. Eine Ausstellung zur Südwestdeutschen Landesgeschichte seit 1790. In: Haus der Geschichte Baden-Württemberg: Landesgeschichten. Der deutsche Südwesten von 1790 bis heute. Stuttgart 2002, S. 10-21. 
Herausforderung für die Neustrukturierung des bisherigen Erfahrungsschatzes. Auch Gefühle und persönliche Identifikation spielen dabei eine sehr wichtige Rolle. Neben diesen Faktoren betont Gudjons außerdem die hohe Relevanz sinnlicher Erfahrungen (ebd., S. 54). Durch Handeln und Bewegung wird die Gedächtniswirksamkeit gefördert, welche sich wiederum positiv auf die Lernmotivation auswirkt. ${ }^{49}$ Belegen lässt sich dies durch Ergebnisse und Befunde der Gedächtnisforschung.

„Trotz vieler ungeklärter Einzelzusammenhänge gilt es als erwiesen, daß reizarme Situationen und einförmige Tätigkeit zur Herabsetzung der psychischen Aktivität, zu Antriebsmangel, Konzentrationsausfällen und Ermüdung führen.“ (Möller zitiert in Gudjons 1995, S. 113)

Lernpsychologisch wurde nachgewiesen, dass der Grad der Erregung der Formatio reticularis ${ }^{50}$ zum Beispiel durch Tast-, Geruchs-, Geschmacks-, Gehör- oder Sichtreize ganz entscheidend die Aktivierungslage auch des Großhirns und die freigestellte Energie bestimmt. Insofern kann Ermüdung nicht nur Folge von Anstrengung, sondern gerade umgekehrt von mangelnder Beanspruchung sein. Dies ist zum Beispiel der Fall, wenn verschiedene sensorische Einströme in die Formatio reticularis ausbleiben. Die pädagogische Konsequenz daraus ist die Bemühung um ein optimales, also weder $\mathrm{zu}$ hohes noch $\mathrm{zu}$ niedriges Aktivierungsniveau (ebd., S. 55). Handlungsintensives Lernen begünstigt die multidimensionale Kodierung von Informationen. Aufgrund der Beteiligung verschiedener Sinnesorgane schwingen mehrere Gehirnregionen mit. Ein breites Netz bedeutungshaltiger Assoziationen wird ermöglicht. Das Bewegungsgedächtnis ist phylogenetisch und ontogenetisch die früheste Form des Gedächtnisses. Obwohl das Bewegungsgedächtnis im menschlichen Entwicklungsprozess an Bedeutung verliert, „bleibt es doch ein elementarer Mechanismus auf allen Stufen der Erkenntnis“ (ebd., S. 175).

49 Eine positive Wirkung handlungsorientierter Objekte auf die Interessen der Besucher stellte auch Stiller fest, der in einer vergleichenden Betrachtung eine Dauerausstellung mit und ohne Hands-on Objekte untersuchte. Stiller, Jürgen: Formen und Wirkungen handlungsorientierter Informationsvermittlung in der Museumspädagogik. Exemplarisch untersucht an der didaktischen Aufbereitung und dem Besucherverhalten in einer Abteilung des Museums für Kunst und Kulturgeschichte in Dortmund. Dortmund 1993, S. 138.

50 Teilgebiet des Hirnstammes 
Die Umsetzung von Handlungsorientierung in musealen Ausstellungen ist umstritten. Befürchtet wird zum Beispiel, dass mit der Installierung von Hands-on Objekten in der Ausstellungsumwelt der Status des originalen Exponats ins Hintertreffen gerät. Auch konservatorische Bedenken werden vorgebracht. Darüber hinaus können Hands-on Objekte ein sehr kostenintensives Vorhaben sein. Die Notwendigkeit der ständigen Wartung zur Gewährleistung der Funktionstüchtigkeit kann hohe Folgekosten nach sich ziehen, die bei der Einrichtung zunächst nicht bedacht werden. ${ }^{51}$

Interaktivität und Erleben mit allen Sinnen entspricht auf der einen Seite dem Erlebnisbedürfnis der gegenwärtigen Gesellschaft. Gerade das jüngere Publikum sowie auch der eher freizeitorientierte Besucher kann mit dieser Methode erreicht werden. Insbesondere für Kinder gilt, dass sie eine Ausstellung sinnlich-aktiv erfahren möchten. Durch rein kognitive Informationsübermittlung werden sie sehr schnell überfordert und gelangen zu der Überzeugung, dass Museen primär für Erwachsene und darüber hinaus lebensfern seien. Andererseits besteht jedoch auch die Befürchtung, dass damit eine Verflachung und Oberflächlichkeit der Erfahrung einhergeht. Als konzeptioneller Ansatz birgt die Methode der Interaktivität Gefahren, wie Gudjons zu bedenken gibt. Handlungsorientierung darf nicht mit permanenter Aktion und Reizüberflutung verwechselt werden (ebd., S. 55). Dieser blinde Aktionismus führt dann nicht zu der gewünschten vertiefenden Erfahrung. Ohne begleitende Betreuung können die Interaktionen zum Selbstläufer werden mit dem Effekt, dass der eigentliche Inhalt verdrängt und überlagert wird. In den vergangenen Jahren wurden die Schwachpunkte des Hands-on bei unreflektiertem Einsatz deutlich und durch das Schlagwort Minds-on erweitert. ${ }^{52} \mathrm{Die}$ Erkenntnis, dass Anfassen zwar eine Qualität an sich darstellt, es jedoch nicht zwangsläufig zu einem besseren Verständnis des dargestellten Sachverhalts beiträgt, trug zu einem reflektierteren und kritischeren Umgang mit dieser Methode bei. Als Folge dieser Diskussion wird der Begriff Hands-on nun seit wenigen Jahren doppeldeutig als potentielles Begreifen der Dinge verstanden. ${ }^{53}$

51 Auch Vandalismus und mutwillige Zerstörung stellen in diesem Zusammenhang ein großes Problem dar.

52 König, Gabriele: Kinder- und Jugendmuseen. Genese und Entwicklung einer Museumsgattung, Impulse für besucherorientierte Museumskonzepte. Opladen 2002, S. 98.

53 Unter diesem veränderten Vorzeichen ist auch das Motto der dritten Europäischen Kinder- und Jugendmuseumskonferenz in Lissabon im Herbst 
Das Anliegen der Handlungsorientierung, insbesondere alle Sinne anzusprechen, steht auch in Zusammenhang mit den Möglichkeiten der technischen Neuerungen auf dem Gebiet der Neuen Medien. Die Hoffnung, dass sich mit dem Einzug elektronischer Medien die Vermittlung von Wissen und Bildung beschleunigen und verstärken würde und sich eine neue Bildungsexplosion ereignen würde, hat sich jedoch nicht erfüllt.

„Wir sind, [...], auf dem Weg, unsere Illusion zu vermehren, etwas zu wissen: Man schaut hin, aber man erkennt nicht. Man weiß, wie man etwas findet, aber man weiß eigentlich nicht, was man finden möchte. “54

Neue Medien haben mittlerweile das Odium des Besonderen verloren, ihre Erscheinungsformen im Umfeld des Museums sind vielfältiger Art. ${ }^{55}$ Sie werden zur begleitenden Vermittlung von Inhalten in Form von akustischen Systemen, Filmen, Touch-Screens, Video- und Audiostationen eingesetzt. Auch lassen sich bei ihrem Einsatz Verknüpfungen von Archiv, Bibliothek und Museum herstellen. Computer und Video, Animation und Virtualität zählen heute bereits zum musealen Alltag. Das Angebot an neuen Technologien ist enorm und stellt ein spannungsreiches Experimentierfeld für Mediendesigner und -gestalter dar. Die Fülle der Möglichkeiten kann verführen. Die Technik fordert den Ausstellungsmacher heraus, Dinge zu produzieren, die früher nicht hätten produziert werden können. Dabei bleibt eine ganz wesentliche Frage offen, nämlich, ob die Fülle an technischen Möglichkeiten dem Betrachter, dem Thema oder dem Objekt gerecht wird. Zwischen den seitens der medialen Programmgestalter reklamierten Erlebniseffekten und Wis-

1998 zu verstehen. Dort wurde die Notwendigkeit der Weiterentwicklung dieses Begriffes und Ansatzes diskutiert.

54 Wechsler, Ulrich: Erst laufen, dann Rad fahren. Nicht die Nutzung der Medien macht den Grad unserer Bildung aus, sondern der Grad unserer Bildung bestimmt, wie sinnvoll die Nutzung der Medien ist. In: Süddeutsche Zeitung vom 06./07.04.02.

55 Die Bezeichnung Neue Medien ist relativ, denn zu allen Zeiten war ein bestimmtes Medium neu und wurde deshalb vermehrt eingesetzt, ob es sich um Fotos, Tondokumente, Hologramme oder virtuelle Architektur handelt. Wohlfromm stellt fest, dass es schwierig sei, eine Prädisposition zu finden, die die Positionierung der Bereiche „Neue Medien und das Museum" angemessen darstellt. Die neuen digitalen Medien lassen sich nämlich nicht mehr lediglich als Bestandteil, Mittel und Werkzeug beschreiben, sondern greifen bereits in das Gebilde Museum ein. Vgl. Wohlfromm 2002, S. 53. 
senstransfer einerseits und den eintretenden Wirkungen und subjektiven Einschätzungen bei den Rezipienten der Medieninstallationen andererseits klaffen noch erhebliche Lücken. ${ }^{56}$

Wie Neue Medien eingesetzt werden können und welche Implikationen dieses mit sich bringt, zählt zu den heiß diskutierten Themen unter Museumsfachleuten. In der Museumswelt ist das Verhältnis dazu ambivalent. Auf der einen Seite findet sich große Begeisterung und Experimentierfreudigkeit, besonders das Internet erfreut sich großer Beliebtheit. Auf der anderen Seite steht die Angst um die Exklusivität der musealen Originale als das Wesentliche, was das Museum zu bieten hat. Gefürchtet wird die „Duplizierung, Verfremdung und Wertminderung des Originals“ (Wohlfromm, 2002, S. 51). Die so genannten Neuen Medien sollten aber nicht nur die Ängste der Verantwortlichen anregen, sondern auch deren Phantasie. Medien, egal wie alt oder neu sie sein mögen, können sehr geschickt und raffiniert eingesetzt werden. Sie können einen zusätzlichen Erkenntnisgewinn liefern und eine neue visuelle Qualität, die dem Besucher ermöglichen, museale Objekte auf eine andere Art und Weise zu betrachten. Der Einsatz Neuer Medien unterliegt den gleichen Gestaltungsgesetzen wie der der konventionellen Medien. Ein Terminal im Ausstellungsparcours garantiert noch keine gute Vermittlung. Auch sollten die Medien nach dem Prinzip der Zielorientierung und der Unterordnung von Gestaltung unter das Primat des Originals und der Information eingesetzt werden.

„Technology, whether it be the hands-on exhibit or the touch-screen computer, is simply the tool with which the museum interpreter communicates with the visitor - it is not an end-product in itself. [...] Each interpretative tool has its advantages and weaknesses, and should be used selectively to help visitors access and gain understanding of the objects, sites or phenomena. ${ }^{\text {"57 }}$ (Caulton 1998, S. 13)

Der Interaktivität via Neue Medien sind Grenzen gesetzt. Was also kann sie leisten? Auf diesem Gebiet eröffnet sich ein sehr weites Forschungsfeld. ${ }^{58}$ Dabei wird deutlich, dass die Breite der möglichen Fragestellun-

56 Klein, Hans-Joachim (Hrsg.): Mediendämmerung - die unaufhaltsame Computerisierung der Museen. Karlsruhe 1995, S. 3.

57 Caulton, Tim: Hands-on Exhibitions - Managing Interactive Museums and Science Centers. London/New York 1998, S. 1.

58 Mit der zentralen Frage, welche Vorteile der Einsatz von Multimedien für das Lernen im Museums bringt, befasst sich zum Beispiel die Dissertation 
gen und die rapide Entwicklungsgeschwindigkeit ein interdisziplinäres Nachdenken über die Bedingungen der Forschung auf diesem Gebiet erfordert. ${ }^{59}$ Die Studien auf diesem Gebiet sind im angloamerikanischen Raum dem deutschsprachigen um einiges voraus, sowohl im Hinblick auf Medieneinsatz in musealen Schausammlungen als auch in der begleitenden Nutzung der Evaluation als Planungskorrektiv und Ergebniskontrolle (Klein 1995, S. 3). ${ }^{60}$

\section{Fragen an die Ausstellung - Handlungsorientierung}

\section{Ansprechen aller Sinne}

- Welche Vermittlungsmedien werden dem Besucher gegeben und wie sind diese im Raum platziert?

- In welcher Form werden alle Sinne angesprochen? Welche Rezeptionskanäle werden angesprochen: emotional, rational, aktional, ästhetisch?

- Welche audiovisuellen Medien werden eingesetzt? Sind diese relevant? Unterstützen sie das Ausstellungskonzept oder sind sie ein nachträglicher Einfall?

zepte, sondern entwickelt aus der Beschreibung verschiedener Projekte praktische Regeln für die Produktion multimedialer Anwendungen. Billmann, Hans-Joachim: Multimedia in Museen. Neue Formen der Präsentation - neue Aufgaben der Museumspädagogik. Bremen, 2000.

59 Als erste Annäherung an dieses komplexe Thema in Deutschland veranstaltete das Institut für Museumskunde der Staatlichen Museen zu Berlin und der Arbeitsbereich Informationswissenschaft der Freien Universität Berlin im Jahr 1997 in Berlin einen Workshop mit dem Titel: Museumsbesuch im Multimedia-Zeitalter: Wie werden die neuen Medien die Optionen der Museen verändern? Dokumentation siehe Schuck-Wersig, Petra/Wersig, Gernot/Prehn, Andrea: Multimedia-Anwendungen in Museen. Berlin 1998.

60 Aufgrund der Komplexität der sich daraus ergebenden Fragestellung, kann ich im Rahmen der Ausstellungsanalyse in Kapitel sechs die eingesetzten Medien nicht im Detail analysieren. Zum Beispiel würde eine Auseinandersetzung mit der interessanten Frage nach dem Für und Wider von Audioguides im Vergleich zu Computerkonsolen als Infopools oder Raumtexten den Rahmen dieser Arbeit sprengen. Der Fokus meiner Studie konzentriert sich darauf, wie die Neuen Medien in den Gesamtkontext der Ausstellungsumwelt eingebunden sind. 


\section{Gegenwartsbezüge}

- Wie wird versucht, an die Interessen der Besucher anzuknüpfen?

- Wie werden Gegenwartsbezüge auf inhaltlicher und gestalterische Ebene hergestellt?

\section{Neue Medien}

- In welcher Form werden Neue Medien eingesetzt?

- Ist der Medienaufwand gerechtfertigt?

- Tragen die Neuen Medien zu einem besseren Verständnis bei?

\section{Besucherforschung}

- Wie wird der Besucher im Ausstellungskonzept berücksichtigt?

- Welchen Stellenwert nimmt Besucherforschung bei der Konzepterstellung ein?

\section{Ganzheit - Ausstellungsumwelten und ganzheitliche Erlebnisse}

Menschliches Erleben ist immer ganzheitlich, auch Momente des Unbewussten gehen damit einher. Das Psychische wird nicht nur von bewussten Erlebnissen bestimmt, sondern auch flüchtige und unauffällige Momente haben Einfluss auf das Erleben.

„Ganzheit bedeutet im Gegensatz zum zufälligen Nebeneinander oder zur additiven Häufung eine urtümliche Geschlossenheit, aus der sich die Bedeutung der integrierten Bereiche ableitet und die sich durch einen unauflöslichen Wirkzusammenhang auszeichnet. ${ }^{\text {c61 }}$

Die Forderung nach ganzheitlicher Betrachtung findet sich unter anderem in der Philosophie, Anthropologie, Psychologie, Pädagogik und Schulpädagogik. ${ }^{62}$ Die Ganzheitspsychologie geht davon aus, dass psychische Erscheinungen nicht als Aneinanderreihung von Elementen, sondern nur als einheitlicher Erlebniszusammenhang begreifbar sind.

61 Schröder, Hartwig: Didaktisches Wörterbuch. München 2001, S. 120.

62 Der Begriff Ganzheit (beziehungsweise Gestalt) hat als methodischer Begriff in der ersten Hälfte des 20. Jahrhunderts in vielen Wissenschaften als Alternative zu mechanistischen, atomistischen Erklärungsmodellen des 18. und 19.Jahrhunderts Eingang gefunden, so in der Medizin, Biologie, Psychologie, Soziologie und Pädagogik. Vgl. Bibliographisches Institut \& F. A. Brockhaus AG, 2001. 
Ähnliche Konzepte verfolgte die Gestaltpsychologie, die den Begriff der Gestalt in der Psychologie zum allgemeinen Prinzip erhob und im Bereich der Wahrnehmung, später auch in der Persönlichkeits- und Sozialpsychologie anwandte. Das ganzheitliche Erleben umfasst innere und äußere Momente. Dem integrativen Zusammenwirken der personalen Bereiche entspricht eine Integration innerer und äußerer Momente. Die ganzheitliche Erlebnisweise ist sowohl geprägt von personenabhängigen Faktoren als auch von Gegebenheiten der Außenwelt.

Dem ganzheitlichen Anspruch fühlen sich die Humanistische Pädagogik als eine Richtung in der Erziehungswissenschaft und die Humanistische Psychologie verpflichtet. Humanistische Pädagogik kann bis zu den Griechen zurückverfolgt werden. Eine Entwicklungslinie dieser Richtung betont, den Menschen als Einheit von Geist, Körper und Seele zu betrachten. Ziel der Erziehung ist es, diese Ganzheit zu fördern. Dieser Ansatz ist sehr oft mit einer Kritik der einseitigen Entwicklung und Betonung des Geistes oder der Vernunft, unter gleichzeitiger Vernachlässigung der Seele oder der Gefühle verbunden. ${ }^{63}$ Die Humanistische Pädagogik entwickelte ein grundsätzlich anderes Lernverständnis im Sinne persönlich bedeutsamen Lernens. „Wird dieser Ausgangspunkt gewählt, kann man von der Faszination Lernen im Sinne persönlich bedeutsamer Lernprozesse sprechen. “64 Es geht dabei um ganzheitliches Lernen, das mit Begriffen umschrieben wird, die in anderen psychologischen Theorien keinen systematischen Platz haben, so zum Beispiel persönliches Wachstum, Bewusstsein, Kontakt und Selbstaktualisierung. Die Bedeutung des Subjekts steht im Mittelpunkt, der Lernende wird als personale Einheit betrachtet. ${ }^{65}$ Ebenso wird der Stoff als Ganzheit aufgefasst. Ganzheitliche Stoffbetrachtung überwindet die fachspezifische Zersplitterung der Inhalte und stellt Lebenszusammenhänge in den Mittelpunkt.

Bezogen auf Ausstellungen umfasst Ganzheit somit drei Betrachtungsperspektiven, die wiederum ineinander verwoben sind. Dies meint zum einen den Besucher, dessen Erlebnis ganzheitlich ist. Ebenso geht es um die Inhalte der Vermittlung, in der es nicht nur um Vermittlung

63 Fatzer, Gerhard: Ganzheitliches Lernen: Humanistische Pädagogik und Organisationsentwicklung. Paderborn 1987, S. 18.

64 Gudjons, Herbert: Pädagogisches Grundwissen. Bad Heilbrunn 1995, S. 225.

65 In diesem Zusammenhang steht auch die von Pestalozzi aufgestellte, oft formelhaft zitierte Forderung nach ganzheitlicher Bildung des Menschen von Kopf, Herz und Hand. 
von kognitiven Wissensinhalten geht, sondern auch darüber hinaus Bewusstseinsbildung impliziert und auf Reflexion gezielt wird. ${ }^{66}$ Und als drittes bezieht sich Ganzheit auf die Gestaltung der Ausstellung einschließlich der gesamten Ausstellungsumwelt.

Falk/Dierking übertragen den Begriff Gestalt auf das Museumswesen. Sie sprechen von „The Museum as Gestalt“ und verweisen damit auf die äußeren Einflussfaktoren, die das Ausstellungserlebnis wesentlich mit beeinflussen (Falk/Dierking 1992, S. 83ff.). Der Besuch einer Ausstellung ist demnach ein hochkomplexes Ereignis, zu dem die bewusste aber auch unbewusste Interaktion mit der gesamten Ausstellungsumwelt gehört. Ein Ausstellungsbesuch beginnt bereits mit der Entscheidung, dieses zu tun. Auch die Anfahrt zum Ausstellungsort beeinflusst das Erlebnis. Weitere Faktoren sind das Verhalten des Museums- und Aufsichtspersonals und andere Ausstellungsbesucher, Orientierungshilfen vor Ort, der Zustand der Toiletten, Verköstigungsmöglichkeiten, Temperatur, Luftfeuchtigkeit, Gerüche und Fremdgeräusche. Auch innenarchitektonische Elemente wie zum Beispiel der Boden, die Decke, die Wände, Treppen, Türen und Fenster, Feuerlöscher, Klimageräte, Telefone und Lichtschalter spielen eine Rolle.

„The museum experience includes feelings of adventure, of awe, of affiliation with loved ones or friends, and of seeing, perhaps touching, and learning about new things.“ (ebd., S. 83)

Bedeutung ist im Museum nicht bloß auf die Interpretation der Ausstellung begrenzt. Eine positive Erfahrung im Café oder am Informationspult beeinflusst die Erlebnisqualität ebenso. Das Verhalten des Ausstellungsbesuchers wird somit maßgeblich auch durch Momente disponiert, die zunächst nichts mit dem Ausstellungsdesign zu tun haben. Auch der soziale Kontext, in dem eine Ausstellung besucht wird, ist entscheidend für die Dauer des Besuchs, das kommunikative Verhalten und die Intensität der Zuwendung zu den Objekten (Wohlfromm 2002, S. 37).

Die Berücksichtigung der psychischen und physischen Dispositionen erhält einen hohen Stellenwert. In diesem Zusammenhang wird oft das Schlagwort Museumsmüdigkeit zitiert. ${ }^{67}$ Ergebnisse der Besucherfor-

66 Siehe Kapitel 2.4.

67 Berühmt wurde eine Untersuchung von Benjamin Gilman, der 1916 einen Artikel über Museumsmüdigkeit veröffentlichte. Besucher wurden gebeten, Texte zu lesen. Von diesem Verhalten wurden Fotographien angefertigt, die zeigten, dass Texttafeln gelegentlich an sehr ungünstigen Stellen 
schung besagen, dass die meisten Menschen insgesamt nur eineinhalb Stunden für einen Besuch einschließlich der Zeit im Museumsshop und Lokal verwenden und dabei sehr schnell Museumsmüdigkeit entwickeln. Um diesem Vorgang entgegenzuwirken, bedarf es der Berücksichtigung der Bedürfnisse der Besucher, die sich während des Rundganges zum Beispiel auch hinsetzen und ausruhen wollen.

Eine ganzheitliche Gestaltung der Ausstellungsdramaturgie trägt dazu bei, das Interesse von Besuchern wach zu halten oder wieder aufzurütteln. Zur Illustration kann ein Vergleich mit einem Kinobesuch herangezogen werden. Im Gegensatz zum Kino, wo der Besucher sich im Ruhezustand befindet und eine Reihe von Bildern und Handlungen an sich vorüberziehen lässt, bewegt sich der Besucher einer Ausstellung durch den Raum. Er erzeugt durch seine Fortbewegung eine Wechselfolge von Szenen. Dieser Tatsache sollte die Gestaltung einer Ausstellung Rechnung tragen: Farben, Formen, Raumeinheiten, Decken in verschiedener Höhe, Flucht und Perspektive - alle diese Elemente entfalten sich im Laufe des Rundgangs. Aufgrund der Komplexität der Kombination aus inhaltlichem und gestalterischem Anspruch sowie der Berücksichtigung des potentiellen Publikums scheint es durchaus berechtigt, von Ausstellungen als Gesamtkunstwerken zu sprechen. Belcher spricht von „exhibitions as an art form" und zieht einen Vergleich zu dreidimensionalen Kompositionen.

„Exhibitions are conceived as sculpture. They are three dimensional compositions which recognize the importance of solids and voids and strive for satisfactory spatial relationships. It is sculpture which people are encouraged not

angebracht waren und dies das Lesen sehr erschwerte. Gillman, B. I.: Museum fatigue. In: Scientific Monthly (1916) Heft 11. S. 62-74.

Die Bezeichnung Museumsmüdigkeit fand jedoch bereits früher Anwendung. Dem im Jahr 1900 eröffneten Bayerischen Nationalmuseum wurde große Bewunderung entgegengebracht. Gelobt wurde, dass dieses aufgrund der künstlerischen Originalität von Bau und Einrichtung Anregungen und Genuss statt strenger, wissenschaftlicher Arbeit ermöglicht. In Artikeln aus dem Jahr 1900 wurden herkömmliche Museumsbauten und Präsentationsformen kritisiert, demgegenüber wurde das Bayerische Nationalmuseum als positives Beispiel gelobt. Vgl. Koch, Michael: Das Museum als Gesamtkunstwerk. Gabriel von Seidls Neubau im Spiegel der Kritik. In: Bauer, Ingolf (Hrsg.): Das Bayerische Nationalmuseum. Der Neubau an der Prinzregentenstraße 1892 - 1900. München 2000, S. 215, Anm. 41. 
only to look at but also to walk in and explore. It is environmental art, which offers a whole range of experiences which may stimulate all the senses." 68

\section{Fragen an die Ausstellung - Ganzheit}

\section{Ausstellungsmüdigkeit - Ausstellungsumwelt}

- Wie kann sich der Besucher topographisch mit Wegweisern, Plänen, Raumlayout orientieren? Wie kann sich der Besucher intellektuell orientieren mit Vorinformation, Überschriften, Faltblättern, Saalzetteln, Katalogen, AV-Programmen und dergleichen?

- Wie wird die Atmosphäre durch das Aufsichts- und Kassenpersonal geprägt? Ist es höflich und hilfsbereit?

- Wird auf psychische und physische Voraussetzungen geachtet, wie Körperhaltung, Betrachtungswinkel, Höhe, Ermüdung, Frustrationstoleranz, aber auch Alter und Behinderung?

- Gibt es genug Bewegungsraum und Ruhemöglichkeiten?

- Wie ist das Raumklima?

- Wie wirkungsvoll ist die Beleuchtung, ist es zum Beispiel hell genug, um die Beschriftung gut lesen zu können?

- Gibt es außerhalb der Ausstellungsräume ein kulinarisches Angebot?

- Wird die Ausstellung auch während der Laufzeit gepflegt?

- Funktionieren die Medienstationen, sind Beschriftungen abgelöst oder abgenutzt?

\section{Ausstellungsdramaturgie}

- Wie ist der rote Faden in der Gesamtgestaltung?

- Sind dramaturgische Kriterien bei der Aufbereitung des Stoffes berücksichtigt?

- Wie ist das Material geordnet? Werden Überlastungen vermieden?

- Ergibt die Gliederung eine nachvollziehbare Reihenfolge?

- Ergibt die Auswahl von Objekten sowie inszenatorischen Elementen ein stimmiges Ganzes? Ziehen Lichteffekte, Farben und Töne die Aufmerksamkeit auf sich? Hat dies etwas mit dem Inhalt der Ausstellung zu tun?

68 Belcher, Michael: Exhibitions in Museums. Washington 1991, S. 41. 


\section{Differenzierung - die Offenheit der Interpretation und die Heterogenität des Publikums}

Differenz ist ein Schlüsselbegriff der modernen, insbesondere französischen Philosophie und des Konstruktivismus. Differenz verweist auf Vielfalt, Pluralität, Widersprüche und auch auf die Anerkennung von Unterschieden. Differenzwahrnehmung verdeutlicht die Beobachtungsabhängigkeit von Wirklichkeit, die Einsicht, dass die eigene Perspektive nicht die einzige ist. Im Hinblick auf meine Studie soll mit dieser Bezeichnung primär auf zwei Aspekte verwiesen werden. Zum einen deutet dies auf die Offenheit der Interpretation hin und markiert die Tatsache, dass es nicht nur eine Sichtweise oder Wahrheit gibt, sondern diese immer in Abhängigkeit von Kontexten entsteht. Zum anderen zielt Differenzierung auf konkrete methodische Maßnahmen als Antwort auf die Heterogenität des Publikums und dessen unterschiedliche Voraussetzungen und Bedürfnisse.

„Differenzen sind Unterscheidungen, die einen Unterschied machen. Differenzen gewährleisten eine Dynamik, eine Offenheit von Wirklichkeiten. Differenzen fördern Neugier, das Interesse am anderen. Sie sind gleichsam die Hefe in Lehr- und Lernprozessen, sie provozieren, fordern zum Nachdenken und zum Überprüfen der eigenen Position heraus.“69

Differenzen verweisen auf das Andersartige und auch das Fremde. Dies kann irritierend sein und vielleicht sogar auf Ablehnung stoßen. ${ }^{70} \mathrm{Im}$ Hinblick auf die Durchführung von Veranstaltungen in der Erwachsenenbildung stellt Siebert fest, dass Seminare ohne Differenzen zwar angenehm und sozialemotional befriedigend sein mögen, lernintensiv sind diese jedoch selten. Ein übermäßiger Wunsch nach Harmonie und Übereinstimmung ist zwar gruppendynamisch verständlich, jedoch nicht unbedingt erkenntnisfördernd (Siebert 1999, S. 95).

Eine Aufgabe für Kustoden besteht nach Ansicht von Rauterberg vor allem darin, Offenheit zu bewahren und auch den Zweifel am eigenen

69 Siebert, Horst: Pädagogischer Konstruktivismus. Eine Bilanz der Konstruktivismusdiskussion für die Bildungspraxis. Neuwied/Kriftel 1999, S. 94.

70 Dies ist ein elementarer Aspekt, wenn es um die Frage der Abgrenzung kommerzieller Erlebniswelten von musealen Ausstellungen geht. Siehe Kapitel 4.3: Differenzierender Kontext: Akzentuierung - Offenheit - Irritation. 
Tun nicht auszublenden. Ein Ausstellungsstück sollte nicht nur ein Bild, sondern immer viele Bilder wachrufen. „Auf Bipolarität von Logik und Magie, ganz im Sinne Aby Warburgs, auf Bedeutungszwitter, in denen Ordnung ebenso aufgehoben ist wie Irrationalität, ließe sich ein neues Selbstverständnis gründen." (Rauterberg 2002, S. 40) Dies fordert einen freien Blick auf die Wissenschaften, die Freude an der Kontroverse und eine Leidenschaft, mit der sich die Verantwortlichen dem Unauflösbaren, dem Ambivalenten widmen.

Am Beispiel historischer Museen, die sehr oft nach einem chronologischen Darstellungsmuster gegliedert sind, lässt sich das Anliegen nach Offenheit und Kontroverse verdeutlichen. Geschichtliche Ereignisse werden in Ausstellungen sukzessiv aneinandergereiht. Die methodische Genesis der dargestellten Geschichte bleibt jedoch in den historischen Museen meist unsichtbar.

„Zeitliche Vor- und Rückgriffe zum Zwecke des Vergleichs und der Spannungssteigerung wie im Kriminalroman kommen kaum vor, Parallelhandlungen und Kontrastreihen sind äußerst selten. Es dominiert meistens die Monotonie des bloßen Nacheinanders." (Parmentier 2003, S. 6)

Auch wenn das wissenschaftliche Personal des Museums bereit ist, die Verfahrensweisen vor wissenschaftlichem Fachpublikum offen zu legen, geschieht dies in der Ausstellung vor Publikum sehr selten. Dadurch bleibt nicht nur das konstruktive Moment an der Geschichtsdarstellung verborgen, sondern auch ihr wissenschaftlicher, das heißt prinzipiell hypothetischer Charakter. Diese methodische Undurchsichtigkeit der Museen äußert sich auch in dem weitverbreiteten Verzicht, wissenschaftliche Kontroversen zu präsentieren. Der wissenschaftliche Streit als organisierendes Prinzip einer musealen Geschichtsinszenierung wird selten dramaturgisch genutzt. Divergierende Hypothesen über die objektiven Gründe, die Motive und Folgen historischer Ereignisse werden in der Ausstellung bestenfalls in Nebenräumen und Nebensätzen gezeigt, kritisiert Parmentier (ebd., S. 6).

Mit der methodischen Undurchsichtigkeit korrespondiert eine Tendenz in Ausstellungen, geschlossene Erzählformen anzuwenden, die dazu neigen, das historische Geschehen in übersichtliche Einheiten zu verpacken und diese mit einem klaren Anfangs- und Enddatum zu versehen. Im Gegensatz dazu hält sich jedoch die Wissenschaft nicht an abgeschlossene Einheiten. „Sie sieht ihre Aufgabe nicht darin, den vorgefundenen Bau fertigzustellen, sondern den Bauplan zu prüfen und seine Re- 
vision zu ermöglichen.“ (ebd.) Die dem problemorientierten Habitus der Wissenschaft angemessene Form der Geschichtsdarstellung ist deshalb die offene Erzählung. Sie stilisiert die historischen Ereignisse nicht zwanghaft zu geschlossenen Abläufen, sondern lenkt die denkende Betrachtung auf das fragmentarische Szenario der vorliegenden Indizien. Das Interesse der Wissenschaft gilt den offenen Fragen, den rätselhaften Dokumenten, den fragwürdigen Zeugen. „Sie scheut die feste Perspektive und verliert sich gelegentlich im Sammelsurium aus vergessenem Kram.“(ebd., S. 7)

Dieses Interesse am Rätselhaften und Fragwürdigen lässt sich auf mögliche Themen übertragen, es bedeutet aber auch eine Offenheit im Hinblick auf unterschiedliche Interpretationsformen. Die künstlerische Sichtweise und Interpretation sind beispielsweise Formen des Umgang mit dieser Offenheit. ${ }^{71}$

Differenzierung in Ausstellungen als methodisches Vorgehen bedeutet eine bewusste Anerkennung der individuellen Unterschiede der Besucher im Hinblick auf deren Interessen und Erfahrungen. Diese bilden zentrale Faktoren bei Zielbestimmung, Inhaltsauswahl und Methodengestaltung. Wie ein Ausstellungsführer sich auf sprachlicher Ebene seinen Zuhörern anpasst - bei Kindern wird er andere Worte wählen als bei einem Fachpublikum - kann analog die visuelle Sprache der Ausstellungsarchitektur variiert und ein differenziertes Angebot geschaffen werden. Die Frage, inwieweit bereits mit der Ausstellungsarchitektur zielgruppenspezifisch vermittelt werden kann, spielt aktuell jedoch noch eine untergeordnete Rolle bei der Neukonzipierung von kulturhistorischen Ausstellungen. Das gezielte Ansprechen unterschiedlicher Besuchergruppen dient auch dazu, neue Besuchergruppen zu erschließen, die mit traditionellen Präsentationsformen nicht erreicht werden können. Vitali sieht es aktuell als elementare Aufgabe, insbesondere jene Gesellschaftsgruppen anzusprechen, die nicht bereits aufgrund ihres Bildungshintergrundes ohnehin in Ausstellungen gehen.

„Es geht am Beginn des dritten Jahrtausends um nicht mehr und nicht weniger als die Frage, ob es genügt, dass das Museum jenen Schichten der Bevölkerung zugänglich ist, die sich schon immer ohne Schwierigkeiten darin zurechtgefunden haben, oder ob es erforderlich ist, heute dringlicher denn je, diese Basis ebenso entschlossen wie radikal zu verbreitern und die Akzeptanz

71 Ausführungen zu Formen künstlerischer Interpretationen siehe Kapitel 3.3: Künstlerischer Ansatz. 
des Museums zu einer allgemeinen, in der ganzen Gesellschaft verankerten Institution auszubauen und auch die Menschen an das Museum zu binden, die weder im Elternhaus noch in der Schule das nötige Rüstzeug für eine intensive und sachkundige Beschäftigung mit der Kunst erhalten haben, ja den Versuch zu machen, ihnen diese Instrumentarien im Museum selber zu vermitteln.“"72

Differenzierung kann auf mehreren Ebenen durchgeführt werden. Zum einen kann zwischen äußerer und innerer Differenzierung unterschieden werden. Eine Form konsequenter, äußerer Differenzierung auf institutioneller Ebene stellen die Kinder- und Jugendmuseen dar, die sich mit den speziellen Bedürfnissen dieser Zielgruppe befassen. Im Rahmen der Museenlandschaft bilden sie eine eigene Gattung. ${ }^{73}$ Kindermuseen werden von den Museen für Erwachsene abgekoppelt und als spezielle Erlebniswelten für Kinder entwickelt. Dieses erleichtert einerseits die konsequente kindgerechte Umsetzung, da Bedürfnisse einer definierten Zielgruppe befriedigt werden sollen. Für Weschenfelder/Zacharias ist diese Entwicklung jedoch auch Ausdruck einer Reaktion auf die methodenarme, inhaltsreduzierte und an den Bedürfnissen der Kinder vorbeigehende Museumspädagogik. ${ }^{74}$ Die Entscheidung für einen speziellen Erlebnisort für Kinder kann jedoch auch mit Schwierigkeiten verbunden sein: „Absonderung, mangelhafte inhaltliche Kooperation, Streit über Etatfragen, Hierarchisierung der pädagogisch und wissenschaftlichen Abteilung und Mitarbeiter usw." ${ }^{\text {"75 }}$

$\mathrm{Zu}$ bedenken ist auch die Tatsache, dass zwischen Eltern und Kindern zunehmend weniger Kommunikation stattfindet. Gerade diese zu fördern, sollte auch Anliegen musealer Ausstellungen als Orte der Kommunikation sein. Ausstellungen, die sowohl unterschiedlichen Zielgruppen als auch anspruchsvollen, wissenschaftlichen Zielsetzungen ge-

72 Vitali, Christoph: Mein ideales Museum. In: Schneede Uwe M. (Hrsg.): Museum 2000 - Erlebnispark oder Bildungsstätte. Köln 2000, S. 103.

73 In Deutschland ist dies eine im internationalen Vergleich relativ junge Entwicklung. Die ältesten Kinder- und Jugendmuseen wurden zwar bereits in den siebziger Jahren des vergangenen Jahrhunderts gegründet, aber erst in den neunziger Jahren gelang es den Initiatoren, diese Museen für Kinder stärker zu etablieren (König 2002, S. 10). Die Idee dieser Museen reicht hundert Jahre zurïck, erste Projekte dieser Art wurden in Amerika gegründet.

74 Vgl. Weschenfelder, Klaus/Zacharias, Wolfgang: Handbuch Museumspädagogik. Orientierung für die Praxis. Düsseldorf 1981, S. 363.

75 Liebertz, Charmaine: Kunstdidaktische Aspekte in der Museumspädagogik - Entwicklung und Gegenwart. Weinheim 1988, S. 251. 
recht werden wollen, können sich allerdings nicht ausschließlich auf die Interessen von Kindern und Jugendlichen konzentrieren. In dieser Hinsicht ist die Etablierung von Kindermuseen zu begrüßen.

Eine zweite Form äußerer Differenzierung bildet das sogenannte $D i$ daktische Kabinett. ${ }^{76}$ Kernpunkt der Diskussion ist die Frage nach einer möglichen Konkurrenz zwischen Objekt und didaktischer Beifügung. ${ }^{77}$ Zur Vermeidung dieses Konflikts gibt es neben einer Hauptausstellung einen eigenen Bereich, der sich unter einem bestimmten Thema ausschließlich der Vermittlung widmet. Charakteristikum des Ansatzes ist eine vorwiegend nach ästhetischen und fachlichen Klassifikationskriterien gestaltete Präsentation, in der weitere Zusatzinformationen als Störfaktor empfunden werden, zu belassen und eine die Sammlung erläuternde Begleitausstellung anzubieten. Auf diese Weise soll dem interessierten Laien ebenso Rechnung getragen werden wie der Aura der Objekte und dem in kontemplativer Versenkung verweilenden Kenner.

„Unter didaktischen Kabinetten verstehen wir direkt an die Schausammlungsräume angrenzende und dennoch von ihr räumlich abgetrennte, kleinere, leicht zugänglich, offene Nischen oder Nebenräume, die unter Einsatz alternativer oder komplementärer Medien wie Texte, exemplarische Originale, Fotos, Neue Medien nach didaktischen Prinzipien gestaltet werden und sich auf den umgebenden Ausstellungsbereich beziehen. Wesentliches Merkmal ist ihre relative räumliche Abschottung vom eigentlichen Ausstellungsbereich.“"78

Ein wesentlicher Vorteil dieser didaktischen Kabinette liegt darin, dass fachwissenschaftliche und didaktische Überlegungen nicht in Konkurrenz treten und somit eventuelle Kommunikationsprobleme im Ausstellungsteam nicht entstehen können, da die Kompetenzbereiche klar voneinander getrennt sind. Dennoch ist diese Vorgehensweise kritisch zu betrachten, da die voneinander abgekoppelten Präsentationen die Verknüpfung der Information mit den Objekten erschwert. Auch besteht die

76 Erstmals sehr erfolgreich wurde diese Idee in Nürnberg im Jahr 1971 mit dem ausstellungsdidaktischen Experiment „Dürer Studio“ verwirklicht. Siehe Kapitel 3 S. 101, Anm. 10/11.

77 Dies verweist auch auf den Konflikt zwischen historischer und ästhetischer Erfahrung. Siehe Kapitel 2.3

78 Hoffrichter, Horst: Kommentierende Bildbeschriftungen, didaktische Kabinette und präferierte Informationsbereiche in Kunstmuseen. In: Klein, Hans-Joachim (Hrsg.): Kunstrezeption - kühle Annäherung an ein heißes Thema. Karlsruhe 1992, S. 32. 
Gefahr, dass zwar ein Didaktikraum eingerichtet wird, dieser inhaltlich jedoch keine Objektbezüge herstellt. ${ }^{79}$

Die Einrichtung von Studien- und Leseräumen mit einem Angebot an Computerstationen, Fachzeitschriften und -literatur bilden eine weitere Form, wie Ausstellungen den unterschiedlichen Ansprüchen der Besucher gerecht werden können. Dieser Studienraum ist wie das didaktische Kabinett von der Hauptausstellung abgekoppelt und bietet dem Interessierten die Möglichkeit zum vertiefenden Nachlesen und Recherchieren.

Im Gegensatz hierzu stellt die innere Differenzierung die weit größere und schwierigere Herausforderungen für die Ausstellungsmacher dar, da dies bedeutet, dass die verschiedenen Mitarbeiter im Team in komplexer Weise zusammenarbeiten müssen. Die Ausstellung soll so konzipiert sein, dass bereits dadurch unterschiedliche Zielgruppen angesprochen werden. Die Umsetzung dieses Anspruches bedeutet in der Praxis, dass Vermittlung eine zentrale Größe darstellt und kommunikative Strategien im Ausstellungskonzept Berücksichtigung finden. Innere Differenzierung lässt sich in vielfältiger Weise denken. Differenzierung im Hinblick auf die Heterogenität des Publikums bedeutet die Beachtung unterschiedlicher Lerntypen und die Schaffung eines dementsprechend variantenreichen Angebots. ${ }^{80}$

Über eine Staffelung der Informationsebenen können Besucher individuell entscheiden, wie tief gehend sie sich mit dieser Thematik befassen wollen. Eine konsequente Hierarchie in drei Informationsebenen wurde im Haus der Geschichte in Bonn realisiert. Die erste Ebene bilden auf jeder Ausstellungsebene - parallel zum chronologischen Fortgang der Geschichte - vier bis fünf Großeindrücke, die den Weg des Besu-

79 Mit dem Argument, ein besseres Verständnis der Ausstellung „Otto der Große Magdeburg und Europa“ zu ermöglichen, richteten die Ausstellungsmacher den Didaktikraum „Lebenswelten vor 1000 Jahren“ ein. An Stellwänden im Stil von sogenannten Lesetapeten erhielt der Besucher allgemeine Informationen zu Lebenswelt, Herrschaft und Klöstern. An diesen Bereich gliederte sich ein Mitmachbereich an, in dem Besucher Tätigkeiten eines frühmittelalterlichen Schreibers haptisch nachvollziehen konnten. Außerdem konnte das Publikum in einem „ComputerVisualistik-Raum“ verschiedene Varianten der Rekonstruktion der ottonischen Pfalz in Magdeburg erleben. Diese unterschiedlichen Angebote existierten nebeneinander, ohne inhaltliche oder objektbezogene Verknüpfungen zur eigentlichen Ausstellung herzustellen.

80 Zwei Beispiele lerntheoretischer Modelle und ihre Nutzanwendung im Museum siehe Kapitel 1, S. 57ff. 
chers begleiten. Auf der zweiten Informationsebene befinden sich bedeutsame Exponate und Objektensembles, die visuelle Großeindrücke konkretisieren. Die dritte Informationsebene führt den Betrachter über Einzelobjekte und Dokumente zu einer tiefer gehenden Beschäftigung mit den Inhalten. Damit wendet sich die Ausstellung an die Mehrfachbesucher und an jene, die mit einem spezifischem Interesse kommen. Dieses Gliederungsprinzip wird auch in der Textstruktur aufgegriffen. GroBe Thementexte mit deutlichen Schlagworten führen die Besucher auf komplexe Oberbegriffe hin, kleinere Thementexte ermöglichen die Beschäftigung mit Einzelthemen, Objekttexte erlauben vertiefende Beschäftigung. Auch der Einsatz audio-visueller Medien folgt diesem Aufbau. Permanent laufende oder sensorgesteuerte Film- und Tondokumente geben erste Informationen auf kongnitiver sowie affektiver Ebene, selektiv abrufbare Beiträge wählt der Interessierte aus, interaktive und gruppeninteraktive Medien regen zur vertiefenden Information und Diskussion an. ${ }^{81}$

Obwohl Kinder und Familien eine wichtige Zielgruppe bilden, werden diese bei der Konzepterstellung oft vergessen. Eine Möglichkeit sie zu erreichen, kann darin bestehen, ein spezielles Angebot zum Beispiel in Form eines Kinderpfades entlang des Ausstellungsrundganges zu schaffen. In den Ausstellungsräumen befinden sich Stationen, die zum Beispiel mittels kindgerechter Texte das jüngere Publikum einladen, ausgewählte Objekte genauer zu betrachten, oder unter Aktivierung aller Sinne zu Handlungen motivieren. Ein Vorteil, didaktische Elemente als Angebot für Kinder auszuweisen, besteht darin, dass das fachwissenschaftlich kritische Publikum eher bereit ist, Dinge zum Anfassen, Riechen und Hören zu akzeptieren, wenn dies als Kinderschiene deklariert ist. Tauchen sehr viele spielerische Elemente im Gesamtparcours auf, kann dies dazu führen, dass der primär Geschichtsinteressierte an der Seriosität der Ausstellung im Gesamten zweifelt. ${ }^{82}$

81 Haus der Geschichte der Bundesrepublik Deutschland (Hrsg.): Erlebnis Geschichte. Das Buch zur Ausstellung. Bonn 2000, S. $14 \mathrm{ff}$.

82 Kritisch angemerkt sei, dass ein Kinderparcours nicht nur eine Alibifunktion nach dem Motto ,,auch an die Kinder wurde gedacht“ erfüllen sollte. Auch bei der Konzipierung des Angebots für Kinder gibt es qualitative Maßstäbe. Es geht nicht nur darum, isolierte Stationen als Art Kinderinseln im Rundgang aufzustellen, sondern ein grundlegendes Element besteht darin, Verknüpfungen mit ausgewählten Exponaten und Inhalten herzustellen. 


\section{Fragen an die Ausstellung - Differenzierung}

\section{Offenheit der Interpretation}

- Werden unterschiedliche Perspektiven der Interpretation wahrgenommen? (zum Beispiel Künstlerperspektive)

- Ist der konstruktive Charakter der Interpretation offensichtlich?

- Gibt es herausfordernde Momente, die Irritation oder Widerspruch bewirken?

- Werden traditionelle Sehgewohnheiten gebrochen?

\section{Heterogenität des Publikums}

- Gibt es institutionelle Grundsätze, Rahmenbestimmungen, die richtungsweisend für die Ausstellungsmacher sind, zum Beispiel welche Besuchergruppen sollen besonders angesprochen werden?

- In welcher Form findet äußere und innere Differenzierung statt?

- Wie wird die Heterogenität des Publikums berücksichtigt?

- Wird auf kleine Menschen, Kinder, Rollstuhlfahrer Rücksicht genommen? Werden unterschiedliche Bildungsvoraussetzungen und Interessenslagen berücksichtigt?

- Wird auf unterschiedliche Lerntypen Rücksicht genommen?

- In welcher Gewichtung werden speziell museumspädagogische Elemente angeboten? Wie werden diese in den Kontext eingebunden?

- Gibt es Möglichkeiten zur inhaltichen Vertiefung, zum Beispiel unterschiedliche Informationsebenen, selektiv abrufbare Informationen? 


\subsection{Strategien besucherorientierter Präsentationen}

Im Folgenden sollen besucherorientierte Ansätze vorgestellt werden, in denen der potentielle Besucher als entscheidende Größe das Konzept beeinflusst. Diese Ansätze bilden ein Pendant zu objektorientierten Präsentationen, da die meist in traditionellen Kunstmuseen praktizierte Form weitgehend auf zusätzliche Vermittlungsmedien in der Ausstellung verzichtet. In Abgrenzung zum erstem Kapitel, in dem eine Typologisierung nach dem äußeren Erscheinungsbild aufgestellt und zwischen den grundlegenden Kategorien rekonstruktiver und abstrahierender Raumbilder unterschieden wird, erfolgt nun eine Darstellung von Präsentationsstrategien mit dem Fokus auf die inhaltliche Gliederung des Materials. Die Exponate können nicht nur nach fachwissenschafltlichen Kriterien geordnet werden, sondern auch erzählerische, künstlerische oder partizipatorische Aspekte können dabei maßgeblich sein. In der Praxis bedeutet dies, dass der verantwortliche Kurator nicht zwingend ein Fachwissenschaftler ist, sondern aus einer anderen Berufsgruppe stammen kann. An führender Stelle steht dann zum Beispiel ein Künstler oder Museumspädagoge, der die inhaltlichen Leitthemen vorgibt. Die Themenwahl bedeutet eine erste grundlegende Weichenstellung. Hier setzen bereits erste kommunikative Überlegungen ein. Während der Wissenschaftler seine Fragen aus der Disziplin, der Historie und dem Sammlungsbestand des Museums bezieht, stellen für den Museumspädagogen neben der Alltagskultur auch gesellschaftspolitische Fragen und Aktualitätsbezug mögliche Anknüpfungspunkte dar. ${ }^{83}$

In meinen Ausführungen stelle ich drei Präsentationsstrategien vor. Dabei unterscheide ich zwischen dem narrativen, dem künstlerischen und dem partizipativen Ansatz. Im weitesten Sinne stehen diese stellvertretend für die drei personellen Kompetenzen, aus denen sich das klassische Ausstellungsteam zusammensetzt: der Fachwissenschaft, der Ges-

83 Eine Auflistung von Gedankensplittern, die die Themenwahl beeinflussen vgl.: Jürgensen, Frank/Schemm von Jürgen: Gedankensplitter aus dem Workshop „Themenfindung“. In: Breithaupt, Julia/Joerißen, Peter: Museumspädagogen machen (andere?) Ausstellungen. Publikation im Anschluß an die Jahrestagung der Arbeitsgemeinschaft der deutsch sprechenden Mitglieder der CECA im ICOM. Erlangen/Nürnberg 1986, S. 38. Der Titel der Publikation wurde mit einem Fragezeichen versehen und verweist darauf, dass die Übergänge zwischen museumspädagogischen und fachwissenschaftlichen Ansätzen fließend sind. Trennscharfe Konturen konnten damals nicht aufgezeigt werden. 
taltung und der Pädagogik. Bei den drei Ansätzen tritt jeweils eine Leitkompetenz in den Vordergrund. Im narrativen Ansatz steht nach wie vor die Darstellung der Historie und so auch die Fachwissenschaft im Vordergrund, jedoch unter Berücksichtigung einer dramaturgisch-erzählerischen Komponente. Mit dem künstlerischen Ansatz wird die historisch-wissenschaftliche Perspektive zu Gunsten einer subjektiven Interpretation verlassen. Der Künstler übernimmt die Aufgabe eines Kurators. Der partizipative Ansatz bemüht sich um Integration des potentiellen Publikums.

\section{Narrativer Ansatz}

Die narrative Methodik der Ausstellungsgestaltung gründet auf der Überzeugung, dass isolierte Exponate Hintergründe nicht erschließen können, sondern die Einbindung in einen illustrierenden Kontext notwendig ist. Mit der erzählerischen Umsetzung findet insbesondere die emotionale Komponente Berücksichtigung. Diese Methodik bildet eine populäre Form der Geschichtsdarstellung für ein primär nicht akademisches Publikum. Damit entwickelte sie neue kulturwissenschaftlich orientierte Fragestellungen, in denen traditionelle Klassifizierungen überschritten werden. ${ }^{84}$

Unter dem Begriff Historisches Erzählen wird zunächst die alltägliche sprachliche Form, in der Geschichte sich artikuliert, verstanden. Hierin manifestiert sich eine Form des Geschichtsbewusstseins. ${ }^{85}$ Historische Erzählungen treten in sehr unterschiedlichen, meist unfertigen und fragmentarischen Formen auf, deren Gemeinsamkeit darin besteht, dass ein Zeitverlauf in der Vergangenheit berichtet wird. Dieser Bericht erfolgt stets in einer kommunikativen Situation, in der ein Erzähler seinen Zuhörern die Vergangenheit vergegenwärtigt, die aus unterschiedlichen Gründen für die Gegenwart wichtig ist. Mit der Frage, welche unterschiedlichen Formen der historischen Erzählung es gibt und welche für

84 Die Spannung zwischen universitärer Historiographie und populärer Geschichtsschreibung ist eine alte Kontroverse zwischen Gelehrten und Literaten, die seit dem 1900 Jahrhundert neue Intensität gewonnen hat. Hardtwig befasst sich in seinem Buch unter anderem mit der wissenschaftlichen Diskussion, ob Geschichte als Wissenschaft oder Kunst aufzufassen sei. Vgl. Hardtwig, Wolfgang: Geschichtskultur und Wissenschaft. München 1990.

85 Rüsen, Jörn: Historisches Erzählen. In: Bergmann 1997, S. 57. 
die Vermittlung von Geschichte fruchtbar gemacht werden können, befasst sich die Geschichtsdidaktik. Das Erzählen von Geschichten erfuhr in den sechziger und siebziger Jahren schwere didaktische Angriffe. Wichtige Kritikpunkte waren unter anderem, dass die Geschichtserzählung verharmlose und romantisiere; sie vermittle einen linearen Verlauf der Geschichte, die Ereignisse monokausal erkläre. Das Erzählen könne manipulative Kraft entfalten, ohne dass sich die Zuhörer dessen bewusst seien. Bei der Wiederbelebung der Methode des historischen Erzählens im Geschichtsunterrichts in den achtziger Jahren war man sich dieser kritischen Punkte bewusst:

„Sie darf nicht zu unzulässigen Vereinfachungen führen, also nicht zu einer Repersonalisierung in Form einer Nichtbeachtung von Strukturen, nicht zur Redramatisierung der Geschichte (wie überhaupt das Inszenierungsmoment, das allem Erzählen innewohnt, mit großer Behutsamkeit zu handhaben ist), vor allem nicht zu einer Vernachlässigung oder gar zu einem Rückschrauben der Fähigkeit zu abstraktem Denken.“ ${ }^{86}$

Im Anschluss an Arthur C. Danto, der eigentliche Inaugurator der narrativen Theorie, weist Schörken darauf hin, dass die Bedeutung der Erzählung nicht notwendig nur in der Veranschaulichung bestehe, dass sie vielmehr ihrem Wesen nach bereits auch eine Form der Erklärung sei (ebd., S. 139). Hiermit wird die traditionelle Vorstellung verlassen, dass sich die Leistung der Geschichtserzählung im Geschichtsunterricht darin zeigt, vergangene Zeiten ausschmückend und emotionalisierend zu veranschaulichen und zu vergegenwärtigen. Das Erzählen wird nicht einfach nur als niederer Modus kindertümlichen Erklärens dargestellt, sondern als logisches Schema, das den Kern der Wissenschaftlichkeit der Geschichtswissenschaft ausmacht.

„Historische Erklärungsmuster und erzählende Beschreibung bilden ein unauflösbares Ganzes, weil eine Erzählung nicht nur ein Vorkommnis erklärt, sondern Auskunft darüber gibt, was innerhalb einer bestimmten Zeitspanne vorgefallen ist." (ebd., S. 139ff.)

Die Geschichtserzählung erfüllt damit keineswegs primär die Funktion von Veranschaulichung oder Vergegenwärtigung „der Buntheit oder der Lebensprallheit" (ebd.), sondern die Funktion der Erklärung. Folglich kann sie nicht einfach als kindertümelnd, elementarisierend, ausschmü-

86 Schörken, Rolf: Geschichte erzählen heute. In: Niemetz, Gerold: Aktuelle Probleme der Geschichtsdidaktik. Stuttgart 1990, S. 138. 
ckend oder harmonisierend an die Peripherie des didaktischen Interesses geschoben werden. Die große Fülle von Erscheinungsformen des historischen Erzählens in den verschiedenen Bereichen und in den verschiedenen Zeiten und Kulturen, die von der stereotypen Alltagsfloskel bis hin zur fachwissenschaftlichen Abhandlung reichen, verlangt nach einem begrifflichen Instrumentarium, mittels dessen sie analysiert und interpretiert werden kann. Verschiedene Typologien des historischen Erzählens wurden entwickelt. ${ }^{87}$ Eine Typologie nach den Charakteristika der Erinnerung, Kontinuität, Identität und Sinn entwarf Rüsen. Er unterscheidet idealtypisch vier Arten des historischen Erzählens, die nie rein vorkommen, dennoch aber wesentliche Bestandteile der unterschiedlichen Manifestationen des Geschichtsbewusstseins sind.

Traditionelles historisches Erzählen erinnert an die Ursprünge, die gegenwärtige Lebensverhältnisse begründen. Es stellt Kontinuität als Dauer dieser verpflichtenden Ursprünge vor. Es bringt Identität durch Affirmation vorgegebener Deutungsmuster. Die Orientierungsfunktion wird durch Geschichten erfüllt, die nicht in Frage gestellt werden, sondern mit Einverständnis in die Gegenwart transportiert werden. Durch traditionelles Erzählen wird Zeit als Sinn verewigt. Beispiele hierfür sind Ursprungsmythen, herrschaftslegitimierende Genealogien oder Rückblicke an Jubiläen.

Exemplarisches historisches Erzählen erinnert an Sachverhalte der Vergangenheit, die Regeln gegenwärtiger Lebensverhältnisse konkretisieren. Es stellt Kontinuität als Geltung dieser Regeln vor, die zeitlich verschiedene Lebensordnungen umgreifen. Dies bewirkt Kommunikation in der Form einer Argumentation mit Urteilskraft. Dieser Erzähltyp wird durch die klassische Devise historia magistra vitae charakterisiert. Dies sind zum Beispiel Geschichten, die Vorbilder präsentieren, die eine bestimmte moralische Sichtweise vertreten oder Einsichten in politische Prinzipien vermitteln. ${ }^{88}$

Kritisches historisches Erzählen erinnert an Sachverhalte der Vergangenheit, von denen aus gegenwärtige Lebensverhältnisse in Frage gestellt werden können. Es stellt Kontinuität dar, jedoch nicht als lineare

87 Einen Einblick über verschiedenen Typologisierungen siehe Rüsen 1997, S. 59ff.

88 Rüsen merkt an, dass eine Reihe von Indizien dafür spricht, dass dieser Erzähltyp, der seine kulturelle Dominanz seit der Entstehung des Historismus verloren hat, nach wie vor als Sinnbildungsmuster des historischen Denkens im Geschichtsunterricht der Schule angewendet wird (ebd.). 
Entwicklung, sondern unter Berücksichtigung unterschiedlicher Perspektiven, und bewirkt Kommunikation in Form einer Abweisung und Abgrenzung von Standpunkten. Durch kritisches Erzählen werden die in den Kontinuitätsvorstellungen enthaltenen Identitätszuschreibungen hinterfragt. Beispiele dafür sind Geschichten, die eingefahrene historische Klischees und Überlieferungen empirisch widerlegen oder Geschichten, die die traditionelle Legitimation dadurch in Frage stellen, dass sie auf historische Erfahrungen verweisen, die den legitimierenden Kontinuitätsvorstellungen widersprechen.

Genetisch historisches Erzählen erinnert an qualitative Veränderungen in der Vergangenheit, die andere und fremde Lebensverhältnisse in eigene und vertraute münden lassen. Es bewirkt Kommunikation in Form diskursiver und reflexiver Beziehung von Standpunkten aufeinander. Damit bringt es Identität als Synthese von Dauer und Wandel. Herkunft und Zukunft werden in der Form einer qualitativen Differenz auseinander gehalten. Geschichten, die diesem Typ nahe kommen, bringen ein dynamisches Moment in die historische Orientierung der menschlichen Lebenspraxis.

Diese vier unterschiedlichen Typen des traditionellen, exemplarischen, kritischen und genetischen Erzählens können nach Ansicht von Rüsen als Entwicklungsphasen des Geschichtsbewusstseins verstanden werden (Rüsen 1997, S. 62)

Schörken weist darauf hin, dass jedoch die Entwicklung eines kritisch verstehenden Verhaltens ebenso bedeutsam sei. Dies bedeutet, eine Sensibilisierung für die suggestive Wirkung von Erzählungen zu wecken. Aus diesem Grund müssen in den glatten Oberflächen des Erzählten „Bruchstellen für kritische Eingriffe“ vorhanden sein (Schörken 1994, S. 126). Historische Erzählungen erwecken, ohne es zu beabsichtigen, leicht die illusionäre Erkenntnis, so und nicht anders sei es gewesen. Die historische Wirklichkeit erscheint dann als etwas, das identisch mit dem Erzählten ist, die Fiktionalität der Erzählung wird vergessen. Zur Vermeidung dieser Problematik fordert Schörken erzählerische Methoden, die Anknüpfungspunkte für Fragen nach der Richtigkeit oder Angemessenheit evozieren. Als mögliche Erzählformen schlägt er Erzähltypen wie das transponierende Erzählen, perspektivische Erzählen, zeitverschobene Erzählen, opponierende Erzählen und verfremdende und identifizierende Erzählen vor (ebd., S. 127). Diese Vorschläge haben nichts gemein mit der traditionellen, novellistischen Geschichtserzählung mit ihren negativen Begleiterscheinungen, sondern verweisen auf die große Bandbreite möglicher alternativer Erzählformen. 
Die didaktischen Überlegungen über die Rolle des Erzählens bei der Vermittlung von Geschichte finden auch ihre Nutzanwendung beim Entwurf von Ausstellungskonzepten. Das Museum verfährt bei seiner Präsentation ähnlich wie die narrative Form der Geschichtsdarstellung. Die res factae müssen sich mit den res fictae verbinden, um historische Anschauung bei einer Ausstellung zu bewirken (Korff 1999, S. 331). Das Ausstellungsspezifische ist in erster Linie das Erzählen von Geschichten anhand ausgewählter authentischer Objekte. Diese Objekte erzählen zunächst ihre eigenen Geschichten, wie zum Beispiel „die durchschossene Glocke des Dußlinger Gemeindedieners, der beim Ausschellen von Durchhalteparolen im April 1945 von den Maschinengewehren eines Tieffliegers tödlich getroffen wurde. “ 89

Narrative Präsentationskonzepte jedoch sind in der Regel eingebunden in eine Gesamtdramaturgie, die konzeptionell einen Leitgedanken verfolgt. „Narrative exhibitions usually have a story line as organising principle. In order to move away from systematic arrangements a booklike pattern was introduced.“ (Mensch 2001, S. 8) Sie beziehen sich auf historische Sachverhalte, doch werden neben traditionellen Gliederungsschemata, wie die chronologische Ordnung, auch andere Lösungsmöglichkeiten der Gliederung des Materials gesucht. Die perspektivierende Darbietung löst zum Beispiel die an Prinzipien der Dokumentation orientierte Systematisierung der Quellen auf. Statt notwendig eindeutigen Zuweisungen an die Rubriken eines vorgegebenen Gliederungsschemas soll die Mannigfaltigkeit der Bezugsfelder der Dingwelt sichtbar gemacht werden.

„Sie erinnert dann daran, daß die Sachüberreste in der Regel ganz unterschiedlichen Zusammenhängen zugehören bzw. zugeordnet werden können und insofern weniger auf eine Geschichte als auf mannigfaltige Geschichten Geschichten beispielsweise der Bedürftigkeit, des Produzierens, der Nutzung, des Repräsentationsverlangens - oder auf Geschichten auch wirtschaftlicher und sozialer Situation hinweisen.“90

Beim Übertragen des narrativen Ansatzes auf Ausstellungskonzeptionen fordert Roberts, nicht nur die historischen Interessen der Fachwissen-

89 Haus der Geschichte Baden-Württemberg in Stuttgart (Hrsg.): Landesgeschichten. Der deutsche Südwesten von 1790 bis heute. Stuttgart 2002, S. 12.

90 Deneke, Bernward: Realität und Konstruktion des Geschichtlichen. Frankfurt/New York 1990, S. 76. 
schaftler zu berücksichtigen, sondern auch die Besucherperspektive und deren Geschichten und Fragestellungen, die bei der Begegnung mit den Objekten entstehen könnten, in Betracht zu ziehen und in Konzepte aufzunehmen. Dabei bezieht sie sich in ihrer Argumentation auf die These, dass die Aussagen der Historiker nicht als Wahrheit verabsolutiert werden könnten und auch deren Darstellungen als Formen von Erzählungen zu werten seien. Aus diesem Grund erhalten auch die Erzählungen der Besucher Legitimität als eine weitere Form des Blicks auf die Geschichte. $^{91}$

Wichtige Ausstellungshäuser in Deutschland, deren Dauerausstellung auf einem narrativem Konzept basiert, sind das Haus der Geschichte der Bundesrepublik Deutschland in Bonn sowie das Jüdische Museum in Berlin. Einzelne Aspekte der Konzepte sowie Kritikpunkte seien im Folgenden kurz vorgestellt.

Ausgehend von der Annahme, dass kein Objekt für sich spricht, besteht das Anliegen der Ausstellungsmacher des Hauses der Geschichte in Bonn darin, die jeweiligen Objekte in der Ausstellungssituation ,zum Sprechen zu bringen“.92 Dafür helfen klare Kriterien bei der Auswahl der Exponate. Sie sollen Besucher anziehen und fesseln und vor allem zur Kommunikation anregen.

„Gewiß beinhaltet jedes von ihnen für sich eine bestimmte Aussagekraft, doch entfaltet sich ihr Kommunikationspotential insgesamt erst überzeugend durch die Einordnung in den spezifischen historischen Kontext und im Zusammenhang mit einer visuellen Rhetorik auf Grundlage klar definierter Gestaltungsvorgaben, die selbst ihr Fundament im konzeptionellen Kontext haben. $\mathrm{Zu}$ diesem Ziel werden die Objekte - kleine und große, beiläufige und bedeutende, private und staatliche - in Szene gesetzt.“ (ebd., S. 13)

Die einzelnen Exponate werden in größere Zusammenhänge gestellt, die Charakteristisches oder Besonderheiten der jeweiligen Themata hervorheben sollen. Die Flut der historischen Informationen und der entsprechend zahlreichen Exponate wird in Ausstellungsszenen gebündelt, die

91 Roberts, Lisa C.: From Knowledge to Narrative. Educators and the Changing Museum. Washington D. C./New York 1997, S. 131ff.

92 Schäfer, Hermann: Erlebnis Geschichte - Eine neue Ausstellung für neue Besucher. In: Haus der Geschichte der Bundesrepublik Deutschland (Hrsg.): Erlebnis Geschichte - Das Buch zur Ausstellung. Bonn 2000, S. 13. 
sich auch dem eiligen Besucher erschließen sollen (siehe Abb. 7). Die konkrete Umsetzung vollzog sich in drei Schritten: Strukturierung des Raumes, Gliederung der Ausstellungseinheiten und Zusammenstellung der Objektensembles. Jeder Zeitabschnitt erhielt sein eigenständiges architektonisches Gefüge. In seiner Ausstellungsgestaltung - in Formen, Materialien und Farben - soll damit ein Grundgefühl der jeweiligen Epoche vermittelt werden. Das Konzept folgt der Idee, Geschichte in einer Weise zu präsentieren, die eigene Erinnerung und Emotionen weckt, aber auch Anlass zu Fragen und Diskussion gibt.

„Wir stellen nicht nur die Geschichte von Konferenzen, Verträgen und Persönlichkeiten aus, sondern versuchen, die historische Entwicklung aller Aspekte des Lebens in Deutschland nachzuzeichnen. Die Politik ist dabei der rote Faden, und Bundestagswahlen dienen als chronologische Wegmarken. Überreste der Politik-, Wirtschafts-, Sozial-, und Kulturgeschichte werden nicht isoliert aufgereiht, sondern in ihrem thematischen Zusammenhang in Szene gesetzt. Erfahrungsberichte und Lebensläufe von Zeitzeugen illustrieren Geschichte und verleihen ihr Leben." ${ }^{\text {‘93 }}$

Nach der Eröffnung im Jahr 1994 erhielt das Haus der Geschichte für die Ausstellungsgestaltung unterschiedlichstes Echo. Es reichte von begeistertem Lob bis zu Fundamentalkritik. Vor allem aber wegen seiner Präsentationsform, die in großem Maßstab Inszenierungen und Medienstationen erstmals in einer zeitgeschichtlichen Dauerausstellung einsetzte, bekam es durchweg positive Beurteilungen.

„Gelobt wurde auch der Pluralismus in der Darstellung, die nicht nur die groBe Politik herausstellt, sondern auch die Protestbewegung der Bundesrepublik einbezieht. “94

Das Haus erfreut sich konstant enorm großer Besucherresonanz. ${ }^{95}$ Schäfer, Direktor des Hauses der Geschichte, beobachtete, dass Bewertungen umso kritischer ausfielen, je historisch vorgebildeter sich das Publikum selbst einschätzte, um so positiver, je mehr es sich um „Alltagsmen-

93 Schäfer, Hermann: Zwischen Disneyland und Musentempel: Zeitgeschichte im Museum. In: Museumskunde 60. (1995) Heft 1. S. 32.

94 Vgl. Glass, Christian: „Aber es soll kein Museum werden“. Die Häuser der Geschichte in Deutschland. In: Museumskunde 66. (2001) Heft 1/01. S. 118.

95 Innerhalb von zehn Jahren besuchten sechs Millionen Menschen das Haus der Geschichte der Bundesrepublik Deutschland. 
schen“ handelte (Schäfer 1995, S. 31). Scharf ablehnende Kritik erfolgte zum Beispiel von dem Historiker Hans Mommsen, der in der Dauerausstellung eine inhaltsleere Selbstbespiegelung anstelle einer wirklichen politischen Analyse sah. Der Erfolg des Museums sei seiner Ansicht nach darauf zurückzuführen, dass die Öffentlichkeit ,im Umgang mit Geschichte ziemlich unkritisch und geistlos geworden" sei. ${ }^{96}$ Auch Michael Fehr, Direktor des Karl Ernst Osthaus-Museums, lehnt diese für ihn aufdringliche Form der Präsentation ab. „Denn man ist in ihr immer wieder nur mit gewissermaßen laut Sieh mich an!-rufenden Einzelheiten konfrontiert." Insbesondere kritisiert er die eindimensionale Darstellung, die „das Dickicht unterschiedlicher Interessen, Ansichten und Stile“ ausklammert und so nur „Oberflächen historischer Daten und Ereignisse präsentiert." Die vielbeschworene vertiefende Beschäftigung stellt er generell in Zweifel. ${ }^{97}$ Auch kritisiert er die mangelnde Offenheit der Darstellung, da die Ausstellungsmacher glauben,

,[...] verbindlich vorführen zu können, wie alles einmal war, anstatt auf die historischen Subjekte, die Besucher, ihr Gedächtnis, ihr Wissen, ihre Ansichten und ihre Mündigkeit zu setzen und anhand von Exponaten zu demonstrieren, wie unterschiedlich bestimmte Ereignisse oder Daten von verschiedenen Gruppen innerhalb der Bevölkerung gesehen oder erfahren wurden oder werden können.“ (ebd.)

Die Dauerausstellung des im Jahr 2001 eröffneten Jüdischen Museums in Berlin basiert ebenfalls auf einem narrativem Konzept. Die erzählte Geschichte umfasst zwei Jahrtausende deutsch-jüdischer Geschichte. Die weitgehend chronologische Erzählung führt die Besucher von den frühesten Anfängen bis in die heutige Zeit. Es veranschaulicht das Leben jüdischer Gemeinschaften und Einzelpersonen, ihre Beziehungen zu den Nachbarn und ihre Lebensweise. ${ }^{98}$ Das Erzählkonzept des Jüdischen Museums wurde von Wissenschaftlern entwickelt. Der Projektdirektor Ken Gorbey distanziert sich jedoch von einer dauerhaften Allgemein-

96 Mommsen zitiert in Reinle, Dominik: „Die Geschichte läuft weiter“. Bonner Haus der Geschichte feiert zehnjähriges Bestehen. Bericht vom 14.06.2004.In: http://www.wdr.de/themen/kultur/1/haus_der_geschichte/ index.jhtml (letzter Zugriff: 10.02.05).

97 Fehr, Michael: Nicht mein Haus, nicht meine Geschichte. Ein Kommentar zum Haus der Geschichte in Bonn. In: http://www.keom.de/kuenstler/ texte/nicht_mein_haus.html (letzter Zugriff: 16.07.04).

98 Stiftung Jüdisches Museum Berlin (Hrsg.): Geschichten einer Ausstellung. Zwei Jahrtausende deutsch-jüdische Geschichte. Oldenburg 2001, S. 20. 
gültigkeit der Interpretation, indem sich das Museum als Forum versteht, welches zur Diskussion ermutigen, unterstützen und anregen und „nicht so sehr als Darsteller einer offiziellen Geschichtsversion“ fungieren solle. ${ }^{99}$

Ähnlich wie beim Haus der Geschichte in Bonn teilten sich die Beurteilungen des Jüdischen Museum in Berlin nach Eröffnung in zwei Lager. Einerseits kann das Museum sehr hohe Besucherzahlen aufweisen und erhält vom breiten Publikum positive Resonanz. ${ }^{100}$ Demgegenüber steht die zum Teil heftig ablehnende Kritik der Fachwissenschaftler, die sowohl auf inhaltliche wie auch gestalterische Aspekte abzielt.

„Die jüdische Kultur erscheint als Nebeneinander von Strömungen, kaum einmal als Schauplatz von Polemik, Streit. Wir begegnen Siegfried Kracauer und Franz Rosenzweig, aber nicht Kracauers scharfer Kritik an Rosenzweigs und Bubers Neuübersetzung der Bibel. Den Mangel an solchen Ecken und Kanten füllt die Ausstellung mit überbordenden Materialfluten zu den jüdischen Warenhäusern Wertheim und KaDeWe, zur AEG, zu den Juden in der Presse und auf dem Theater.“101

Statt die allgegenwärtige Knappheit an Exponaten zur Konzentration zu nutzen, wichen die Ausstellungsmacher in die Beliebigkeit aus. Wefing kritisiert, dass die wenigen vorzüglichen Stücke, die das Museum besitzt, in diesem großen Durcheinander verloren gehen.

„Die mittlere Sensation beispielsweise, die die Präsentation des konstantinischen Dekrets aus der sonst so zugeknöpften Vatikanischen Bibliothek bedeutet, wird hart bedrängt von der Banalität des künstlichen Granatapfelbäumchens nebenan, in dessen Krone läppische Kleinstmonitore blinken. “"102

99 Gorbey, Ken: Das Jüdische Museum Berlin. Der Auftrag, das Publikum, das erzählerische Konzept. In: Museumskunde. 66. (2001) Heft 2/01 S. 75.

100 Im Jahr 2003 haben rund 660.000 Besucher das Jüdische Museum Berlin besichtigt - ebenso viele wie im Jahr 2002. „Die hohen Besucherzahlen bestätigen, dass sich das Jüdische Museum als eines der beliebtesten Museen der Hauptstadt etabliert hat.“ Vgl. http://www.jmberlin.de (letzter Zugriff: 27.07.04).

101 Müller, Lothar: Der strenge Gott der Didaktik. Original und Fälschung: Das Jüdische Museum in Berlin. In: Süddeutsche Zeitung vom 11.09.01.

102 Wefing, Heinrich: Wo die Fülle den Mangel nicht verhüllen kann. Die Dauerausstellung im Jüdischen Museum Berlin. In: Museumskunde. 66. (2001) Heft 2/01. S. 78. 
Er sieht in diesem populären Zugang einen Weg, der nirgendwohin führt. „In dem Strudel von Schnipsel und Splittern werden alle Thesen unscharf, geht jede Tiefe verloren.“ (ebd.) Dieser Kritik schließt sich Gudehus an, indem er bemängelt, dass trotz einer vorbildhaften Abteilung für Besucherforschung, die beispielsweise die Les- und Verstehbarkeit der Texte überprüft, die Frage nach den Inhalten und danach, ,,was denn tatsächlich in den Köpfen bleibt“, nicht gestellt worden ist. Dieses mit qualitativen Methoden zu erforschen, erscheint ihm als lohnendes Ziel. $^{103}$

Wefings Zitat zu der Problematik der Gegenüberstelllung von hochwertigsten Exponaten und illustrativem Beiwerk spiegelt den bereits mehrfach erwähnten Konflikt zwischen historischer und ästhetischer Erfahrung wider. Diese Problematik liegt generell narrativen Ansätzen zugrunde, da der Fokus der Ausstellungsmacher sich nicht nur auf die Exponate richtet, sondern auch die Besucher und deren Rezeption als relevante Größe in das Konzept miteinfließen.

Die zwei vorgestellten Beispiele dienen der Illustration narrativer Ansätze. In der kurzen Beschreibung können diese nur schlaglichtartig beleuchtet werden. Die kritischen Kommentare liefern lediglich einen facettenhaften Eindruck geprägt von Subjektivität. Beim Haus der Geschichte in Bonn zeigte sich dies sogar in widersprüchlichen Bewertungen desselben Sachverhalts, indem einerseits Glass darauf verweist, dass der Pluralismus in der Darstellung gelobt wurde und andererseits Fehr gerade das Festschreiben verbindlicher Interpretationen kritisiert. Trotz punktueller Kritik von Seiten der Fachwissenschaft kristallisiert sich heraus, dass beide Häuser mit ihrem narrativen Ansatz vom breiten Publikum akzeptiert werden und somit das Ziel, unterschiedlichste Bevölkerungsschichten anzusprechen, erreicht haben.

103 Gudehus, Christian P.: Was bleibt, zählt. Kritische Überlegungen zum Jüdischen Museum Berlin. Ausstellungsbesprechung vom 24.01.02. http://www.vl-museen.de/aus-rez/gudehuso2-1htm (letzter Zugriff: 08. 02.02) 


\section{Künstlerischer Ansatz}

Mit der künstlerischen Interpretation wird die wissenschaftliche, vor allem also die historische Perspektive verlassen. In den Vordergrund treten die Künstlerpersönlichkeit und deren subjektive, kreative Sichtweise. Insbesondere Künstler können sich, was anderen Interpreten von Sinneswelten nicht erlaubt ist, der leidenschaftlichen Subjektivität hingeben. Die Künstler dürfen nach Belieben mit Alltagswelten verfahren, wie es ihnen zur Deutung der Erscheinungsformen der Welt richtig erscheint. ${ }^{104}$ Plessen findet für diese Formen der Präsentation, in der das Prinzip Leidenschaftlichkeit bestimmend ist, den Begriff Autorenmuseum. In der Subjektivität der Ordnungskriterien sieht Plessen eine Analogie zu der Tradition der Kunst- und Wunderkammern der ausgehenden Renaissance, die die Welt nach artefacta, naturalia und meraviglia um ihrer Besonderheit willen ordneten (ebd., S. 181). ${ }^{105}$

Die künstlerische Zusammenstellung von Dingen und die Inszenierung trivialer und wertvoller Gegenstände haben eine lange kulturhistorische Tradition. ${ }^{106}$ Erweitert man den Begriff des Ausstellens von Dingen um die Dimension der Architektur, eröffnet sich das 18. und 19. Jahrhundert als Quelle temporär inszenierter Festarchitekturen. Verantwortlich hierfür waren in erster Linie die Weltausstellungen, welche in der

104 Plessen, Marie-Louise von: Das Duell der Sinne und der Dinge - das Autorenmuseum. In: Korff/Roth 1990, S. S. 179.

105 Die Kunst- und Wunderkammern entstanden im Europa des 16. Jahrhunderts, als vornehmlich die fürstlichen Höfe von der Sammelleidenschaft ergriffen wurden. Gesammelt wurde nicht nur Kunst, sondern alles, was der Zeit wesentlich erschien und darum ein Interesse beanspruchte: Gemälde, Kupferstiche und Plastiken gehörten natürlich hinein, ebenso aber Bücher aller Wissensgebiete, Münzen und Medaillen, astronomische Geräte, Globen und Atlanten, Skelette, Fossilien und Mineralien sowie bis an die Grenze der technischen Möglichkeiten vorgetriebene Drechselarbeiten aus Elfenbein, kunstvoll gravierte Straußeneier, kostbar gefasste Kokosnüsse und noch vieles mehr. Die Kostbarkeiten sind unterteilt in naturalia (Naturalien) - Werke der Natur - und artificialia (Artefakte) von Menschenhand Geschaffenes. Ihre Vielfalt spiegelt das Bestreben wider, in der Kunstkammer das Universum im Kleinen festzuhalten. Vgl. http://www.kunstkammer.at/index1.htm (letzter Zugriff: 10.02.05).

106 Einen gut zusammengefassten Überblick zur Ausstellungsarchitektur im 20. Jahrhundert siehe Werner, Frank R.: Raum-Zeiten und Zeit Räume: Ephemere Architektur im Spiegel der Geschichte. In: Werner 1999, S. 12-35. 
Folge der ersten Großveranstaltung im Jahr 1851 dazu tendierten, ,ihrem novitätensüchtigem Publikum einen stetig anwachsenden Fundus technologischer Neuerungen anschaulich zu präsentieren." (Werner 1999, S. 13). Mit dem einsetzenden 20. Jahrhundert und seinen weitreichenden weltpolitischen Ereignissen verwandelten sich Ausstellungen unterschiedlichster Art in Ausdrucksträger ideologischer Botschaften unter Einsatz künstlerischer Inszenierungen. Politische Botschaften, medial umgesetzt, wurden vorübergehend „,bedeutender als die Authentizität bzw. die gesellschaftlich ausgrenzende Aura sakrosankt präsentierter Wertobjekte" (Werner 2001, S. 13). Eine Vorreiterrolle übernahm die junge Sowjetunion. Teils unter freiem Himmel, teils in eigens hierfür geschaffenen fliegenden Bauten, teils in alten Feudaleinrichtungen errichtet, sind die Inszenierungen heute nicht mehr existent, trotzdem jedoch aufgrund der Erzählkraft und der auf das Wesentlichste reduzierten politischen Ikonographie außergewöhnlich. El Lissitzkys Sowjetpavillon „Pressa“ auf der Internationalen Presseausstellung 1928 in Köln ging aufgrund der spektakulären Ausstellungsgestaltung in die Architekturgeschichte ein. El Lissitzky wollte das schwierige Thema Kommunikation für jedermann nachvollziehbar und anregend darstellen.

„In einer fulminanten Raum-Zeit-Collage, bestehend aus Photomontagen, skulpturalen Objekten, dreidimensionalen Kulissen, rotierenden Apparaten und ausgeklügelten Lichteffekten bediente sich Lissitzky erstmals in der ungeschriebenen Geschichte großer Ausstellungen kinematischer Mittel.“ (ebd., S. 15)

Sehr innovativ experimentierten während der Weimarer Republik Künstler des Bauhauses auf dem Gebiet der Ausstellungsgestaltung in Kooperation mit dem Deutschem Werkbund. Namhafte Vertreter waren Walter Gropius, Herbert Bayer sowie Lilly Reich. Gearbeitet wurde mit offenen Raumkonzepten, mit Groß-Collagen und Objekt-Montagen. Auch Wand und Boden wurden in die Gestaltung miteinbezogen. Herbert Bayer setzte sich zum Beispiel mit unterschiedlichen Betrachtungsperspektiven auseinander und entwickelte Anschauungskonzepte für günstige Sehwinkel. ${ }^{107}$ Eine Zäsur in der theatralischen Darstellungsund Inszenierungskunst brachte die ideologische Vereinnahmung durch

107 Vgl. Staniszewski, Mary Anne: The Power of Display - A History of Exhibition Installations at the Museum of Modern Art. Cambridge/ London 1998, S. 26ff. 
die Nationalsozialisten. ${ }^{108}$ Dies führte zunächst in den fünfziger und sechziger Jahren zu einer strengen „zisterziensischen Selbstdisziplin“ im Ausstellungswesen (Werner 2001, S. 19). Der italienische Architekt Carlo Scarpa entdeckte das Thema der kunstvollen Inszenierung neu und widmete einen Großteil seines Werkes der Ausstellungsarchitektur.

„Er interpretierte Vergangenheitszeugnisse vielmehr als eine Serie von Objekten, die er zu Helden episch angelegter, selbstverfaßter Dramen oder, etwas weniger freundlich ausgedrückt, zu Versatzstücken ausgeklügelter DesignRapporte machte.“ (ebd., S. 21)

Eine ganze Reihe von Künstlern hat sich seitdem mit Präsentationsstrategien, mit der Rolle der Künstler im Museumswesen und mit den Besuchern künstlerisch auseinandergesetzt. Es entstand eine Vielzahl unterschiedlichster Konzepte, die zum Teil an die Museumssystematik angelehnte Konzepte verfolgten oder völlig andere Wege in der Arbeit mit den Ausstellungsräumen oder Exponaten beschritten. ${ }^{109}$ Die Grenzen zwischen kulturhistorischer Präsentation und Kunstinstallation verschwimmen. ${ }^{110}$ Der Künstler wurde zum Erfahrungsgestalter.

„Die Totalinstallation der Surrealisten war nicht nur eine Negation der Galerieausstellung, sondern sie leitete die Besucher zu einer umfassenden sinnlichen Wahrnehmung durch die Erregung und Fesselung von Begierden, durch die scheinbare Gefährdung, den Geruch, die Geräusche und schließlich durch

108 Weitere Ausführungen hierzu siehe Kapitel 4, S. 188ff.

109 Stellvertretend sei auf zwei Bücher, in denen Künstler sowie Ausstellungen vorgestellt werden, verwiesen. Das von Michael Fehr herausgegebene Buch „Open Box - Künstlerische und wissenschaftliche Reflexion des Museumsbegriffs“ (Köln, 1988) stellt eine große Anzahl von Künstlerarbeiten vor, die sich auf unterschiedlichste Weise mit dem Museum und seinen Mechanismen beschäftigen oder seine Techniken für die Entwicklung eigener Konzeptionen nutzen. In einem weiteren Teil des Buches setzten sich Autoren auf wissenschaftlicher Ebene mit dem Museumsbegriff auseinander. Die Publikation von James Putnam „Art and Artifact: The Museum as Medium“ (New York, 2001) gibt mit 280 Abbildungen von Ausstellungen einen umfangreichen Überblick zur künstlerischen Auseinandersetzung mit der Institution Museum, insbesondere mit dem System Ausstellung, der Rolle des Künstlers und der dadurch veränderten Rolle der Besucher.

110 Einen Überblick zur Entwicklung der Kunstinstallation mit zahlreichen Abbildungen Vgl.: Oliveira, Nicolas de/Oxley, Nicola/Petry, Michael/ Archer, Michael (Hrsg.): Installation Art. London 1996. 
das Visuelle. Es handelt sich hier um die Erfindung der Erlebnisausstellung im Bereich der Kunst.“111

Unter dem Einfluss der Postmoderne entwickelte zum Beispiel Hans Hollein in den achtziger Jahren zwei Großausstellungen zu kulturgeschichtlichen Themen, nämlich zum einen im Jahre 1982/1983 „Die Türken vor Wien. 1683 - 1983“, zum anderen im Jahre 1984/85 „Traum und Wirklichkeit, Wien 1870 bis 1930“. Das Innere manifestierte sich Raum für Raum und unter Einbeziehung zahlreicher Rekonstruktionen gleichsam als filmischer Zeitraffer, der alle Sinne ansprach und nicht nur die kulturgeschichtlichen Artefakte, sondern auch Stimmungen und Strömungen thematisierte.

„Die blutbefleckte Uniform, in der Franz Ferdinand in Sarajewo ermordet wurde, konfrontiert mit Klimts Kuß. Mit einem Augenschlag kann das Auge Egger-Lienz's Namenlose, Winterhalters Porträt der Kaiserin Sissi und Klimts Beethoven-Fries kombinieren. Von den Exponaten des Karl-Marx-Hofes aufschauend - und Mahlers Fünfte Symphonie im Ohr - wird man mit Hanaks brennenden Menschen konfrontiert. Sigmund Freuds Behandlungscouch und Wittgensteins, Tractatus' begegnen sich über Raum und Zeit hinweg als zwei Pole intellektueller Inspiration.“ (Werner 2001,. S. 25)

Es sollte nicht nur Information vermittelt werden, sondern vor allem Atmosphäre, die den Geist der jeweiligen Epoche traf. Der Ausstellungstitel „Traum und Wirklichkeit“ sollte eine komplexe Dialektik collagenähnlicher Konfrontationen und Kollisionen begünstigen. Hans Hollein betrachtet seine Arbeit als spirituelle und technologische Angelegenheit für psychologische und physische Zwecke. Er begreift Architektur sowie Ausstellungsgestaltung als integriertes Ganzes. Im Unterschied zur herkömmlichen Auffassung, die im Kunstwerk das Ziel sieht, betrachtet Erfahrungsgestaltung „die Installation als Mittel zur Auslösung eines Erfahrungsprozesses“" (Bätschmann 1997, S. 232). Dies impliziert den Wandel des Publikums zum aktiven Partner. Dieser schwierige Vorgang richtet sich, wie Bätschmann feststellt, auf Partizipation und Einbezug durch Einladung, Verlockung, Überwältigung, Schock und Gefährdung. Künstlerische Interpretationen verlangen vom Betrachter, sich mit den Dingen eigenständig auseinander zu setzen, da gattungsgeschichtliche Kriterien fehlen, nach denen innere Bezüge durch Beschriftungsformeln hergestellt werden können. Die Betrachter müssen

111 Bätschmann, Oskar: Ausstellungskünstler - Kult und Karriere im modernen Kunstsystem. Köln 1997, S. 190. 
diese Bezüge selbst herstellen, „die Enträtselung selber vollziehen, am inneren Dialog der Dinge aktiv teilnehmen“" (Plessen 1990, S. 181). In der Forderung, Stellung zu beziehen, sieht Plessen einen großen Vorteil von Autorenmuseen gegenüber normalen Präsentationen. Wenn die Präsentation der Künstler gelungen ist, lässt es den Besucher nicht gleichgültig, weil sie über die bloße Dokumentation hinauswächst und den Betrachter in ihre Erzählweise einbeziehen will.

Künstlerische Interpretationen stellen sowohl für die Museumsmitarbeiter als auch für die Künstler eine spezielle Herausforderung dar, da unterschiedliche Gedanken- und Vorstellungswelten aufeinandertreffen. Wesentlich für das Gelingen eines solchen Projektes ist die intensive Auseinandersetzung der Wissenschaftler mit den Künstlern, so dass beide Seiten voneinander genau wissen, welche Vorstellungen und Ziele zugrunde liegen. Ein Vorteil für die Künstler besteht darin, dass sie nicht wie die Wissenschaftler in fachwissenschaftlichen Kriterien denken und zudem nicht in die Museumshierarchie eingebunden sind. Als Künstler engagiert fällt es ihnen unter Umständen leichter, festgefahrene Strukturen innerhalb von Museumshierarchien aufzubrechen. Die Gründe für die Beauftragung von Künstlern mit der Neuaufstellung der Sammlung sind vielfältig. Zum einen soll durch Aktionen die Attraktivität einer Dauerausstellung wieder belebt werden, in der pragmatischen Hoffnung, damit neue Besucherschichten zu erreichen.

„The reason for engaging contemporary artists are often linked to a new way of looking: to offer new meaning, draw an emotional response, give visitors a different perspective. Another common rationale is the challenge: to shake up the reminiscence factor of the reconstructed scene, to question the reality portrayed in displays. And then there is the wish to bring the contemporary into museums: to make collections relevant and accessible to today's visitor, to counter museum stereotypes." ${ }^{112}$

Außerdem erhoffen sich die Kuratoren durch die ungewöhnliche Art der Präsentation eine Neuinterpretation. Aufgrund der in der Regel fehlenden fachwissenschaftlichen Prägung gehen Künstler mit dem Museumsbestand freier, ungezwungener und schöpferischer um als ein Fachexperte. Wenn Künstler beauftragt werden, kann dies zu einer fruchtbaren Auseinandersetzung „Zwischen den eingefrorenen Wiederbelebungsversuchen der Museologen und dem ungebrochenen und daher unbeein-

112 Latimer, Sue: Artistic licence. In: Museums Journal 101. (2001) Heft 8. S. 30. 
flussten Künstlerauge“ führen. (Plessen 1990, S. 185). Damit können Fragen an die Dinge neu formuliert, Spannungen zwischen den Objektgattungen neu erstellt und Zuordnungen nach anderen Kriterien geschaffen werden. Die wissenschaftliche Exaktheit tritt in den Hintergrund, die materielle Aussage gewinnt an Bedeutung. In einer postmodernen Umwelt, die aus Furcht vor Verlust der eigenen Erinnerung den Drang hat, alles zu bewahren und zu ordnen, besticht das Autorenmuseum nach Ansicht von Plessen durch Unordnung jenseits von Gattungen. Es schafft damit eine neue Welt der Sinnlichkeit, die anregend auf die Phantasie der Betrachter wirkt. Martin fordert Museumskuratoren auf, sich von alten, autoritären Begründungsmustern zu verabschieden, die davon ausgehen, dass alles rational erklärbar sei. Für ihn gibt es ein „Mysterium der Schöpfung und die Künstler wissen meist mehr darüber als die Wissenschaftler"113 (Martin 2002, S. 9).

Hartwig sieht einen wesentlichen Unterschied zwischen der künstlerischen und der historischen Arbeitsweise darin, dass der Nachlass für eine andere Wahrnehmungsform als die historische präsentiert wird. In dieser Wahrnehmungsform ist Platz für einen Überschuss, den der ordnende historische Blick nicht registriert. Die Blicke des Historikers sind von einem Interesse geleitet, das sich auf bereits vorhandene Ordnungssysteme bezieht.

„Es sind Blicke auf das, was ein Messer, eine Kaffeekanne, ein Stein, ein Dokument stellvertretend für viele andere Dinge und soziale Zusammenhänge bedeuten und aussagen kann. Sein Blick sucht nach Bedeutungen, die einen bereits erkannten Zusammenhang illustrieren können." ${ }^{114}$

Gesichert sind museale Bedeutungen durch die Erkenntnisse der Wissenschaften, die den Hintergrund für die Entfaltung von Sinnbeziehungen von Gegenständen bilden. Im Gegensatz dazu präsentieren Künstler Gegenstände in Ordnungen, die ,nicht vorgängig gesichert sind, auch wenn er sich in seiner Präsentation auf vorgegebene Ordnungen bezieht" (ebd.). Ein wichtiges Kriterium für künstlerische Elemente ist für Hartwig, dass ein Verunsicherungsfaktor in der Wahrnehmung auftritt. Dies

113 Martin, Jean-Hubert/Til, Barbara/Zeisig, Andreas: Künstlermuseum. Bogomir Ecker, Thomas Huber. Eine Neupräsentation der Sammlung des museum kunst palast. Düsseldorf 2002, S. 9.

114 Hartwig, Helmut: Spurensicherung zwischen historischer und ästhetischer Praxis. In: Bätz, Oliver/Gößwald, Udo (Hrsg.): Experiment Heimatmuseum. Berlin 1988, S. 100-105. 
bedeutet eine Sinnverschiebung weg vom Historischen und von den durch die Fachwissenschaft gesicherten Ordnungen. Gleichzeitig schränkt Hartwig jedoch ein, dass durch diese Offenheit und möglicherweise sogar Verantwortungslosigkeit künstlerischer Produktionsweisen gegenüber vorgegebenen Ordnungen auch eine Unvereinbarkeit mit der historischen Aufklärungsarbeit entsteht (ebd., S. 102). Bei der Reflexion über den Grenzbereich der Zusammenarbeit von Künstler und Historiker geht es darum, die eigenständige Art von Kreativität der Sinnproduktion anzuerkennen, wenn der Künstler nicht nur als effektiver Designer beansprucht werden soll. Es muss der künstlerischen Arbeit die Chance gegeben werden, im Kontext des historischen Ensembles Gefühle, Wahrnehmungen und Erkenntnisansätze zu erzeugen, die nicht durch die Daten der wissenschaftlichen Forschung abgesichert sind. Das bedeutetet jedoch nicht gleichzeitig, dass dies sich unwissenschaftlich darstellt.

„Vielmehr geht es darum, daß die Besucher beim Ansehen eines Gegenstandes, beim Betreten eines Environments in einen Zustand versetzt werden, in dem sie ein Gefühl für das noch nicht Fertige, das Unabgeschlossene, oder, in einer anderen Wendung: für die Ungesichertheit, Fragwürdigkeit und Gesetztheit der vorgestellten Ordnungen bekommen." (ebd.)

Hartwig gebraucht bei dieser Aufzählung bewusst auch das Wort Gefühl, weil es deutlich macht, dass es nicht nur um andere Erkenntnisformen geht, sondern um Wahrnehmungszustände, die es erlauben, mit den Sinnen zu reagieren, ohne dass für das Gefühlte und Gesehene sofort der richtige historische Begriff assoziiert werden muss.

Die Zusammenarbeit von Künstlern mit Ausstellungshäusern oder Museen wird in höchst unterschiedlichen Formen realisiert. Eine grundlegende Differenzierung kann darin getroffen werden, ob Künstler sich in ihrem Werk mit Vergangenheit und Erinnerung in ihrer Arbeit auseinandersetzen und dadurch ein neues Kunstwerk schaffen oder ob diese die Rolle eines Kurators einnehmen und damit die Aufgabe der Gliederung des Ausstellungsmaterials übernehmen. Im ersten Fall führt dies zu einer künstlerischen Produktion von Geschichte - der Künstler wird zum Historiker. Über die künstlerische Arbeit wird Vergangenes vergegenwärtigt oder reflektiert. ${ }^{15}$ Zeitgenössische Kunstwerke stehen dann zum Beispiel in Kontrast zu musealen Sammlungsgegenständen. Im zweiten

115 Künstlerische Arbeiten von Ilya Kabakov, Anselm Kiefer oder Joseph Beuys zählen zum Beispiel hierzu. 
Fall besteht die künstlerische Arbeit in der Schaffung neuer Sichtweisen durch ungewöhnliche Anordnungen des Sammlungsbestandes.

Zur historischen Verortung entwirft Martin eine Typologie vergleichbarer Ansätze, die zwar keinen Anspruch auf Vollständigkeit erhebt, jedoch einen Orientierungsrahmen bildet und deshalb im Folgenden vorgestellt werden soll (Martin 2001, S. 12ff.). Er unterscheidet zwischen Künstlersammlungen, Künstlern als Ausstellungskuratoren und Künstlern als Sammlungskuratoren.

In die erste Kategorie gehören Künstler, die ihre eigene Sammlung zeigen, also eine Sammlung von bereits vorhandenen Objekten, die dann entweder in einem vom Künstler konzipierten Rahmen oder zusammen mit eigenen Werken des Künstlers präsentiert werden. ${ }^{116}$ Künstlerische Sammlungen, deren Intention in der Erinnerung liegt, „,schöpfen aus dem Reservoir der Gedächtnismetaphorik, die sich seit der antiken Mnemotechnik entwickelt hat. "'117 Künstler bereichern diese mit neuen Metaphern und Denkbildern. Die künstlerischen Formen reichen von fulminaten Waren- und Schrottberginstallationen bis hin zu leisen und stillen Arbeiten, die im Unscheinbaren und scheinbar Nebensächlichen, im zufällig Gefundenen und in verstaubten Zeugnissen nach Spuren alltäglicher Biographien oder des traumatischen Schicksals anonymer kleiner Leute suchen.

„Die plakative Pop-Welt der Waren und der Werbung wird durch die leiseren Stimmen dieser Spurenleser unterwandert, die in Familienalben und Schulheften, in Schnappschüssen, Spielsachen und Andenken, in pseudo-ethnografischen Krimskrams und Kleidersammlungen, in Nachlässen anonymer Personen, Karteien und Akten die Schrift entziffern, die sich als Spur eines unbekannten Lebens, auch als blutige Narbe oder Brandmal in diese fragmentarischen Indizien eingegraben hat.“ (ebd.)

116 Weitere Beispiele für diese Formen siehe Martin 2001, S. 13ff. Siehe auch Katalog zur Ausstellung „Deep Storage - Arsenale der Erinnerung“ im Haus der Kunst in München im Jahr 1997. Diese Ausstellung befasste sich mit dem Thema Sammeln, Speichern und Archivieren in der Gegenwartskunst und stellte Modelle künstlerischer Gedächtnisarbeit vor. Vgl. Schaffner, Ingrid/Matthias Winzen (Hrsg.): Deep Storage - Arsenale der Erinnerung. Sammeln, Speichern, Archivieren in der Kunst. New York/München 1997.

117 Vitali, Christoph/Schuster, Peter-Klaus/Wiese, Stephan von: Vorwort im Ausstellungskatalog „Deep Storage“. In: Schaffner/Winzen 1997, S. 7. 
Diese Lebensspuren sollen vergleichbar einer vorsprachlichen Schrift entziffert werden, die weder eindeutige Botschaften vermitteln, noch ursprünglich für einen Leser vorgesehen waren. Stellvertretend für diese Form stelle ich die Arbeit des Künstlers Christian Boltanski vor. ${ }^{118}$ Es geht ihm nicht um die interpretierende Rekonstruktion eines originären Ereignisses der Vergangenheit, stattdessen thematisiert Boltanski das Erinnern als anthropologisch-existenzielles Grundgeschehen, insbesondere in der durch Rationalität gekennzeichneten Industriegesellschaft. Als Spurensicherer richtete er in Anlehnung an wissenschaftliche Präsentationsformen zum Beispiel Objektkästen ein, um Fossilien einer vergangenen und verdrängten Kultur innerhalb der modernen Zivilisation zu sichern. Boltanski produziert Spuren, die Betrachter zu einem neuen Blick auf gewohnte Gegenstände und Handlungen bewegen sollen. Objekte des täglichen Gebrauchs, fotographische Dokumente familiärer Ereignisse und anonyme Fundstücke werden als scheinbare Indikatoren anthropologischer Strukturen inszeniert.

Eine Arbeit von Boltanski mit dem Titel „Signal“ zeigt, wie sich künstlerische und historische Auseinandersetzung gegenseitig bereichern können. ${ }^{119}$ Boltanskis Verdienst war nicht allein der künstlerische Umgang mit dem Material, sondern auch eine bisher von der deutschen Ge-

118 Christian Boltanski wurde 1944 in Paris geboren und lebt und arbeitet jetzt in Malakoff bei Paris.

119 Diese Arbeit wurde erstmals in dem von Jussen Bernhard herausgegebenen Buch „Signal - Christian Boltanski“ (Göttingen, 2004) publiziert, erschienen in der Reihe „Von der künstlerischen Produktion von Geschichte“. Ausgangspunkt dieser Publikationen waren mehrere ambitionierte Veranstaltungen, die der Mediävist Jussen am Göttinger MaxPlanck-Institut für Geschichte organisierte. Diskutiert wurden die Fragen nach dem Verhältnis von Kunst und Geschichte, Künstlern und Historikern. Die gemeinsame Prämisse lautete, dass der künstlerische und der geschichtswissenschaftliche Umgang mit der Vergangenheit sowohl durch konstitutive Differenzen als auch durch Ähnlichkeiten gekennzeichnet sei. Es sollte versucht werden, Künstler und Wissenschaftler miteinander ins Gespräch zu bringen, um das Verständnis in der Geschichtswissenschaft für aktuelle ästhetische Arbeitsweisen an den historischen Imaginerien der Gesellschaft zu schärfen. Aus den Kolloquien gingen jeweils Sammelbände hervor. Jussen, Bernhard (Hrsg.): Von der künstlerischen Produktion der Geschichte I. Jochen Gerz, Göttingen 1997. Ders. (Hrsg.): Archäologie zwischen Imagination und Wissenschaft. Göttingen 1999. Ders. (Hrsg.): Hanne Darboven - Schreibzeit. Köln 2000. Ders. (Hrsg.): Ferne Zwecke - Ulrike Grossarth. Köln 2003. 
schichtswissenschaft kaum rezipierte Zeitung unter Historikern bekannt zu machen. ${ }^{120}$

Boltanski hatte auf Pariser Flohmärkten einige Ausgaben der Wehrmachtszeitschrift „Signal“ gekauft. Er nahm die Hefte auseinander und wählte zwanzig der farbigen Blätter aus. Drucktechnisch bedingt stoßen auf einem Bogen immer zwei Bilder aufeinander, die im Heftzusammenhang nichts miteinander zu tun haben. Das Auswahlprinzip bestand darin, von diesen Zufallsnachbarschaften solche zu nehmen, bei denen Bilder zur Kriegführung einerseits und Bilder aus Kultur, Natur, Wissenschaft und Sport andererseits nebeneinander geraten waren. Daraus resultierten überraschende Konstellationen und Konfrontationen. In den Bildseiten treten Paradoxien zutage, die nicht nur die propagandistischen Ziele des nationalsozialistischen Regimes und der Illustrierten darstellen, sondern gerade in Kontrastkoppelungen entscheidende Momente des Nationalsozialismus, seines Selbstverständnisses, seiner Selbstdarstellung und seiner Wirkungen in signifikanter Weise repräsentieren: Die Verheißung von bislang unerhörter Sinngebung und Lebenserfüllung mit der Androhung von Tod und Vernichtung, etwa in der Produktion von Kampfflugzeugen. ${ }^{121}$ Beklemmend ist es, neben der David-Statue von Michelangelo mit der Bildlegende „Symbole de Jeunesse“ ein Foto offenbar frisch angelegter Soldatengräber zu sehen mit der Bildlegende „Novembre - Souvenir des Morts - Souvenir des Héros“. An anderer Stelle werden deutsche Panzertruppen in der Ukraine und Hans Albers als Münchhausen-Darsteller der Ufa kontrastiert. Diese Bildpaare spiegeln Goebbels Überzeugung: „Auch die Unterhaltung ist heute staatspolitisch wichtig, wenn nicht sogar kriegsentscheidend“; denn es sei „auch kriegswichtig, unser Volk bei guter Laune zu halten. “ ${ }^{122}$

120 Die Zeitschrift „Signal“ ist von April 1940 bis März 1945 mit wenigen Lücken 14-tägig erschienen, produziert von der Abteilung Wehrmachtspropaganda des Oberkommandos der Wehrmacht. Die höchst professionelle, für die Zeit sensationelle Aufmachung und das moderne, herausragende Layout sowie erstklassiges Photomaterial vermittelten einem ausschließlich ausländischen Millionenpublikum sublime deutsche EuropaPropaganda. Die Auflage betrug bis zu 2,5 Millionen Exemplare. Insgesamt ist die Zeitschrift sehr schlecht erforscht und kaum zu finden. Vgl. Jussen, Bernhard: Signal - Zur Einleitung. In: Bernhard, Jussen (Hrsg.): Signal - Christian Boltanski. Göttingen 2004, S. 53.

121 Oexle, Gerhard Otto: Memoria und Kulturelles Gedächtnis im Werk Christian Boltanski. In: Jussen 2004, S. 97ff.

122 Goebbels zitiert in Oexle 2001, S. 98. 
Die zweite Kategorie künstlerischer Ansätze bilden Ausstellungen, bei denen Künstler als Kuratoren arbeiten. ${ }^{123}$ Sie beschäftigen sich mit Werken verschiedener Besitzer und treten damit in wissenschaftlichen Institutionen als Kuratoren auf. ${ }^{124}$

Ein Beispiele für einen künstlerischen Umgang mit Museumsexponaten bildet die Idee des Musée Sentimental. Das Prinzip des Musée Sentimental bemüht sich um eine Auswahl und Zusammenstellung von Gegenständen nach anekdotischen Gesichtspunkten. Dinge, die zwar keinen historischen oder kunsthistorischen Wert haben, beinhalten dennoch gefühlsimmanente Werte. An sich sind die Objekte nicht mit Gefühlen behaftet, aber sie leben aus dem subjektiven Gefühl, das der Betrachter gleichsam als Biograph ihnen zukommen lässt - durch Erinnerung an eigene Erlebnisse, Erfahrungen, Empfindungen, seine Entdeckungen am Objekt (Plessen 1990, S. 15).

„Wären nicht die wortreichen, bis auf Tageszeit, Sonnenstand und gesundheitliches Befinden genauen Schilderungen des Kölner Ratsherrn Hermann von Weinsberg aus dem 16. Jahrhundert überliefert, so hätte ein Schröpfglas dieser Zeit im Musée Sentimental keinen Stellenwert; da Weinsberg aber genüßlich schildert, wie oft, wo und mit wie vielen Köpfen er sich in den Kölner Badstuben hat schröpfen lassen, kommt diesem Schröpfkopf die Bedeutung eines Zeugnisses über die hygienischen Verhältnisse dieser Zeit zu, die wiederum durch Weinsbergs Bericht anschaulich gemacht wird.“125

Damit gewinnen Relikte vom vergangenen Alltagsleben durch anekdotische Belege zu überlieferten Ereignissen und Geschichten eine ihnen eigentümliche, sentimentale Bestimmung. Kleine, unscheinbare Gegenstände fangen an zu leben, sobald sie ihre Vereinzelung in der Stadtchronik auflösen können. Das Prinzip der Zuordnung von Objekten und ihnen zugehörigen Geschichten stellt das Konzept des Musée Sentimental zumindest im historischen Rahmen über alle anderen nach Sachgebieten unterteilten oder auf Kategorien verengten Ordnungsbestimmungen.

123 Als Gastkuratoren arbeiteten zum Beispiel der Filmregisseur Peter Greenaway, der Theaterregisseur Robert Wilson oder der Architekt Dieter Schaal.

124 Das Deutsche Hygiene Museum in Dresden beispielsweise zählt zu den experimentierfreudigsten Häusern in Deutschland, die für Sonderausstellungen die Kooperation mit Künstlern suchen.

125 Plessen, Marie-Louise von/Spoerri, Daniel (Hrsg.): Entwurf zu einem Lexikon eines Musée Sentimental Cologne. Köln 1979, S. 15. 
„Es läßt einen Teppich von Zusammenhängen entstehen, der näher an die Wirklichkeit vergangener Zeit rührt als jede positivistisch gesäuberte Auffassung von Geschichte, die nur die wesentlichen Meilensteine des Geschichtsverlaufs oder nur die Erzeugnisse der Hochkunst in den Blick nimmt." (Plessen 1979 , S. 15)

Das Konzept eines Musée Sentimental will das sinnliche Neuentdecken, Anders- und Wiederentdecken von Geschichte in anekdotischen Bezügen. Sentimentale Museen vermitteln die Werke nicht über die Rekonstruktion von Geschichte, sondern über Geschichten, die zu den Objekten erzählt werden. Aus diesem Grund ergibt sich daraus ein Ordnungsproblem in der Form, wie einzelne Objekte und die zu ihnen gehörigen Geschichten zusammengeführt werden können. Um das zu gewährleisten, müssen Objekte und Geschichten, unabhängig von der Reihenfolge, wenigstens mit Zahlen oder Buchstaben versehen werden, jedoch ohne dass die Auflistung eine inhaltliche Bedeutung erhält.

Erstmals in Deutschland realisierte im Jahr 1979 Daniel Spoerri als Wiederentdecker des Musée Sentimental die Idee im Kölner Kunstverein. ${ }^{126}$ Dieser Ausstellungstypus wurde in der Museumswelt als Vorbild vielfach aufgegriffen und in unterschiedlichen Formen auch als Element in Dauerausstellungen realisiert. ${ }^{127}$ In Köln wurde der Versuch unternommen, die Geschichte einer Stadt mit Hilfe von Relikten aus dem Alltagsleben zu erzählen. In Zusammenarbeit mit Studenten der Fachhochschule für Kunst und Design sowie unter der Mitarbeit der Historikerin Marie-Louise von Plessen entstand das Projekt „Musée Sentimental de Cologne“. Spoerri wählte für seine Objektordnungen die alphabetische Reihenfolge, wie sie in Lexika verwendet wird. Es wurde versucht, wesentliche Merkmale einer Stadt mit Stichworten zu erfassen.

126 Die Idee des Musée Sentimental wurde von Daniel Spoerri erstmals im Zusammenhang mit einem Ausstellungsprojekt im Jahr 1977 im Centre Georges Pompidou in Paris realisiert. Vgl. Kamber, André (Hrsg.): Stichworte zu einem sentimentalen Lexikon um Daniel Spoerri und um ihn herum. München 1990, S. 71.

127 Zum Beispiel integrierte das Geldmuseum in Frankfurt in die Dauerausstellung ein Musée Sentimental vgl. Nowak, Stefan/Teufel, Philipp: Die Kuh, der Gestalter, das Geld und ihre Liebhaber. Integrative Ausstellungsplanung am Beispiel des Geldmuseums Frankfurt. In: Schwarz/ Teufel 2001, S. 87. Weitere Beispiele siehe unter http://www.vlmuseen.de/musgesch.htm (letzter Zugriff: 25.08.04). 
„,[...] im Sinne einer alten Universalkunst dilettierend zwar, also mit viel Freude und Spaß an der Sache, aber vielleicht manchmal auch ohne die nötige Sachkenntnis (was unsere Ungehemmtheit förderte) sowohl historisch als auch phänomenologisch das Stichwort Köln in seiner ganzen Vielfältigkeit und Breite auszuloten und vielleicht sogar mit oder anhand dieser Funde, die wir machen würden, die Identität dieser Stadt zu finden.“ ${ }^{128}$

Die Objekte wurden nicht nach ihrem monetären oder ästhetischen Wert beurteilt, sondern nach ihrer Geschichte, auch wenn sie vielleicht nur einen marginalen Platz in der Historie beanspruchen konnten. Ein wichtiges Prinzip bestand in der Kontrastierung von Gegensätzen - vom Sakralen zum Trivialen bis hin zum Vulgären. Es ging darum zu zeigen, dass in einer Stadt wie in einem Menschen diese Gegensätze vereint sind (ebd., S. 10). Spoerri illustriert diesen Gegensatz an den Objektensembles „der drei Ursulas“, die als Kölnerinnen diesen Namen tragen, jedoch für drei extrem verschiedene Persönlichkeiten und Assoziationen stehen.

„Das eine ist ein bedeutendes Barock-Reliquiar der heiligen Ursula im Verein mit einer Sammlung von Reliquien-Knochen vom sog. Ursula-Acker, das zweite ist [...] das Totenschild der Ursula Maria Columba von Groote geb. zum Pütz, die angeblich die Geliebte Casanovas gewesen sein soll, und drittens wäre Ursula Gerdes zu nennen, die erste Mieterin des neuerbauten ErosCenters in Köln.“ (ebd.)

Das Anliegen bestand darin, einen Schwerpunkt auf derartige Verbindungen und Querbezüge, aber auch Widersprüche zu legen. Über diesen Weg wurden die Objekte in einen neuen Zusammenhang gestellt. Mit diesem Ansatz des Spekulativen sollte die Phantasie des Zuschauers angeregt werden. Für Spoerri ist es der persönliche Beitrag eines jeden, der dem Ganzen erst einen Sinn gibt. Martin sieht in diesem Ansatz Spoerris eine neue Wertschätzung der Erzählung über die Objekte oder ganz allgemein das Narrative. Dies führt wie bei Boltanski zu einer Art „Geschichte von unten“ (Martin 2001, S. 18).

Die dritte Form, in der Künstler als Kuratoren tätig werden, besteht darin, dass sie sich auf die Sammlung eines bestimmten Museums oder

128 Spoerri, Daniel: Einleitung. In: Plessen/Spoerri 1979, S. 9. 
auf eine museale Situation vor Ort beschränken und basierend auf diesen Bedingungen eine neue Präsentation entwickeln. ${ }^{129}$

Ein spektakuläres Projekt verwirklichte Robert Wilson in der Villa Stuck in München. ${ }^{130}$ Die Villa Stuck mit ihren kostbar ausgestatteten Räumen, mythologischen Geschöpfen und erlesenem Ambiente bildete die Kulisse zum Environment von Robert Wilson. Die Arbeit des international renommierten Künstlers und Theaterregisseurs war eine Installation, bestehend aus zwölf Tableaus und dreidimensionalen Bildern mit Licht und Ton kombiniert. Den Tableaus liegen Photos, Gemälde und Lebenszeugnisse Franz von Stucks zugrunde. Wilson bediente sich dieser Vorlagen in unterschiedlicher Weise. Aus Fotovorlagen entstanden wie Geistererscheinungen wirkende Figuren von Franz von Stuck und seiner Familie. Als weitere Art der Darstellung wurde das Originalphoto in eine neue, unerwartete Form übertragen, so zum Beispiel in eine dreidimensionale Landschaft im Rauchsalon. Die Gemälde dienten vor allem als Vorlage für lebensechte Nachbildungen der Fabelwesen, die in Franz von Stucks Gemälden zu finden sind.

„Im Empfangs- und Musiksalon jagen Kentauren aus dem Gemälde Phantastische Jagd durch den Raum, während die Trunkene Kentaurin aus dem gleichnamigen Gemälde sich im Rausch auf den Boden des Ateliers niederstreckt. Im ehemaligen Schlafzimmer stößt man auf einen flötenspielenden Kentaur. “131

Künstlerische Inszenierungen sind jedoch nicht beschränkt auf große Kunst- oder kulturhistorische Ausstellungen. Auch für regionale Museen bietet dies eine Möglichkeit, die traditionellen Formen zu erweitern und damit neue Perspektiven zu schaffen. Das Freilichtmuseum Detmold entschied sich bei der Neugestaltung eines Tagelöhnerhauses für diese Form der Musealisierung. Anders als in den übrigen historischen Gebäuden des Freilichtmuseums finden die Besucher in diesem Gebäude keine

129 Eine Auflistung interessanter Projekte siehe Martin 2001, S. 20ff. Unter anderem verweist er auf Projekte von Harald Szeemann, Hans Haacke, John Cage und Christian Boltanski.

130 Die Ausstellung „Robert Wilson/Villa Stuck“ fand am 25.11.97-08. 02.98 in der Villa Stuck in München statt. Der Katalog zur Ausstellung beschreibt Robert Wilsons' Tätigkeit als Künstler und enthält eine vollständige fotographische Dokumentation der Ausstellung. Vgl. Danzker, Jo-Annie Birnie: Robert Wilson - Steel Velvet. München 1997.

131 Zitat aus dem Flyer „Robert Wilson/Villa Stuck“. 
klassische, der jeweiligen Region, dem Zeitschnitt und der Sozialschicht entsprechende museale Inszenierung. Sie sind vielmehr mit dem Kunstprojekt „InnenLeben - Haus der Gefühle“ konfrontiert, eine Arbeit der Essener Künstler Gabriele Wilpers und Herbert Galle. ${ }^{132}$

Wilpers und Galle sahen das Tagelöhnerhaus nicht allein als historisches Objekt, sondern verstanden es als symbolisches Haus von großer Integrationskraft für Gedanken, Erinnerungen und Träume der Menschen. Ausgehend von den Lebensgeschichten der ehemaligen Bewohner, den Gegenständen, die sie hinterlassen haben, und der Baugeschichte des Hauses sowie unter Einbeziehung der jetzigen Raumwirkung werden die Wohn- und Lebensverhältnisse von Tagelöhnern sowie Grundbedingungen menschlicher Existenz reflektiert. Insgesamt sind in den verschiedenen Räumen des Hauses elf künstlerische Arbeiten und Installationen in unterschiedlichen Techniken zu sehen: Gemälde und plastische Arbeiten, Graphiken, Foto- und Videokunst. Durch diese künstlerischen Eingriffe erfährt die historische Substanz des Tagelöhnerhauses eine für die Besucher ungewohnte Interpretation und eine neue sinnliche Präsenz. Die künstlerischen Installationen in den einzelnen Räumen sind mit Titeln versehen. Der ehemalige Stall trägt den Titel „Ungewöhnlicher Blick auf Gewohntes“, die einstige Schlafkammer ist mit „Raum der verborgenen Gefühle“ bezeichnet.

„Wie eine Himmelsleiter durchschneidet eine alte, immer wieder reparierte Holzleiter den Raum der verrinnenden Zeit. Um sie herum sind alle noch erhaltenen, von der letzten Bewohnerin des Hauses zurückgelassenen Alltagsgegenstände angeordnet. Sonst mit Inventarnummern versehen, katalogisiert, gut verpackt und magaziniert, liegen sie hier: die ,Hab-selig-keiten' des Lebens. Um die Leiter und in den Raum hinein windet sich eine Spirale, bestückt mit Sanduhren als Symbol der menschlichen Lebenszeit. Im oberen Bereich sind die Sanduhren farbig, so dass sich ein aktuelles Bild des Lebensfadens assoziieren lässt: die DNA, das universelle Prinzip der Vererbung (siehe Abb. 8).“

Das Kunstprojekt „InnenLeben“ versteht sich hinsichtlich seiner Wirkungen bewusst als ergebnisoffen. Gemäß den Erwartungen der Verantwortlichen zeigten sich konträre Reaktionen, wobei, wie Projektmitar-

132 Stephan Pahs: Warum der Holzschuh geröntgt werden musste - oder: Musealisierung eines Tagelöhnerhauses mit den Mitteln moderner Kunst. Das Projekt „Innenleben - Haus der Gefühle“ im Westfälischen Freilichtmuseum Detmold. In: Museum heute. Fakten, Tendenzen, Hilfen. (2002) Heft 23. S. 53-57. 
beiter Pahs feststellt, die positiven Rückmeldungen überwiegen und das Team des Projekts ermutigen, neben der klassischen Inszenierung auch weitere Formen der Musealisierung zu erproben.

Ein sehr kontrovers diskutiertes Projekt wurde im Düsseldorfer museum kunst palast verwirklicht. ${ }^{133}$ Die Düsseldorfer Künstler Bogomir Ecker und Thomas Huber haben in Zusammenarbeit mit den Kuratoren des Museums eine neue Ordnung erstellt. Die Neupräsentation der Kunstwerke, sowohl bekannte Meisterwerke als auch viele bisher im Depot gelagerte Exponate, erfolgte nach thematischen Fragestellungen, bei denen der Blick der beiden Künstler zum Ausdruck kam. Konventionelle Ordnungsprinzipien nach Chronologie, Gattung, Stilrichtung, Epochenzugehörigkeit oder Materialbeschaffenheit wurden gleichzeitig aufgegeben. In der Themenfolge „Die Akademie, das Atelier und die Befindlichkeit des Künstlers“ finden die Besucher zum Beispiel Werke, die im Zeichen von Trauer und Melancholie, Religiosität und Erotik, Humor und Lust, Ekstase, Messianismus, Sehnsucht und Exotik stehen. In einem anderen Bereich liegt der Akzent hingegen auf dem „Blick des Künstlers“. Dargestellt ist der Blick nach innen, nach außen und nach oben, der ordnende, der wissenschaftliche, der verbergende oder auch der horizontlose Blick. ${ }^{134}$

Bereits vor Eröffnung der Neupräsentation übte die Fachgruppe kulturhistorischer Museen und Kunstmuseen im Deutschen Museumsbund heftige Kritik. ${ }^{135}$ An dieser Kontroverse lassen sich umstrittene Aspekte derartiger Präsentationen aufzeigen, die sich auf die vorher genannten Formen künstlerischer Interpretation übertragen lassen. An erster Stelle stand die Befürchtung, dass diese Formen der Präsentation eine Antwort auf den derzeitigen Kulturbetrieb darstellen und dies eine weitere Form

133 Die Eröffnung der neu präsentierten Schausammlung im museum kunst palast fand am 1. September 2001 statt. Der Ausstellungskatalog spiegelt die vielschichtigen Überlegungen der mit der Neupräsentation der Sammlung beauftragten Künstler wider, ein umfangreicher Bildteil zeigt die Sammlungspräsentation der Künstler. Außerdem gibt ein Dokumentationsteil einen Einblick in die Kontroverse von Fachkollegen und Kunstkritikern. Vgl. Kapitel 3/Anm. 113.

$134 \mathrm{Vgl}$. http://www.museum-kunst-palast.de/dt/sites/s2s2.asp (letzter Zugriff: 10.02.05).

135 Brief der Fachgruppe kulturhistorischer Museen und Kunstmuseen im Deutschen Museumsbund an den Oberbürgermeister Joachim Erwin der Stadt Düsseldorf, 2. Juli 2001. In: Martin 2001, S. 186. 
von „Ausverkauf der Kultur zugunsten effektheischenden Entertainments“ unter Aufgabe jeglichen Bildungsanspruches sei (ebd.).

„Der Versuch, das Museum durch die Subjektivität des Künstlers kurieren zu wollen, [leistet] einer neuen Geschmackskultur Vorschub, die ihr Nichtwissen verbrämt, Denkfaulheit mit Innovation, Blindheit mit Sensibilität verwechselt und den Künstler zum Kollaborateur stempelt.““136

Da nicht mehr deutlich wird, worin die Erkenntnispotentiale liegen, befürchtet Rauterberg, dass dieses fröhliche Durcheinander geschichtlich entwurzelter Präsentation in irrelevante Beliebigkeit mündet, die zwar für „,nostalgische Entzückung oder esoterische Entrückung“ sorgt, jedoch zu einer Erklärung der Werke nichts beiträgt (Rauterberg 2002, S. 37).

Dem Kritikpunkt des undefinierbaren Unterhaltungswertes setzt Martin entgegen, dass die Künstler in ihrem Papier von einer „Schule des Sehens" sprechen und die Räume in ihrer Unterschiedlichkeit die Besucher dazu anregen sollen, neben klassisch wissenschaftlichen Gruppierungen auch Kriterien künstlerischen Urteilens auszuprobieren (Martin 2001, S. 188). Zur Erfassung der Komplexität von künstlerischen Werken bedarf es eines vielfältigen Instrumentariums; dazu reicht nicht nur das ,analytische[n] Sezierwerkzeug[s]“ der traditionellen Kunstgeschichte mit ihren vielen Kategorien für Stile und Einzelleistungen. Die Geschichte der Kunst in ihren einzelnen Beispielen verstehen zu wollen, bedeutet auch, ,immer wieder andere Blicke auf sie zu riskieren, Nachbarschaften herzustellen, die auf willkürlichen Setzungen fuße.“137

Der Umgang mit der Offenheit der Interpretation kann tatsächlich jedoch problematisch sein, wenn dies lediglich zu Unverständnis und Verwirrung führt und auch zu einem späteren Zeitpunkt nicht in eine vertiefende Auseinandersetzung mündet. Es stellt sich die Frage, welches Publikum von diesen künstlerischen Formen angesprochen wird.

„Kennt man sich genauer in der Kunstgeschichte aus, ist das Querbürsten vielfach erfrischend. Das große Publikum aber wird sich überrumpelt fühlen, es

136 Wagner, Thomas: Künstler an die Macht. Ein Düsseldorfer Exempel: Wo liegt die Zukunft der Museums? In: Frankfurter Allgemeine Zeitung vom 22.08.01. Zitiert in: Martin 2001, S. 192ff.

137 Krempel, Ulrich: Neue Sichten haben etwas Verführerisches. Aufgabe des Museums muss es sein, dem Betrachter etwas von den Potentialen des eigenen Sehens deutlich zu machen. In: Die Welt vom 8. August 2001. Zitiert in: Martin 2001, S. $191 \mathrm{ff.}$ 
versteht nichts mehr und muß sich um die tieferen Gehalt der Kunstgeschichte betrogen fühlen." ${ }^{138}$

Da bewusst auf klassische Formen der Interpretation verzichtet wurde, kann dies dazu führen, dass die künstlerische Ordnung nicht zu der erwünschten Erweiterung der Sichtweise führt, sondern diese Irritation lediglich die Sprach- und Verständnislosigkeit des Besuchers bewirkt. Der Wunsch der Künstler, die Kunst möglichst pur zu präsentieren, führte dazu, auf Bildbeschriftungen, Saaltexte oder Kapitelüberschriften zu verzichten. So kritisiert Schneede, dass ein „der Aufklärung und dem öffentlichen Bildungsauftrag entsagendes Institut entstanden [ist]: ein sprach- und begriffsloses Spezialmuseum für Künstler und Kenner.“139 Allein auf die assoziativen Bildwirkungen vertraut Schneede nicht. Für ein umfassendes Verständnis hält er die Auseinandersetzung mit der Historie für elementar und dieses funktioniert nur über eine Vermittlung, die sich auch der Sprache und des Begriffs bedient. Nur dann kann seiner Meinung nach das Museum seinen Bildungsauftrag erfüllen.

Ernste Bedenken formulierte die Fachgruppe kulturhistorischer Museen und Kunstmuseen gegen die Pläne, die nach kunstgeschichtlichen Epochen ausgerichtete Ordnung der Kunstsammlung durch eine künstlerisch motivierte, assoziative Ordnung zu ersetzen. An die Stelle der wissenschaftlichen Argumentation tritt die künstlerische Inspiration. Dies bedeutet ein Verzicht auf „in schlüssiger Weise historisch gewachsenen Grundprinzipen eines Kunstmuseums [...], ohne etwas Ebenbürtiges an ihre Stelle zu setzen“ (ebd. S. 186). Die Vorbildlichkeit und Autorität moderner Museen liegt darin, die Ordnungskriterien und Qualitätsentscheidungen wissenschaftlich, dies bedeutet durchschaubar und kritisierbar, zu begründen.

„Es gehört zu den fundamentalen Entwicklungen des Kunstmuseums, dass sich diese Institution im Laufe ihrer Geschichte aus dem rein privaten Geschmacksurteil von Sammlern (im 18. Jahrhundert) und dem egoistischen

138 Beaucamp, Eduard: Geweihte Exotik, gefleddertes Abendland. Doppelschlag eines ästhetischen Strategen: Jean-Hubert Martin mischt das Düsseldorfer Kunstmuseum auf und ruft in seiner Ausstellung „Altäre“ zum Niederknien auf. In: Frankfurter Allgemeine Zeitung vom 1. September 2001. Zitiert in: Martin 2001, S. 194.

139 Schneede, Uwe M.: Besinnungslose Experimente. Wie internationale Museen mit neuen Konzepten ihre alte Autorität aufs Spiel setzen. In: Die Zeit vom 13. Dezember 2001. In: Martin 2001, S. $197 \mathrm{ff}$. 
Lobbyismus von Künstlern (im 19. Jahrhundert) zu einer von wissenschaftlicher Begrifflichkeit bestimmten Bildungseinrichtung emanzipiert hat.“ (ebd.)

Wenn die Entscheidungen über Ordnungen wieder in die Verantwortung von Künstlern gelegt werden, dann begibt sich das Museum - so die Argumentation der Fachgruppe - zurück in sein vorwissenschaftliches Stadium. An die Stelle einer kunsthistorischen Argumentation, die das Entstehen der jeweiligen künstlerischen Position nachvollziehbar macht, treten dann ,private Assoziationen und ein undefinierter Unterhaltungswert" (ebd.).

Dieser These der Rückkehr zum vorwissenschaftlichem Stadium tritt Martin mit der Feststellung entgegen, dass zur Wissenschaft auch schon immer das Experiment zählte. Um ein derartiges Experiment handelt es sich. Auch die Ordnung eines Künstlermuseums bleibt durchschaubar und auch kritisierbar, ,eben gerade weil die Prämissen offen gelegt werden, statt - wie es oft auch in vorgeblich wissenschaftlichen Präsentationen geschieht - das Geschmacksurteil des jeweiligen Direktors als objektiv auszugeben“ (ebd. S. 188).

Einen weiteren Kritikpunkt in der Diskussion über die Rolle und Funktion von Künstlern als Historiker stellt der Vorwurf der Ästhetisierung oder sogar Geschichtsverfälschung dar. Dies führt über die Diskussion zum museum kunst palast hinaus. Insbesondere bei zeitgeschichtlich problematischen Themen tritt dieser Konflikt zutage. Anhand des Streites um eine geplante Ausstellung über die Rote-Armee-Fraktion in den Berliner Kunst-Werken soll diese Schwierigkeit skizziert werden. ${ }^{140}$ Ausgangspunkt der Kritik war ein intern publiziertes Konzeptpapier, in

140 Unter der Leitung des Ausstellungsmachers Klaus Biesenbach hätte im Herbst 2003 eine Ausstellung zur Geschichte der Rote-Armee-Fraktion in den KW Institute for Contemporary Art in Berlin eröffnet werden sollen. Neben künstlerischen Arbeiten sollte es auch einen historischen Teil geben, den der Historiker Wolfgang Kraushaar vom Institut für Sozialforschung erarbeitet hätte. Aufgrund der scharfen Kritik von Seiten der Politiker sowie ehemaliger Angehöriger beschloss man, das Konzept zu überarbeiten. Die neu konzipierte Ausstellung wurde am 29. Januar 2005 eröffnet und konzentrierte sich auf eine kritische Reflexion der RAF in künstlerischen Positionen. Zusätzlich präsentierte eine Medienleiste Zeitungen, Zeitschriften und Fernsehnachrichten zu den 29 Tagen, die in Bezug auf die Geschichte der RAF von Bedeutung sind. Verzichtet wurde jedoch in der Ausstellung auf eine historisch-analytische Perspektive. 
dem unter dem Titel „Mythos RAF“ nach den Idealen und Ideen der RAF gefragt wurde, die die Zeit überdauert hätten und die man nicht als naiv abtun könne. Vorab hatten es die Ausstellungsmacher jedoch versäumt, die Nachkommen der Opfer der RAF in die Konzeption miteinzubeziehen. Die Kritiker warfen der Ausstellung eine Ästhetisierung des Schreckens vor und sprachen ihr jegliches Recht ab, die Geschichte der RAF zu thematisieren.

„Denn wer [...] nur nach den Ideen und Idealen, die ihren Wert durch die Zeit behalten, fragt, der muss sich zu Recht dem Vorwurf einer heimlichen Verklärung und der Geschichtsverfälschung stellen.“"141

Es geht bei den Vorwürfen um den Verdacht, dass es dem Thema mit den Mitteln der Kunst prinzipiell nicht gerecht werden kann. Befürchtet wird, dass sich automatisch ein affirmatives Verhältnis zwischen Inhalt und Form einstellt. Somit wird darin die Gefahr einer Legitimierung und Verharmlosung der RAF gesehen. „Damit rückt jede ästhetische Annäherung in den Verdacht der moralischen Verantwortungslosigkeit.“142 Demgegenüber verteidigt Biesenbach die Ausstellung, da die Hauptintention gerade darin liege, eine „Entmythologisierung“ zu bewirken und ,jeglicher Glorifizierung der RAF“ entgegenzuwirken. ${ }^{143}$

Boris Groys sieht im Kunstsystem in der heutigen Demokratie ein erweitertes Parlament. Meinungen, Positionen und Wünschen können präsentiert werden, die im politischen System unter die Fünf-ProzentHürde fallen. Im Kunstsystem können extreme, utopische, sogar moralisch inakzeptable Positionen ihre Repräsentation finden. ${ }^{144}$ Groys ist

141 Padtberg, Carola: Terrormythos RAF. An der Ausstellung über die RoteArmee-Fraktion scheiden sich die Geister. In: Die Zeit. Nr. 30/2003. http://zeus.zeit.de/text/2003/31/raf-ausstellung (letzter Zugriff: 28.08 . 04).

142 Zekri, Sonja: Angst vor der Bildermaschine. Zum Streit um die Berliner RAF-Ausstellung: Wie die Kunst in den Verdacht moralischer Verantwortungslosigkeit gerückt wird. In: Süddeutsche Zeitung vom 25.07.03.

143 Ralf Husemann: „RAF war keine Art Bonnie und Clyde“. Der Ausstellungsmacher Klaus Biesenbach verteidigt sein Projekt. In: Süddeutsche Zeitung vom 20.07.03.

144 Dies zeigte sich zum Beispiel in der Satire Ausstellung „Feinkost ADAM(C“ im Jüdischen Museum in Fürth vom 06.03.-16.06.02 unter der Leitung von Bernhard Purin. Die jüdische Künstlerin Anna Adam verwandelte das Museum in einen Feinkostladen. Mit viel Humor thematisierte sie typische Klischees vom Judentum in Deutschland, indem 
davon überzeugt, dass es nicht möglich ist, die Reaktion auf eine Ausstellung oder einen Text zu kontrollieren. Genau dies sollte in einem demokratischen System auch möglich sein, da alles andere eine totalitäre Position wäre.

„Die totalitäre Haltung besteht in erster Linie nicht darin, bestimmte Bilder zu produzieren, sondern darin, eine Maschine der Propaganda und Kontrolle zu schaffen, die festlegt, wie die Bilder zu verstehen sind. Wir leben in einer Gesellschaft, die auf diese Kontrolle verzichtet, wir riskieren mit jedem Bild oder Text unterschiedliche Reaktionen, die auch nicht gewünschten entsprechen können. Das ist Realität des öffentlichen Lebens. " ${ }^{145}$

Die heftige Diskussion um diese Ausstellung zeigte, dass der ästhetischen Wirkung künstlerischer Arbeiten mit Argwohn begegnet wird, da dies bei Betrachtern zu nicht gewünschten Interpretationen führen kann. Eine „Angst vor der Bildermaschine“ kursiert. ${ }^{146}$ Die RAF zählt zu den dunklen Kapiteln der bundesdeutschen Nachkriegsgeschichte. Eine Auseinandersetzung mit dieser Phase der deutschen Geschichte ist notwendig. Fraglich ist, ob eine Kunstausstellung das richtige Medium ist, über dieses schwierige Kapitel unserer Zeitgeschichte zu informieren. Vielen Künstlern, die sich mit der RAF auseinandergesetzt haben, ging es um eine seismographische Annäherung an das unbewältigte Potential bundesdeutschen Terrors. Es ging um die Herausforderung, „den unverdauten Rest dieser Historie ans Licht zu bringen.“ Insofern können künstle-

sie diese ad absurdum führte. Damit verärgerte sie Vertreter örtlicher Gemeinden sowie den Landesverband der Jüdischen Gemeinden in Bayern aufs heftigste, die eine sofortige Schließung der Ausstellung forderten, da sie darin eine Erniedrigung jüdischer Religion sahen, die bestehende Vorurteile gegen Juden vertiefen würde. Kissler, Alexander: Sodom und Andorra. Wie eine Fürther Ausstellung über das Bild vom Judentum unsere Erinnerungskultur verändern könnte. In: Süddeutsche Zeitung vom 09.04.02. Siehe auch: http://www.judentum.net/kultur/ adam-2.htm (letzter Zugriff: 27.04.04).

145 Zekri, Sonja: Die RAF-Geschichte wird zum Ready-made. Über Nutzen und Risiko gefährlicher Bilder: Ein Gespräch mit dem Medientheoretiker Boris Groys über die umstrittene Ausstellung in Berlin. In: Süddeutsche Zeitung vom 28.07.03.

$146 \mathrm{Ab}$ dem Ende der siebziger Jahre entstanden auch einige künstlerische Positionen, die naiv für die Terroristen Position bezogen oder zumindest Verständnis äußerten. 
rische Interpretationen „nie mehr bieten als Fragmente, Zuspitzungen der Wirklichkeit.“147

Ein Kernpunkt der Problematik liegt in der Offenheit der künstlerischen Interpretation begründet, sowohl im Hinblick auf die Frage, worin der Erkenntnisgewinn besteht als auch auf die Art und Weise, wie sich Künstler mit dem historischen Thema auseinandersetzen, indem sie auch nicht gesellschaftskonforme Positionen vertreten können. Zusammenfassend kann festgestellt werden, dass Formen künstlerischer Interpretation dazu beitragen können, die Perspektive zu ändern und Ereignisse aus anderen Blickwinkeln zu sehen. Die Relativierung und Transparenz der subjektiven Interpretation sollte jedoch gewährleistet sein. In der Diskussion um Legitimität der künstlerischen Interpretation scheint mir ein wesentliches Kriterium zu sein, die grundlegenden Zielvorstellungen der Ausstellungsmacher in Betracht zu ziehen. Entsprechen diese Vorstellungen dem Anspruch einer kritischen Bildungsarbeit, so zum Beispiel als „Schule des Sehens“ oder „Entmythologisierung“, dann erweist sich der Weg zwar als unkonventionell, erhält jedoch dadurch meines Erachtens Legitimität. Steht die Konfrontation und Reflexion im Vordergrund, bedeutet dies keine Aufgabe des Bildungsanspruches. Diffiziler erscheinen mir die Formen, in denen Museen in den Sog der Vermarktung geraten und zu kommerziellen Ausstellungshäusern großer Unternehmen mutieren.

„Wirklich skandalös aber sind Ausstellungen mit Titeln wie ,The Art of Motorcycles' oder ,The Mythos of Mercedes', die in Kunsträumen als Kunstereignisse gefeiert werden. Wo blieb der Einspruch des Deutschen Museumsbundes, als die Nationalgalerie oder die Deichtorhallen unter der Überschrift Kunst zum Autosalon verkamen?“"148

147 Liebs, Holger: Im Echoraum der Geschichte. Zum Streit um die RAFAusstellung: Warum die Kunst die Freiheit besitzt, unverdaute Historie ans Licht zu bringen. In: Süddeutsche Zeitung vom 21.08.03.

148 Thomas Deecke: Leserzuschrift zum Artikel „Immer neue Ghettos“ von Wulf Herzogenrath (in: Die Welt, 31.7.2001) In: Die Welt vom 8. August 2001. Zitiert in: Martin 2001, S. 191. 


\section{Partizipativer Ansatz}

Die Orientierung am Besucher führt zu der nahe liegenden Idee, die potentiellen Rezipienten bei Ausstellungen mitwirken zu lassen. Formal betrachtet wird mit der Teilnahme des Besucherpublikums an den Entscheidungsprozessen für die Planung einer Ausstellung das lineare Verhältnis zwischen Ausstellungsleitung, Ausstellung und Ausstellungsbesucher in ein zirkuläres umgewandelt.

Das generelle Bestreben, nicht die Dinge, sondern die Menschen ins Zentrum der Überlegungen zu stellen, führt zu den Tätigkeiten und Reflexionen im Umfeld der Bewegung Neue Museologie. ${ }^{149}$ Die Neue $\mathrm{Mu}$ seologie ist kein fest gefügtes theoretisches Gebäude, welches versucht, Museumstätigkeit neu zu begründen, sondern sie ist eine vor allem praktische Weiterentwicklung. ${ }^{150}$ Obwohl diese in den achtziger Jahren aufgekommenen Ideen damals als neu bezeichnet wurden, haben sie im internationalen Vergleich eine Tradition. Bereits im 19. Jahrhundert wurde die im Dienste der Gesellschaft stehende Bildungseinrichtung Museum entwickelt. Die soziale Aufgabe der Museumsarbeit wurde erstmals im Museumskonzept des Freiherrn von und zu Aufseß ernsthaft und konsequent berücksichtigt. Alltagsweltliche Bezüge, das heißt die Kultur und Geschichte des so genannten kleinen Mannes, seine Bedürfnisse und Interessen sollten die Museumsarbeit bestimmen (Hauenschild 1988, S. 5).

Seit Mitte des 19. Jahrhunderts gab es immer wieder Bestrebungen zur Demokratisierung von Museen. Sie waren jedoch nur in seltenen

149 Als verbandsmäßiger Zusammenschluss wurde im Jahr 1985 in Lissabon die Organisation MINOM (mouvement international pour une nouvelle muséologie) gegründet. Dieses internationale Komitee bildet eine Vereinigung innerhalb von ICOM (International Council of Museum). Ziel der MINOM ist es, Reflexionen, Gedankenaustausch, Kooperation und gemeinsame Projekte derjenigen Personen, Institutionen und Organisationen zu ermöglichen und zu unterstützen, die weltweit im Bereich der Neuen Museologie aktiv sind. Zu diesem Zweck werden jährliche Konferenzen organisiert.

150 In Deutschland gibt es bislang ein grundsätzliches Werk. Die beim Überseemuseum Bremen erschienene Dissertation der Ethnologin Andrea Hauenschild beschreibt verschiedene Strömungen der Neuen Museologie und gibt eine Zusammenfassung der wichtigsten Stationen der Entwicklung. Hauenschild, Andrea: Neue Museologie. Anspruch und Wirklichkeit anhand vergleichender Fallstudien in Kanada, USA und Mexiko. Bremen 1988. 
Fällen von dauerhaftem Erfolg gekrönt. Unzufrieden mit den Reformversuchen traditioneller Museen suchten Museologen in verschiedenen Ländern nach Möglichkeiten einer radikaleren Veränderung im Hinblick auf Arbeitsweisen, Inhalte und Strukturen. All dies geschah mit dem Ziel, Museen zu gesellschaftlicher Bedeutung zu verhelfen, weniger im Sinne von Anerkennung und steigenden Besucherzahlen als vielmehr im Sinne konkreter Beiträge des Museums zur Alltagsbewältigung, zur Gestaltung von Lebenspraxis und Heimat bestimmter gesellschaftlicher Gruppen. Die Überlegungen mündeten schließlich zum Teil in der Konzeptualisierung und Erprobung neuer Museumsformen. Hierbei sind drei Parallelentwicklungen festzustellen, die sich in unterschiedlichen Kontexten vollzogen haben: Neighborhood Museums in den USA, Museos integrales in Lateinamerika, und Ecomusées in Frankreich und Quebec (ebd., S. 12). In Deutschland wurde die Bewegung der Neuen Museologie kaum zur Kenntnis genommen. In den Ländern, in denen die Neue Museologie ihren stärksten Rückhalt hat, war die Einrichtung regionaler Museen eine Neuerung und zugleich ein Fortschritt, da das Museumswesen bisher in diesen Ländern auf die Metropolen konzentriert war. In Deutschland hingegen können lokale Museen auf eine Tradition zurückblicken, die bis ins 19. Jahrhundert zurückreicht. Heimatmuseen sind nicht nur Zeitgenossen, sondern in mancher Hinsicht sogar Vorläufer der Neuen Museologie, ohne jedoch von dieser zur Kenntnis genommen zu werden (ebd., S. 372). Grundsätzlich stellt Hauenschild fest, dass für moderne, aktionsorientierte Heimatmuseen ebenso wie für Neue Museen die Gleichung „Museum = Territorium + Bevölkerung + Kollektives Erbe“ gelten kann (ebd., S. 386).

Ausgangspunkt der Überlegungen ist, dass sich Museen stärker sozialen Aufgaben zuwenden. Sie begrenzen sich nicht auf die traditionellen Felder des Forschens, Sammelns und Bewahrens, sondern sie beschäftigen sich auch mit den Problemen der Gesellschaft, in der ein Museum existiert. Die Arbeit Neuer Museen als Bildungsinstitution zielt darauf ab, einer Bevölkerung deren Identität bewusst zu machen und zu stärken. Die Zielsetzung geht jedoch über Identitätsbildung hinaus. Das Neue Museum will konkrete Beiträge zur Alltagsbewältigung leisten, indem es Probleme und Lösungsmöglichkeiten aufzeigt.

„Oder weniger problemlastig formuliert: Es geht darum, einen Beitrag zur Integration, Selbstvergewisserung und Entwicklung der Menschen in dieser Gesellschaft zu leisten, deren Teil das Museum ist, wobei es nicht nur um das Geistig-Kulturelle geht, sondern - so jedenfalls der Anspruch - auch ganz 
konkret und praktisch um Hilfe und Unterstützung im Alltag bestimmter Personenkreise.“151

Entscheidendes Element des Aufbaus und der Organisation des Neuen Museums ist das Angebot der aktiven Mitgestaltung und Partizipation an die Bevölkerung. Der verfolgte Ansatz beinhaltet den Anspruch, die Vergangenheit, das heißt das kulturelle und natürliche Erbe, nicht nur zu erfassen, zu dokumentieren, konservieren, zu erforschen und museographisch-didaktisch aufzubereiten, sondern es mit dem Heute zu verbinden, es durch kritische Bewusstmachung für die Bewältigung der Gegenwart nutzbar zu machen (Hauenschild 1988, S. 101). Auch wendet sich die Neue Museologie gegen die rein fachwissenschaftliche Interpretation der Geschichte. Stattdessen sollen alternative Sichtweisen ein Forum bekommen.

Am Beginn eines Ausstellungsprojektes mit Laien steht die Frage, welche Personengruppe bei einem Projekt mitwirken will oder soll. Aus langjähriger Erfahrung am schwedischen Institut Riksutställningar ${ }^{152}$, welches dem Leitspruch „Let the Public make exhibitions!“ folgt, stellt Mitarbeiter Hjorth fest, dass es äußerst schwierig sei, Begeisterung bei Erwachsenen für die zeitintensive Tätigkeit eines Ausstellungsprojekts zu wecken. Leichter ist es, Kinder und Jugendliche, manchmal auch Erwachsene mit ihren Kindern, dafür zu gewinnen. Das Ansprechen konkreter Zielgruppen, zum Beispiel Vereine und Verbände, erleichtert den Zugang zu einem Projekt. Hauenschild stellt in einer zusammenfassenden Bewertung ihrer Studie ebenfalls sachlich ernüchternd fest, dass mit regionaler Museumsarbeit meist nur wenige mobilisiert werden können. „Zum harten Kern der regelmäßig aktiven Laien, die an Entscheidungsund Arbeitsprozessen teilnehmen, können maximal 10-30 Personen gezählt werden.“ (ebd., S. 426)

Die Präsentation einer Ausstellung in einem Neuen Museum unterliegt den gleichen Anforderungen wie jede konventionelle Ausstellung. Die Herausforderung, Ausstellungsinhalte anschaulich darzustellen, ist trotz der partizipativen Ausrichtung nicht selbstverständlich gegeben. Die komplexe und ausstellungsdidaktisch zu lösende Problemstellung des Verhältnisses von Ausstattung und Aussage, Form und Inhalt bleibt

151 Paatsch, Ulrich: Neue Museologie, Nachbarschaftsmuseen, Ecomuseen. Theoretische Bezüge von integrativer Museumsarbeit in Regionalmuseen. Bundesakademie für kulturelle Bildung, Wolfenbüttel, unveröffentl. Skript, 2002, S. 1.

152 Siehe Kapitel 3, Anm. 163. 
bestehen. Insbesondere bei diesem Ansatz sollte die optische Gestaltung nicht dilettantisch wirken und sich in der Qualität der Präsentation nicht von fachwissenschaftlichen Ausstellungen unterscheiden.

Umgesetzt wird das Anliegen der Partizipation in unterschiedlichsten Formen mit variierender Schwerpunktsetzung. ${ }^{153}$ Einerseits gibt es Ausstellungsprojekte, die auch als Sozialarbeit bezeichnet werden können. Dies entspricht am ehesten den Vorstellungen, wie sie in den Leitgedanken der Neuen Museologie formuliert sind. Daneben gibt es aber auch Formen ohne sozialkritische Orientierung, in der nach traditioneller Form museale Objekte im Zentrum stehen und sich die Art der Themenbearbeitung am Laienblick orientiert.

„A focus on youth has enlived the Walker Art Center in Minneapolis, the Aldrich Museum in Ridgefied, Conn. and the New Museum in New York, three institutions have long-term programs with teenagers. Young people are used as advisers, docents, publications producers and even exhibition organizers, thereby encouraging the next generation to feel at home with contemporary art. “" ${ }^{154}$

Ein Beispiel für ein auf Partizipation basierendes Projekt in Zusammenarbeit mit Künstlern und Kulturschaffenden bildet das Festival der Regionen. Das Festival der Regionen ist eines der größten zeitgenössischen Kulturfestivals in Österreich. Es findet seit 1993 alle zwei Jahre im Wechsel mit jährlichen Landesausstellungen an dezentralen Orten im Bundesland Oberösterreich statt. Das Charakteristische dabei ist, dass in

153 Hochreiter verweist darauf, dass ein Museum, welches Komponenten der alltagskulturellen Gegenstandserweiterung, der Territorialität, der Ansprache und Einbeziehung der Bevölkerung und der Interdisziplinarität inkorporiert, als Integriertes Museum bezeichnet und diskutiert wird. Im Jahr 1981 brachte Hermann Auer diesen Begriff in die deutsche Diskussion ein. Das Integrierte Museum als neuer Museumstyp unterscheidet sich in mehrfacher Hinsicht vom traditionellen Museum, nämlich durch seine Eingebundenheit in die Lebenswelt, die Verknüpfung seiner vielfältigen Aktivitäten mit dieser und den Bezug zu aktuellen Problemen sozialer Entwicklung sowie durch die Aufhebung von Spezialisierung und die Vernetzung verschiedener Kulturbereiche zu einer ganzheitlichen Auffassung von Kultur. Vgl. Hochreiter 1994, S. 240.

154 Tucker, Marcia: Museums Experiment with New Exhibition Strategies. In: The New York Times on the WEB vom 1.01.99. http://www. nytimes.com/yr/mo/day/artleisure/museum-exhibit-strategies.html (letzter Zugriff: 01.11.99). 
vielen Projekten die regionale Bevölkerung in den Entstehungsprozess und/oder in die Präsentation eingebunden ist und eine aktive Rolle im Gesamtprojekt hat. Während die Besucher im Museum immer mit dem Produkt eines Prozesses und den Objekten konfrontiert werden, tritt die Bevölkerung der Schwerpunktregionen des Festivals direkt mit dem Prozess in Beziehung. Vermittlung ist ein integrierter Bestandteil des Projektes. Diese Rahmenbedingungen schaffen Raum und Möglichkeit, sich mit Ungewohntem und Fremdem im Kontext des Gewohnten auseinanderzusetzen. Damit bilden sich neue Sichtweisen in vielschichtiger Art und Weise. ${ }^{155}$

Zentrales Kriterium für die Auswahl der Projekte ist die Eingebundenheit vor Ort. Die Bevölkerung ist Akteur und Publikum zugleich. An der Nahtstelle von Kunst und Alltagsleben beziehen die Projekte des Festivals die Bevölkerung in die Auseinandersetzung mit gesellschaftlichen, politischen und künstlerischen Fragestellungen ein. Abseits der Zentren verbindet das Festival der Regionen zeitgenössische Kulturarbeit und Kunstformen mit lokalen Traditionen, Geschichten und Eigenheiten. Programmatisch und inhaltlich soll es kein reines Kunstfestival sein, sondern eine Plattform, auf der ,ansonsten Unmögliches denkbar wird, wächst und geschieht. “" ${ }^{\text {156 }}$ Kunstschaffende, Laien und Bevölkerung, die aufgrund der Programmatik und Logik des Kulturbetriebes keinen Ort haben, sollen zusammengebracht werden. Außerdem sollen die Menschen außerhalb der Städte mit zeitgenössischer Kunst und Kulturarbeit und ebenso umgekehrt bekannt gemacht werden.

„Das erfrischende Charakteristikum des Festivals der Regionen ist der Umgang mit Vielfalt in jeder Hinsicht. Es verbindet die Regionen unseres Bundeslandes, ohne willkürliches Streben nach einer einzig gültigen Darstellung von Kultur und arbeitet konsequent mit den verschiedenartigsten Themen. [...] Es geht nach Programm vor, aber es bleibt im Geschehen beweglich, dem Unvermuteten und Überraschenden verbunden. Vor allem aber wendet es sich ohne die Barriere einer kulturellen Vorbildung - direkt und ohne Umschweife

155 Hutterer, Claudia: Über Begriffs- und Bedeutungsver(w)irrungen. Möglichkeiten, Aufgaben und konkrete Chancen der Kunst- und Kulturvermittlung im Rahmen des Festivals der Regionen. In: Blickpunkte (1999) Heft 2., S. 27.

156 http://www.fdr.at/index.html (letzter Zugriff: 20.08.04). 
an alle Menschen des Landes. Einzige Vorbedingung für einen Festivalbesuch ist Offenheit und Neugier."“157

Das Organisationsteam des Festivals der Regionen formuliert eine Rahmenhandlung in Form eines Themas, in dem sich gesellschaftspolitische, ästhetische und regionale Fragestellungen verknüpfen. ${ }^{158}$ Anhand dieser inhaltlichen Skizze fordert es Interessierte jedweder Provenienz und Profession auf, zu den gestellten Fragen eine mögliche Antwort in Form eines Projektes zu formulieren. Das Gemeinsame aller Projekte ist das Überspringen herkömmlicher Kunstklassifizierungen und die Beziehung zum Ort des Geschehens durch die Beteiligung der Bevölkerung als Akteure und Publikum zugleich. An dieser Nahtstelle arbeiten Künstler mit Kulturinitiativen und den Bewohnern vor Ort zusammen. Das Band der Festivalprojekte ist breit: Es lässt Raum für die kleine, unspektakuläre, aber wirksame Intervention, ebenso für große Entwürfe unter Beteiligung Hunderter von Mitwirkenden. Neben Ausstellungen entstehen Musik- oder Tanzperformances, Klanginstallationen oder Symposien. ${ }^{159}$ „Momentaufnahmen einer Stadt“ nannte sich zum Beispiel das vom Rieder Kulturverein KIK entwickelte Projekt:

„Ein photografischer Zustandsbericht. Ried i. I., 14. August 1997, 11.00 Uhr. Die Feuerwehrsirene heult. Innerhalb von 30 Sekunden versuchen hunderte Personen, ihre jeweilige Lebenssituation zu dokumentieren. Anschließend ist eine Fotoausstellung der Momentaufnahmen in Rieder Schaufenstern zu sehen." (ebd.)

Bei dem Konzept Ausstellungstätigkeit als kulturelle Sozialarbeit stellen Zielgruppenarbeit und Stadtteilbezug Kerngedanken dar. Nicht nur aktuelle Themen zu sozialen Brennpunkten wie Ausländerfeindlichkeit, Arbeitslosigkeit, Drogen, sondern auch Geschichtliches - beispielsweise Herkunft und Tradition bestimmter ethnischer Gruppen - bilden den Inhalt von Ausstellungen, die zur Auseinandersetzung anregen und damit

157 Rammerstorfer, Kurt zitiert in: Verein Festival der Regionen (Hrsg.): Festival der Regionen 1999 - Randzonen, ein Katalog. Linz 2000, S. 138.

158 Titel vergangener Festivals lauteten: Das Fremde (1993), Heiße Heimat (1995), Kunst.Über.Leben - Entdeckungsreisen zu Alltagswundern (1997), Randzonen (1999), Das Ende der Gemütlichkeit (2001), Die Kunst der Feindschaft (2003), Geordnete Verhältnisse (2005).

159 Eine Auflistung und kurze Beschreibung aller Projekte von 1993-2003 siehe http://www.fdr.at/index.html (letzter Zugriff: 20.08.04). 
eine Identität stiftende und zum eigenverantwortlichen Handeln motivierende Funktion erfüllen sollen. Zur Veranschaulichung dieses Konzepts sei eine Ausstellung des Historischen Museums in Amsterdam kurz vorgestellt. Dieses Projekt wollte Zielgruppen dazu verhelfen, sich und ihre Geschichte aktiv ins Museum einzubringen und sie wiederum an vergleichbare oder auch gerade nicht betroffene Zielgruppen zu vermitteln.

Im Jahr 1996 fand die Ausstellung „Amsterdam'daki Anadolu Anatolien in Amsterdam" statt. ${ }^{160}$ Die soziale Dimension stand in solchem Maße im Vordergrund, dass von dieser aus Themenwahl und Themenbearbeitung festgelegt wurden. Die Museumsmitarbeiter übernahmen lediglich beratende und unterstützende Funktion. Das Museum hatte sich mit diesem Projekt vorgenommen, ein Bild des Lebensalltags der türkischen Gemeinschaft in Amsterdam zu vermitteln. Zugleich bildeten diese türkischen Amsterdamer die Hauptzielgruppe. Um die Hemmschwelle für diese Gruppe so niedrig wie möglich zu halten, versuchten die Museumsmitarbeiter Wiedererkennungseffekte zu erzielen. Dies bestimmte die Themenwahl für die Ausstellung und auch deren Aufbereitung, wobei bei der Vorbereitung besonders auf die aktive Beteiligung der Mitbürger aus der türkischen Gemeinschaft gesetzt wurde. Damit sich die Sichtweise der türkischen Bevölkerung in der Themenwahl niederschlagen konnte, wurden zu diesem Zweck die einzelnen Ausstellungseinheiten in enger Zusammenarbeit mit den Mitgliedern der türkischen Gemeinschaft und der türkischen Kulturstiftung Kulsan entwickelt. Ein Anliegen bestand auch darin, dass sich Besuchende während der laufenden Ausstellung noch selbst einbringen konnten:

„Unsere Objektwand war bei der Eröffnung der Ausstellung mit 14 Objekten von türkischen Amsterdamern nur zu einem Teil bestückt. Die Gegenstände waren jeweils mit einer Geschichte verbunden und wir animierten die Besucher, dieses Tableau von Objekten im Verlauf der Ausstellung zu erweitern: Denken Sie einmal über ein wichtiges Ereignis nach, seit Sie hier in Amsterdam wohnen, und denken Sie sich ein dazu passendes Objekt aus - so lautete die Aufforderung. Tatsächlich nahm die Zahl der Objekte an dieser Wand im Verlauf der Ausstellungsdauer stetig zu.“ (ebd., S. 26)

160 Eine skizzierte Darstellung der Grundzüge der Ausstellung siehe: Konsten, Marie-Thérèse: „Amsterdam'daki Anadolu - Anatolien in Amsterdam“ Türken im Historischen Museum. In: Museumsblatt, Mitteilungen aus dem Museumswesen Baden-Württembergs. 21. (1997) S. 26-29. 
Ausstellungskuratorin Konsten betonte die absolute Notwendigkeit eines out-reach-workers als Vermittler zwischen Museum und den türkische Gruppen in Moscheen, Vereinen und Nachbarschaftshäusern der Stadt.

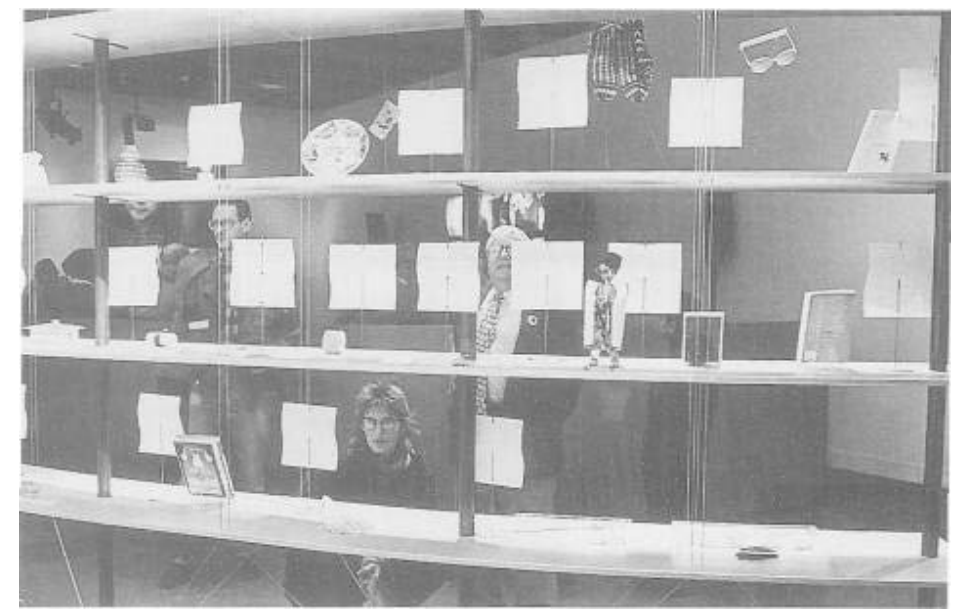

Abbildung 9: Objektwand in der Ausstellung „Amsterdam'daki Anadolu - Anatolien in Amsterdam" im Historischen Museum Amsterdam.

Zum einen war dies nötig, um diese Gruppen zu einem Besuch der Ausstellung generell zu motivieren und zum andern, um sie dazu zu bewegen, bei diesem Besuch ein Exponat mit einer neuen Geschichte für die Objektwand mitzubringen. Anders wäre die Zielgruppe kaum zu erreichen gewesen.

Selbstkritisch fragt Konsten, was mit diesem Projekt erreicht wurde. Die erhofften hohen Besucherzahlen blieben aus, individuelle Besuche blieben gering. Im Gegensatz dazu waren die Gruppenbesuche ein groBer Erfolg. Das Anliegen, gesellschaftspolitisch schwierige Aspekte zu thematisieren oder spezielle Randgruppen zu integrieren, entspricht oft nicht dem breiten Geschmack der Massen. Fehlen berühmte Namen oder Kunstwerke, bleiben große Besucherströme weg und die Presseresonanz fällt geringer aus. Im Vergleich zu populären Themen ist es für weniger prestigeprächtige Projekte zudem schwerer, Sponsorengelder zu akquirieren. Aus ökonomischer Perspektive rechnen sich derartige Ausstellung nicht. „Wenn Sie die Kosten eines solchen Projektes ausschließlich gegen die Einnahmen abwägen, dann sollten Sie sich dieser Art von Projekten sicher nicht zuwenden.“ (ebd., S. 28) 
Die Erfolg des Projekts ist unter ideellen Gesichtspunkten zu betrachten, und so kommt Konsten zu einer nuancierten, positiven Schlussfolgerung. Bei den türkischen Zielgruppen wurde man auf das Historische Museum aufmerksam, und die Ausstellung führte zu Gesprächen und Diskussionen. Für das Museum bot dieses Projekt die Gelegenheit, seine Erfahrung mit den Problemen gegenwartsbezogener Sammlungsstrategien zu erweitern. In diesem Fall ging es nicht allein um den Gegenwartsbezug, sondern zusätzlich um das Thema von Objekten aus einer multikulturellen Gesellschaft.

Berechtigt ist in diesem Zusammenhang sicherlich der Einwand, dass auf Partizipation ausgerichtete Konzepte gemäß der Thesen der Neuen Museologie nur über begrenzte Anwendbarkeit verfügen. Das heißt, dass es sicher kein Modell für jegliche Art von Ausstellung sein kann, sondern eine Ergänzung zum traditionellen Museum ist. Jeder der beiden Museumstypen, das traditionelle Museum sowie das Neue Museum, füllt Leerstellen aus. Ausdrücklich betont Hauenschild, dass sich die Neue Museologie mit der von ihr vertretenen Idee des neuen Museums nicht als Alternative, sondern als neue Dimensionen eröffnende Ergänzung zum etablierten Museumswesen versteht (Hauenschild 1988, S. 12). Die Konzepte der Neuen Museologie sind vor allem für Museen auf lokaler und regionaler Ebene relevant und richten sich an überschaubare, relativ homogene Bevölkerungsgruppen.

Ein auf Partizipation ausgerichtetes Verständnis führt zu einer Neugewichtung musealer Aufgaben. Eine solche Orientierung hat zur Folge, dass Funktion und Aufgabe musealer Ausstellungen neu formuliert werden müssen, die museologische und nicht mehr nur ausstellungsdidaktische Fragestellungen zum Inhalt haben. Wenn Ausstellungen unter dem Leitgedanken der Partizipation oder - allgemeiner betrachtet - Besucherorientierung konzipiert werden, kann damit eine Verschiebung der Schwerpunkte von objektorientierten hin zu rezeptionsorientierten Präsentationen führen. ${ }^{161}$

„The showing of objects has been the museums historic mission. Exhibition traditionally put objects on view, inviting visitors to inspect and contemplate them, guided by the epistemically privileged museum authority. But what is observed in the museum today is no longer unequivocally an object; objects

161 Vergleichsweise dominiert in Amerika gegenwärtig die kontextuelle, identifikationsstiftende Vermittlungsmethode des story telling, eine Form der narrativen Ausstellungsinszenierung, die Museumskonzeptionen. 
have been reconstituted as sites of experience, and museums increasingly hold themselves accountable for delivering experiences.“" ${ }^{162}$

Ähnlich wie bei dem narrativen sowie künstlerischen Ansatz verändert sich damit die Rolle und Bedeutung der Museumsexponate. Ein gemeinsames Kennzeichen liegt darin, dass die musealen Exponate, die eigentlich die Hauptakteure einer Ausstellung gemäß traditioneller Vorstellung sind, in manchen Fällen in den Hintergrund treten. Im Gesamtarrangement der Ausstellungsinszenierung spielen diese dann eine beigefügte oder untergeordnete Rolle. In der Weiterführung dieses Ansatzes kann sogar völlig auf museale Exponate verzichtet werden. Provokativ formulierte ein Mitarbeiter des renommierten Instituts Riksutställningar ${ }^{163}$, dass er Exponate als Gebrauchsgut betrachtet, die für eine Öffentlichkeit existieren und deshalb gezeigt werden sollten, auch auf die Gefahr hin, dass Objekte Schaden nehmen könnten. ${ }^{164}$ Berechtigterweise führte dies zu vehementen, ablehnenden Reaktionen von Seiten der Restauratoren und Konservatoren.

$\mathrm{Ob}$ das Museum als Forum unterschiedlicher Gruppen dient, indem es deren Geschichte oder aktuelle Probleme dokumentiert, stellt einen museologisch zu analysierenden Problemkreis dar. Kritisch verweist Paatsch darauf, dass dies zu der berechtigten Frage führt, ob es sich bei diesem Museumsverständnis noch um ein Museum handelt oder in manchen Fällen der Begriff Stadtteilzentrum passender wäre. Die Grenzen erweisen sich als fließend, auch deshalb, weil sozialpädagogische Einrichtungen zunehmend mit musealen Methoden unter anderem mit Ausstellungen arbeiten (Paatsch 2002, S. 1).

162 Hein, Hilde S.: The Museum in Transition. A philosophical Perspective. Washington/London 2000, S. 5.

163 Das staatliche Institut Riksutställningar in Schweden wurde 1965 gegründet und übernahm die Aufgabe, Wanderausstellungen zu konzipieren. Mit dem Ziel der Demokratisierung der Bildung sollen Ausstellungen auch in die Landregionen transportiert werden. Die Arbeit des Instituts zeichnet sich durch Experimentierfreude in der Ausstellungsgestaltung aus. So wird zum Beispiel immer wieder das Publikum eingeladen, Ausstellungen zu gestalten. http://www.riksutstallningar.se/riksnyform/ eng/index2.html. (letzter Zugriff: 23.08.03).

164 Gegen diese Position wehrt sich jedoch seit dreißig Jahren vehement Jan Hjorth, Mitarbeiter bei Riksutställningar. Hjorth, Jan: Travelling exhibits: the Swedish experience. In: Miles, Roger/Zavala, Lauro (Hrsg.): Towards the museum of the Future - New European Perspectives. London/New York 1994, S. 106. 
Tatsächlich gewinnen Museen als Orte der Begegnung und Verständigung unterschiedlicher sozialer Gruppen im internationalen Maßstab immer mehr an Gewicht. In der aktuellen Diskussion geht es unter anderem darum, was Museen sowie Kulturzentren zur Pflege der noch lebenden, kulturellen Tradition beitragen können oder wie durch sie die kulturelle Identität von Minderheiten bewahrt werden kann.

„Wenn der Internationale Museumsrat (ICOM) den Internationalen Museumstag 2000 unter das vielleicht etwas zu sehr nach Weltverbesserung klingende Motto ,Museums for Peace and Harmony in Society' gestellt hat, so wird damit nichtsdestoweniger ein durchaus ernst zu nehmender sozialpolitischer Auftrag formuliert. “ 165

Selbst wenn im nationalen und im regionalen Umfeld die sozialen Unterschiede weit weniger scharf ausgeprägt sind, können Museen dazu beitragen, mehr Verständnis für gesellschaftliche Gruppen zu entfalten, denen man in seinem engeren Lebenskreis, der heute zunehmend auf die Kleinfamilie und Berufskollegen zusammenschrumpft, nicht ohne weiteres begegnet. Langenstein stellt in diesem Zusammenhang die Frage nach dem gesellschaftlichen Standort der Museumspädagogik. Seiner Meinung nach sollten Museumspädagogen vorurteilsfrei, offen und dialogbereit sein, also nicht dogmatisch oder gar ideologisch. Er stellt aber fest, dass Museumspädagogen nicht unpolitisch sein können. Sie müssen Interesse an gesellschaftlichen Problemen und Fragen haben (ebd., S. 8). Dies führt zu Stellungnahme und Interpretation. Inwiefern dies einerseits notwendig, aber dennoch gleichzeitig problematisch sein kann, soll im nächsten Kapitel erörtert werden.

165 Langenstein, York: Geleitwort. In: Landesstelle für die nichtstaatlichen Museen in Bayern 2002, S. 8. 


\section{Metakommunikative Aspekte der INTERPRETATION}

Museale Ausstellungen sind immer räumliche Konstruktionen einer Auseinandersetzung mit Geschichte, Kultur und Gesellschaft. Diese Konstruktionen basieren auf Forschungen innerhalb der Sammlung und der Wissenschaften sowie auf Vorstellungen und Vorgängen innerhalb einer Gesellschaft. Ausstellungen sind dabei immer verknüpft mit aktuellen Überzeugungen, Haltungen und Interessen der Mitarbeiter, die wiederum in ein gesellschaftliches System eingebunden sind. Daraus folgt, dass die Art und Weise der Präsentation neben den Ausstellungsinhalten immer auch Hinweise auf akademische Überzeugungen, Lehrhaltungen und -intentionen gibt. Ausgewählte Exponate und -themen verweisen auf Sammlungsinteressen der Kuratoren. Die Raumnutzung und Gestaltungsmittel geben Hinweise auf die hauseigene Geschichte sowie auf die Ausstellungsgestalter. Diese vielfältigen Verweise können als metakommunikative Aspekte von Ausstellungen beschrieben werden. ${ }^{1}$

Die Metakommunikation von Ausstellungen betrifft alle Kommunikationsphänomene, die sich nicht direkt auf Objekte und deren Geschichten beziehen, sondern auf die der Präsentation zugrunde liegenden akademischen, museologischen, politischen und individuellen Standpunkte. Damit widmet sich die Metakommunikation Phänomenen außerhalb des Ausstellungskontextes, jedoch nicht im Sinne des Verweisens auf Gegenstände selbst, sondern auf diese als kulturelle Phänomene innerhalb der Zuordnungen von Bedeutungen. Metakommunikation fragt nach den subtil wirkenden Botschaften, die auch in einer negativen Funktionalisierung durch politische Systeme propagandistisch ausgenutzt werden können.

In Kapitel drei zeigte ich auf, dass die Integration des Museumspädagogen im Ausstellungsteam in der Konsequenz dazu führt, dass lineare

1 Scholze, Jana: Medium Ausstellung. Lektüren musealer Gestaltung in Oxford, Leipzig, Amsterdam und Berlin. Bielefeld 2004, S. 35ff. 
Modelle musealer Kommunikation, bei denen der Fachwissenschaftler allein für die Formulierung der Inhalte zuständig ist, aufgegeben werden. Wirkt ein Museumspädagoge bei der Gestaltung der Inhalte mit, bedeutet dies, dass er auch für die Form der Interpretation verantwortlich wird. Diese generell positive Möglichkeit muss jedoch auch kritisch beleuchtet werden. Zwei Problemfelder kristallisieren sich heraus: Da der Entstehungsprozess einer Ausstellung im Spannungsfeld vieler Wirkungsfaktoren von politischen Machtkonstellationen bis hin zu finanzieller Einflussnahme stattfindet, verweist dies aus historischer Perspektive zunächst auf die Problematik der ideologischen Vereinnahmung der Museumspädagogik. Zum anderen ist die Museumspädagogik gegenwärtig mit den Auswirkungen der Eventkultur konfrontiert.

Neutralität und Objektivität der vermittelten Inhalte sind Qualitäten musealer Ausstellungen. Dies kann zu weitgehend kritikloser Wahrnehmung der Ausstellungsinhalte führen. Damit entsteht die Gefahr von Mythosbildung und ideologischer Beeinflussung. Ausstellungen sind jedoch, wie bereits mehrfach festgestellt, weder in Bezug auf ihre gesellschaftliche Position noch auf ihre präsentierten Inhalte neutrale Orte. Werden in Ausstellungen zum Beispiel gesellschaftspolitische Themen aufgegriffen, bedeutet dies Stellungnahme und Positionierung. Dies kann, wie die deutsche Geschichte zeigte, sich auch in das Negative verkehren. Die Ausnutzung dieser Möglichkeit fand in extremer Form während des Nationalsozialismus statt. Auch in den Museen der ehemaligen sozialistischen Länder wurde der Bereich Museumspädagogik der Propagandaabteilung zugeordnet.

Demgegenüber steht die Museumspädagogik heute vor den Herausforderungen des Einzugs der Eventkultur. Stärker als bisher haben Veranstaltungen, die früher eher der Unterhaltungskultur als der Bildungsarbeit zugerechnet wurden, Eingang in das Museum gefunden. Kindler/Liebelt sprechen in diesem Zusammenhang von einem Perspektivenwechsel. Sie erkennen das Hauptproblem der Museumspädagogen darin, dass unter dem Diktat leerer Kassen vom Museum attraktive und populäre Ereignisse gefordert werden, die sich mit Erfolg in der Medien- und Freizeitlandschaft behaupten, um damit ein Massenpublikum zu mobilisieren. (Kindler/Liebelt 2002, S. 27). Manche Museumspädagogen befürchten, dass dabei die individuelle Qualität erlebter Sinnlichkeit und erkennender Betrachtung in musealen Ausstellungen ins Hintertreffen geraten kann. Kritisch merkt Hauenschild an, dass die alltäglichen, museumspädagogischen Aktivitäten häufig nicht über einen kurzweiligen 
Freizeitspaß hinausgehen. Dies sei eine Form der Integration der Museen in die übermächtige Unterhaltungsindustrie (Hauenschild 1988, S. 9).

Diese zwei Problemkreise stehen im Zentrum des vierten Kapitels. Sie bilden die Basis für metakommunikative Aspekte der Ausstellungsanalyse, in der ich die politische sowie auch die kommerzielle Komponente von Ausstellungen hinterfrage.

\subsection{Die politische Dimension}

Ästhetische und pädagogische Überlegungen spielen bereits bei der Themenfindung und Konzeptualisierung von Ausstellungen eine entscheidende Rolle. Bei der politischen Dimension richtet sich der Blick auf die Ausstellungsmacher und die Frage, inwiefern die Auftrags- und Geldgeber, sei es aus der Politik, Wirtschaft oder Gesellschaft, die Ausstellungsinhalte subtil bestimmen. Durch historische Erinnerungsangebote werden zum Beispiel politische oder wirtschaftliche Interessen subjektiv verankert und abgesichert. Auch Fragen nach der Repräsentation, Legitimation von Herrschaft bzw. der Organisation von Machtverhältnissen spielen eine Rolle. In den vorherigen Kapiteln argumentierte ich für einen ganzheitlichen Ansatz bei der Konzipierung von Ausstellungen unter Berücksichtigung der ästhetisch-sinnlichen Ebene und somit der emotionalen Komponente. Die kognitive Ebene des rationalen Erfassens wird damit zunächst zurückgedrängt. Doch gerade diese Indienstnahme und Funktionalisierung von Emotionen erweist sich als höchst problematisch, wenn sie im Dienste von Ideologien steht. Die Schlussthese Roths zu seiner Studie über die Institution Heimatmuseum fasst dies treffend zusammen:

„Die Untersuchung der Institution Museum erbringt den Beweis, daß die Geschichte dem gehört, der sich der Institution, ihrer Interpretation und Vermittlung bemächtigt, wobei die Methoden und Formen der Bemächtigung äuBerst differenziert und indirekt sein können.“ (Roth 1990, S. 263) ${ }^{2}$

2 Die Forschungsarbeit von Martin Roth untersucht die Geschichte der Institution Heimatmuseum und geht dabei auf die Reglementierung des volkskundlich-kulturhistorischen Museums durch die nationalsozialistische Kulturverwaltung sowie auf die Präsentationsästhetik und Darstellungspraxis ein. Siehe Kapitel 1, Anm. 12. 


\section{Emotionalisierung und die Rhetorik einer Ausstellung}

Die rhetorischen Aspekte konstituieren sich aus Elementen wie die Auswahl von Themen, deren Reihenfolge und Beziehungen untereinander sowie ihre Darstellung im Kontext der Gesamterzählung. Mittel wie Hierarchisierung und Betonung einiger Themen gegenüber solchen, die nur gestreift und beiläufig erwähnt werden, legen die Codierung innerhalb der Darstellung fest. Die Entscheidungen dafür werden von den Initiatoren der Ausstellung getroffen, weswegen sie als metakommunikative Elemente definiert werden können (Scholz 2004, S. 135). Die diesen Entscheidungen zugrunde liegenden Motivationen können politischer, historiographischer, sozialer, pädagogischer, akademischer oder auch individueller Art sein. Sie beabsichtigen immer, mit der Präsentation zumindest eine Interpretation und Haltung zu dem ausgewählten Thema zu demonstrieren. Die subtilen Botschaften wirken meist auf affektiver Ebene und entziehen sich zunächst der bewussten Reflexion.

Wie verschiedene Studien gezeigt haben, war zum Beispiel die separierende Darstellung der Kulturen in Völkerkundemuseen des 19. Jahrhunderts bis weit ins 20. Jahrhundert hinein eine wirksame Methode, ein Schubladendenken zu erzeugen. ${ }^{3}$ Dies gründete auf der Vorstellung, dass sich Kulturen klar voneinander trennen ließen. Das Durchwandern des geographischen Raums bedeutete, nacheinander jeweils für sich stehenden Kulturen zu begegnen. Dies diente auch dazu, durch den Vergleich mit anderen gerade die kulturelle, technologische oder moralische Überlegenheit des eigenen Landes herauszustellen. Die Bemühung des Geschichtsfortschritts entsprach einer Strategie, geographisch bedingte Unterschiede durch einen mehr oder weniger hohen Entwicklungsstand zu erklären. Das räumlich Entfernte wurde stillschweigend, manchmal aber auch ganz unverblümt, zugleich früheren, weniger fortschrittlichen Epochen zugeordnet. Das Museum artikulierte damit zum einen den ganz unverwechselbar eigenen Werdegang einer Nation und zum anderen die Nation als triumphales Endstadium eines stetigen Fortschreitens.

„Da sich dieser objektive Blick in Museen hauptsächlich auf Darstellungen mehr oder weniger schubladisierter, fein säuberlich voneinander abgegrenzter Welten richtete, half er gleichzeitig, nationale Identitäten und kulturrassenoder geschlechtsbezogene Unterschiede zu objektivieren.“ (ebd. 130)

3 Macdonald, Sharon J.: Nationale, postnationale, transkulturelle Identitäten und das Museum. In: Beier 2000, S. 128. 
So fanden sich im Museum Rassentypologien, Verkettungen und Entwicklungsabläufe optisch aufbereitet, die nicht zuletzt wegen ihrer Anschaulichkeit Faktizitätscharakter erhielten. Die Ordnungsprinzipien der Ausstellungen galten als Abbild zugrunde liegender Wirklichkeiten, die den durch die ausgestellten Artefakte präsentierten Tatsachen angeblich innewohnten. Den hohen Grad an Glaubwürdigkeit der visuell aufbereiteten Fakten im Rahmen musealer Präsentationen machte sich auch das nationalsozialistische System zu Nutze. Propagandaausstellungen, eingebettet in ein Gesamtsystem propagandistischer Maßnahmen, trugen dazu bei, die nationalsozialistische Weltanschauung zu verbreiten. Dazu wurde ein hoch reflektiertes Instrumentarium sowohl auf kommunikativer, inhaltlicher als auch gestalterischer Ebene eingesetzt. ${ }^{4}$

Die dramaturgischen Inszenierungen nationalsozialistischer Propagandaausstellungen vermittelten ideologische Botschaften auf emotionaler Ebene. Dabei hatten moderne Gestaltungsprinzipien eine entscheidende Bedeutung. Der damit erzielten Propagandawirkung wurde ein künstlerischer Eigenwert zugestanden, der sich nicht vom Inhaltlichen und Gegenständlichen her ergab, sondern auf der bewusst abgestimmten Anordnung von Inhalt und Stoff beruhte, die insbesondere auf die Emotionen der Rezipienten zielte. ${ }^{5}$ Mit Hilfe expressionistischer und dadais-

4 Die Propagandaausstellungen aus dem Zeitabschnitt von 1932 bis 1945, die zwar mit künstlerischem Anspruch gestaltet, jedoch auf ein außerkünstlerisches, wissenschaftliches, ökonomisches oder politisches Thema bezogen waren, sind gegenwärtig noch in eine Tabuzone abgedrängt. Eine erste Annäherung im Sinne einer Grundlagenforschung zu einem interdisziplinären Diskurs wurde 1999 von Kivelitz vorgelegt, der sich umfassend mit den Propagandaausstellungen in europäischen Diktaturen befasste. Zur Rekonstruktion der Ausstellungen unterzog Kivelitz erstmals umfassendes Bild- und Quellenmaterial einer Analyse. Aufgrund der Fülle des Materials blieben zwangsläufig viele Fragen unbeantwortet, so zum Beispiel eine Analyse der Ausstellungskonzepte im Detail oder karrierebiographische Aspekte der Gestalter und deren nationalistischer Ausbildungs- und Werdegang. Kivelitz, Christoph: Die Propagandaausstellung in europäischen Diktaturen. Konfrontation und Vergleich: Nationalsozialismus in Deutschland, Faschismus in Italien und die UdSSR der Stalinzeit. Bochum 1999.

5 Der hohe Stellenwert der Gestaltung drückte sich zum Beispiel auch in den Worten eines zeitgenössischen Rezensenten aus: „Die in Wort und Bild vor uns hingestellten Tatsachen müssen wie Hammerschläge, wie Schüsse auf uns fallen. Höchste Kunst der Propaganda ist Einwirkung auf die Fassungskraft und die Gemütslage des Beschauers. Er muß mitgehen, 
tischer Verfahren wurden „psychologische Stimmungsarchitekturen“ entworfen, die das ausgestellte Material in eine geschlossene Dramaturgie einbanden (Kivelitz 1999, S. 343). Mittels kulissenhafter Inszenierungen wurden die ideologischen Botschaften zu eindringlichen Erlebnissen.

Das NS-System griff in der Aufbauphase zur Inszenierung von Propagandaausstellungen auf Methoden, die vom Bauhaus, zum Teil auch vom Konstruktivismus sowjetischer Prägung entwickelt worden waren, zurück. ${ }^{6}$ Walter Gropius steht zusammen mit anderen Mitarbeitern des Bauhauses als Repräsentant einer experimentellen Ausstellungsgestaltung, die aufgrund ihrer ästhetischen Merkmale unter den weiten Begriff der Neuen Sachlichkeit subsumiert werden kann. Die Neue Sachlichkeit wurde nach 1933 in das von einem Stilwirrwarr gezeichnete Repertoire nationalsozialistischer Gestaltung aufgenommen und durch das Symbolund Zeichen-System der NS-Ideologie modifiziert. Die meisten gestalterischen Mittel entstanden in den 1920er Jahren und wurden im Dritten Reich mit den typischen Elementen nationalsozialistischer Präsentation ausgestattet, nämlich mit „eindringlicher Symbolkraft und Übersteigerung der Größenverhältnisse“ (Roth 1990, S. 196). Als andere Konstituente galt das Prinzip der Montage, die zur Sachlichkeit in einem gewissen ideologisch-antagonistischen Verhältnis stand. Beide Anteile sind als dichotomes Begriffspaar zu verstehen. In der Methode der Mischung von Sachlichkeit in Bezug auf die graphische Gestaltung und Montage in Bezug auf die Symbol-Pädagogik sieht Roth wesentliche Gestaltungselemente der Propaganda-Ausstellung des Dritten Reichs (Roth 1990, S. 195).

Die Kombination dieser Gestaltungsstrategien lässt sich in der Darstellung „Das Anwachsen der kommunistischen Wählermassen“ in der Abteilung „Die revolutionäre Kampfzeit der Weimarer der Republik“ fassbar nachvollziehen. ${ }^{7}$

damit er den Rhythmus dieses politischen Geschehens empfindet." Vgl. N.N.: Antibolschewistische Schau - Ihre künstlerische Gestaltung. In: Münchener Neueste Nachrichten vom 18.11.36.

6 In den ersten Jahren der NS-Diktatur arbeiteten noch berühmte Vertreter des Bauhauses an exponierter Stelle für den Staat. Walter Gropius, Joost Schmid und Mies van der Rohe gestalteten zum Beispiel 1934 die „NEMetall-Schau“ in der Ausstellung „Deutsches Volk - Deutsche Arbeit“. Vgl. Roth 1990, S. 203.

7 Diese Abteilung befand sich in der Ausstellung „Der Bolschewismus Große antibolschewistische Schau“ in München, Bibliotheksbau des Deut- 


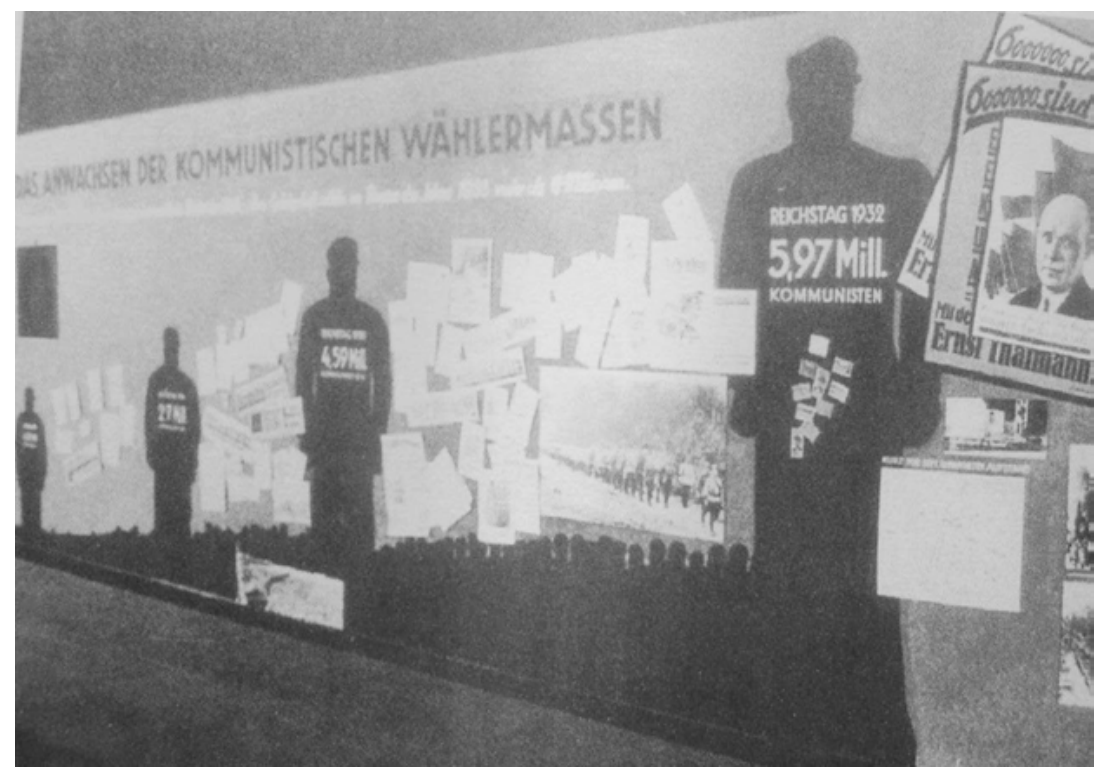

Abbildung 10: Blick in die Abteilung „Die revolutionäre Kampfzeit der Weimarer Republik“, „Das Anwachsen der kommunistischen Wählermassen“ in der Ausstellung „Der Bolschewismus - Große Antibolschewistische Schau“.

Eine Abfolge bedrohlich anwachsender, schwarzer Silhouetten versinnbildlichte hier den Zustrom der Wählermassen zur kommunistischen Partei. Die dunkle Figur wuchs bedrohlich und wurde überlebensgroß. Dennoch wurde eine Seriosität der Information vermittelt, indem die schwarze Silhouette lediglich den Bildhintergrund für statistische Angaben über die steigende Zahl der Kommunisten bildete. Ergänzt wurde dieses Schaubild durch in chaotischer Anordnung über die Wand verteilte Zettel, Plakate und Fotographien ,von zerfetzten und zerstümmelten Körpern deutscher Menschen, die von den roten Untermenschen niedergemetzelt wurden.“ (Brunner zitiert in Kivelitz 1999, S. 217) Dies stand der Entstehung und Ausbreitung der NSDAP entgegen, die dem Gegenüber ein Sinnbild für Ordnung präsentierte. Bolschewismus und Nationalsozialismus repräsentierten so den Gegensatz von Zerstörung und Aufbau. Dieser Gegensatz spiegelte sich in der Gestaltung wider: Auf einem großformatigen Photo waren in gleichförmigem Schritt Sol-

schen Museums vom 07.11.36-31.01.37. Eine ausführliche Beschreibung und fotographische Dokumentation siehe Kivelitz 1999, S. $216 \mathrm{ff}$. 
daten zu sehen, wie sie sich in die Marschordnung der SA fügten. Dem Betrachter wurde somit suggeriert, dass mit dem Fortschritt der völkischen Bewegung die destruktiven, negativen Kräfte des Bolschewismus gebannt werden können.

In der Darstellungspraxis orientierte man sich zunehmend weniger am Originalexponat, sondern bezog dieses in eine didaktisch aufbereitete Präsentation ein. Das Exponat an sich wurde zu Gunsten einer lehrbuchartigen Aufbereitung abgewertet (Roth 1990, S. 197). Fotomontagen, symbolhafte Schautafeln, montierte Szenarien aus dreidimensionalen Objekten, dreidimensionale Schautafeln, Karten, Statistiken, Diagramme und plakative Verarbeitungen von Schriften dienten einer rein sinnbildhaften, allegorischen Verdeutlichung nationalsozialistischer Propaganda und politischer Erziehungsformeln. Die eindeutige Illustration bestimmte die Interpretation. Großmontagen hatten durch eine verwirrende Vielfalt vor allem eine assoziativ-erzieherische, eine unbewusst leitende, hinführende Wirkung.

In den Großausstellungen wurde mit neuen Darstellungsformen experimentiert und Präsentationsmodelle entwickelt. Statt der üblichen Kojen bevorzugte man offene, mit Glas- oder Plexiglas unterteilte Hallen. Wand, Boden und Decke wurden in die Gestaltung mit einbezogen. Herbert Bayer experimentierte zum Beispiel im Jahr 1935 mit unterschiedlichen Betrachtungsperspektiven. Er entwickelte Anschauungskonzepte, die durch günstige Sehwinkel eine plastische Gesamtsicht vermitteln sollten. Die Räume waren so angeordnet, dass sie für einen Rundgang geeignet waren, durch den der Besucher unmerklich geleitet wurde (Staniszewski 1998, S. 33). Die nach ganzheitlichen Gesichtspunkten entwickelte Präsentation und die Einbindung in einen dramaturgischen Aufbau unterbanden reflektiertes Erfassen oder kritische Distanz.

Im Rahmen dieser Studie kann die medien- und massenwirksame Darstellung nationalsozialistischer Propagandaausstellungen, die überzeugende Beispiele für den Einsatz von rhetorisch manipulativer Ausstellungssprache sind, nur angedeutet werden. Da sich auf diesem Feld ein Forschungsdefizit zeigt, sollte dieser Kontext jedoch nicht ausgeblendet werden. ${ }^{8}$

8 Eine umfangreiche, wissenschaftliche Aufarbeitung dieses Themenbereichs steht bis heute aus. Obgleich Recherchen des Berliner BauhausArchivs zur Rolle einzelner Bauhaus-Künstler und ihrer Schüler in der Zeit des Nationalsozialismus ahnen lassen, dass das Medium der Propagandaausstellung im NS-Regime eine ebenso wichtige Rolle wie im fa- 
Trotz des mittlerweile in den Wissenschaften vorhandenen Bewusstseins über die Konstrukthaftigkeit von Wissen und Forschung bedeutet dies jedoch nicht zwingend eine Abkehr von Ausstellungspräsentationen, die es vermeiden, eindimensionale Geschichtsbilder zu produzieren. Scholze verweist darauf, dass die Art und Weise des Vorbringens einer Überzeugung oder des Vermittelns einer Haltung einflussreich sei . Diese könne beispielsweise „persuasiv, appelativ, präskriptiv oder präsumptiv“ sein (Scholz 2004, S. 36).

Ein aktuelles Beispiel für unterschiedliche Formen von Rhetorik und der damit intendierten Ziele der Ausstellungsmacher zeigte sich an den zwei Versionen der Ausstellungen über die Verbrechen der Wehrmacht. In der Gegenüberstellung lassen sich die unterschiedlichen konzeptionellen Ansätze aufzeigen. Während die erste Fassung plakative, appelative Mittel einsetzt, verfolgte die überarbeitete Ausstellung einen kritisch differenzierenden Ansatz.

Die historische Ausstellung „Vernichtungskrieg. Verbrechen der Wehrmacht 1941 bis 1944“ des Hamburger Instituts für Sozialforschung bewirkte großes öffentliches Interesse, gleichzeitig polarisierte sie aber auch Besucher in Befürworter und heftige Gegner. ${ }^{9}$ Widerspruch erfolgte zunächst von politischer Seite und später von namhaften Historikern. ${ }^{10}$ Kritisiert wurden Einseitigkeiten, Verzerrungen und Pauschalverurteilungen. Die Ausstellung setzte bewusst auf die Wirkung von schockierenden Bildern. Sie verfolgte in der Präsentation und Didaktik ein konventionelles Schema. Auf Ausstellungstafeln entwickelte sie ihre Thesen in Textkolumnen mit Überschriften und Photos. In den Ausstellungsmedien nahm sich diese Ausstellung somit zurück. Die mitunter sehr plakativen und den Inhalt verkürzenden Überschriften der Textelemente gaben eine Grundorientierung über die Ausstellung, vermittelten

schistischen Italien gespielt hat, findet die Propagandaausstellung von westlicher Seite bisher kaum Beachtung.

9 Diese Ausstellung ist als Beitrag des Hamburger Instituts für Sozialforschung unter der Leitung von Prof. Dr. Jan Philipp Reemtsma zum 50. Jahrestag des Kriegsendes konzipiert worden. Sie wurde in dem Zeitraum zwischen 1995 bis 1999 in 34 Städten gezeigt und nach Angaben der Veranstalter von circa 850.000 Menschen besucht.

10 Eine ausführliche Beschreibung der Ausstellung sowie der vorgebrachten Kritik siehe Bartov, Omer/Brink, Cornelia u.a.: Bericht der Kommission zur Überprüfung der Ausstellung „Vernichtungskrieg. Verbrechen der Wehrmacht 1941 bis 1944“. 2000. 
aber zugleich eine eindringliche Deutung des präsentierten Materials. ${ }^{11}$ Im Textteil hingegen wurden die Überschriften selbst wiederum relativiert. In der inszenatorischen Hervorhebung der Abteilung „Eisernes Kreuz" bündelte sich die Darstellungstechnik der Ausstellung. Dort war die Rhetorik der Präsentation am besten erkennbar. Die Fotos hingen unkommentiert in langen Bildreihen. Durch Wiederholung der gleichen Bildthemen, so zum Beispiel 89 Fotos von Erhängungen und 75 Fotos von Erschießungen, verstärkten die aneinandergereihten Fotos den Eindruck der Massenhaftigkeit der Verbrechen der Wehrmacht. Eine Klärung der Orte oder Kontexte unterblieb. Ein unbegrenzter und undifferenzierter Vorwurf der aktiven Beteiligung der gesamten Wehrmacht an der Vernichtungsmaschinerie entstand.

Bei der Argumentation der Ausstellung kam den über 1400 historischen Fotographien, die schon rein quantitativ die Textdokumente deutlich überwogen, die tragende Rolle zu. Die Fotographien wurden in der Ausstellung als die eigentlichen Beweise dafür gezeigt, dass Verbrechen stattgefunden hatten. Die Ausstellung präsentierte die Täter am Tatort im Augenblick der Tat, während sie quälten, erhängten, erschossen oder den Verbrechen zuschauten. Diese Fotographien wurden durch schriftliche Dokumente, Zeugenaussagen, historische Erklärungen und Bildlegenden ergänzt. Die Ausstellungsmacher bedienten sich anklagender, rhetorischer Mittel, um Ausmaß und Brutalität der Verbrechen anschaulich zu machen.

„Sie [die Ausstellung, Anm. d. V.] häuft Beweise und spitzt die Beweislage durch Auswahl und Anordnung der Fotos visuell zu, um diejenigen, die sich ihr Urteil bilden sollen, vom vorgetragenen Vorwurf zu überzeugen und ihre Empörung über das massenhaft begangene Unrecht zu wecken. Aus der fotografischen Trophäe, dem Erinnerungsobjekt, dem Reportagebild wird der Tatbeweis, aus der Ausstellungswand gleichsam ein Pranger.“(ebd. S. 19)

11 Besonders auffällig war dies in der Abteilung „Partisanenkrieg“ mit der griffigen, aber stark verkürzenden Überschrift „Partisanenkrieg ohne Partisanen“. Eine Differenzierung erfolgte im anschließenden Text. 


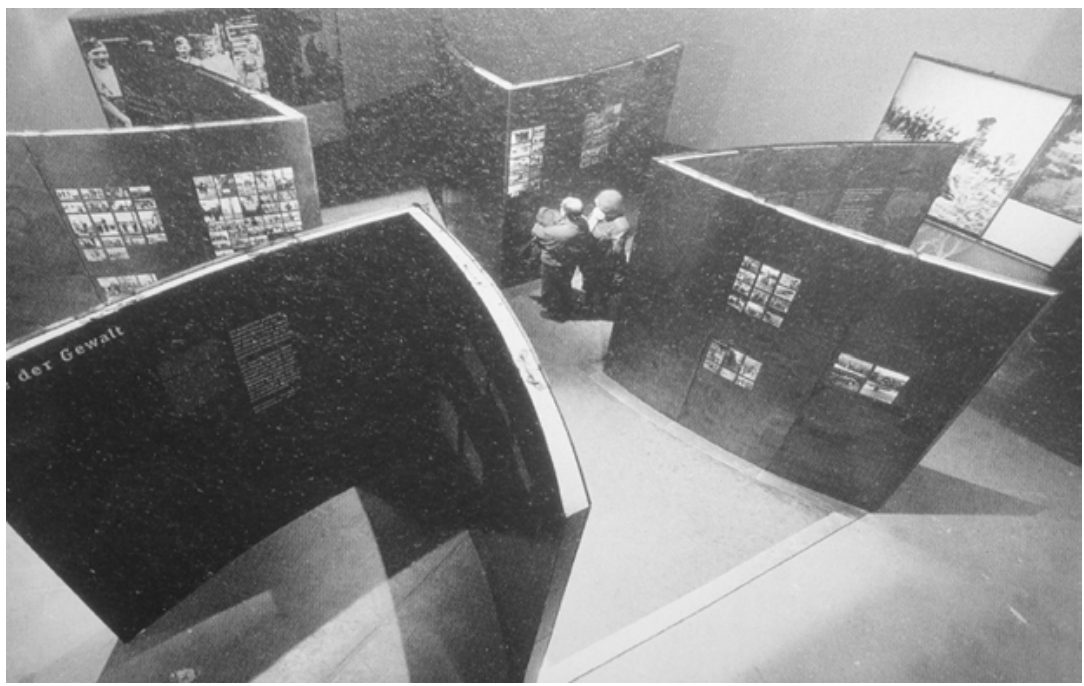

Abbildung 11: Inszenierung „Eisernes Kreuz“ in der Ausstellung „Vernichtungskrieg - Verbrechen der Wehrmacht 1941-1944“, Ausstellungsraum Hamburg im Jahr 1995

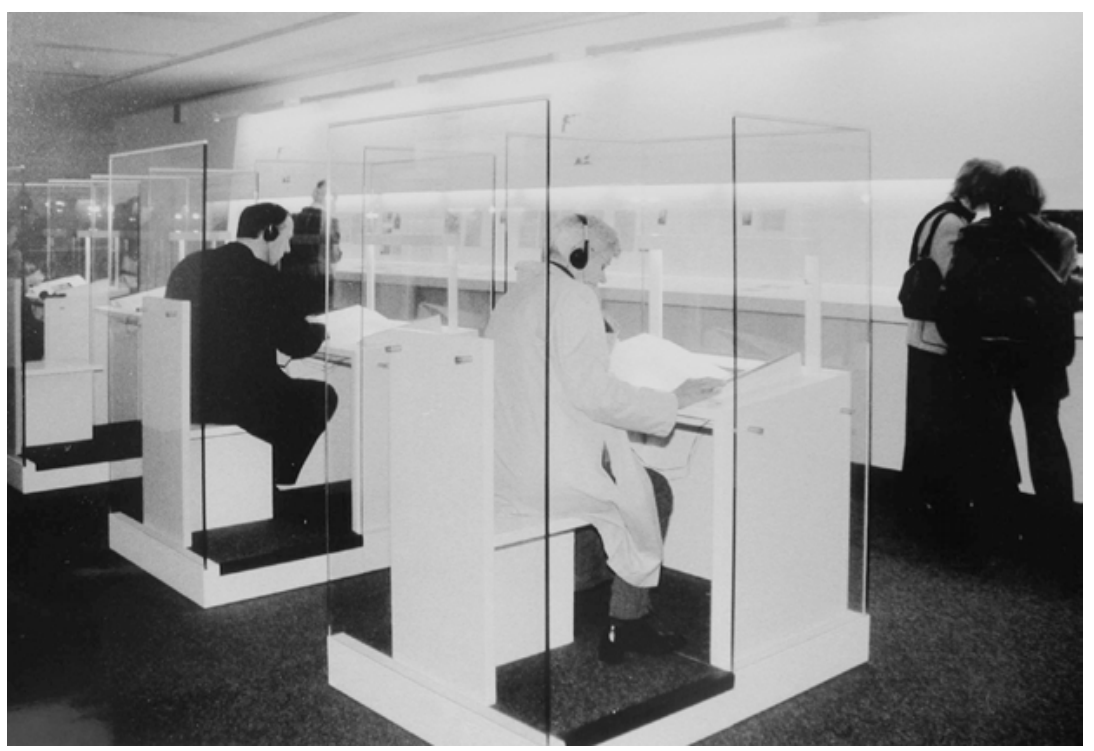

Abbildung 12: Blick in die Ausstellung „Verbrechen der Wehrmacht. Dimensionen des Vernichtungskrieges 1941-1944“,

Stadtmuseum München im Jahr 2002. 
Nachdem die Glaubwürdigkeit der Präsentation aufgrund zahlreicher Kritik nicht mehr gegeben war, wurde die Ausstellung geschlossen und eine unabhängige Kommission von Wissenschaftlern zur Überprüfung eingesetzt. ${ }^{12}$. Der ausführliche Bericht der Untersuchungskommission entlastete das Ausstellungsteam vom Vorwurf der Fälschung im Sinne der leitenden Fragestellungen und Thesen (ebd. S. 91). Dennoch führte die Überprüfung zu der Erkenntnis, dass bei der Gestaltung der Ausstellung sachliche Fehler, Ungenauigkeiten und Flüchtigkeiten bei der Verwendung des Materials aufgetreten waren. Vor allem durch die Art der Präsentation entstanden allzu pauschale und suggestive Aussagen (ebd.). Aufgrund dessen empfahl die Kommission, die Ausstellung gründlich zu überarbeiten.

„Auch sollte die Argumentation der Ausstellung weniger durch den Gestus der Staatsanwaltschaft als durch die Theorie und Methodologie der Geschichtswissenschaft geprägt sein. Die Ausstellung sollte ihr Material präsentieren, aber die Schlussfolgerung so weit wie möglich den Besuchern überlassen.“ (ebd. S. 92)

Die überarbeitete Ausstellung mit dem abgeänderten Titel „Verbrechen der Wehrmacht. Dimensionen des Vernichtungskrieges 1941-1944“"war geprägt von einem präzisen, analytischen Zugriff. ${ }^{13}$ Dem Besucher wurde abverlangt, Zeit zu investieren und sich mit umfangreichem Textmaterial auseinander zusetzen. Die neue Ausstellung setzte nicht mehr auf die Suggestivkraft der Bilder, sondern auf die aufklärerische Wirkung

12 Eine ausführliche Dokumentation der Kontroverse über die Ausstellung "Vernichtungskrieg. Verbrechen der Wehrmacht 1941 bis 1944“" siehe Ausstellungskatalog: Hamburger Institut für Sozialforschung (Hrsg.): Verbrechen der Wehrmacht. Dimensionen des Vernichtungskrieges 19411944. Hamburg 2002, S. 687-729. Mitglieder der Kommission waren Prof. Dr. Omer Bartov, Dr. Cornelia Brink, Prof. Dr. Gerhard Hirschfeld, Prof. Dr. Friedrich Kahlenberg, Prof Dr. Manfred Messerschmidt, Dr. Christian Streit, Prof. Dr. Reinhard Rürup, Prof. Dr. Hans-Ulrich Thamer. Der Kommission arbeiteten die Wissenschaftler Peter Klein, Andrej Angrick und Florian Dierl zu.

13 Die zweite Ausstellung, ebenfalls konzipiert von dem Hamburger Institut für Sozialforschung unter der Leitung von Ulrike Jureit, wurde von November 2001 bis März 2004 in 13 Orten gezeigt. Sie hatte, laut Presseinformation des Hamburger Instituts für Sozialforschung vom 29.03.04, insgesamt 420000 Besucher. Die Ausstellung wird nun im Depot des Deutschen Historischen Museums in Berlin eingelagert. 
der Texte. In jeder Abteilung konnten die Besucher sich zunächst in Sitzvitrinen über Kopfhörer und durch Lektüre mit Basisinformationen vertraut machen. Die Stellwände zeigten dann exemplarisch ausgewählte Tatorte. Auch überwog der Anteil der Dokumente, ergänzt durch Täteraussagen in Nachkriegsprozessen, die über Monitore abgerufen werden konnten. Die Zahl der Fotos wurde gering gehalten. Bei Unsicherheiten der Überlieferung wurde dies ausdrücklich vermerkt. Ein neues Ausstellungsteam vermied die Angriffspunkte der alten Ausstellung, indem der anklägerische Gestus verschwand und auf plakative Stilmittel ganz verzichtet wurde.

„Der Eindruck strenger, fast unterkühlter Sachlichkeit wird durch das Ausstellungsdesign unterstrichen: Alles ist, wie in einem Forschungslabor, in weißer Farbe gehalten - die Stellwände, die Vitrinen, die aufgereihten Holzstühle. Nichts soll vom konzentrierten Lesen und Betrachten ablenken.“14

Auch zeigte die Ausstellung, dass es Möglichkeiten der Verweigerung innerhalb des Systems von Befehl und Gehorsam gab. In einem durch Vorhänge abgegrenzten Bereich „Handlungsspielräume“ konnte der Besucher einer Frauenstimme zuhören, die acht Geschichten von Wehrmachtsangehörigen in der Spannbreite von individueller Verantwortung über die übereifrige Erfüllung eines Mordbefehls bis hin zu Verweigerung und Desertion erzählte. Das Thema Widerstand innerhalb der Wehrmacht fehlte demgegenüber in der ersten Ausstellung völlig. Im Gegensatz zur ersten Ausstellung, die mit dem rhetorischen Mittel der Überzeugung arbeitete, setzte die neue Ausstellung auf Differenzierung. Das neue Konzept wollte nach Aussagen der Sprecherin des Ausstellungsteams Ulrike Jureit „,den Besucher in die Lage versetzen, sich über das, was historisch geschehen ist, auch selbst eine Meinung zu bilden. “15

Ausstellungsmacher müssen sich bewusst sein, dass jede Ausstellung eine Verarbeitung der Vergangenheit ist, dass jede Zusammenstellung und Auswahl von historischen Objekten bereits interpretiert und wertet. Jede Ausstellung muss auswählen, akzentuieren, sie braucht Leitthemen und Schwerpunkte. Das konstruktive Element der Geschichtsdarstellung

14 Ullrich, Volker: Von strenger Sachlichkeit. Die neue Wehrmachtsausstellung zeigt ein noch dunkleres Bild des NS-Militärs als die alte. In: Die Zeit vom 06.12.01.

15 Ullrich, Volker: Fragwürdiger Augenzeuge. Die neue Wehrmachtsausstellung ist eröffnet - ein Gespräch mit der Historikerin Ulrike Jureit, Sprecherin des Ausstellungsteams. In: Die Zeit vom 29.11.01. 
tritt beim Medium Ausstellung besonders hervor, da hier die Reduktion besonders ausgeprägt ist. Jedoch stellt sich die Frage, wer für sich das Recht in Anspruch nehmen darf, Geschichte zu interpretieren und die Form der Erzählung zu wählen. ${ }^{16}$

„The transformation of the museum from reliquary to forum has forced curators to reassess their role as cultural custodians. Increasingly, curators must ask if museums retain the responsibility of validating and confirming tradition. Who has the authority to interpret history to the public - indeed, who owns history?"“ (Henderson/Kaeppler 1997, S. 2)

Bewusst oder unbewusst steht die Interpretation in direktem Zusammenhang mit der Präsentation, in der Art und Weise wie die Umgebung gestaltet ist, was inhaltlich thematisiert oder auch verschwiegen wird. Als Spezialist für den Inhalt war der Wissenschaftler traditionell verantwortlich für die Art der Interpretation. Es geht aber heutzutage nicht nur um die Frage, ob die Ausstellungsgegenstände gut präsentiert und Inhalte verständlich kommuniziert werden, sondern auch darum, welche Inhalte kommuniziert werden sollen. In dieser Hinsicht liegt es einerseits in der Verantwortung der Pädagogen, Themen aufzugreifen, die nicht zum klassischen Wissenschaftskanon gehören. ${ }^{17}$ Andererseits zeigt sich insbesondere in der didaktisch aufbereiteten Wissenschaftspopularisierung die problematische Seite der Museumspädagogik. ${ }^{18}$

16 Die Methodendiskussion innerhalb der Geschichtswissenschaft spiegelt ebenfalls diese kritische Reflexion wider. Sie neigte zu dichotomischen Begriffsbildungen und überspitzten Gegensätzen: Struktur- oder Ereignisgeschichte, Objektivität oder Parteilichkeit, Ideengeschichte oder Historische Sozialwissenschaft, Sozialgeschichte oder Kulturgeschichte. Als letzten Stand der Diskussion konstatiert Lutz eine Vielstimmigkeit und Pluralität der Ansätze, die auf paradigmatische Verbindlichkeiten oder Ansprüche imperialer Supertheorien verzichten. Lutz, Raphael: Geschichtswissenschaft im Zeitalter der Extreme. Theorie, Methoden, Tendenzen von 1900 bis zur Gegenwart. München 2003.

17 Wie sich dies in der Praxis der Ausstellungsgestaltung umsetzen lässt, siehe Kapitel 3.3: Partizipativer Ansatz.

18 Der Begriff Museumspädagogik wurde 1934 von K. H. Jacob Friesen geprägt, konnte sich damals allerdings nicht durchsetzen. Waidacher sieht in der Museumspädagogik ein aktuelles Beispiel für den gescheiterten Versuch, Museen für ideologische Propagandazwecke einzusetzen, indem man sie in Lehranstalten umdeutete. Dreißig Jahre später nahm eine politische Arbeitsgruppe am damaligen Museum für Deutsche Geschichte in 


\section{Präsentation, Museumspädagogik und Ideologie}

$\mathrm{Zu}$ Beginn des 20. Jahrhunderts besannen sich die Museen auf die didaktische Darstellung ihrer Sammlung für eine breite Öffentlichkeit. ${ }^{19}$ Besondere Aufmerksamkeit verdient die 1903 unter dem Thema „Museen als Volksbildungsstätten“ veranstaltete Konferenz der Centralstelle für Arbeiter-Wohlfahrtseinrichtungen in Mannheim. ${ }^{20}$ Diskutiert wurden dort vor allem didaktische Ansätze mit dem Ziel, Museen als „Bildungsstätten“ für breitere Bevölkerungsschichten nutzbar zu machen. In den Anfängen der Volksbildungsbewegung ging es in der Diskussion um ein nützliches Verhältnis zwischen Schule und Museum. Dieser Ansatz entwickelte sich im Laufe der Jahre zu einem viel beachteten öffentlichen Thema. Ganz besonders im Zusammenhang mit der Auseinandersetzung um eine neue demokratische Pädagogik in den 1920er Jahren schlug sich die Theorie in einer vielseitigen Anwendungspraxis nieder (Roth, 1990 S. 87).

In der Zeit des Nationalsozialismus entwarf Adolf Reichwein erstmalig ein Modell für die Unterrichtung von Schulklassen im Museum. Seine Prinzipien von Schule und Museum, wie zum Beispiel die Auswahl von Sammlungsgegenständen nach didaktischen Gesichtspunkten oder die wissenschaftliche Arbeitsgemeinschaft der Museumsleute mit Lehrkräften sind auch heute noch aktuell. Reichwein begründete eine innovative, richtungsweisende Museumspädagogik zu einer Zeit, als die Kulturarbeit dem Diktat des totalitären Staates unterlag und dem Muse-

Ostberlin den Begriff neuerlich auf. Durch forcierte Publikationstätigkeit etablierte sich diese Bezeichnung in der Literatur und verbreitete sich mit Unterstützung von Pädagogen im gesamten deutschen Sprachraum. Vgl. Waidacher 1999, S. 112.

19 Die Vorgeschichte der Museumspädagogik ist rund zweihundert Jahre alt. Sie fällt in die napoleonische Zeit und findet ihren ersten Ausdruck in der wachsenden Zugänglichkeit der damals überwiegend fürstlichen Sammlungen für eine breitere Öffentlichkeit. Eine Fülle von Materialien und Kommentaren zu diesem Prozess siehe: Vieregg, Hildegard: Vorgeschichte der Museumspädagogik. Münster/Hamburg 1991.

20 Als entscheidender Schritt hin zur Entwicklung der Museumspädagogik im 20. Jahrhundert gilt das Wirken des Hamburger Museumsdirektors Alfred Lichtwark und sein Grundsatzreferat von 1903. Lichtwark ist der Erste, der den Museen eine neue und konsequente Bildungsinitiative abverlangt. Seine Position steht im Mittelpunkt der Konzeption vom Museum als ,Volksbildungsstätte“. 
um die nationalsozialistische Erziehung zur offiziellen Aufgabe gemacht worden war (Roth 1990, S. 92).

Die beiden Weltkriege markieren einen tiefen Einschnitt für die $\mathrm{Mu}-$ seumspädagogik. Die Entwicklung der Ziele der Vermittlung in den Museen unterlag in der Zeitspanne zwischen 1914 bis 1945 dem Wandel der Weltanschauung und den Einflüssen der Wissenschaften. Die in der Entstehung sehr fortschrittlichen Thesen mündeten in nationalsozialistische Indoktrination. Die Nationalsozialisten richteten von Anfang an die Taktik ihrer Usurpation auf die wirkungsvollsten Instrumentarien: Propaganda und Erziehung. Die vollkommene Durchdringung des gesamten Erziehungsapparates mit autoritären Bildungsvorstellungen war das Ziel. In den Prozess der Umformulierung von Bildung in nationalpolitische Erziehung wurden das Museum als Medium und die Propagandaausstellungen ebenfalls mit einbezogen (Roth 1990, S. 95). Es gab ein sehr ausgefeiltes Instrumentarium, um möglichst effizient ideologisch erzieherische Ziele im Sinne des Nationalsozialismus mit modernen Mitteln der Gestaltung umzusetzen.

Die ideologische Ausrichtung von inszenierten Ausstellungen durch das nationalsozialistische Regime führte in Deutschland in den fünfziger Jahren als Konsequenz zu Präsentationen, die sehr um Neutralität bemüht waren. In den sozialistischen Ländern, somit auch in der DDR, vollzog sich eine gegensätzliche Entwicklung. Die Propagandaausstellung erfuhr höchste Wertschätzung und wurde als eigenständige, künstlerische Gattung theoretisch aufgearbeitet. Im Rekurs auf die in der Vergangenheit gesammelten Erfahrungen entwickelten Museologen ein kanonisches Instrumentarium für die zukünftige Praxis der Ausstellungsgestaltung (Kivelitz 1999, S. 16). ${ }^{21}$ Die sozialistische Museologie bekannte sich offen zur marxistischen Ausrichtung historischer Präsentationen. Nicht fachwissenschaftliche Systematisierungskriterien gliederten die Ausstellung, sondern erzieherische und propagandistische Inhalte standen im Vordergrund. Somit bildet die Museumspädagogik der DDR ein ausgewiesenes Beispiel für Funktionalisierung zur Stützung eines ideologischen Gesellschaftssystems.

21 Herbst, Wolfgang/Levykin K. G.: Museologie. Theoretische Grundlagen und Methodik in den Geschichtsmuseen. Berlin 1988. Dieses Buch war ein Standardwerk und Lehrbuch für die Ausbildung an Universitäten und Hochschulen der DDR. Es befasst sich mit den theoretischen Grundfragen der Museologie als Wissenschaft und den politisch-ideologischen und wissenschaftlichen Aufgaben bei der Gestaltung der sozialistischen Gesellschaft. 
Das wichtigste Prinzip bei der Schaffung einer historischen Ausstellung bestand gemäß sozialistischer Museologie darin, dass die wissenschaftliche Konzeption auf der marxistisch-leninistischen Lehre von der Entwicklung der Gesellschaft basiert (Herbst/Levykin 1988, S. 197). In Übereinstimmung mit den Grundsätzen des historischen Materialismus spiegelte die museale Ausstellung die historische Wirklichkeit als einheitlichen, jedoch vielgestaltigen, gesetzmäßig verlaufenden Prozess unter Berücksichtigung neuester Erkenntnisse der marxistisch-leninistischen Geschichtswissenschaft wider. Die ideologische Zielrichtung der Ausstellungen musste eindeutig und frei von Objektivismus sein. Als charakteristischer Zug sollte das erfolgreiche Wirken der kommunistischen Partei an behandelten historischen Erscheinungen und Prozessen deutlich hervortreten. Das sollte dem Museumshistoriker „den richtigen Blick für die klassenmäßige Einschätzung historischer Fakten“ geben (ebd., S. 198). Dieses parteiliche Herangehen fand seinen Ausdruck auch bei der Festlegung der Proportionen zwischen den Ausstellungsabschnitten, denen ein angemessener Platz einzuräumen war. Die wichtigste Art musealer Kommunikation war die Bildungs- und Erziehungstätigkeit, durch die das Museum seine gesellschaftlichen Grundfunktionen ausfüllte. Das Aufgabenfeld und die ideologische Ausrichtung der Museumspädagogen wurde ebenfalls deutlich formuliert: „Am ehesten entsprechen zwei Bezeichnungen dem Inhalt ihrer Arbeit: PropagandaAbteilung oder Pädagogische Abteilung.“ (ebd., S. 269)

Unter Bildungs- und Erziehungstätigkeit verstand man sowohl die Vermittlung wissenschaftlicher, propagandistischer und kultureller Bildungsinhalte als auch die politisch-ideologische, moralische und ästhetische Erziehung (ebd., S. 265). Die Museen nahmen an der Vermittlung der marxistisch-leninistischen Weltanschauung, an der Herausbildung sozialistischer Grundüberzeugungen, an der Erziehung zu Patriotismus und Internationalismus, an der Festigung des Staatsbewusstseins und des Stolzes auf den sozialistischen Staat teil. Basierend auf einem marxistisch-leninistischen Geschichtsbild verbreiteten Geschichtsmuseen historisches Wissen und wirkten mittels Geschichte erzieherisch (ebd., S. 266). Bei der Propagierung historischen Wissens galt für den Museumsmitarbeiter das Leninsche Prinzip:

„Die Kunst eines Propagandisten und eines jeden Agitators besteht eben darin, einen gegebenen Hörerkreis auf die beste Weise zu beeinflussen, indem er eine bestimmte Wahrheit so darstellt, daß sie für diesen Hörerkreis möglichst überzeugend ist, dieser Kreis sie sich möglichst leicht zu eigen machen kann, 
sie für ihn möglichst anschaulich und fest einprägsam ist." (Lenin, W.I., Werke, Bd. 17, Berlin 1962, S. 330 zitiert in Herbst/Levykin 1988, S. 266)

Hauptsächlich untersuchten Museumspädagogen die pädagogisch wirkungsvolle Präsentation aller Ausstellungsmaterialien und ihre nachhaltige Rezeption durch den Besucher, das heißt Fragen der musealen Kommunikation. Das museumspädagogische Arbeitsfeld umschloss Ausstellungen - Vorbereitung, Gestaltung, Aufbau - und ihre Nutzung durch Einzelbesucher und Besuchergruppen (ebd., S. 267). Das Hauptanliegen der Museumspädagogik war es, eine pädagogisch optimale Nutzung der Ausstellungen, der Bestände und der Objekte für die Erziehung allseitig entwickelter Persönlichkeiten und bewusster Staatsbürger zu erreichen (ebd.). Selbstverständlich war, dass der Museumspädagoge über sichere Kenntnisse des Marxismus-Leninismus und der marxistisch-leninistischen Geschichtsauffassung verfügte.

In der vorhergehenden Beschreibung des Aufgabenbereichs der sozialistischen Museumspädagogik wurde offen auf die propagandistische Ausrichtung der Ausstellungen verwiesen. Im Kontext einer radikalen Gesellschaftskritik waren in der Bundesrepublik Deutschland dagegen in den siebziger Jahren die Museen trotz ihrer um Neutralität bemühten objektorientierten Präsentationen mit heftigen Vorwürfen konfrontiert. ${ }^{22}$ Die umfassende Kritik am herrschenden Gesellschaftssystem und an den bestehenden Institutionen betraf alle gesellschaftlichen Bereiche und erfasste somit auch das Kultur-Establishment. Die Existenzberechtigung einer rein elitären Kulturlandschaft wurde in Frage gestellt (Hauenschild 1988, S. 8).

Kritisiert wurde an den bestehenden Museen, dass durch die Art der Präsentation Herrschaft legitimiert und stabilisiert werde. Sie trügen zur Durchsetzung und Aufrechterhaltung von ästhetischen Werten und Nor-

22 In diesem Zusammenhang wurden auch die Inhalte des Faches Kunstpädagogik im Hinblick auf ihre gesellschaftliche Funktion hinterfragt. Kritisiert wurde unter anderem, dass der Kunstunterricht die jungen Menschen in die Unmündigkeit führe und der unkritische Genuss von Kunst von der gesellschaftlichen Realität ablenke. Durch ein neues Unterrichtsmodell Visuelle Kommunikation sollte die Informationsvermittlung durch visuelle Medien untersucht werden und damit die mögliche und tatsächliche Manipulation durch die Medien bewusst gemacht werden. Vgl. Ehmer, Hermann K. (Hrsg.): Visuelle Kommunikation. Beiträge zur Kritik der Bewußtseinsindustrie. Köln 1971. 
men bei. Das Museum wurde als charakteristische Einrichtung der Moderne beschrieben, der es oblag, kompensatorisch die durch die Modernisierung entstehenden Defizite zu mildern. Indem die Museen die Kategorien der Beschreibung festlegen und den kanonischen Umgang mit ihnen regeln, wird Macht ausgeübt, werden etwa Distinktionen zwischen sozialen Klassen geschaffen. Dies betrifft auch den Heimlichen Lehrplan von Ausstellungen. ${ }^{23}$

Kulturpolitisch stand eine Neubewertung der Überlieferung im Mittelpunkt. Dies führte zu einer Erschließung neuer Bereiche wie zum Beispiel Familie, Arbeitswelt, Ausbildung, Gewerbe, Politik und zur Hinwendung zu gesellschaftskritischen Themen wie Dokumentation von Massenphänomenen oder Wandlungen der Lebensweise. Die Museumskritiker forderten auch einen methodischen Neuansatz für die museale Darstellung. Ein Ziel bestand darin, die gesellschaftliche Bedingtheit von Kultur durch die Demonstration der Mannigfaltigkeit der Erklärungszusammenhänge sichtbar zu machen. Gefordert wurde eine Demokratisierung des Museums nicht nur auf formaler Ebene, sondern auch durch die Vermittlung eines anderen Geschichtsverständnisses, welches Geschichte nicht nur aus der Perspektive der Herrschenden interpretiert. Theoretische Reflexionen zu Ausstellungskonzepten der siebziger Jahre spiegeln die ideologiekritischen Forderungen der damaligen Diskussion wider. Kramer stellte zum Beispiel im Jahr 1976 fest, dass die Darstellung des Zusammenhangs von Armut und Luxus nur mit Hilfe der Darstellung der Herrschaftsbeziehungen als einer konkreten Form von Klassenbeziehungen möglich sei. Damit könne wesentlich mehr anschaulich gemacht werden, als lediglich eine Erklärung von Armut zu liefern.

„Mit der Darstellung von Herrschaft ist es gleichzeitig möglich, wesentliche Aspekte der konkreten Gestalt sowohl der herrschenden Kultur als auch der

23 Der Begriff hidden curriculum stammt aus den Vereinigten Staaten. Korrekt übersetzt, bezeichnet er sachlich nüchtern den verborgenen oder den unsichtbaren Lehrplan. Die radikale Gesellschaftskritik der siebziger Jahre hat ihn aufgegriffen. Als Heimlicher Lehrplan wurde er in der Bundesrepublik Deutschland zum zentralen Vorwurf einer Schulkritik, die offizielle Ziele des Schulwesens als verlogen bezeichnete. Hinter einer schönen Fassade sollte das eigentliche Ziel von Schule versteckt werden - die jungen Menschen für den Kapitalverwertungsprozess abzurichten und sie so um ihr Recht auf Selbstverwirklichung, auf Emanzipation zu betrügen. Die Schule diene dazu, die Gesellschaft zu reproduzieren und das System zu stabilisieren. 
Kultur und Lebensweise der beherrschten Klassen zu erklären. Versuche, im Museum gesellschaftliche Zusammenhänge durchschaubar zu machen, können daher nicht auf die Darstellung von Herrschaft verzichten.“ (Kramer 1976, S. 27)

Ein prägnantes Beispiel für ein Museum im Geist der siebziger Jahre ist das Historische Museum in Frankfurt. Unter Berücksichtigung der Überlegung, Geschichte im Museum nicht wie in einem Kunstmuseum zu präsentieren, stellte das Museum die Objekte in Zusammenhänge. Die Objekte erhielten den Charakter von Belegen und traten in die zweite Linie zurück, während im Vordergrund museumsdidaktische Texte standen. Diese Texte waren jedoch eindeutig dem linken politischen Flügel zuzuordnen.

,[Eine] unzweideutig links orientierte Geschichte: einseitig, häufig auch falsch und überdies voll bizarrer Brüche. Der jähe Übergang von einer gelegentlich etwas sterilen, oft ahistorischen Kunstwissenschaft zu einer marxistisch orientierten Geschichtssicht, die augenscheinlich den Weg einiger Mitarbeiter geprägt hatte, führte $\mathrm{zu}$ einem erstaunlich kritiklosen Umgang.“ (Boockmann 1987, S. 30)

Im Hinblick auf den didaktischen Ansatz entsprach das Frankfurter Historische Museum den damaligen gesellschaftspolitischen Forderungen, da mit der strikten Kontextualisierung historischer Objekte konsequent eine andere Präsentationsmethode realisiert wurde. ${ }^{24} \mathrm{Zu}$ kritisieren war allerdings die politische Einseitigkeit. Dies verweist jedoch auf das grundsätzliche Problem der subtil vermittelten Botschaften, die dem Besucher eurozentrische, rassistische, sexistische oder sonstige Werthaltungen vermitteln. ${ }^{25}$

24 Dieser didaktische Ansatz ist aus heutiger Perspektive überholt. Auch war er nicht wirklich innovativ, verwiesen sei auf Adolf Reichweins Methodik der Museumsdidaktik und -pädagogik Ende der dreißiger Jahre. Vgl. Roth 1990, S. 210.

25 Im Gegensatz zu Deutschland wird dem Thema der Interpretation und den damit einhergehenden Botschaften im angloamerikanischen Raum ein großer Stellenwert eingeräumt. Dementsprechend gibt es hierzu zahlreiche Publikationen, die sich kritisch mit Ausstellungspräsentationen als Formen von Machtausübung auseinandersetzen. Stellvertretend sei auf das Buch „Exhibiting Dilemmas“ verwiesen. Die Autoren, die allesamt Mitarbeiter des renommierten Smithsonian Instituts sind, setzen sich selbstkritisch mit ihrer Ausstellungspraxis auseinander. Es werden die soziologischen, politischen und ethischen Fragen, denen sich Museumskuratoren in ihrer Rolle 
Doch auch durch den direkten Einfluss von Mäzenen und privaten Geldgebern können Botschaften des Museums gelenkt und beeinflusst werden. Aus der fortschreitenden Privatisierung der Kulturfinanzierung ergibt sich eine Verzahnung von politischen und ökonomischen Interessen. Durch die Streichung von Geldern von Seiten der öffentlichen Hand sehen sich Museen gezwungen, private Geldgeber zu finden. Oft erwarten die Spender jedoch eine Gegenleistung. Dies kann dazu führen, dass Spender den Beschenkten indirekt ihre persönlichen Vorlieben aufzwingen. Selten bekommt die Öffentlichkeit Einblick in die Konflikte zwischen den Kulturschaffenden und ihren Geldgebern, die zum Beispiel in den Aufsichtsräten direkten Druck ausüben können. Ein konkreter Fall von direkter Einflussnahme zeigte sich in mehreren Fällen bei Ausstellungen des renommierten Smithsonian Instituts ${ }^{26}$, bei denen der Direktor Lawrence Small ${ }^{27}$ den Wünschen ,zahlungskräftiger Manipulatoren“ entsprach:

„So ließ er [Direktor Small, Anm. d. V.] den Ölkonzern Phillips, der eine Wikingerausstellung in Norwegen unterstützt hatte, in einer Anzeige im Ausstellungsplan des Natural History Museums die ökologischen Schäden von Ölbohrungen in Alaska herunterspielen: ,Es wird sein, als seien wir nie da gewesen.' Zur selben Zeit peitschte Präsident Bush ein Gesetz durch den Kongress, das genau diese Ölbohrungen erlauben sollte.“28

als Wächter über die Kultur stellen müssen, thematisiert. Das Buch konzentriert sich dabei auf die Herausforderungen, die durch die Veränderungen der Ausstellungen von objektzentrierten Präsentationen zu erlebnisorientierten Themenausstellungen entstehen. Siehe Einleitung, Anm. 21.

26 Das Smithsonian Institut mit Hauptsitz in Washington D.C., zu dem 16 Museen und Galerien gehören und das gleichzeitig ein bedeutendes Forschungszentrum ist, zählt zu den bedeutendsten kulturellen Institutionen in Amerika. Es sieht seinen Auftrag in der Bildung der Allgemeinheit, dem Dienst an der Nation und der Vergabe von Stipendien in den Bereichen Kunst, Naturwissenschaften und Geschichte. Das Smithsonian wurde im Jahre 1846 mit Mitteln aus der Hinterlassenschaft des englischen Wissenschaftlers James Smithson zu Gunsten der Vereinigten Staaten mit dem Auftrag ,der Vermehrung und Verbreitung von Wissen“ gegründet. Vgl. http://www.si.edu (letzter Zugriff: 10.02.05).

27 Mit dem Ex-Banker und Ex-Manager kam erstmals ein fachfremder Mann an die Spitze der Kulturorganisation.

28 Jörg Häntzschel: Im Namen des Geldes. Wie sich das Smithsonian in den Netzen seiner Sponsoren verfängt. In: Süddeutsche Zeitung vom 27.08.02. 
Nicht die privaten Spenden an sich stellen das Problem dar, sondern deren strategischer Einsatz. Im Vergleich zu Amerika machte der Künstler Hans Haacke die Erfahrung, dass in europäischen öffentlichen Institutionen immer noch kontroverse Themen präsentiert werden können und verhältnismäßig offen darüber gesprochen werden kann. Dies wäre in Amerika in dieser Form nicht möglich. ${ }^{29}$ Die Kuratorien amerikanischer Museen sind selten mit öffentlichen Vertretern und Fachleuten besetzt, sondern vornehmlich mit Privatleuten, die sich nicht gegenüber der Öffentlichkeit verantworten müssen. Meist sind dies Leute mit großer finanzieller Potenz und den damit verbundenen Interessen und Verhaltensmustern. Darunter befinden sich Stifter und Sammler, die hofiert werden und deren Wünsche erheblichen Einfluss auf Ankäufe, Programmgestaltung und Personalien haben. Kritisch merkt Haacke an, dass sich Europa ebenfalls in diese Richtung bewegt. Politische Präferenzen, wirtschaftliche Interessen und gesellschaftliche Rücksichtnahme fließen in die Förderentscheidungen von Projekten der Kuratorien ein. Bevorzugt wird in „gesicherte Werte“ der Vergangenheit oder aus exotischen Ländern investiert, die ohne ein Risiko auf Konfrontation präsentiert werden.

„Selten werden Klassiker und ihre Umwelt in einer historisch kritischen Weise präsentiert, die es erlauben würden, Geschichte in die Gegenwart zu verfolgen und Parallelen in Verhaltensmustern von heute zu entdecken. Aufklärung im Sinne emanzipatorischer Erkenntnis könnte den Investitionszielen schaden.“(ebd.).

\subsection{Die ökonomische Dimension}

Ein Grund für die Annäherung der Museen an Erlebnisparks liegt darin, dass auch Museen sich Fragen der Rentabilität stellen müssen. Staatliche Zuschüsse öffentlicher Träger werden aufgrund der aktuellen politischen und wirtschaftlichen Entwicklung gekürzt. Museen sehen sich dadurch verstärkt gezwungen, selbst Finanzmittel einzuwerben oder zu erwirtschaften. Neben Geldern von Sponsoren sorgen auch die Besucher für Einnahmen, beispielsweise über Eintrittsgelder, den Museumsladen und das Museumsrestaurant. Folglich schenken Museen der Zufriedenheit und dem Wohlbefinden der Besucher immer größere Aufmerksamkeit.

29 Hoffmann, Gabriele: Für eine Kunst mit Folgen. Der Künstler Hans Haacke im Gespräch. In: Neue Züricher Zeitung vom 13.04.04. 


\section{Besucherorientierung in kritischer Revision}

Das Leitziel der Besucherorientierung gehört mittlerweile zu den zentralen Begriffen des Vokabulars der Museumswelt. Besucherorientierung beinhaltet die Änderung der Einstellung zu den Museumsbesuchern, „die von geduldeten Anstaltsbesuchern zu umworbenen Kunden aufgestiegen sind." ${ }^{30}$ Sie bezieht sich nicht nur auf Marketingstrategien, sondern bedeutet eine grundsätzliche Einstellung, ,wie man Besuchern in einer partnerschaftlichen und dialogbereiten Weise gegenübertritt" (ebd.). Besucherorientierung im Museum kann vieles bedeuten. Dies beginnt bei der Beschriftung von Exponaten mit mehr oder weniger ausführlichen Informationen. Ebenso zählt hierzu die Bereitstellung von Sitzgelegenheiten, museumspädagogischen Angeboten, die Einrichtung einer Cafeteria bis hin zu Ausstellungsinszenierungen im Stil einer Filmkulisse. Als positive Konsequenz lässt sich feststellen, dass das Publikum als relevante Einflussgröße bei der musealen Arbeit ernst genommen wird. Dementsprechend, so die Hoffnung der Museumsmanager, steigt auch die Bereitschaft der Besucher, für ein breites Angebot mehr Geld ausgeben zu wollen.

Nichtsdestotrotz erscheint es bedeutsam, das Leitziel Besucherorientierung kritisch zu beleuchten und nach negativen Auswirkungen zu fragen. Besucherorientierung geht meist mit ökonomischen Überlegungen einher. Aus der strategischen Planung einer Verbindung von wirtschaftlichen und inhaltlichen Zielen erhoffen sich Entscheidungsträger Synergieeffekte. In der Kulturpolitik spielt beim Einsatz der verfügbaren Haushaltsmittel zunehmend auch der Gesichtspunkt der Besucherakzeptanz eine Rolle.

„Selbst wenn die Größenordnung von Besucherzahlen - bzw. ihre Zunahme oder Abnahme - nicht der primäre oder gar alleinige Maßstab für erfolgreiche Museumsarbeit sein kann, handelt es sich beim Publikumsinteresse jedenfalls um einen wichtigen Indikator, der nicht zuletzt auch innerhalb der Entscheidungskriterien der Museumsfinanzierung seinen Stellenwert hat.“ (Langenstein 2000, S. 7)

30 Langenstein, York: Geleitwort. In: Landesstelle für die nichtstaatlichen Museen in Bayern (Hrsg.): Geöffnet! Das Museum für den Besucher, Tagungsbericht zum 10. Bayerischen Museumstag in Landshut. München, 2000, S. 7-8. Die Tagung befasste sich mit der zwar nicht neuen, aber gerade intensiv geführten Diskussion über das Verhältnis der Museen zu ihren „Kunden“. 
Verglichen mit europäischen Maßstäben sind amerikanische Museen auffallend besucherorientiert. Dafür gibt es verschiedene Gründe. ${ }^{31}$ Einerseits sind Museen der Öffentlichkeit und dem Gemeinwohl aufgrund der staatlichen Unterstützung, obwohl diese meist nicht sehr hoch ist, verpflichtet. Andererseits sind die Museen zur Deckung des Budgets auf die Einnahmen durch Besucher angewiesen. Mit besucherorientierten Konzepten verfolgen Museen das Ziel, hohe Besucherzahlen und Kundenzufriedenheit zu erreichen, um somit auch die benötigten Einnahmen zu sichern. Dies bedeutet, dass Besucherorientierung nicht nur eine ideelle Verpflichtung und freiwillige Leistung darstellt, sondern aufgrund wirtschaftlicher Notwendigkeit durchgeführt wird. Daraus ergibt sich die schwierige Aufgabe, eine Balance zwischen dem ideellen und dem kommerziellen Bereich zu finden. Mögliche Konsequenzen der Orientierung an marktwirtschaftlichen Vorgaben lassen sich an der amerikanischen Entwicklung ablesen.

Selbstverständlich erscheint - Langenstein bezeichnet dies als „Binsenweisheit" unter Museumsleuten -, dass Qualität und Profil einer Sammlung, dazu die im Interesse der Objekte jeweils zu beachtenden konservatorischen Belange, Eckdaten für einen verantwortungsbewussten Umgang mit den Exponaten und für die Entwicklung von Präsentationskonzepten setzen (Langenstein 2000, S. 7). Diese Grundsätze können jedoch in Frage gestellt werden, wenn betriebswirtschaftliche Effizienz zum obersten Maßstab erhoben wird. Für die Sammlungspflege bedeutet dies, dass sie allzu sehr in den Hintergrund tritt. Controlling verlangt nach Kennzahlen, diese sind im Ausstellungsbetrieb leichter zu definieren und auch zu überprüfen. Kamen die Finanzmittel der privaten Förderer früher von den Kulturstiftungen, so obliegt gegenwärtig die Entscheidung über Zuschüsse den Marketingabteilungen. Marketingexperten stellen für die Kulturförderung die gleiche Kosten - Nutzen - Rechnung auf, wie dies bei der traditionellen Werbung der Fall ist. Ausstellungen müssen Aufmerksamkeit erzeugen. Aus marketingtechnisch nachvollziehbaren Gründen suchen sich Sponsoren für Werbung Ausstellungsprojekte aus, die große Besucherzahlen und ein positives Echo versprechen. Kaum ein Geldgeber ist daran interessiert, für weniger publikumswirksame, langfristige Maßnahmen wie zum Beispiel Bestandspflege, Restaurierung, oder Betriebskosten Gelder zu investieren.

31 Bosch-Schairer, Carmen: Besucherorientierung als Marketingstrategie amerikanischer Museen - ein Vorbild für deutsche Museen? (unveröffentl. Skript) Weinsberg 2004. 
„Öffentlichkeitswirksames, wie Ausstellungen, kooperative Projekte, Publikationen, Veranstaltungen oder spektakuläre Erwerbungen haben die Nase ebenso vorne wie alles, was termingebunden ist, z.B. Ausstellungen, Jubiläen, geförderte Projekte. Den Kürzeren zieht im Zweifelsfall die Basisarbeit an der Sammlung, z. B. kontinuierliches Umsetzen von Sammlungsstrategien, die konservatorische Versorgung des Altbestandes, das Erforschen des Einzelobjektes, das sorgfältige Dokumentieren der Provenienz von Neuerwerbungen. “ 32

Auch verlagern sich Kapazitäten weg von der Sammlungs- hin zur Publikumsbetreuung. Ein modernes, besucherorientiertes amerikanisches Museum besitzt neben einer Abteilung für Museumspädagogik auch eine Marketingabteilung mit eigenem Fachpersonal und Budget. Dagegen verliert der klassische Kurator, der dem Kanon von Sammeln, Bewahren, Forschen, Präsentieren verpflichtet ist, an Bedeutung (Bosch-Schairer 2004, S. 5). Gemäß dem Selbstverständnis amerikanischer Museen als Dienstleistungsbetrieb, der der Öffentlichkeit Wissensvermittlung und neuartige, interessante und unterhaltsame Erlebnisse bietet, verliert die Sammlung an Bedeutung. Ein Trend sind Museen ohne Sammlungen. ${ }^{33}$ Bei bestehenden Museen kann dies in logischer Konsequenz zur Veräußerung einer Sammlung führen, wenn diese nicht von außerordentlicher Qualität ist. „Manche Museen verkaufen ihre Sammlungen sogar und richten sich neu aus wie das Boston Science Museum oder Aldrich Museum of Contemporary Art." (ebd., S. 11)

32 Schuler, Thomas: Drei Betriebe unter einem Dach - Plädoyer für eine neue Organisationsstruktur für Museen. In: Treff, Hans-Albert (Hrsg.): Museen unter Rentabilitätsdruck. Engpässe - Sackgassen - Auswege. Bericht über ein internationales Symposium 1997, veranstaltet von den ICOM Nationalkomitees der Bundesrepublik Deutschland, Österreichs und der Schweiz. München 1998, S. 111.

$33 \mathrm{Zu}$ Museen ohne Sammlung zählen zum Beispiel das Newseum in Washington D.C., ein interaktives Museum der Zeitungsnachrichten. Das Aldrich Museum of Contemporary Art bei New York hat seine Sammlung in den achtziger Jahren verkauft, um sich als internationaler Vorreiter der Entwicklung innovativer Museumspädagogik im Bereich zeitgenössischer Kunst zu etablieren. Auch in Deutschland gibt es zunehmend mehr Beispiele dafür. Das Literatur-Museum Wolfram von Eschenbach inszeniert die höfische Welt, die epischen Werke und Lieder sowie auch die Biographie des Dichters. Das Nibelungenmuseum in Worms bedient sich moderner Medien, um die Geschichte dieses Epos zu erzählen. 
Die Veräußerung von Sammlungsgegenständen oder gar von kompletten Sammlungen mag sich aus betriebswirtschaftlichen Gesichtspunkten rechnen, spiegelt jedoch auch ein kurzfristiges Denken wider. Kritisch zu fragen ist zum Beispiel, ob aus der momentanen Perspektive beurteilt werden kann, welche Objekte Relevanz in der Zukunft besitzen werden.

Die amerikanische Entwicklung lässt sich nicht Eins-zu-Eins auf Deutschland übertragen. Generell existiert in Deutschland ein ausgeprägteres Geschichtsbewusstsein als dies in Amerika der Fall ist. Daraus folgt, dass auch Sammlungen in Deutschland einen höheren Stellenwert als in den USA einnehmen. Sie werden als nationales Kulturgut betrachtet, und dies verpflichtet öffentliche Träger zur Bewahrung (Dauschek 2001, S. 216).

Die unterschiedliche Bewertung des Stellenwertes von Sammeln und Vermitteln hat weit reichende Konsequenzen. Statt einer additiven Aneinanderreihung der Grundaufgaben der Museumsarbeit wurden in Ameri$\mathrm{ka}$ in den mission statements diese häufig hierarchisch gegliedert: „Um zu vermitteln, sammeln, bewahren und forschen die Museen.“ (ebd.) Dieser wertenden Abstufung stehen deutsche Museumsdirektoren distanziert gegenüber. Dauschek stellt fest, dass in Deutschland in einigen Häusern die Vermittlung als ein wesentliches Ziel genannt wird, dem hohen Stellenwert der Vermittlung in den amerikanischen Museen jedoch mit Zurückhaltung begegnet wird. Die befragten Direktoren unterstrichen immer wieder die Bedeutung der Sammlung und ebenso die Abhängigkeit der Zielsetzung von der Geschichte des Hauses und dem Charakter der Sammlung. Begründet wird dies mit der Befürchtung, dass eine Hervorhebung der Vermittlung aus dem musealen Aufgabenkanon dazu führt, dass politische Entscheidungsträger die Museen allein nach ihren Besuchszahlen beurteilen und damit die Kommerzialisierung der Museen vorantreiben würden. Im extremen Fall müssen sich Museen gegen die politische Forderung wehren können, „durch den Verkauf von Depotbeständen Mittel zu erwirtschaften“ (ebd., S. 217). ${ }^{34}$ Die Gewichtung der Aufgaben kann für ein Museum als öffentliche Einrichtung auch ein Politikum bilden. Während nach außen und zum Publikum Be-

34 In den von Dauschek geführten Interviews mit Museumsdirektoren in Deutschland wurde mehrfach auf dieses Problem verwiesen. Dass dies eine berechtigte Sorge ist, liegt auch in der Tatsache begründet, dass die Museen in Deutschland, im Gegensatz zum Beispiel zu Österreich, sich meist nicht auf einen gesetzlichen Auftrag berufen können. Vgl. Dauschek 2002, S. 217. 
sucherorientierung und Vermittlung betont werden, kann es gegenüber dem staatlichen Träger wichtig sein, die Bedeutung der Sammlung und den gleichsam staatlichen Auftrag zur Sammlung, Bewahrung und Forschung hervorzuheben (ebd.).

Als weitere negative Auswirkung von Besucherorientierung wird befürchtet, dass mit zunehmender Kommerzialisierung die Qualität des Angebots leidet. Ein Vergleich mit der Entwicklung des Fernsehprogramms zeigt, dass eine Ausrichtung nach Kundenwünschen und der Höhe der Einschaltquoten zu einem qualitativen Abwärtstrend bei der Programmgestaltung geführt hat. Die Ausrichtung an den Besucherzahlen als alleiniges Kriterium für die Verteilung von finanziellen Zuschüssen würde analog zum Quotenfernsehen zum Quotenmuseum führen. Dies wäre nach Ansicht von Roth mit einem Alptraum für die Museumswelt zu vergleichen. ${ }^{35}$ Die Orientierung an ausschließlich populistischen Themen würde dann ebenfalls in eine Negativspirale münden. Für Roth ergibt sich daraus die klare Maxime, dass Besucherzahlen weder ein Finanzierungskriterium noch ein Maßstab für die Bewertung des Erfolges einer Ausstellung sein dürfen. Gerade weil es in Ausstellungen auch darum geht, zum Beispiel gesellschaftskritische Themen aufzugreifen, die nicht einem aktuellem Mainstream-Interesse entsprechen, müsse man sich auf den Bildungsauftrag des Museums besinnen.

Roth betont, dass aus diesem Grund nicht Blockbusterausstellungen oder erfolgreiche Wanderausstellungen Ziel der Museumsarbeit bilden dürfen. Die Entscheidung, welches Thema als wichtig erachtet wird, muss ausschließlich in den Museen selbst getroffen werden (ebd.). Die finanzielle Unabhängigkeit bewahrt auch vor einer inhaltlichen Abhängigkeit von möglichen Sponsoren. ${ }^{36}$ Aufgrund der zunehmenden finanziellen Einschränkung öffentlicher Zuwendungen werden jedoch in der Realität auch Museen in Deutschland dazu gezwungen, mit Geschichte Geschäfte zu machen. (Urban 1999, S. 189) Die Geschichtsmuseen konkurrieren mit anderen Anbietern auf dem Markt der Freizeitkultur. Urban stellt fest, dass es den auf Hintergründigkeit und Kontinuität ausgerichteten Museen einerseits schwer fällt, innovativ und spektakulär aufzutreten. Dort, wo es jedoch geschieht, wird es oft mit Oberflächlichkeit

35 Roth, Martin: Aktuelle Weichenstellung für das Museum von Morgen. In: Landesstelle für die nichtstaatlichen Museen 2000, S. 17.

36 Dass Geldgeber durchaus auf die inhaltliche Gestaltung Einfluss nehmen, lässt sich an konkreten Beispielen aufzeigen, siehe zum Beispiel Kapitel 4, S. $203 f$. 
und Reflexionsverlust erkauft. Der Hauptkritikpunkt der popularisierten Geschichte liegt darin, dass diese selbst zu einem belanglosen Konsumartikel wird und eine aufklärende Vermittlungsintention aufgegeben wird (Urban 1990, S. 190).

Der Einsatz von fiktionalen und erzählenden Elementen bei der medialen Geschichtspräsentation im Fernsehen begründet sich vor allem auf den Gewinn an Lebendigkeit, Detailreichtum, Vorstellungskraft und Dramatik durch die künstlerische Gestaltung der Vergangenheitsdarstellung. Ähnliche Folgerungen lassen sich auch für das Geschichtsmuseum ziehen. Auch dort werden mittels szenographischer Ausstellungskonzepte Formen der künstlerisch-animierenden Darbietung mit dem Ziel praktiziert, die Vorstellungskraft der Besucher anzuregen. ${ }^{37}$ Diese aufwendige und kostenträchtige Methode der Rekontextualisierung stellt eine Konzession an das Erlebnisbedürfnis der Besucher dar. Die Geschichtsdidaktik bestätigt, dass der am Fernsehgerät rezipierte Film über eine Faszinationskraft, Suggestivität, Ausdrucksstärke, Erlebnisqualität und Realitätsnähe verfügen kann, die in dieser Intensität von keinem anderen Geschichtszeugnis erreicht wird. Zugleich weist die Geschichtsdidaktik aber auch auf die damit verbundenen Gefahren hin, da die Faszination der Bilder und die Freisetzung von Emotionen durch das Miterleben kritische Distanz verhindert und manipulierte Identifikation fördert (Urban 1999, S. 192). Zudem gehe es in den historisierenden Filmen so die Kritik - nicht um ein Verständnis der Geschichte, sondern diese werde lediglich als Rahmen oder Bühne benutzt, um die Produkte der Traumfabrik leichter vermarkten zu können. ${ }^{38}$

Ähnliche Erfahrungsmuster lassen sich im touristischen Bereich beobachten. Die touristische Reise in die Vergangenheit ist in den meisten Fällen eine Reise in eine artifizielle Scheinwelt mit mehr oder weniger pittoresken Kulissen. „Eine Geschichte, die uns nicht betrifft und die uns

37 Wie bei Spielhandlungen im Film treten sogar kostümierte Schauspieler in Ausstellungen auf. Dies war beispielsweise im Jahr 1998 bei der großen Ausstellung zur Revolution 1848 im Badischen Landesmuseum Karlsruhe der Fall. Auch in Freilichtmuseen wird seit vielen Jahren mit Schauspielern und Statisten gearbeitet, die in traditioneller Kleidung zum Beispiel Handwerksvorführungen geben.

38 Analogien lassen sich hier zu den Erlebniswelten mit Mittelalterambiente aufzeigen. Auch hier geht es nicht um konkrete historische Fakten, sondern um ein wie auch immer geartetes positives Lebensgefühl. Siehe Kapitel 5.1: Mittelalter in zeitgenössischen, kommerziellen Präsentationen. 


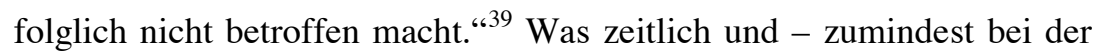
Reise der Touristen - räumlich weit genug entfernt ist, verliert einen Teil seiner Irritationskraft. Die Distanz schwächt die Gegenwartsrelevanz der Geschichte ab, besonders dann, wenn eine gezähmte, nostalgisch verklärte Geschichte präsentiert wird. Geschichte - wie sie den Touristen präsentiert wird - ist befreit vom Schmerzhaften und Unangenehmen, sie dient der Unterhaltung und Zerstreuung (ebd.). Die Ferienreise ins Gestern, argwöhnt Müllenmeister, ist eher ein Urlaub von der Gegenwart. „Ein wenig Erholung, ein bisschen Freizeit, eine kleine Flucht.“ (ebd.) Dieser nostalgische Retroeffekt lässt sich auch in Geschichtsmuseen beobachten. Mit Geschichte, kritisiert Müllenmeister, hat dies jedoch nichts zu tun. Eher das Gegenteil ist der Fall, indem auf Denkprozesse in historischen Kategorien konsequent verzichtet und ein Geschichtsbewusstsein gefördert wird, das sich aus zwar bunten, aber starren Klischees ferner Zeiten zusammensetzt.

Die Folgen der Versinnlichung und Emotionalisierung musealer Ausstellungen ausschließlich unter einem negativen Blickwinkel zu betrachten, führt jedoch in der Diskussion nicht weiter. Programmatische Entscheidungen oder Konzepte, die sich auf die Dichotomie Bildung Unterhaltung zurückziehen, unterstützen das Museum weder dabei, innovative Strategien zur Vermittlung der ihm eigenen Inhalte zu entwickeln, noch der Konkurrenz aus dem kommerziellen Bereich angemessen zu begegnen (Wohlfromm 2002, S. 47). Aus diesem Grund soll im Folgenden eine diametral entgegengesetzte Perspektive eingenommen werden. Der Fokus liegt auf der Betrachtung kommerzieller Erlebniswelten und der Frage, worin die typischen Elemente dieser auf Gewinn bedachten Orte liegen und welche davon für museale Ausstellungen nutzbar gemacht werden können, ohne dabei deren eigenes Profil zu schwächen.

39 Müllenmeister, Hans Martin: Geschichte und Tourismus. In: Füßmann/ Grütter/Rüsen 1994, S. 257. 


\section{Präsentationsstrategien kommerzieller Erlebniswelten}

Thematische Erlebnis- und Konsumwelten erleben seit einigen Jahren in Deutschland einen außerordentlichen Boom. Die Bandbreite unterschiedlicher Formen ist groß: Ferienparks und Themenhotels, Urban Entertainment Center, Brand Lands oder Infotainment Center. Dementsprechend verschieden gestaltet sich auch die Qualität des Angebots.

„Eine Erlebniswelt ist ein künstlich geplanter, kommerzieller Freizeit- (oder Urlaubs-)bereich, in dem geplant versucht wird, den dafür i.d.R. Eintritt zahlenden Menschen besonders viele Funktionen zu vermitteln und dabei als besondere Dienstleistung emotionale Erlebnisse für einen begrenzten Zeitraum zu verschaffen. Es geht um eine Angebotsvielfalt, es geht aber auch um Gefühle - Spaß, Freude, Glückszustände.“ ${ }^{40}$

Gemäß der Erlebnisorientierung der Konsumenten richtet sich die Freizeitindustrie danach aus, den Verkauf von Produkten mit eindrucksvollen Erlebnissen zu verknüpfen. Ein Einkauf ist nicht mehr nur eine Tätigkeit, sondern das Shoppingerlebnis wird durch Emotional Design gestaltet. Durch die emotionale Verschmelzung des Konsumenten mit dem Produkt verspricht man sich eine Verkaufsförderung. Dies führt von der reinen Produktqualität weg hin zu einer Steigerung der Erlebnisqualität. Dabei geht es um Strategien zur Vermittlung von Emotionen, die den Einkauf zu einem persönlichen Erlebnis werden lassen. ${ }^{41}$

Ein weiterer Grund für die Emotionalisierung ist die Informationsüberlastung als zentrales Phänomen unserer Gesellschaft. Darunter versteht man den Anteil der beachteten Informationen am gesamten Informationsangebot. Damit wächst die Bedeutung der visuellen Vermittlung. Sie unterliegt nicht den Restriktionen kognitiver Informationsverarbeitung und eignet sich besonders für emotionales Erleben. Daraus folgt, dass das Erlebnismarketing sich vor allem der visuellen Kommunikation

40 Kagelmann, Jürgen H.: Erlebniswelten. Grundlegende Bemerkungen zum organisierten Vergnügen. In: Rieder, Max/Bachleitner, Reinhard/Kagelmann, Jürgen H. (Hrsg.): Erlebniswelten. Zur Kommerzialisierung der Emotionen in touristischen Räumen und Landschaften. München/Wien 1998, S. 61.

41 Der Verkauf von Erlebnissen als eigenständiges, wirtschaftliches Angebot bildet nach Ansicht von Pine/Gilmore den Schlüssel zu zukünftigem wirtschaftlichem Wachstum. Vgl. Pine/Gilmore 2000. 
bedient. $^{42}$ Die emotionale Erlebnisvermittlung durch Produkte und Leistungen spielt insbesondere auf gesättigten Märkten eine entscheidende Rolle. In diesem Zusammenhang weist Kroeber-Riel auch auf die nicht-kommerziellen Institute hin. Die meisten öffentlichen Museen, Bibliotheken und Bildungseinrichtungen funktionieren für den Konsumenten im Hinblick auf die rein sachlichen Ansprüche. Jedoch bieten sie keine emotionalen und sensualen Anreize, ohne die sie für viele Konsumenten langweilig und ohne Interesse bleiben. ${ }^{43}$ Der Erfolg von Einrichtungen, die sich an der Schnittstelle von Freizeit, Tourismus und Versorgung positionieren, basiert auf zahlreichen Faktoren. Als wichtigen Punkt führt Kagelmann an, dass eine Erlebniswelt eine andere Welt sein muss: „eine Kontrastwelt mit Paradiescharakter“ (Kagelmann 1998, S. 79). Der besondere Reiz liegt darin, dass sie Alternativen zum Alltag bietet, indem alltägliche Sorgen für kurze Zeit vergessen werden können. Das Bestreben zielt darauf, die Illusion einer alles überdeckenden Harmonie zu schaffen und gleichzeitig alle störenden Brüche oder Irritationen zu eliminieren: ,[A] world of people past and present seen through the eyes of my imagination, a place of warmth nostalgia, of illusion and color and delight.“" 44

Die Perfektion des Gebotenen macht einen großen Teil der Faszination der Erlebniswelten aus. Es geht jedoch um mehr als nur um ein äußeres Erscheinungsbild. Auch die Innengestaltung, die Dekoration der Räume, die Hintergrundmusik, die Uniformen der Angestellten tragen zu einem stimmigen Gesamtensemble bei. Das Thema soll auf vielfältige Weise dekliniert und bis ins kleinste Detail entwickelt werden. Die Organisation der Gesamtanlage von Disneyland basiert zum Beispiel auf dem Prinzip der Montage von verschiedenen Sequenzen vor einem sorgfältig komponierten Hintergrund. ${ }^{45}$

42 Kroeber-Riel, Werner/Weinberg, Peter: Konsumentenverhalten. München 1999, S. 125.

43 Kroeber-Riel weist hier auf eine Entwicklung der öffentlichen Schwimmbäder hin. Zahlreiche Bäder mussten wegen mangelnder Besucher schlieBen. Eine Stunde Sport- und Hygieneveranstaltung bot offensichtlich nicht genügend Reiz für einen Besuch. Seit die Schwimmbäder jedoch in Spaßbäder mutierten, können sie wieder steigende Besuchszahlen aufweisen. Vgl. Kroeber-Riel/Weinberg 1999, S. 126.

44 Disney zitiert in Dunlop, Beth: Building a Dream. The Art of Disney Architecture. New York 1996, S. 25.

45 Bédarida, Marc: Euro Disney Park. In: Euro Disney Park. In: Arch+ Zeitschrift für Architektur und Städtebau. 114/115. (1992) S. 92/93. 
Ein weiteres Charakteristikum besteht in der thematischen Ausrichtung mit phantastischen, mystischen, magischen oder märchenhaften Elementen. Die Methode des Storytelling dient dazu, die Besucher emotional zu involvieren. Diese Geschichten sollten möglichst unverwechselbar und einzigartig sein, damit sich diese klar von anderen Erlebniswelten unterscheiden. Die Anordnung der einzelnen Elemente unterliegen einer ausgefeilten Dramaturgie. Mehrere Attraktionen liegen nicht unverbunden nebeneinander, sondern sind miteinander verwoben. Dahinter steckt die Idee, einen Filmablauf mit verschiedenen Szenen dreidimensional mit theatralischen Mitteln zu realisieren.

„Man kann eine Achterbahn aufstellen und - wie sie vergleichsweise häufig auf der Kirmes und auf dem Volksfest anzutreffen ist - auf Erfolg hoffen. Man kann aber auch - so geschehen im Europa-Park Rust - die Euro-MirAchterbahn neben einer echten russischen Weltraumstation platzieren und die Fahrt als Abschuss ähnlich einer richtigen Weltraumrakete gestalten." (Kagelmann 1998, S. 87)

Freizeitunternehmer sind deshalb notwendigerweise auch Emotion Managers, da sie neben den Kenntnissen über die innenarchitektonischen Aspekte der Inszenierung von Erlebnissen auch Kenntnisse über die Gefühlsarchitektur ihrer Einrichtung erwerben müssen, da sie sonst kein erfolgreiches Emotional Engineering betreiben können. ${ }^{46}$

Eine hohe Dienstleistungsqualität zählt zu den Mindeststandards von kommerziellen Orten. Der professionell organisierte Service kommt „,der Idee vom Kunden als König" nahe (Kagelmann 1999, S. 83). Erreicht wird der hohe Standard an Dienstleistung durch intensive Angestelltenschulung sowie Markt-, Akzeptanz- und Zufriedenheitsforschung, aber auch durch strenge Sicherheitskontrollen, vor allem im Technik- und Hygienebereich. Dies bedingt eine gleichbleibende Freundlichkeit des Personals, ein umfassendes Serviceangebot für alte Menschen, Behinderte und Familien mit kleinen Kindern und umfassende Information über alle Angebote. Mit der expliziten Kundenorientierung geht das Bemühen einher, jegliche Unzufriedenheit, Frustrationen und Stressmomente zu vermeiden. Dies geschieht durch ein geschicktes WartezeitenManagement, Kontrolle der Laufströme und Kontrolle von Lärm- und

46 Grötsch, Kurt: Emotionales Management und emotionales Lernen in Erlebniswelten. In: Nahrstedt, Wolfgang/Brinkmann, Dieter u.a.: Lernen in Erlebniswelten. Perspektiven für Politik, Management und Wissenschaft. Bielefeld 2002, S. 43. 
Müllbelastung. Als Maßnahmen gegen Besucherstress werden die Gäste zum Beispiel umfassend informiert und die Warteräume attraktiv gestaltet.

Die Orte des touristischen Konsums werden auch als Mixed-UseCenter $^{47}$ bezeichnet: Sie sind komplexe, multifunktionale Einrichtungen mit vielfältigen und unterschiedlichen Angeboten, aus denen sich die Konsumenten die individuelle Mischung nach aktuellem Bedürfnis jeweils selbst zusammenstellen können. Sie entwickelten sich in den neunziger Jahren „zu den neuen Bühnen des touristischen Konsums.“48 $\mathrm{Ne}$ ben der Multifunktionalität sind der Erlebnischarakter und der Komfort zentrale Merkmale dieser Einrichtungen. Zumeist liegt der Schwerpunkt und damit das Profil der Einrichtung auf einem dieser Angebotsbereiche als Anker, der um zusätzliche, meist branchenfremde Leistungen ergänzt wird. Die konsumorientierten Mixed-Use-Center setzen hinsichtlich Multioptionalität und Erlebnisorientierung zunehmend auch die Standards für öffentliche Einrichtungen im Bereich von Kultur und Freizeit und somit auch für Museen. Neben einer Dauerausstellung gibt es Sonderausstellungen, ergänzt mit Events, Gastronomie und einem Erlebnisshop. ${ }^{49}$

Den Konkurrenzkampf gegen die Unterhaltungs- und Ausstellungsindustrie können Museen im Hinblick auf die Konzipierung von kostenintensiven Shows nicht gewinnen. Im Normalfall können mit Ausnahme von einzelnen, großen Häusern mit überdurchschnittlicher Ausstattung weder die hohen Produktionskosten mit dem Museumsetat bestritten

47 Die Mixed-Use-Centers sind nicht mehr eindeutig einem Handels- oder Dienstleistungsbereich zuzuordnen, ihr Angebotsspektrum kann zahlreiche Dimensionen aufweisen, wie zum Beispiel Einkaufsmöglichkeiten Abendunterhaltung, Serviceleistungen sowie Freizeit- und Kulturveranstaltungen.

48 Steinecke, Albrecht: Tourismus und neue Konsumkultur: Orientierungen Schauplätze - Werthaltungen. In: Steinecke, Albrecht (Hrsg.): Erlebnisund Konsumwelten. München/Wien/Baltimore 2000, S. 21.

49 Eine konsequente Umsetzung dieser Strategie kann bei der Neugestaltung des Museum of Modern Art in New York registriert werden. Der Eintrittspreis liegt bei 20 Dollar. Demgegenüber bekommt der Besucher jedoch ein Erlebnisgesamtpaket angeboten; das Museum wird zur „GanztagesDestination“. Der Besucher kann von der Ausstellung ins Kino, vom Skulpturengarten in die Buchhandlung und dazwischen in ein Café oder Restaurant, welches es auf jeder Ebene gibt, gehen. N.N.: The New EconoMoma. In: Süddeutsche Zeitung vom 28.09.04. 
werden, noch ist genügend Museumspersonal vorhanden, um kontinuierlich Events realisieren zu können. Dennoch können Museen von der Unterhaltungsindustrie auf bestimmten Gebieten etwas lernen. Dies betrifft vor allem drei Bereiche: Service, Marketing und Erlebnisdesign.

Einen elementaren Bereich mit einem hohen Stellenwert bei kommerziellen Anbietern bildet der Service- und Dienstleistungsbereich. Dies verweist auf das Faktum, dass Ausstellungsbesuche ganzheitliche Erlebnisse sind. ${ }^{50}$ „Disney staff, for example, are experts at knowing, pleasing, and caring for their guests.“ (McLean 1993, S. 5) Ein weiterer Punkt besteht in der Berücksichtigung der Tatsache, dass Ausstellungen für ein Publikum gemacht und dieses auch erreicht werden sollte. Dies bedeutet anzuerkennen, Ausstellungen professionell publik zu machen und sich bewährter Marketingstrategien und PR-Methoden zu bedienen. ${ }^{51}$ Im Hinblick auf Erlebnisse besitzen museale Ausstellungen ein enormes Potential; dieses gilt es, nicht brach liegen zu lassen, sondern auszuschöpfen und zu nutzen. ${ }^{52}$

„In den Vitrinen und Depots lagern die Rohstoffe für unzählige Bilder. Es müßte doch gelingen, die Schwelle zum Museum als eine Schwelle zum Wunderland der Geschichte und der Geschichten für eine breite Öffentlichkeit interessant zu machen. Es fehlt nur an Ideen.“.53

50 Überlegungen zum Punkt ganzheitliches Erlebnis siehe Kapitel 3.2: Ganzheit - Ausstellungsumwelten und ganzheitliche Erlebnisse.

51 Ein erstes zusammenfassendes Handbuch für strategische Planung von Marketingmaßnahmen für Museen stammt von Neil und Philip Kotler. Bevor Neil Kotler Präsident des Kotler Museum and Cultural Marketing wurde, war er Programmdirektor und Koordinator bei den SmithsonianInstituten. Kotler, Neil/Kotler, Philipp: Museums Strategy and Marketing. Designing Missions, Building Audiences, Generating Revenue and Resources. San Francisco 1998.

52 Vorbilder dafür lassen sich auch in der Vergangenheit der Ausstellungsgeschichte finden. Die Berücksichtigung der lustvollen Komponente neben Wissensvermittlung und Pädagogik ist keine zeitgenössische Erfindung. Die Formel, Museen sollten „belehren und erfreuen“ oder auch „,bilden und unterhalten“" hat mehrere Vorläufer. Zum Beispiel wählte der Großherzog Ludwig I. bei der Stiftung des Hessischen Landesmuseum in Darmstadt die Formulierung „Unterhalten und Belehren“ und stellte beide Komponenten gleichwertig nebeneinander. Vgl. Herles 1996, S. 184.

53 Mazzoni, Ira Diana: Von Disney lernen? Zukunftsperspektiven für das Museum: Themenpark? Multi-Media-Salon? Kulturzentrum. In: Museumskunde 63. (1998) Heft 2. S. 14-16. 
Mazzoni schlägt vor, das Museum auf der Basis des gesammelten Wissens zu poetisieren, um das Publikum auf geistvolle Weise zu unterhalten: So könnte zum Beispiel das Museums als theatrum historicum wieder attraktiv werden. Sinnzusammenhänge sinnlich erfahrbar zu machen, zählt zu den vorrangigen Aufgaben von Ausstellungen. Dabei sollte jedoch nicht jedes Museum mit Edelstahlvitrinen und gravierten PlexiglasTafeln bestückt werden, denn damit wird gerade kein unverwechselbares Ambiente geschaffen. In einer selbstkritischen Analyse der Ausstellungsorte unter Berücksichtigung der spezifischen Gegebenheiten geht es darum, die jeweiligen Stärken eines Ortes zu finden und kreativ zu kommunizieren. Das Besondere der Museen liegt meist im Sammlungsbestand begründet.

„Manchmal sind es gerade die alten Wunderkammern und Sammlermuseen des 18. Jahrhunderts, die einen Besuch zum Erlebnis werden lassen. Manchmal sind es gerade die alten, mit Samtvorhängen vor Licht geschützten Vitrinen, die den Entdeckungstrieb wecken. Von Disney lernen heißt nicht, Themenparks zu kopieren. Von Disney lernen heißt, Phantasie in den Dienst des Kunden zu stellen. Heißt, mit Ideen Profil gewinnen.“(ebd.)

Auch Erlebniswelten unterliegen dem Zwang, sich im Konkurrenzkampf durch ein spezifisches eigenes Profil von der breiten Masse abzuheben. Ein qualitätsvolles Angebot entscheidet über das zukünftige Bestehen von kommerziellen Erlebniswelten. ${ }^{54}$ Die Kriterien zur Bestimmung von Qualität in musealen Ausstellungen unterscheiden sich jedoch in wesentlichen Punkten von denen der auf Profit bedachten Orte. Für Erlebniswelten gilt basierend auf Besucherbefragungen und Marktanalysen als wichtigster Erfolgsfaktor „,der zufriedene Gast.“" ${ }^{65}$ Der Zufriedenheitsfaktor der Besucher darf aber nicht als das wichtigste Qualitätskriterium zur Bewertung musealer Ausstellungen herangezogen werden, wie im Folgenden erörtert werden soll.

54 Die Liste der erfolglosen und wieder geschlossenen Erlebnisparks ist lang. Zum Beispiel scheiterte das mit großen Vorschusslorbeeren versehene Infotainment Center „PlayCastle“ im österreichischen Seefeld/Tirol bereits nach 17 Monaten. http://www.landtag.noe.gruene.at/pr2000/301100erlebniswelt.html.

55 Kreft, Michael: Europa-Park - von der Unternehmervision zum Marktführer. In: Steinecke 2000, S. 144. 


\subsection{Gegenüberstellung musealer und kommerzieller Strategien}

Aus den vorangegangenen Ausführungen ergibt sich die deutliche Forderung, dass auch der lustvollen Komponente in musealen Ausstellungen Raum gegeben werden sollte, wenn diese nicht nur ein elitäres Fachpublikum erreichen wollen. Die Berücksichtigung dieser sinnlichen Ebene führt dazu, Exponate nicht nur nach fachwissenschaftlichen Kriterien zu ordnen, sondern zum Beispiel auch narrative Erzählstrukturen als Ordnungsschemata zuzulassen. Gleichzeitig jedoch drängt sich die Frage auf, wann Grenzen musealer Inszenierungen überschritten sind und sich diese dem Diktat der Kommerzialisierung beugen.

\section{Annäherung musealer und kommerzieller Welten}

Zur differenzierten Analyse dieser unterschiedlichen Formen der Vergangenheitsbetrachtung und komplexen Wechselwirkungen unterscheidet Lowenthal zwischen History und Heritage ${ }^{56}$ Unter History definiert er die Geschichtswissenschaft, die basierend auf Quellenarbeit Vergangenheit aus ihren eigenen Bedingungen heraus zu verstehen versucht. Heritage dagegen sei ,der wie auch immer mit der historischen Wahrheit bemäntelte Kreuzzug, die Vergangenheit im Interesse der Gegenwart zu manipulieren." (ebd., S. 71) Heritage nutzt historische Spuren, um Geschichtsmärchen zu erzählen. Sie ist ein Glaubensbekenntnis zu dieser Vergangenheit. Loyalität und Verbundenheit verlangen unkritische $\mathrm{Zu}$ stimmung und schließen Dissens aus. Heritage gibt verschwommener Mystifizierung den Vorzug vor Detailwissen. Ihr Ziel ist es zu verklären, nicht zu erklären (ebd. S. 78). Heritage-Methoden legen Wert auf einen spielerischen Zugang zur Geschichte und gehen jeder Bestimmtheit aus dem Weg. Chronologische Daten, Kontext oder Zusammenhänge werden willkürlich kombiniert. Mittelalter, Renaissance und jüngere Geschichte verschmelzen zu einer schablonenhaften Vergangenheit (ebd. S. 79). Denkmalfeiern, historische Spektakel oder thematische Erlebniswelten befriedigen dieses Heritage-Bedürfnis. So unterschiedlich diese zwei Formen der Vergangenheitsdeutung sind, bedingen sie sich und befruchten sie sich doch gegenseitig. Die Historik bildet das Fundament

56 Lowenthal, David: „History“ und „Heritage“ - widerstreitende und konvergente Formen der Vergangenheitsbetrachtung. In: Beier 1999, S. 71-94. 
der Heritage und Heritage wiederum bereitet der Geschichtsforschung den Boden.

„Finnlands wertvoller Sagenschatz wurde von patriotischen Volkskundlern gehoben. Historischer Bildungsdrang entspringt häufig persönlichen Wurzeln: so brachte - um ein berühmtes Beispiel zu nehmen - die Beschäftigung mit der eigenen Familiengeschichte den Historiker Philippe Ariès dazu, die akademische Laufbahn einzuschlagen.“ (ebd. S. 91)

Die neutrale, auf Fakten reduzierte Geschichte kann schwer Begeisterung wecken. Heritage hingegen hat den Beiklang von persönlicher Nähe, von Identität und Lebendigkeit. Historiker lehnen eine Konfrontation und Auseinandersetzung mit Heritagephänomenen im allgemeinen ab. Wohlfühlgeschichten haben ihrer Ansicht nach sämtliche Geschichtsbücher kaputt gemacht. Doch Heritage-Anhänger stoßen sich ebenso am Wahrheitsfetischismus der Historiker.

„Um mit alten Mythen und Vorurteilen aufzuräumen, wollte die Regierung Sir Francis Drake auf menschliches Maß zurechtstutzen. Doch Drake war wie das Herzblut von Plymouth: Was Robin Hood für Nottingham und Mickey Mouse für Disneyland, ist Francis Drake für Plymouth. Die Heritage brauchte ihn. Wenn du etwas zu verkaufen hast, dann verpacke es richtig und bringe es an den Mann, meinte Plymouths Gedenkfeierveranstalter: Wozu Geschichte, wenn man sie nicht ein wenig ummünzen kann?“ (ebd. S. 91)

Die Grenzen zwischen History und Heritage verändern sich kontinuierlich. Was früher als verbürgte Geschichte galt, wird heute als Heritage verstanden. Objektive und subjektive Formen des Vergangenheitsverständnisses sind gleichermaßen unabdingbar. Beide Formen können sich nie ganz der jeweils anderen entledigen. Dies wird, stellt Lowenthal fest, Historikern und Heritage-Hütern heutzutage in zunehmenden Maße bewusst (ebd., S. 92).

In diesem Spannungsfeld zwischen History und Heritage bewegen sich kulturhistorische Ausstellungen. Von einem Heritage-Bedürfnis zeugt zum Beispiel die steigende Anzahl kleiner kommunaler Museen und Museumsinitiativen. Musealisierungsphänomene erzeugen einen ambivalenten Sachverhalt. Statt ihrem Bildungsanspruch mit dem Ziel der Aufklärung gerecht zu werden, führt die Musealisierung zur Verklärung, Verzeichnung und Mystifizierung der Erinnerung. Korff sieht in dieser Entwicklung, wie sie sich aktuell vollzieht und auch von den $\mathrm{Mu}-$ seen selbst betrieben wird, die Gefahr, einen zu reduzierten Begriff von 
Museum zu etablieren und es zu einem Medium zu machen, dessen Ziel allein die Selbstentrückung ist.

„Die Fatalität der Entwicklung, deren Zeugen wir sind, ist vor allem deshalb so bedenklich, weil das Bild des Museums unmittelbar mitbetroffen ist, weil dieses in dem Maße reduziert wird, wie Geschichtsaneignung nur noch im Schema von fetischisierten Objektfixierungen zugelassen ist, wobei das Fixativ nicht anderes als ein mixtum nostalgium ist." ${ }^{\text {"5 }}$

Korff befürchtet, dass sich das Museum durch die Musealisierung um die Chance bringt, seine Möglichkeiten zur sinnlichen Bildung und Emanzipation weiterzuentwickeln. Der emotionale Zugang des Heritage bildet die Basis der Begeisterung für die Dingwelt der Vergangenheit. In der Museumswelt lassen sich Beispiele finden, wie diese emotionale Begeisterung ausgenützt wird, um damit den Verkauf von Devotionalien des Museumsshops anzukurbeln. Der Geschäftsführer der Swarovski Kristallwelten ${ }^{58}$ Andreas Braun bekennt sich offen zur kommerziellen Ausrichtung dieses Ortes.

„Wir haben einen unikaten Ort des Erlebnisses - des Kauferlebnisses - geschaffen. Die Besucher wollen eine unikate Sinneserfahrung erwerben und mit nach Hause nehmen. [...] An einem guten Ort muß etwa drei Viertel des Umsatzes auf den Verkauf von Devotionalien beruhen. ${ }^{\text {"59 }}$

Das primäre Ziel der Ausstellung liegt nun nicht mehr im Bildungsbereich, sondern die Faszination der Objekte und des Ortes wird als Mittel zum Zweck der Gewinnsteigerung eingesetzt. Auch Steiner vertritt die These, dass an die Spitze großer Museen Unternehmer und nicht Fachwissenschaftler gehören, da das Verkaufen und Vermarkten der Schlüs-

57 Korff, Gottfried: Aporien der Musealisierung. Notizen zu einem Trend, der die Institution, nach der er benannt ist, hinter sich gelassen hat. In: Zacharias, Wolfgang (Hrsg.): Zeitphänomen Musealisierung - Das Verschwinden der Konstruktion und die Konstruktion der Erinnerung. Essen 1990, S. 67.

58 Im Jahr 1995 eröffneten in Wattens, Tirol, die Swarovski Kristallwelten, ein von André Heller geschaffenes, auf Dauer angelegtes HightechLabyrinth in einem unterirdischen Raumsystem. Der Firmenname Swarovski steht für Erzeugung von feinem Kristall, präziser Optik und perfekten Schleifmitteln.

59 Braun, Andreas: Emotionale Besuchererlebnisse in Ausstellungen. In: Landesstelle für die nichtstaatlichen Museen in Bayern 2000, S. 58. 
sel zu einer besseren Wirtschaftlichkeit und zu einer autonomen $\mathrm{Zu}$ kunftsbestimmung sei. ${ }^{60}$ Erklärtes Ziel seiner eigenen Präsentation bestand darin, Besucher ,sinnesbesoffen zu machen, [...] zu berühren, zu bezirzen“ (ebd. S. 206). Dies wirkte sich als positive wirtschaftliche Begleiterscheinung auf steigende Umsatzzahlen der verkauften Produkte aus. „Emotionalisierte Menschen verlieren die volle Kontrolle über sich, was sich eindeutig im Kaufverhalten auswirkt. Wer mit leuchtenden Augen aus dem Museum kommt, der will etwas mit nach Hause nehmen." (ebd.)

Diese zwei Beispiele zeigen, dass sich museale Ausstellungen in manchen Fällen tatsächlich nicht nur in ihrer haptisch-sinnlichen Gestaltung des Ausstellungsparcours, sondern auch in ihrer gewinnorientierten Ausrichtung den kommerziellen Erlebniswelten annähern. ${ }^{61}$ Nach wirtschaftlichem Kalkül würden nur jene Ausstellungsorte zukunftsträchtig sein können, die durch attraktive oder außergewöhnliche Ausstellungsgegenstände und eine reizvolle Umgebung oder Besonderheit des Ortes Besuchermassen anlocken können. Anderen Orten, die nicht diese Vorzüge aufweisen, würde dann deren Berechtigung als Ausstellungsort abgesprochen werden. Diese Reduzierung auf marktanalytische Faktoren vernachlässigt jedoch bildungsrelevante Aspekte. So ist zum Beispiel die historische Bedeutung von Orten und Objekten nicht immer anlockend - extremes Beispiel dafür sind ehemalige Konzentrationslager - dennoch besteht aufgrund ihrer historischen Bedeutung eine öffentliche Aufgabe zur Bewahrung.

Obwohl die Trennlinien zwischen Erlebniswelten und musealen Ausstellungen fließend verlaufen, erscheint es aufgrund der Annäherung bedeutsam, mögliche Kriterien für eine Abgrenzung aufzuzeigen.

60 Steiner war Direktor des Glasmuseums in Hergiswil bei Luzern. Unter seiner Leitung entwickelte sich die von der Schließung bedrohte Glashütte $\mathrm{zu}$ einem florierenden Unternehmen und dies vor allem dank des Museums. Vgl. Steiner, Otto, Jolias: Museen unter Rentabilitätsdruck - Wieviel Geld kann man mit einem Museum verdienen? In: Treff 1997, S. $203 \mathrm{ff}$.

61 Auch von Seiten der Erlebniswelten ist eine Tendenz zu beobachten, dass sie typische Elemente musealer Präsentation in ein Gesamtensemble integrieren. 


\section{Differenzierender Kontext: Akzentuierung - Offenheit - Irritation}

Insbesondere multimedial inszenierte Ausstellungsumwelten sind mit dem Vorwurf konfrontiert, dass sie zu sehr dem erlebnishungrigen Menschen antworten, ohne diesem eine vertiefende Erfahrung zu geben. In der Konsequenz hieße dies eine Rückkehr zu traditionellen Formen objektorientierter Präsentationen. Doch auch diese von kunsthistorischer Seite bevorzugte Präsentationsform ist kritisch zu überdenken, da auch damit implizit Werthaltungen und Einstellungen vermittelt werden. $\mathrm{Mu}$ sealisierungsphänomene bedingen den ambivalenten Sachverhalt der Verklärung und Mystifizierung, statt dem eigentlichen Aufklärungsanspruch gerecht zu werden.

Sehr deutlich führte der Künstler Guillaume Bijl mit dem Ausstellungsprojekt „Museum für die Souvenirs der sechziger Jahre“ das Phänomen vor Augen, wie durch das museale Umfeld die Rezeption der Besucher gesteuert wird. ${ }^{62}$ Dem Künstler ging es mit dieser Aktion nicht um eine Parodie der Kunst, sondern um eine provokative Kritik an der Art und Weise, wie die Gesellschaft mit Kunst und Kultur umgeht und auf welche Art und Weise Erinnerung praktiziert wird. In der Ausstellung wurden mit Gebrauchsspuren versehene Gegenstände aus den sechziger Jahren sorgsam in Vitrinen präsentiert und mit Lichtspots präzise angestrahlt. $\mathrm{Zu}$ sehen gab es zum Beispiel den Füllfederhalter von Adenauer, das Pillendöschen der Piaf, die Angelrute von Hemingway, die Filmkamera von Faßbinder, die Polaroidkamera von Warhol, den Schuh von Monroe und den Schreibtischstuhl von Kennedy. Die Auratisierung der Objekte durch die Inszenierung gelang perfekt. Bijl stützte die Simulation durch ein Videoband, das im Mitschnitt bedeutende Ereignisse der sechziger Jahre wie zum Beispiel Mauerbau und Kubakrise, Fußballweltmeisterschaft und Beatlesbegeisterung zeigte.

Die meisten Besucher der Ausstellung hielten die präsentierten Objekte für echt. Die perfekte Simulation wurde wirklicher als die Wirklichkeit, allein aufgrund der Tatsache, weil dies in einem Museum stattfand. Am Ende des Rundgangs waren die Besucher empört, ärgerlich und enttäuscht, als sie erfuhren, dass es sich bei den Gegenständen um Fakes handelte. So spiegelt die Desillusionierung der Besucher am Ende der Ausstellung in gewisser Weise auch die Desillusionierung durch die eigene Geschichte wider, „die man am liebsten selig gesprochen hätte“

62 Stoeber, Michael: Guillaume Bijl. Städtische Galerie Nordhorn, 12.01.18.3.2001. In: Kunstforum 145. (2001) S. 400-401. 
(ebd., S. 401). Obgleich die Exponate in einer von Kunsthistorikern favorisierten Form der objektorientierten Präsentation gezeigt wurden, sind dennoch die Konnotationen kritisch zu befragen.

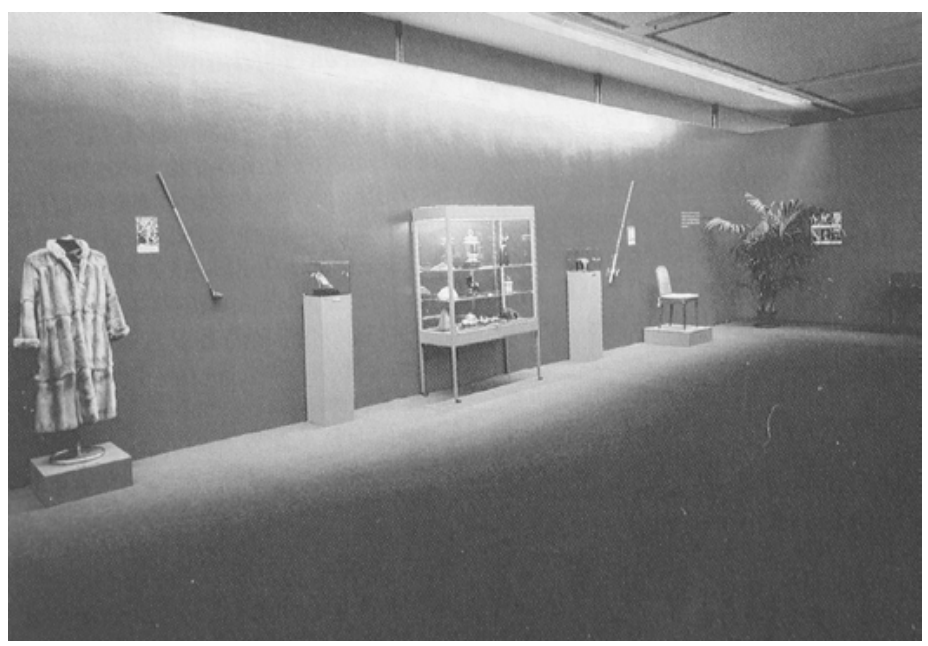

Abbildung 13: Installationsansicht zur Ausstellung „Museum für die Souvenirs der sechziger Jahre" des Künstlers Guillaume Bijl.

Einen Reflexionsschwerpunkt gegenwärtiger Museologie markiert der Begriff Kontext. „It follows from the notion that next to physical characteristics and meaning context is one of the three basic categories of information of objects." "63 Der Kontext bezieht sich auf den Gesamtzusammenhang der Ausstellungsumwelt, in welchen die musealen Objekte eingebettet sind. Im Folgenden stelle ich drei Aspekte heraus, die insbesondere für die Gestaltung musealer Ausstellungen gelten und somit als Kriterien für eine Abgrenzung von kommerziellen Welten herangezogen werden können.

Ein erster Gesichtspunkt befasst sich damit, welche Akzentuierungen in einer Präsentation gesetzt werden. Diese Betrachtung bezieht sich auf den Gesamtkontext und erörtert die Frage, in welches Umfeld inszenatorische Elemente eingebunden sind. Ein phantasievoller Umgang mit der Historie kann als Motivationsfaktor dienen und Interesse wecken, tiefer

63 Mensch, Peter van: Museum Buildings \& Urban Context. (unveröffentl. Skript). Reinwardt Academy, Amsterdam 2000, S. 1. 
in die Materie einzudringen. Ein sinnlich aufgemachtes Interieur beispielsweise besitzt eine höhere Attraktivität als eine Aufreihung von Exponaten gegliedert nach Entstehungszeit oder Formprinzipien.

Wie bereits festgestellt, kann tatsächlich eine Annäherung von musealen und kommerziellen Welten beobachtet werden. Anhand eines pointierten Vergleichs zwischen einer Inszenierung in der Landesausstellung „Römer zwischen Alpen und Nordmeer"64 und dem Caesar's Palace ${ }^{65}$ in Las Vegas lassen sich auf den ersten, oberflächlichen Blick frappierende Ähnlichkeiten finden. Beide Inszenierungen beinhalten das Motiv römischer Legionäre in einem stimmungsvoll gestalteten Ambiente. Bei genauerer Betrachtung zeigen sich allerdings grundlegende Unterschiede.

Die Eingangsinszenierung in der Landesausstellung bezog sich auf einen konkreten historischen Sachverhalt. Sie zeigte römische Legionäre im Alpenvorland von Oberammergau im Jahr 15 v. Chr. (siehe Abb. 14). Unter Caesars Adoptivsohn Octavian/Augustus eroberten römische Truppen das bayerische Alpenvorland, das durch Militärlager und stadtähnliche Siedlungen erschlossen wurde. In Caesar's Palace wird das imperiale Rom mit allen Mitteln der Kulissenkunst, mit Trompe-l'oeilEffekten und Manipulationen des Maßstabes inszeniert (siehe Abb. 15). Die Kopie löst sich völlig von den historischen Vorgaben, benutzt positiv codierte Elemente und vermischt in ihre Gestaltung Originalzitat und freie Nachbauten. Dabei geht es nicht eigentlich um die Referenzorte, sondern um deren Erinnerungspotential. ${ }^{66}$ Zitiert werden Orte oder Exponate, die mit atmosphärischer Bedeutung aufgeladen sind und die an Höhepunkte politischer und kultureller Historie erinnern. ${ }^{67}$

64 Die Ausstellung, konzipiert unter der Leitung der Prähistorischen Staatssammlung München, fand im Lokschuppen Rosenheim vom 12.05.05.11.00 statt. Wamser, Ludwig (Hrsg.): Die Römer zwischen Alpen und Nordmeer. Zivilisatorisches Erbe einer europäischen Weltmacht. Mainz, 2000. Siehe auch: http://www.roemer-ausstellung.de (letzter Zugriff: 10. 02.05).

65 Eine ausführlichere Beschreibung siehe Anderton, Frances/Chase, John: Las Vegas. Ein Führer zur zeitgenössischen Architektur. Köln 1997, S. $48 \mathrm{ff}$.

66 Hirschmüller, Markus/Madundo, Peter/Schindele, Harald: Identität ist das Ziel. Die Orte sind herstellbar. In: StadtBauwelt. (1999) Heft 36. S. 2030.

67 Vor dem Caesar's Palace befindet sich eine Reproduktion von Michelangelos David-Statue, ein Hauptwerk der Hochrenaissance; ein vergoldeter, vier Tonnen schwerer Bronze-Brahme aus Thailand steht vor dem Hotel. 
In der Landesausstellung waren vier Figurinen in marschierender Haltung in eine Waldsituation aus Wurzelwerk, Ästen und Bäumen platziert. Dieser Hintergrund war in einer dezenten schwarz-weiß Optik gestaltet. Die Gesichtszüge der weißen Figuren zeigten nur angedeutete menschliche Züge. Die einzigen buntfarbigen Akzente bildete die auf wissenschaftlicher Basis rekonstruierte Bekleidung und Ausstattung der Legionäre. Im Caesar's Palace steht ein als Fußsoldat verkleideter Mensch vor einem Pseudotempel mit Versatzstücken korinthischer Säulenordnung mit integrierten Leuchtstrahlern. Im Inneren des Tempels befinden sich „sprechende Festival-Fountain-Statuen“, die als Dekoration sowie mechanisch gesteuertes Schauspiel dienen. „Und für den Fall, daß Sie sich fragen, ob die Vorführung irgendeine Handlung hat - mitnichten. Hier geht es nur um die Show - um den Clou, daß die Statuen aufstehen, sich bewegen, singen und tanzen.“ (ebd., S. 50).

Nach Durchschreiten der Eingangsinszenierung der Landesausstellung gelangte der Besucher in einen Ausstellungsraum, in dem die Exponate in Vitrinen präsentiert wurden. Der weitere Ausstellungsrundgang vollzog sich in einem Wechsel von objektorientierter Präsentation, interaktiven Medien sowie inszenierten Räumen. Die Inszenierung in Caesar's Palace überwölbt ein Trompe-l'oeil-Himmel, der sich stündlich in der Simulation des Tagesablaufes von Morgen- bis Abenddämmerung ändert. Der Pseudotempel bildet das Zentrum des Forum-Shops mit einer Ansammlung exklusiver Geschäfte.

Im Rahmen der Landesausstellung hatten die Inszenierungen eine illustrierende Funktion mit dem Ziel, das zivilisatorische Erbe einer europäischen Weltmacht in Einzelaspekten zu beleuchten. Im Gegensatz dazu dient das reizmaximierende Ambiente in Caesar's Palace mit einer Mischung von Entertainment und Shopping als Rahmen für die kommerzielle Welt des Glücksspiels.

In der polarisierenden Gegenüberstellung lässt sich aufzeigen, dass zwar im äußeren Erscheinungsbild auf den ersten Eindruck eine Annäherung stattfindet, in den Grundstrukturen, in der Ausführung und auch in ihrer Funktion sich beide Inszenierungsformen jedoch grundlegend unterscheiden. In der Landesausstellung blieb der rekonstruktive Charakter bewahrt. Die inhaltlichen Bezugspunkte bezogen sich auf konkrete Sachverhalte; die Figurinen zeigten lediglich angedeutete menschliche Züge, auch fehlten illusionierende Effekte, wie dieses in der Las Vegas Inszenierung der Fall ist. Die Illusion des Eintauchens in vergangene Welten wird in musealen Präsentationen in der Regel auch durch die Präsenz der Exponate gebrochen. Hochreiter relativiert, dass die Nach- 
stellung eines vergangenen Lebenskontextes von Fall zu Fall danach entschieden werden muss, ob sie didaktisch im Rahmen der intendierten Ausstellungsziele zu rechtfertigen ist und nicht nur danach, ob sie im Sinne der Geschichtswissenschaft historische Wahrheit produziert (Hochreiter 1994, 225). ${ }^{68}$ Selbst wenn unter Umständen aus kunsthistorischer Perspektive inszenatorische Elemente als spielerisches Beiwerk abqualifiziert werden, so kann dies aus besucherorientierter Perspektive dennoch gerechtfertigt werden. Problematisch werden Inszenierungen jedoch dann, wenn das Verhältnis zwischen sinnlichen Erlebnissen und rationalen Momenten an Ausgewogenheit verliert. Ist es das primäre

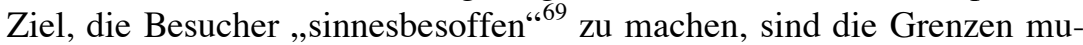
sealer Inszenierung überschritten.

Ein zweiter Gesichtspunkt bezieht sich auf die Offenheit der Narration im Gegensatz zu linearen und geschlossenen Formen der Erzählung. Mehrdeutige Ausstellungswelten geben dem konnotativen, individuellen Bildgedächtnis ebenso Raum wie dem aufklärenden Text. Statt dem begehbaren Buch der siebziger Jahre meint dies ein offeneres Setting, welches zum Beispiel Elemente der Wunderkammer enthält. Purin fordert, dass sich auch kulturgeschichtliche Museen und Ausstellungen vom tatsächlichen oder zugeschriebenen Anspruch als „hehrer Ort der Wahrheit" distanzieren sowie Mehrdeutigkeit und Rückfragen zulassen sollten.

„Die Professionellen sollten sich vom Muster narrativer Ausstellungen und den Ansprüchen nachträglicher Sinngebung entschlossen lösen und als fragmentarische Einladungen zur Reflexion radikal-subjektivistische Gedankenblitze und begehbare Zettelkästen anbieten." ${ }^{" 70}$

68 Als Beispiel für die Diskrepanz zwischen geschichtswissenschaftlichem Anspruch und Besucherorientierung sei auf die didaktisch-künstlerische Inszenierung „Treue Weggefährten Heinrichs II. “ in der Landesausstellung „Kaiser Heinrich II: 1002-1024“ verwiesen. Siehe Kapitel 6, S. $347 f f$.

69 Zitat von Steiner siehe Kapitel 4, Anm. 60.

70 Bernhard Purin, Direktor des Jüdischen Museum in München, zitiert in Reichling, Norbert: Bericht über den Workshop: „Reliquien oder Relikte? Zwischen Bewahrpädagogik und NS-Devotionalienschau. Tagung in Düsseldorf vom 4.11.03-9.12.03. In: http://hsozkult.geschichte.hu-berlin.de/ tagungsberichte/id=368 (letzter Zugriff: 10.02.05). 
Pädagogische Interpretationen repräsentieren somit eine mögliche Sichtweise im Rahmen eines multiperspektivischen Ansatzes, ohne diese jedoch in einer geschichtspädagogischen Überwältigung zu verabsolutieren. Hooper-Greenhill plädiert dafür, dualistische Denkansätze mit ihrer klaren Unterscheidung in Gut oder Böse, schwarz oder weiß zu Gunsten einer dialektischen Annäherung, in der Differenzen weder absolut noch ausschließlich dargestellt werden, aufzugeben. „Today concepts of both/and rather than either/or seem to offer more useful explanations.“ (Hooper-Greenhill 2000, S. 141) Dies zielt darauf, möglichst viele Erzählmöglichkeiten und -wissen in einer Ausstellung zu präsentieren und zuzulassen.

Ein dritter Ansatzpunkt besteht in der Gegenüberstellung von Irritation und Perfektion. Ein gemeinsames Kriterium kommerzieller Konzepte besteht in der Perfektionierung der Schaffung von Erlebniswelten, die einen Kontrast zur Alltagswelt bieten. Besucher sollen vorübergehend ihre Alltagssorgen und Belastungen im Beruf vergessen, sich in eine Phantasie- und Traumwelt versetzt fühlen, die bewusst nicht an die wirkliche Welt erinnert. Gemäß dem Slogan „Happiness is our business“ gewähren die künstlichen Traumwelten ,märchenhafte Stunden der Freude, Entspannung und Zerstreuung“, um Alltagsmonotonie, Stress, Langeweile oder Vereinsamung für kurze Stunden des Glücks vergessen zu können (Opaschowski 2000, S. 47).

Das bildungsrelevante Anliegen musealer Ausstellungen mit dem Ziel der Aufklärung und Reflexion wirkt im Hinblick auf kommerzielle Ziele oft jedoch geradezu kontraproduktiv, indem es eben nicht darum geht, eine perfekte Illusion zu schaffen, sondern die Konstrukthaftigkeit der Vergangenheitsbilder zu betonen und Irritationen im Fluss der Wahrnehmung zu erzeugen. ${ }^{71}$

Beispielsweise böten sich nach Urban die von Modernisierungsprozessen gekennzeichneten historischen Stadtkerne, in denen die Festkultur allgemein ihren Sitz hat, dazu an, kommunale Identifikationsprozesse der Bewohner zu fördern. Durch eine Thematisierung des Wandels und der Bedeutung von Geschichte in der Gegenwart könnte ein offener Dialog über die Gestaltung der Stadträume und die Rolle der Geschichte geführt werden (Urban 1999, S. 195). Konsequenterweise wird jedoch eine gegenwartsbezogene Problematisierung ausgeklammert, da dies nicht einem nach quantitativen Kriterien ausgerichteten, erfolgsorien-

71 Siehe Kapitel 2.4 
tierten Konzept entspricht. Die kritischen Gegenwartsbezüge verhindern das Vergessen des Alltags und das Eintauchen in eine andere Welt. Folglich konterkariert die gängige Festkultur eine solche das Verhältnis von Geschichte und Gegenwart problematisierende Fragehaltung.

Auch bei musealen Präsentationen besteht die Gefahr, dass sie in diesen Sog der Kommerzialisierung mit einem berechnenden Blick auf gefüllte Kassen geraten. Im Hinblick auf Folklorisierungstendenzen fördern diese einen Nostalgie-Tourismus, der sich auch zum Beispiel nicht scheut, historische Requisiten und hübsche Trachten neu zu erfinden. Dann jedoch wird die Wiederbelebung der Vergangenheit zur Simulation. Als Konsequenz für die gesellschaftliche Rolle des Museums bedeutet dies, dass damit das Erinnerungsorgan Museum überflüssig wird. Wenn die Differenzen zwischen Gegenwart und Vergangenheit eingeebnet werden, verliert es sein Anregungspotential zur Reflexion.

Die hier aufgezeigten Punkte bilden deutliche Gegenpositionen zur kommerziellen Ausrichtung von Ausstellungen. Nichtsdestotrotz gibt es zweifellos Ausstellungen in Abhängigkeit von Orten, Themen oder Exponaten, in denen sich kommerzielle und bildungsrelevante Faktoren in einer gelungenen Symbiose kombinieren lassen. In dem Konzept zu einem „konstruktivistischen Museum“ verweist Hein auf die Notwendigkeit der intellektuellen Herausforderung. Die Konfrontation mit Neuem sollte als Ausgangspunkt zwar auf dem Vorwissen der Besucher basieren, sich jedoch nicht darauf beschränken, sondern darüber hinaus auch weiterführende Angebot bereit stellen. „The trick, of course, is to find just the right degree of intellectual challenge to leave the learner slightly uncomfortable." (Hein 1998, S. 176) Anspruchsvolle Themen oder unkonventionelle Aufarbeitung irritieren zunächst und fordern vom Betrachter Offenheit und auch die Bereitschaft, sich auf die Anstrengung der Auseinandersetzung einzulassen.

Selbst wenn die Tatsache „Kultur darf auch Spaß machen“72, wie dies der Freizeitforscher Opaschowski fordert, anerkannt wird, bedeutet dies andererseits nicht, dass der Genuss- und Spaßfaktor als einziger Gradmesser herangezogen werden kann. In den konzeptionellen Überlegungen können derartige Faktoren eine Rolle spielen, jedoch sollten sie nicht das Ziel musealer Präsentationen bilden. Dies als Kriterium zu definieren, würde zu einer Verarmung und Reduzierung der Vielfältigkeit des kulturellen Angebots führen. Anspruchsvollen, schwierigen, ernsten

72 Zekri, Sonja: Verstehen Sie Spaßkultur? In: Süddeutsche Zeitung vom 18.11.03. 
und sperrigen Themen wäre damit die Daseinsberechtigung abgesprochen. Eine wichtige demokratische Funktion kulturhistorischer Ausstellungen liegt auch darin, Foren für Themen zu bilden, die über andere Massenmedien nicht kommuniziert werden können oder dürfen. ${ }^{73}$

73 Ein Beispiel für das Aufgreifen eines Tabuthemas bildet die kritische Ausstellung „Das Schweigen brechen“ in Tel Aviv vom 01.06.-25.06.04 mit Fotos und Zeugenaussagen von früheren israelischen Wehrpflichtigen über Demütigungen und Misshandlungen an palästinensischen Männern, Frauen und Kindern in Hebron. Diese Ausstellung sorgte für heftige Reaktionen von Israelis. Den Ex-Soldaten wurde Nestbeschmutzung vorgeworfen. Kritik an der Armee in Israel kommt einem Tabubruch gleich. Vgl. http://www.nahost-politik.de/israel/armee/ausstellung.htm (letzter Zugriff: 10.02.05). 



\section{BILDER VOM MITTELALTER IN KOMMERZIELLEN UND MUSEALEN FORMEN}

Die in den bisherigen Kapiteln erfolgten Reflexionen zur Ausstellungsgestaltung waren allgemeiner Art und unabhängig von thematischen Eingrenzungen. In der Hinwendung zu einem inhaltlichen Schwerpunktthema sollen die theoretischen Gedanken eine Verdichtung erfahren. Die Wahl fiel dabei auf das Thema Mittelalter. Diese Entscheidung basiert auf mehreren Überlegungen.

Ein erster Grund liegt darin, dass zwar generell eine Faszination für alles Gewesene beobachtet werden kann, das Mittelalter jedoch zu den bevorzugten Themen zählt. Die Begeisterung für das Vergangene äußert sich in einer Vielzahl von Angeboten in allen Medien und Sparten, sei es in Film, Fernsehen, Musik oder Literatur. ${ }^{1}$ Bei den Geschichtszeitschriften werden zum Beispiel täglich im Schnitt mehrere tausend Exemplare verkauft, ${ }^{2}$ insbesondere Mittelalter-Zeitschriften können enorme Absatzzahlen verbuchen. ${ }^{3}$ In den Sommermonaten locken weit über tausend

1 Auf dem Gebiet der Literatur wird immer wieder auf den Historienroman „Der Name der Rose“ von Umberto Eco verwiesen. Neben anderen Faktoren wird diesem Roman eine Initialwirkung für die Begeisterung für das Mittelalter zugeschrieben. Die Frage, worin die Faszinationskraft dieses Romans liegt, beschäftigt auch Fachwissenschaftler. Vgl: Heit, Alfred: „Die ungestillte Sehnsucht“ - Versuch über ein Movens historischer Faszination in Umberto Ecos Roman „Der Name der Rose“ In: Füßmann/Grütter/Rüsen 1994, S. 113-128. Kerner, Max: Das Mittelalter als „Kindheit Europas“. Zu den Geschichtsromanen Umberto Ecos. In: Segl 1997, S. 289-304. Fuhrmann, Horst: Einladung ins Mittelalter. München 2000, S. 273-276.

2 Fischer, Stefan: Gestern ist heute. Pyramiden, Minnesang, Feuersturm: Auch bei den Zeitschriften ist Geschichtliches plötzlich sehr gefragt. In: Süddeutsche Zeitung vom 27.08.03. Im Schnitt werden täglich mehrere Tausend Geschichtszeitschriften verkauft, das sind jährlich fast drei Millionen Exemplare.

3 Die Zeitschrift Karfunkel ist auf diesem Gebiet Marktführer. Seit der ersten Ausgabe im Jahr 1993 hat sich diese Zeitschrift mittlerweile fest auf 
Veranstaltungen zu Mittelalterfesten. ${ }^{4}$ Aufgrund des großen Booms des Mittelalters kann davon ausgegangen werden, dass Vorstellungsbilder vorhanden sind, diese jedoch vorwiegend von populären, kommerziell erfolgreichen Bildern geprägt sind. Daraus ergeben sich bildungstheoretische Folgerungen, die bei der Erstellung von Vermittlungskonzepten in die Überlegungen einfließen sollten.

Ein zweiter Grund für die Konzentration auf diese Epoche war, dass die Präsentation von mittelalterlichen Themen aufgrund der Andersartigkeit dieser Zeit sowie auch der Bruchstückhaftigkeit der Überlieferung eine besondere Herausforderung an die Ausstellungsmacher darstellt. Die mittelalterliche Welt war von einer Gesellschaft geprägt, in der zum Beispiel nur ein geringer Teil der Bevölkerung lesen und schreiben konnte, weshalb der Zeichenhaftigkeit größte Bedeutung zukam. Die Symbolik der mittelalterlichen Bildersprache können die wenigsten Laien gegenwärtig noch interpretieren.

Zudem werden die Überreste der Vergangenheit mit der zunehmenden Entfernung der Gegenwart spärlicher. In ihrer zufälligen Existenz sind sie in keiner Weise repräsentativ für die Komplexität der mittelalterlichen Gesellschaft. Urkunden und Bücher verdanken ihre Überlieferung nicht der Dauerhaftigkeit des Materials, sondern ihrer gesellschaftlichen Funktion. Liturgische Geräte blieben aufgrund ihrer sakralen Bedeutung unverhältnismäßig lang erhalten. Die mittelalterliche Dingwelt der einfachen Leute dagegen ist kaum noch vorhanden. Daraus ergibt sich ein verschobenes Verhältnis in der Überlieferung, welches sich in einer Vielzahl religiöser Objekte gegenüber einer nur geringen Anzahl von Alltagsobjekten manifestiert. So sind diese Objekte zwar Stellvertreter für die Welt des Mittelalters, doch sie repräsentieren es

dem Markt positioniert. Aus der anfänglichen Sammlung von Terminen zu historischen Themenfesten, Ritterturnieren, historischen und mittelalterlichen Märkten, Veranstaltungen zu Stadt- und Gemeindejubiläen wurde eine Zeitschrift mit Leserbriefen, Titelgeschichten, Buchbesprechungen, Veranstaltungskritiken sowie zahlreichen Hintergrundinformationen. Gegenwärtig erscheinen sechs Hefte pro Jahr mit einer Auflage von 22.000 Stück. Siehe auch: http://www.karfunkel.de (letzter Zugriff: 26. $10.04)$.

4 Im Jahr 2003 listete die Zeitschrift Karfunkel über 1500 Termine auf. 
nicht. Die Tatsache der Überlieferung ist ebenfalls Teil ihrer Geschichte. ${ }^{5}$

Eine Ausstellung über das 19. Jahrhundert verfügt in der Regel über einen vergleichsweise weit größeren und umfangreicheren Objektbestand. Auch die Objekte selbst entstammen einer modernen Welt, die den Besuchern nicht derart fremd sind. Zur Vergleichbarkeit von Ausstellungen war es somit nötig, den betrachteten Zeitraum einzuschränken. Aus der unüberschaubaren Anzahl gegenwärtiger Ausstellungen zum Thema Mittelalter beschränke ich mich auf drei Präsentationsformen. In Bezug auf die in Kapitel eins getroffene Terminologie rekonstruktiver sowie abstrahierender Raumbilder stelle ich zum einen Ausstellungen vor, die mittels eines rekonstruktiven Ansatzes ein nostalgisches Mittelalterbild entwerfen. Zum anderen beschreibe ich stellvertretend für den Typus abstrahierender Raumbilder unter dem Schlagwort Theatralik dramaturgische Inszenierungen. Im Gegensatz zu diesen zwei Inszenierungsformen steht die objektorientierte Präsentation mit einer Betonung der Aura der Objekte, die gleichzeitig zu einer Ablehnung von inszenatorischen Elementen führt, die in der Aufmerksamkeit der Besucher in Konkurrenz zu den Exponaten treten könnten.

\subsection{Reflexionen zur Rezeption des Mittelalters}

Trotz grundsätzlicher Bedenken aus universalhistorischer Sicht hat sich der Epochenbegriff Mittelalter in der modernen Geschichtsschreibung behauptet. Als problematisch erweist sich sowohl die Abgrenzung des Mittelalters von Antike und Neuzeit als auch die Periodisierung innerhalb des Mittelalters. ${ }^{6}$ Den Begriff Mittelalter prägten die Humanisten

5 Borsdorf, Ulrich/Grütter, Heinrich Theodor: Überdachte Fragmentarik: Die Ausstellung ,Vergessene Zeiten. Das Mittelalter im Ruhrgebiet‘. In: Fröhlich 1992, S. 179ff.

6 Ein eindeutiger Beginn des Mittelalters lässt sich nicht festlegen, die Spanne entsprechender Datierungen reicht von der Krise des Römischen Reiches im 3. Jahrhundert über den Untergang Westroms (476) bis zur Kaiserkrönung Karls d. Gr. (800). Als Übergang von der Antike zum Mittelalter gilt die Zeit der Völkerwanderung (4.-6. Jahrhundert), in der durch die Begegnung von Antike, Germanentum und Christentum wesentliche Grundlagen der frühmittelalterlichen Gesellschaft entstanden. Als Zäsur wird auch das Vordringen des Islams in den Mittelmeerraum ab dem 7. Jahrhundert angesehen. Im Ergebnis von Völkerwanderung und islami- 
des 15./16. Jahrhunderts für die Zeit zwischen dem Ende der Antike, der ihrer Ansicht nach eine Epoche des allgemeinen Verfalls der lateinischen Sprache und Bildung folgte, und der Renaissance als Wiedergeburt antiker Gelehrsamkeit. Während die Aufklärung das finstere Mittelalter missachtete, verklärte die Romantik diese Epoche als Idealzeit der gläubigen, ritterlichen Gemeinschaft des christlichen Abendlandes. Diese zwei gegensätzlichen Vorstellungsbilder prägen auch die heutige Sicht auf das Mittelalter.

\section{Das ,entzweite Mittelalter“6}

Das Mittelalter ist im Denken der Moderne in zwei Formen gegenwärtig. Diese besteht in einer positiven und einer negativen Auffassung sowie gleichzeitig einer positiven und negativen Besetzung des Begriffs. Beide Auffassungen stehen nach Ansicht von Oexle in einem kontradiktorischen Gegensatz zueinander; sie schließen sich einerseits wechselseitig aus, gleichzeitig beziehen sie sich aufeinander. Die Moderne deutet das Mittelalter in der polaren Spannung zweier entgegengesetzter grundsätzlicher Wahrnehmungsformen. Diesen Sachverhalt bezeichnet Oexle mit dem Begriff das „entzweite Mittelalter“.?

Wenn in der Sprache des Alltags unhaltbare Zustände jeglicher Art bezeichnet werden sollen, wird häufig die Chiffre von mittelalterlichen Zuständen bemüht. Die Epoche des Mittelalters dient gleichsam als dunkler Hintergrund, vor dem sich Zustände und Errungenschaften der Moderne umso heller abheben sollen. Von den Errungenschaften des modernen, aufgeklärten Menschen aus gesehen bildet die mittelalterliche Welt das Gegenbild, gleichsam die überwundene Gesellschaftsform. Diese finstere Zeit sieht man gekennzeichnet von Inquisition, Hexen-

scher Expansion bildete sich bis zur Mitte des 8. Jahrhunderts das Mächtesystem heraus, in dem Byzanz, das Reich der Kalifen und das aufstrebende Fränkische Reich die dominierenden Faktoren darstellten. Später hatten das Heilige Römische Reich und seit dem 13. Jahrhundert Frankreich eine Vormachtstellung im Abendland. Das Ende des Mittelalters wird mit dem Beginn des Zeitalters der großen Entdeckungen (1492 Landung von C. Kolumbus in Amerika) beziehungsweise mit dem Einsetzen der Reformation (1517), auch mit der Entfaltung des Humanismus verbunden. Vgl. Bibliographisches Institut \& F. A. Brockhaus AG, 2001.

7 Oexle, Gerhard Otto: Das entzweite Mittelalter. In: Althoff, Gerd (Hrsg.): Die Deutschen und ihr Mittelalter. Darmstadt 1992, S. 8ff. 
verbrennungen, die eigentlich erst der frühen Neuzeit zuzurechnen sind, von geschundenen Bauern, von der Herrschaft der Kirche und eines Königs von Gottes Gnade. Das Mittelalter erscheint als starre und festgefügte Hierarchie und unterdrückende Standesordnung, als primitive Stufe des Wissens und Rechtslebens. ${ }^{8}$ In plakativer Weise wird die Phrase $\mathrm{Zu}$ rück in das Mittelalter je nach Anlass in emotionaler Besetzung regelmäßig dort verwendet, wo es um die Darstellung von politischen, sozialen, intellektuellen oder ökonomischen Vorgängen geht, die als Attacken gegen den Fortschritt und gegen moderne Errungenschaften verstanden werden können (Oexle 1992, S. 8). Das Wort mittelalterlich begegnet aber auch in fast völlig inhaltsleerer, gewissermaßen rein diffamierender Verwendung, indem es eine Sache bezeichnet, die als schlecht und alt abgetan wird (ebd., S. 9).

Ein zweites Bild vom Mittelalter steht gleichzeitig zur Verfügung, welches mit gleicher Selbstverständlichkeit gegenwärtig benutzt wird. In diesem zweiten Bild mischen sich Staunen und Bewunderung mit einem sehnsüchtigen Blick in eine andere Welt, die deshalb mit Sehnsucht betrachtet wird, weil sie nicht die Welt der Moderne ist. (ebd., S. 10). Gegenüber dem aufklärerischen Schlagwort vom finsteren Mittelalter entstand im 18. Jahrhundert dieses epochal neue Bild vom Mittelalter. ${ }^{9}$ Ein Verlangen nach einer industrie- und technikfernen Welt entwickelte sich daran und ein Interesse an urtümlichen Lebensformen wurde geweckt. Das Mittelalterbild diente als Projektionsfläche für die Sehnsucht nach Ursprung und Einheit, Eintracht, Glück und nach einer Zufriedenheit, die in der Gegenwart nur noch in der Phantasie, durch Träume und Märchen oder durch poetisch-philosophische Interpretationen von Fragmenten heraufbeschworen werden konnten. Die Suche nach dem verlorenen $\mathrm{Pa}$ radies bildete für Künstler der Romantik ein zentrales Motiv:

„Die sehnsüchtige Wiederherstellung eines verlorenen Ganzen aus den Bruchstücken des einstigen Glücks kraft Imagination, das ist der romantische Auftrag an die Künste gegen die kalkulierende Vernunft der Aufklärung. Die

8 Weinfurter, Stefan: Mittelalterliche Geschichte. In: Schreiber, Waltraud (Hrsg.): Erste Begegnungen mit Geschichte. Grundlagen historischen Lernens. Neuried 1999, S. 741.

9 Fastert, Sabine: Die Entdeckung des Mittelalters. Geschichtsrezeption in der nazarenischen Malerei des 19. Jahrhunderts. München/Berlin 2000 S. $239 \mathrm{ff}$. 
Vernunft stammt vom Baum der Erkenntnis, ist mithin durch den Sündenfall unter die Menschen gekommen, die dafür das Paradies eingebüßt haben." ${ }^{10}$

Eine umfassende Wiederbelebung der Ideen vom Neuen Mittelalter begann in Deutschland aber nicht in der Romantik, sondern erst seit den 1870er Jahren. Dies steht im Zusammenhang mit der raschen Verflüchtigung des Fortschrittsglaubens, der vor allem von der Wirtschaftskrise, von der sogenannten „Großen Depression der Bismarck-Zeit“ und den dadurch erzeugten Enttäuschungen und Verbitterungen stark gefördert wurde. ${ }^{11}$ Die Große Depression entfesselte eine Welle von Pessimismus, von Emotionen und Angstvorstellungen. Dies schürte eine archaische Angst vor den slawischen Völkern. Klassen- und Judenhasses bewirkten eine leidenschaftliche Verstärkung konfessioneller Gegensätze. Hinzu kamen die als immer belastender empfundenen Wirkungen der zunehmenden Modernisierung der 1880er und 1890er Jahre. Oexle verweist in diesem Zusammenhang auf die Macht der Bilder, und zwar realer wie gedachter Bilder. Dabei geht es um die Imaginationen vergangener Epochen und ihre Beschwörung für die Gegenwart. Die „MittelalterImaginationen" dienten zur Begründung und Inszenierung der Kritik an der Gegenwart (ebd., S. 330).

Kapitalismus wurde gleichgesetzt mit dem Ende volkstümlicher Lebensformen, mit Entpersönlichung und Entseelung. Der Asphaltkultur der Moderne wurde die Ganzheit vormoderner Lebensformen gegenübergestellt. Die alte Handwerkerkultur und ihre Gemeinschaften standen für natürliches Wirtschaften in überschaubaren Verhältnissen. An der Schaffung derartiger Mythologien mit Hilfe eines imaginierten Mittelalters beteiligten sich nach 1900 Vertreter aller Kulturwissenschaften. Oexle verweist darauf, dass sich hier bereits Traditionslinien abzeichnen, die sich mit dem nach 1933 favorisierten Geschichtsbild verbinden (ebd., S. 334). Die Wissenschaft, die Publizistik und die Literatur repräsentierten eine politische Mediävistik der Weimarer Zeit und das kommende Neue Mittelalter als Epoche der Ganzheit, der Gemeinschaft, der organi-

10 Schuster, Peter-Klaus: Auf der Suche nach dem verlorenen Paradies: Runge - Marc - Beuys. In: Vitali, Christoph (Hrsg.): Ernste Spiele. Der Geist der Romantik in der deutschen Kunst 1790-1990. München 1995, S. 47.

11 Oexle, Otto Gerhard: Die Moderne und ihr Mittelalter. Eine folgenreiche Problemgeschichte. In: Segl, Peter (Hrsg.): Mittelalter und Moderne. Entdeckung und Rekonstruktion der mittelalterlichen Welt. Sigmaringen 1997, S. 327. 
schen Einheit, im Gegensatz zu Individualismus, Rationalismus und Relativismus.

Die Erinnerung an das mittelalterliche Reich nahm in der nationalsozialistischen Geschichtspolitik eine herausragende Stellung ein. Das Reich Karls des Großen, die Jahrhunderte der Ottonen, der Salier und der Staufer galten als erste Phase deutscher Größe. Es waren die Zeiten der weitesten Ausdehnung des Reiches. Diese Jahrhunderte deutscher Macht und Einheit wurden in der Geschichtsschreibung und Publizistik ebenso wie in historischen Ausstellungen mit den Epochen der Zersplitterung kontrastiert. Die Phase des Niedergangs begann mit dem Sturz der Staufer, wurde kurz unterbrochen von der Zeit des Bismarckreiches und reichte bis in die unmittelbare Vergangenheit der Weimarer Republik. Zur Erinnerungsfeier an die Reichsgründung und nationalsozialistische Machtübernahme an der Universität Marburg rechtfertigte der Präsident der „Monumenta Germaniae Historica“ Theodor Mayer zum Beispiel die Eroberung der europäischen Hegemonialstellung durch Hitler mit der Berufung auf die mittelalterliche Reichstradition: „Das großdeutsche Reich nimmt die geschichtliche Entwicklung dort auf, wo sie unter den Staufern fallengelassen wurde.“ Diese Tradition gäbe „,dem deutschen Volk als dem Volk der Mitte und dem deutschen Reich als dem politischen Mittelpunkt Europas die Aufgabe [...], im mitteleuropäischen Raum eine planmäßige politische Ordnung herzustellen." ${ }^{12}$ Im Namen des Reiches erhielt die deutsche Geschichte ihren vermeintlichen historischen Sinn und darüber hinaus diente es als Vorbild für die Neuordnung des europäischen Kontinents unter dem Hakenkreuz.

Ein Neues Mittelalter wurde auch in der Kunstgeschichte verkündet. Der angesehene Kunsthistoriker Wilhelm Pinder sah zum Beispiel in der neuen Kunst den Ausdruck einer neuen Gemeinschaft, welche der Führer schaffe. Das Mittelalter war gemäß Pinder eine „noch gänzlich gesunde Epoche europäischer Kultur gewesen“, und was jetzt in Deutschland heraufgekommen sei, das wolle ,im edelsten Sinne wieder einmal ein Neues Mittelalter werden. “13 Ausgewählte mittelalterliche Kunstwerke wurden so zu Kunst-Ikonen des Nationalsozialismus erniedrigt. ${ }^{14}$ Dazu zählte zum Beispiel auch die Skulptur „Der Bamberger Reiter“ stellvertretend

12 Mayer zitiert in Kramp, Mario (Hrsg.): Krönungen, Könige in Aachen Geschichte und Mythos. Mainz 2000, S. 830.

13 Pinder zitiert in Oexle 1997, S. 353.

14 Oexle, Gerhard Otto: Geschichtswissenschaft im Zeichen des Historismus. Studien zur Problemgeschichte der Moderne. Göttingen 1996, S. 157. 
für das heldische Wunschbild. Diese Objekte wurden dazu funktionalisiert, nationalsozialistische Weltanschauung zu untermauern. ${ }^{15}$

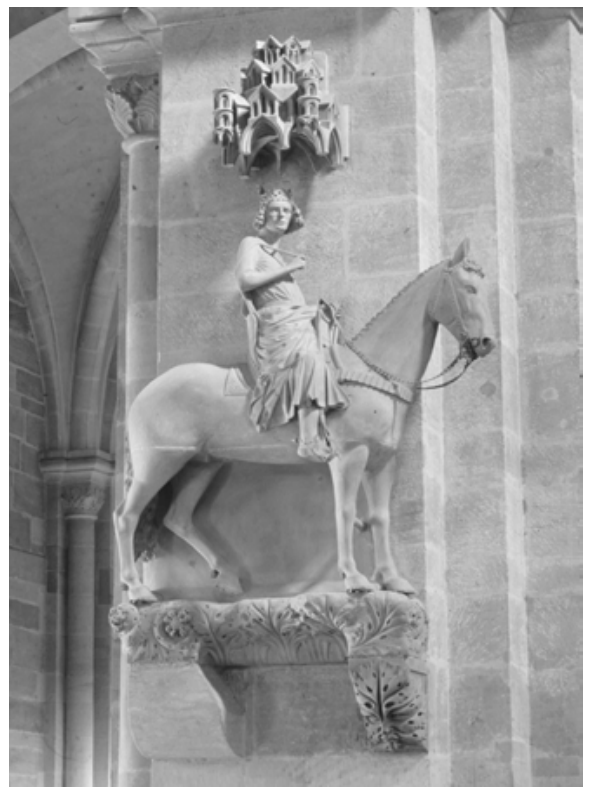

Abbildung 16:

Der „Bamberger Reiter“ an

der Westseite des nördlichen

Choreingangspfeilers

des Bamberger Doms.

„Und wenn wir das Tor des Domes zu Bamberg öffnen würden und hineinschauen könnten in den heiligen Raum, dann würde uns das Antlitz des Reiters entgegenschauen, der dort auf dem Pferd sitzt. Es ist kein katholisches, kein protestantisches Gesicht, es ist das Antlitz des deutschen Menschen im Kampfe gegen Rassen und Stände für ein einiges deutsches Reich. Wir verstehen die Zeichen dieser Zeit, wir verstehen sie, weil wir zutiefst in unserem Herzen unsere Sendung begreifen und unsere Sendung erfüllen. ${ }^{\text {“16 }}$

Der ganzheitliche Charakter der deutschen Kunst lag nach Ansicht von Pinder darin, dass sie nicht frei sein, sondern dienen wollte und darin sei auch ihre Zukunft begründet (Oexle 1996, S. 157). Der Missbrauch der

15 Zur nationalsozialistischen Aneignung dieses Kunstwerkes vgl. Hinz, Berthold: Der Bamberger Reiter. In: Warnke, Martin (Hrsg.): Das Kunstwerk zwischen Wissenschaft und Weltanschauung. Gütersloh 1970, S. 2647.

16 Bamberger Volksblatt vom 11. Sept. 1937 in: Fuchs Marga (Hrsg.): „Ihr habt Euer Leben dem Führer geweiht!“ Darstellungen und Quellen zur Geschichte Bambergs 2. Bamberg 1989. 
mittelalterlichen Geschichte äußerte sich in konkreten symbolischen Handlungen. Ein Beispiel für die symbolische Politik der Mittelalterbeschwörungen im Nationalsozialismus bilden die Reichskleinodien. ${ }^{17}$ Der Anschluss Österreichs im März 1938 machte die Rückführung der Reichskleinodien nach Nürnberg möglich, von wo aus sie nach dem Verlust der Nürnberger Reichsherrlichkeit gegen Ende des Heiligen Römischen Reiches 1796 nach Wien verbracht worden waren. Der Direktor des Germanischen Nationalmuseums begründete diesen Auftrag mit folgenden Worten:

„Am politischen Wallfahrtsort des Dritten Reiches würden die uralten Reichskleinodien von vielen großdeutschen Träumen über Jahrhunderte Kunde geben und dadurch den historischen Sinn des neuen Großdeutschen Reiches augenfällig machen. ${ }^{\text {"18 }}$

Nicht als Glanzstücke des Museums, sondern als Symbol eigener Großmachtansprüche sollten nach dem Willen Hitlers die Reichskleinodien im Jahr 1938 kurz vor Beginn des Reichsparteitages nach Nürnberg gebracht werden. Sie sollten nicht im Germanischen Nationalmuseum, sondern zunächst für ein Jahr in der Meistersingerkirche ausgestellt werden, um später für immer in der noch im Bau befindlichen Kongresshalle auf dem Parteitagsgelände präsentiert zu werden. ${ }^{19}$ Die hohe Wertschät-

17 Die Reichskleinodien waren im Heiligen Römischen Reich und anderen Ländern die symbolischen Schmuckstücke bei der Krönung der Herrscher und zugleich Attribute der Königsherrschaft. Im Heiligen Römischen Reich gehörten dazu erstens die Reichsinsignien im engeren Sinn mit Krone, Reichsschwert und -zepter, Reichsapfel als Weltkugel mit Kreuz, zweitens das Krönungsornat, Handschuhe und das Reichsevangeliar und drittens die Reichsheiligtümer mit der Heiligen Lanze, Schwerter u.a.. Die Reichskleinodien, auch Reichsinsignien im weiteren Sinn genannt, wurden zunächst auf Reichsburgen und Pfalzen verwahrt, 1424 bis 1796 und 1938 bis 1946 in Nürnberg, seit 1800 beziehungsweise 1813 (außer 1938 bis 1946) in Wien in der Hofburg, Schatzkammer des Kunsthistorischen Museums. Vgl. Bibliographisches Institut \& F. A. Brockhaus AG, 2004.

18 Museumsdirektor Heinrich Kohlhausen zitiert in Kramp 2000, S. 835.

19 Der Vormarsch der Alliierten zwang dazu, die kostbaren Stücke der Macht in Kisten und später in Kupferbehälter verpackt in die Bunker unter der Kaiserburg zu bringen. Dort wurden sie im August 1945 von der amerikanischen Besatzungsmacht geborgen und im Januar 1946 nach Wien zurückgeführt. Heute ist der Nürnberger Kunstbunker, der sich 24 Meter unter der Erde befindet, ein Museum ohne museale Exponate. Historische 
zung der Symbolträchtigkeit der Reichskleinodien zeigte sich zum Beispiel auch daran, dass sich bei der Eröffnung des Reichsparteitages im Jahr 1934 im Nürnberger Rathaussaal auf dem Podium eine Vitrine mit den Aachener Nachbildungen der Reichskleinodien sowie der Nürnberger Reliquienschrein befand (Kramp 2000, S. 829).

Die Nachkriegszeit war gekennzeichnet durch ein völliges Desinteresse an der Geschichte. Die bundesrepublikanische Identität gewann Inhalt und Profil kaum aus der Historie, sondern vielmehr aus den wirtschaftlichen Leistungen ihrer Gegenwart. Das öffentliche Bewusstsein verlor die deutsche Vergangenheit und insbesondere die mittelalterliche Geschichte aus den Augen. Für Althoff ist es bis heute interessant und zugleich rätselhaft, dass sich mitten in dieser Abstinenz ein neues Interesse am Mittelalter bemerkbar machte, welches allerdings nicht unter dem Stichwort der nationalen Identität zu fassen war (Althoff 1992, S. 5). Eine erste massive Manifestation des Mittelalterinteresses zeigte sich an der Staufer-Ausstellung im Jahr 1977. ${ }^{20}$ Dieses Interesse konnte auch bald bei vergleichbaren Ausstellungen beobachtet werden. Der Grund für die Begeisterung der Besucher für das Mittelalter liegt jedoch nicht primär darin, ,[...] Bausteine für ihre nationale oder regionale Identität [...]“ zu suchen. Nach Ansicht von Althoff liegt dies hauptsächlich an der Andersartigkeit der Epoche.

„Das Mittelalter scheint seinen Reiz heute in erster Linie durch ästhetisch sehr eindrucksvolle Exponate zu gewinnen, die von einem als frappierend anders empfundenen Zeitalter Zeugnis geben. An Erbe, Vermächtnis oder gar Auftrag denkt man in solchen Situationen nicht mehr." (Althoff 1992, S. 5)

Die Art der gegenwärtigen Rezeption des Mittelalters zeigt eine große Spannbreite. Neben kommerziellen Formen, die sich wie zu Beginn des Kapitels erwähnt in der großen Anzahl von mittelalterlichen Events äußert, entwickelte sich zeitgleich eine spezielle mittelalterliche Szene, die in akribischer Ernsthaftigkeit ihrem Hobby nachgeht. Dem Erreichen einer möglichst hohen Authentizität des Nachgelebten wird dabei ein sehr hoher Stellenwert eingeräumt.

Schwarzweißfotos zeigen den Bunker mit den dort verwahrten kostbaren Exponaten.

20 Aus Anlass des 25jährigen Bestehens des Bundeslandes Baden-Württemberg fand auf Initiative der Landesregierung die Ausstellung ,Die Zeit der Staufer“ vom 26.03.-05.06.77 im Stuttgarter Alten Schloss statt. 
,[...] die gleichsam fetischhafte Beschäftigung mit Material und Vorlage läßt das Hobby zum zweiten, für manchen zum wahren Beruf werden. Die Nostalgie des Handwerks feiert dabei Hochkonjunktur, nichts ist maschinell hergestellt, alles dafür Handarbeit in bester deutscher Gründlichkeit.“21

Eine populäre Form der Vermittlungsarbeit mit wissenschaftlichem Anspruch bildet jedoch die angewandte Archäologie, die Erkenntnisse mit museumspädagogischen Methoden über das eigene Tun vermittelt. Ausgehend von fächerübergreifenden Untersuchungen in Zusammenarbeit mit den Naturwissenschaften werden alte, vergessene Techniken wieder entdeckt und durch Fachleute aufbereitet weitergegeben. ${ }^{22}$

Geschichtsbilder werden außerdem wesentlich durch die Breitenwirkung von Fernseh- und Kinofilmen konstituiert. Mittelalterfilme bilden jedoch keine eigenständige Gattung, sondern das mittelalterliche Kolorit spielt in verschiedenen Gattungen wie dem biographischen Film, den historischen Themenfilmen oder dem Abenteuerfilm eine Rolle. ${ }^{23}$ Als Kulisse oder Inhalt von Filmen besteht die Möglichkeiten zur Vermittlung von historischen Fakten und ihrer Deutung. Dabei besitzen die filmischen Vorstellungen häufig stereotypen Charakter, indem sie auf Allgemeinwissen zurückgreifen und dieses wiederum bestätigen. ${ }^{24}$ Dieses Genre der Historienfilme stellt ein eigenes Forschungsfeld dar, auf das

21 Meißner, Joachim: Indianer gegen Hunnen, Freizeitstämme auf dem Kriegspfad. In: Kemper 2001, S. 112.

22 Als Zusammenschluss von Archäologen, Handwerkern, Pädagogen, Biologen, Medienexperten und anderen Fachleuten praktiziert zum Beispiel das Büro für angewandte Archäologie AGIL eine ernsthafte Auseinandersetzung mit handwerklichen Techniken vergangener Zeiten. AGIL entstand aus der Praxisarbeit beim Aufbau von Museen und archäologischen Sonderausstellungen. Das Angebot für öffentliche und private Auftraggeber spannt sich von archäologischen Funktionsrepliken über museumspädagogische Schulprogramme, Creativkurse in alten Handwerkstechniken, Erfahrungsurlaub bis hin zu Aktionspräsentationen und ganzen Projektentwicklungen mit praktischer Umsetzung. Vgl. http://www.agil-online.de (letzter Zugriff: 15.10.04).

23 Timmer, Jan: Bericht über die Tagung „Antike und Mittelalter im Film“. http://hsozkult.geschichte.hu-berlin.de/tagungsberichte/id=282 (letzter Zugriff: 25.10 .04$)$.

24 Diesem Umstand Rechnung tragend wurde am Zentrum für interdisziplinäre Forschung der Universität Bielefeld die Tagung „Antike und Mittelalter im Film“ vom 17.07.-19.07.03 veranstaltet, die sich intensiv mit einem interdisziplinären Zugang zu diesem Thema beschäftigte. 
ich im Rahmen der Studie nicht näher eingehen kann. Als weitere populäre Form der Mittelalterrezeption konzentriere ich mich auf die Betrachtung von kommerziellen Erlebniswelten.

\section{Mittelalter in zeitgenössischen, kommerziellen Präsentationen}

Es sind hauptsächlich Ausschnitte aus der spätmittelalterlichen Welt, die in verschiedenartiger Weise Bilder für mittelalterliche Szenarien liefern. Manchmal weisen diese horrorartige Züge auf, meist jedoch spiegelt sich darin die Sehnsucht nach einer noch nicht technisierten Natur ohne Kernkraftenergie oder Kunstdünger wider. Mittelalter gilt als Synonym für alles nicht Moderne: keine Elektrizität, kein Auto, keine Eisenbahn oder Zentralheizung. Die Einordnung der mittelalterlichen Zeit bleibt vage. Mit Mittelalter wird weniger auf ein konkretes Zeitalter verwiesen, sondern auf eine Lebensform (Fuhrmann 2000, S. 263).

In der kommerziellen Umsetzung lassen sich Formen unterschiedlicher Intensität der mittelalterlichen Thematisierung aufzeigen. Im Folgenden treffe ich zwei Unterscheidungen: In der ersten Form konzentrieren sich alle Aktionen auf das mittelalterliche Thema mit dem Ziel einer möglichst perfekten Inszenierung dieser vergangenen Welt. In der zweiten Art wird das Thema Mittelalter auf seine kulissenhafte Funktion mit der Absicht reduziert, positiv aufgeladene Bilder zu stimulieren. Dabei werden stereotype, bisweilen auch phantasievolle Bilder entworfen, die wiederum unvermittelt neben anderen Attraktionen stehen. Sie dienen auch dazu, für andere Zwecke, zum Beispiel den Verkauf von Spielsachen, Interesse zu wecken.

Die Fokussierung auf das Thema Mittelalter bildet das Kennzeichen der ersten Form der Rezeption des Mittelalters. Dabei wird auf allen Ebenen in phantasievoller Ausgestaltung das mittelalterliche Thema dekliniert. Als Beispiel dafür ziehe ich das Ritterturnier in Kaltenberg heran, welches sich innerhalb der vergangenen 25 Jahre zu einem der größten mittelalterlichen Spektakel entwickelte. ${ }^{25}$ Während drei Wochenen-

25 Auf Initiative des Schlossherren Luitpold Prinz von Bayern fand im Jahr 1980 das erste Ritterturnier in Kaltenberg, Kreis Landsberg am Lech in Bayern, statt. Seitdem lockt es jährlich mehr als 100.000 Besucher an. Eine ausführliche Beschreibung siehe: König, Stefan/Ernszt, Peter: Das Kaltenberger Ritterturnier. München, 2004. www.ritterturnier.de (letzter Zugriff: 20.10.04). 
den im Juli verwandelt sich das Schlossareal in eine Bühne für mittelalterliche Szenerie. Mehr als tausende von Mitwirkenden lassen diese Veranstaltung jährlich zu einem Großereignis der Region werden. Als „Schlaraffenland für alle Sinne“"26 lädt das Ritterturnier ein „zum Schauen und Staunen, zum Schlemmen und Schwärmen“"27.

„Da sind die Barbaren in ihrem barbarischen Lager, finstere und zugleich gesellige Gestalten. Oder die Rittergruppe Canis Cornutus, die gefahrvoll und elegant zugleich den Schwertkampf demonstriert. Da ist das neue Orientalenlager mit dem Flair des Morgenlandes, mit einem geradezu hypnotisierenden Märchenerzähler, mit Kamelen und Geschichten und Bildern aus 1001 Nacht. [...], die Spielleute mit ihren Instrumenten, die spontanen Komödianten mitten im Volk, da sind Raubritter und edle Ritter, Herzöge und Bettler, Musikanten und Moriskentänzer.“(Wüst 2003, S. 22)

Eine wichtige Attraktion bildet der mittelalterliche Markt (siehe Abb. 17). Die Besucher können zahlreiche Handwerker wie Schneider, Kürschner, Drechsler oder Klöpplerinnen bei ihrer Arbeit beobachten. Sie sehen zum Beispiel, wie eine Buchmalerin filigran Blätter und Seiten illustriert (siehe Abb. 18), ein Schuster aus Leder Schuhe fertigt, oder alte, zum Teil heute unbekannte Musikinstrumente gefertigt werden. Auch dem Schmied kann bei der schweren Arbeit in seiner Werkstatt über die Schulter geblickt werden. Zum Markt gehören ebenso die kulinarischen Angebote. Gleichsam an jeder Ecke können die Besucher die verschiedensten „Schmeckereien und Leckereien“ probieren. Einen weiteren elementaren Erlebnisfaktor bilden „die Magie“ und „der Zauber des mittelalterlichen Spiels" (ebd.), dessen Bandbreite alle Sparten und Bereiche mit Musik und Minnesang, Tanz, Theater, Ritterkampf und vieles mehr integriert. Als ein Höhepunkt des Besuches gilt ein Besuch des Ritterturniers in der Arena. Ritterturniere an diesem Ort lassen sich weder durch Urkunden noch durch historische Funde belegen. Dennoch wurde im Jahr 1980, als das Kaltenberger Ritterturnier erstmals stattfand, darauf Wert gelegt, dies als Fortführung einer großen Tradition anzusehen (König 2004. S. 118). Selbst wenn bei Ritterturnieren in Kaltenberg heute keiner mehr sein Leben riskiert, so wollen die Veranstalter dennoch, dass es ähnlich intensiv und stimmungsvoll wird, so „dass es

26 Wüst, Rainer: Mittendrin im mittelalterlichen Markt zu Kaltenberg. Altes Handwerk, sinnenfrohes Spektakel, kulinarische Köstlichkeiten und köstliches Kaltenberger Bier. In: Begleitprogamm: Kaltenberger Ritterturnier 2003, St. Ottilien 2003, S. 22.

27 Begleitprogramm Kaltenberger Ritterturnier 2003, S. 5. 
auch im Mittelalter hätte stattfinden und sein Publikum begeistern können“" (ebd.).

Ein wesentlicher Aspekt der gegenwärtigen Begeisterung für das Mittelalter ist wohl darauf zurückzuführen, dass es genau das bietet, was Marketingfachleute für Erlebniswelten gegenwärtig fordern, nämlich „eine Kontrastwelt mit Paradiescharakter" ${ }^{\text {“28 }}$ mit der Möglichkeit den Alltag für wenige Stunden zu vergessen.

„Nicht planen, nicht zielen, sich einfach treiben lassen. Eintreten ins verheiBene Mittelalter, so bald das große Tor sich öffnet. Und dann immer den Augen, den Ohren und der Nase nach. Schon ist man mittendrin im Markttreiben, und man ist es nicht als staunender Zaungast, sondern man gehört dazu, ist plötzlich mittelalterlicher Mensch auf mittelalterlichem Markt, ist in der Zeit zurück versetzt um Jahrhunderte und fühlt sich anders, besser als zuvor.“ (Wüst 2003, S. 20)

Der Mythos von Ursprünglichkeit und Idyll wird auch heute noch dem Mittelalter zugeschrieben. Die positiven, nostalgisch verklärenden Projektionen in dem Sinne „Zurück ins Mittelalter: Wo die Guten siegen“ stehen dabei im Vordergrund, wie sich auch durch andere Beispiele belegen lässt. ${ }^{29}$ So wird zum Beispiel auf dem Rügener Bodden seit 1993 jeden Sommer auf einer Naturbühne das sagenumwobene Schicksal vom Robin Hood der Meere aufgeführt. Die verschiedenen Episoden weisen eine Gemeinsamkeit auf: Den Reichen wird genommen und den Armen wird gegeben. Die Hoffnung auf den Sieg der Guten wird in diesen Geschichten immer erfüllt. Eine klare Unterscheidung von Gut und Böse betrachtet Faget ${ }^{30}$ als Erfolgsgarantie. Auch bei den jährlichen Ritterturnieren in Kaltenberg werden die Mächte des Bösen oder die Herren der Finsternis immer von den guten Mächten und Rittern besiegt. Das Mittelalter eignet sich auch als Projektionsfläche weiterer Sehnsüchte: Die Ständeordnung wies jedem seinen Platz in der Gesellschaft zu und bot einen überschaubaren Rahmen das alltäglichen Lebens. Hobby-Ritter wohnen in historisch rekonstruierten Behausungen zusammen, kochen über einem offenen Feuer und führen einem lebendigem Museum ver-

28 Vgl. Kagelmann 1998, S. 78. Mit diesem Ausspruch verweist Kagelmann auf eines der wichtigsten Kriterien von Erlebniswelten, siehe auch Kapitel 4, S.172.

29 Klot, Kristina von: Zurück ins Mittelalter: Wo die Guten siegen. In: mobil (2003) Heft 6, S. 72ff.

30 Johannes Faget ist Geschäftsführer des Veranstalters „Fogelvrey“. Dieser organisiert circa 30 Mittelaltermärkte im Jahr. 
gleichbar vor, wie Brot gebacken, Kettenhemden geknüpft, getöpfert oder geschmiedet wurde. Es ist wie ein Fenster zu einer Zeit, in der man den Sinn seiner Hände Arbeit noch verstehen, begreifen konnte. Begreifen wie die Waren, die hier feilgeboten werden." (Wüst 2003, S. 20)

Als Beispiele für die Reduzierung des Themas Mittelalter auf Kulisse und Fassade beziehe ich mich auf den Erlebnispark Schloss Thurn ${ }^{31}$, das LEGOLAND Deutschland ${ }^{32}$ sowie das PlayCastle ${ }^{33}$. Die Liste der möglichen Beispiele ließe sich erweitern. ${ }^{34} \mathrm{Im}$ Hinblick auf die Funktionalisierung des mittelalterlichen Sujets weisen die Themenwelten ähnliche Strukturen auf. Nicht ein historischer, konkreter Bezugspunkt bildet den Ausgangspunkt, sondern märchenhafte, nostalgisch verklärte MittelalterImaginationen sollen assoziiert werden. Fuhrmann bezeichnet dies als „freischwebendes, geldbringendes Mittelalter mit Bilderbuch- und Amüsiercharakter" (Fuhrmann 2000, S. 264).

Ein markantes Merkmal der Erlebniswelten besteht darin, emotional aufgeladene Bilder wachzurufen und diese gleichzeitig auf typische, einprägsame Ikonen zu reduzieren. Eine dieser oft zitierten Ikonen bildet das Motiv der Burg. Wenige mittelalterliche Objekte vermitteln gegenwärtig den Eindruck von Naturnähe und Abenteuer besser als Burgen. Dieses Klischee wurde bereits in den hochmittelalterlichen Ritterepen

31 Der Erlebnispark Schloss Thurn zwischen Nürnberg und Bamberg wurde im Jahr 1975 eröffnet. Graf Hannfried von Bentzel-Sturmfeder Horneck hat den großzügig angelegten Schlosspark in einen Erlebnispark umgestaltet und somit für die Öffentlichkeit zugänglich gemacht. Siehe auch: http://www.schloss-thurn.de (letzter Zugriff: 12.12.01).

32 LEGOLAND Deutschland eröffnete am 17. Mai 2002 im bayerischen Günzburg. In den ersten beiden Jahren besuchten über 2,6 Millionen Gäste den weltweit vierten Themenpark der LEGO Company. Siehe auch: http://www.legoland.de (letzter Zugriff: 08.11.04).

33 Das PlayCastle in Seefeld/Tirol in Österreich eröffnete am Mai 1999. Nach nur siebzehn Monaten Betriebszeit war dieses Projekt gescheitert. Vgl. Rösch, Stefan: Zerplatzte Träume, zerstörte Illusionen: Das Scheitern von Freizeitgroßprojekten. Eine Analyse von möglichen Fehlerquellen in der Projektentwicklung und im Betrieb von Freizeitgroßprojekten am Beispiel des PlayCastle in Seefeld/Tirol. In: Schmude, Jürgen (Hrsg.): Tegernseer Tourismus Tage 2002. Regensburg 2003, S. 125ff.

34 Im Europapark Rust kann der Besucher in einem mittelalterlichen Castillo nächtigen. In Las Vegas erinnert das Hotel Excalibur mit seinen zahllosen Türmen in simplen Primärfarben an die Tradition von Disneylands Schneewittchenschloss. 
erfolgreich instrumentalisiert und vor allem im 19. Jahrhundert durch die Ritterromantik einer breiten Öffentlichkeit dauerhaft als das wahre Mittelalter erschlossen.$^{35}$ In dem Vorstellungsbild zur Burg bündeln sich die auf das Mittelalter projizierten Sehnsüchte. Insofern verzichtet kaum ein Themenpark auf diese Symbolik. Bereits beim Betreten dieser Orte besteht das Anliegen darin, die Besucher positiv zu stimulieren. Bei allen drei genannten Beispielen wird der Besucher im Eingangsbereich mit dem Motiv einer Burg konfrontiert. Den Schlosspark Thurn betreten die Besucher durch ein stilisiertes Burgtor mit Blick auf Burgmauer und Turm (siehe Abb. 19). Auch der Eingangsbereich zum LEGOLAND stellt Burg-Assoziationen her. Obgleich dies in einer phantasievollen, bunten LEGOLAND-Optik geschieht, bleibt dennoch die Burgidee offensichtlich (siehe Abb. 20). Im PlayCastle wurde der ankommende Besucher am Parkplatz und auf dem Weg zum Burggraben von mittelalterlichen Geräuschen begleitet. Beim Betreten des Schlosses über eine Zugbrücke begrüßte ein „Ritter Merlot“ die ankommenden Besucher. In der ersten Zone ging es laut Morasch ${ }^{36}$ darum, die Kunden mental in die gute alte Zeit zurückzuführen. In der Küche des Wehrturms gab es eine bemüht originalgetreue Ausstattung einer mittelalterlichen Landsknechtküche. Essensgerüche sollten den realen Eindruck verstärken.

„Der Mischung aus Abenteuer, guter, alter Zeit und einem realen, greifbaren Erleben kommt hier ein hoher Stellenwert zu. [...] Die historische Realitätstreue der Kulissenbauer vermittelt dem Kunden einen dermaßen hohen Wirklichkeitsbezug, daß er den Unterschied zwischen echt und unecht nicht erkennen kann. ${ }^{\text {" } 37}$

Themenparks sind in sich abgeschlossene, großflächige Bereiche, die ihr Angebot in Form von Geschichten verkaufen. In der klassischen Form werden verschiedene Geschichten nebeneinander erzählt, die jeweils manchmal bis ins kleinste Detail entwickelt und in einem überschauba-

35 Daim, Falko/Kühtreiber, Thomas: Sein \& Sinn, Burg \& Mensch. St. Pölten 2001, S. 414ff.

36 Ludwig Morasch entwickelte das PlayCastle Projekt. Der gebürtige Österreicher, der seit 20 Jahren in den USA lebt, gilt als Begründer der europäischen Erlebnisgastronomie. Weitere Projekte von ihm sind Infotainmentkonzepte wie „Krystall-Palast“, „FunDome“ oder „Movietainment“. Vgl. Steinecke 2000, S. 237

37 Morasch, Ludwig: PlayCastle: Europas erstes Infotainment Center - eine entgrenzte Freizeitwelt. In: Steinecke 2000, S. 229. 
ren Rahmen angeboten werden. Die Organisation einer Gesamtanlage basiert meist auf dem Prinzip der Montage von verschiedenen Sequenzen. ${ }^{38}$ Diese inselhafte Aneinanderreihung verschiedenster Attraktionen lässt sich auch bei den genannten Erlebniswelten beobachten. Die mittelalterlichen Facetten in Form von Burg- und Ritteranspielungen stehen neben weiteren Angeboten. Im Erlebnispark Thurn gibt es neben einem Ritterturnierplatz eine Westernstadt, einen historischen Märchenwald und noch weitere Offerten.

Auch im LEGOLAND ist das „Land der Ritter“ ein Angebot neben zahlreichen anderen Anreizen. ${ }^{39}$ In „Merlins Zauberreich“ selbst lädt „die massive Ritterburg [...] zu einer Zeitreise ins Mittelalter ein..${ }^{“ 40}$ Die Königsburg mit dem großen Innenhof bildet das Wahrzeichen von „Knigths' Kingdom““41. Über eine Zugbrücke gelangt der Besucher in das Innere der Burg. Der Weg auf die Burg ist gleichzeitig der Aufgang zur Achterbahn, die als Themenbahn gestaltet ist. Ein Märchen vom mächtigen Zauberer Merlin und einem gefährlichen Feuerdrachen wird erzählt. Die Fahrt auf einem „,grünen Glücksdrachen“ führt durch die Gemächer der Bewohner vorbei an Rittern und Hofnarren und einem feuerspeienden Drachen, die alle aus Legobausteinen geschaffen sind. Höhepunkt des Besuches ist eine schwindelerregende Fahrt: „8 Meter pro Sekunde schafft der Glücksdrache“ (ebd. S, 37). Darüber hinaus können sich die Kinder als Goldwäscher betätigen, in der „Schatzkammer“ alles Nötige

$38 \mathrm{Um} \mathrm{zu}$ verhindern, dass die enge Nachbarschaft der verschiedenen Elemente allzu bunt zusammengewürfelt wirkt, wird als verbindendes Element die Außengestaltung meist erfahrenen Landschaftsarchitekten übertragen, die dann über die Gestaltung von Wegen und Blickachsen ein stimmiges Gesamtbild schaffen. Vgl. Bédarida, Marc: Euro Disney Park. In: ARCH+ - Zeitschrift für Architektur und Städtebau. 114/115. (1992) S. 93.

39 Darüber hinaus gibt es zum Beispiel noch folgende Themenbereiche: „Imaginationen“, „Land der Abenteuer“, „LEGO City“, „Miniland“ und „LEGO X-treme“. Siehe Parkübersicht des Jahres 2003.

40 Wißner, Bernd: Das große Buch von LEGOLAND Deutschland. Augsburg 2002, S. 34.

41 In einer aktualisierten Presseinformation wird das „Land der Ritter“ nun als „Knigths’ Kingdom“ bezeichnet. Vgl. LEGOLAND Deutschland/ Hintergrundinformation: Knigths' Kingdom: Eine Reise ins Mittelalter. http://www.lego.com/legoland/deutschland/press/backgroundinfo.asp?loca le $=1031$ (letzter Zugriff: 08.11.04). 
für Ritter und Prinzessinnen einkaufen oder sich beim „Ritterschmaus“ verköstigen.

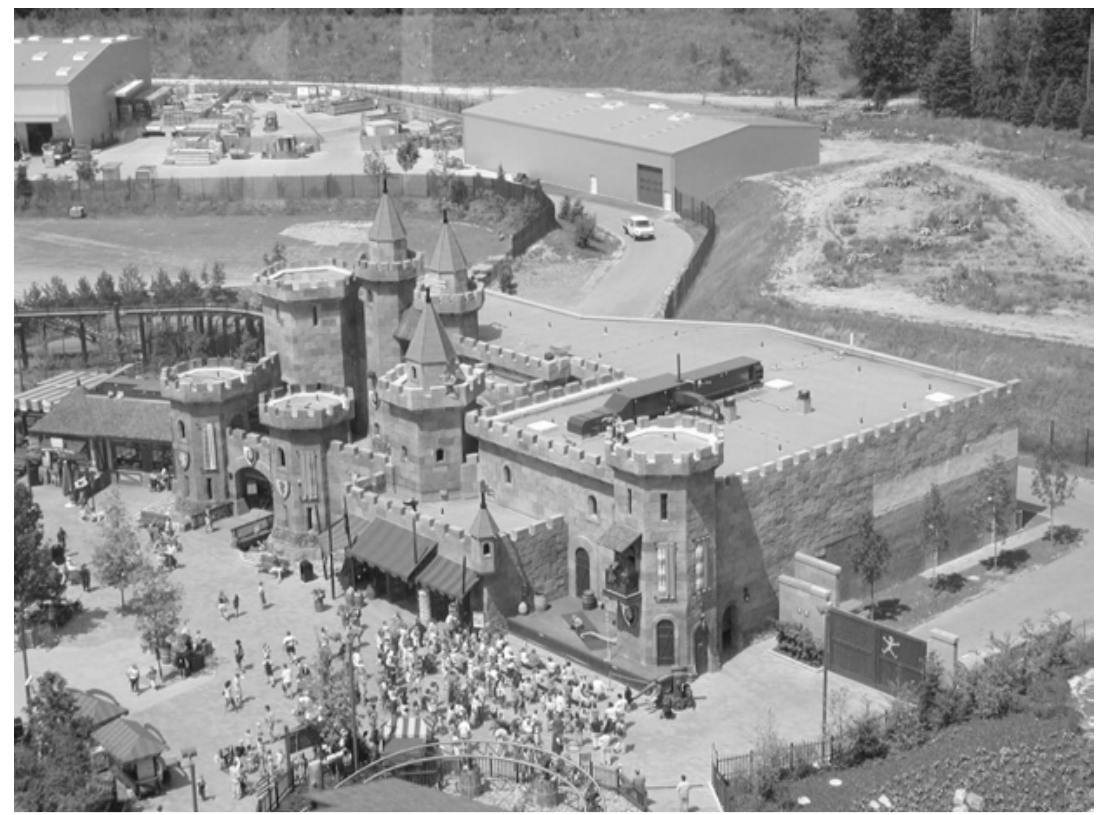

Abbildung 21: Blick auf „Knigths' Kingdom“ im LEGOLAND Deutschland.

Das PlayCastle warb damit, nicht nur das „größte Kindererlebnisschloss“, sondern auch „ein Spielwarengeschäft der neuen Generation“ zu sein (Morasch 2000, S. 223). Die einzelnen Infotainment-Bereiche waren in sieben verschiedene Zonen eingeteilt. Von der mittelalterlichen Welt führte diese über die Kinder-Spielwelten in ein Restaurant mit einem Shop und Merchandising Angeboten zu virtuellen Spielzonen und einem „FunDome“.

„Das Knistern des offenen Kamins, der König auf seinem Thron, die Ritterrüstungen, Waffen, Fresken und Fahnen entführen den Besucher endgültig in das Mittelalter - bis plötzlich ein Roboter aus dem Weltall herangerollt kommt und den Besucher begrüßt.“ (ebd., S. 230)

$\mathrm{Zu}$ den erklärten Zielen der Veranstalter zählt es, die Ideen so „authentisch wie nur möglich“ umzusetzen (König 2004, S. 24). Dies lässt sich an den Werbeprospekten ablesen, in denen wiederholt auf die original- 
getreue Ausstattung der Kulissen und Dekorationen verwiesen wird ${ }^{42}$ „Ein mittelalterlicher Markt war ziemlich genauso, wie man ihn heutzutage in Kaltenberg erleben, sehen, riechen, schmecken kann. Ein geradezu unüberschaubares Theatrum der Lebenslust.“ (Wüst 2003, S. 18)

Dies hindert jedoch nicht daran, bei Bedarf phantasievolle Ergänzungen zu integrieren. Diese Diskrepanz zwischen einerseits angestrebter Authentizität und andererseits jedoch freier Umsetzung lässt sich damit rechtfertigen, dass es einem eindrucksvollen Gesamtambiente dienlich ist. Der offensichtliche Widerspruch zwischen der im Prospekt beworbenen mittelalterlichen Authentizität und der gleichzeitigen Akzeptanz zeitgenössischer, phantasievoller Interpretationen spielt keine Rolle. ${ }^{43}$

Die Themenparks wollen Unterhaltung und Spaß bieten, sie sind nicht primär auf Lernen oder Bildung angelegt. ${ }^{44} \mathrm{Im}$ Vordergrund steht die lustvolle Komponente des Erlebens. Die soziale Komponente des Gemeinschaftserlebnisses sowie die sinnlich-haptischen Erfahrungen lassen einen Besuch im Normalfall zu einer schönen Erinnerung werden. Dennoch ist aus gesellschaftspolitischer wie pädagogischer Sicht äußerst kritisch zu sehen, dass von privatwirtschaftlichen Unternehmen dabei die

42 Auch auf der Homepage des Erlebnisparks Schloss Thurn wird darauf verwiesen: „Originalgetreue Kulissen und Dekorationen versetzen den $\mathrm{Zu}$ schauer in die Zeit des Mittelalters". Vgl.: http://www.schloß-thurn.de/ um_liveschows.html (letzter Zugriff: 12.12.01).

43 Deutlich zeigt sich dies zum Beispiel auch an der Beschreibung der Musikgruppe „Corvus Corax“. Die international renommierte Kultgruppe des Mittelalters interpretiert auf zeitgemäße Art mittelalterliche Melodien mit Trommeln, Dudelsäcken und Schalmeien. Dabei entsteht eine Mixtur aus rockigen Rythmen und mittelalterlichen Fragmenten.

44 Wobei eingeschränkt angemerkt sei, dass auch Erlebniswelten mittlerweile mit ihren Lernpotentialen werben und dies als innovatives Qualitätsmerkmal definieren. Wissen und Inhalte spielerisch vermitteln, ist dabei Anspruch und Programm. Hierin wird eine Möglichkeit gesehen, zusätzliche Besuchergruppen zu gewinnen oder auch eine frühzeitig Kundenbindung zu forcieren. LEGOLAND Deutschland bot zum Beispiel während der Sommersaison 2004 ein speziell für Schüler entwickeltes Schulprogramm an. Das Programm wurde im Hinblick auf konkrete Lernziele im Lehrplan entwickelt, so dass die Lehrkraft dies als Baustein für ihren Unterricht integrieren konnte. Vgl. LEGOLAND Deutschland: Gruppenbroschüre 2004, S. 6-9. Siehe auch: Nahrstedt, Wolfgang/Brinkmann, Dieter u.a.: Lernen in Erlebniswelten - Perspektiven für Politik, Management und Wissenschaft, Bielefeld 2002. 
historischen Mythen genutzt werden, um diese für ihre Zwecke zu vermarkten.

Der historische Erkenntnisgewinn bleibt bei Besuchen dieser Erlebniswelten jedoch gering. Das sinnenreiche Eintauchen in die vergangene Welt bildet ein zentrales Motiv. Nostalgische Mittelalterprojektionen werden entworfen und damit naive Geschichtsbilder gefördert. Doch gerade das Wissen über die Konstrukthaftigkeit der Deutung von Geschichte bildet ein wesentliches Element eines reflektierten Geschichtsbewusstsein. ${ }^{45}$

\subsection{Bildungstheoretische Überlegungen}

Die Frage der Selektion des Stoffes mittelalterlicher Themen sowie auch deren Wertung zählt zu den kontrovers diskutierten Gegenständen innerhalb der Fachwissenschaft (Fuhrmann 2000, S. 277). Die Erörterungen konzentrieren sich auf Aspekte, die sich aus einer gegenwartsbezogenen Perspektive ergeben und auch Mittelalterprojektionen ins Blickfeld nehmen. Aus den vorangegangenen Überlegungen lässt sich die Schlussfolgerung ziehen, dass generell Vorstellungen über das Mittelalter existieren, diese jedoch von einem zwiespältigen Bild, das die Moderne vom Mittelalter geschaffen hat, geprägt sind. Hinzu kommt ein phantastisches Mittelalter, welches durch die Science-Fiction-Szene und Filmbranche geprägt wird. ${ }^{46}$ In mittelalterlicher Aufmachung mit Schwert und Keule kämpfen dabei beispielsweise menschenähnliche Wesen in Phantasiewelten $^{47},[\ldots]$ Tolkiens, Herr der Ringe für Analphabeten, mit Gnomen

45 Zum Thema Geschichtsbewusstsein und Geschichtsbilder siehe Kapitel 2.1: Geschichtsbewusstsein.

46 Auch bei Computerspielen wird zum Beispiel auf mittelalterliche Kulisse und Attribute zurückgegriffen. Kehr, Wolfgang: Zweimal „Diablo“? Gewalt und Schrecken in der romanischen Portalplastik der Kathedrale SaintLazare in Autun (Burgund). In: Kirschenmann, Johannes (Hrsg.): Ikonologie und Didaktik: Begegnungen zwischen Kunstwissenschaft und Kunstpädagogik. Weimar, 1999, S. 37ff.

47 Die Bücher von John Ronald Tolkien (1892-1973) haben eine begeisterte Fangemeinde mit Millionen von Lesern und eigenen Clubs, in der die mysterienhafte Welt der „Hobbits“ und des „Herren der Ringe“ beschworen wird. In Nachbarschaft zu diesem Kult einer imaginierten Welt bewegen sich Filmerfolge wie „Excalibur“, dessen Stoff der Artussage entnommen ist. Mit großem Erfolg sind in der vergangenen Zeit auch Motive 
und Lindwürmern unter bleiernem Himmel: so düster und spinnert ist das Mittelalter nicht einmal in den darkest ages gewesen, [...].“48

Ein Aspekt, der die Auseinandersetzung mit der mittelalterlichen Geschichte zudem erschwert, ist der Sachverhalt der ideologischen Funktionalisierung des Mittelalters und mittelalterlichen Herrscher im Dienst des Nationalsozialismus. Die daraus erwachsende Hypothek verhindert seit dem Ende des Zweiten Weltkrieges einen unbefangenen Blick auf die nationale Geschichte (Fuhrmann 2000, S. 265).

Um die unterschiedlichen Voraussetzungen für das Geschichtswissen und das Geschichtsverständnis zu begreifen, muss auch bedacht werden, wie zum Beispiel mittelalterliche Geschichte im Schulunterricht behandelt wird. Stellvertretend sei der Lehrplan für das bayerische Gymnasium betrachtet. ${ }^{49}$ Die über tausend Jahre währende Epoche des Mittelalters beschäftigt die Schüler vornehmlich in der siebten Klasse. ${ }^{50}$ Das Jahr gliedert sich in mehrere Schwerpunktthemen. Zunächst wird die Grundlegung von Herrschafts- und Lebensformen des europäischen Mittelalters im Frankenreich betrachtet, dabei wird im Überblick die Entstehung und Ausbreitung des fränkischen Großreichs und das Herrschertum Karls des Großen besprochen. Die weltliche und geistliche Macht als bestimmende Strukturen mittelalterlicher Herrschaft bilden den zweiten Schwerpunkt. Im dritten Teil des Schuljahres erfolgt eine Betrachtung der Lebensformen und gesellschaftlichen Entwicklungen in der Aufbruchsepoche des Hochmittelalters. Erneut aufgegriffen wird dieses Zeitalter erst wieder in der 11. Klasse. In einem historischen Längsschnitt wird „Das Reich und Reichsidee in der Stauferzeit“" stellvertretend für das Mittelalter neben vier weiteren Epochen betrachtet. Auf-

aus der Merlin-Sage und aus dem Artus-Stoff mehrfach literarisch verwendet worden. Vgl. Fuhrmann 2000, S. 278.

48 Esch, Arnold: Beobachtungen zu Stand und Tendenzen der Mediävistik aus der Perspektive eines Auslandsinstituts. In: Oexle, Gerhard Otto (Hrsg.): Stand und Perspektiven der Mittelalterforschung am Ende des 20. Jahrhunderts. Göttingen 1996, S. 19.

49 Lehrplan für das bayerische Gymnasium (1990): http://www.isb.bayern.de /bf.isbl/lps/gym.html (letzter Zugriff: 21.11.02).

50 Auch in den bayerischen Realschulen sowie Hauptschulen steht die Epoche des Mittelalters in der 7. Klasse auf dem Lehrplan. Lehrplan für die Realschule siehe unter: http://www.isb.bayern.de/rs/Lehrplan, Lehrplan für die Hauptschule siehe unter: http://km.bayern.de/index2.html. (letzter Zugriff: 21.11.02). 
grund der Realität eines beschränkten Kontingents an Stunden besteht die Notwendigkeit zu einer exemplarischen Auswahl. Im Vergleich zu neuzeitlichen Themen nimmt im Hinblick auf die Stundenzahl diese Epoche einen geringen Raum ein. Da dieses Thema hauptsächlich in der siebten Klasse behandelt wird, ist auch zu vermuten, dass das noch vorhandene Wissen in späteren Jahren weitgehend gering ist. Fuhrmann kritisiert, dass sich die Beschäftigung mit Geschichte zu sehr auf eine Auseinandersetzung mit der jüngsten Vergangenheit konzentriert und kaum vor das 19. Jahrhundert zurückreicht, „zumal manche Schulpläne die Degradierung der Vergangenheit zur Vorgeschichte der Moderne förmlich anw[ei]sen“ (Fuhrmann 2000, S. 265). Zusammenfassend lässt sich feststellen, dass der Epoche des Mittelalters zumindest im schulischen Lehrplan des Gymnasiums eine untergeordnete Bedeutung zukommt.

Es stellt sich also die Frage, welchen Erkenntnisgewinn die Menschen aus der Beschäftigung mit dem Mittelalter gewinnen können? Allein das Phänomen der Popularität und der massenhaften Begeisterung für das Mittelalter legt eine reflektierende Auseinandersetzung mit diesem Zeitraum nahe. Zunächst seien verschiedene Positionen von Mittelalterhistorikern vorgestellt, die diverse Aspekte schlaglichtartig beleuchten. Dies führt über diesen unmittelbar, pragmatischen Ansatz der Beschäftigung mit dem Mittelalter zu Fragen grundsätzlicher Art hinaus. Dabei geht es etwa um die Entstehung und Wirkung von Mythen für die Selbstvergewisserung und Legitimation bestimmter Gruppen und Institutionen. In den Blickpunkt gerät dabei die Frage der Rezeption der mittelalterlichen Geschichte in der Vergangenheit und deren Relevanz für die gegenwärtige Rezeption. 


\section{Die Aktualität des Mittelalters}

Unter dem Schlagwort „Überall ist Mittelalter"sil wird der Sachverhalt beschrieben, dass gegenwärtige Siedlungs- und Verkehrsstrukturen Deutschlands und Europas zum größten Teil auf das Mittelalter zurückgehen. Die Ursprünge von historischen Ortskernen, Kirchen, Klöster, Burgen und Residenzen, Straßenzüge und Dorffluren liegen im Mittelalter. Die europäische Völkerwelt ist in der Hauptsache ein Produkt des Mittelalters. Etwa vor tausend Jahren entstanden die Reiche und Völker der Deutschen und Franzosen, der Dänen, Polen und Ungarn, Spanier, Schweden und Russen. Die historisch verwurzelten, weit zurückreichenden Traditionen innerhalb der Identität der Völker können nach wie vor große Kraft entwickeln, wie die aktuelle Entwicklung auf dem Balkan zeigt. Völker sind keine naturgegebenen Gebilde, sondern historisch politische Größen. Weinfurter verweist darauf, dass eine Voraussetzung für das Überwinden von nationalen Grenzen und damit ein erfolgreicher $\mathrm{Zu}$ sammenschluss in einer europäischen Union auch von einer guten Kenntnis der Nachbarn und deren Einstellungen und Befindlichkeiten abhängig ist. Europa kann demnach nicht als künstliche Neuschöpfung betrachtet werden, sondern wird auf seine Völker, Regionen und Kulturkreise Rücksicht nehmen müssen (Weinfurter 1999, S. 743..52

Eine kritische Beschäftigung mit dem Mittelalter konfrontiert mit dem ganz Anderen. In seiner Fremdheit fordert diese Andersartigkeit im idealen Fall zur Auseinandersetzung heraus. Damit könnten die Maßstäbe der Gegenwart nach Ansicht von Fried relativiert werden. ${ }^{53}$ Er stellt die Frage, ob damit soziale und politische Phantasie und Kreativität aktiviert werden könnten. Diese wären dann hilfreich zur Gestaltung der eigenen Gegenwart, indem beispielsweise Handlungs- und Denkmuster der damaligen Welt oder religiöser Fundamentalismen gesammelt und verglichen würden. Das Mittelalter kann zwar nicht als Ideenlieferant für

51 Fuhrmann zitiert in Weinfurter 1999, S. 742.

52 In der 27. Europaratsausstellung „Europas Mitte um 1000“ als deutschpolnisches-slowakisch-tschechisch-ungarisches Projekt stand genau dieses Anliegen im Zentrum. Vor einem Jahrtausend formierten sich in der Mitte Europas jene Länder und Völker, die heute im dritten Jahrtausend nach neuer Einheit streben. Mit dem Beitritt Polens, Tschechiens und Ungarns zur Euorpäischen Union schließt sich symbolisch der Bogen einer tausendjährigen gemeinsamen Geschichte. Siehe Kapitel 5, Anm. 67.

53 Fried, Johannes: Die Aktualität des Mittelalters. Gegen die Überheblichkeit unserer Wissensgesellschaft. Stuttgart 2002, S. 23. 
heute dienen, gleichwohl jedoch könnte es laut Fried als kollektiver Erfahrungsspeicher genutzt werden. Geschichte kann zwar keine allgemeingültigen Handlungsanweisungen geben, jedoch lassen sich aus der Geschichte erprobte Handlungsmuster ablesen, aus denen sich dann Orientierungswissen ableiten lässt (Fried 2002, S. 28).

Oexle fordert die Mediävisten auf, ihre Fragestellungen nicht nur auf das Mittelalter zu richten. In der öffentlichen, fachlichen und politischen Diskussion über die Rolle der Geschichte und über die unterschiedlichen Bedeutungen einzelner historischer Epochen wird Mediävistik nur dann relevant sein, wenn sie sich auch damit befasst, was das Mittelalter mit der Moderne zu tun hat, so zum Beispiel, welches die mittelalterlichen Bedingungen sind, in denen wir gegenwärtig leben (Oexle 1997, S. 364). Auch Fried betont die Notwendigkeit, die Vergangenheit im Hinblick auf gegenwärtige Fragestellungen zu analysieren und das Mittelalter für heutige Zeitfragen transparent zu machen. Zusätzlich zu den traditionellen Bereichen der Wissenschaft sollten sich die Historiker auch mit dem aktuellen Nutzen der Geschichtswissenschaft für die Gesellschaft befassen:

„Es verlangt von uns [...] einen Umgang mit der Historie, wie wir ihn heute gewöhnlich nicht praktizieren; einen, der heutigen und künftigen, der menschlichen Nutzen ins Auge faßte und die tiefreichenden Wurzeln sichtbar machte, mit denen die Gegenwart unausrottbar aus der Vergangenheit Nahrung saugt, Blüten treibt und Früchte trägt.“ (Fried 2002, S. 29)

In dieser Hinsicht eröffnet der Blick ins Mittelalter einen Ausblick über den Zusammenprall von Zivilisationen, wie er auch in unserer Gegenwart entscheidend zu werden verspricht. Ein solcher Zusammenstoß erfolgte in den mittleren Jahrhunderten mehrfach (ebd., S. 52). Die rohe Welt der Germanen und Slawen traf auf die Hochzivilisation des Mittelmeeres, das lateinische Abendland auf das orthodoxe Byzanz, die christliche Welt auf den Islam, der europäische Westen auf Vorder-, Mittel- und Ostasien. Die Beispiele weisen Unterschiede auf, seien sie sozialer, religiöser, kultureller Natur. Dennoch wiederholten sich manche Erfahrungen und sind heute noch relevant. Dauer und Wirkungen derartiger Konfrontations- und Aneigungsprozesse lassen sich erfassen, kulturelle Inkubationszeiten bemessen, die Geschwindigkeit von Assimilationsprozessen abschätzen sowie die Ergebnisse des Ausgleichs, das entstehende Neue und das Fortwirken des Alten, die Begründung des Erfolgs, die Wirkung von Handel und Religion, die umfassenden Folgen analysieren. Die Menschheit verfügt über einen ausgedehnten Erfah- 
rungsschatz, ,den sie jederzeit zu heben vermöchte und von dem sie ohne Geschichte - dumpf ergeben zehrt“. (ebd., S. 53). Eine Analyse der Geschichte schult den Blick für gleichartige Prozesse in der Gegenwart.

Die gegenwartsbezogene Perspektive bietet sich auch als möglicher thematischer Ansatzpunkt für Ausstellungen an. Über diese Ebene können Anknüpfungspunkte zur Erfahrungswelt der Betrachter hergestellt werden $^{54}$

\section{Mittelalterbilder in der Rezeption}

Neben aktuellen Fragestellungen besteht ein weiterer, wichtiger Aspekt in der Frage der Rezeption des Mittelalters. Dabei geht es um die Deutungen des Mittelalters, um die Bilder vom Mittelalter in der Moderne und um den konstitutiven Zusammenhang, der seit Beginn des 19. Jahrhunderts zwischen der Wahrnehmung der Moderne und der Deutung des Mittelalters besteht. Oexle betont, dass Fachwissenschaftler sich nicht nur für die historischen Geschehnisse interessieren sollten, sondern auch dafür, wie diese Ereignisse im Laufe der Zeit jeweils interpretiert wurden. Er fordert, dass die Erforschung der verschiedenen Betrachtungsweisen zu einem integralen Bestandteil der historischen Forschung werden sollte, weil die Vergangenheit die Folgezeiten nicht nur durch geschaffene konkrete Bedingungen mitbestimmt, sondern auch durch überlieferte Vorstellungen, die neben bewussten Traditionen in überlieferten Stereotypen, sogar im emotional verfärbten Wortschatz der gesprochenen Sprache zum Ausdruck kommen und Denkweisen bestimmen (Oexle 1996, S. 138).

Die Instrumentalisierung mittelalterlicher Geschichte und daraus abgeleiteter Sinnstiftungen zeigte sich am Gebrauch bzw. Missbrauch des Mittelalters für die deutsche Identitätsstiftung. Den mittelalterlichen Kaisern wurde das attestiert, was die Deutschen selbst erstreben wollten: Glanz, Größe und Macht. Die Deutschen als Vor- und Ordnungsmacht im Abendland, so lautete die Botschaft, die das Mittelalter dem 19. und 20. Jahrhundert in dessen Augen verkündete (Althoff 1992, S. 4). Die Popularität der mittelalterlichen Herrscher hing davon ab, wie energisch und erfolgreich diese sich dem angeblichen Verfall ihrer Macht entgegen

54 Diese Vorgehensweise entspricht auch der kommunikativen Dimension Handlungsorientierung, siehe Kapitel 3.2: Handlungsorientierung - Die Besucherinteressen und Erfahren mit allen Sinnen. 
gestemmt oder ob sie ihn sogar schuldhaft beschleunigt hatten. Althoff sieht es als Aufgabe, derartige Geschichtsbilder nicht noch einmal als Mythen zu entlarven, sondern deutlich zu machen, was diese Sinnstiftungen bewirkten, nämlich dass sie neben anderen Faktoren die Deutschen mental dazu bereit gemacht haben, sich Macht, Glanz und Größe zurückzuerobern.

„Der sehnsüchtige Blick auf die Geschichte, besonders die mittelalterliche, der einstige Größe vorführte, um der Gegenwart einen Auftrag für die Zukunft $\mathrm{zu}$ vermitteln, schaffte ein Bewußtsein, das fraglos den Prozeß der Einigung forcierte, aber auch kriegerische Auseinandersetzungen rechtfertigte und beförderte, die bald eine bis dahin unbekannte Größenordnung annahmen und schließlich von einem nie dagewesenen Vernichtungswillen geprägt wurden.“ (Althoff 1992, S. 4)

Der Ottone Heinrich I. zählt zu den mittelalterlichen Herrschern, die von der nationalsozialistischen Propaganda trotz der bis heute sehr unsicheren Quellenlage als Vorreiter der Politik Hitlers dargestellt wurden. Anhand der Ausstellung „Auf den Spuren der Ottonen“ im Schlossmuseum Quedlinburg lässt sich exemplarisch zeigen, wie die Darstellung der Rezeptionsgeschichte in einer Ausstellung umgesetzt werden kann. ${ }^{55}$ Die Präsentation umfasst insgesamt drei Kellergewölbe unter dem Quedlinburger Schloss. ${ }^{56}$ In zwei Sälen wird die Entstehungsgeschichte des reichsunmittelbaren, freiweltlichen Damenstiftes dargestellt. Den thematisch roten Faden bildet die Memoria. Diese zeitgenössische Geisteshaltung stellte das Motiv dar, auf dem Quedlinburger Schlossberg nach dem Tod Heinrichs I. ein Damenstift errichten zu lassen. In diesen zwei Räumen werden die Kostbarkeiten des Museums gezeigt.

In dem dritten Tonnengewölbe wird das Erinnern auf die Neuzeit bzw. Zeitgeschichte erweitert. Damit erhält die Ausstellung ihre besondere Bedeutung. Unter dem Untertitel „Geschichte und Propaganda“ erfolgt die Thematisierung des Missbrauchs der mittelalterlichen Geschichte Quedlinburgs. Die Rezeptionsgeschichte Heinrich I. steht im Mittelpunkt. Chronologisch werden das 19. und 20. Jahrhundert mit besonderer Berücksichtigung der Zeit zwischen 1933 und 1945 thematisiert. Himmler ließ die Stiftskirche in Quedlinburg zu einer Kult- und

55 Mühldorfer-Vogt, Christian: „Auf den Spuren der Ottonen“ - Konzeptionelle Überlegungen zu einem musealen Projekt. (unveröffentlichtes Skript) Quedlinburg 2004.

56 Die Eröffnung der Ausstellung fand am 01.04.04 statt. 
Weihestätte der SS umbauen. Der steinerne Sarkophag, der im Sommer 1937 angefertigt worden war, symbolisiert in dieser Abteilung zum Beispiel die pervertierte Geschichtsauffassung der Nationalsozialisten. Im Jahr 1937 hatte die Bestattung der für das Regime symbolträchtigen vermeintlichen Gebeine Heinrichs I. in einer Wiederbeisetzungsfeier mit großem Pathos stattgefunden. In der Ausstellung dokumentieren hinter dem Sarkophag angebrachte Schrifttafeln sein Heben und Öffnen im Februar 1948 (siehe Abb. 22). Anstelle der bis heute nicht aufgefundenen Gebeine befanden sich darin Bretter. Die Fotos entlarven die demagogische Geschichtslüge und geben sie damit der Lächerlichkeit preis (ebd.).

„Ziel soll es sein, den Begriff der objektiven Geschichte zu hinterfragen. Die bewusste Instrumentalisierung oder besser gesagt, Verfälschung und Missbrauch von Geschichte muss insofern als besondere Zuspitzung dieses objektiven Geschichtsverständnisses verstanden werden. ${ }^{\text {(57 }}$

Die Ausstellung war während der Planung bis zur Eröffnung von heftigen Diskussionen begleitet. Der extreme politischen Missbrauchs wurde über Jahrzehnte verdrängt und verschwiegen. So konnte es passieren, dass Quedlinburg für einen Teil der rechtsextremen Szene zu einem symbolischen Ort wurde. Kritiker wollten die Episode auch weiterhin dem Vergessen überlassen und stellten generell in Frage, ob man dieses dunkle Kapitel deutscher Geschichte überhaupt thematisieren solle. Auch wurde kritisch kommentiert, ob das Nebeneinander von mittelalterlicher Geschichte und Rezeptionsgeschichte zu vertreten sei (Mühldorfer-Vogt 2004, S. 2).

Diese Schwierigkeiten im Vorfeld weisen sowohl auf die Brisanz des Themas als auch auf die Notwendigkeit der Aufarbeitung hin. Ausstellungsmacher sehen sich mit unerwarteten Problemen konfrontiert. ${ }^{58} \mathrm{Um}-$ so mehr fordert dies einen sensiblen Umgang und auch eindeutige Interpretation des Materials, um einer Fehlinterpretation entgegenzuwirken.

57 Mühldorfer-Vogt zitiert in einer Pressemitteilung der Stadt Quedlinburg 24/2004: Vom Mittelalter bis zur Rezeptionsgeschichte I. - Neue Ausstellung im Quedlinburger Schlossmuseum ab 2. April.

58 Von einem ,diffusen Widerstand“ innerhalb der Stadt berichtet zum Beispiel Kranert. Kranert, Hendrik: Schlossmuseum Quedlinburg. Verdrängtes kommt ans Licht. Schau nimmt sich erstmals des Heinrich-Kultes der Nazis an - Gemeinde musste ihre Stiftskirche überlassen. In: Mitteldeutsche Zeitung vom 03.03.04. 
Neben Schrifttafeln und Ausstellungsstücken unterstützen multimediale Elemente und originale Tondokumente die Gesamtpräsentation. Das Nebeneinander von mittelalterlicher Geschichte und neuzeitlicher Rezeptionsgeschichte wurde gestalterisch durch einen bewussten Bruch zwischen beiden Teilen markant abgetrennt. Der Mittelalterbereich wird von einem farbintensiven Design beherrscht, dagegen wird der Bereich „Geschichte und Propaganda“ von Grau- und Schwarztönen mit kaltem, gleißendem Licht geprägt (Mühldorfer-Vogt 2004, S.2). Zudem wird mit gestalterisch-rhetorischen Mitteln eindeutig interpretiert. Dies zeigt sich zum Beispiel an einem mit Stacheldraht umwickelten Kerzenständer, der im Eingangsbereich der Ausstellung liegt. Um das christliche Erscheinungsbild der Kirche zu brechen, ließ die SS im Jahr 1938 eigene Machtsymbole aufstellen, dazu gehörten jene übergroßen, speziell angefertigten Kerzenständer. ${ }^{59}$

Die Rezeptionsgeschichte des 19. und 20. Jahrhundert wie auch die gegenwärtige Popularität des Mittelalters mit ihren phantasievollen Ausformungen bedeutet für Ausstellungsmacher eine spezielle Herausforderung. Gerade die Forderung nach hohen Besucherzahlen stellt Kuratoren und auch Gestalter vor die Aufgabe, Verführungsstrategien zu entwickeln und zu entwerfen, die ein Massenpublikum bewegen und begeistern können. Kritisch merkt hierzu der Designer Heller an, dass zwar Szenographen Konzepte nach wirtschaftlichen und vermarktungsrelevanten Vorgaben der Auftraggeber umsetzen, andererseits sich alle an dem Konzept Beteiligten der Verantwortung bewusst sein müssen, dass Inhalte und Zusammenhänge nicht willfährig als vordringliches Mittel zur Optimierung von Besucherzahlen eingesetzt werden sollen. ${ }^{60}$

Aufgrund der Popularität des Mittelalters besteht jedoch die Gefahr, in musealen Präsentationen ähnliche Strategien anzuwenden, wie sie im kommerziellem Bereich erfolgreich wirken. Wie bei der Beschreibung der Erlebniswelten deutlich wurde, kommt einer möglichst hohen Authentizität des wahren Mittelalters ein hoher Stellenwert zu. Die Werbung mit dem Slogan, das wahre Mittelalter zu zeigen, und das Versprechen, einen realistischen Einblick in das Leben und Denken der Men-

59 Schneider, Jens: Des Königs nackte Bretter. Die Ausstellung „Auf den Spuren der Ottonen“ im Quedlinburger Schlosskeller. In: Süddeutsche Zeitung vom 04.05.04.

60 Heller, Andreas: Inszenierte Authentizität? - Die Grenzen von Design und Szenographie. In: Museumskunde 66. (2001) Heft 1 S. 34. 
schen im Mittelalter zu erhalten, sind auch in Faltblättern von kulturhistorischen Ausstellungen zu finden:

„Wer kennt sie nicht, die tapferen Ritter in ihren glänzenden Rüstungen aus den Filmstudios Hollywoods!? - Aber kaum einer weiß, in welcher Welt sie wirklich leben. Wir haben für Sie hunderte von Dokumenten ausgegraben und tausende von Scherben zusammengesetzt, im Ihnen das Mittelalter erlebbar zu machen. Gehen Sie mit uns auf Forschungsreise, entdecken Sie die Zeit des Mittelalters, so wie sie wirklich war." ${ }^{\text {"61 }}$

Den Anspruch, das wahre Mittelalter zu zeigen, kann auch eine museale Ausstellung nicht einlösen. Statt klischeehaften Bildern entgegenzuwirken und Sensibilität für die Unterschiedlichkeit der Deutungen zu schaffen, mündet dies vergleichbar den mittelalterlichen Erlebniswelten in starre Geschichtsbilder. Historische Sachverhalte lassen sich an Ausstellungsobjekten zeigen, jedoch das Leben der Menschen im Mittelalter zu zeigen, ist nur in Andeutungen möglich.

„Die Leute gehen satt und warm an einem mickrigen, in die Ausstellung hingestellten Hüttchen mit einer Schüssel auf dem Tisch vorbei und schauen sich das an. Wie sich jedoch Hunger oder Kälte anfühlt, wissen sie deshalb nicht. Hier müsste man den Leuten sehr ausführlich Biographien erzählen und darauf hoffen, dass sie ein Minimum an Empathie haben, um dies nachfühlen zu können. “62

Demgegenüber entwickelt sich in der Geschichtswissenschaft zunehmend ein Bewusstsein für die Relativität der Geschichtsüberlieferung und auch deren Deutungen. So wünscht sich Esch zum Beispiel eine Reflexion über die Quellenproblematik. Damit verweist Esch auf die Frage, wie sich historische Wirklichkeit in historischen Quellen überhaupt abbilden kann. Dies deutet auf das Problem der unterschiedlichen Überlieferungschancen von Quellengattungen und die daraus in der Rückschau kaum wahrnehmbare Verzerrung der Erkenntnis hin. Auch betrifft dies den Wandel von Erinnerungsweisen und des Zeitbewusstseins, der Wahrnehmung von Geschichte durch die Betroffenen (Esch 1996, S. 43).

61 Zitat aus dem Faltblatt zur Ausstellung „Faszination Mittelalter“ vom 04.05.-03.11.02 im OberhausMuseum Passau.

62 Interview mit Frau Dr. Brigitte Herrbach-Schmidt, Konservatorin für den Bereich Mittelalter, Skulptur, Textil am Badischen Landesmuseum in Karlsruhe, am 21. März 2002. 
Fried weist ebenfalls auf die Quellenproblematik hin und stellt die Frage, wem überlieferte Werke zu verdanken sind.

„Mann oder Frau, Kleriker oder Kanonisse? Das 19. Jahrhundert hatte ausschließlich an Männer gedacht; das 20. Jahrhundert schrieb dieses maskuline Vorurteil fort. Doch gab es nicht in Quedlinburg gelehrte Frauen, inhaltsreiche Handschriften, Schulunterricht durch Nonnen? Thietmar von Merseburg wurde dort von seiner Tante erzogen und in die Geheimnisse der 'Artes' eingeführt. ${ }^{\text {663 }}$

So ergibt sich auch für die Rezeption des Mittelalters in musealen Ausstellungen, vor allem in Abgrenzung zur Thematisierung in Erlebniswelten, die Forderung nach einem differenzierenden Kontext, in der es nicht um die Schaffung von vergangenen Welten geht. Statt geschlossenen Erzählungen in einer möglichst realitätsgetreuen Darstellung geht es um Offenheit der Interpretation, statt perfekten Traumwelten sollte die Konstrukthaftigkeit der Geschichte im Vordergrund stehen. ${ }^{64}$ Das Bedürfnis der Menschen nach schönen, skurrilen, nostalgischen oder auch phantasievollen Bildern wird umfassend von kommerziellen Anbietern bedient. Darüber hinaus obliegt es den Museen, die Vielschichtigkeit, Nuancen und auch Unwägbarkeiten der Überlieferung zu thematisieren.

\subsection{Mittelalter in musealen Ausstellungen}

Das Interesse an Ausstellungen zum Mittelalter wurde in den siebziger Jahren geweckt und dauert bis heute mit steigender Tendenz an. Als erster großer Erfolg gilt die Staufer-Ausstellung in Stuttgart im Jahr 1977. ${ }^{65}$ Um die Jahrtausendwende konnte ein wahrer Boom von Ausstellungen zu mittelalterlichen Themen beobachtet werden. Das Spektrum der Themen war von umfassenden Epochenausstellungen hin zu regionalen Spezialthemen breit angelegt. Bei der großen Anzahl der Ausstellungen kann nur punktuell auf wenige Präsentationen verwiesen wer-

63 Fried, Johannes: Vom Zerfall der Geschichte zur Wiedervereinigung. Der Wandel der Interpretationsmuster. In: Oexle, 1996, S. 56.

64 Siehe Kapitel 4.3: Differenzierender Kontext: Akzentuierungen - Offenheit - Irritation.

65 Diese Ausstellung besuchten insgesamt 650.000 Besucher, damit zählt sie bis heute zu den best besuchten Ausstellungen der vergangenen drei Jahrzehnte. Siehe Kapitel 5, Anm. 20. 
den. In zwei Europaratsausstellungen, die wohl zu den Mammutprojekten im Ausstellungsbetrieb zählen, stand die mittelalterliche Epoche im Zentrum. Dazu gehört zum einen die Ausstellung „Otto der Große Magdeburg und Europa“. Sie beeindruckte durch eine große Anzahl von Goldschmiedekunst, Elfenbeinschnitzereien sowie spektakulären Leihgaben ${ }^{66}$ Bei der zweiten Ausstellung „Europas Mitte um 1000“ wirkten Wissenschaftler und Institutionen aus Deutschland, Polen, der Slowakei, Tschechien und Ungarn mit. Die mit über 3000 Exponaten bestückte Schau wurde an sechs verschiedenen Ausstellungsorten gezeigt. ${ }^{67}$ In Karlsruhe gab es ebenfalls ein Kooperationsprojekt zwischen dem Badischen Landesmuseum sowie der Staatlichen Kunsthalle in Karlsruhe unter dem gemeinsamen Titel „Spätmittelalter am Oberrhein“. In einer sich gegenseitig ergänzenden Perspektive widmete sich die Staatliche Kunsthalle dem Thema „Maler und Werkstätten 1450-1525“68, demgegenüber befasste sich das Landesmuseum mit „Alltag, Handwerk und Handel 1350-1525“. ${ }^{69}$ Außerdem entwickelte das Kindermuseum hierzu eine Begleitausstellung. ${ }^{70}$ Auch über Deutschland hinaus erweckt das Mittelalter Interesse. Zum Beispiel näherte sich das Victoria and Albert Museum in London unter dem prägnanten Titel "Gothic" mit einer theatralischen Inszenierung dieser Epoche. ${ }^{71}$

Obwohl sich die Ausstellungslandschaft aufgrund der Fülle der möglichen Themen wie auch deren inhaltlicher und gestalterischer Realisierung als sehr vielfältig und nuancenreich darstellt, sollen im folgenden

66 Kulturhistorischen Museum Magdeburg vom 27.08.-02.12.01. Puhle, Matthias (Hrsg.): Otto der Große, Magdeburg und Europa. Mainz 2001. Siehe auch Kapitel 2, Anm. 40-46.

67 Der große Umfang des Projekts zeigt sich auch am Umfang des Ausstellungskatalogs sowie zwei Essaybänden mit insgesamt über 1500 Seiten. Wieczorek, Alfried, Hinz, Hans-Martin (Hrsg.): Europas Mitte um 1000. Stuttgart 2000. Siehe auch Kapitel 5, Anm. 52.

68 Staatliche Kunsthalle Karlsruhe vom 29.09.01-03.02.02. Lüdtke, Dietmar/Jacob, Friesen (Hrsg.): Spätmittelalter am Oberrhein, Teil 1: Maler und Werkstätten 1450-1525. Stuttgart 2001.

69 Badisches Landesmuseum Karlsruhe vom 29.09.01-03.02.02. Badisches Landesmuseum Karlsruhe (Hrsg.): Spätmittelalter am Oberrhein, Teil 2: Alltag, Handwerk und Handel 1350-1525. Stuttgart 2001.

70 Kindermuseum Karlsruhe vom 21.09.01-03.03.03, Ausstellung „Fenster zum Mittelalter - Wie Kunst vor 500 Jahren entstand“.

71 Victoria and Albert Museum London vom 09.10.03-18.01.04. Marks, Richard/Williamson, Paul: Gothic-Art for England 1400-1547. London 2003. 
Kapitel drei typische Formen näher betrachtet werden, die in ihrer Gegensätzlichkeit Diskussionsfelder deutlich hervortreten lassen. In der gestalterischen Umsetzung beschreiten diese Ausstellungen sehr konträre Wege. Dennoch ist allen Konzeptionen die Betonung der ästhetischen Komponente gemeinsam. Hintergrundinformationen in Form von Raumbeschriftungen beispielsweise wird eine geringe Bedeutung zugemessen.

\section{Nostalgie - das romantische Bild}

Zunächst beschreibe ich Präsentationen, wie sie das 19. Jahrhundert prägte, die jedoch auch heute noch fortwirken und im musealen Bereich gegenwärtig existent sind. Diese Formen im Stil der malerischen Präsentationsweise $^{72}$ fühlen sich weniger dem wissenschaftlichen Prinzip verpflichtet, vielmehr richtet sich die Anordnung der Exponate nach emotionalen Effekten. Das stimmige Gesamtambiente und das Erlebnis einer Zeitreise in die Vergangenheit sowie das Staunen über die gezeigten Gegenstände stehen primär im Vordergrund. Charakteristisch für diese Präsentationen waren Ensemblebildungen von Objektgruppen derselben Stilepoche mit annähernd gleicher Entstehungszeit. Diese Ensembles wurden durch Hinzufügen von Architekturzitaten oder Skulpturen in Form von Gipsabgüssen ergänzt. Auch historische Bauteile wie Wandvertäfelungen und Holzdecken fanden Verwendung, um komplette Raumeindrücke zu erzielen. Die Wände wurden in Farbstimmung und Ornamentik dem Stil der Exponate entsprechend bemalt. Auch die Gestaltung des Ausstellungsmobiliars, wie Vitrinen und Podeste, entsprach dem Gesamtstil des jeweiligen Saals. ${ }^{73}$

$\mathrm{Zu}$ den Vorreitern auf dem Gebiet der musealen Präsentation zählt Alexandre Du Sommerard ${ }^{74}$. Er nahm die spätere museale Darstellungsform von Lebenswelten, wie sie in Frankreich erst auf den Weltausstel-

72 Zur malerischen Präsentationsweise siehe Kapitel 1, S. $31 \mathrm{ff}$.

73 Sangl, Sigrid: ,... die Wände geblümelt im Sinne der Zeit...“. Die Innendekoration des Bayerischen Nationalmuseums und die Rolle von Rudolf Seitz. In: Bauer 2000, 117.

74 Das heutige „Musée national du Palais des Thermes et de l'Hotel de Cluny“ wurde 1844 offiziell eröffnet. Es verdankt seine Existenz dem engagierten Sammler Alexandre Du Sommerand (1779-1842), der im Jahr 1832 einige Räume im Stadtpalais von Cluny zur Einrichtung seines $\mathrm{Mu}-$ seums anmietete. Vgl. Plato 2001, S. 63. 
lungen vorgeführt wurden, vorweg. Du Sommerand legte weniger Wert auf eine Ordnung nach Jahrhunderten, sondern betonte vielmehr zusammenhängende Rekonstruktionen in den Ausstellungsräumen. Dabei gelang es ihm - wenn man zeitgenössischen Texten und bildlichen Darstellungen Glauben schenken darf -, eine lebensnahe Atmosphäre herzustellen. Du Sommerand lieferte gewissermaßen das Dekor für Romane und Theaterstücke. Auf den ersten Blick schien der Raum trotz der präsentierten Vielfalt geordnet zu sein. Sieht man jedoch näher hin, so gehören die Waffen nicht ins Bett und auch die Teile auf dem Tisch passen nicht zusammen. Aber das gemütliche Durcheinander machte das Zimmer wohnlich, es wirkte geradezu bewohnt.

„Das Zimmer Franz’ I. war - glaubt man Du Sommerands Abbildung aus seinem eigenem Werk - ein behaglicher Raum mit Utensilien des täglichen Gebrauchs aus verschiedenen Zeiten und Bereichen: einem großen Bett, einem Tisch, Schränken, einem Spiegeltisch, an einem kleinen Seitentisch sitzenden Ritterrüstungen, einer weiteren Rüstung auf dem Bettaufbau, [...].“ (Plato 2001, S. 72)

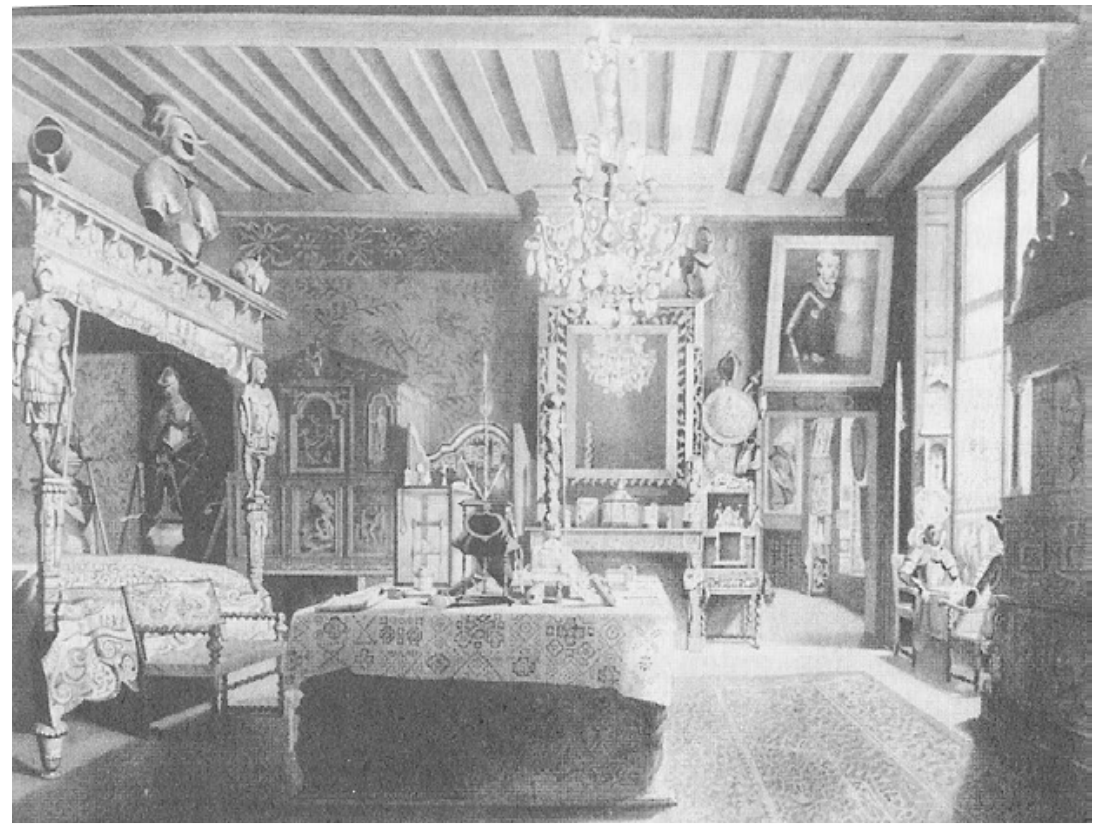

Abbildung 23: Das Zimmer von François I. in der Sammlung des Hôtel de Cluny. 
Du Sommerand vermochte es, seine Besucher in die Lebenswelt eines mittelalterlichen Edelmannes zu entführen. Die Besucher fühlten sich von einer verschwundenen Kultur der guten alten Ritterzeit umgeben (ebd.).

Architektonisch diente das Musée de Cluny als internationales Vorbild für die Konzeption kulturgeschichtlicher Museen. Boten sich keine historischen Bauten an, so entstand wie etwa in München mit dem Bayerischen Nationalmuseum eine Art künstliches Musée Cluny (ebd., S. 91). Das im Jahr 1900 wieder eröffnete Bayerische Nationalmuseum wurde konsequent im malerischen Stil eingerichtet. ${ }^{75}$ Die Säle des kulturhistorischen Rundgangs sollten sowohl in der architektonischen wie in der künstlerisch-dekorativen Ausgestaltung dem Stil der dort ausgestellten Gegenstände entsprechen. Neben dem hauptsächlichen Gliederungskriterium nach Regierungszeiten von Wittelsbacher Herrscherpersönlichkeiten und nach einzelnen kunst- und kulturgeschichtlichen Epochen gab es mehrere Säle, deren thematische Ordnung sich in inszenierten Raumfunktionen ausdrückte, so zum Beispiel einem Kirchensaal, einer Kapelle oder einem Audienzzimmer (Sangl 2000, S. 116). Jedes Detail sollte dem Prinzip der Stilreinheit entsprechen. Auch die Fußböden wurden teilweise historischen Vorbildern nachempfunden. In der gesamten Mittelalterabteilung befand sich zum Beispiel ein Fliesenboden aus Keramik, der Vorbildern aus dieser Epoche nachempfunden war. Ebenso wurde das Ausstellungsmobiliar konsequent dem Prinzip der Stilreinheit angepasst. So gab es im Saal der romanischen Kleinkunst Vitrinen, deren Holzsockel mit irischen Knotenornamenten dekoriert waren.

Der Kirchensaal wurde als Imagination eines tatsächlichen Kirchenraums von zeitgenössischen Rezensenten als besonders gelungen betrachtet. Der bewusst angeordnete Übergang von einem kleineren Vorraum, der wegen des Kontrasts absichtlich niedrig gehalten worden war, in den neuen Kirchensaal bereitete die Einstimmung des Besuchers vor. Durch das große Ostfenster des Vorraums erschien dies wie ein Hinabsteigen in einen mystischen Raum (ebd., S. 118ff.). Gestaltet wie ein Kirchenschiff mit je sechs seitlichen Kapellennischen bot er für die Zeitgenossen Anlass zu vielerlei romantischen Assoziationen:

75 Die Innengestaltung des Neubaus für das Bayerische Nationalmuseum übernahm Rudolf von Seitz. Als Künstler und Mitarbeiter eines Museums stand er in einer seit dem Beginn des 19. Jahrhunderts geübten Tradition, die in dem Phänomen der sogenannten Künstlerkonservatoren ihren Abschluss fand. Vgl. Sangl 2000, S. 103. 
„[W]ir erwarten im nächsten Augenblick Weihrauch zu riechen und Orgeltöne zu hören, [...] wir wundern uns förmlich, daß nicht Faust's Gretchen vor einem dieser Madonnenbilder kniet, oder aus dem Chorgestühl ein düstrer Mönch auf uns zuschreitet“"

Ein umfangreiches Vitrinenprogramm ergänzte die Anschaulichkeit der Präsentation. Die Vitrinen standen häufig im Zentrum des Saals oder diagonal, damit der Besucher die Objekte bei guter Beleuchtung von allen Seiten mit allen Details betrachten konnte. Innerhalb der Vitrinen waren die Gegenstände oft auf verschieden hohen Sockeln angeordnet, um jeden Eindruck der Reihenhaftigkeit zu vermeiden. Auch Textilien spielten in der Inszenierung eine bedeutende Rolle. In den Vitrinen sorgten verschiedene Stoffstrukturen und Farben für eine effektvolle Wirkung der Exponate. Jeder Saal war für sich bis in das kleinste Details durchgestaltet (ebd., S. 121).

Die Ausrichtung auf die Bedürfnisse der Besucher und nicht unbedingt die der Wissenschaftler kennzeichnet die Inneneinrichtung des Bayerischen Nationalmuseums um 1900. Das Prinzip des Wechsels der räumlichen Proportionen, der Farben, der Oberflächen, der Beleuchtung und der Dekoration führte zu einem weitgehend ermüdungsfreien Rundgang durch die fast einhundert Ausstellungssäle. Die Argumente für eine ganzheitliche Raumwirkung, in der die Ausstellungsgegenstände mit hoher Selbstverständlichkeit zur Wirkung kommen sollten, verstanden sich auch als Bezug auf die Bedürfnisse des Besuchers. Man wollte ein möglichst getreues und für ein breites Publikum verständliches Bild vergangener Zeit bieten. Die sinnliche Erschließung, durch die das Publikum zunächst den Zugang findet, wurde in vieler Hinsicht bedient.

„Wenn dabei auch vielfach von den strengen Anforderungen des wissenschaftlichen Systematikers abgewichen ist [...], so wäre es doch für weit nachtheiliger zu erachten, wenn der kleinen Schar von Fachgelehrten zuliebe eine nüchterne systematische Aufstellung ohne künstlerischen Reiz vorgenommen worden wäre, die den Mann aus dem Volke und den Laien der Wissenschaft nicht anziehen, sondern nur abstoßen könnte.“77

Trotz aller Versuche, die Aufstellung für die Besucher möglichst anschaulich zu gestalten, wurde auf die Beschriftung der Objekte verzichtet. Nach der Vermutung Sangls befürchtete der Künstlerkonservator

76 Kirchner zitiert in Sang1 2000, S. 119.

77 Graf zitiert in Koch, Michael: Das Museum als Gesamtkunstwerk. Gabriel von Seidls Neubau im Spiegel der Kritik. In: Bauer 2000, S. 216. 
Seitz möglicherweise, dass zu viele Schrifttafeln die Gesamtbilder der Arrangements stören könnten (Sangl 2000, S. 128). Weiterhin merkt Sangl kritisch an, dass mit den dekorativen Bemühungen zweifellos Grenzen überschritten wurden. Mit dem Ziel einer möglichst hohen Anschaulichkeit einer Epoche wurden nicht nur Kopien von Bauteilen verwendet, sondern vermehrt auch der Bestand der ausgestellten Objekte durch von Seitz als legitim empfundene neuere Nachbildungen ergänzt (ebd. S. 127).

Die Debatte um den Sinn historisierender Museumseinrichtungen, die sich an den Epochen ausgestellter Objekte orientieren, begleitete die Präsentation und führte zum Teil zu heftiger Kritik. Im Zentrum der Diskussion stand die Frage der Stilreinheit. Bestrebungen, die Vergangenheit in einem fiktiven Raumzusammenhang eines neuen Gebäudes wieder zu verlebendigen, führten zu einer Vermischung echter und falscher Objekte, die von einem unbefangenen Besucher angesichts der hohen Qualität des zeitgenössischen Kunsthandwerks tatsächlich nicht mehr auseinandergehalten werden konnten. Dies wurde später ein wesentlicher Kritikpunkt an den Seitzschen Einrichtungen mit dem Resultat, dass die Konservatoren schon bald nach der Eröffnung des Bayerischen Nationalmuseums alle möglichen Fälschungen und Repliken von Tellern, Vasen oder Möbelstücken wieder entfernten.

Einer der schärfsten Kritiker dieser Form der Präsentation war Lessing. ${ }^{78}$ Er forderte zwar nicht die Abschaffung, jedoch die Verifizierung der Einrichtung im Sinn größerer historischer Wahrheit. Wenn im Museum versucht würde, Kulturgeschichte anhand konstruierter Zimmereinrichtungen zu illustrieren, dann sollten diese zumindest aufgrund von Quellenstudien einer historischen Wahrheit entsprechen (ebd., S. 125). Bereits 1870 hatte Esswein, Direktor des Germanischen Nationalmuseums in Nürnberg, auf die Gefahren derartiger Kulturbilder zur Darstellung des häuslichen Lebens hingewiesen:

„[Wenn man ein] malerisches Ensemble zusammenstellt und dadurch beim Publikum den Eindruck hervorruft, als ob es in der Vorzeit irgendwo wirklich so ausgesehen habe, so belügt man es einfach und wenn dies durch eine öffentliche wissenschaftliche Anstalt geschieht, damit es etwa dem Publikum besser gefalle und sentimentale Seelen schwärmen können, so ist das eben Schwindel.“79

78 Julius Lessing war der erste Direktor des Deutschen Gewerbemuseums in Berlin.

79 Esswein zitiert in Sangl 2000, S. 126. 
Trotz der bereits damals kursierenden Kritik ist diese Form der Präsentation nicht verschwunden. In abgeschwächter und veränderter Form lebt der Stil der malerischen Präsentation fort. ${ }^{80}$ Insbesondere in den siebziger Jahren des 20. Jahrhunderts erfuhr sie eine Renaissance. Die Ensemblegruppierung schien durch ihren Alltagsbezug eher die Gewähr zu bieten, den Besucher anzusprechen und einen demokratischen Bildungsanspruch einzulösen. Darüber hinaus besitzt ein sinnlich aufgemachtes Interieur für die breite Masse der Besucher eine höhere Attraktivität, wie sich an kulturtouristisch erschlossenen Zielen zeigt.

Auf Schloss Tratzberg ${ }^{81}$ erfolgte die Inneneinrichtung der Räumlichkeiten ebenfalls nach Gesichtspunkten einer Gesamtwirkung. Die Besucher werden zu einer „Zeitreise ins Mittelalter“ eingeladen. Die ehemalige Burg präsentiert sich heute nach mehreren Phasen des Verfalls und Wiederaufbaus als Schloss mit spätgotischen und RenaissanceElementen. Dementsprechend besteht die Inneneinrichtung primär aus Mobiliar des 16. und 17. Jahrhunderts. Die Ausstattung und die Anordnung des Mobiliars erweckt den Eindruck, als seien diese noch in Benutzung der ehemaligen Bewohner (siehe Abb. 24). ${ }^{82}$ Was im 19. Jahrhundert noch nicht möglich war, kann heute mittels elektronischer Medien verwirklicht werden: Personen der Vergangenheit sprechen zu den Besuchern. Anhand einer Tonbandführung werden die Besucher durch die Räumlichkeiten geführt und dadurch wird der Eindruck lebendiger Vergangenheit intensiviert. So spricht zum Beispiel scheinbar Graf Enzenberg als Hausherr seit Mitte des 19. Jahrhunderts; auch Anna, die Frau von Jakob Fugger, Hausherr im Jahr 1589, kommt auf dem Tonband zu Wort und beschreibt ihr damaliges Leben.

Ebenso wie im 19. Jahrhundert erfährt diese Darstellungsweise in der Gegenwart Kritik, weil sie - wie bereits auch die malerische Inszenie-

80 Siehe auch Darstellung rekonstruktiver Raumbilder in Kapitel 1.1: Rekonstruktive Raumbilder.

81 Die Familienstiftung Schloss Tratzberg, in der Nähe von Jenbach in Tirol, befindet sich seit 1848 in Privatbesitz der Grafen Enzenberg. Die erste urkundliche Erwähnung datiert im 13. Jahrhundert. Möller, Roland/Zeune, Joachim: Schloss Tratzberg. Renaissancejuwel im Inntal, Tirol. Innsbruck, 2001. Siehe auch: http://www.schloss-tratzberg.at (letzter Zugriff: 27.11. 04).

82 Auf Abbildungen in dem Begleitband zum Schloss Tratzberg wird dieser Eindruck bestätigt. Auf einem Teil der Bilder sind die Räumlichkeiten mit Personen in historischen Gewändern belebt. (Möller/Zeune 2001, S. 49, $58,84)$. 
rung im Bayerischen Nationalmuseum - zu der Illusion verleitet, eine vergangene Epoche sei rekonstruierbar und vom Besucher als solche unmittelbar zu erfahren. Die Zusammenstellung zu Ensembles und ihre sinnliche Ansprache verführen den Besucher dazu, die museale Rekonstruktion für ein tatsächliches Abbild vergangener Realität zu halten.

Nichtsdestotrotz weist aus der gegenwärtigen, besucherorientierten Perspektive die malerische Präsentationsweise des 19. Jahrhunderts innovative Ideen auf, wie sie auch heute von Ausstellungsdramaturgen erneut eingefordert werden. In den rhythmisch gegliederten und architektonisch gestalteten Räumen mit wechselnden Bodenbelägen und koloristisch erzeugten Stimmungswerten entspricht die malerische Präsentationsweise den Ideen einer ganzheitlich gestalteten Ausstellungsumwelt.

\section{Schatzkammer - die Auratisierung der Objekte}

Die vielmals vorgetragene Kritik an historisierenden Präsentationen führte zu einer zurückgenommenen Präsentation, die auf massive oder geschlossene Einbauten völlig verzichtete. Während in München das Bayerische Nationalmuseum noch im Stil der malerischen Präsentation eingerichtet wurde, kam es um die Jahrhundertwende an anderen Orten zu einem Wechsel der Form der Ausstellung. In dem Jahrzehnt vor 1914 begannen die meisten großen deutschen Museen, ihre Bilder in einer neuen Art und Weise auszustellen. ${ }^{83}$ Man fing an, wichtige Kunstwerke zu isolieren, die Wände waren heller und geräumiger, die Räumlichkeiten waren nicht mit Möbeln voll gestellt. ${ }^{84}$ Die Veränderung der Raumkonzepte war aufs Engste mit der Entwicklung moderner Kunst verbunden. Die Vorstellung einer idealen Galerie entwarf das Bild eines weiß getünchten Raumes, der vom Kunstwerk alles fernhält, was die Tatsache stören könnte, dass es sich hierbei um Kunst handelt. O'Doherty führte für diese Raumkonzepte im Jahr 1976 den Begriff white cube ein.

83 Als Musterbeispiel wird oft das Kölner Ereignis von 1912 zitiert, das in der Präsentationstechnik den neuen, zuerst von den Sezessionisten eingeführten Zielen Rechnung trug. Ein zeitgenössischer Bericht beschreibt die Ausstellungshalle als moderne Glaskonstruktion, in der die Gemälde und plastischen Arbeiten durchweg vor weißer Bespannung ausgestellt waren. Vgl. Mai 1986, S. 45.

84 Sheehan, James J.: Geschichte der deutschen Kunstmuseen. Von der fürstlichen Wunderkammer zur modernen Sammlung, München 2002, S. 270. 
„Eine Galerie wird nach Gesetzen errichtet, die so streng sind wie diejenigen, die für eine mittelalterliche Kirche galten. Die äußere Welt darf nicht hineingelassen werden, deswegen werden Fenster normalerweise verdunkelt. Die Wände sind weiß getüncht. Die Decke wird zur Lichtquelle. Der Fußboden bleibt entweder blank poliertes Holz, so daß man jeden Schritt hört, [...]. ${ }^{685}$

Damit verwandelt sich in der Moderne die Alltagswahrnehmung zu einer Wahrnehmung der formalen Werte. Hierin sieht O'Doherty eine fatale Entwicklung: „[S]chattenlos, weiß, clean und künstlich“ sind diese Räume ganz der Technologie des Ästhetischen gewidmet. (ebd., S. 10).

Nach der Zerstörung zahlreicher Museumsbauten durch den Zweiten Weltkrieg erfolgte die Neueinrichtung nach diesen Prinzipien der objektorientierten Präsentation mit einer fachwissenschaftlichen Ausrichtung. Auch gegenwärtig ist der white cube die klassische Präsentationsweise für Kunstwerke und kann als die typische Form kunsthistorischer Ausstellungen bezeichnet werden. Anhand von zwei Beispielen mit jeweils unterschiedlicher Akzentuierung sollen die dahinter liegenden Überzeugungen sowie Kritikpunkte kurz skizziert werden.

Die Neukonzipierung der Dauerausstellung des Badischen Landesmuseums in Karlsruhe, die 1959 eröffnet wurde, entstand nach den damals neuen museologischen Erkenntnissen. ${ }^{86}$ Auf historisierende Gestaltung der Ausstellungsräume, auf massive oder geschlossene Einbauten verzichtete man konsequent. Grundsätzlich wurden Schausammlung und Studiensammlung voneinander getrennt. In die nach historischen Epochen klar gegliederte Schausammlung wurden nur Werke von hohem künstlerischem Rang aufgenommen. Die architektonische Gestaltung der großen Ausstellungssäle wurde mit dezenten, innenarchitektonischen Mitteln auf das jeweilige Sammlungsgut abgestimmt. Bei der Raumgestaltung kamen als Materialien vor allem Holz, Stein und Metall zum Tragen. Die Ausstellungsräume waren schlicht weiß getüncht. Große Objekte wurden frei und isoliert aufgestellt. Sockel und Stellwände wurden knapp und sachlich gestaltet. Das Gleiche galt für die Vitrinen, die kleinere Objekte in Werkgruppen aufnahmen. ${ }^{87}$

85 Kemp, Wolfgang (Hrsg.): Brian O’Doherty: In der weißen Zelle - Inside the White Cube. Berlin 1996, S. 10.

86 Grimm, Ulrike: Das Badische Landesmuseum in Karlsruhe. Zur Geschichte seiner Sammlungen. Karlsruhe 1993.

87 Dresch, Jutta: Das Badische Landesmuseum im wieder aufgebauten Karlsruher Schloss. In: Landesstelle für Museumsbetreuung Baden-Württem- 
„Als oberstes Gebot herrscht Zurückhaltung in der Farbe. Die Vitrinen sind ausgelegt mit einem japanischen Baststoff in Weißgrau, Grüngrau, Maisgelb; davor kommt die feine Plastizität der griechischen Töpferware bestens zur Geltung. [...] Bei der Ausstellung von mittelalterlicher Kunst in einem Museum geht es, nach Schnellbachs Konzeption, weder darum, dekorative Ensembles zu arrangieren [...], noch um die Erstellung einer Pseudobasilika mit falscher Sakralität." ${ }^{88}$

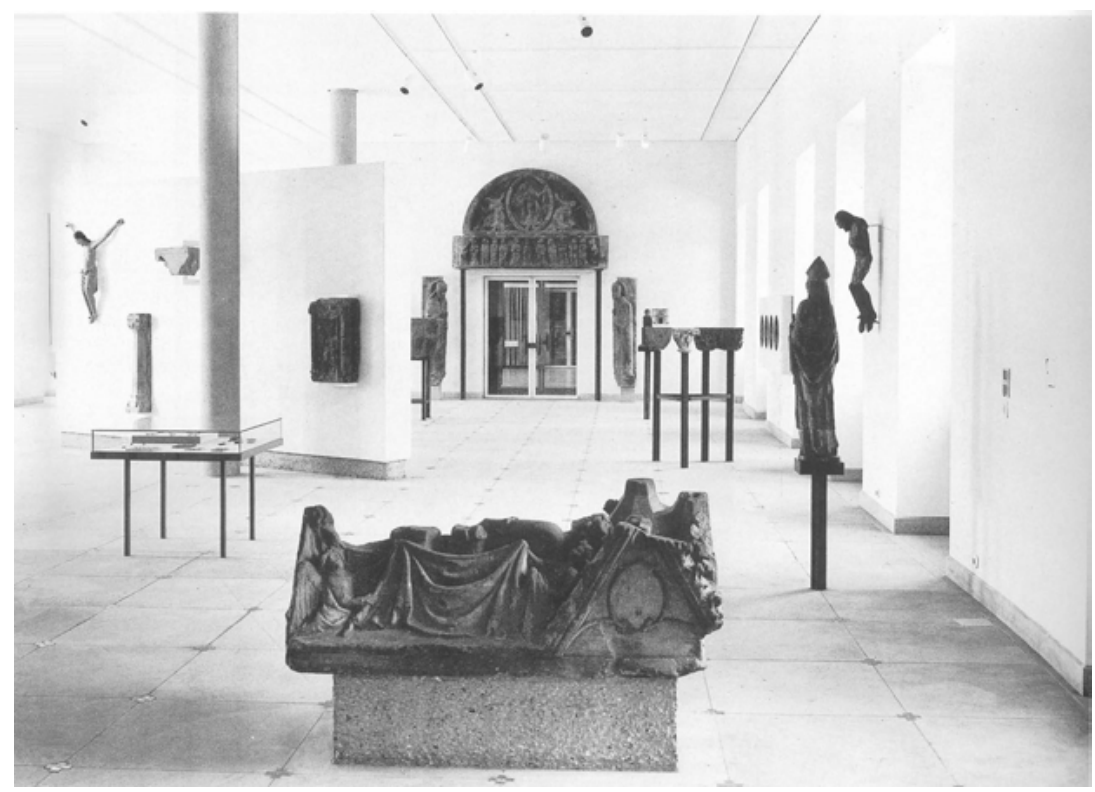

Abbildung 25: Mittelaltersaal im Erdgeschoss im Badischen

Landesmuseum in Karlsruhe bei der Teileröffnung im Jahr 1959.

Bei der Aufstellung der mittelalterlichen Skulpturen im Erdgeschoss kamen statt Sockel schmale Stützen aus profiliertem Stahl zum Einsatz, die in speziellen Halterungen im Steinfußboden eingelassen wurden. In den Sälen des Museums gab es keine Raumbeleuchtung, sondern nur an Deckenschienen befestigte Punktstrahler als Objektbeleuchtung sowie Vitrinenbeleuchtung. Ansonsten nutzte man das durch die beidseitigen Fenster einfallende Tageslicht. In dem zur Teileröffnung publizierten

berg (Hrsg.): Neuordnungen: Südwestdeutsche Museen in der Nachkriegszeit. Tübingen 2002, S. 197.

88 Hagelstange-Binder zitiert in Dresch 2002, S. 197. 
Katalog der Meisterwerke des Badischen Landesmuseums erläuterte Schnellbach ${ }^{89}$ seine Konzeption:

„Hier sprach die Erkenntnis mit, dass es sich bei Museumsobjekten um Einzelwesen handelt, die ihre ursprüngliche sachliche wie räumliche Bindung verloren haben. [...] Auch wenn man für diese Kunstwerke eigene Paläste erbauen würde, müssten sie in ihrer Vereinzelung verharren. Dieser Situation hat eine moderne museale Aufstellung Rechnung zu tragen. “90

Mit mittelalterlicher Kunst wird oft auch Schatzkunst assoziiert. Als Topos entwickelte sich die Schatzkammer zu einem speziellen Ausstellungstypus (Mai 1986, S. 72). Auch bei dieser Präsentation stehen die Objekte im Zentrum, sie werden jedoch zusätzlich durch eine weihevolle Atmosphäre in ihrer auratischen Wirkung erhöht.

Aus der großen Anzahl möglicher Beispiele beziehe ich mich auf die Ausstellung „Ornamenta Ecclesiae“91 unter der Leitung des damaligen Direktors des Schnütgen - Museums Anton Legner. ${ }^{92}$ Die Ausstellung spiegelte die Überzeugung, dass sich die Objekte selbst vermitteln. Das Wirken der Aura der Objekte stand im Vordergrund und bedingte gleichzeitig eine Ablehnung von kontextualisierender Information. Legners Anliegen bestand darin, die Aura des Kunstwerks im Zusammenspiel von Raum und Licht in Inszenierung und Didaktik für den Menschen von heute schaubar und erlebbar zu machen (Welsch 1985, S. 9). Mittelalterliche Kunst erschließt sich nach Legners Auffassung im Wesentlichen über das Auge, im Betrachten und Anschauen. Aus dieser Vorstellung gelangt Legner zu der Überzeugung, dass die Aufgabe des Museums darin besteht, jedes einzelne Objekt durch Architektur und Licht in seinen geistigen Zusammenhang zu setzen und es damit zur Wirkung zu bringen (ebd., S. 10). Neben der Beachtung von konservatorischen Bedingungen sollte ein den Kunstwerken angemessenes ästheti-

89 Rudolf Schnellbach war von 1952-1967 Direktor des Badischen Landesmuseums. Vgl. Grimm 1993, S. 181-193.

90 Schnellbach zitiert in Dresch 2002, S. 197.

91 Kölner Kunsthalle vom 07.03.-09.14.85. Legner, Anton (Hrsg. ): Ornamenta Ecclesiae. Kunst und Künstler der Romanik. Köln 1985.

$92 \mathrm{Zu}$ dieser Ausstellung sowie zwei weiteren Ausstellungen unter der Leitung von Anton Legner existiert eine ausführliche museumspädagogische Analyse. Welsch, Judith: Die Ausstellung „Ornamenta Ecclesiae“ zum Jahr der romanischen Kirchen in Köln aus museumspädagogischer Sicht. (unveröffentl. Skript) Schriftliche Hausarbeit im Rahmen der Ersten Staatsprüfung für das Lehramt für die Sekundarstufe I. Bonn 1985. 
sches Niveau geschaffen werden, welches auf die Harmonie sowohl im Kleinen und als auch im Großen Rücksicht nimmt.

Gemäß dieser Überzeugung ergab sich für die Ausstellung „Ornamenta Ecclesiae" das Bild einer Schatzkammer, in der Gold, Silber und Steine zum Funkeln gebracht wurden. Skulpturen traten durch gezielte Beleuchtung geheimnisvoll aus dem Dunkel hervor und die Ornamente und Buchstaben der Handschriften konnten stilvoll wie bei Kerzenlicht entziffert werden.

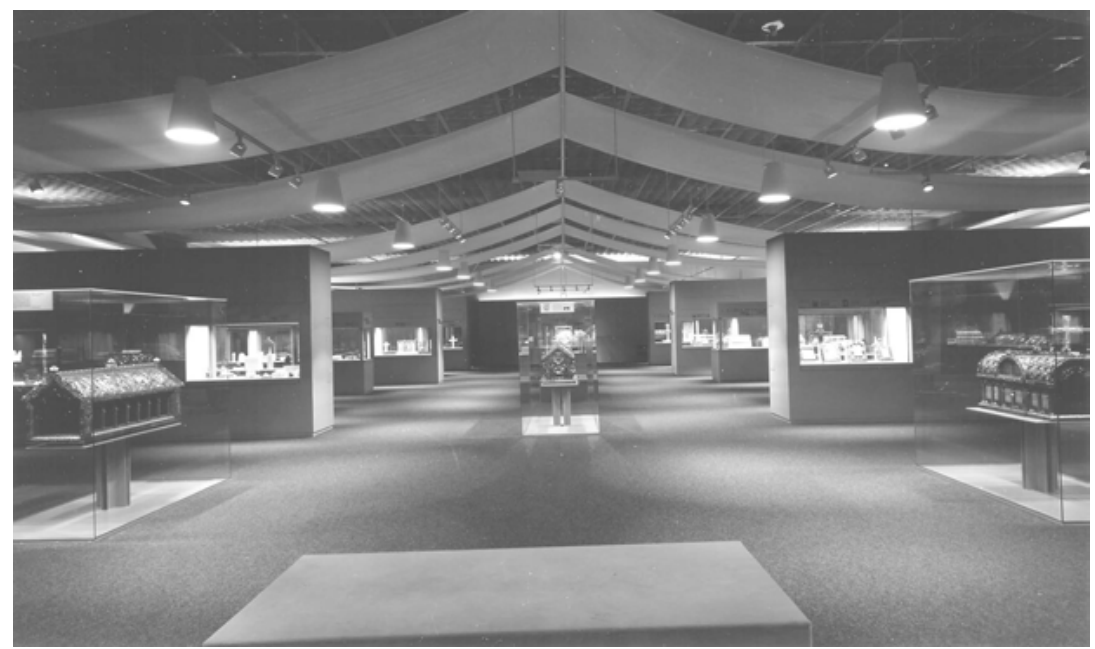

Abbildung 26: Blick in die Ausstellung „Ornamenta Ecclesiae“ in der Kunsthalle Köln im Jahr 1985.

Am Beispiel der Präsentation von Reliquienschreinen soll der Zusammenhang zwischen den Exponaten und ihrer Anforderung an Konzept und Präsentation aufgezeigt werden. Wie bereits der Titel der Ausstellung „Ornamenta Ecclesiae“ versprach, handelte es sich bei dem Ausstellungsgut ausnahmslos um kostbare Werke christlicher Kunst, liturgische Geräte und sonstige Ausstattungsgegenstände der Kirchen wie Reliquienbehälter oder Schreine, die einst ihre Funktion im umfassenden Bereich christlicher Liturgie erfüllten. Diese ursprüngliche Bedeutung im Dienst des Glaubens und der Kirche ging im Laufe der Jahrhunderte zum Teil verloren oder wurde durch neue Sinnbezüge ersetzt. Das veränderte Weltbild der Neuzeit wies den ehemaligen Heiltumträgern einen neuen Stellenwert zu: Heute erfüllen Kelche, Monstranzen und Reli- 
quienschreine zum einen ihre Funktion als Kunstwerke innerhalb musealer Präsentation als Zeugen der Vergangenheit und sind als solche Anlass wissenschaftlicher Reflexion. Zum anderen sind sie zum Teil nach wie vor Gegenstand anhaltender Verehrung und Frömmigkeit.

„Wert und Anspruch eines mittelalterlichen Ausstellungsexponats von der charakterisierten Art als Kunstgegenstand und als heute z. T. noch verehrter Kultgegenstand verlangen im Rahmen einer musealen Präsentation vom $\mathrm{Mu}-$ seumsbesucher ein Höchstmaß an Kenntnis und Einfühlungsvermögen, um durch diese Voraussetzungen zu einem differenzierten Verständnis der Werke zu gelangen zu können.“ (ebd., S. 65)

Wenn sich das Erlebnis nicht auf die ästhetische Bewunderung des Objekts beschränken soll, fordert dies einen entsprechend äußeren Rahmen, der diesen Prozess des Museumsbesuchers unterstützt. Im Fall der Ausstellung „Ornamenta Ecclesiae“ waren es die Kostbarkeiten der Kirche und unter ihnen vor allem die kunstvoll verzierten Behälter der Reliquien - deren Anblick im Rahmen musealer Präsentation vergessen ließ, „daß man Schreine mit Wein übergoß, Kreuze in Balsam tauchte und aus Heiligenschädeln trank." ${ }^{{ }^{93}}$ Die Aufbietung aller nur möglicher Sicherheitsvorkehrungen wie klima- und alarmgesicherte Vitrinen und kontrollierte Beleuchtung sowie die den ästhetischen Ansprüchen genügende Anordnung und Beschriftung verstärkte die Auratisierung der Exponate.

Von diesem einstigen Umgang mit den Reliquien - ob es sich um die sterblichen Überreste eines Heiligen oder um Gegenstände dieser verehrungswürdigen Person handelte - versprach sich der mittelalterliche Mensch unmittelbare Nähe und Teilhabe an dem, was er im großen Heiligen verkörpert sah, nämlich die Gnade Gottes und das Gute schlechthin. Von dieser ihrer ehemaligen Funktion und Bedeutung erzählen die erhaltenen Stücke selbst wenig. Ihre äußere Gestalt lässt lediglich Schlüsse des Kunsthistorikers bezüglich Datierung, Stil oder Ikonographie zu. Welsch bemerkt hierzu, dass der grundlegende Ansatz des Legner'schen Ausstellungskonzepts, die Exponate als Zeugen des Mittelalters selbst sprechen zu lassen, in der Anwendung auf die Exponate der Gattung Reliquiare wenig vielversprechend ist. Da dieses Ritual in der Gegenwart nicht mehr gepflegt wird, ist davon auszugehen, dass der Kenntnisstand über diese Art des praktizierten Glaubens sowohl bei den praktizierende Christen wie auch Nichtgläubigen weitgehend gering ist.

93 Kroos, Renate: Vom Umgang mit Reliquien. In: Legner 1985, S. 25. 
Allein aufgrund dieser Tatsache erweist sich der objektorientierte Ansatz Legners als problematisch (Welsch 1985, S. 70).

Die Inszenierung der Exponate auf dem Hintergrund zusätzlich ästhetisierenden Designs und perfekter Technik verwandelte den sachlichen Ausstellungsraum in eine glänzende Schatzkammer und ließ die meist aus religiösem Umfeld stammenden Exponate als unantastbare, kostbare und kommentarlos strahlende Kunstwerke erscheinen, deren autonomer Charakter dadurch betont wurde, dass sie sich unbeeinflusst von didaktischer Aufbereitung dem Betrachter unmittelbar präsentierten.

„Das, was diese Art von Erlebnisästhetik erreicht, ist, daß der Museumsbesucher sich am Anblick der äußeren, von kostbaren Materialien wie Edelmetallen und -steinen geprägten Gestalt des Kunstgegenstandes zwar erfreuen, sein Kunsterlebnis aber nur oberflächlich bleiben kann, weil er mangels Aufklärung über dessen Funktion und Bedeutung nicht zum einem tieferen Verständnis des Werkes gelangt.“ (Welsch 1985, S. 66)

Ebenso wie die historisierenden Formen unterliegt auch diese Form der Präsentation vielfältiger Kritik vor allem von Seiten der Museumspädagogik. Im Gegensatz zu der malerischen Präsentationsform, die das Erlebnis des Besuchers als wichtiges Kriterium erachtet, orientiert sich diese Präsentation an den Interessen der Wissenschaft und wendet sich primär an ein interessiertes Fachpublikum. Ein wichtiges Ziel von kunsthistorischen Sonderausstellungen besteht darin, wissenschaftlich neue Kenntnisse zu erarbeiten und neue Zusammenhänge vergleichend und verifizierend optisch darzulegen. Überspitzt formuliert dies Mai folgendermaßen: „Im besten Fall erreicht sie Wissenschaft und Publikum zugleich, im schlechtesten verabsolutiert sie sich zum puren Denk-mal der Macher unter Ausschluß der Öffentlichkeit.“ (Mai 1986, S. 79)

Diese Art der Präsentation veranlasste die Kritiker immer wieder zu dem Vorwurf, dass sie als ein Relikt der Erlebnisästhetik des 19. Jahrhunderts über die Erzeugung einer konsumierenden Genusshaltung hinaus dem Besucher nichts zu bieten habe und als solche $\mathrm{zu}$ überwinden sei. Das Objektinteresse allein führt bei Besuchern zu keinem vertiefenden Verständnis von Exponaten. Zur Würdigung der Kunstwerke muss Wissen hinzukommen - nämlich Vertrautheit mit den Kategorien und ihren Implikationen. Diese Erfahrung aber ist über die reine Anschauung 
von Objekten nicht zu erhalten, sondern erst über die Kenntnisse entsprechender Wissensbereiche selbst zu erreichen. ${ }^{94}$

Eine Verlebendigung des Mittelalters, die vorwiegend im Katalog stattfindet, genügt nach Meinung der Kritiker nicht. Dazu bedarf es zusätzlicher, vermittelnder und auf das moderne Museumspublikum und seine Bedürfnisse hin abgestimmter Maßnahmen, die sich nicht scheuen, das Exponat in ein kontextualisierendes Umfeld zu platzieren. Neben Fotos oder erklärenden Raumtexten führt dies zu innenarchitektonisch, dramaturgisch aufbereiteten Inszenierungen.

\section{Theatralik - die dramaturgische Inszenierung}

Mit der aufkommenden Kritik an den wissenschaftsorientierten Präsentationen in den siebziger Jahren begann erneut eine Hinwendung zu besucherorientierten Konzepten. Einerseits entstanden rekonstruktive Inszenierungen im Rückgriff auf die Tradition der malerischen Präsentation. Darüber hinaus entwickelten sich Präsentationskonzepte im Sinne abstrahierender Raumbilder, die in eine geschlossene Dramaturgie eingebunden sind..$^{95}$ Insbesondere die Bruchstückhaftigkeit der Überlieferung sowie die Andersartigkeit des Mittelalters motivierte zu Inszenierungen dieser Form, die teilweise zu höchst umstrittenen Ausstellungsprojekten führten. Schlaglichtartig sollen in diesem Zusammenhang zwei Ausstellungen vorgestellt werden.

Eine museologisch intensiv reflektierte Ausstellung wurde im Jahr 1990 im Ruhrlandmuseum mit dem Titel „Vergessene Zeiten. Mittelalter im Ruhrgebiet“ verwirklicht. ${ }^{96}$ Sie war ,,als virtuelles Problematisieren dessen zu lesen, was Geschichte und historische Ausstellungen leisten können - und was nicht" (Borsdorf/Grütter 1992, S. 192). Als Leitlinie galt eine strikte Besinnung auf die spezifische Leistungsfähigkeit des Mediums Museum, die bei der Darstellung von Geschichte sich nicht auf Texte beschränkt, sondern die ästhetische Dimension der Präsentation

94 Treinen, Heiner: Was sucht der Besucher im Museum? In: Fliedl, Gottfried (Hrsg.): Museum als soziales Gedächtnis? Klagenfurt 1988, S. 30.

95 Eine Darstellung abstrahierender Raumbilder siehe Kapitel 1.1: Abstrahierende Raumbilder.

96 Die Ausstellung „Vergessene Zeiten. Mittelalter im Ruhrgebiet“ vom 26.09.90-03.02.91 wurde als Gemeinschaftsprojekt der Ruhr-Universität Bochum und des Ruhrlandmuseums Essen konzipiert. Seibt, Ferdinand (Hrsg.): Vergessene Zeiten. Mittelalter im Ruhrgebiet. Essen 1990. 
wahrnimmt. Dementsprechend waren die Texte sehr knapp oder fehlten zum Teil ganz. Dies sollte auch die nötige Offenheit der Interpretation gewährleisten (ebd., S. 178). Die Ausstellung sollte die „Konstrukthaftigkeit von Geschichtsbildern" mit gewollten Brüchen bloßstellen und damit zu Diskussionen einladen. Die Auswahl der Aspekte, die nachzuvollziehen die Besucher eingeladen, aber nicht gezwungen waren, erfolgte nicht beliebig, sondern orientierte sich am Plausibilitätskriterium der Wissenschaft (ebd., S. 179). Die Zusammenhänge der Bedeutung einzelner Objekte und Ensembles erschlossen sich dem Betrachter nicht auf den ersten Blick. Individuelle Interpretationen waren erwünscht.

„Dies nicht bis in Lehr- und Lernziele des Stoffs hinein kontrollieren zu wollen, sondern dem Bedeutungsüberschuß der Objekte zu ihrem ästhetischen Recht zu verhelfen, der Multiperspektivität als demokratisch-pluralistischer Auffassung von Geschichte dinglich Ausdruck zu verschaffen - darin liegen Angebot und Anspruch des Museums.“ (ebd., S. 179)

Für die Ausstellung war die ,räsonierte Fragmentarik authentischer Objekte ${ }^{697}$ puristisches Prinzip, indem die Lücken originaler Überlieferung nicht künstlich überbrückt wurden. Dennoch sollten gestalterische Ideen, Katalog und Ausstellungstexte sowie zusätzliche Bilder die Objekte in Kontexte einweben. In der Gestaltung bediente sich die Ausstellung einer ebensolchen nüchternen und möglichst klaren Architektursprache. Als Material für die Ausstattung dienten moderne Materialien wie Neon, Kunstglas und vor allem Stahl. Die Ausstellungsarchitektur versuchte an keiner Stelle, ihre konstruktiven Elemente zu verbergen. Vielmehr unterstrichen frei liegende Kabel der Beleuchtungssysteme ebenso wie die Verarbeitungsspuren an Vitrinen oder Stellagen den Produktionscharakter und das Provisorium der zeitlich begrenzten Präsentation. Der artifizielle Charakter und somit in der Weiterführung das gedankliche Konstrukt der Erinnerung wurden damit betont.

Vermieden wurde, die Exponate aus dem sakralen Bereich so zu positionieren, wie sie heute als reine Kunstgegenstände behandelt werden. Die Präsentation von mittelalterlichen Reliquien in einem Stahlgehäuse, das nur durch wenige Öffnungen den Blick auf die Exponate freigab, sollte die Zeit und vor allem die Wahrnehmungsdistanz, die einen direkten Zugang zu ihrer ursprünglichen Bedeutung schwer macht, veranschaulichen. Zugleich deutete dies ihren Charakter weniger als kostbare

97 Borsdorf, Ulrich: „et in flumen rura vadunt“. Das Mittelalter im Ruhrgebiet - Vergessene Zeiten? In: Seibt 1990, S. 16. 
Pretiosen, denn als Behältnisse verborgener und mythischer Geheimnisse und Heilsversprechen an. Auch die Positionierung von Heiligenfiguren außerhalb des vertrauten Blickfeldes auf hohen Stahlgerüsten, zu denen die Besucher aufschauen mussten, verhinderte eine gängige Betrachtungsweise. Zudem wurde ihr mittelalterlicher Nimbus als Kultobjekt und Kunstgegenstand durch das Material ihrer Stellagen gebrochen und gleichzeitig durch stilisierte Heiligenscheine, die sie in Form von Baulampen von oben beleuchteten, ironisiert.

Die Ausstellung verweigerte sich damit bewusst und vehement der Versuchung der bei einer Pretiosenschau gern gewählten sakralen Atmosphäre. Insbesondere aufgrund der Tatsache, dass ein beträchtlicher Teil der Exponate aus dem Sakralbereich stammte und in seiner Materialität und Bedeutung einen immensen Wert darstellte, verbot den Ausstellungsmachern geradezu ,die auratische Präsentation der Objekte und das Eintauchen in eine wie auch immer geartete mittelalterliche Imagination, die nur Scheinrealität sein kann“ (ebd., S. 182).

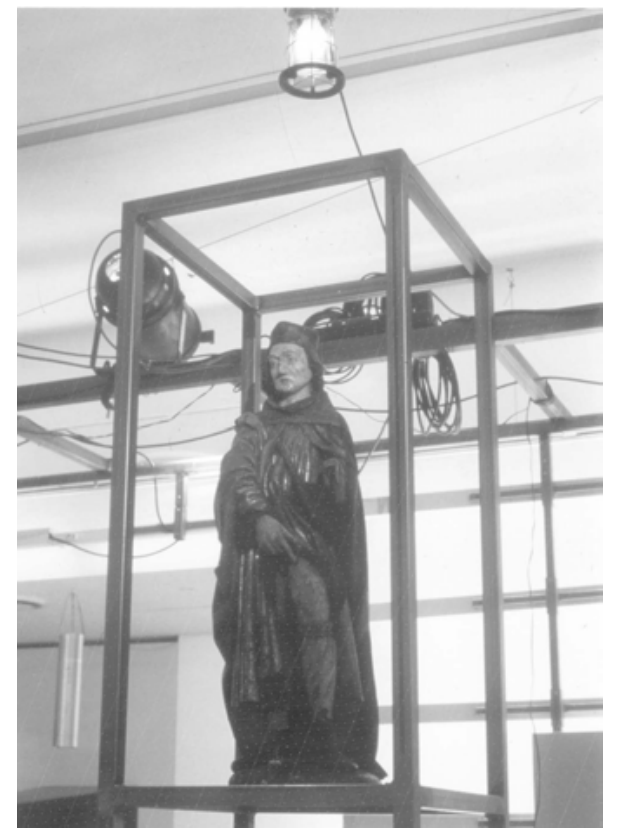

Abbildung 27: Bereich „Heiligenverehrung “ in der Ausstellung „Vergessene Zeiten. Mittelalter im Ruhrgebiet" im Ruhrlandmuseum in Essen im Jahr 1990.

Viele Besucher waren zunächst von der Ausstellungsarchitektur, die mittelalterliche Objekte auf hochmoderne, industrielle Materialien wie 
Neon und Stahl montierte, irritiert. Die zahlreichen Interpretationsangebote und die Tatsache, dass die vielfältigen Klammern und Strukturierungsprinzipien der Ausstellung nur im Gesamtkontext zu erfassen waren, stellten an die Besucher einen sehr hohen intellektuellen Anspruch. Die puristische Radikalität der Ausstellungsprinzipien, die historisch räsonierte Fragmentarik authentischer Objekte sowie die starke Rolle der Gestaltung und Architektur provozierte eine Vielzahl von Reaktionen. Bei einer Diskussion unter Fachleuten in den Ausstellungsräumen zeigte sich die Grundproblematik historischer Ausstellungen. Vor allem Kunsthistoriker forderten eine stärkere Separierung und Auratisierung der einzelnen, künstlerisch wertvollen Objekte, wie es in der Kunstausstellung üblich ist. Dagegen klagten die Historiker die verstärkte Unterordnung der Exponate in einen Erzählzusammenhang ein, wie es dem Charakter von Geschichte als Sinnbildung über Vergangenheit in Form des Geschichtsbuches entspricht (ebd., S. 191). Ein wesentlicher Kritikpunkt bestand auch darin, dass die Gestaltung zu markant in den Vordergrund trat, ein Eigenleben entwickelte und den Exponaten als zusätzliche Dimension gleichsam übergestülpt war und damit historische Erfahrungen verhindert wurden.

„Exponatenversteckspiel, nur wenig Gegenstände in Augenhöhe präsentiert. Sie bringe keinen Erkenntnisgewinn, sondern nur optische Verweigerung. Dies entspräche einem postmodernen Standpunkt der Verfügbarkeit von allem, der seine traurige Bestätigung in einer zur Dekorationsorgie verkommenen Geschichtsvermittlung fände. [...] keine Geschichtsgegenstände werden zur Anschauung gebracht, vielmehr feiert sich deren Darstellung selbst." “98

Darüber hinaus lautete eine häufig geäußerte Kritik, dass zur Erweiterung des Blickes die Aussteller dem Besucher einiges zumuteten (ebd., S. 190). Dies weist darauf hin, dass eine wesentliche Voraussetzung für das Gelingen derartiger experimenteller Präsentationen auch darin besteht, dass die Besucher innerlich bereit sind, sich auf diese atypische Gestaltungsidee einzulassen und sich damit auseinanderzusetzen. Ein weiterer Aspekt dieser anspruchsvollen Gestaltungskonzepte liegt darin, dass diese nur dann funktionieren können, wenn der Betrachter gleichsam als Schlüssel zur Interpretation die Grundprinzipien der Konzeption kennt. Der fatale Haken dieser phantasievollen Schau war, dass viele

98 Alberg, Werner im Handelsblatt vom 19./20.10.90 zitiert in Borsdorf/ Grütter 1992, S. 190. 
Details allein kaum zu entschlüsseln waren, und damit geriet der große Entwurf „ohne Führer zum Ratespiel“ (ebd.).

Die Schwierigkeit der Decodierung abstrahierender Formen von Inszenierungen durch den Besucher weist auf ein grundsätzliches Problem hin. Lankes bezeichnet dieses Phänomen als ,selbstreferentielles System im Team “99. Das Ausstellungsteam beschäftigt sich zum Teil mehrere Jahre mit einem Thema. Die Vertrautheit mit dem Stoff verhindert die Erkenntnis, dass ein Großteil der nicht mit dem Thema versierten Besucher die Bezüge nicht herstellen kann. Zusammenhänge, die für Mitarbeiter evident sind, können Außenstehende ohne Unterstützung nicht entschlüsseln.

Zu den ebenfalls strittigen Projekten zählte die Ausstellung „Hölle und Himmel - Das Mittelalter im Norden“" ${ }^{100}$, die unter der Regie von Peter Greenaway ${ }^{101}$ verwirklicht wurde. Es ging ihm dabei nicht nur um eine Präsentation von Gegenständen, sondern um die Schaffung einer Atmosphäre, die das mittelalterliche Verständnis von Himmel und Hölle sowie die mittelalterlichen Erfahrungen der Niederländer mit der Kirche und der Bedrohung durch das Meer veranschaulichen sollte. ${ }^{102}$ Für die unspektakulären Exponate wie Bücher, Skulpturen, Münzen oder verblichene Mönchsknochen entwickelte Greenaway eine drastische Form der Präsentation unter Zuhilfenahme aller moderner Kommunikationstechniken, die eine eindrucksvolle, zum Teil unheimliche Atmosphäre schufen und den Besucher kaum unberührt lassen konnten.

Die Schau wurde um die Chronik des Abtes Emo herum angelegt, der zu Beginn des 13. Jahrhunderts im Kloster von Wittewierum lebte. Sie bildete den Leitfaden, anhand dessen der Regisseur durch das mittelal-

99 Interview mit Herrn Dr. Christian Lankes, wissenschaftlicher Mitarbeiter beim Haus der Bayerischen Geschichte, am 6. Juli 2002.

100 Groninger Museum vom 14.04-02.09.01. Knol, Egge/Hermans, Jos M. M./Driebergen, Matthijs: Hel en Hemel. De Middeleeuwen in het Noorden. Groningen 2001.

101 Peter Greenaway wurde als Regisseur von Filmen wie „The Cook, the Thief, his Wife and her Lover“, „Prospero's Books“ und „The Pillow Book" bekannt. Gleichzeitig gestaltete er bereits für zahlreiche Museen Ausstellungen. „Hell and Heaven“ war Greenaways zweite Kuratoriumsausstellung in den Niederlanden, nach „The Physical Self“ in Rotterdam 10 Jahre zuvor. Eine ausführlichen Überblick zu seinem Schaffen siehe unter: http://www.peter-greenaway.de (letzter Zugriff: 31.01.05).

102 Greenaway zitiert in Kolsteren 2001, S. 3. 
terliche Verständnis von Himmel und Hölle leitete. Der Weg des Besuchers führte durch einen mit wechselnden, dämmernden Spotlichtern beleuchteten Eingangsraum, der als Skriptorium konzipiert mit zahlreichen mittelalterlichen Schriftstücken als Zeugnissen der Vergangenheit bestückt war. In dem dahinter liegenden Raum zeigte eine großformatige Videoprojektion die kalligraphische Erstellung einer Abschrift, überblendet von mehreren Ebenen mit Meeresbildern, Feuersbrünsten und verschwindenden Schriften. Davor befand sich in einer Vitrine die Chronik von Wittewierum von den Äbten Emo und Menco des Klosters Bloemhof. Rechts konnte der Besucher durch ein breites Portal in die drei Höllenräume oder links durch eine kleine, enge Tür in die drei Himmelsräume gehen. Die einzelnen Räume gliederten sich in drei Achsen. In dem mittleren Bereich befanden sich die drei verbindenden Räume der Schriftzeugnisse und Schrifterstellung, der Gebeinkatalog sowie Urkunden und Münzen. Das Licht sowie die Akustik in diesen Räumen veränderten sich ständig und erzeugten so unterschiedliche Stimmungen.

„Greenaway führt den Weg des Besuchers nach rechts, durch das breite Tor der Höllenpforte, während links das enge Tor zum Himmel fast übersehen werden könnte. Er leitet ihn vorbei an den Schädeln der Höllenhunde, direkt auf einen gedeckten Tisch zu, auf dem sich zwei Laibe Brot, Wurst, Kohl, Lauch, Radieschen, Schalen mit Nüssen und Erbsen befinden. Stilleben oder Henkersmahlzeit? Oder schon eine der sieben Todsünden, die Völlerei, die in die Hölle führen? Jedenfalls flackert das Licht, reflektiert in zerbrochenen Spiegeln, Wasser plätschert, und vom Nebenraum lärmt es. “"103

Im größten, zentralen Raum befand sich der Gebeinraum „Raum der Toten“. Die Knochen - von herabhängenden, schwingenden Lampen unterschiedlich beleuchtet - waren sortiert und auf Tischen entlang den vier Seitenwänden aufgereiht (siehe Abb. 29). In der Mitte des Raumes waren weitere, in durchsichtigen Zellophantüten aufgehängte Knochen. Alle unterschiedlich nummerierten Tüten zu je neun in zwei Reihen und drei Ebenen wurden von oben oder unten von Reflexlichtern der Bruchspiegel in einer Wasserwanne beleuchtet (siehe Abb. 28). Dazu hörte der Besucher das Geräusch stetig tropfenden Wassers, ein plötzlich lautes Wasserplatschen und gelegentliches Glockengeläute. Schädel und Ge-

103 Reiter, Markus: Hunderttausend heulende Höllenhunde - Weh dem, der Symbole hört: Peter Greenaway inszeniert in Groningen eine laute und deutliche Mittelalterausstellung. In: Frankfurter Allgemeine Zeitung vom 18.05.01. 
beine stammten von 400 Mönchen aus dem niederländischen Kloster Aduard in der Nähe Groningens. Greenaway erweckte diese Knochen noch einmal zum Leben und wies ihnen eine Hauptrolle in der Inszenierung zu. Sie fungierten in der Ausstellung als Mittler zwischen Himmel und Hölle. In einem Gespräch äußerte sich Greenaway selbst über die Intention dieses Gebeinraumes: Er will die Besucher auffordern, über das Tabuthema des Umgangs mit dem Tod in der gegenwärtigen Gesellschaft zu reflektieren: „Das Tabu des Todes ist immer noch stark vorhanden. Mit Medikamenten können wir den Tod eine Weile aufschieben, verhandeln lässt sich mit dem Tod aber nicht. Das merkwürdige Tabu stellen wir also absichtlich zur Diskussion." ${ }^{104}$

Darüber hinaus verfolgte die Ausstellung einen wissenschaftlichen Anspruch, der neben Greenaways Interpretation eine eigene Thematisierung verfolgte. Eine Reihe äußerst hochwertiger Handschriften konnten für die Ausstellung gewonnen werden, die in der Regel aufgrund konservatorischer Bedenken sonst nicht in der Öffentlichkeit gezeigt werden. Die Archivalien wurden unter verschiedenen Aspekten gruppiert. So ging es zum Beispiel um das Thema Verschriftlichung, ein weiterer Teil umfasste eine Anzahl von Musikhandschriften und eine dritte wichtige Gruppe beinhaltete das Thema Recht.

Das Ausstellen von alten Schriften bringt generell spezifische Probleme mit sich. Neben höchsten konservatorischen Ansprüchen zählen Archivalien zu den wenig illustrativen Objekten. Sie unterscheiden sich für den Laien zwar durch die Vielfalt der Einbände, von Papier und Schriften, der Inhalt bleibt jedoch oft unverständlich. In dieser Hinsicht fordert dies von den Ausstellungsmachern einen kreativen Ansatz. Nüchtern pragmatisch kommentiert dies Hermans ${ }^{105}$ : „So ein Greenaway macht daraus eine schöne Show, und das ist ein Pluspunkt.“"106

Diese weitere wissenschaftliche Dimension der Ausstellung trat in den Hintergrund. Wie sehr Greenaways expressive, dreidimensionale Bildsprache hervortrat, lässt sich zum Beispiel an den Ausstellungsrezensionen ablesen, die primär Greenaways theatralische Inszenierung

104 Greenaway zitiert in Kolsteren 2001, S. 2.

105 Jos M.M. Hermans ist Professor für westliche Handschriftenkunde und Buchwissenschaften der Abteilung Mediävistik an der Rijksuniversiteit Groningen und war einer der Initiatoren der Ausstellung.

106 Hermans zitiert in Jonge, Ad de: Ein Schatz an interessanten Daten. Die Suche von Prof. Jos M.M. Hermans nach mittelalterlichen Handschriften. In: Deutsche Ausgabe der Groninger Museumskrant. (2001) Heft 1. S. 6. 
kommentierten. Diese Ausstellung provozierte zu einer Vielzahl von Fragen: Ist es ethisch und moralisch vertretbar, Gebeine toter Mönche wie in einem Gruselfilm zu arrangieren? Kann mit Kunstgriffen der Moderne der Alltag des Mittelalters wiedergegeben werden? Kann mittels Filmtechnik, Computeranimation, Lichteffekten und raffinierter Geräuschkulisse mittelalterliches Leben nahe gebracht werden? Macht die mit Sinnenreizen angefüllte Präsentation es dem Besucher beim Bemühen um die Auseinandersetzung mit Vergangenheit zu leicht? ${ }^{107}$ So spaltete die Ausstellung die Zuschauer dementsprechend in zwei Lager von Anhängern und Verächtern. Und in der Tat lässt sich dieses Projekt in Abhängigkeit des Betrachterstandpunkts verurteilen oder loben. Ohne die aufgeworfenen Fragen diskutieren zu können, lässt sich feststellen, dass die Imaginationen und Stilisierungen, wie sie mit der Ausstellung „Hölle und Himmel“ entworfen wurden, ebenfalls kein authentisches Mittelalter entwerfen. Es entstand ein authentischer Greenaway in einem theatralisch kreierten Ambiente.

107 Tenzer, Eva: Der tote Mönch in der Tüte. Die Klischees werden per Computer faszinierend bedient - Peter Greenaway inszeniert im Groninger Museum „Hölle und Himmel“. In: Süddeutsche Zeitung vom 26./27.05.01. 


\section{KunStPÄDAgOgische ANALYSE DER Ausstellung „KAiser HeinRiCh II. 1002-1024“6}

Mit diesem Kapitel erfolgt eine weitere Fokussierung. Sollte durch das vorherige Kapitel eine vergleichende Darstellung unterschiedlicher Konzeptionen das weite Feld der Möglichkeiten schlaglichtartig beleuchten, steht nun eine Ausstellung als Reflexionsmedium im Zentrum der Betrachtung. Anhand dieser Präsentation sollen einzelne Aspekte vertiefend betrachtet werden.

Die Wahl fiel auf die vom Haus der Bayerischen Geschichte in Augsburg konzipierte Landesausstellung „Kaiser Heinrich II. 10021024",' die vom 9. Juli bis zum 20. Oktober in Bamberg präsentiert wurde. Diese Entscheidung basiert auf mehreren Erwägungen. Zum einen kann das Haus der Bayerischen Geschichte mittlerweile auf eine langjährige Tradition der Konzeption von Ausstellungen zurückblicken. ${ }^{2}$ Die daraus gewonnenen Erfahrungen fließen wiederum in neue Präsentationskonzepte ein. Begleitend hierzu werden die Ausstellungen im Rahmen einer Langzeitstudie in Form von Besucherbefragungen ausgewertet. ${ }^{3}$ Die Kommunikation der Ausstellungsinhalte nimmt dabei einen sehr hohen Stellenwert ein. Das Haus der Bayerischen Geschichte verfolgt einen konsequenten Weg der Besucherorientierung, mit dem Ziel, über die fachwissenschaftlichen Besucher hinaus vor allem ein breites

1 Kirmeier, Josef/Schneidmüller, Bernd/Weinfurter, Stefan/Brockhoff, Evamaria (Hrsg.): Kaiser Heinrich II. 1002-1024. Augsburg 2002.

2 Haus der Bayerischen Geschichte (Hrsg.): 20 Jahre Haus der Bayerischen Geschichte - 20 Jahre Geschichtsarbeit in Bayern. Augsburg, 2003. Siehe auch: http://www.hdbg.de (letzter Zugriff: 06.12.04).

3 Bereits 1985 wurden erstmals Besucher von Ausstellungen des Hauses der Bayerischen Geschichte nach soziologischen Kriterien befragt. Seitdem erfolgte eine kontinuierliche wissenschaftliche Begleitung der Besucherströme in den Ausstellungen. Die Untersuchungen wurden zunächst von Prof. Dr. Siegfried Lamnek (München/Eichstätt) und ab 1993 von Dipl. Soz. Werner Fröhlich (Sozialwissenschaftliches Institut München) durchgeführt. 
Publikum anzusprechen. Die Bedürfnisse der potentiellen Besucher flieBen somit in die Ausstellungskonzeptionen ein.

Ein weiterer Grund für die Heinrichsausstellung lag in der besonderen Konzeption, die drei unterschiedliche Präsentationsstrategien mit archäologischer Rekonstruktion, Inszenierung sowie Schatzkammer vereinte. Damit war in Bamberg vor Ort im direkten Nebeneinander eine Vergleichbarkeit dieser Ansätze möglich. Im Besucherurteil führte diese Ausstellung zu äußerst kontroversen Meinungen von höchstem Lob bis zu vernichtender Kritik. ${ }^{4}$ Der inszenierte Bereich zur Lebenswelt Heinrichs II. in der Alten Hofhaltung provozierte unterschiedlichste Reaktionen und Stimmungen, auch häufig zu denselben Raumensembles. Diese Gegensätzlichkeit des Besucherurteils legt es nahe zu ergründen, wie sich diese Urteile bilden und in welchem Kontext diese zu betrachten und zu bewerten sind.

\subsection{Darstellung der Ausstellungsanalyse}

Erst allmählich beginnen sich mit fortschreitender museumstheoretischer Auseinandersetzung vereinzelt im deutschsprachigen Raum Analysemethoden und Begriffsinstrumentarien für Museumspräsentationen zu entwickeln. ${ }^{5}$ Gegenwärtig spiegelt sich dieser Mangel an Beschreibungsmodellen sowohl in der alltäglichen Museumspraxis als auch in den Ausstellungskritiken der Feuilletons wider. Eine Ursache hierfür liegt nach Ansicht von Scholze in der ausgeprägt fachwissenschaftlichen und nur eingeschränkt museologischen Ausrichtung der Museen und ihres Personals (Scholze 2004, S. 13). Im Hinblick auf Ausstellungsrezensionen stellt Waidacher zwar fest, dass viele Kritiker über ausgezeichnete Kenntnisse in den Fachbereichen, die sich mit den ausgestellten

4 Die Kommentare in den Besucherbüchern ließen diese gegensätzlichen Meinungen, die sich sowohl im Hinblick auf positive wie auch negative Äußerungen rein quantitativ weitgehend die Waage hielten, sehr deutlich zu Tage treten. Vgl. Besucherbücher zur Landesausstellung „Heinrich II.“ vom 10.07-13.09.02 in der Alten Hofhaltung sowie im Diözesanmuseum.

5 Ein Analysemodell basierend auf den Methoden der Semiotik entwickelte zum Beispiel Scholze im Rahmen ihrer Dissertation. Die zentralen Begriffe Deskription, Denotation, Konnotation und Metakommunikation verwendet sie, um den Prozess der Codierung des Mediums Ausstellung anhand vor vier Ausstellungsbeispielen nachvollziehbar zu machen. Siehe Kapitel 4, Anm. 1. 
Objekten selbst befassen, verfügen. Er ergänzt jedoch, dass die Rezension erfordere, die Ausstellung als Ganzes zu betrachten, die ihr zugrunde liegenden Gesetze zu berücksichtigen und analytisch darzustellen. Dieser Ansatz fehlt aber vielen Besprechungen musealer Präsentationen.

„Tatsächlich wird die Leserschaft zwar immer wieder über Picassos Blaue Periode, die formalen Gesetze Etruskischer Ornamentik oder die Reproduktionsgewohnheiten flügelloser Fliegen belehrt; aber kaum je erhält sie Informationen über das Ausstellungskonzept, seine Umsetzung, das Design, die Beleuchtung, die Texte - all dies, wie man erwarten sollte, gemessen an den Absichten und Zielen der Ausstellung und an den gegebenen Möglichkeiten.“6

Über inhaltliche sowie objektbezogene Belange hinaus bedeutet dies, den Blick zu weiten und auch gestalterische oder besucherorientierte Aspekte zu berücksichtigen. ${ }^{7}$ Jede Form der analytischen Betrachtung kann lediglich einzelne Teilaspekte beleuchten, ohne das Gesamtphänomen wiedergeben zu können. Andererseits sind für genaues Betrachten und kritisches Beschreiben von Ausstellungen Begriffsinstrumentarien notwendig, die die Ausstellungen unter einer spezifischen Fragestellung beleuchten.

\section{Das kunstpädagogische Analysekonzept}

Im Zentrum dieser Studie stehen pädagogische sowie gestalterische Fragestellungen von Ausstellungsinszenierungen unter der Perspektive kommunikativer sowie metakommunikativer Aspekte. Das Fundament dafür bilden die in den Kapiteln drei und vier erfolgten Überlegungen. Die Ausstellungsanalyse spannt einen Bogen und befasst sich unter der dargestellten, spezifischen Fragestellung mit drei elementaren Bezugsgrößen musealer Kommunikation, nämlich den Ausstellungsmachern als Sendern der Botschaft, der Botschaft selbst sowie den Besuchern als Empfängern der Botschaft.

6 Friedrich Waidacher: Ausstellungen besprechen. http://www.vl-museen. de/m-online/00/00-2.pdf (letzter Zugriff: 01.12.04).

7 Ein umfangreicher Fragenkatalog als Leitfaden für eine Ausstellungskritik unter besucherorientierter Perspektive wurde im Jahr 1990 während einer Tagung der American Association of Museum erstellt. Vgl. McLean 1993, S. 163-166. Diese Zusammenstellung von Fragen und Hinweisen wurde von Waidacher zur praktischen Anwendung für Ausstellungskritiker modifiziert und ergänzt. Siehe Kapitel 6, Anm. 6. 
Im ersten Teil der Analyse geht es darum, das Umfeld der Heinrichsausstellung zu beleuchten. Zunächst soll die ausführende Institution, das Haus der Bayerischen Geschichte, vorgestellt und Leitgedanken auch im Hinblick auf museumspädagogische Belange beschrieben werden. Diese Grundgedanken spiegeln sich im Entstehungsprozess der Ausstellung wider, der anhand wichtiger Etappen punktuell nachvollzogen wird. Ebenso werden die Gestalter, die wesentlich das Erscheinungsbild der Ausstellung mitbestimmen, charakterisiert. Nach einem Überblick über Inhalte und Ziele der Ausstellung soll das Gesamtkonzept der Gestaltung vorgestellt werden. Die Ausstellung verteilte sich auf mehrere Orte um den Bamberger Domplatz, deren spezifische Charakteristiken skizziert werden. Im Gegensatz zur Präsentation im Diözesanmuseum sowie in der Staatsbibliothek, in der eine traditionelle, zurückhaltende Gestaltung angestrebt war, bildeten die Räume der Alten Hofhaltung den Ort der Inszenierung der Lebenswelt des Herrschers Heinrich II. Aus diesem Grund befasst sich die Analyse schwerpunktmäßig mit diesem Teilbereich der Ausstellung.

Im zweiten Teil der Analyse dienen als Gliederungskriterium die vier Dimensionen kommunikativer Strategien mit Anschaulichkeit, Handlungsorientierung, Ganzheit und Differenzierung. Dabei stehen exemplarisch ausgewählte Inszenierungseinheiten in der Alten Hofhaltung im Zentrum der Betrachtung. Eine Beschreibung einzelner Arrangements, Ausstellungsräume oder -abschnitte, ergänzt mit Abbildungen, bilden dafür die Grundlage. Jedoch muss auch hier angemerkt werden, dass keine vollständige Darstellung im Sinne eines Nacherlebens geliefert werden kann. Die Entscheidung für bestimmte Fragmente der Ausstellung erfolgt zwar nach individuellen Gesichtspunkten, doch orientiert sich die Selektion an signifikanten Merkmalen, die jeweils Anknüpfungspunkte für eine Diskussion kommunikativer Strategien liefern. Ergänzend hierzu fließen die Ergebnisse der Besucherbefragungen ein.

Der dritte Teil der Analyse ist gleichartig aufgebaut. Unter der Perspektive metakommunikativer Aspekte soll anhand konkreter Raumbilder die politische und ökonomische Dimension der Ausstellung diskutiert werden. 


\section{Die Besucherbefragung}

Die Besucher nehmen eine besondere Stellung im Gefüge der Museumskommunikation ein, denn sie bilden das Ziel der Bemühungen. Wird eine Ausstellung nicht wahrgenommen, bleibt sie bedeutungs- und wirkungslos. Doch als Empfänger oder reine Projektionsfläche wird der Rezipient grundsätzlich missverstanden, da er aktiv an der Konstruktion von Bedeutungen beteiligt ist. Wohlfromm vergleicht in diesem Zusammenhang die Besucher mit ungleichmäßig lichtempfindlich beschichtetem Material, auf das der Text, der Film der Ausstellung projiziert wird. „Jeder Rezipient gestaltet die Oberfläche seines Trägermaterials selbst, indem er die Stellen bestimmt, auf denen sich die intentionale Aussagen des Museums oder der Ausstellung abzeichnen können." (Wohlfromm 2002, S. 36)

In diesem Sinne besteht das Anliegen der Ausstellungsanalyse darin, das Meinungsbild der Rezipienten zur Heinrichsausstellung schlaglichtartig zu beleuchten. Die Angaben hierzu stützen sich auf zwei Erhebungen. Zum einen beziehe ich mich auf Ergebnisse des Sozialwissenschaftlichen Instituts München, das mittels eines empirischen, quantitativen Ansatzes standardisierte Besucherbefragungen durchführt. Zum anderen basieren die Aussagen auf einer qualitativen Studie anhand von halb-standardisierten Interviews, die ich vor Ort mit Ausstellungsbesuchern durchführte.

Die empirische Befragung zur Heinrichsausstellung ist in eine Langzeitstudie eingebettet, die das Haus der Bayerischen Geschichte seit 1993 zusammen mit dem Sozialwissenschaftlichen Institut München durchführt. ${ }^{8}$ Die kontinuierliche Besucherbefragung soll die lückenhafte Erkenntnis über Museums- und Ausstellungsbesucher in komparativsystematischer Weise verbessern. ${ }^{9}$ Auch geht es darum zu ermitteln, wie

8 Das Sozialwissenschaftliche Institut München (SIM) ist ein unabhängiges Dienstleistungsunternehmen im Bereich der sozial- und wirtschaftswissenschaftlichen Beratung und Forschung. Von 1993 bis 2003 führte das Institut insgesamt 11 Besucherbefragungen zu Ausstellungen des Hauses der Bayerischen Geschichte durch. Einen Überblick zu den Projekten sowie Methodik siehe unter: http://www.sim-sozialforschung.de (letzter Zugriff: 06.12.04).

9 Sechs Besucherstudien zu Landesausstellungen von 1998 bis 2003 sowie ein Aufsatz zu ausgewählten Ergebnissen der Besucherforschung des Hauses der Bayerischen Geschichte sind auf der Homepage veröffentlicht. http://www.hdbg.de/basis/index_extern.html (letzter Zugriff: 06.12.04). 
die einzelnen Ausstellungen vom breiten Publikum aufgenommen werden und inwieweit es gelungen ist, den Besuchern neue Informationen zu vermitteln.

„Schließlich sollen die von den Besuchern vorgenommenen Bewertungen dazu dienen, die Konzeption der jeweiligen Ausstellung in ihrer Gesamtheit, aber auch die Ausgestaltung der Texte und der eingesetzten pädagogischen und didaktischen Elemente zu überprüfen und für zukünftige Ausstellungen fruchtbar zu machen. ${ }^{* 10}$

Die Befragung erfolgte in schriftlicher Form mittels eines achtseitigen Fragebogens, der einschließlich des soziodemographischen Abschnitts 54 Fragen umfasste. ${ }^{11}$ Der Fragebogen wurde in seiner Gestaltung möglichst einfach gehalten, um von einem breiten Personenkreis problemlos beantwortet werden zu können. Auf Filterführungen ${ }^{12}$ wurde daher fast gänzlich verzichtet. Die zu befragenden Ausstellungsbesucher wurden nach einem Zufallsverfahren ausgewählt, etwa jeder zwanzigste Besucher wurde zur Teilnahme gebeten. Die einzelnen Fragen ließen zum Teil Mehrfachantworten zu. Die Befragung erfolgte in drei Wellen von jeweils einer Woche. ${ }^{13}$ Damit wurden insgesamt 1.023 Besucher erfasst. ${ }^{14}$ Neben einem Sozialprofil der Ausstellungsbesucher sowie ausgewählten Aspekten des Besucherverhaltens und einer Bewertung der Infrastruktur und Serviceleistungen durch die Besucher ist für meine Untersuchung insbesondere das Unterkapitel „Wahrnehmung und Bewertung der Ausstellungsinhalte" des Ergebnisberichts relevant, in dem

10 Fröhlich, Werner/Nöthen, Joachim: Besucherbefragung zur Landesausstellung. Kaiser Heinrich II. 1002-1024. Bamberg 9. Juli 2002 bis 20. Oktober 2002 - Ergebnisbericht. München 2003, S. 4.

11 Eine detaillierte Darstellung der Untersuchungsmethode sowie des Erhebungsinstruments vgl. Fröhlich /Nöthen 2003, S. 4ff.

12 Mittels einer Filterführung lässt sich die Datenqualität erhöhen. Die Fragebogendramaturgie kann spezifisch für einzelne Nutzergruppen gestaltet werden. Je nach Antwort auf bestimmte Schlüsselfragen (Filterfragen) können unterschiedliche Folgefragen gestellt werden.

13 Die erste Befragungswelle wurde vom 26. August bis zum 1. September in der Haupturlaubszeit, die zweite Welle vom 23. bis 29. September kurz nach den bayerischen Sommerferien und die dritte Befragungswelle vom 7. bis 13. Oktober kurz vor Ende der Ausstellung durchgeführt. Vgl. Fröhlich/Nöthen 2003, S. 137.

14 Bei einer Gesamtbesucheranzahl 205.920 Personen bedeutet dies, das circa jeder 200. Besucher von der Befragung erfasst wurde. 
zum Beispiel Angaben zur Bewertung der optischen Präsentation durch die Besucher aufgeführt sind.

Als Pendant zur quantitativen Studie des Sozialwissenschaftlichen Instituts München dienen die halb-standardisierten Interviews mit den Besuchern, die auf einem qualitativen Ansatz basieren. Bei dieser Befragungsform ist der Fragebogen nicht endgültig festgelegt, sondern entspricht einem zwar systematisch, aber flexibel aufgebauten Frageschema, das Rückfragen des Befragten und Zusatzfragen des Interviewers gestattet. ${ }^{15}$ Der Vorteil dieser Leitfadengespräche liegt darin, ergründen zu können, wie positive oder negative Urteile zustande kommen. Eine flexible Reaktion auf unerwartete Meinungen ist möglich, so dass diese ebenfalls berücksichtigt werden und in die Auswertung einfließen können. Der Grund für die Entscheidung, mit dieser Methode zu arbeiten, liegt darin, die subjektiven Urteile der Besucher zu ergründen, um damit ein facettenreiches Bild von diesen erhalten zu können. Auch sollte ermittelt werden, inwieweit die Gestaltung die Rezeption und das Erinnerungsvermögen der Besucher beeinflusst. Ebenso interessierte, wie ausgewählte, gestalterische Elemente bewertet werden und wie diese in $\mathrm{Zu}-$ sammenhang mit weiteren Faktoren stehen.

Meine Fallstudie mit punktuellen Fragen kann keine grundlegenden Aufschlüsse über museale Rezeptions- und Wahrnehmungsbedingungen geben. Diese sind psychologischer Grundlagenforschung vorbehalten. Systematische, feldexperimentelle Forschungen fehlen jedoch bisher. ${ }^{16}$ Im Sinne eines heuristischen Verfahrens ${ }^{17}$ sollen die Interviews dazu beitragen, das noch aufzuarbeitende Analysefeld schlaglichtartig zu beleuchten und letztlich Impulse für meine theoretischen Überlegungen zu liefern.

Die Besucherbefragung führte ich vom 1. September 2002 bis 14. September 2002 durch. Täglich interviewte ich im Durchschnitt vier Personen. Befragt wurden nur Besucher, die bereits die gesamte Ausstellung, also alle fünf Ausstellungsbereiche, besucht hatten. Die Aus-

15 Vgl. Pürer, Heinz: Einführung in die Publizistikwissenschaft, Systematik, Fragestellungen, Theorieansätze, Forschungstechniken, München 1990, S. 165.

16 Klein, Hans-Joachim: Gemischtes Doppel - Evaluation der Ausstellungen Spätmittelalter am Oberrhein in der Staatlichen Kunsthalle und im Badischen Landesmuseum, beide in Karlsruhe. Karlsruhe 2002, S. 86.

17 Eberhard, Kurt: Einführung in die Erkenntnis- und Wissenschaftstheorie. Geschichte und Praxis der konkurrierenden Erkenntniswege. Stuttgart 1999, S. 109. 
wahl der Befragten erfolgte nach einem Zufallsprinzip, wobei ich darauf achtete, dass das breite Spektrum der unterschiedlichen Besuchergruppen und die unterschiedlichen Altersgruppen abgedeckt wurden. Da viele Besucher das Diözesanmuseum in ihrem Rundgang als letzten Ort besichtigten, positionierte ich mich benachbart zur Kasse im Ausgangsbereich. Die Interviews anhand des Gesprächsleitfadens dauerten circa 15 bis 30 Minuten.

Der Interviewleitfaden untergliederte sich in vier Fragekomplexe. ${ }^{18}$ Die Fragen bezogen sich auf die Gestaltung in der Alten Hofhaltung sowie im Diözesanmuseum. Diese zwei Teilbereiche wählte ich aus, da sich hier mit inszenierten Parcours und der Schatzkammer zwei unterschiedliche Präsentationskonzepte gegenüberstanden.

Der erste Block umfasste Fragen zum Gesamteindruck sowie zu positiven wie negativen Erinnerungen. Diese Fragen waren bewusst sehr weit gefasst, um die Vielfältigkeit der unterschiedlichen Eindrücke zuzulassen. Der zweite Teil der Fragen bezog sich auf das Vermittlungsangebot für die Besucher in der Ausstellung in Form von Text, Audioguide, Computer und Fühlstationen. Der dritte Fragenblock befasste sich mit Inszenierungseinheiten in der Alten Hofhaltung. Zur Unterstützung des Erinnerungsvermögens wurde den Befragten jeweils ein Photo des Raumes gezeigt. Hier wählte ich exemplarisch zwei Räume aus. Dieses waren der Raum „Der neue König - Triumphat Baioaria - Bayern triumphiert“ sowie der Raum „Der Kaiser - Decus Europae - Zierde Europas “. Die Wahl fiel auf diese zwei Räume, da sie jeweils eine gestalterische sowie inhaltliche Einheit bildeten und sich einer ungewöhnlichen Ausstellungssprache bedienten. Die Fragen zielten darauf, ob Besucher diesen Raum inhaltlich einordnen konnten, was generell in Erinnerung blieb und wie die Gestaltung bewertet wurde. Eine besondere aus dem üblichen Rahmen fallende Gestaltungseinheit waren die Keramikfiguren „Treue Weggefährten Heinrichs II.“ in einer Koje des Raumes „Unterwegs im Reich“. Diese waren zugleich Kunstwerk und didaktisches Element. Hierzu sollten die Besucher ihre Meinung abgeben. Im vierten Fragenteil sollten die Besucher zu ihrem Gesamteindruck Stellung nehmen. Dabei interessierte besonders die Bewertung der unterschiedlichen Präsentationsstrategien durch die Besucher. Da auch Alter, Bildungsstand und Beruf wesentlich die Wahrnehmung beeinflussen, hielt ich darüber hinaus die soziodemographischen Angaben der Besucher fest.

18 Interviewleitfragen für die Besucherbefragung in der Landesausstellung „Kaiser Heinrich II. 1002-1024“ siehe Anhang S. 425. 
Für die Nutzbarmachung transkribierte ich die auf Kassette aufgezeichneten Interviews. Bei der Auswertung fasse ich tendenzielle Meinungen zusammen. Bei mehrfach formulierten Äußerungen ähnlicher Art wählte ich stellvertretend ein Zitat aus und gebe dieses als Stimmungsbild wörtlich wieder. ${ }^{19}$

Die Ergebnisse beider Besucherbefragungen fließen im Anschluss an die Beschreibung und Diskussion der exemplarisch ausgewählten Inszenierungseinheiten ein. Das Nebeneinander der empirischen Studie des Sozialwissenschaftlichen Instituts München sowie des heuristischen Ansatzes wird zeigen, ob diese zu vergleichbaren Ergebnissen führen. Insbesondere interessant wird diese Gegenüberstellung dann, wenn ähnliche Fragen gestellt wurden, wie dies zum Beispiel bei der Bewertung der fünf unterschiedlichen Ausstellungsbereiche der Fall ist.

\subsection{Die Ausstellung „Kaiser Heinrich II. 1002-1024“}

Die Geschichte des Herrschers Heinrich II. wurde auf dem Bamberger Domberg an mehreren Schauplätzen erzählt: in der Alten Hofhaltung, in der Staatsbibliothek, im Diözesanmuseum und im Dom. Veranstaltet wurde diese große Erinnerungsausstellung vom Haus der Bayerischen Geschichte in Kooperation mit der Stadt Bamberg, der Staatsbibliothek Bamberg und dem Diözesanmuseum Bamberg. Die Zeit um die Jahrtausendwende wurde jedoch nicht nur in den Ausstellungsräumen verlebendigt, sondern durch ein umfangreiches Rahmenprogramm und Begleitmedien ergänzt, welche die unterschiedlichsten Interessensgruppen berücksichtigten. Diese Analyse wirft den Fokus auf die Vermittlung der Exponate und Inhalte in den Ausstellungsräumen selbst. Ohne das Begleitprogramm im Detail darstellen zu können, sollen jedoch touristische, künstlerische und museumspädagogische Angebote überblicksartig vorgestellt werden, da diese weitere Komponenten eines umfassenden Vermittlungskonzeptes bildeten.

Neben Konzerten mit mittelalterlicher Musik gab es eine Vortragsreihe zu wissenschaftlichen Spezialthemen. Handwerklich Interessierte konnten entweder bei Vorführungen zum Beispiel zur Beinbearbeitung,

19 Wie ein Besucher jedoch selbst einschränkend feststellte, ist eine wirklich faire Beurteilung der Ausstellung durch Besucher nur dann möglich, wenn er diese in Ruhe betrachten kann, da sich viele Dinge erst auf den zweiten Blick erschließen lassen. 
Buchmalerei, Kalligraphie, Wollherstellung zusehen oder selbst im Rahmen von Kursen beispielsweise zur Kamm-, Pfeil- oder Schmuckherstellung ihr Können schulen. Mit einem vielfältigen Schul- und Kinderprogramm wurde auch an die jüngeren Besucher gedacht. ${ }^{20}$

Als Begleitmedium gab es neben dem reich bebilderten Ausstellungskatalog, in dem neue Forschungsergebnisse präsentiert wurden, einen Kurzführer, in dem die Stationen der Ausstellung mit ihren bedeutenden Objekten vorgestellt wurden, ergänzt mit zeitgenössischen Zitaten aus mittelalterlichen Handschriften. Statt einer Lehrerhandreichung, wie dies in vorherigen Ausstellungen der Fall war, gab es die Spiele-CDROM „Reise nach Burgund“. ${ }^{21}$

Unkonventionelle Hinweise auf die Landesausstellung gab es im Stadtbereich im öffentlichen Raum auf dem Weg vom Bahnhof zum Domplatz mit fünf „Historischen Haltestellen“: Sumpfgewächse im Kasten, eine Stele mit Kunigundengesängen, die Mitra Benedikts VIII., die Kunigundenschale sowie ein Pilgerbedarfsautomat. Dieses künstlerische Projekt von Rosemarie Zacher ${ }^{22}$ spielte auf vergangene Lebenswelten an und ironisierte zugleich die Gegenwart, indem sie Themen der Landesausstellung in den Kontext des 21. Jahrhunderts transportierte.

„Keine Fußgängerzone ohne Pflanzkübel - aber Morastpflanzen? Musik dudelt überall und unentwegt, aber mittelalterliche Gesänge? Automaten stehen

20 Beim Kindertheater „Heinrich will nicht der Zweite sein“ stand zum Beispiel ebenfalls das Leben Heinrichs im Mittelpunkt. In den großen Sommerferien konnten die Kinder an der Kinderfreizeit „Mittelalterliche Burgfestspiele“ teilnehmen oder unter dem Motto „Mit dem Spielmobil in die Zeit Heinrichs II“ im Aktionsbereich „Kurzweyl“ mit Stelzen, Reifen, Brummkreisel Spiele wie vor tausend Jahren spielen. Auch gab es an zwei Wochenenden beim Mittelalterlichen Gehöft einen Streichelzoo mit jungen Schafen.

21 Darüber hinaus gab es weitere CD-ROM Produktionen. Das „Perikopenbuch Kaiser Heinrich II.“ sowie das „Evangeliar Ottos III.“” wurden als Handschriften zum Blättern in digitalisierter Form herausgebracht. Im Eingangsbereich der Staatsbibliothek konnte virtuell an PC-Stationen darin geblättert werden.

22 Seit 1991 arbeitet Rosemarie Zacher als freischaffende Künstlerin und Buchillustratorin. Ein charakteristisches Merkmal ihrer künstlerischen Arbeiten ist ein heiter-ironischer Grundzug. Seit 1997 entwirft sie museumspädagogische Konzepte für das Haus der Bayerischen Geschichte. 
an allen Ecken, aber gefüllt mit Licht verheißenden Pilgermuscheln? Geld gibt es an jedem Bankautomat, aber gerechten Lohn?‘23

Die „Historischen Haltestellen“ bargen erzählerische Qualitäten. Obgleich sie auf die Zeit um das Jahr 1000 Bezug nahmen, waren sie jedoch nicht mit der Absicht konzipiert über Geschichte zu belehren. Vielmehr sollten sie die Betrachter in ihrer Alltagswahrnehmung irritieren und auf die Landesausstellung aufmerksam machen.

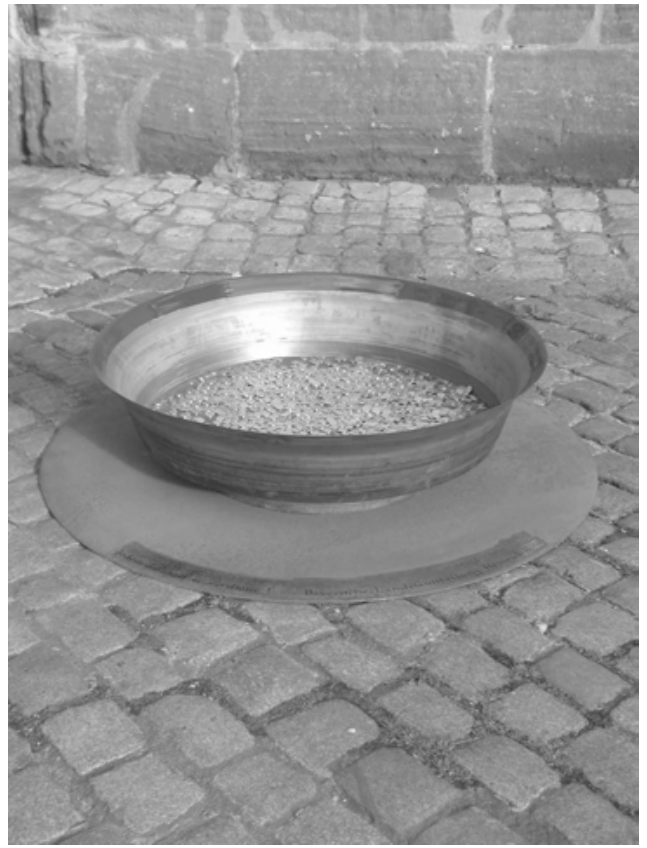

Abbildung 30:

"Historische Haltestellen" von Rosemarie Zacher im öffentlichen Raum vom Bahnhof zum Domplatz in Bamberg, Station Nr. 4 „Kunigundenschale“.

23 Schurr, Eva: Historische Haltestellen. Auf den Spuren Kaiser Heinrichs II. und Kunigundes im Stadtraum Bamberg. Faltblatt zu den Historischen Haltestellen, 2002. 


\section{Das Haus der Bayerischen Geschichte und sein Ausstellungsteam}

Das Haus der Bayerischen Geschichte in Augsburg ist heute eine etablierte und in ganz Bayern wirksame Vermittlungsinstanz für historische Bildung. ${ }^{24}$ Bereits in den Anfängen der Diskussion um das Haus der Bayerischen Geschichte nahm dieses im Hinblick auf konzeptionelle Überlegungen eine Vorreiterrolle in Deutschland ein. ${ }^{25}$ Im Jahr 1965 wurde eine Konzeption ${ }^{26}$ vorgelegt, die Elemente enthielt, wie sie dann später in den siebziger Jahren in der bundesweit geführten Museumsdiskussion „Lernort contra Musentempel“ ${ }^{\text {27 }}$ ebenfalls thematisiert wurden. Dieses Haus sollte in Abgrenzung zur altväterlichen Bildungsanstalt Museum „lebhafter auf seine Besucher einwirken als durch Ausstellung von Erinnerungsstücken; [...] zu intensiverer Beschäftigung auffordern als zu bloßem Durchschreiten; [...] andere Arten des Studiums ermöglichen als reine Betrachtung“. (Bayerische Staatskanzlei 1965, S. 24ff.). In diesem Sinne wurden ehrfurchtgebietende Säle abgelehnt und für eine flexible Innengestaltung und eine kombinierte multimediale Präsentationsweise plädiert. Schaubilder, Modelle, Karten, Reproduktionen, Kopien, aber auch aufgrund ihrer Aura unverzichtbare Originale waren in diesem Konzept ebenso vorgesehen wie filmische und Tondokumente. Das Haus sollte keinesfalls museal sein. ${ }^{28}$ Dies bedeutete, dass der historische Aus-

24 Vollhardt, Ulla-Britta: Geschichtspolitik in Bayern. Das Haus der Bayerischen Geschichte zwischen Privatinitiative und Institutionalisierung. München, 2003. In diesem Buch skizziert Vollhardt die wechselvolle Entstehungsgeschichte des Hauses der Bayerischen Geschichte von den ersten Plänen bis zur formellen Gründung 1978/83.

25 Auch die grundsätzliche Idee zu einem Haus der Geschichte wurde in Bayern bereits in den sechziger Jahren konzipiert und diskutiert, bevor Häuser der Geschichte an anderen Orten wie in Bonn 1994 oder in Stuttgart im Jahr 2002 eröffnet wurden. Glass stellt fest, dass mit Blick auf die Entstehungsgeschichte dieses bayerische Projekt alle wesentlichen Merkmale beinhaltete, die auch für die Konzeption der Nachfolgehäuser maßgeblich waren. Vgl. Glass, Christian: „Aber es soll kein Museum werden.“ Die Häuser der Geschichte in Deutschland. In: Museumskunde. 66. (2001) Heft 1/01 S. 119.

26 Bayerische Staatskanzlei (Hrsg.): Das Haus der Bayerischen Geschichte, München 1965, S. 24ff.

27 Siehe Einleitung, Anm. 19.

28 Vollhardt merkt hierzu an, das es auffällig ist, in welchem Maße der Begriff museal seit Ende der fünfziger Jahre pejorativ konnotiert war. Museal 
sagewert eines Exponats einen Vorrang vor seinem formalen Gehalt als Kunstgegenstand erhielt. Durch bewusste Auswahl von großen Leitgedanken sollte die bayerische Geschichte nicht vordringlich ästhetisch illustriert, sondern demonstriert werden. Die Visualisierung der bayerischen Staatlichkeit und eine besondere didaktische Zielsetzung sollten den besonderen Charakter des Hauses bestimmen (Vollhardt 2003, S. 79).

Nach einer langen und kontroversen Entstehungsgeschichte mit zahlreichen Transformationen kam es 1979/83 zu seiner formellen Gründung. Das Haus der Bayerischen Geschichte hat laut Auszug aus seiner Verordnung die Aufgabe:

„1. die geschichtliche und kulturelle Vielfalt Bayerns in allen Bevölkerungsschichten, vor allem der jungen Generation, in allen Landesteilen zugänglich zu machen. 2. die Gesamtstaatlichkeit Bayerns und die Entwicklung von Staat und Gesellschaft bis zur Gegenwart im historisch-politisch-kulturellen Rahmen darzustellen. 3. das Geschichtsbewußtsein zu fördern und zu pflegen und dadurch das geschichtliche Erbe für die Zukunft des Freistaates Bayern im deutschen und europäischen Rahmen fruchtbar zu machen. ${ }^{\text {“29 }}$

Heute stellt es die Ausstellungs- und Publikationszentrale des Freistaats Bayern dar. Den Schwerpunkt der landesweiten Tätigkeit des Hauses der Bayerischen Geschichte bilden Ausstellungen. In der über zwanzigjährigen Geschichte kann das Haus mittlerweile auf ein vielfältiges Ausstellungsprogramm zurückblicken. Die Kommunikation der Ausstellungsinhalte hat gemäß des Auftrags des Hauses der Bayerischen Geschichte einen sehr hohen Stellenwert. Diese schwierige und anspruchsvolle Aufgabe wird als solche wahrgenommen und spiegelt sich auch im Bewusstsein der Ausstellungsleiter wider. ${ }^{30}$

hieß verstaubt, altväterlich-pädagogisierend, kumulativ-historisch. Vgl. Vollhardt 2003, S. 183, Anm. 277.

29 Auszug aus der Verordnung für das Haus der Bayerischen Geschichte vom 11. Mai 1985, §2.

30 Dieser Gesamteindruck kam bei Gesprächen mit Ausstellungsleitern des Hauses der Bayerischen Geschichte sehr deutlich zum Ausdruck. Sowohl Herr Dr. Wolfgang Jahn (Projektleitung bei der Landesausstellung „Bayern - Ungarn tausend Jahre“ im Oberhausmuseum in Passau im Jahr 2001) wie auch Herr Dr. Josef Kirmeier betonten den hohen Stellenwert des Besuchers und den daraus resultierenden Vermittlungsauftrag. 
„Der Besucher ist sehr wichtig. Nicht nur was die Zahlen betrifft, sondern auch die Resonanz, wie dem Besucher die Ausstellung gefällt, was im Besucherbuch steht. Hier muss man die Sehgewohnheiten und Lesegewohnheiten berücksichtigen, da sich diese immer wieder ändern. Man kann heute Inhalte nicht mehr mit langen Texten vermitteln. Die Leute sind durch alle möglichen Kommunikationsmittel heutiger Zeit SMS-artig gekürzt. Dementsprechend plakativ visuell muss die Information vermittelt werden. “31

Neben einem umfangreichen pädagogischen Begleitprogramm mit Führungen und Museumswerkstatt gehört die didaktische Aufbereitung der Ausstellungsthemen $\mathrm{zu}$ den grundsätzlichen und selbstverständlichen Aufgaben (HdBG 2003, S. 48). ${ }^{32}$ Auf personeller Ebene versucht man diesem Anspruch auch dadurch gerecht zu werden, indem Geschichtslehrer von ihrem Schuldienst freigestellt sind und für einen bestimmten Zeitraum bei Ausstellungsprojekten mitwirken.

Die Projektleitung der Heinrichsausstellung übernahm Herr Dr. Josef Kirmeier. ${ }^{33}$ Zum engeren Ausstellungsteam vom Haus der Bayerischen Geschichte zählten Dipl. Hist. Markus Schütz sowie der Geschichtslehrer Herr Peter Lengle. Verantwortlich für einen museumspädagogischen Kinderpfad im Ausstellungsgelände war Frau Rosemarie Zacher. Darüber hinaus wurde dieses Team von einer Reihe temporärer Mitarbeiter ergänzt. $^{34}$ Die wissenschaftliche Fundierung der Historie leisteten die Professoren Bernd Schneidmüller und Stefan Weinfurter. Frau Dr. Gude Suckale-Redlefsen war für die kunstwissenschaftlichen Inhalte der Ausstellungsteile in der Staatsbibliothek und mehrere Abteilungen im Diözesanmuseum verantwortlich. Die Rekonstruktion des mittelalterlichen Gehöfts basierte auf der Grundlage der wissenschaftlichen Forschungen von Prof. Walter Sage. Prof. Manfred Schuller und Prof. Achim Hubel verantworteten die Erforschung des Heinrichsdoms und die Darstellung für die Ausstellung und den Katalog.

31 Interview mit Herrn Dr. Josef Kirmeier, Projektleitung der Landesausstellung „Kaiser Heinrich II. 1002-1024“ des Hauses der Bayerischen Geschichte, am 17. Oktober 2001.

32 Um den Schulen eine optimale Vorbereitung für den Ausstellungsbesuch im Klassenverband zu ermöglichen, werden in der Regel zu den Landesausstellungen Lehrerhandreichungen erarbeitet.

33 Herr Dr. Josef Kirmeier zählt zu den langjährigen Mitarbeitern am Haus der Bayerischen Geschichte. Seit 1987 beschäftigt er sich mit Ausstellungen und war bei circa 20 Projekten beteiligt.

34 Einen Überblick zum umfangreichen Mitarbeiterstab siehe Kirmeier u.a. 2002, S. 8. 
Die Gestaltung der Ausstellung übernahm die Gruppe Gut. ${ }^{35}$ Mit dieser Ausstellung setzte das Haus der Bayerischen Geschichte die erfolgreiche Zusammenarbeit mit diesem Gestaltungsbüro fort. ${ }^{36}$ Der Schwerpunkt ihrer Gestaltungsaufgaben lag in den Räumen der Alten Hofhaltung, für die sie einen inszenierten Parcours entwickelten. An den weiteren Ausstellungsorten im Diözesanmuseum sowie in der Staatsbibliothek waren aufgrund konservatorischer Bedenken keine umfangreichen, inszenatorischen Eingriffe möglich. Charakteristisch für die Arbeitsweise der Gruppe Gut ist ein ganzheitlicher Ansatz. Das Wohlbefinden der Besucher bildet dabei ein Kriterium, indem die Gestaltung ein angenehmes Raumgefühl erzeugen soll. Durch eine prägnante Raumgestaltung sollen die Besucher ihre Erinnerungen mit Raumerlebnissen verbinden können. Ebenso sollen Verknüpfungen zur persönlichen Erfahrungswelt die Merkfähigkeit der Besucher unterstützen.

„Ich sehe die Ausstellung wie einen Film. Die Leute gehen durch, es muss Höhen und Tiefen geben, vergleichbar einer Partitur. Gleichzeitig werden Emotionen stimuliert, und mit Spannung werden die nächsten Ereignisse erwartet. Es geht nicht nur darum, das einzelne Thema zu interpretieren oder zu inszenieren, sondern der Faden der gesamten Ausstellung ist wichtig.“37

In ihren Entwürfen berücksichtigt die Gruppe Gestaltungsgrundsätze, wie sie in Analogie auch bei Bildkompositionen Anwendung finden. Auf die Stimmigkeit einzelner Innenräume im Detail wird ebenso geachtet wie auf die Atmosphäre des Ausstellungsparcours im Gesamten. Dies bedeutet, Akzente zu setzen, zu verdichten oder aufzulockern. Auch

35 Das Gestaltungsbüro Gruppe Gut mit Sitz in Bozen existiert seit 1990. Die Inhaber Alfons Demetz und Uli Prugger legen ihren Schwerpunkt auf Ausstellungs- und Museumsgestaltung. Sie bieten dabei Komplettlösungen von der Konzepterstellung über die Einrichtungsgestaltung inklusive Inszenierung bis zur Entwicklung von Drehbüchern für Filmspots, Drucksorten und Presse-Präsentationen an. Projekte von Gruppe Gut sind zum Beispiel: Südtiroler Archäologiemuseum (Ötzi) in Bozen 1998, Loden Erlebniswelt in Vintl 2000, „Die Welt von Byzanz“ in der Archäologischen Staatssammlung in München 2004, „Franken im Mittelalter“ in Forchheim 2004.

36 Die Kooperation des Hauses der Bayerischen Geschichte mit der Gruppe Gut begann im Jahr 1999 mit den Planungen für die Landesausstellung „Bayern - Ungarn tausend Jahre“, die im Jahr 2001 stattfand.

37 Interview mit Herrn Uli Prugger, Gestaltungsbüro Gruppe Gut in Bozen, am 8. Juli 2002. 
Leerräume, freie Flächen und Luft fließen dabei in den Gesamteindruck ein. Bei der Anordnung der Objekte im Raum erfolgt dies nicht nach einem symmetrischen Muster, sondern ein ausgewogenes Spannungsverhältnis wird angestrebt. In der konkreten Umsetzung bedeutet dies, dass zum Beispiel eine Vitrine nicht mittig platziert, sondern an den Rand gerückt oder schräg in den Raum positioniert wird. Auch die Charakteristik des zu bespielenden Ortes bildet dabei einen wichtigen Bezugspunkt. ${ }^{38}$

Ein sensibler Umgang in der Farb- und Materialwahl stellt für die Gruppe Gut ein besonderes Anliegen dar. Die Festlegung einer bestimmten Material- und Farbfamilie erfolgt sowohl nach inhaltlichen wie auch symbolischen Kriterien. Eine Goldfolie kann auf erlesene Schätze hinweisen oder eine Vitrinenverschalung mit Kupfer eine Reminiszenz an Kupferhandel darstellen. Auch im Hinblick auf die dramaturgische Komponente einer Gefühlsregie zur Erzeugung von Atmosphäre und Stimmungen spielen Material und Farben eine wichtige Rolle. Ebenso kann die Möglichkeit, damit ein Orientierungsschema für die Besucher zu schaffen, zum Beispiel als thematische Eingrenzung, ein Entscheidungskriterium für eine Farbe sein. Grundsätzlich verfolgt die Gruppe Gut den Leitgedanken, mit möglichst reduzierten und einfachen Mitteln die gewünschte Wirkung zu erzielen.

Auf eine solide, wissenschaftliche Fundierung des Projektes legten die Ausstellungsmacher großen Wert. Dies erschien insbesondere deshalb wichtig, da der Ausstellungsteil, der sich mit dem historischen Umfeld von Heinrich II. befasste, mit nur wenigen musealen Exponaten gestaltet und inszeniert wurde. Bereits im Jahr 1997 begann eine intensive Zusammenarbeit mit Schneidmüller und Weinfurter, deren wissenschaftliches Ausstellungskonzept im September 1999 vorlag. ${ }^{39}$ Dieses stellte eine Konzeption aus der Perspektive der Geschichtswissenschaft dar und verstand sich, wie die Autoren selbst einschränkend bemerkten, „als

38 Zum Beispiel drehten die Gestalter in Passau bei der Ausstellung „Bayern - Ungarn tausend Jahre" den üblichen Museumsparcours um. Gemäß der Idee, dass die Chronologie die Hülle respektieren soll, erschien es der Gruppe Gut sinnvoll, die Ausstellung zur frühen Zeit des Mittelalters im Erdgeschoss in den niedrigen Räumen zu beginnen und im Obergeschoss in den hohen Räumen die späteren Jahrhunderte zu zeigen.

39 Schneidmüller, Bernd/Weinfurter, Stefan: Bayerns Triumph Europas Glanz/Zierde, Kaiser Heinrich II. und sein Reich. Ausstellung des Hauses der Bayerischen Geschichte 2002 in Bamberg, wissenschaftliches Ausstellungskonzept. (unveröffentl. Skript) 1999. 
Diskussionsgrundlage für die weitere Arbeit mit den Sachkennern“ (ebd., S. 4). Innenarchitektonische oder dramaturgische Überlegungen flossen in dieses Konzept nicht mit ein.

„Es entstand eine wunderbare Buchgliederung mit Einleitung, Bibliographie und Exponatangaben. Unsere Aufgabe bestand darin, dieses Konzept in die Räume einzupassen. Dieses Konzept haben wir furchtbar gequält, portioniert und neu strukturiert. Raumgröße und Raumart spielen eine Rolle.““40

Das wissenschaftliche Konzept bildete den Ausgangspunkt zur Erstellung eines zweiten Ausstellungskonzepts, welches dann auf die spezielle, räumliche Situation vor Ort in Bamberg zugeschnitten war. ${ }^{41} \mathrm{Im}$ März 2001 stellte das Haus der Bayerischen Geschichte im Rahmen eines groBen wissenschaftlichen Kolloquiums ${ }^{42}$ diese überarbeitete zweite Version vor. ${ }^{43}$ Im Fachkreis wurden Einzelaspekte diskutiert und abgesichert.

Am Kolloquium ebenfalls beteiligt waren die Gestalter sowie die Museumspädagogin. Dieses Ausstellungskonzept bildete auch die Grundlage für die ersten Raumskizzen: Die Entwürfe wurden mit wenigen Korrekturen so realisiert. Dieses lag, wie die Gestalter feststellten, an dem bereits gut durchdachten Konzept der Wissenschaftler. Grundlegende Eingriffe erfolgten nicht. Die markanteste Veränderung betraf den letzten Raum des Ausstellungsparcours im ehemaligen Marstall der Alten Hofhaltung. Ursprünglich hätten diese fast dreißig ehemaligen Pferdeboxen mit unterschiedlichsten Einzelaspekten zu ausgewählten Themen des Reiches Heinrichs II. gefüllt werden sollen. Die Gestalter kritisierten, dass am Ende des Rundganges die Besucher nicht erneut mit einer Vielzahl kleinteiliger archäologischer Objekte, wie dies zu Beginn

40 Interview mit Herrn Dr. Josef Kirmeier, Projektleitung der Landesausstellung „Kaiser Heinrich II. 1002-1024“ des Hauses der Bayerischen Geschichte, am 17. Oktober 2001.

41 Haus der Bayerischen Geschichte: Landesausstellung Heinrich II., Bamberg, 8. Juli bis 20. Oktober 2002. Konzept: Stand 12.02.01. (unveröffentl. Skript) Augsburg 2001.

42 Dieses Kolloquium fand am 8./9. März 2001 in der Otto-FriedrichUniversität Bamberg statt, veranstaltet vom Haus der Bayerischen Geschichte in Kooperation mit dem Zentrum für Mittelalterstudien der Universität Bamberg.

43 Dieses Vorgehen unterschied sich damit von der oft praktizierten Form, die Vorträge eines Kolloquiums als Ausgangspunkt für die Entwicklung eines Ausstellungskonzeptes zu nehmen und diese Vorträge gesammelt im Katalog zu publizieren. 
des Rundganges bereits der Fall war, konfrontiert werden können, da dies eine Überforderung für den bereits mit vielen Eindrücken angefüllten Besucher sei. So stellt Kirmeier fest, dass der wohl wichtigste Impuls des Kolloquiums eine beiläufige Bemerkung eines Stadtarchivars war, der darauf verwies, dass im Marstall etwas mit Pferden und Reisen gezeigt werden müsste. Damit war die Idee geboren, die vielen Einzelaspekte unter dem Begriff „Reisekönigtum“ zu bündeln.

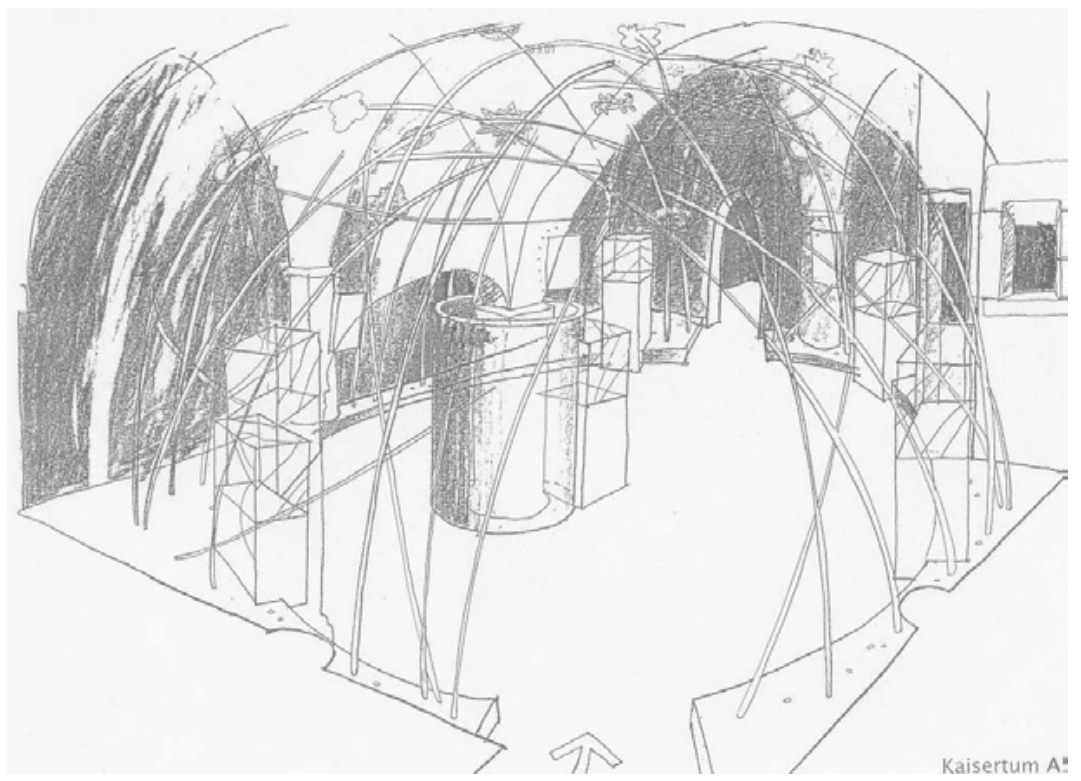

Abbildung 31: Skizze der Gestalter Gruppe Gut des Raumes

„Der Kaiser“, Stand: September 2001.

\section{Ziele und Inhalte der Ausstellung}

Die Geschichte des Herrschers Heinrich II. stand - wie der Titel besagt im Zentrum der Ausstellung. Anhand von Thesen des wissenschaftlichen Konzeptes sowie des Ausstellungskonzeptes soll dargelegt werden, worin die Schwerpunkte der Interpretation und Präsentation lagen. ${ }^{44} \mathrm{Im}$

44 Im Jahr 1996 wurde in Bamberg ein Symposium abgehalten, auf dem Kontroversen um die Person Heinrichs II. und die methodischen Möglichkeiten einer Geschichtsschreibung zur ersten Jahrtausendwende diskutiert wurden. Die Ergebnisse liegen in einem Sammelband vor: Schneidmüller, 
zeitlichen Umkreis des Millenniums fanden weitere bedeutende Großausstellungen zur mittelalterlichen Geschichte, insbesondere zur Zeit der Wende vom ersten zum zweiten Jahrtausend statt. Die bedeutendsten waren die Ausstellungen „Otto der Große, Magdeburg und Europa“45 sowie „Europas Mitte um 1000“46. In Paderborn stand unter dem Titel „Kunigunde - empfange die Krone“ die Frau an der Seite Heinrichs II. im Mittelpunkt. ${ }^{47}$ Diese Ausstellungen waren insofern für die Konzeption der Heinrichsausstellung von Bedeutung, da eine gewisse Konkurrenzsituation gegeben war sowie inhaltliche Überschneidungen zu bedenken waren.

In Abgrenzung zu diesen genannten Ausstellungen betonte das wissenschaftliche Konzept, dass das zentrale Anliegen sich auf Kaiser Heinrich II., Kaiserin Kunigunde, den Wirkverbund im Reich und die europäischen Verflechtungen konzentrieren müsse (Schneidmüller/Weinfurter 1999, S. 7). Dabei sollte jedoch nicht nur die Biographie einer einzelnen Herrscherpersönlichkeit oder die Gründung eines Reichsbistums dargestellt, sondern gleichgewichtig die gesamte Reichsgeschichte am Beginn des zweiten Jahrtausends in den Blick genommen werden. Das Thema Heinrich II. führt zu weiteren Fragestellungen, die politische, kirchliche, soziale, künstlerische und mentale Dimensionen von Vergangenheit hervortreten lassen (ebd., S. 3).

„In die Konzepte und Wirklichkeiten des spätliudolfingischen Kaisertums sind der reichsbezogene Denk- und Aktionsrahmen wie die europäischen Dimensionen der Politik am Beginn des zweiten Jahrtausends einzufügen. Der neue Osten mit Polen, Böhmen und Ungarn gehört ebenso dazu wie traditionelle Westbindungen zu Frankreich und Burgund.“ (ebd. S. 7)

Die Besinnung auf eine solche europäische Weite als Basis des Raumund Zivilisationsbewusstseins in der Zeit Heinrichs II. besitzt nach Ansicht von Schneidmüller/Weinfurter eine besondere Bedeutung für die

Bernd/Weinfurter, Stefan (Hrsg.): Mittelalter Forschungen 1. Sigmaringen, 1997. Die zahlreichen einschlägigen Forschungen sind inzwischen auch in einer Biographie zur Synthese gebracht worden: Weinfurter, Stefan: Heinrich II. (1002 1024) - Herrscher am Ende der Zeiten. Regensburg 1999. Die Ergebnisse dieser Abhandlung flossen in die Konzeption der Ausstellung ein.

45 Siehe Kapitel 5, Anm. 66.

46 Siehe Kapitel 5, Anm. 67.

47 Museum in der Kaiserpfalz vom 24.08.02-13.10.02. Wemhoff, Matthias (Hrsg.): Kunigunde - empfange die Krone. Paderborn 2002. 
historisch politische Bildung der Gegenwart. Die Ausstellung sollte durchaus auf die neuen und wichtigen mittelalterlichen Aktivitäten in Ostmitteleuropa verweisen, aber auch die bleibenden Bindungen an die alten Landschaften im Süden und Westen mit ihrem zivilisatorischen Vorsprung und ihrem herrschaftlichen Legitimationspotential herausarbeiten (ebd., S. 8).

Trotz der historisch-politischen Bedeutung ist Heinrich II. dennoch weit weniger in unserer kollektiven Erinnerung als vergleichsweise Karl der Große, Otto der Große oder Friedrich Barbarossa. Heinrich II. wurde am 6. Mai 973 als ältester Sohn und Nachfolger des bayerischen Herzogs Heinrich des Zänkers geboren. Im Jahr 1002 wählte man ihn als Heinrich II. in Mainz zum ostfränkischen König. Mit der Krönung Heinrichs II. am 7. Juni 1002 wurde erstmals ein bayerischer Herzog König und in der Folge 1014 Kaiser. Obgleich er mächtige Konkurrenten erst von seinem Herrschaftsanspruch überzeugen musste, wurden die zweiundzwanzig Jahre seines Königtums und das Jahrzehnt seiner Kaiserherrschaft zu einem Höhepunkt des mittelalterlichen Reiches: Zusammen mit den Bischöfen und Äbten verhalf er dem Reich zu kultureller Blüte. Auf Synoden und Königstreffen festigte er sein Ansehen als Beschützer der Christenheit. Über das Reich hinaus ist Heinrichs Herrscherzeit mit der endgültigen Einbindung Polens und Ungarns in das christliche Abendland verbunden. ${ }^{48}$

Bereits die zeitgenössische Wertschätzung und auch die der Nachwelt zeigte zwiespältige Züge. Einerseits wird er als großzügiger Stifter herrlicher Kunstwerke verehrt, gleichzeitig wird er aber auch als rücksichtsloser Räuber wertvoller Handschriften für seine Stiftung Bamberg dargestellt. In der Überlieferung zeigt sich eine sehr facettenreiche historische Persönlichkeit:

„Ein Herrscher am Ende der Zeiten, ein Herrscher in der Mitte des Mittelalters, Herzog, König, Kaiser, Heiliger - welch ein Aufstieg!““ [...] Ein strenger Herr, unerbittlich und unnachgiebig auf der einen Seite, Friedensstifter und Diplomat auf der anderen Seite. Er war ein Inszenator seiner von Gott gegebenen Herrscherwürde, der gekonnt auf der Klaviatur der Macht und Selbstdarstellung spielt. Ein König, der sich als Kollege seiner Bischöfe sieht und darum wie selbstverständlich in ihre Belange eingreift. Ein Herrscher, dem nach den Vorstellungen seiner Zeit - Wichtiges versagt bleibt: die Sicherung der Nachfolge durch einen Sohn. Ein Heiliger, dessen gute Werke der Legen-

48 Haus der Bayerischen Geschichte: Landesausstellung Heinrich II., Bamberg, 8. Juli bis 20. Oktober 2002. Konzept: Stand 24.07.01. (unveröffentl. Skript) Augsburg 2001. 
de nach gerade einmal ausreichten, um sein Seelenheil zu retten. Ein Kaiser schließlich, der höchstes Lob auf sich zog: als ,Zierde Europas' wird er auf dem kostbaren Sternenmantel bezeichnet, den ihm der apulische Fürst Ismahel schenkte." (Kirmeier u.a. 2002, S. 11)

Als Integrationsfigur für das Reich, Stütze für das Papsttum, kriegerischer Herr und frommer Gläubiger war er somit eine umstrittene Herrscherpersönlichkeit. Dennoch nahm ihn im Jahr 1146 Papst Eugen III. in die Reihe der anerkannten Heiligen auf. Kaiser Heinrich II. blieb der einzige Herrscher, der heilig gesprochen wurde und mit seiner Gemahlin Kunigunde bis heute verehrt wird.

Ziel der Landesausstellung war es unter anderem, dieses facettenreiche Bild nachzuzeichnen. Man wollte diesen Überlieferungen nachspüren, die durch die Rhetorik des Herrscherlobs und die Kraft der Legende geprägt sind. Die Ausstellung sollte die mittelalterliche Herrscherfigur aus unterschiedlichen Blickwinkeln - aus der Geschichte, der Kunst, der Wissenschaft, der Religion, der Liturgie - beleuchten und lebendig werden lassen. Ebenso wollte die Ausstellung den vielen Exponaten, die gegenwärtig primär als Kunstwerke aufgefasst werden, im Abstand eines Jahrtausends zumindest einen Teil ihrer historischen Aussagekraft zurückgeben (ebd., S. 12). Dazu wurde neben die beiden Schatzkammern und den Bamberger Dom als originären Ort ganz bewusst die historische und archäologische Rekonstruktion gestellt.

Die Ausstellung fand am historischen Ort inmitten baulicher Zeitzeugnisse statt. Die Ausstellung „könnte deshalb nicht sinnreicher und erlebnisnäher untergebracht sein als in den [...] Räumen rund um den Bamberger Dom “49 Sie gliederte sich in fünf Bereiche, die die vorhandenen Möglichkeiten um den Bamberger Dom nutzten. Zwei Schatzkammern zur Buch- und Sakralkunst bildeten einen allgemeinen Schwerpunkt mit Objekten aus der gesamten Herrschaft Heinrichs II. Im Bamberger Dom wurde besonders der Stiftung Heinrichs und dem ersten Dombau nachgegangen. Die thematische Zuspitzung auf spezielle Aspekte der Zeit Heinrichs II. erfolgte in den Räumen der Alten Hofhaltung. Auf dem Domplatz selbst stand ein rekonstruiertes Mittelalterliches Gehöft.

49 Grimm, Claus: Grußwort. In: Kirmeier u.a. 2002, S. 5. 


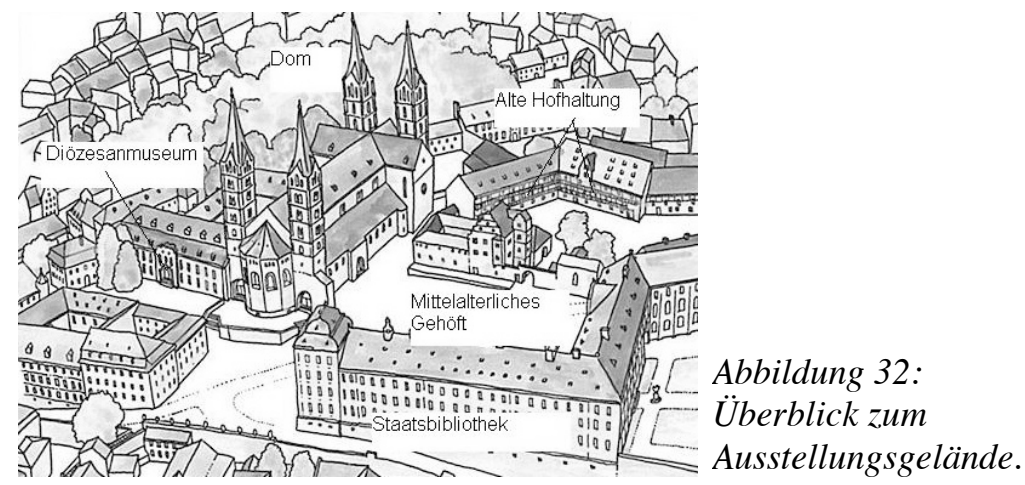

\section{Der Bamberger Dom}

Im Bamberger Dom als authentischem Ort der mittelalterlichen Gedächtniskultur befinden sich die Reliquiare mit den Häuptern Heinrichs II. und Kunigunde. Diese unmittelbaren Zeugnisse des Kaiserpaares werden bis heute verehrt. Das Grab des Kaisers als symbolische Mitte des Doms verkörpert einen Verknüpfungspunkt verschiedener Aspekte wie die religiös-liturgische und die politische Komponente von Reichsherrschaft, Kirchenschutz sowie persönlicher Memoria. Der Rundgang durch den Dom umfasste neben dem Ostchor und der Westkrypta die beiden Ostportale mit den figürlichen Darstellungen des Kaiserpaares, die Adamspforte mit den neuen Abgüssen der originalen Gewändefiguren und die Gnadenpforte mit dem Kaiserpaar neben Maria und Georg als Dompatrone im Tympanon. Im Dom wurde der Weg an jeder Station anhand einer Karte mit Standort erklärt.

\section{Das Mittelalterliche Gehöft}

In augenfälligem Kontrast zur imposanten Kulisse des Bamberger Doms befand sich auf dem Domplatz als größte Inszenierung ein Mittelalterliches Gehöft. Dieses Gehöft, bestehend aus einem Pfosten- und einem Grubenhaus, sollte den Bogen zur Alltagswelt schlagen und eine Ahnung von den Existenzbedingungen der Menschen zur mittelalterlichen Jahrtausendwende geben. Am dritten Objekt eines Steinfundamentshauses wurde während der Ausstellung gebaut. In dem Pfostenhaus mit zwei Räumen hätten angewandte Handwerkstechniken sowie die Wohnverhältnisse des 11. Jahrhunderts verdeutlicht werden sollen. Dieses Pla- 
nungen zur experimentellen Archäologie konnten jedoch so nicht realisiert werden, da zwei Wochen vor Eröffnung der Ausstellung die mittelalterlichen Nachbauten durch Funkenflug beim Schweißen in Brand gesetzt und schwer beschädigt wurden. ${ }^{50}$

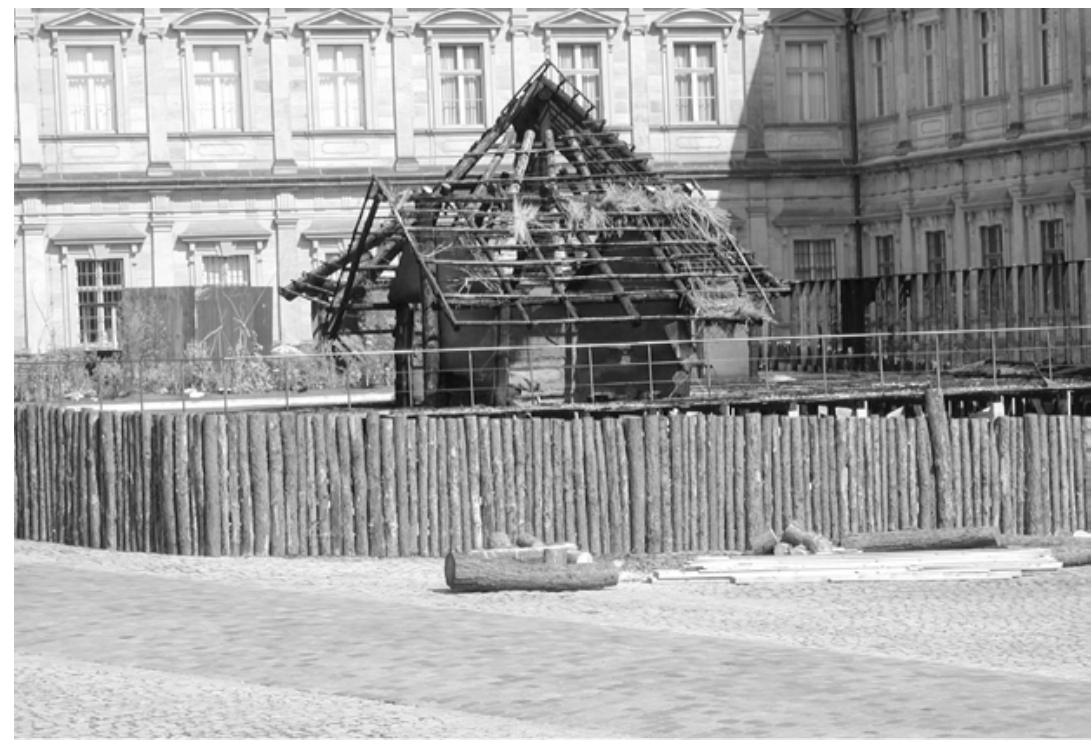

Abbildung 33: Mittelalterliches Gehöft auf dem Domplatz.

Da das mittelalterliche Gehöft jedoch mit der Illustrierung der Alltagswelt im Gesamtkonzept ein wichtiges Pendant zu den Schatzkammern sowie der Alten Hofhaltung gebildet hätte, soll das ursprüngliche Konzept des Gehöfts kurz beschrieben werden

Vom Umgang mit dem lebendigen, universell einsetzbaren Rohstoff Holz hätte in einer Schauwerkstatt die Abteilung Holzhandwerk berichtet, in der verschiedene Handwerke sowie Geräte zur Holzverarbeitung gezeigt worden wären. Der Prozess vom Bergbau über die Verhüttung und Verarbeitung zum Produkt wäre in der Abteilung Erze und Schmiede nachvollzogen worden. Ein dritter Bereich hätte sich dem Thema Beinverarbeitung gewidmet. Als zentraler Teil der Alltagsgeschichte wäre in einer weiteren Abteilung das Thema Textilherstellung von den

50 Fröhling, Stefan/Andreas Reuß: Brand auf dem Domplatz. Gefahr für die Landesausstellung. In: Bayerische Staatszeitung vom 28.06.02. 
Rohmaterialien der Farben und Stoffe über ihre Aufarbeitung und Verarbeitung bis zum fertigen Produkt illustriert worden. Ergänzt worden wären diese Abteilungen mit Rekonstruktionen von mittelalterlichen Handwerkszeugen wie zum Beispiel durch den Nachbau eines Gewichtswebstuhls oder einer Drechseldrehbank. Auch sollte es Objekte zum Anfassen geben, so zum Beispiel ein Trinkhorn sowie weitere während der Ausstellung gefertigte Objekte.

Nach dem Brand entschied die Ausstellungsleitung, die abgebrannten Balken als Mahnmal und realistisches Dokument für die Bedrohung mittelalterlicher Städte durch Feuersbrünste stehen zu lassen. Fast alle dort geplanten Präsentationen und Aktionen mussten kurzfristig umgeplant werden. Ein Gemüsebeet mit alten Getreidesorten, Kräutern und anderen Nutzpflanzen wurde auf dem Podest des abgebrannten Gehöfts verwirklicht. Die Präsentationen zum Holz- und Metallhandwerk sowie zur Beinverarbeitung und Textilherstellung wurden in reduzierter Form in einen Nachbarraum des Eingangsbereichs in der Alten Hofhaltung verlegt.

\section{Staatsbibliothek}

In zwei Ausstellungsräumen der Staatsbibliothek wurden die Bücherschätze, die Buch-Stiftungen von Heinrich II. sowie von Verwandten und Gefolgsleuten Heinrichs II., gezeigt (Räume IX siehe Abb. 34). Es wurde versucht, durch ausgesuchte Miniaturen das Charakteristische einer heinrizischen Kunst herauszuarbeiten. ${ }^{51}$ Neben der weitgehend bekannten Bedeutung Heinrichs II. als Auftraggeber sollte auch seine bisher weniger berücksichtigte Sammelleidenschaft älterer Preziosen berücksichtigt werden.

51 Im Aufsatzkatalog äußert Suckale-Redlefsen ein Unbehagen gegenüber den üblichen Modellen einer durch relativ ortsfeste Klosterwerkstätten getragenen Buchmalerei, mit denen ihrer Meinung nach der Austausch und die Wechselwirkungen kaum befriedigend zu erklären sind. SuckaleRedlefsen stellt die Buchmalerei in den Kontext einer heinrizischen Kunst. Sie verlagert damit die Abhängigkeit aus einem Werkstatt- beziehungsweise Schulzusammenhang in eine konzeptionelle Annäherung an eine Art „Hofkunst“ mit Rezeption verschiedener Werkstätten. Ob diese Thesen von der weiteren Forschung bestätigt werden, wird sich in zukünftigen Studien zeigen. Vgl. Suckale-Redlefsen, Gude: Prachtvolle Bücher zur Zierde der Kirchen. In: Kirmeier u.a. 2002, S. 52-77. 


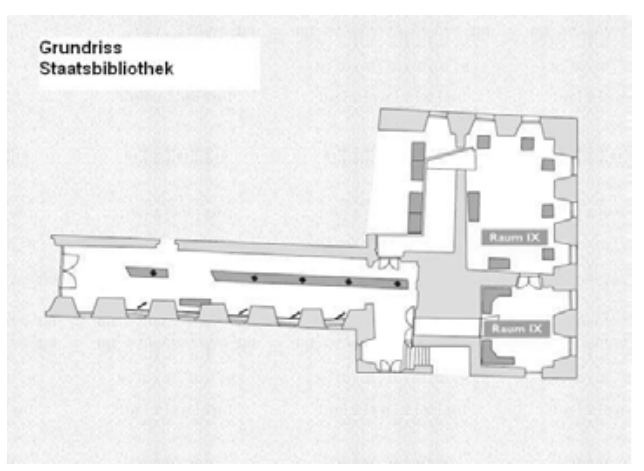

Abbildung 34:

Grundriss Staatsbibliothek.

Die Buch-Stiftungen Heinrichs II. wurden unter drei Schwerpunkten präsentiert. Teile des Bamberger Domschatzes konnten durch Leihgaben aus München sowie durch die Bestände der Bamberger Staatsbibliothek gezeigt und damit die Frühphase einer Hofkunst Heinrichs II. vorgestellt werden. Da das „Regensburger Sakramentar“52 des Bamberger Doms ausgebunden war, bot sich die einmalige Möglichkeit, mehrere Bildseiten nebeneinander und gleichzeitig den kostbaren Einband zu zeigen. Dieser Codex dokumentiert die Frühphase des heinrizischen Stiftungswerkes. Für die darauf folgenden Ausdrucksformen heinrizischer Kunst standen das „Evangeliar“ aus München ${ }^{53}$ sowie die „Bamberger Apoka-

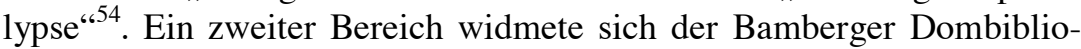
thek, die Heinrich II. einrichten ließ und die von Zeitgenossen als vorbildlich gerühmt wurde. Heinrich, der selbst eine geistliche Bildung genossen hatte, sorgte durch die Gründung der Bamberger Domschule in besonderer Weise für die Ausbildung des hohen Klerus. Neben wissenschaftlichen Lehrbüchern, von denen ein repräsentativer Teil im Diözesanmuseum vorgestellt wurde, gab es in dieser Sammlung illuminierte Kommentarhandschriften, die in der Staatsbibliothek gezeigt wurden. Neben Dom und Domschule bedachte Heinrich II. auch andere Orte mit Buchstiftungen, so zum Beispiel das Kollegiatstift St. Stephan und das Benediktinerkloster St. Michael. Seine besondere Verehrung für das Mutterkloster des Benediktinerordens Montecassino brachte er ebenfalls durch die Stiftung eines kostbaren Evangeliars zum Ausdruck. ${ }^{55}$

52 Kirmeier u.a. S. 268, Nr. 112.

53 Ebd., S. 303, Nr. 135.

54 Ebd. S. 287, Nr. 122.

55 Ebd., S. 275, Nr. 115. 
Unter dem Thema Buch-Stiftungen von Verwandten und Gefolgsleuten Heinrichs II. wurde eine Auswahl von Prunkhandschriften kaisernaher Reichsbischöfe und Äbte gezeigt, die anhand von Miniaturen mit deutlichen Bezügen zu heinrizischen Werken die Ausstrahlung dieser Kunst auf die Buchproduktion des Reiches aufzeigen sollten.

\section{Diözesanmuseum}

In fünf Ausstellungsräumen im Diözesanmuseum versammelte sich die Schatzkunst der Heinrichszeit mit Textilen und sakralen Stiftungen. Goldschmiedearbeiten und Elfenbeinschnitzereien, Handschriften und seidene Gewänder bezeugen den hohen Stand des Kunsthandwerks.

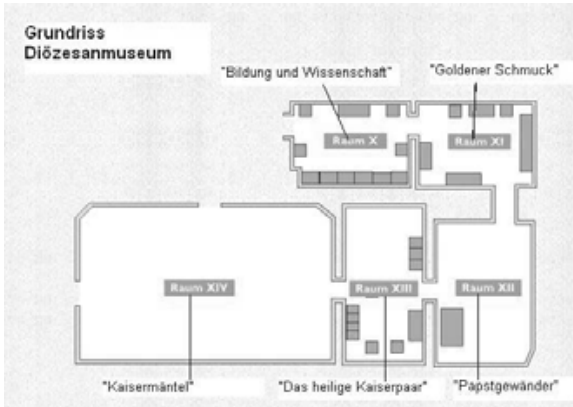

Abbildung 35:

Grundriss Diözesanmuseum.

Der erste Raum widmete sich dem Thema „Bildung und Wissenschaft“ und zeigte Handschriften, die den Grundstock für die neu eingerichtete Bibliothek der Domschule bildeten. Einige dieser Bücher stammten aus der Bibliothek Ottos III. in Piacenza oder von Gerbert von Aurillac. Andere stammten aus Frankreich und Italien. Die Handschriften sollten den geistlichen Bildungshorizont sowie das wissenschaftliche Erkenntnisinteresse Heinrichs II. und seiner Umgebung zeigen.

Der zweite Raum unter dem Titel „Goldener Schmuck“ zeigte den Kirchenschatz Heinrichs II. mit filigranen Elfenbeinschnitzereien, edelsteinbesetzten Kreuzen, Kelchen, reich verzierten Tragaltären und kostbar eingebundenen Handschriften (siehe Abb. 36). An kostbaren Exponaten zu sehen waren zum Beispiel das „Elfenbein mit der Himmelfahrt 
Christi“ ${ }^{* 56}$, der „Wattenbacher Tragalter“57 sowie der „Abtsstab des hl. Godehard“" ${ }^{65}$.

Auch in den Jahrzehnten nach Heinrich II. blieb die Reichskirche eng verbunden mit dem Papsttum, wie im dritten Raum „Papstgewänder“ mit dem Papstornat sowie weiteren Textilien deutlich wurde. Der zweite Bamberger Bischof Suidger wurde 1046 als Clemens II. zum Papst gewählt. In seinem Grab in Bamberg, dessen Inhalt erst im Jahr 1942 geborgen wurde, haben sich bedeutende Textilien erhalten. Eine Untersuchung ergab, dass der Papst in einem vollständigen Ornat bekleidet bestattet worden war. Seidengewebe wie „Pontifikalstrümpfe“"59 oder „Dalmatika“60 blieben nahezu vollständig erhalten, während die Unterkleider aus Seide zerfallen waren.

Dem Kaiser der Kirche war ein vierter Raum „Das heilige Kaiserpaar" gewidmet. Zu den von Heinrich II. erworbenen liturgischen Gegenständen reihten sich Kultobjekte aus der Zeit, als der Kaiser und seine Gemahlin Kunigunde selbst zum Gegenstand der Erinnerung und Verehrung geworden waren, so zum Beispiel die „KaiserpaarMonstranz"61 sowie das „Reliquiar des Hl. Kaisers Heinrich II.“62

Den krönenden Abschluss des Rundgangs durch das Diözesanmuseum bildete der prachtvolle Schatz der Kaisermäntel (siehe Abb. 37). Neben weiteren erlesenen Textilien wie dem „Blauen Kunigundenmantel“63 galt als Höhepunkt des Raumes der „Sternenmantel Kaiser Heinrichs II.“ " ${ }^{64}$ (siehe Abb. 57), den Fürst Ismael aus Apulien dem Kaiser bei seinem Besuch in Bamberg im Jahr 1020 überreichte. Die Stickereien auf dem kostbaren Geschenk aus byzantinischer Seide bilden das Himmelsgewölbe ab und preisen Heinrich als Zierde Europas.

56 Ebd., S. 227, Nr. 169.

57 Ebd., S. 334, Nr. 167.

58 Ebd., S. 328, Nr. 161.

59 Ebd., S. 353, Nr. 182 D.

60 Ebd., S. 352, Nr. 182 B.

61 Ebd., S. 372, Nr. 195.

62 Ebd., S. 364, Nr. 189.

63 Ebd., S. 380, Nr. 202.

64 Ebd., S. 382, Nr. 203. 


\section{Alte Hofhaltung}

In der Alten Hofhaltung spannte sich ein dramaturgischer Bogen, beginnend mit der Darstellung der Lebensumwelt um die Jahrtausendwende über die wichtigsten Etappen der zweiundzwanzigjährigen Regierungszeit Heinrichs II. bis hin zum Vermächtnis des Kaiserpaars und der Erinnerung durch die Nachwelt.

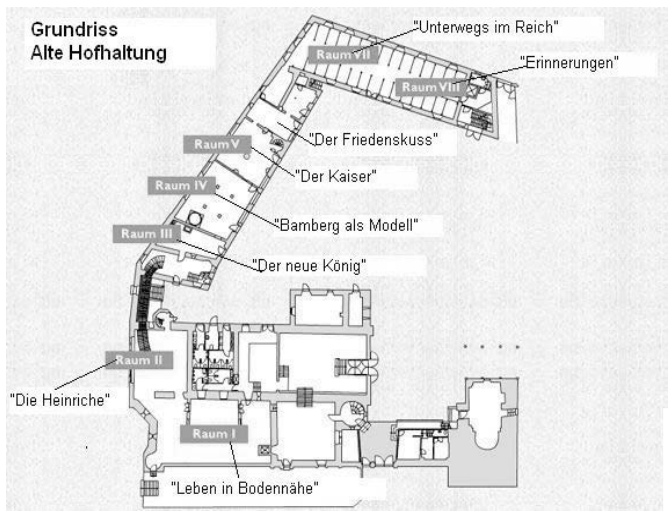

Abbildung 38:

Grundriss Alte Hofhaltung.

Im ersten Teil der Ausstellung wurde unter dem Raumtitel „Leben in Bodennähe" das soziologische Umfeld der Menschen im Mittelalter in Einzelaspekten illustriert. Archäologische Artefakte wie Schmuckstücke oder Kinderspielzeug, der Nachbau einer mittelalterlichen Vorratskammer, Informationen zu Krankheiten, zum Speiseplan und dem Problem begrenzter Konservierungsmöglichkeiten sowie einer Inszenierung zum Abgabensystem sollten den Alltag der Menschen, ihre Bedürfnisse, Ängste und Nöte schlaglichtartig beleuchten.

Im nächsten Raum „Die Heinriche“ wurde das bayerische Herzogtum Heinrichs sowie das seiner gleichnamigen Väter thematisiert. Die mit dem Herzogtum Bayern abgefundenen „Heinriche“ hatten ihren Anspruch auf die Königswürde niemals aufgegeben. Anhand der Stadt Regensburg als urbanes Zentrum zwischen Herzog, Bischof und König wurde vorgeführt, in welchem Rahmen sich das Leben in den großen Bischofssitzen mit ihrer römischen und karolingischen Tradition abspielte - von den Wegen, Waren und Welten des Handels über die Sakrallandschaft einer Bischofsstadt mit ihren Kirchen, Stiften und Pfalzan- 
lagen bis zur herrschaftlichen Repräsentation des Herzogs von Bayern in der Jugendzeit Heinrichs II.

In den anschließenden zwei Krönungsräumen „Der neue König“ wird das Herrschaftsverständnis sowie die Thronbesteigung von Heinrich II. thematisiert. Trotz erheblicher Vorbehalte mancher Fürsten setzte sich der bayerische Liudolfinger durch. Anhand des Reichsumritts, mit dem Heinrich II. in den Anfangsmonaten demonstrativ das gesamte Reich erfasste, wurde an sieben Stationen exemplarisch gezeigt, wie Heinrich seinen Machtanspruch und seine Autorität zur Geltung brachte. Die „Heilige Lanze“ ${ }^{65}$ als das wichtigste Krönungssymbol dieser Zeit wurde 1002 dabei zur zentralen und umkämpften Insignie.

Im Raum „Bamberg als Modell“ wurde am Beispiel der Gründung und Ausgestaltung Bambergs die charakteristische Herrschaft Heinrichs im Verbund mit den fortschrittlichen Organisationsformen der Kirche behandelt und damit die Funktion der Reichskirche vor Augen geführt. Selbst von adeliger Herkunft bildeten Bischöfe und Äbte das einigende Bindeglied zwischen Königtum und Adel.

Dem Kaisertum und Europa war der Raum „Der Kaiser“ gewidmet. Im Jahr 1014 erhielten Heinrich und Kunigunde in Rom von Papst Benedikt VIII. die Kaiserkrone. Mit dieser Krönung veränderte sich der Verantwortungsrahmen Heinrichs II., sein Horizont umfasste fortan Rom, das Papsttum und die benachbarten Reiche Europas. Der neue Anspruch und die Schutzfunktion gegenüber dem Papst führten zu scharfen Auseinandersetzungen mit Byzanz. Von großer Brisanz waren die Beziehungen zu Böhmen.

Der Raum „Der Friedenskuss“ thematisierte den Besuch des Papstes Benedikt VIII. und italienischer Fürsten im Jahr 1020. Damit erreichte im Jahr 1020 Heinrichs Herrschaft ihren Höhepunkt.

Im letzten Raum des Rundganges durch die Alte Hofhaltung im vorderen Bereich stand das Reisekönigtum „Unterwegs im Reich“ im Zentrum der Betrachtung. Für die Geschichtsschreiber der Heinrichszeit war das Reich schwer beschreibbar. Es besaß weder eine Hauptstadt noch feste Grenzen oder eine gemeinsame Sprache. Dennoch war dieses Reich erfahrbar: Heerzüge und Romfahrten, persönliche Kontakte über die verschiedenen Reichsteile hinweg und vor allem das beständige Bereisen dieses Herrschaftsraumes schufen trotz der großen Distanzen und der mühsamen Fortbewegungsmittel einen gemeinsamen Horizont und eine Handlungsebene. In dem permanenten Umritt lag eine große Leistung

65 Ebd., S. 177, Nr. 51. 
des Kaisers für die Integration des Reiches. Einige Facetten und Erfahrungen davon, die durchaus eine Herausforderung für Heinrich II. darstellten, wurden in dieser Abteilung vorgestellt.

Der hintere Bereich des letzten Raumes widmete sich unter dem Titel „Erinnerungen“ Kunigundes und Heinrichs Tod. Legenden rankten sich um das Leben von Heinrich und Kunigunde, die mit den historischen Personen des 11. Jahrhunderts nur wenig zu tun hatten. Zur Wirkung des einzigen heilig gesprochenen Kaiserpaars des Mittelalters gehört neben dem Kult auch eine andere, widersprüchliche Rezeption. Schon im 11. Jahrhundert erschien Heinrichs Kirchenherrschaft in einem zwiespältigen Licht. In der Tradition Joachims von Fiore konnte der Kaiser dann sogar zu einem Kopf der siebenköpfigen apokalyptischen Schlange werden.

\section{Das Präsentations- und Vermittlungskonzept}

Jede Ausstellung muss sich an die örtlichen Gegebenheiten einpassen. In Bamberg zeigte sich eine besondere räumliche Situation, die die Ausstellungsmacher zunächst vor Probleme stellte. Die Innengestaltung der Ausstellungsräume in der Staatsbibliothek durfte nicht verändert und die Vitrinen im Diözesanmuseum konnten nicht verrückt werden. Diese unveränderbare Tatsache hatte Konsequenzen für das Ausstellungskonzept. Es bedeutete, dass an diesen zwei Orten keine umfangreichen räumlichen Veränderungen vorgenommen werden konnten und somit auch keine Inszenierungen möglich waren. Diese strikte Vorgabe sahen die Ausstellungsmacher als Last, aber zugleich als Chance, indem sie eine bewusste Trennung zwischen zwei Schatzkammern einerseits und inszenierten Flächen in der Alten Hofhaltung sowie einem Mittelalterlichen Gehöft andererseits vornahmen.

„Die Einbindung mittelalterlicher Kostbarkeiten, seien es Prunkcodices oder Sakralgegenstände, in historische Erklärungszusammenhänge ist m.E. immer schwierig. Die hier vorgenommene Trennung zwischen museumspädagogischer Präsentation der historischen Ereignisse und der Zeitumstände in der Alten Hofhaltung einerseits und den kunsthistorisch zusammengestellten musealen Präsentation der Schatzstïcke in den beiden Schatzkammern andererseits gibt beiden Komplexen Eigenständigkeit und Würde.“66

66 Kirmeier, Josef: Landesausstellung „Kaiser Heinrich II.“ - Ein Resümee. In: Haus der Bayerischen Geschichte: Expertentagung „Ausstellung und 
Damit wurde eine reine Schatzkammer singulärer Glanzstücke vermieden. Vielmehr stand die Einbindung der präsentierten Prachthandschriften, Goldschmiedekunstwerke sowie einzigartiger Textilien in ihre Entstehungszusammenhänge und ursprüngliche Funktion im Vordergrund. „Der berühmte Sternenmantel Heinrichs II. begegnet nicht nur als Objekt kunsthistorischer Begierde, sondern auch als Zeichen mittelalterlicher Herrschaftspraxis.“ (Kirmeier u.a. 2002, S. 11) Den Besucher aus der Moderne herausholen, ihm die andere Umwelt des Mittelalters bewusst zu machen, war das Ziel des ersten Komplexes mit der Rekonstruktion des Mittelalterlichen Gehöfts sowie der Inszenierung der Lebenswelt Heinrichs II. in der Alten Hofhaltung. Das Mittelalterliche Gehöft mit seinen Nachbauten, Rekonstruktionen und Repliken ohne originale mittelalterliche Exponate legte den Schwerpunkt auf das sinnlich-haptische Erleben. Damit sollte die enorme Spannbreite, in der sich das Leben zwischen Lehmboden und goldbesticktem Seidengewand abspielte, den Besuchern sinnfällig vor Augen geführt werden. Das von der historischen Hofhaltung zum Leben erweckte Dorf hätte damit die Einordnung der Ausstellungsobjekte unterstützt. Aufgrund des Brandes des Mittelalterlichen Gehöfts reduzierte sich diese sinnliche Einstimmung auf die verkohlten Balken. Durch diesen unglücklichen Umstand fiel ein wichtiges Element im Gesamtkonzept der Ausstellung praktisch weg.

Die Rekonstruktion des Mittelalterlichen Gehöfts sowie der inszenierte Parcours durch die Alte Hofhaltung zur Lebenswelt um die Jahrtausendwende und der historischen Person Heinrichs II. mit Modellen und Repliken standen im extremen Gegensatz zur Präsentation in der Staatsbibliothek und dem Diözesanmuseum, die ausschließlich Originale zeigten. In Vitrinen aufgereiht wurden die wertvollen Pretiosen präsentiert. ${ }^{67}$ Aufgrund konservatorischer Bedenken konnten zwei Hauptstücke des Bamberger Domschatzes, das „Perikopenbuch Heinrichs II.“ und das „Evangeliar Ottos III.“, nicht im Original gezeigt werden. So nutzte man die Möglichkeit moderner Technologien. Im öffentlich genutzten Gang im Eingangsbereich der Staatsbibliothek standen in den Fensternischen EDV-Systeme, die den Besuchern ermöglichten, virtuell in den digitalisierten Handschriften zu blättern. An drei PC-Stationen konnten die Be-

Tourismus“ 26.-27.02.03 in Kloster Banz. http://www.hdbg.de/basis/05_ content_shop/content/6000_artikel_downloads/download-dateien/banz_ protokoll.pdf. (letzter Zugriff: 31.01.05).

67 Zum Zeigen der Bücherschätze Heinrichs II. wurden die in der Staatsbibliothek vorhandene Vitrinen genutzt. 
sucher entweder in den zwei genannten Handschriften sowie in der „Bamberger Apocalypse“ schmökern. Da auch im Diözesanmuseum keine umfangreichen baulichen Veränderungen möglich waren, nutzte man die dort vorhandenen Vitrinen. Die Exponate aus dem reichen Bestand des Diözesanmuseums wurden um Leihgaben ergänzt. Da Anzahl und Größe der Exponate nicht das gesamte Vitrinenvolumen beanspruchten, wurden diese durch eine vorgelagerte Verkleidung verborgen, so dass nur die benötigten Ausschnitte sichtbar waren. Ergänzt wurde die Präsentation in jedem Raum durch Raumtexte.

Bei der Vermittlung der Inhalte bediente man sich über Objektbeschriftungen und Raumtexte bzw. Inszenierung hinaus in den verschiedenen Ausstellungsbereichen unterschiedlicher Methoden. Gruppenführungen gab es ausschließlich im Bereich der Alten Hofhaltung. Mit dem Argument, dass bereits die Gestaltung in der Alten Hofhaltung sehr multimedial und anschaulich sei, verzichtete man dort im Gegensatz zum Diözesanmuseum und zur Staatsbibliothek auf einen Audioguide.

Als Angebot für die jüngeren Besucher gab es im gesamten Ausstellungsgelände einen Kinderpfad, der sich mit insgesamt acht Stationen auf die jeweiligen Ausstellungsorte - ausgenommen den Dom - verteilte (siehe Abb. 39). ${ }^{68}$ Den roten Faden dieses Kinderparcours bildete die Idee, als Gefolgsmann Heinrichs II. durch die Ausstellung zu reisen, um auf diesem Weg unterschiedliche Aufgaben zu erfüllen. Die Verknüpfung der einzelnen Stationen erfolgte anhand einer originell, farbenfroh und kindgerecht gestalteten Karte zum Ausfüllen, die die Kinder motivierte, in der Ausstellung selbst aktiv zu werden und auf Suche zu gehen. In der Staatsbibliothek sollten die Kinder den Anfangsbuchstaben ihres Namens in karolingischer Schrift nach einer Vorlage auf die Karte zeichnen. Im Diözesanmuseum stand ein Tisch mit zwölf Stempeln nach Motiven der Sternzeichen aus dem Sternenmantel Heinrichs II. Das eigene Sternzeichen sollte gefunden und auf die Karte gestempelt werden (siehe Abb. 40). Nach Erfüllen der sechs weiteren Aufgaben konnten sie ihren Lohn beim Münzmeister abholen, der - auch als Angebot für Erwachsene - eine Münzprägemaschine betreute.

68 Eine ausführliche Beschreibung des Kinderpfades sowie Hürden bei der Umsetzung siehe: Kaiser Brigitte: Museumspädagogik und Ausstellungsarchitektur. Der Kinderpfad in der Landesausstellung „Heinrich II.“ in Bamberg. In: Museum heute, Fakten - Tendenzen - Hilfen 24. (2002) S. 36-40. 
Die Verteilung auf fünf unterschiedliche Orte machte es außerdem nötig, dem Besucher Hilfestellung zur Orientierung im Ausstellungsgelände zu geben. Einen ersten Überblick erhielten die Besucher durch die Eintrittskarte, auf deren Rückseite eine Graphik mit den fünf Ausstellungsorten abgebildet war. Darüber hinaus waren im Ausstellungsgelände Hinweisschilder und großformatige Stelen verteilt, die jeweils den Eingangsbereich markierten und als Wegweiser eingesetzt wurden.

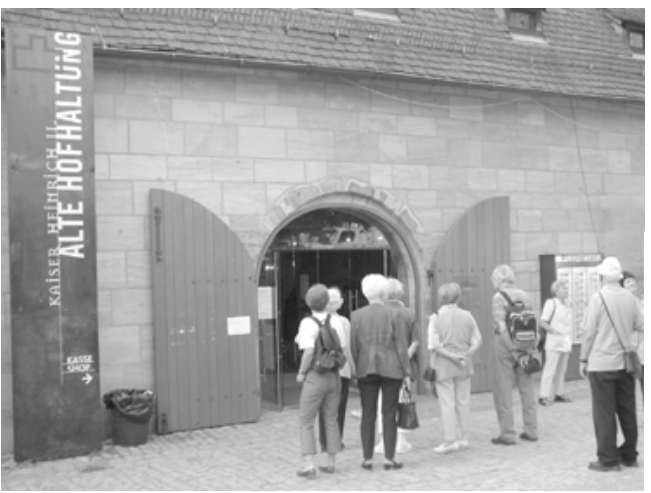

Abbildung 41:

Orientierungshilfen in Form von großformatigen Stelen aus Cortenstahl an den Eingängen der verschiedenen Ausstellungsorte.

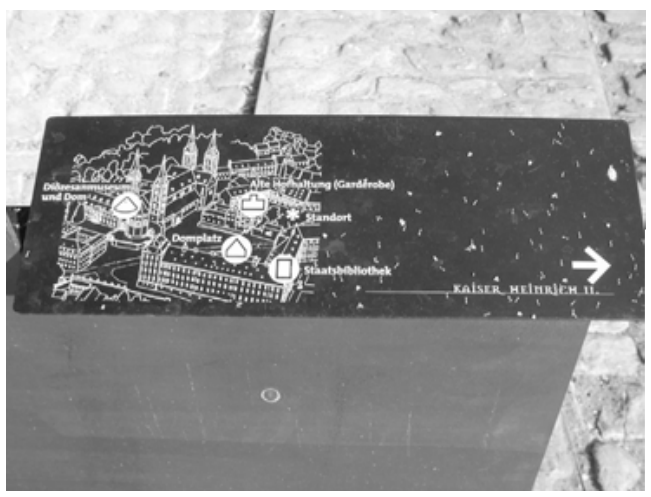

Abbildung 42:

Orientierungshilfen in Form von Hinweistafeln aus Cortenstahl mit Überblicksgraphiken zum Ausstellungsgelände. 


\subsection{Analyse unter den Dimensionen kommunikativer Strategien}

Insbesondere im Bereich der Alten Hofhaltung stand die Kommunikation der Inhalte mittels eines dramaturgisch inszenierten Parcours unter Einsatz einer Vielzahl von Medien im Vordergrund. Aus diesem Grund konzentriert sich die Ausstellungsanalyse auf diesen Teil. Neben Überlegungen grundsätzlicher Art sollen anhand exemplarisch ausgewählter Inszenierungseinheiten, die ausführlicher beschrieben werden, Reflexionen zu den vier Dimensionen kommunikativer Strategien erfolgen. Die Ergebnisse aus den zwei Besucherbefragungen ergänzen diese um einem weiteren Blickwinkel.

\section{Anschaulichkeit}

Ausstellungen als räumliche Organisation in einem vorgegebenen Gebäude stellen in besonderem Maße Anforderungen an die gestalterische Umsetzung. Diese haben die Aufgabe, nicht nur den Exponaten einen adäquaten Rahmen zu bieten, sondern die komplexen Inhalte anschaulich und begreifbar zu machen. Neben der Vermittlung durch Texte lässt die Gestaltung eine Ausstellung sinnlich erfahrbar werden. In der Alten Hofhaltung griffen die Ausstellungsmacher auf eine umfangreiche $\mathrm{Pa}-$ lette inszenatorischer sowie didaktischer Möglichkeiten zurück.

Die Architektur der Alten Hofhaltung zeichnet sich durch eine starke Eigencharakteristik aus. Die historischen Gemäuer stammen von unterschiedlichen Bauphasen vom 11. bis ins 19. Jahrhundert. ${ }^{69}$ Allein diese Tatsache bewirkte, dass jeder Raum eine eigene Wirkung entfaltete. Diese Eigencharakteristik der Räume griffen die Gestalter entweder auf oder drängten sie mit der Intention zurück, für jede thematische Einheit ein einprägsames Raumbild zu schaffen.

„Aus der Besucherforschung wurde klar, dass sich Besucher nur in sehr geringem Teil an Ausstellungsobjekte erinnern können. Aus diesem Grund arbeiten wir insbesondere in der Alten Hofhaltung mit visuellen Eindrücken.“ ${ }^{\text {70 }}$

69 Burandt, Walter: Die alte Hofhaltung in Bamberg: Kaiserpfalz und Bischofspfalz. Bamberg, 1999.

70 Interview mit Herrn Dr. Josef Kirmeier, Projektleitung der Landesausstellung „Kaiser Heinrich II. 1002-1024“ des Hauses der Bayerischen Geschichte, am 17. Oktober 2001. 
Die einzelnen Räumen standen nicht singulär nebeneinander, sondern entfalteten Bezüge über mehrere Räume hinweg. So wurden zum Beispiel die archäologischen Fundstücke nicht auf unterschiedlichen Ebenen frei in einer Vitrine, sondern in Bauchhöhe auf einer Ebene liegend gezeigt. Diese Höhe griff ein stilisiertes Landschaftsmodell auf und stellte damit fiktiv über mehrere Räume hinweg eine Verbindung her. Auch inhaltlich sollte dies den Bezug zum erdenhaften Dasein der damaligen Menschen assoziieren. Dies wiederum nahm Bezug auf ein lateinisches Zitat „Prospica Terrigenas“, welches sich als Teil einer Inschrift auf dem „Basler Antependium“" ${ }^{\text {"B }}$ befindet. Zugleich diente dieses Zitatfragment auch als Raumtitel „Prospica Terrigenas - Achte auf die Erdgeborenen“, das ebenfalls auf Bauchhöhe an der Eingangswand des ersten Ausstellungsraumes angebracht war. Dieser erdenhafte Bezug wurde erneut im Bereich „Der neue König“ aufgegriffen. Auch dort sollten die amorph geschwungenen Vitrinen und deren Einkerbungen auf der Vitrinenoberfläche Landschaft und Wege assoziieren. Damit durchschritten die Besucher erneut fiktiv die Erde. ${ }^{72}$

Trotz der einerseits akzentuierten innenarchitektonischen Gestaltung, die jedem Raum seine eigene Prägung verlieh, gab es andererseits kontinuierliche Strukturen, die sich im gesamten Ausstellungsparcours in jedem Raum wiederfanden und dem Besucher damit einen übergeordneten Orientierungsrahmen gaben.

Zur ersten thematischen Einordnung des Raumes gab es auf schriftlicher Ebene zwei Hinweise. Zum einen erfolgte dies durch die Titel der Raumtexte, die sich an den PC-Informationsystemen befanden. Einen zweiten inhaltlichen Verweis gaben Titel in lateinischer Sprache, die in die Raumgestaltung eingebunden waren, sich meist an den Vitrinen auf Bauchhöhe befanden und somit zum Teil erst auf den zweiten Blick bei genauerer Betrachtung entdeckt werden konnten.

$\mathrm{Zu}$ jeder Raumeinheit standen PC-Informationssysteme als Infopools zur Verfügung. Diese waren eine Kombination aus einer Leuchtgraphik als Raumtext sowie einer PC-Station. Die Leuchtgraphik beinhaltete drei Spalten mit circa zehn bis höchstens zwanzig Zeilen für den deutschen und englischen Text sowie eine Nebenspalte mit Platz für eine ergänzende Illustration in Form einer Karte, eines Zitats oder eines Bildes. Über diese Grundinformationen hinaus konnten die Besucher anhand dieser PC-Station weitere Informationen zu ausgewählten Objekten abrufen.

71 Kirmeier 2002, S. 130ff., Nr. 11.

72 Beschreibung der Räume "Der neue König" siehe Kapitel 6, S. $334 f$. 
Neben inhaltlichen Erläuterungen zu den Exponaten stellte dieses Medium einen Überblick zum gesamten Ausstellungsgelände sowie Grundrisse zu den einzelnen Ausstellungsräumen zu Verfügung. Damit konnten sich Besucher eine Orientierung im gesamten Ausstellungsgelände sowie jeweils in den Ausstellungsräumen verschaffen. ${ }^{73}$

„Wir wollten keine Raumtexte an die Wand hängen, sondern wie am Bahnhof einen Informationspunkt, so dass sich die Besucher hier ihre Informationen selbst abholen können. Ein weiterer Beweggrund dafür war, die Moderne auf diese Weise zu integrieren und den Bezug zum Heute zu schaffen. Dies steuert gegen eine historisch schwerfällige Ausstellung. “74

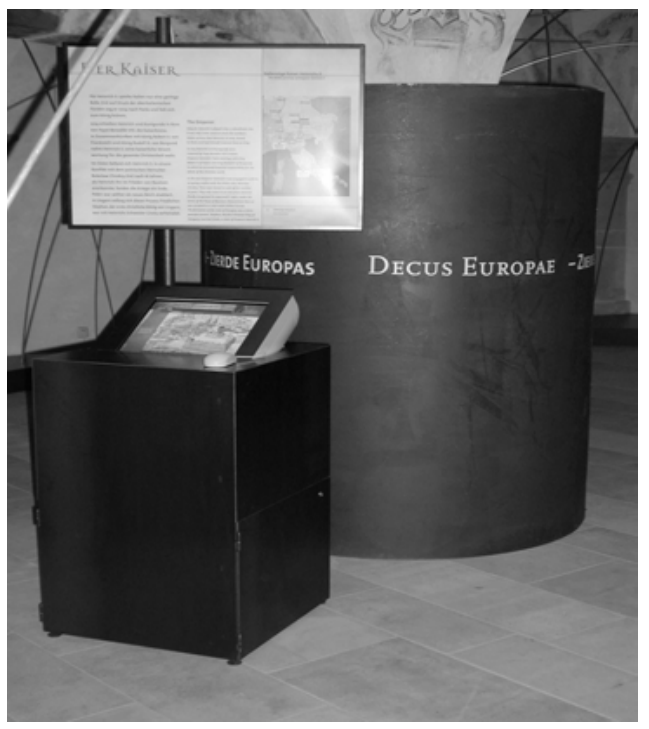

Abbildung 43:

PC-Informationssystem mit

Leuchtgraphik als Raumtext.

Neben den Raumtexten gab es weitere, zum Teil verdeckte Informationsebenen, die für das Verständnis des roten Fadens der Ausstellungsinhalte unbedeutsam waren, jedoch dem Interessierten eine Vertiefung ermöglichen sollten.

73 Diese Informationen stehen dem Publikum weiterhin auf einer Homepage zur Verfügung: http://www.heinrichII.de (letzter Zugriff: 12.01.05).

74 Interview mit Herrn Uli Prugger, Gestaltungsbüro Gruppe Gut in Bozen, am 8. Juli 2002. 


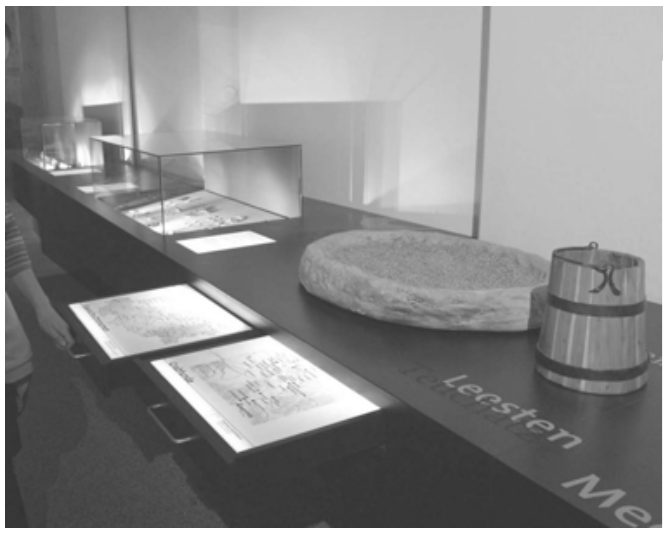

Abbildung 44:

Versteckte zweite Ebene mit Informationen:

Im Raum „Leben in

Bodennähe" befanden sich im Vitrinenunterbau zwei Schubläden. Ergänzend zu den archäologischen Exponaten enthielten diese Karten zu den slawischen Fundorten.

Die Vitrinen traten nicht dominant in den Vordergrund, sondern waren in das innenarchitektonische Gestaltungskonzept integriert. Statt Standardformen oder -größen waren sie den jeweiligen Ausstellungsobjekten angepasst. Im Wesentlichen gab es drei unterschiedliche Formen. Die individuell den Objektmaßen angepassten Wandvitrinen waren bündig in die Wandvorbauten integriert. Die Tischvitrinen bildeten geradlinige, kubusartige Formen mit meist schwarzer Verkleidung des Sockels, in deren Oberfläche die Glasquader der Vitrinen integriert waren und deren Böden unter die Oberfläche des Sockels versenkt waren. Die Raumvitrinen setzten sich aus einem schwarzen Unterbau und einem schlichten Glaskubus zusammen. Die Sockel für Großobjekte wie zum Beispiel für das „Basler Antependium“ glichen denen der Raumvitrinen.

Für die Objektbeschriftungen wählten die Veranstalter zwei Formen. Entweder lag direkt in der Vitrine zum Objekt benachbart ein Plexiglastäfelchen mit weißer Schrift oder die Beschriftung befand sich in der Nähe der Vitrine oder des Objekts als hinterleuchtete Graphik. Inhaltlich waren sie einheitlich gestaltet. In der ersten Zeile stand eine Nummer, die mit der Zahl im Katalog identisch war und der Titel des Objekts. Als nächstes folgten die objektbezogenen Informationen mit Angaben zu Datierung, Material sowie Leihgeber. Als drittes gab es in durchschnittlich vier Zeilen Kontextinformation, die zum inhaltlichen Verständnis beitrug. 


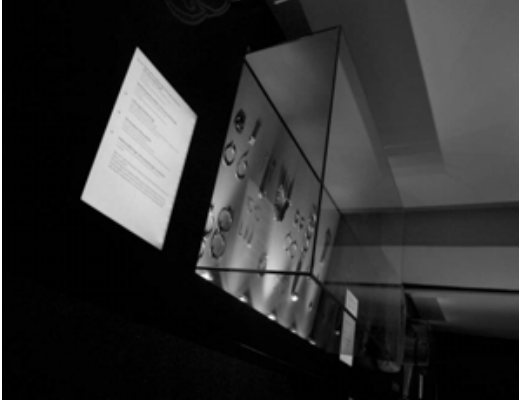

Abbildung 45: Beschriftung mit Leuchtgraphik.

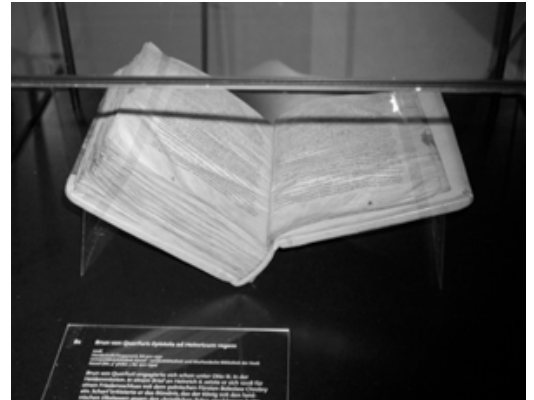

Abbildung 46: Beschriftung mit Plexiglastäfelchen in weißer Schrift.

Beim Werkstoff setzten die Gestalter auf einfache, aber gezielt ausgewählte Materialien: ungehobelte Bretter, schwarzes und braunes $\mathrm{MDF}^{75}$ sowie angerosteter Cortenstahl. Neben wenigen weiteren Farben und Stoffen bestimmten diese drei Hauptmaterialien die Farbigkeit der gesamten Ausstellung und dienten auch als Leitsystem. ${ }^{76}$ Mit den ungehobelten Brettern sollte ein Bezug zur Einfachheit der damaligen Lebenswelt in Analogie zur Rekonstruktion des Mittelalterlichen Gehöfts assoziiert werden. Der vorgerostete Stahl entsprach nach Ansicht der Gestalter dem ambivalenten Charakter Heinrichs II. als streng Gläubigem und gleichzeitig machtbewusstem Politiker, da auch dieses Material zwei konträre Eigenschaften birgt.

„Der Cortenstahl hat ebenfalls eine innere Wärme. Dieses Material ist aber auch hart und kalt, symbolisch passt dies gut zur Persönlichkeit Heinrichs II., der in den Archivalien als durchaus ambivalente Persönlichkeit dargestellt wird. [...] Es ist kein Fremdmaterial wie eine Inoxstahlplatte.“"77

75 MDF ist die Abkürzung für mitteldichte Faserplatte. Dieser Holzwerkstoff hat in alle Richtungen ein homogenes Gefüge. Die Holzfasern werden wie eine dicke Pappe zu einer Platte gepresst. MDF-Platten haben eine besonders feine Oberfläche. Die Platten werden oft farbig lackiert und im Möbelbau, im Innenausbau oder als Paneele verwendet.

76 Dies steht im Gegensatz zu einer oft praktizierten Variante, bei der Farben Themen zugeordnet werden, um inhaltliche Abgrenzungen zu markieren.

77 Interview mit Herrn Uli Prugger, Gestaltungsbüro Gruppe Gut in Bozen, am 8. Juli 2002. 
Eingangsinszenierung: „Bamberger Götzen“ in Gegenüberstellung zum „Basler Antependium“ (siehe Abb. 47)

Der erste Eindruck im Ausstellungsparcours durch die Alte Hofhaltung wurde durch die Eingangsinszenierung bestimmt. Sie zeigte eine mit blauem Licht angestrahlte „Gruppe Antropomorpher Steinfiguren“78 ${ }^{\text {“78 }}$ die auch als „Bamberger Götzen“ bezeichnet werden. Diese befanden sich auf einer Anschüttung von Steinen in Gegenüberstellung zu einer Kopie des „Basler Antependiums“ am Ende der Raumflucht. Das blaue Licht sollte den Fundort im Wasser sowie den Wasserkult andeuten. Die rechte Wandseite war mit wilden gestischen Spuren in rot, braun und weißer Farbigkeit bemalt. Inhaltlich sollte damit das primitive, unzivilisierte Dasein und auch der Kontrast zwischen heidnischer und christlicher Welt angedeutet werden. Eine in diese bemalten Wand eingelassene Vitrine zeigte Kleinobjekte zu christlichen und heidnischen Glaubenswelten.

Das Original des „Basler Antependiums“ stellt ein einzigartiges, höchst kostbares Kunstwerk dar. Durch die Art der Präsentation - ungeschützt ohne Sicherheits- und Klimavitrine, vom Besucher lediglich durch eine Holzrampe abgeschirmt - gingen die Ausstellungsmacher davon aus, dass dies neben einem Hinweis in der Objektbeschriftung den Besuchern deutlich mache, dass es sich hierbei nicht um das Original handeln könne. ${ }^{79}$

An dieser Inszenierung traten die konkurrierenden Erfahrungsformen von historischer und ästhetischer Erfahrung zutage. Als inhaltliche Einführung sollte sie einen Spannungsbogen zwischen der noch kultisch,

78 Kirmeier u.a. 2002, S. 127ff., Nr. 10.

79 Im Hinblick auf die Fähigkeit der Unterscheidung zwischen Replik und Original stellte Herr Prof. Schemmel, Direktor der Staatsbibliothek Bamberg, aufgrund seiner eigenen Erfahrungen ernüchtert fest, dass die meisten Menschen ein Faksimile von einem Original in ihrer Wertschätzung nicht unterscheiden konnten. Dabei verweist er auf ein Erlebnis, welches er im Zusammenhang mit der Präsentation eines Faksimiles einer Handschrift von Heinrich den Löwen hatte. Mit Erstaunen, Bewunderung und großer Resonanz hatte das Publikum aufgrund von Medieninformationen wahrgenommen, dass in der Staatsbibliothek dieses ausgestellt sei. Ein Faksimile mit einem Wert von lediglich circa 15000 Euro steht jedoch in keinem Verhältnis zum Original, mit einem schätzbaren Wert von circa 15 Millionen Euro. Vgl. Interview mit Herrn Prof. Dr. Bernhard Schemmel, Direktor der Staatsbibliothek Bamberg, am 20. Nov. 2001. 
heidnisch geprägten Welt der einfachen Menschen und der kunsthandwerklich hochrangigen, glanzvollen christlichen Sakralkunst bilden. Durch die Art der Präsentation erfolgte indirekt eine Bewertung, die auch die dementsprechende Wertzuschreibung bestimmte. Das Gold der Replik erstrahlte im hellen Licht. Demgegenüber traten die amorphen Steinfiguren angestrahlt mit blauem Licht in den Hintergrund und erfüllten eine hinführende Funktion. Die Replik erfuhr damit einen höheren Stellenwert als das Original. „Die Objekte könnten ebenso aus Pappmache oder Gips sein, wie das Basler Antependium. Dies wirkt ebenfalls sehr prächtig. Zwischen Original und Replik wird nicht unterschieden." ${ }^{\text {" } 0}$

Die „Gruppe Anthropomorpher Steinfiguren“ bildet eines der Glanzstücke der Sammlung des Historischen Museums in Bamberg (siehe Abb. 48). Die Figuren mit kaum erkennbaren Gesichtern und durch Rillen und Wülste angedeuteten Gewändern wurden 1858 aus der Regnitz geborgen. Die Schätzung des Alters reicht von der Jungsteinzeit bis in das erste Jahrtausend nach Christus. Die Bandbreite der Deutungen zu diesen Figuren ist groß. Sie geht von heidnischen Götzendarstellungen bis zu frühchristlichen Glaubenszeugnissen. Nach aktueller Forschungslage wird, wie im Katalog dargestellt, eine Deutung als heidnische Kultobjekte in Frage gestellt und stattdessen eine Interpretation der Steinfiguren als frühe, christliche Bildzeugnisse von Bischöfen favorisiert.

„[...] Vergleiche mit Kult- oder Grabstelen aus dem steppennomadischen wie auch slawischen Milieu [sind, Anm. d. V.] schlecht möglich, wo Figurengruppen kaum nachzuweisen sind und die Gottheit, zumindest im westslawischen Bereich, in der Einzahl verehrt wurde. Dagegen ist für die christliche Bildsymbolik die Darstellung von Personengruppen nicht ungewöhnlich.““81

Trotz der Unzulänglichkeit aller Interpretationsversuche im Hinblick auf die Frage, ob es sich bei diesen Objekten um Zeugen christlicher oder heidnischer Glaubensvorstellungen handelt, sind diese Figuren einzigartige Zeugnisse früher Religionsvorstellungen. Die Einmaligkeit dieser Exponate wurde in dieser Aufstellung nicht zur Geltung gebracht. Auch eine Objektbeschriftung, die auf diesen Sachverhalt aufmerksam machte,

80 Interview mit Frau Dr. Regina Hanemann, Direktorin der Museen in Bamberg, am 2. Sept. 2002.

81 Haberstroh, Jochen: Gruppe Anthropomorpher Steinfiguren - Die Bamberger Götzen - ein Zeugnis vorchristlicher Kultvorstellungen? In: Kirmeier u.a. 2002, S. 129. 
genügt nach Ansicht von Hanemann, Direktorin des Historischen Museums, nicht. ${ }^{82}$ Um der historischen Bedeutung entsprechend gerecht zu werden, hätten die Exponate in einer anderen Form präsentiert werden müssen: beispielsweise zentral in den Raum gerückt, auf Sockeln hinter Vitrinenglas präsentiert und lichtdramaturgisch anders in Szene gesetzt.

Ein derartige Präsentationsform hätte jedoch wiederum nicht in das dramaturgische Gesamtkonzept der Ausstellung gepasst, in der es nicht darum ging, die Einzigartigkeit von Exponaten in den Vordergrund $\mathrm{zu}$ rücken. Vielmehr wurde den erzählerischen Qualitäten der Objekte ein höherer Stellenwert eingeräumt. Das Anliegen des ersten Raumes in der Alten Hofhaltung bestand darin, die Lebensumwelten um die Jahrtausendwende in ausgewählten Einzelaspekten zu illustrieren. Eine ähnliche Diskrepanz zwischen der historischen Bedeutung des Exponats sowie der Art der Präsentation zeigte sich auch am Ende des Rundganges durch die Alte Hofhaltung im letzten Ausstellungsraum, dem ehemaligen Marstall.

Der Raum: „Unterwegs im Reich“ (siehe Abb. 49), Koje „Der Sarkophagtrog aus dem Bamberger Dom“ (siehe Abb. 50)

Inhaltlich untergliederte sich dieser Raum in zwei Bereiche. Die vorderen acht gegenüberliegenden Kojen gehörten zum Thema Reisekönigtum. Der hintere Bereich widmete sich dem Andenken an das Herrscherpaar und der Legendenbildung. Die heutige Architektur ist auf das Jahr 1740 zurückzuführen. ${ }^{83}$ Zur Verdeckung der barocken Architektur installierten die Gestalter an die Decke Bandeisen, an denen weiße und graue Stoffbahnen hingen. Damit wurde die barocke Formensprache der Architektur, die nicht zur mittelalterlichen Thematik passte, verdeckt. Der Kojencharakter selbst blieb dadurch jedoch erhalten. Gleichzeitig diente dieser Vorhang als Träger für Hintergrundinformationen in Form von Texten und Graphiken. Das Erscheinungsbild im Marstall wurde somit durch eine serielle Aneinanderreihung der ehemaligen Pferdeboxen geprägt, die unterschiedlich mit in Vitrinen präsentierten Archiva-

82 Interview mit Frau Dr. Regina Hanemann, Direktorin der Museen in Bamberg, am 2. Sept. 2002.

83 Die Pferdeboxen des heutigen Marstalles mit ihren Arkadenbögen nehmen Bezug auf die barocke Eingangstür, über die mehrere Jahreszahlen gemalt sind, unter anderem das Jahr 1740. Eine dendrochronologische Untersuchung bestätigte diese Jahreszahl als Erbauungszeit des Stalles. Vgl. Burandt 1999, S. $61 \mathrm{ff}$. 
lien oder musealen Exponaten, PC-Stationen, Hands-on Objekten oder Inszenierungen bestückt waren. Im dramaturgischen Konzept bildete der Marstall einen abschließenden Höhepunkt mit einem abwechslungsreichen Angebot zum Sehen, Hören und Anfassen. Entgegen der sogenannten Ausstellungsmüdigkeit sollte die Vielfalt dieses Angebots die Leute nochmals in ihrer Aufmerksamkeit wachrütteln.

Eingereiht in dieses Konglomerat unterschiedlichster Exponate sowie Präsentationsformen befand sich in einer Koje im Marstall der „Sarkophagtrog aus dem Bamberger Dom“" ${ }^{* 4}$. Dieses Ausstellungsstück zählte zu den herausragenden Objekten in der Alten Hofhaltung. In der Nachbarschaft zu Hands-on Objekten und Medienstationen wurde es jedoch in seiner Besonderheit marginalisiert.

Die Eingangsinszenierung sowie die Präsentation des Sarkophagtrogs bilden zwei Beispiele für den Wahrnehmungskonflikt zwischen historischer und ästhetischer Erfahrung. Das Ansprechen unterschiedlicher Sinne und die abwechslungsreiche Präsentation lässt sich aus dramaturgischen Überlegungen einer besucherorientierten Perspektive rechtfertigen. Der Einsatz von Repliken sowie die illustrative Nutzung der Objekte entsprach im Bereich der Alten Hofhaltung den Zielen der Ausstellungsmacher:

„Die historische Ausstellung sieht ihre Aufgabe darin, die Objekte in dieser Form zu nutzen. Die kunsthistorische Ausstellung würde andere Perspektiven haben. Sie würde die Reichenauer Buchmalerei vergleichen. Sie würde diese jedoch nicht in den Kontext eines Herrschers und seiner Lebensverhältnisse stellen. ${ }^{85}$

Die Dramaturgie des narrativen Ansatzes erhielt einen höheren Stellenwert als die Einzigartigkeit der Exponate. Das Ziel der Ausstellungsmacher bestand in der Alten Hofhaltung darin, die Lebenswelt um die Jahrtausendwende anhand von inszenierten Raumbildern zu illustrieren. Dieses Anliegen lag höher als die Betonung der Kostbarkeit der Exponate. Aus der Perspektive der Ausstellungsmacher und im Hinblick auf

84 Kirmeier u.a., 2002, S. 256ff., Nr. 103. Die Zuschreibung des 1969/72 gefundenen Sarkophags an Heinrich II., Kunigunde oder anderen Würdenträgern ist bis heute offen, formal lässt er sich einer ottonisch-romanischen Oberschichtbestattung zuweisen.

85 Interview mit Herrn Dr. Josef Kirmeier, Projektleitung der Landesausstellung „Kaiser Heinrich II. 1002-1024“ des Hauses der Bayerischen Geschichte, am 17. Oktober 2001. 
die für die Alte Hofhaltung formulierten Vermittlungsziele kann deshalb diese Form der Präsentation gerechtfertigt werden.

Demgegenüber bestand das Ziel der Präsentation im Diözesanmuseum, die Pretiosen der Ausstellung ihrem hohen Wert entsprechend im Stile einer Schatzkammer zu zeigen. Allerdings wurde die Präsentation im Diözesanmuseum nur bedingt diesem Anliegen gerecht. Die äußerst hochrangigen Exponate wurden nebeneinander aufgereiht präsentiert (siehe Abb. 36). Damit entstand ein serieller Charakter, der eine Sakralisierungen und Auratisierung der Objekte behinderte. „Wenn ich alles auf einen Sockel stelle, mache ich es gleichwertig. ${ }^{\text {" }} 6$ Obgleich in diesem Fall nicht die Gefahr der Verwechslung mit einer Replik bestand, wurde die Kostbarkeit der Exponate nicht in vollem Maße zur Wirkung gebracht. Vergleichsweise sinnvoll wäre eine aneinanderreihende Präsentation von musealen Exponaten, wenn diese auch in ihrem historischen Kontext nichts Exklusives, sondern Massenprodukte waren. ${ }^{87}$

In diesem Zusammenhang verweist Hanemann auf die Präsentation des Teppichs von Bayeux. ${ }^{88}$ Erst nachdem die Besucher in Bayeux einen langen Informationsparcours mit Texten und Filmen durchschritten haben, werden sie zum Höhepunkt, dem originalen Teppich, vorgelassen. „Am Ende schaut man diesen Teppich wirklich ehrfürchtig an, man hat alles darüber gelernt." Die Präsentation des Teppichs von Bayeux erfüllt konservatorische Anforderung und dennoch wird das Erlebnis dieses Teppichs besucherorientiert inszeniert. Auch die Kaisermäntel des Diözesanmuseums böten hier nach Ansicht Hanemanns reichhaltiges Potential. $^{89}$

86 Interview mit Herrn Kurt Ranger, Büro Kurt Ranger Design in Stuttgart, am 20. März 2002.

87 Beispielsweise trifft dies auf viele erhaltene Keramiken der Griechen zu, die auch damals zur Alltagsware zählten.

88 In Bayeux, in der unteren Normandie in Frankreich gelegen, befindet sich das Museum „Teppich von Bayeux“. Auf dem aus dem 12. Jahrhundert stammenden Teppich, der 70 Meter lang ist, ist die Geschichte der Schlachten zwischen Engländern und Normannen zu Zeiten Wilhelm des Eroberers dargestellt.

89 Interview mit Frau Dr. Regina Hanemann, Direktorin der Museen in Bamberg, am 2. Sept. 2002. 


\section{Ergebnisse der Besucherbefragung}

Der Ausstellungsparcours zur Veranschaulichung der Lebenswelt um die Jahrtausendwende und der Herrscherpersönlichkeit Heinrichs II. bediente sich intensiv einer Vielzahl von Gestaltungsmitteln unter Einsatz optischer, haptischer sowie akustischer Medien. Dies führt zu der Frage, wie dieser Parcours vom Publikum wahrgenommen und bewertet wurde und was im Gesamtbild in Erinnerung blieb.

Ein Punkt der Besucherbefragung des Sozialwissenschaftlichen Instituts München ${ }^{90}$ befasste sich mit der „Bewertung der optischen Präsentation der Ausstellung“. ${ }^{91}$ Sie kommt zu dem Ergebnis, dass die überwiegende Mehrheit der Befragten die Ausstellung positiv einschätzte. Mit „sehr gut“ bewerten 28 Prozent, mit „gut“ 47 Prozent der Befragten die optische Präsentation (ebd., S. 82).$^{92}$ Insgesamt vermittelte die Ausstellung laut SIM ein harmonisches Gesamtbild (ebd. S. 83). Die Ergebnisse deuten darauf hin, dass die Besucher einen gewissen Gesamteindruck bezüglich der Ausstellung entwickelten, der sich auf die Bewertung der einzelnen Kriterien eher positiv oder eher negativ auswirkt.

„Die Bewertung der optischen Präsentation der Ausstellung hängt überdies eng mit der Einschätzung der eigenen Kenntnisse der europäischen Geschichte zusammen. Befragte, die ihre Kenntnisse eher als gering oder mittelmäßig bezeichnen, bewerteten die optische Präsentation etwas besser als die Befragten, die über hohe Kenntnisse verfügen." (ebd. S. 84)

„Versierte Ausstellungsbesucher/innen“, die aufgrund häufigen Ausstellungsbesuchs bessere Vergleichsmöglichkeiten haben und eventuell mehr auf Details der Präsentation achten und diese dann in ihre Bewertung mit einfließen lassen, beurteilten die optische Präsentation der Ausstellung kritischer als Befragte, die nur gelegentlich in einer Ausstellung waren (ebd. S. 85).

90 Um den Textfluss nicht zu behindern, werde ich im weiteren Text auf die Besucherbefragung des Sozialwissenschaftlichen Instituts München mit dem Kürzel „SIM“ verweisen.

91 Fröhlich/Nöthen 2003, S. 82-85.

92 Die Besucher konnten zwischen sieben verschiedenen Bewertungen wählen: sehr gut, gut, befriedigend, ausreichend, mangelhaft, ungenügend, keine Angabe. 
Auch in meinen persönlichen Interviews wurde die Gestaltung überwiegend positiv bewertet, obgleich auch Kritik angebracht wurde. Wirklich vernichtende Urteile, wie dies vereinzelt im Besucherbuch der Fall war, wurden im Gespräch mir gegenüber nicht geäußert. Das abwechslungsreiche dramaturgische Konzept der Alten Hofhaltung fand im Großen und Ganzen Anerkennung. Hervorgehoben wurde, dass dies eine lebendige Form sei, sich mit geschichtlichen Dingen zu befassen, die Lebenswelt kennenzulernen und das eigene Wissen zu erweitern.

„Dies sind interessante Informationen, die über den Schulunterricht und deren politgeschichtliche Inhalte hinausweisen.“ (Mutter, geb. 1960)

Die erste Frage im Rahmen der Interviews zielte auf das persönliche Erinnerungsvermögen. In Abhängigkeit von Vorwissen sowie persönlichen Präferenzen fielen die Antworten erwartungsgemäß sehr heterogen aus. Auch flossen in die Bewertungen momentane, subjektive Stimmungen ein. Bestätigt werden kann die Feststellung, dass als wichtige Einflussgröße auf die Wahrnehmung die Biographie des Besuchers fungiert.

„Tendenziell scheinen daher bei begünstigenden Bestimmungsgründen für die Merkfähigkeit im gegebenen Fall eher Individualeigenschaften und -präferenzen eine Rolle zu spielen. Dazu gehört das geäußerte starke grundlegende Interesse für kunst- und kulturgeschichtliche Museen. Sind solche thematischen Neigungen habituell ausgebildet, so tritt in nachvollziehbarer Weise bei entsprechenden Anlässen auch eine konzentrierte und nachhaltige Objektrezeption in Erscheinung. “93

Bei der Auswertung der Frage nach der prägnantesten Erinnerung kristallisierten sich drei Hauptgruppen heraus. Dieses waren inhaltsbezogene, objektbezogene oder gestaltungsbezogene Erinnerungen.

Die erste Gruppe mit inhaltsbezogenen Erinnerungen zählte historische Fakten auf, wie zum Beispiel die Vereinigung von kirchlicher und staatlicher Macht in der Person Heinrichs II. oder die beeindruckende Größe des Reichs.

Die zweite Gruppe mit objektbezogenen Erinnerungen führte ästhetisch beeindruckende Objekte an. Sehr oft wurden die kunstvoll gestalteten Handschriften in der Staatsbibliothek erwähnt, die aufgrund des Alters, der Aufwendigkeit und Kunstfertigkeit im Gedächtnis haften

93 Klein, Hans Joachim: Gemischtes Doppel. Evaluation der Ausstellung Spätmittelalter am Oberrhein in der Staatlichen Kunsthalle und im Badischen Landesmuseum, beide in Karlsruhe. Karlsruhe 2002, S. 94. 
blieben. Auffallend häufig zählte der „Sternenmantel Kaiser Heinrichs II.“ zu den am besten erinnerten Objekten. Es faszinierten die Größe, das Alter, die Motive und der gute Erhaltungszustand. ${ }^{94}$ Noch weitere Objekte wurden genannt, wie zum Beispiel der „Sarkophagtrog“, die „Replik der Reichskrone“" sowie die „Nachbildung der Heiligen Lanze“.

Eine dritte Gruppe verwies bei der Frage nach der prägnantesten Erinnerung auf gestalterische Aspekte der Ausstellung. Hier wurden zum Beispiel die Hands-on Angebote, die karikierende „Nachrichtensendung zum Papstbesuch in Bamberg“" oder die auffallende Innenarchitektur des Raumes „Der Kaiser“" genannt.

Diese eingangs weit gestellte Frage lässt erkennen, dass im Hinblick auf die Neigungen der Besucher drei Kategorien gebildet werden können. Aus diesem Grund habe ich mich für folgende Differenzierung entschieden. Dieses sind

\section{- historisch orientierte Menschen}

- objektorientierte Menschen

- allgemein visuell orientierte Menschen

Historisch orientierte Menschen lenken ihre Wahrnehmung zunächst auf Texte und wollen Zusammenhänge erfahren: Museale Objekte werden als Dokument und Ergänzung wahrgenommen. Hierbei ist der Laie vom Fachwissenschaftler zu unterscheiden. Diese Besuchergruppe zählt zu den äußerst Kritischen, die aufgrund ihrer historischen Fachkompetenz den Inhalt sachlich hinterfragen. Inszenatorische, abstrakte Elemente stoßen eher auf Ablehnung und Unverständnis, da der Bezug zur historischen Ausstellung fehlt.

Die zweite Gruppe konzentriert sich auf die Objekte der Ausstellung. Ihr primäres Interesse richtet sich darauf, die Originale zu betrachten. Der ästhetische Genuss der Objekte steht im Vordergrund. Das Erfassen von historischen Zusammenhängen und Ereignissen wird eher als anstrengend empfunden. Das Lesen über die Geschichte kann ihrer Meinung nach später an einem anderen Ort erfolgen.

Die dritte Gruppe der visuell orientierten Menschen lässt sich vom Gesamteindruck leiten. Texte werden nur ausschnitthaft gelesen, die mu-

94 Die häufige Nennung dieses Objekts lag sicherlich nicht nur an objektimmanenten Faktoren. Der Mantel befand sich am Ende des Rundgangs und war somit am frischesten in Erinnerung. Außerdem ist er vergleichsweise sehr groß und steht dominant in einer Vitrine zentral im Raum. 
sealen Objekte stehen in der Aufmerksamkeit gleichwertig neben anderen Medien. Sie lässt assoziative Stimmungen auf sich wirken, ihr Besuch entspricht einem freizeitorientiertem Verhalten.

Bei dieser Einteilung in drei unterschiedliche Interessensgruppen muss kritisch angemerkt werden, dass dies letztlich eine Vereinfachung der Wirklichkeit ist. Überschneidungen sind möglich; so kann ein Besucher sowohl objektorientiertes Verhalten zeigen und gleichzeitig aber auch den Unterhaltungswert der Ausstellung schätzen. Trotzdem hilft diese Kategorisierung dabei, Besuchermeinungen in Bezug zu Interessensschwerpunkten einzuordnen. In Abhängigkeit davon kommen die Besucher zu völlig unterschiedlichen Bewertungen. Im fortlaufenden Text werde ich mich auf diese Einteilung beziehen.

\section{Handlungsorientierung}

Über die innenarchitektonische, optische Gestaltung hinaus wird mit dem Begriff Handlungsorientierung auf die Tatsache verwiesen, dass sich über das Ansprechen aller Sinne und durch eigenes Tun eine Intensivierung des Erlebnisses vollzieht. Im Ausstellungsrundgang durch die Alte Hofhaltung sollte diesem Anliegen entsprochen werden, indem es neben Angeboten zum Sehen auch Objekte zum Anfassen, Fühlen sowie Hören gab.

Die PC-Stationen in Form von Infopools für Hintergrundinformationen, die sich über das gesamte Ausstellungsgelände verteilten, bildeten eine erste Möglichkeit für die Besucher, über die Hauptinformation der Raumtexte hinaus individuellen Interessen im Hinblick auf Objekte nach eigener Auswahl zu vertiefen (siehe Abb. 43). Neben diesen selektiv abrufbaren Informationen gab es in der Alten Hofhaltung integriert in die Ausstellungsarchitektur verdeckte Informationsebenen. Diese waren für das Verständnis des roten Fadens der Ausstellung sekundär und erst durch Öffnen von kleinen Türen oder Schubläden zugänglich. So gab es ergänzend zu den Vitrinen mit archäologischen Funden von Schmuckstücken für Arme und Reiche sowie Kinderspielzeug im Vitrinenunterbau zwei Schubläden mit Karten zu slawischen Fundorten (siehe Abb. 44). ${ }^{95} \mathrm{Im}$ anschließenden Raum „Die Heinriche“ verbarg sich hinter einer Klappe der Vitrinenwand eine Replik des „Privilegs Kaiser Ot-

95 Kirmeier u.a. 2002, S. 137ff., Nr. 17. 
tos II.“ “96 Im Raum „Bamberg als Modell“ hingen an drei Außenwänden insgesamt acht stilisierte Kaseln aus Cortenstahl, stellvertretend für die acht Altäre, die im Bamberger Dom im Jahr 1012 geweiht wurden. Jede Kasel enthielt drei Klappen, die dem interessierten Besucher die näheren Umstände zur Weihe des jeweiligen Altars schilderten. ${ }^{97}$
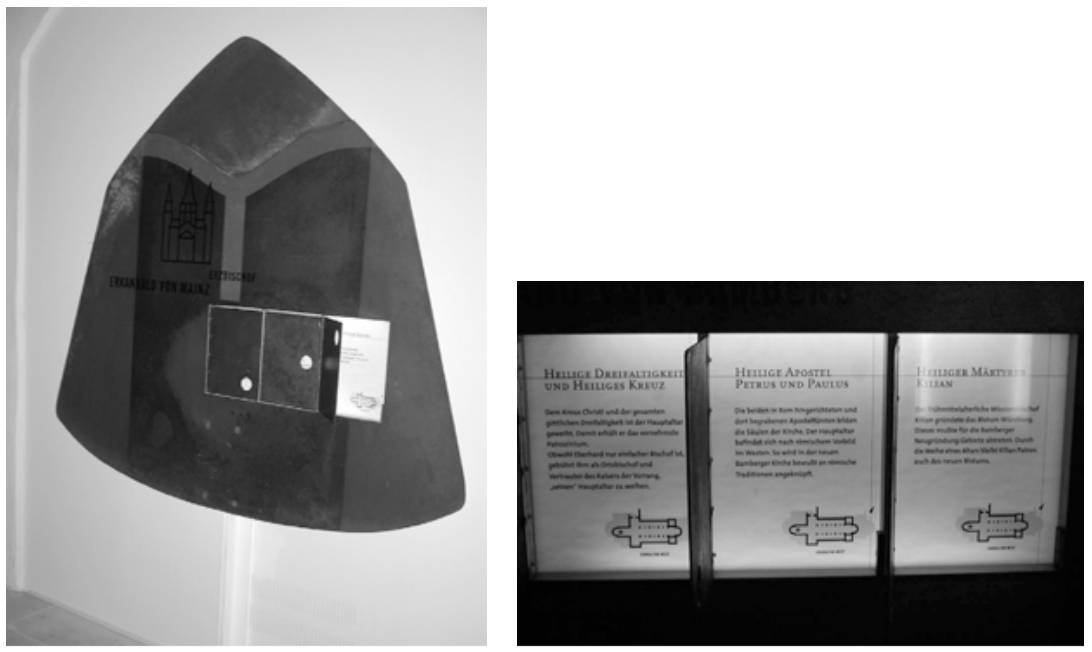

Abbildung 51/52: Stilisiert Kasel mit drei Klappen zum Öffnen mit Informationen zur Weihe der Altäre im Bamberger Dom.

Angebote zum Hören verteilten sich ebenfalls über den gesamten Ausstellungsparcours. Im ersten Raum „Leben in Bodennähe“ konnten die Besucher mittels Kopfhörer, integriert in das Landschaftsmodell, einer plastischen Beschreibung der fatalen Folgen einer Mutterkornvergiftung lauschen. Bei der Hörstation im Raum „Der neue König“ gab es eine Rekonstruktion der Musik zur Krönungszeremonie. Wie einschränkend in der Objektbeschriftung hingewiesen wurde, können die teils virtuosen wie auch schlichten Melodien lediglich aus verschiedenen Handschriften rekonstruiert werden, da diese im Gegensatz zu den Texten nicht überlie-

96 Ebd., S. 165ff., Nr. 42.

97 Neben einer Graphik mit einem Grundriss des Doms und der Kennzeichnung des Standpunktes des Altars informierte der Text, wem der Altar geweiht wurde, welcher Bischof dies durchführte und welche Bedeutung der Heilige im zeitgenössischen Umfeld hatte. 
fert sind. ${ }^{98}$ Im letzten Raum „Unterwegs im Reich“ konnten die Besucher in zwei Kojen betitelt mit „Ein Reich und viele Sprachen“99 an PCStationen einer hypothetischen Rekonstruktion der zur Zeit Heinrichs II. gebräuchlichen Volkssprachen lauschen. Dieses Angebot gab es nur über Kopfhörer, so dass sich in diesen Räumen keine kontinuierlichen Klangkulissen ausbreiteten. Ein Ausnahme bildete die Vertonung des Films „Nachrichtensendung zum Papstbesuch in Bamberg“100 im Raum „Der Friedenskuss", die über Lautsprecher sowohl diesen Raum wie auch die jeweiligen Nachbarräume beschallte.

Die Angebote zum Riechen beschränkten sich auf den Raum „Der neue König“. Hier konnte eine Klappe geöffnet werden und an einem mit Salböl getränkten Wattebausch gerochen werden.

Mehrere Stationen luden zum Anfassen und Fühlen ein. Im ersten Raum gab es eine sogenannte „Abgabenwanne“, in der Holzbottiche mit unterschiedlichen Getreidearten, Säckchen mit Salz und Leinenstoff lagen. Auch im nächsten Raum konnten die Besucher bei der Inszenierung zum Thema „Handelswege und Handelswaren“, die zugleich ein optisches Pendant zur Gehöftabgabe bildete, ihren Tastsinn einsetzen (siehe Abb. 53). In einer Koje im Raum „Unterwegs im Reich“ konnte ein Nasalhelm aufgesetzt und ein Schwert angefasst werden, benachbart zu einer Koje mit einer Vitrine mit musealen Exponaten eines Reiterkriegers des 10./11. Jahrhunderts (siehe Abb. 54/55). ${ }^{101}$

Neben der Aktivierung der Sinne wird unter dem Begriff Handlungsorientierung auch eine Anknüpfung an die Interessenslagen der Besucher verstanden, die einen Gegenwarts-, Lebens- oder Situationsbezug der Themen oder Fachinhalte impliziert. Gegenwartsbezüge inhaltlicher Art mit dem Ziel, ein Vergleichstableau zwischen dem Geschehenen und dem Aktuellen zu inszenieren, wurden in der Ausstellungsdramaturgie nicht explizit hervorgehoben. Man stellte jedoch an mehreren Stellen in

98 Ebd., S. 180ff., Nr. 54. Welche Hymnen beim Übergang von der Krönung zur Krönungsmesse zum „Te Deum“ zu singen waren, teilen die Quellen nicht mit, dennoch gibt es im Repertoire durchaus Kompositionen zum Empfang. Somit kann der Charakter der Zeremonie partiell vermittelt werden.

99 Ebd., S. 253ff., Nr. 102.

100 Beschreibung des Films zum Papstbesuche siehe Kapitel 6, S. 364ff.

101 Ebd., S. 241ff., Nr. 92-97. 
der Ausstellung Bezüge zur Gegenwart indirekt über die Gestaltung her. $^{102}$

\section{Die Rauminszenierung „Der Kaiser“ (siehe Abb. 56)}

Mit dem Raum „Der Kaiser“ versuchten die Gestalter eine Assoziationskette zwischen gegenwärtigen Vorstellungsbildern, Inhalt sowie Ausstellungsobjekten zu schaffen. Inhaltlich war dieser Raum dem Kaisertum Heinrichs II. und dem Thema Europa gewidmet.

Der ursprüngliche, leere Ausstellungsraum wurde durch ein mit Wappen, Spruchbändern, Ranken und Blüten gestaltetes Gewölbe auf Rundpfeilern mit einem zentralen Mittelpfeiler charakterisiert. Da diese aus dem Jahr 1925 stammende phantasievolle Wandmalerei inhaltlich nicht in die Ausstellungsdramaturgie passte, ${ }^{103}$ bestand das Anliegen darin, diese markante Wandmalerei durch innenarchitektonische Elemente in den Hintergrund zu drängen. Umgesetzt wurde dieses Vorhaben durch den Einbau einer Kuppel aus dünnen Metallstäben. An diesen Stäben waren Sterne befestigt, deren Motive dem „Sternenmantel Kaiser Heinrichs II." entnommen waren (siehe Abb. 57). ${ }^{104}$ Unterstrichen wurde die Atmosphäre des Raumes durch eine Beleuchtung der Sterne mit blauem Licht, das in dem sonst abgedunkelten Raum die Sterne zum Leuchten brachte. ${ }^{105}$

102 Dazu zählt zum Beispiel auch der Einsatz von Terminals zum Abrufen von Informationen, Beschreibung der PC-Informationssysteme siehe Kapitel 6, S. 317f.

103 Diese ehemalige, ruinöse Gesindeküche setzte der Bamberger Marienritterorder wieder instand. Vgl. Burandt 1999, S. 67.

104 Auf dem Sternenmantel als Abbild des Himmelsfirmaments breiten sich goldene Sterne strahlenförmig über den halbkreisförmigen Umhang aus und fügen sich zu einem astrologischen Programm. Die Stickereien auf dem Mantel wurden bei Restaurierungen im 15. Jahrhundert jedoch verändert. Bei der Aufbringung der goldbestickten Motive hielt man sich an deren Anordnung aus dem Mantel des 11. Jahrhunderts. Von den ursprünglichen astrologischen Texten blieben nur wenige erhalten. Baumgärtel-Fleischmann, Renate: Ausgewählte Kunstwerke aus dem Diözesanmuseum Bamberg. Bamberg 1992, S. 12-15.

105 Dies bedeutete auch für die Gestalter ein Wagnis, mit der Gefahr, damit eine Raumwirkung vergleichbar einer Disko- oder Kaufhausbeleuchtung zu erzeugen. Interview mit Herrn Uli Prugger, Gestaltungsbüro Gruppe Gut in Bozen, am 8. Juli 2002. 
Diese Kuppel bildete einen Raum, innerhalb dessen sich vier Vitrinen und drei Leuchtgraphiken aufreihten. Neben der „Replik der Reichskrone"106 als dreidimensionalem Exponat zeigten diese Archivalien, die im Zusammenhang mit der Kaiserkrönung standen, das „Heinricianum““107, die „Bamberger Tafel““108, die „Kaiserbulle Heinrichs II.““109, das „Sacramentarium Udalricianum“ “110 sowie die Handschrift „Epistola ad Heinricum Regem“ von Brun von Querfurt. ${ }^{111}$

Ergänzend zu den Handschriften gab es zwei Leuchtgraphiken zu den Themen „Herrschertreffen“ und „Polenzüge“. Eine weitere Leuchtgraphik zeigte als Doppelseite das Krönungsbild und das Widmungsgedicht aus dem „Perikopenbuch Heinrichs II.“112 mit beigefügter Übersetzung des Gedichts .

Am unteren Saum des Sternenmantels ist eine lateinische Inschrift eingestickt: „O DECUS EUROPAE CESAR HEINRICE BEARE AUGEAT IMPERIUM TIBI REX QUI REGNAT IN EVUM“"113. Damit wird Kaiser Heinrich als Zierde Europas gepriesen. Diese Inschrift diente den Ausstellungsmachern als Grundlage für den lateinischen Raumtitel „Decus Europae - Zierde Europas“ auf der CortenstahlUmmantelung der mittigen Säule.

Einerseits fand mit der Idee der Installation einer „Sternenkuppel“ eine Verknüpfung mit dem „Sternenmantel“, eines der hochkarätigen

106 Kirmeier u.a. 2002, S. 214ff., Nr. 72.

107 Ebd., S. 218ff., Nr. 74. Mit dem „Heinriciarum“ bestätigte Kaiser Heinrich II. dem Papst sämtliche Rechte und Besitzungen der römischen Kirche.

108 Ebd., S. 216ff., Nr. 73. In der „Bamberger Tafel“ werden Kunigunde und Heinrich II. als Nachkommen zweier großer Kaisergeschlechter dargestellt.

109 Ebd., S. 221ff., Nr. 78. Die älteste erhaltene Goldbulle im Abendland befindet sich an einer Urkunde für das Kloster Göß.

110 Ebd., S. 222ff., Nr. 79. Im „Sacramentarium Udalricianum“ sind die Namen der Teilnehmer an den Italienzügen Heinrichs II. festgehalten.

111 Ebd., S. 226ff., Nr. 82. In dieser Handschrift übt Brun von Querfurt harsche Kritik an der unerbittlichen Haltung Heinrichs II. gegen den Polenherrscher Boleslaw Chrobry.

112 Ebd., S. 219ff., Nr. 75.

113 Die Inschrift ist im rechten Teil aus Platzgründen nicht vollständig. Der Ergänzung zu zwei Hexametern durch den Aachener Kanonikus Franz Bock (1823 - 1899) wurde bisher nicht widersprochen: „Heil sei dir, zur Zierde Europas, Kaiser Heinrich, dein Reich mehre der König, der da herrschet ewiglich." Ebd., S. 382, Nr. 203. 
Ausstellungsexponate im Diözesanmuseum, statt. Damit wurde der Sternenmantel inhaltlich mit dem Europagedanken und der Huldigung Heinrichs als Kaiser in Verbindung gebracht. Darüber hinaus bestand das Anliegen der Gestalter jedoch auch darin, einen Anknüpfungspunkt zur gegenwärtigen Vorstellungswelt zu schaffen. Mit den Sternen sollten Assoziationen zur Europaflagge und Weltkugel hergestellt werden.

\section{Der Raum „Der nеие König“ (siehe Abb. 58)}

Dieses Thema umfasste zwei Räume, die jedoch aufgrund der geschlossenen Raumwirkung mit Kreuzrippengewölbe, Sandsteinboden sowie leicht schiefen Wänden eine Einheit bildeten. Die Atmosphäre des Raumes wurde durch ein warmes, gelbes Licht unterstrichen. Die amorphen Formen der beigefarbenen Vitrinen mit schlangenförmigen Einkerbungen sollten den Königsumritt Heinrichs II. durch die Länder visualisieren, der mit insgesamt sieben, exemplarisch ausgewählten Stationen vorgestellt wurde. Diese sieben Stationen wurden auf von der Decke herabhängenden Textfahnen näher beschrieben. Vergleichbar mit Haltestellen eines U-Bahn-Fahrplans erhielt jede Station eine Nummer, die jeweiligen Orte waren rot markiert (siehe Abb. 59). Damit stellten die Gestalter auf subtile Art einen Bezug zur Erfahrungswelt der Besucher her.

„Hier arbeiteten wir ganz bewusst mit der Assoziation eines Fahrplans mit sieben Stationen. [...] Man würde dies zwar nicht unbedingt sofort einem Fahrplan zuordnen, aber trotzdem ist dies als Merkhilfe für den Besucher sehr unterstützend.“114

Die kurzen Beschreibungen mit circa zehn bis fünfzehn Zeilen wurden mit charakteristischen Symbolen für die jeweiligen Orte illustrierend ergänzt. Die Stationen vier, fünf und sechs zeigten in Ergänzung zu den Textfahnen jeweils stilisierte, in beiger Farbe gestaltete dreidimensionale Modelle, die nochmals auf dieser haptischen Ebene die Inhalte visualisierten. Bis auf die erste Station, die als Exponat die „Nachbildung der Heiligen Lanze“"115 zeigte (siehe Abb. 59), waren die weiteren drei Stationen mit Archivalien ergänzt. Die Zahl der originalen Exponate war in diesen zwei Räumen gering. Statt dessen lag der Schwerpunkt der Gestaltung darauf, die Aussage anhand visueller Mittel zu verdichten.

114 Interview mit Herrn Uli Prugger, Gestaltungsbüro Gruppe Gut in Bozen, am 8. Juli 2002.

115 Ebd., S. 177ff. Nr. 51. 
„Ein Objekt muss eine Geschichte erzählen. Wenn man sehr viel Information zusätzlich zum Verständnis liefern muss, dann ist es besser, man nimmt es heraus. Natürlich gibt es dann noch die Kompromisse aufgrund von Leihgebern sowie aufgrund des historischen Kontexts."

Das Leitobjekt - museales Exponat, Archivalie oder Modell - kam folglich in jeder Station in dreifacher Weise vor: Als dreidimensionales Objekt, durch den inhaltlichen Bezug im Text und die graphische Darstellung auf der Textfahne. Hier setzten die Gestalter den Multiplikatoreffekt zur Verdeutlichung der Inhalte ein.

\section{Ergebnisse der Besucherbefragungen}

Die SIM-Studie fragte nach einer Bewertung der Ausstellungstexte, der Nutzung des Audiosystems und der Informationssysteme sowie nach einer Bewertung der eingesetzten Medien in der Ausstellung.

Die Bewertung der Ausstellungstexte wurde unter zwei Gesichtspunkten erfasst, nämlich der Verständlichkeit und der Ausführlichkeit. Dies bezog sich auf eine Gesamtbewertung, ohne zunächst zwischen dem Angebot der PC-Stationen sowie der Raumtexte zu differenzieren. Die Bewertung der Texte, obgleich abhängig von verschiedenen soziodemographischen Merkmalen, fiel insgesamt sehr positiv aus. „94 \% der Befragten bewerteten die Verständlichkeit mit sehr gut bzw. gut.“ (ebd. S. 147) ${ }^{117}$ Die Befragten mit einem hohen Interesse an Geschichte bzw. an Kunst und Malerei schätzten die Verständlichkeit der Texte häufig besser ein als Befragte mit niedrigem bzw. mittlerem Interesse (ebd., S. 92). Die Ausführlichkeit der Texte wurde von der überwiegenden Mehrheit der Befragten mit $83 \%$ ebenfalls als angemessen empfunden (ebd. S. 147). ${ }^{118}$

Das den Besuchern im Diözesanmuseum sowie in der Staatsbibliothek zur Verfügung gestellte Audiosystem, das über Kopfhörer genutzt wer-

116 Interview mit Herrn Uli Prugger, Gestaltungsbüro Gruppe Gut in Bozen, am 8. Juli 2002.

117 Im Hinblick auf die Verständlichkeit der Texte konnten die Besucher zwischen fünf Bewertungskategorien wählen: sehr gut, gut, weniger gut, schlecht, keine Angabe.

118 In Hinblick auf die Ausführlichkeit der Texte konnten die Besucher zwischen vier Bewertungskategorien wählen: Zu knapp, gerade recht, zu ausführlich, keine Angabe. 
den konnte, wurde laut Angaben von SIM von $71 \%$ der Befragen verwendet. Insbesondere Gruppenbesucher, die mit ihrer Familie in der Ausstellung waren, griffen auf dieses Audiosystem zurück. Die versierten Besucher verwendeten es ebenfalls häufiger als die Gelegenheitsbesucher (ebd. S. 148). Von der Mehrheit der Befragten wurde dieses System als hilfreich eingeschätzt und die vermittelten Informationen von $79 \%$ der Befragten für angemessen gehalten (ebd.).

In den persönlichen Interviews kam zum Ausdruck, dass die Bewertung des Audiosystems maßgeblich davon abhängig war, ob die Besucher dieses Angebot selbst nutzten oder darauf verzichteten. Auffällig war, dass die Benutzer dieses System allgemein positiv bewerteten und die Hintergrundinformationen als hilfreich bei der Erschließung der Objekte empfanden. Dagegen zeigten sich die Nichtbenutzer zum Teil über die Benutzer verärgert, da diese sehr lange vor den Objekten verweilten und somit den Blick auf die Exponate verstellten. Positiv im Vergleich zu Führungen wurde die Möglichkeit bewertet, dass der Text beliebig oft angehört werden könne. Von den ablehnenden Nichtbenutzern wurde als Begründung für den Vorzug von Texttafeln angeführt, dass hier quer gelesen und eine selektive Auswahl getroffen werden könne. Die Länge und der Inhalt der Information seien überschaubar und dies sei beim Audioguide ähnlich, wie bei Führungen, naturgemäß nicht der Fall. Angemerkt wurde auch, dass ein Audioguide in der Alten Hofhaltung statt der Führungen das Erlebnis der Ausstellung für den Individualbesucher verbessert hätte, da sich der Geräuschpegel erheblich reduziert hätte.

Das PC-Informationssystem nutzten laut SIM $57 \%$ der Besucher (ebd., S. 148). Vor allem die Befragten mit hohen Kenntnissen in europäischer Geschichte und längerer Verweildauer nutzten dieses Angebot. Die über das Computersystem vermittelten Informationen wurden von circa zwei Drittel der Befragten als angemessen beurteilt. Insgesamt wurde dieses System als hilfreich eingeschätzt (ebd., S. 149). Der Einsatz moderner Medien wurde von der überwiegenden Mehrheit der Befragten ebenfalls mit $81 \%$ positiv bewertet (ebd. S. 151).

Auch bei den persönlichen Interviews kam zum Ausdruck, dass das Angebot eines PC-Informationssystems für vertiefende Hintergrundinformationen allgemein von den Besuchern geschätzt wurde. Hier störte die Nichtbenutzer die Integration von Medienstationen nicht, wie dies 
bei dem Einsatz der Audioguides der Fall war. ${ }^{119}$ Insbesondere wurde anerkennend hervorgehoben, dass moderne Medien Einzug in historische Ausstellungen gefunden haben, was bisher eher in naturwissenschaftlichen Ausstellungen der Fall sei.

Die Frage, ob die Besucher den Computer zum vertiefenden Nachlesen nutzten, wurde allerdings überwiegend verneint. Es wurde allein die Tatsache positiv bewertet, dass es möglich gewesen wäre. Primär wurde der Computer dazu eingesetzt, sich eine allgemeine Orientierung über das Ausstellungsgelände zu verschaffen. Von einigen Besuchern wurde bedauert, dass das Recherchieren in Ruhe aufgrund des großen Besucherandrangs kaum möglich war. Als Verbesserung wurde die Einrichtung eines speziellen Medienraums zum Recherchieren vorgeschlagen. Es wurde beobachtet, dass viele Besucher die Computer ausprobierten, aber nicht wirklich zur Informationsrecherche nutzten. Bei großem Besucherandrang hat der Text an der Wand im Gegensatz zum Computerbildschirm den Vorteil, dass diesen mehrere Leute gleichzeitig lesen können. Vor dem Monitor können maximal zwei Leute stehen. Außerdem wird im Wandtext die gesamte Information auf einmal präsentiert, am Computer muss geblättert werden. Das Lesen des Textes an der Wand fällt aufgrund der Typographie wesentlich leichter als das Erfassen von Texten auf einem Bildschirm. Auch ist aufgrund der strengen Reduzierung des Wandtextes eine Vorauswahl getroffen und die Information überschaubarer.

Die Präsentation von Archivalien, so zum Beispiel das „Perikopenbuch Kaiser Heinrichs II.“ oder das „Evangeliar Ottos III.“ mittels Computer, die das Betrachten des gesamten Werkes ermöglicht, wurde als sinnvolle und bereichernde Form des Ausstellens von alten Handschriften beurteilt. Auch die Medienstationen im Raum „Unterwegs im Reich“ mit den Hörbeispielen zu den verschiedenen Sprachen des Reiches wurden positiv erwähnt.

Ein Fragenblock der persönlichen Interviews mit den Besuchern befasste sich mit dem Thema "Wahrnehmen mit allen Sinnen“. ${ }^{120}$ Die Idee der versteckten Texte wurde mittlerweile bereits in verschiedensten Variationen in Ausstellungen praktiziert. Das historisch interessierte Publikum stand diesem weitgehend tolerant gegenüber und beurteilte es als

119 Die Benutzerführung für Menschen mit wenig Computererfahrung war allerdings schwierig. Erschwert wurde dies dadurch, dass im Computerprogramm die Funktionstaste „Zurück“ fehlte.

120 Dieser Komplex wurde in der SIM-Befragung nicht thematisiert. 
eine didaktische Spielerei, die für Kinder schön sein mag, jedoch für sich selbst nicht nötig sei.

„Bei mir wirkt dies nicht.“ (Freiberuflich, geb. 1970)

Ein Großteil der Besucher hielt dies aber für eine gute Idee, um auf Informationen neugierig zu machen. Die meisten jedoch mussten eingestehen, dass das Öffnen der Türchen sie lediglich zum Anlesen der Texte animierte. Eine Besucherin verglich das Öffnen der Türchen mit einem Adventskalendereffekt. Dies motiviere jedoch nicht unbedingt zum Lesen, zumal die Texte, zum Beispiel im Raum „Bamberg als Modell“, nicht unbedingt von allgemeinem Interesse waren. Vereinzelt störte das laute Klicken der Magneten. Auch wurde beobachtet, dass manche nicht wagten, wenn alle Türen geschlossen waren, diese anzufassen.

Unklar war, weshalb zum Beispiel die Replik einer Archivalie „Privileg Kaiser Ottos II.“ angefasst werden konnte. Das Anfassen trug weder zum Erschließen des inhaltlichen Zusammenhangs bei, noch ermöglichte es die sinnliche Erfahrung des Befühlens von mittelalterlichem Papier, da es sich um eine Replik handelte.

Die Bewertung der weiteren Hands-on Angebote durch die verschiedenen Besuchergruppen fiel ebenfalls, wie bei den Texten hinter den Türchen, positiv oder wertneutral aus. Ablehnende Stellungnahmen gab es keine. Der eher auf Unterhaltung ausgerichtete Besucher hätte sich gerne noch mehr gewünscht. Die Dinge zum Anfassen wurden als solche zwar wahrgenommen, doch führte dies nicht unbedingt dazu, diese auch ausprobieren $\mathrm{zu}$ wollen.

„Das Ausprobieren hat mich nicht gereizt, ich bin eher ein Mensch, der mit den Augen arbeitet.“ (Freiberuflich, geb. 1970)

Obwohl mit der Aufforderung „Anfassen erwünscht“ ein deutlicher Hinweis gegeben war, hinderte viele Erwachsene das über Jahrzehnte eingeprägte museale Dogma „Berühren verboten“ dennoch daran, dies tatsächlich zu tun. Kinder standen diesem unverkrampft gegenüber. Das Heben des Schwerts und das Aufsetzen des Nasalhelms begeisterte jedoch nicht nur die Kinder. Im Gegensatz zur Möglichkeit des Anfassens der Replik einer Archivalie erscheint dieses Angebot sinnvoll, da damit die Schwere eines derartigen Helms gespürt werden kann. 
Obgleich über die Gestaltung Gegenwartsbezüge hergestellt wurden, fehlten diese auf inhaltlicher Ebene. Bei einem Teil der Besucher kam zum Ausdruck, dass sie sich diese zum tieferen Verständnis an manchen Stellen gewünscht hätten. Zum Verständnis von Mengen und Zahlen hätten zum Beispiel Vergleiche mit aktuellen Zahlen das Vorstellungsvermögen unterstützt, um diese Informationen aus heutiger Sicht einordnen zu können. So gab es auf der Texttafel „Grundherrschaft“ zwar Aussagen darüber, wieviel Naturalabgaben Bauern zu leisten hatten. Es fehlten aber die Angaben, wieviel ein Bauer innerhalb eines Jahres verdiente und welchen Teil er im Verhältnis davon abliefern musste. ${ }^{121}$

Die Gestaltung des Raumes „Der Kaiser“ wurde als angenehm empfunden, auch von den eher kritischen, primär an historischen Zusammenhängen interessierten Besuchern. Obwohl die Gestaltung mit der Sternenkuppel den Raum sehr prägte, trat sie für die Besucher nicht unbefriedigend in den Vordergrund. Die Abgrenzung des Raumes sowie das dezente Licht wurden als konzentrationsfördernd empfunden. Die Besucherurteile waren unabhängig davon, ob Bezüge zwischen Gestaltung, Inhalt und dem Exponat „Sternenmantel“" hergestellt werden konnten. Auch das blaue Licht, welches, wie die Gestalter befürchteten, vielleicht unangenehm an Discolicht hätte erinnern können, wurde nicht negativ erwähnt.

„Die Motive aus dem Sternenmantel haben sich mir nicht erschlossen, ästhetisch fand ich dies gut. Ein abgeschlossener Raum, der in sich stimmig ist, erzeugt ein heimeliges Gefühl und fördert die Konzentration beim Betrachten der einzelnen Gegenstände.“ (Informatiker, geb. 1961)

Erst auf meine Frage, worin die Intention der Gestalter gelegen haben könnte, wurden die Befragten motiviert, darüber nachzudenken.

„Darüber habe ich mir keine Gedanken gemacht. Ich habe es einfach auf mich wirken lassen.“ (Student, geb. 1985)

Assoziationen zu Europa stellten sich bei einigen Besucher ein, doch darüber hinaus regte dies noch zu weiteren Vermutungen an, beispielsweise, dass die Gestaltung als Symbol für die Rast- und Ruhelosigkeit der Zeit gelten könne. Den Bezug zum „Sternenmantel“ konnten nur diejenigen Besucher herstellen, die diesen bereits kannten. Obwohl die

121 Diese Texttafel ergänzte die „Abgabenwanne“ mit den Hands-on Angeboten im Raum „Leben in Bodennähe“. Siehe Kapitel 6, S. 331. 
Interpretation der gestalterischen Elemente von den Besuchern als schwierig empfunden wurde, wurde diese Form als legitim bewertet.

Im Raum „Der neue König“, in dem die Gestalter sowohl auf den Multiplikatoreffekt wie auch auf Fahrplan-Assoziationen bei der Vermittlung der Inhalte setzten, war das Erinnerungsvermögen der Besucher an Einzelheiten der Räume dementsprechend auffallend gut: Die inhaltliche Aussage war klar, Stationen der Reise konnten aufgezählt und die „Heilige Lanze" als auffallendstes Exponat zugeordnet werden. Eine weitergehende Einordnung in den historischen Kontext war jedoch nur möglich, wenn bereits Vorwissen vorhanden war. Die Gestaltungsidee der schlangenförmigen Einkerbungen auf den amorph geschwungenen Vitrinen als Visualisierung des Königsumritts wurde von keinem der befragten Besucher so interpretiert.

\section{Ganzheit}

Ausgehend von der Annahme, dass menschliches Erleben generell ganzheitlich ist, spielt für das Erleben einer Ausstellung das gesamte Umfeld eine bedeutsame Rolle. In konsequenter Weiterführung führt dies dazu, dass über die inhaltliche Konzeption der Ausstellungsräume hinaus Überlegungen bedeutsam werden, die die bewusste oder auch unbewusste Interaktion mit der gesamten Ausstellungsumwelt betreffen. Diese beginnen mit der Frage, welche Orientierungsmöglichkeiten den Besuchern vor Ort zur Verfügung gestellt werden. Eine weitere wichtige Komponente bildet die Berücksichtigung der psychischen und physischen Dispositionen, welche unter dem Begriff Ausstellungsmüdigkeit zusammengefasst werden.

Im Hinblick auf die Heinrichsausstellung flossen diese ganzheitlichen Gesichtspunkte in die konzeptionellen Überlegungen ein. So wurden Orientierungsmöglichkeiten im Gelände den Besuchern ausreichend zur Verfügung gestellt. Die Hinweisschilder im Ausstellungsgelände (siehe Abb. 41/42), eine Graphik zum Ausstellungsgelände auf der Rückseite der Eintrittskarte wie auch die Übersichtpläne an den PCStationen dienten diesem Zweck. ${ }^{122}$

122 Zum Thema Orientierungshilfen im Gelände siehe auch Kapitel 6, S. 315. 
Das Problem der Ausstellungsmüdigkeit spielte vor allem in der Gestaltung des Parcours durch die Alte Hofhaltung eine bedeutsame Rolle. Dramaturgische Kriterien bei der Aufbereitung des Stoffes, um das Interesse der Besucher wach zu halten, wurden auf mehreren Ebenen in unterschiedlichen Formen berücksichtigt. Dieses Anliegen zeigte sich bereits bei der Entwicklung des Ausstellungskonzeptes ${ }^{123}$ und spiegelte sich in der konzeptionellen Gestaltung des gesamten Parcours sowie auch der Einrichtung einzelner Räume wider. Inhaltlich bindet der Rundgang die einzelnen Räume in eine geschlossene Dramaturgie ein. Dies beginnt mit den Lebenswelten über wichtige Stationen der Herrschaft hin zur Rezeption durch die Nachwelt. ${ }^{124}$ Durch den rhythmisierten Einsatz didaktischer Angebote wie Fühl- oder Hörstationen sowie dramaturgischer Elemente mit einem Wechsel von Raum-, Farb- oder Lichtstimmungen wurden die menschlichen Sinne unterschiedlich angesprochen und eine Gefühlsregie aufgebaut. Diese Spannung konnte jedoch nur in der Gesamtwirkung des Parcours erlebt werden.

„Dieser Raum [„,Der neue König“ Anm. d. V.] hatte bereits leer eine sehr angenehme Ruhe und Stimmung. Diese Spannung wird erst deutlich, wenn man die anderen Räume kennt. Man muss auch die anderen Räume spüren, damit man dort zu diesem Gefühl kommt. Nur dieser Raum wäre ohne den Kontext der Ausstellung nicht möglich. “" ${ }^{125}$

Es wurde versucht, neben ruhigen Angeboten im Wechsel ein anregendes Ambiente zu schaffen. Bevor die Besucher in den letzten Raum des Rundganges, dem Marstall, mit einem vielfältigen Angebot zum Sehen, Hören, Lesen und Fühlen gelangten, durchschritten sie vorher einen reduziert gestalteten, schmalen Durchgangsraum.

„Dieser Ruheraum dient zum Verschnaufen, bevor es in den Schlussraum geht, der noch mal eine Steigerung im Parcours darstellt. “126

123 Siehe Kapitel 6, S. 299.

124 Problematisch war jedoch die Entschlüsselung dieses roten Fadens, der sich nicht sofort auf den ersten Blick erschloss. Dies kam bei der Besucherbefragung in der persönlichen Interviews deutlich zum Ausdruck.

125 Interview mit Herrn Uli Prugger, Gestaltungsbüro Gruppe Gut in Bozen, am 8. Juli 2002.

126 Interview mit Herrn Uli Prugger, Gestaltungsbüro Gruppe Gut in Bozen, am 8. Juli 2002. 
Dieser Raum zeigte drei großformatige mit Cortenstahl gestaltete Silhouetten, die jeweils auf einer Leuchtgraphik Anekdoten aus dem Leben Heinrichs II. schilderten. ${ }^{127}$ Ein stilisierter Esel stand für die Geschichte „Der Maultiere Seelenheil“, der Umriss eines Bären symbolisierte die Anekdote „Der Mönch, der Kaiser und des Bären Appetit“" und die Silhouette eines Kelchs verwies auf die Legende „Ein geheiligter Raub“. Diese Geschichten regten zum Schmunzeln an und sorgten so für Entspannung.

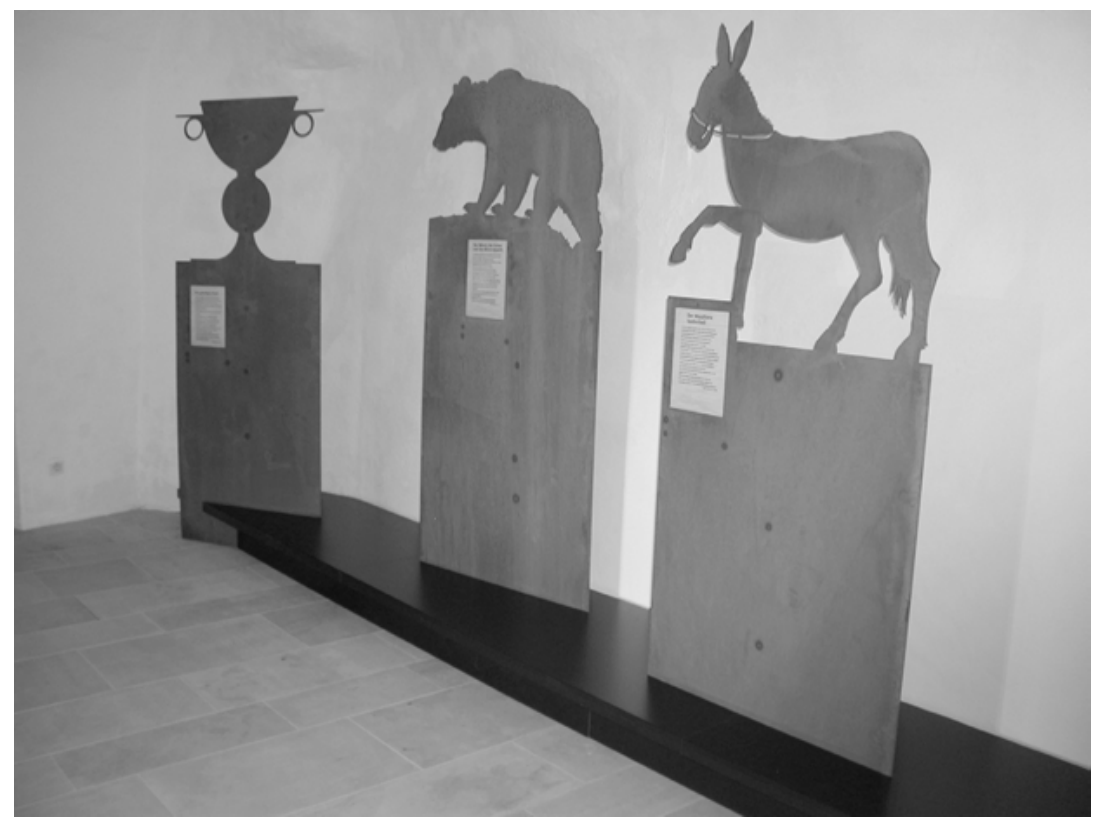

Abbildung 60: Durchgangsraum zwischen den Räumen „Der Friedenskuss“ und „Unterwegs im Reich“.

Im Raum „Die Heinriche“ lässt sich anhand der übersichtlichen Einheit einer Vitrinenwand aufzeigen, wie die Gestalter hier das Anliegen umsetzten, dem Sehen Abwechslung zu bieten. An einer Wand entlang stand ein raumhohes, orangefarbenes Paneel, gestaltet mit einer angedeuteten, unregelmäßigen Ziegelstruktur in Andeutung der Regensburger Stadtmauer (siehe Abb. 61). In dieses Wandpaneel waren Vitrinen unter-

127 Ebd., S. 236ff., Nr. 86. 
schiedlicher Größe und Formen integriert. Eine längliche, querformatige Vitrine zeigte Kleinfunde wie Alltagsgegenstände und Schmuck aus dem Regensburger Damenstift Niedermünster. ${ }^{128}$ In der benachbarten, länglich hochformatigen Vitrine befand sich ein Fenster aus dem Kloster St. Emmeran. ${ }^{129}$ Kleine Gucklöcher in unterschiedlicher Höhe mit Münzen aus der Zeit Heinrichs II. forderten die Besucher zum genauen Hinsehen auf (siehe Abb. 62/63). ${ }^{130}$ Sowohl zum Anfassen als auch zum Sehen gab es anschließend hinter einer Klappe zum Öffnen die bereits erwähnte Replik des „Privilegs Kaiser Ottos II““. ${ }^{131}$ Am Ende dieser stilisierten Stadtmauer stand die Stahlwanne mit der Inszenierung zum Thema „Handelswege und Handelswaren“, die ebenfalls ergänzend zum optischen Eindruck zum Berühren einlud (siehe Abb. 53).

„Diese Abfolge sorgt bewusst für Abwechslung. Es sind verschiedene Möglichkeiten des Sehens. Nach einem Ausschnitt folgt ein Fenster, dann kleine Gucklöcher - der Besucher muss hingehen, sich bücken und genau fokussieren, danach kann er ein Fenster mit der Hand öffnen, dann wieder folgt eine normale Vitrine. Dieser Rhythmus hilft, weniger schnell zu ermüden. Der Gegensatz dazu wären fünf gleichmächtige Vitrinen.“'132

Die Aneinanderreihung unterschiedlicher, kleinteiliger Exponate im Gegensatz zu großen Objekten gab dem Auge Abwechslung im Sehen. Zudem ergänzt mit Hands-on Objekten wurde neben dem Augensinn auch der Tastsinn angesprochen.

Obwohl die Ausstellungsmacher versuchten, unter einer ganzheitlichen Perspektive auf die psychischen und physischen Bedürfnisse der Besucher zu achten und diese Komponente dementsprechend auch im Ausstellungskonzept zu integrieren, klafften dennoch an manchen Stellen Konzept und Wirklichkeit auseinander. Insbesondere in der Alten Hofhaltung erwiesen sich die hohen Besucherzahlen problematisch für Raumklima und -atmosphäre.

128 Ebd., S. 159ff., Nr. 37, 38, 39. Dieses waren eine Emailscheibenfibel, ein Spielstein sowie zwei Schankgefäße.

129 Ebd., S. 162, Nr. 40. Das Fenster hat sich als besonders altes Holzfenster erhalten.

130 Ebd., S. 163ff., Nr. 41.

131 Ebd., S. 165ff., Nr. 42.

132 Interview mit Herrn Uli Prugger, Gestaltungsbüro Gruppe Gut in Bozen, am 8. Juli 2002. 
Diese Diskrepanz zwischen einerseits angestrebter Raumwirkung und andererseits Erleben des Raumes durch die Besucher zeigte sich insbesondere in den zwei Räumen zum Thema „Der neue König“ (siehe Abb. 58). Die angenehme, fast weihevolle Atmosphäre des Raumes konnte sich am besten entfalten, wenn man sich alleine darin befand. Aufgrund der großen Anzahl von Besuchern war dieses jedoch während der Öffnungszeiten kaum der Fall. Im Gegenteil bildete die Enge des Raumes geradezu ein Nadelöhr, an dem sich die Besuchergruppen in Stoßzeiten stauten. Dies führte dazu, dass viele Besucher versuchten, möglichst schnell diese drangvolle Enge hinter sich zu lassen und kaum Zeit blieb, sich auf die Exponate und das Thema des Raumes einzulassen. Ein Besucher bemerkte hierzu, dass es doch unsinnig sei, diese kleine Räume durch zusätzliche Einbauten noch weiter zu verkleinern. Dementsprechend negativ fielen manche Besucherkommentare aus.

\section{Ergebnisse der Besucherbefragungen}

In der standardisierten SIM-Untersuchung gab es keine Kategorie, die das Thema Wohlbefinden oder psychische Komponente erfasste, so dass die Aussagen hierzu sich ausschließlich auf die persönlichen Interviews mit den Ausstellungsbesuchern stützen. Sehr deutlich kam hier zum Ausdruck, wie sehr die äußeren Faktoren der Ausstellungsumwelt die Urteile über die gesamte Ausstellung beeinflussen. Ärger über schlecht lesbare Objektbeschriftungen an vereinzelten Objekten führte bei manchen Besuchern dazu, die Ausstellung im Gesamten schlecht zu beurteilen. Das, was zunächst als marginal oder sekundär erscheinen mag, wird dann im Besucherurteil über die Ausstellung die bestimmende Größe.

Die am häufigsten vorgebrachte Kritik, die zum Teil zu sehr aufgebrachten Reaktionen bei Besuchern führte, galt den schlechten klimatischen Bedingungen und der drangvollen Enge in den Ausstellungsräumen. ${ }^{133}$ Führungen blockierten Engstellen, so dass Einzelbesucher nicht weitergehen konnten. Die hohe Geräuschkulisse, auch aufgrund von Führungen, störte die eigene Konzentration. Auch wurde mehrfach der Wunsch nach mehr Ruhepunkten in der Ausstellung zum Verweilen, Betrachten und Verarbeiten geäußert.

Ein zweiter, oft geäußerter Kritikpunkt galt der Beleuchtung der Räume. Vielen Besuchern war das Licht in den Räumlichkeiten zu dun-

133 Sehr deutlich kam diese Unzufriedenheit in den Besucherbüchern zum Ausdruck. 
kel, dies wurde als bedrückend empfunden. Vor allem für alte Leute führte dies zu Orientierungsproblemen. Für Rollstuhlfahrer und Kinder waren die Objekte oft zu hoch präsentiert.

Kritik riefen zudem die Objektbeschriftungen hervor. In der Alten Hofhaltung konnten die Bezifferungen in den Leuchtkästen bzw. Objektbeschriftungen den Objekten nicht eindeutig zugeordnet werden, da es in den Vitrinen keine Hinweisnummern gab (siehe Abb. 45). ${ }^{134} \mathrm{Im}$ Diözesanmuseum wurde ebenfalls die Objektbeschriftung kritisiert. Hier war sie zwar eindeutig zuzuordnen, jedoch war die schwarze Schrift auf grauem Grund zu klein und schlecht beleuchtet.

Teilweise waren die haptischen Elemente nicht auf den ersten Blick zu erkennen. Erst mit der Beobachtung anderer Personen stellte eine Besucherin fest, dass die Löcher in der Vitrinenwand im Raum „Die Heinriche“ keine Lichtquellen, sondern Gucklöcher zum Betrachten der Münzen waren. Die Schubläden mit den Karten zu dem Thema „Slawen in Bayern“ im Raum „Leben in Bodennähe“ blieben auch von manchen Besuchern unentdeckt (siehe Abb. 44).

Inhaltliche Kritik wurde primär von historisch orientierten Menschen vorgebracht. Zur Erleichterung des Einstiegs hätten sich diese eine einführende Information am Anfang der Ausstellung gewünscht. Ein chronologischer Überblick zu wichtigen Lebensdaten von Heinrich II fehlt beispielsweise. Ebenso blieb einigen der rote Faden der Ausstellung verborgen. Die Systematik der Gestaltung erschloss sich den Besuchenden nicht sofort. Eine Hinführung über den Aufbau der Ausstellung und die damit verbundenen Ziele wäre als hilfreich empfunden worden.

„Nachdem ich die Systematik des gestalterischen Aufbaus verstanden habe, empfand ich es als sehr schön gemacht, so zum Beispiel die Schritte zur Legitimation. Es wäre jedoch einfacher gewesen, man wäre auf den roten Faden mehr hingelenkt worden.“ (Betriebswirt, geb. 1957)

Dass sich Zusammenhänge und Hintergründe erst bei genauerer Betrachtung erschlossen, scheint auch die SIM-Untersuchung zu bestätigen. Diese kommt zur Feststellung, dass die optische Präsentation umso positiver bewertet wurde, je länger sich die Befragten in der Ausstellung aufhielten (Nöthen/Fröhlich 2002, S. 85).

134 Dieses war zum Beispiel im Raum „Leben in Bodennähe“ bei der Tafel: „Die Sorge ums tägliche Brot“, Objekte Nr. 29 a-d oder bei den Tischvitrinen mit den archäologischen Funden, Objekte Nr. 15-27, der Fall. 


\section{Differenzierung}

Unter dem Begriff Differenzierung sollen in dieser Analyse insbesondere zwei Aspekte betrachtet werden. Zum einen verweist dieser Begriff auf den konstruktiven Charakter der Interpretation entgegen monokausaler Erklärungszusammenhänge zu Gunsten einer Anerkennung vielfältiger Unterschiede und sogar Widersprïche. Zum anderen bedeutet Differenzierung eine methodische Maßnahme, mittels derer den unterschiedlichen Bedürfnissen und Interessen der Besucher entsprochen wird und damit die Heterogenität des Publikums ins Blickfeld gerät.

Der Rundgang durch die Alte Hofhaltung verfolgte einen narrativen Ansatz. Gegliedert nach einem chronologischen Darstellungsmuster wurden wichtige Etappen des Herrscherdaseins entfaltet, ohne das konstruktive Moment der Geschichtsdarstellung zu thematisieren. Fragen provozierende oder irritierende Elemente wurden nicht explizit ausgebreitet. So merkt Sauerländer kritisch im Vergleich mit der "Gothic“ Ausstellung in London im Victoria \& Albert Museum an:

„Wir stellen in Deutschland die Ottonen, die Salier, die Staufer aus - das ist ferne auratisierte Vergangenheit, allenfalls von Kaisernostalgie umwoben. Aus einer englischen Ausstellung wie Gothic schlägt einem die Gegenwärtigkeit von Bräuchen entgegen, die bis in das späte Mittelalter zurückreichen.“"135

So hätte sich zum Beispiel die im historischen Urteil ambivalente Herrscherpersönlichkeit Heinrichs II. angeboten, diese kontroversen Beschreibungen noch intensiver $\mathrm{zu}$ thematisieren. Zeitliche Vor- und Rückgriffe zum Zwecke eines Vergleichs wären möglich gewesen, so zum Beispiel die provokante Frage nach einer Verquickung von Geld, Macht und Kirche sowie die Erkundung der Gründe für die Heiligsprechung Heinrichs II. im Jahr 1146 nur zweiundzwanzig Jahre nach seinem Tod. Weiterhin hätte sich auch die Rezeptionsgeschichte bis in unsere Gegenwart fortführen lassen. Die im Raum „Der neue König“ präsentierte „Nachbildung der Heiligen Lanze“ markierte die erste Station in Polling im Februar/März 1002, als der bayerische Herzog Heinrich II. den Leichenzug Kaiser Ottos III. empfing (siehe Abb. 59). Heinrich II. erzwang die Herausgabe der Heiligen Lanze sowie der übrigen Herrscherinsignien und demonstrierte so seinen Anspruch auf die Königs-

135 Sauerländer, Willibald: Laut, farbig und nicht ohne Witz. Eine theatralische Inszenierung des Mittelalters: die große „Gothic“-Ausstellung. In Süddeutsche Zeitung vom 01.12.03. Siehe Kapitel 5, Anm. 71. 
würde. ${ }^{136}$ Die „Heilige Lanze“ erweckte im Nationalsozialismus erneut Begehrlichkeiten. Als Kultwaffe ließ Hitler diese aus der Wiener Schatzkammer zum Burgberg nach Nürnberg bringen. ${ }^{137}$ Mit einer Thematisierung dieses Zusammenhangs hätte die Bedeutung der Symbolkraft dieses Objekts eine weitere Dimension erhalten.

Das historische Erzählprinzip wurde an einer Stelle der Ausstellung verlassen und zwar am Ende des Rundganges in einer Koje im Raum „Unterwegs im Reich“. Dieses Element bedeutete einen Bruch in der Erzählstrategie, da neben dem historisch-narrativem Ansatz der künstlerischen Interpretation Raum gegeben wurde.

\section{Raum „Unterwegs im Reich“}

Koje mit Inszenierung: „Treue Weggefährten Heinrichs II“

Die künstlerische und zugleich didaktische Inszenierung „Treue Weggefährten Heinrichs II. “" ${ }^{138}$ von Rosemarie Zacher ${ }^{139}$ befand sich im letzten Raum des Rundganges durch die Alte Hofhaltung in einer Koje im Marstall mit dem Leitthema „Unterwegs im Reich“. Mit zwei anderen benachbarten Kojen bildete sie eine thematische Einheit zum Thema Verwaltung und Bischöfe. Diese Koje erfüllte eine Doppelfunktion und fiel aus dem üblichen Rahmen der Gesamtgestaltung. Einerseits war sie ein didaktisches Element zur Illustration der großen Zahl von zweiundsechzig Bischöfen, die unter der Regentschaft Heinrichs II. zwischen 1002 und 1024 geweiht wurden. Zugleich aber war dies auch eine künstlerische Interpretation, die versuchte, sich den unterschiedlichen Charakteren der Bischöfe anzunähern und diese zur Anschauung zu bringen.

Zweiundsechzig individuell gestaltete Keramikfiguren, circa dreißig Zentimeter groß, waren auf einer Ebene kniehoch mit gleichmäßiger Beleuchtung präsentiert. Davor stand ein schwarzes Pult mit drei Druckknöpfen mit jeweils einer Zahl. Nur beim Drücken des richtigen Knopfes

136 Kirmeier u.a, 2002, S. 177ff. Nr. 51. Nach dem Tod Ottos III. 1002 galt die Heilige Lanze als zentraler Bestandteil des königlichen Reliquienschatzes und als wichtigstes Herrschaftssymbol. Die Heilige Lanze verhieß Sieg und sollte zum ewigen Leben führen.

137 Die „Heilige Lanze“ zählt zu den Reichskleinodien. Sie sind ein Beispiel für die symbolische Politik der Mittelalterbeschwörungen im Nationalsozialismus. Siehe Kapitel 5, S. $239 f$.

138 Ebd., S. 239ff. Nr. 89.

139 Siehe Kapitel 6, Anm. 22. 
erstrahlte das Licht der Leuchtgraphik, auf der die große Anzahl der „Weggefährten Heinrichs II.“ namentlich aufgelistet waren. Eine sechszeilige Beschreibung auf der Stoffbahn gab ergänzende historische Informationen.
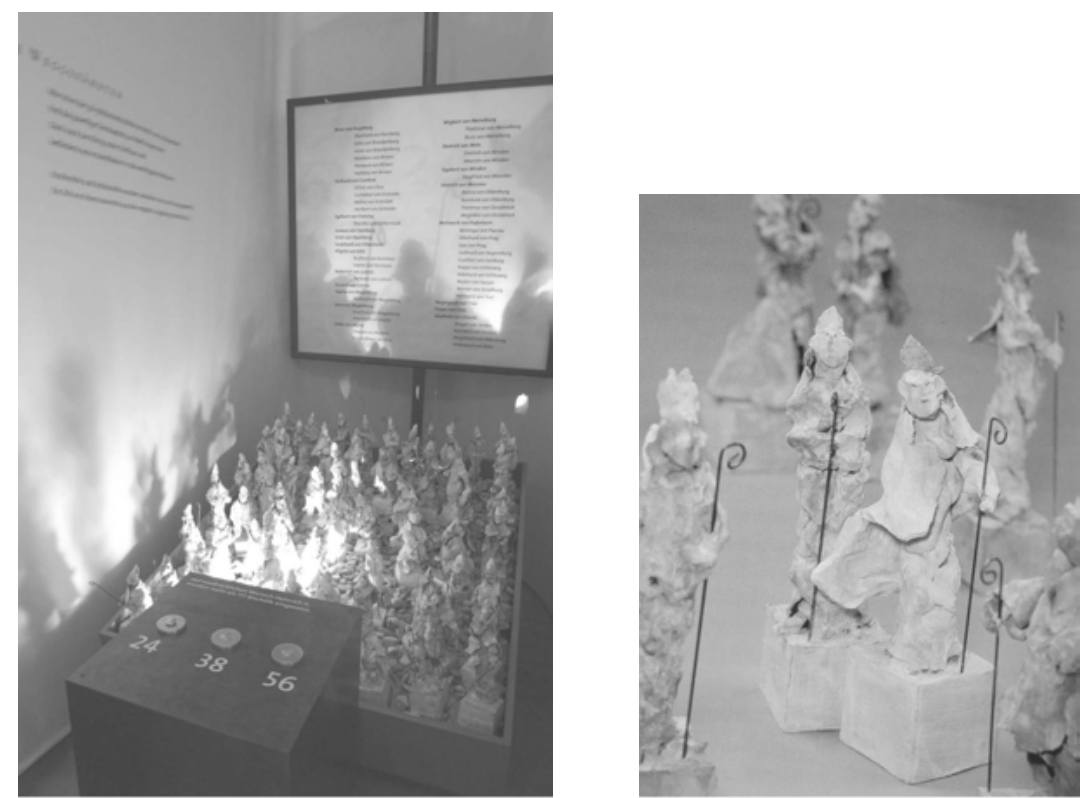

Abbildung 64/65: Inszenierung „Treue Weggefährten Heinrichs II.“ in einer Koje des Raumes „Unterwegs im Reich“von Rosemarie Zacher.

Die Keramikfiguren dienten der Verlebendigung des inneren Zirkels um Heinrich II. Die Absicht bestand darin, mit den Figuren skizzenhafte Entwürfe einer nicht wieder belebbaren Vergangenheit zu schaffen, die über die bloße Rekonstruktion hinaus sogar individuelle Züge trägt. Die handgeformten Plastiken verweisen auf die Menschen ihrer Zeit als Schlüssel zu einer weit zurückliegenden und fremd erscheinenden Epoche:

„Der Joviale, der zurückhaltend Vorsichtige, der Taktierer, der mürrisch Verstockte, der Eingeweihte, der Skurrile, die graue Eminenz sind hier versammelt in ihrer Gegenwart." (Brockhoff, Evamaria in: Kirmeier u.a. 2002., S. 241). 
Die Dargestellten verweisen auch auf unsere Gegenwart: Dies drückt sich in ihrem Erscheinungsbild aus. Die Spuren des Herstellungsprozesses bleiben durch Fingerabdrücke im gekneteten Lehm bestehen.

„Die kalkig gesinterte Patinierung verbirgt nicht, dass es sich hier um eine Suche nach dem Menschlichen im Menschen handelt, wobei ein heiterironischer Grundzug, wie er sich im Werk von Rosemarie Zacher häufig feststellen lässt, den cantus firmus der Personengruppe bildet.“ (ebd.)

Wie bereits festgestellt, wurden mit dieser Einheit zwei verschiedene Ziele verfolgt. Einerseits dienten diese Bischöfe dem didaktischen Ziel der Illustration ihrer großen Zahl. Andererseits war dies eine zeitgenössische künstlerische Interpretation, die sich mit den menschlichen Zügen der Bischöfe befasste. Sie versuchte den entindividualisierten Bischöfen, reduziert auf eine blanke Zahl, die Anonymität zu nehmen und wieder einen individuellen Charakter zu verleihen. Präsentiert wurden die Bischöfe kniehoch in einer Ebene dicht aneinandergereiht mit gleichmäßiger Beleuchtung. Dies förderte zwar das didaktische Anliegen, der künstlerische Ausdruck hingegen konnte auf diese Art kaum erfahren werden. Damit der Detailreichtum der individuellen Charaktere der Bischöfe hätte sichtbar werden können, wäre eine andere Präsentation, beispielsweise in verschiedenen Ebenen jeweils auf einzelnen Sockeln mit Spotlichtern beleuchtet, nötig gewesen. Dies hätte jedoch dem Ziel der Präsentation der hohen Zahl widersprochen. Die Wahrnehmung des Besuchers wäre in eine andere Richtung gelenkt worden. Die Wahlmöglichkeiten der Aufmerksamkeit traten in Konkurrenz, und so nahm man in Kauf, dass die Figuren in ihrer Individualität zurücktraten.

Deshalb fehlte auch eine Objektbeschriftung mit einem Hinweis auf die Künstlerin und ihre Arbeit. Dies wäre allerdings wichtig gewesen, um den Besuchern den Wechsel vom narrativen Erzählprinzip hin zur individuellen, künstlerischen Annäherung an das historische Thema deutlich zu machen. Ein klärender Kommentar hätte dem Besucher transparent machen können, dass diese künstlerische Interpretation eine ergänzende Sichtweise zur historisch-archivalischen Rekonstruktionsarbeit darstellt.

Als methodische Maßnahme der Differenzierung boten sich aufgrund der räumlichen Situation mit unterschiedlichen Ausstellungsorten ideale äuBere Bedingungen an und ermöglichten eine klare räumliche Trennung zwischen einer objektorientierten Präsentation in Abgrenzung zu den 
inszenierten Bereichen. Damit konnte bereits durch die unterschiedlichen Ausstellungsbereiche eine konsequente äußere Differenzierung umgesetzt werden. Die vorrangig an den kostbaren musealen Exponaten interessierten Besucher konnten ihre Interessen in den beiden Schatzkammern des Diözesanmuseums sowie in der Staatsbibliothek befriedigen. Damit wendeten sich diese zwei Bereiche primär an das Fachpublikum. Im Gegensatz dazu sollte mit der Rekonstruktion des Mittelalterlichen Gehöfts die „Zielgruppe der Nicht-Museumsbesucher" ${ }^{\text {“140 }}$ über die haptisch - sinnliche Ebene angesprochen und dieser damit eine emotionale Einstimmung ermöglicht werden. Auch der inszenierte Parcours durch die Alte Hofhaltung war für ein breites Publikum konzipiert, gemäß dem Auftrag des Hauses der Bayerischen Geschichte, das historische Bewusstsein in der gesamten bayerischen Bevölkerung zu mehren.

„Wir wollen die Nicht-Akademiker ansprechen. Der informierte Besucher ist ein begehrter Ausstellungsbesucher, weil er zum einen sicher kommt und zum anderen einen Katalog kauft. Aber jeder, den ich zusätzlich gewinnen kann, der normalerweise in keine Ausstellung geht, ist mir persönlich wichtiger." (ebd.)

Als spezielles Angebot für die jüngeren Besucher gab es darüber hinaus den Kinderpfad (siehe Abb. 39/40). ${ }^{141}$ Die Alte Hofhaltung wandte sich an das breite Publikum. Dementsprechend wurde dort versucht, gemäß einer inneren Differenzierung den unterschiedlichen Interessenslagen gerecht zu werden, indem - wie bereits dargestellt - unterschiedlichste Formen der Aneignung angeboten wurden, die alle Sinne ansprachen. Den Wissensbedarf nach weiterführenden Informationen deckte zum Beispiel das gestaffelte Angebot an Texten. Für Eilige standen die kurz gefassten Raumtexte zur Verfügung, wer mehr wissen wollte konnte weiterführende Hintergrundinformationen über die PC-Stationen abrufen.

140 Interview mit Herrn Dr. Josef Kirmeier, Projektleitung der Landesausstellung „Kaiser Heinrich II. 1002-1024“ des Hauses der Bayerischen Geschichte, am 17. Oktober 2001.

141 Beschreibung des Kinderpfades siehe Kapitel 6, S. 314. 


\section{Ergebnisse der Besucherbefragungen}

Die künstlerische Inszenierung „Treue Weggefährten Heinrichs II.“ bewerteten die Besucher sehr unterschiedlich, ohne eine klare Befürwortung oder Ablehnung, jedoch mit differenzierten Antworten unter Abwägung unterschiedlicher Aspekte. Der hauptsächliche Grund für den Besuch einer Geschichtsausstellung besteht für einen historisch interessierten Menschen darin, zusätzliche Information über die Historie zu gewinnen: Aus einem Fantasieprodukt jedoch könne man nichts über Geschichte lernen, so die Meinung dieser Interessensgruppe. Der Hauptgrund für die Ablehnung dieses künstlerischen Elements bestand darin, dass aufgrund mangelnder Authentizität kein Bezug zu Heinrich II. gesehen wurde. Unklar war, mit welcher Motivation künstlerische Elemente in eine historische Ausstellung integriert werden. Würde ein Interesse an Kunst bestehen, dann wäre man in eine Kunstausstellung und nicht in eine historische Ausstellung gegangen.

„Der Sinn der Fahrt nach Bamberg ist das Interesse an der Geschichte Heinrichs II. Ohne die Legitimität dieser Form bestreiten zu wollen: Da ich mein Aufnahmevermögen ökonomisch nützen muss, lasse ich Dinge dennoch weg, die mir persönlich nicht wichtig sind.“ (Senior, geb. 1920)

Die allgemein visuell orientierten Menschen befürworteten dieses Element, weil es Abwechslung bietet und neugierig macht. Die Ausstellung wirke weniger streng. Im Rundgang bedeutet dies Erholungsphasen, da es hier nicht nötig sei, sich Information anzulesen, sondern diese spielerisch mitgenommen werden können, ohne sich nochmals intensiv mit einem Thema befassen zu müssen.

„Dies ist schön.“ (Lehrerin, geb. 1948)

"Auf poetische Art wird der Mangel an Archivalien ausgeglichen und ein Weg zur Visualisierung von Vergangenheit gefunden." (Germanist, geb. 1970)

Einer generellen Befürwortung des Einsatzes von Künstlern als Gestaltern stehen viele positiv und zugleich kritisch gegenüber. Es müsse darauf geachtet werden, in welcher Formensprache dieser das Kunstwerk umsetzt. So dürfe es weder zu abstrakt werden, da die Aussage entschlüsselbar bleiben solle, genauso wenig solle es aber zu konkret sein, um die Offenheit der Deutung zu gewährleisten. 
Aufgrund der besonderen Situation des direkten Nebeneinanders von einem inszenierten Bereich im Vergleich zur objektorientierten Präsentation drängte sich die Frage geradezu auf, wie dieses Nebeneinander vom Publikum aufgenommen wurde und welcher Präsentationsform der Vorzug gegeben wurde. Diese Frage stellten sowohl die SIM-Untersuchung wie auch ich in den persönlichen Besucherinterviews.

Die SIM-Studie untersuchte, wie die Ausstellungsbesucher die Einteilung in fünf Ausstellungsbereiche mit dem Dom, dem Mittelalterlichen Gehöft, der Alten Hofhaltung, der Staatsbibliothek und dem Diözesanmuseum werteten. Eine klare Mehrheit von $78 \%$ hielt dieses Konzept für gut, mit der Begründung eine bessere Möglichkeit der Pausengestaltung zu haben $(16 \%)$ und auch größere Abwechslung zu erleben (Fröhlich/Nöthen 2003, S. 60). ${ }^{142}$

Um ein differenziertes Bild zu erhalten, forderte die SIM-Untersuchung das Ausstellungspublikum auf, die fünf Ausstellungsbereiiche in eine Rangfolge zu bringen. Dabei zeigte sich, dass die Alte Hofhaltung mit einem mittleren Rangwert von 1,82 am besten bewertet wurde, gefolgt vom Diözesanmuseum $(2,11)$ und der Staatsbibliothek $(2,47)$. Den letzten Rang nahm das Mittelalterliche Gehöft ein (ebd., S. 62). ${ }^{143}$ Bestätigt wurde mit der SIM-Untersuchung die Annahme, dass Personen mit geringerem Bildungsabschluss inszenierte Formen bevorzugen bzw. dass objektorientierte Präsentationen mehr für das Fachpublikum ausgerichtet sind.

„Die Alte Hofhaltung wurde von den Befragten ohne bzw. mit Hauptschulabschluss am besten bewertet, wohingegen die Staatsbibliothek von den Akademikern den Vorzug erhielt. Das Mittelalterliche Gehöft bekam einen um so höheren Rangplatz zugeteilt, je niedriger der Bildungsabschluss der Befragten war.“ (ebd., S. 63)

Ein ähnliches Ergebnis zeigte sich auch im Vergleich der fünf Ausstellungsbereiche bezüglich des Besucherinteresses an Kunst und Malerei. Den Niedriginteressierten gefiel die Alte Hofhaltung häufiger, wohingegen die Staatsbibliothek eher von den Hochinteressierten bevorzugt wur-

142 Die Besucher konnten zwischen drei Bewertungskategorien wählen: Halte ich für gut, teils/teils, halte ich nicht für gut. In einer offenen Antwort konnten die Besucher ihre persönlichen Gründe nennen, weshalb sie das Konzept für gut bzw. nur teilweise gut bzw. nicht für gut hielten.

143 Die Besucher sollten dem Ausstellungsbereich, der am besten gefiel den Rang 1 zuteilen, demjenigen der am zweitbesten gefiel den Rang 2 usw. 
de (ebd., S. 65). Auch die Häufigkeit der Ausstellungsbesuche hat laut SIM-Untersuchung einen Einfluss auf die Beurteilung der fünf Ausstellungsbereiche. Gelegenheitsbesucher wiesen der Alten Hofhaltung und dem Mittelalterlichen Gehöft im Schnitt höhere Ränge zu, wohingegen die habituellen Besucher der Staatsbibliothek den Vorzug gaben (ebd.).

Die Ergebnisse lassen laut SIM-Studie klar erkennen, dass unterschiedliche Besuchergruppen von jeweils anderen Ausstellungsteilen angesprochen wurden. Dementsprechend können über die Auswahl und Gestaltung der Ausstellungsteile gezielt bestimmte Besuchertypen angesprochen und $\mathrm{zu}$ einem Ausstellungsbesuch angeregt werden (ebd., S. 71).

Diese Ergebnisse können durch meine persönlichen Interviews tendenziell gestützt werden. Bestätigt werden kann die These der SIMUntersuchung, dass Personen mit geringerem Bildungsabschluss eher von inszenierten Formen angesprochen bzw. dass objektorientierte Präsentationen vom Fachpublikum bevorzugt werden. Wie jedoch in den persönlichen Interviews auch deutlich wurde, bedeutet dies in der Umkehrung nicht, dass Besucher mit hohem Bildungsabschluss inszenierte Formen ablehnen. Auch hier gab es unterschiedliche Positionen von lobender Erwähnung bis hin zu abwertenden Kommentaren. Nicht allein der Bildungsabschluss ist das entscheidende Kriterium für die Bevorzugung bestimmter Präsentationsformen, sondern weitere Komponenten wie persönliche Vorlieben und Interessen beeinflussen die Bewertungen.

Im Hinblick auf die Gestaltung wurde die Mischung der Präsentationsarten positiv hervorgehoben. Die historisch orientierten Menschen könnten zwar auf die inszenatorischen Elemente verzichten, dieses jedoch gefällt gerade den visuell orientierten Menschen. Sie schätzten die Unterschiedlichkeit des Informationsangebots auf verschiedenen sinnlichen Ebenen. Auch die Wege zwischen den einzelnen Ausstellungsorten wurden als angenehme Abwechslung empfunden, die der oft zitierten Museumsmüdigkeit entgegenwirkt.

„In der Alten Hofhaltung ist jeder Raum für sich eine kleine ExtraAusstellung, das Raumerlebnis wechselt und hält wach, bei der Art der Präsentation wie im Diözesanmuseum macht man irgendwann zu." (Betriebswirt, geb. 1957)

Die unterschiedlichen Präferenzen bezüglich der Präsentationsform lassen sich ebenfalls den verschiedenen Gruppen zuordnen. Eine klare Bevorzugung eines der zwei Präsentationskonzepte kristallisierte sich je- 
doch nicht heraus. Jede Ausstellungsform fand in Abhängigkeit von Bildung, Vorwissen und persönlichen Vorlieben ihre Befürworter.

Tendenziell kann festgestellt werden, dass der Typus des allgemein visuell orientierten Menschen die Alte Hofhaltung bevorzugt. Historisch orientierte Menschen halten diese Form der Darstellung für problematisch. Bei einer Bewertung der unterschiedlichen Präsentationsarten fließt auch die Toleranz der Besucher sowie die aktuelle Stimmung mit ein. Manche Befragten konnten den ironisierenden Elementen der Alten Hofhaltung persönlich nichts abgewinnen, ließen diese aber als solche gelten. Andere konnten sich sehr dagegen ereifern. Diejenigen, die das Präsentationskonzept der Alten Hofhaltung bevorzugten, gaben folgende Gründe an:

- Das Geschichtsinteresse wird bedient.

- Das ironische Element lockert den Rundgang auf, denn „vor Ehrfurcht erstarren ist nicht mehr zeitgemäß.“

- Die Möglichkeit zu Aktivität sorgt für eine längere Aufenthaltszeit.

- Durch die Inszenierung entsteht ein bildlicher Eindruck. Dadurch wird die Erinnerung plastischer, vom Gesamteindruck bleiben folglich mehr Bilder in Erinnerung.

- Die Information wird zwischen den Zeilen vermittelt, es gibt nicht nur Objekte, sondern Themenkomplexe.

- Durch die Beanspruchung aller Sinne ist die Vermittlung nicht so trocken. Es ist lebendig und macht Spaß.

- Die Gestaltung zeugt von Einfallsreichtum.

Ein anderer Teil der Besucher befürwortet generell Inszenierungen, steht jedoch der Art und Weise, wie dies in der Alten Hofhaltung der Fall war, eher ablehnend gegenüber. Das abgebrannte Mittelalterliche Gehöft hätte deren Vorstellungen eher entsprochen. Basierend auf wissenschaftlichen Forschungen könnten Inszenierungen akzeptiert werden, da diese dann $\mathrm{zu}$ einem besseren Vorstellungsvermögen beitragen. Inszenierungen sollten nach Meinung dieser Besuchergruppe wiedergeben, wie es zur damaligen Zeit war, wie die Menschen vielleicht Dinge gesehen oder empfunden haben könnten.

Die Befürworter der objektorientierten Präsentation im Sinne des Diözesanmuseum gaben folgende Gründe an:

- Die Objekte können ohne Ablenkung in Ruhe betrachtet werden. 
- Der ästhetische Genuss beim Betrachten der Originalobjekte steht im Vordergrund, die Historie ist weniger wichtig, diese kann in Ruhe daheim im Katalog nachgelesen werden.

- Die Würde der Objekte soll gewahrt bleiben, aus diesem Grund können die sakralen Objekte nicht in einer inszenierten Form mit witzigem Unterton wie in der Alten Hofhaltung präsentiert werden.

Die salomonische Lösung in der Kombination unterschiedlicher Präsentationskonzepte hielten die meisten Besucher für das Beste. Das Nebeneinander wurde als angenehm empfunden, da unterschiedliche Interessensgebiete abgedeckt werden konnten.

„Die Mischung macht's! Man kann nicht sagen, entweder oder, sondern jede Präsentationsform hat in seinem Wollen ihre Berechtigung. Dies ist abhängig von den Exponaten, Inhalten und Zielen, hierfür gibt es keine Pauschalantwort. Wirklich differenzierte Vermittlung geht nur über strukturierten Unterricht." (Studentin, Vergleichende Sprachwissenschaft, geb. 1981)

\subsection{Analyse unter den Dimensionen metakommunikativer Aspekte}

Mit diesem Kapitel soll der Blick auf Zusammenhänge geworfen werden, die sich nicht direkt auf Objekte und deren Geschichten beziehen. Damit geraten die Metafunktionen von Ausstellungen ins Blickfeld. Kulturhistorische Ausstellungen lassen sich gegenwärtigen Situationen sowie aktuellen politischen und wirtschaftlichen Interessenslagen anpassen. Der Ausstellungsbetrieb ist daher besonders geeignet für die „Forcierung von Metafunktionen“"144, denn Ausstellungen sind nicht nur als Foren für politische Darstellung, sondern darüber hinaus auch als Wirtschaftsfaktor relevant.

\section{Die politische Dimension}

Das Haus der Bayerischen Geschichte als geschichtliche Ausstellungsund Publikationszentrale versteht sich als staatliche Institution, die im Auftrag staatlicher Organe wie durch eigene Sacharbeit tätig wird (Vollhardt 2003, S. 152). Bereits während der langen Entstehungsphase vor

144 Fliedl zitiert in Schober 1994, S. 55. 
der formellen Gründung des Hauses zeugen die Diskussionen und kritische Presseäußerungen von der Befürchtung, dass dieser Ort zur bayerischen Selbstpräsentation politisch funktionalisiert werden könne (ebd., S. 89). ${ }^{145}$ So wurde zum Beispiel das Vorhaben, den Sitz des Instituts in der Bayerischen Staatskanzlei in München zu verwirklichen, aufgrund öffentlicher Proteste revidiert. Die SPD-Opposition im Landtag kritisierte heftig die auf dem Gelände vorgesehene Kombination von Politik und Geschichte und sprach von einem ,zum Wurmfortsatz der Staatskanzlei degeneriert[en], ${ }^{146}$ Haus der Bayerischen Geschichte. Auch der SPD-Abgeordnete Schmolcke sprach von einem Selbstbeweihräucherungsinstitut, das sich die Staatskanzlei zu machen anschicke.

,[Die] räumliche Nähe zwischen der unionsgeführten Staatsregierung und der Geschichtsbehörde suggeriere sozusagen die Identität von bayerischer Geschichte und bayerischer Gegenwart im Zeichen der Staatspartei CSU, affirmiere damit die bestehenden Parteienverhältnisse und lasse auch eine inhaltliche Kongruenz befürchten.“147

Da die ursprüngliche Leitidee einer zentral angesiedelten, fest installierten Dauerausstellung zur geschichtlichen Selbstdarstellung Bayerns aufgegeben wurde, entfiel auch die Notwendigkeit nach einer repräsentativen baulichen Manifestation. Die Aufgabe der Konzeption und Durchführung von Wechselausstellungen in jeweils verschiedenen Städten konnte auch dezentral erledigt werden. So befindet sich der heutige Sitz des Hauses der Bayerischen Geschichte in Augsburg in einem neutralen Bürogebäude in der Nähe des Bahnhofs.

145 Auch das im Jahr 2002 eröffnete Haus der Geschichte Baden-Württemberg hat eine über zwei Jahrzehnte dauernde Entstehungsgeschichte. Es stand von Anfang unter Ideologieverdacht. Dies führte zu Verzögerungen bei der Verwirklichung des Vorhabens. „Die LandtagsOpposition keuchte unter nächtlichen Alpträumen, in denen das Geschichtshaus als Ruhmeshalle der Landes-CDU erschien." Vgl. Ruf, Reiner: Eine schwere Geburt - Schau für die Sinne - und keine historische Sinnstiftung. http://www.suedwest-aktiv.de (letzter Zugriff: 13. 12.02).

146 Böddrich (SPD) zitiert in Vollhardt, 2003, S. 154.

147 Schmolcke zitiert in Vollhardt 2003, 154. Bereits zuvor war auch in der Presse befürchtet worden, dass unter der Ägide des Ministerpräsidenten Strauß eine Propagandaschau im Sinne des „,schönen neuen Bayern“ entstehe. Hackelsberger, Christoph: Der Hofgarten, Besitz der Bürger. In: Süddeutsche Zeitung vom 08./09.12.84. 
Diese Diskussion um den Sitz des Instituts verweist jedoch auf den tatsächlichen Zusammenhang von Politik und Öffentlichkeitsarbeit. So geht auch Grimm, der Direktor des Hauses der Bayerischen Geschichte, in der Jubiläumsschrift zum zwanzigjährigen Bestehen auf diese Problematik ein. Sensibilisiert durch die zahlreichen Kontroversen im Vorfeld der Gründung des Hauses wurde dem anfänglichen Vorwurf kritischer Beobachter einer politischen Einflussnahme der Bayerischen Staatskanzlei bewusst entgegengetreten. Durch Themenwahl sowie inhaltliche Gestaltung der Ausstellungen sollte das Gegenteil bewiesen werden (Grimm 2003, S. 17). ${ }^{148}$

Für die Mitarbeiter des Hauses und die öffentliche Präsentation gilt, dass Texte weder den wissenschaftlichen Anspruch einzelner Verfasser hervorheben noch „staatsamtliche Definitionen“ sein dürfen. Vielmehr ist darauf zu achten, dass die abgesicherte Information den „ForumsCharakter des Hauses“" gewährleistet (ebd.). Orientiert an zeigbaren Gegenständen und auf nachvollziehbare Lebenszusammenhänge ausgerichtet sollen die Ausstellungen Neugier wecken (ebd., S. 19). Mit einer kulturgeschichtlichen Betrachtung soll ein Perspektivenwechsel erreicht werden, der die bayerische Geschichte nicht als abgrenzbare Entwicklung betrachtet, ,sondern als die in Bayern stattgehabte, von Bayern gestaltete und erlittene Geschichte." (ebd., S. 19). Jedoch auch die Zwiespältigkeit der Geschichte, die fern ,aller unberechtigten Selbstfeier zu vergegenwärtigen ist“, soll laut Grimm thematisiert werden.

„Neben der Entdeckung des Vorbildlichen steht die Konfrontation mit dem Abgründigen, neben dem Stolz auf Entfaltungsmöglichkeiten der eigenen Kultur steht die Mahnung des ,Nie wieder!‘. [...] Nicht die Selbstbestätigung in lieb gewonnenen Traditionen steht hinter dem Auftrag, bayerische Geschichte darzustellen, sondern die Frage nach den Möglichkeiten und Verpflichtungen, die Bayern als deutsches Bundesland und Region Europas für sich und alle Menschen, die mit ihm zu tun haben, mitbringt." (ebd., S. 19ff.)

Das Haus der Bayerischen Geschichte verfolgt damit die Intention, Geschichtsbewusstsein zu fördern, jedoch ohne staatspolitische Vereinnahmung. Trotz der angestrebten politischen Neutralität ist das Haus der

148 Die Themen der Ausstellungen wurden von Kooperationspartnern aus dem ganzen Land angeregt, von Fraktionen des Landtags ebenso wie von regionalen Mandatsträgern, und wurden dann den Austarierungsgremien wie Ausstellungskuratorien und dem Beirat des Hauses vorgelegt. Vgl. Grimm 2003, S. 17. 
Bayerischen Geschichte auf die Unterstützung der Staatskanzlei angewiesen. Da das Institut keine eigenen Objektsammlungen besitzt, kann es bei Leihverhandlungen mehr Schwierigkeiten haben, als dies bei Museen mit bedeutenden Objektbeständen der Fall ist. Deshalb sichert die Anbindung an die Staatskanzlei und das Wissenschaftsministerium die Wahrnehmung des staatlichen Auftrags.

Unter dieser politischen Dimension soll nun die Heinrichsausstellung betrachtet werden. Bereits bei den Überlegungen im wissenschaftlichen Konzept zum Titel dieser Ausstellung spiegeln sich nationale Erwägungen wieder. Schneidmüller/Weinfurter schlagen als Titel „Bayerns Triumph - Europas Glanz/Zierde“149 vor. Dies erfolgte mit der Begründung, dass sich darin deutliche Voraussetzungen und Ziele herzoglicher und kaiserlicher Politik am Beginn des zweiten Jahrtausends spiegeln würden. Die Wortwahl begründen sie auch damit, dass dies nicht, wie vielleicht vermutet, eine Erfindung bayerischer Geschichtspolitik sei, sondern auf zeitgenössischen Kommentaren basiert:

„Der Satz, daß Bayern in Heinrich II. triumphiert, wird dem italienischen Reichsbischof Geovon Vercelli verdankt (Triumphat Baioaria = Bayern triumphiert, MGH. Poetae latini 5, S. 482). Das Lob Heinrichs als Schmuck, Zierde oder Glanz (DECUS EUROPAE) hat sich auf der Inschrift des Sternenmantel Heinrichs II. erhalten.“ (ebd. S. 5)

Mit diesem Titel wären zwei Aussagen italienischer Anhänger Heinrichs II. vereinigt. Gleichzeitig wiesen Schneidmüller/Weinfurter auch darauf hin, dass dieser Titel sicherlich Diskussionen über bayerischen Geschichtsstolz hervorrufen könne, jedoch aufgrund der Authentizität einen Vorteil gegenüber anders lautenden „Kunsttiteln“ hätte (ebd.). Dieser Vorschlag wurde von den Entscheidungsträgern des Hauses der Bayerischen Geschichte nicht aufgegriffen. Dem neutralen Titel „Kaiser Heinrich II. 1002-1024“" wurde der Vorzug gegeben. Stattdessen fanden diese zeitgenössischen Äußerungen aber Anwendungen als Raumtitel. Im Raum „Der Kaiser“ stand „Decus Europae - Zierde Europas“ in weißer Schrift auf der Cortenstahl-Ummantelung der zentralen Mittelsäule (siehe Abb. 43). Im Raum „Der neue König“ war der archivalische Raumtitel „Triumphat Baioaria - Bayern triumphiert“ in schwarzer Schrift in

149 Offen blieb zunächst die Übersetzung von decus als Glanz oder Zierde. Beides war philologisch möglich. „Zierde klingt feiner, aber auch altertümlicher, Glanz plakativer, eingängiger, aber vielleicht auch aufdringlicher.“ Vgl. Schneidmüller/Weinfurter 1999, S. 5. 
Bauchhöhe auf dem beigefarbenen Vitrinenunterbau angebracht (siehe Abb. 59). Darüber war in der Vitrine das Exponat die „Nachbildung der Heiligen Lanze“, die als Christusreliquie und Herrschaftszeichen mit höchster Symbolkraft beladen ist. ${ }^{150}$

Auch die Eröffnungsrede zur Landesausstellung des Bayerischen Staatsministers Zehetmair war nicht frei von bayerischem Patriotismus. Sie begann mit dem Hinweis darauf, dass genau vor tausend Jahren erstmals ein bayerischer Herzog zum König und später zum Kaiser des mittelalterlichen Römischen Reiches gewählt wurde.

„Ich sage ganz bewusst, dass Heinrich bayerischer Abstammung war, auch wenn er noch manchmal mit Blick auf seinen sächsischen Großvater von Sachsen vereinnahmt wird. [...]. Mit Heinrich II. war für die Bayern endlich einer der Ihren Träger des Reichs geworden, [...]. ${ }^{151}$

Diese Ausstellung wurde während des Wahlkampfes zum Bundestag eröffnet. Ministerpräsident Stoiber kandidierte für das Amt des Bundeskanzlers. Mit einem Wahlsieg hätte erstmals ein bayerischer Politiker dieses Amt inne gehabt. So spiegelte sich dieser aktuelle Zusammenhang auch in den Pressekommentaren:

„Ob diese Ausstellung etwas mit der zweiten derzeit stattfindenden Baiuvarisierung Deutschlands zu tun habe, wurde Kunstminister Zehetmair gestern am Rande der Ausstellung gefragt. Da schluckte der ansonsten so eloquente Bayer erst einmal. Natürlich bezweifle er als Mann der CSU nicht, dass Herr Stoiber sich bestens als Diener des Staates eigne.“152

In noch deutlichere Worte fasste diesen Zusammenhang die Schlagzeile „Wie ein Bayer von Deutschland Besitz ergriff. Kaiserkandidat vor tausend Jahren: die Bamberger Ausstellung über Heinrich II.“" ${ }^{153}$ Obgleich in dem Artikel keine Verknüpfung zum Kanzlerkandidat Stoiber herge-

150 Siehe Kapitel 5, S. 239f. sowie Kapitel 6, S. 347f.

151 Rede des Bayerischen Staatsministers für Wissenschaft Forschung und Kunst, Hans Zehetmair, anlässlich der Eröffnung der Bayerischen Landesausstellung 2002 „Kaiser Heinrich II. 1002 - 1024“ am 8. Juli 2002 in Bamberg. Schriftlicher Abdruck der Presseinformation. S. 1.

152 Kirch, Raimund: Wie Bamberg zum Zentrum des Reiches wurde. In: Nürnberger Zeitung vom 09.07.02.

153 Schostack, Renate: Wie ein Bayer von Deutschland Besitz ergriff. In: Frankfurter Allgemeine Zeitung vom 23.07.02. 
stellt wurde, verwies dieser dennoch subtil auf vergleichbare Ambitionen.

Das Ziel dieser Landesausstellung bestand unter anderem darin, den im kollektiven Gedächtnis vergessenen Herrscher Heinrich II. wieder in Erinnerung zu rufen und damit auch auf die Leistungen dieses Herrschers bayerischer Abstammung zu verweisen. Mit den Raumtiteln „Der neue König - Triumphat Baioaria - Bayern triumphiert“ sowie „Der Kaiser - Decus Europae - Zierde Europas" wird unmissverständlich auf die historische Bedeutung Bayerns verwiesen. Berechtigt erscheint in diesem Kontext deshalb die Feststellung, dass diese Landesausstellung auch der Selbstdarstellung Bayerns diente.

Kulturhistorische Ausstellungen übernehmen integrierende Funktion, indem sie Identifikationsangebote bereit stellen. Sie bieten beispielsweise „national oder territorial gefärbte Wir-Identitäten“ oder „Identifikationsmöglichkeiten mit Herrscherdynastien“. (Schober 1994, S. 58ff.). In diesen Fällen dienen nach Ansicht von Schober Ausstellungen der Projektion von Wunschvorstellungen der Gegenwart in die Vergangenheit. Die Identifikationsangebote werden dabei den je aktuellen politischen Interessenslagen angepasst (ebd.).

Weiterhin stellt Schober fest, dass neben diesen Regionalidentitäten gegenwärtig auch verstärkt versucht wird, über Ausstellungen europäische Identität zu vermitteln. ${ }^{154}$ Auch dies trifft auf die Heinrichsausstellung zu. Wie bereits an mehreren Stellen erwähnt, wurde mit dem Raum „Der Kaiser“ die europäische Bedeutung des Herrschers illustriert. Auch im Kontext der weiteren großen Mittelalterausstellungen zur Jahrtausendwende kann diese Feststellung untermauert werden. Die Ausstellung „Europas Mitte um 1000“ thematisierte die mit dem Eintritt der Westslawen und Ungarn in den abendländischen Kulturkreis beginnende Genese der Mitte Europas. ${ }^{155}$

„Heute, an der Wende vom zweiten zum dritten Jahrtausend, gewinnt die Frage nach dem gemeinsamen, die Ausbildung nationaler Vielgestaltigkeit und Individualität tragenden Fundament an Bedeutung. Polen, Tschechen und Un-

154 Dieses war beispielsweise in der von Fiat finanzierten Großinszenierung „i celti - la prima Europa“ der Fall, die 1991 im Palazzo Grassi in Venedig stattfand. In dieser wurde das heutige Europa in die Zeit der Kelten zurückprojiziert, wobei diese als erste Europäer identifiziert wurden. Vgl. Schober 1994, S. 59.

155 Siehe Kapitel 5, Anm. 52 und 67. 
garn wurden um das Jahr 1000 Teil eines sich zur geistig-kulturellen Einheit formenden Europa, [...]. Der Blick in die europäische Vergangenheit eröffnet so den Blick in die europäische Zukunft. ${ }^{156}$

Jedoch ist, wie Helzel beobachtete, die Tendenz bemerkbar, dass bei den Ausstellungen zu den wichtigen mittelalterlichen Kaisergeschlechtern der Salier, Staufer und Ottonen in den vergangenen Jahrzehnten die nationale Erinnerung hinter der europäischen Ausrichtung verschwindet. $^{157}$

An Bedeutung gewinnen auch touristische und damit ökonomische Gesichtspunkte. Die Ausstellung „Otto der Große, Magdeburg und Europa“ war mit täglich fast zweitausend Besuchern ein enormer Erfolg. Gelobt wurde das aktive Standortmarketing, das den Magdeburger Tourismuseinrichtungen nie gesehene und erlebte Zuwachsraten bescherte (ebd., S. 288). Mit Blick auf die Ottonen-Ausstellung kritisiert Helzel, dass bei aller Europa-Orientierung die Rezeption der Vergangenheitsbilder eines Jahrtausends keinen Widerhall in der Ausstellung fand. Ohne Objekte in der Ausstellung thematisierte lediglich Fried am Schluss des EssayBandes dieses Thema. Als einziger stellte er über eine Rezeptionsanalyse eine Verbindung zwischen den historischen Ottonen und der Gegenwart her, die schließlich zoomend an die unmittelbare, nationalsozialistische Vergangenheit heranreicht. ${ }^{158}$ Doch wegen dieser Erinnerung wäre man, wie Helzel einschränkend anmerkt, nicht so massenhaft nach Magdeburg gepilgert. „So bleibt das restaurierte Wandgemälde von 1906 im Ausstellungsgebäude mit Otto dem Großen als Krieger und Sieger über Slawen und Wenden stumm.“ (Helzel 2004, S. 290).

156 Wieczorek, Alfried, Kretzschmar, Ulrike: Exposé zum Ausstellungsprojekt „Europas Mitte um 1000“. Stand: 11.05.99, Mannheim, 1999.

157 Helzel, Frank: Ein König, ein Reichsführer und der Wilde Osten. Heinrich I. (919 - 936) in der nationalen Selbstwahrnehmung der Deutschen. Bielefeld, 2004, S. 287.

158 Siehe Kapitel 2, Anm. 40-46 sowie Kapitel 5, Anm. 66. 


\section{Die ökonomische Dimension}

Eine weitere Metafunktion von Ausstellungen stellt die wirtschaftliche Seite dar. Transportfirmen, Verlage, Reisebüros, Verkehrsunternehmen, Hotel- und Restaurantbetriebe, Bauunternehmen, Andenkenläden, Boutiquen u.s.w. profitieren von diesen kulturellen Großveranstaltungen. Somit bilden die Landesausstellungen neben dem Bildungsauftrag des Hauses der Bayerischen Geschichte eine Möglichkeit, den Tourismus und Einzelhandel in den Regionen zu fördern. ${ }^{159}$ Die Heinrichsausstellung hatte aufgrund der unerwartet hohen Besucherzahlen einen nachhaltig positiven Einfluss auf Handel, Gewerbe und Hotellerie in Bamberg und Umgebung. Bei der Stadt Bamberg deckten die Einnahmen alle Ausgabenposten und sogar ein Überschuss konnte verbucht werden. ${ }^{160}$

„Auch der Einzelhandel profitierte unmittelbar vom Heinrich-Boom, der Bamberg erfasste. Mit Ideenreichtum machte die Bamberger Geschäftswelt Heinrich und Kunigunde zum kulinarischen Wirtschaftsfaktor: HeinrichPralinen, Kaiser-Heinrich-Brot, Kunigundenkringel oder das Kaiser-HeinrichBier waren wahre Verkaufsschlager.“161

159 Die Ausstellung hatte einen staatlichen Etat von 1,3 Mio. Euro. Die Stadt stellte die Räume kostenlos zur Verfügung und beteiligte sich an Begleitkosten mit 70.000 Euro. Hinzu kam eine Förderung durch die Oberfrankenstiftung in Höhe von 150.000 Euro. Dieser für Mittelalterausstellungen äußerst geringe Finanzansatz war nur in diesem speziellen Fall möglich, weil Kaiser Heinrich der Stadt Bamberg eine Vielzahl von Exponaten geschenkt hat, die sich zum großen Teil noch hier befinden. Die Ausstellung konnte so zu einem erheblichen Teil mit Exponaten der drei beteiligten Institutionen Staatsbibliothek, Diözesanmuseum und Historisches Museum bestritten werden. Dies sparte erheblich an Versicherungs- und Transportkosten. Vgl. Kirmeier 2003, S. 4

160 Lauer, Herbert: Landesausstellung „Heinrich II.“ als Wirtschaftsfaktor/Stellungnahme der Stadt Bamberg. In: Haus der Bayerischen Geschichte (Hrsg.): Expertentagung „Ausstellung und Tourismus“ vom 26. bis 27. Febr. 2003 in Kloster Banz. 2003, S. 15.

161 Auch die Zahl der Gästeankünfte stieg ab Beginn der Ausstellung deutlich an, die Hotels waren bis weit ins Umland ausgebucht. N.N: „Bamberg hat gar nichts Besseres passieren können.“ Landesausstellung „Kaiser Heinrich II.“ endete mit Rekordergebnis. http://www.bamberg.de/ rathaus/journal/021101t1/htm (letzter Zugriff: 30.11.04). 
Der große Erfolg der Landesausstellung lässt sich auf ein Bündel von Faktoren zurückführen. Allein das reizvolle Ambiente um den Bamberger Dom besitzt an sich bereits hohe Attraktivität. Professionelle Pressearbeit wie auch das umfangreiche Rahmenprogramm lockten viele Besucher an. Einen weiteren Baustein für die positive Resonanz bildete das besucherorientierte Ausstellungskonzept, welches insbesondere in der Alten Hofhaltung und mit dem Gehöft auf eine populäre Form der Wissensvermittlung setzte. Dieser am breiten Publikum orientierte Weg führte insbesondere beim kritischen Fachpublikum zu höchster, zum Teil auch polemischer Kritik und Ablehnung.

„Die Grenzen zwischen wertvollem Exponat, Vitrinen und improvisierter Präsentationsarchitektur werden dabei mit aller Gewalt vermischt, etwa indem man zur Betrachtung von Exponaten kleine Türen in einer MDF-Platte öffnen muss. [...] Beschallungen mit Klischeegeräuschen, interaktive Computersimulationen, geneigte Rampen mit naturnaher Beschichtung, Fühlkästen und Riechlöcher inszenieren eine umfassende Inanspruchnahme aller Sinne. [...] Es entsteht ein Potemkinsches Dorf der hyperreal gewordenen Historie, eine Art didaktischer Geisterbahn, ohne jeden inneren Bezug zur Anmutung und Präsenz der ausgestellten Objekte.“162

Diese exemplarisch herausgegriffene Meinung steht stellvertretend für kritische Kommentare, die insbesondere den inszenierten Parcours in der Alten Hofhaltung betrafen. ${ }^{163}$ So stellt sich nun die Frage, ob der Vorwurf der Trivialisierung und Disneysierung an das Haus der Bayerischen Geschichte gerechtfertigt ist. Wurden mit der Inszenierung in der Alten Hofhaltung die Grenzen überschritten? Insbesondere der oft als flapsig empfundene Papstfilm bewirkte sehr unterschiedliche Reaktionen.

Raum: „Der Friedenskuss“,

Filmsequenz: „Nachrichtensendung zum Papstbesuch in Bamberg“

Im Raum „Der Friedenskuss“ illustrierte ein unter der Regie von Rainer Lewandowski entstandener Film das historische Ereignis des Besuchs des Papstes Benedikt VIII. in Bamberg zur Osterzeit im Jahr 1020 ${ }^{164}$ In Analogie zu aktuellen Nachrichtensendungen kündigte eine Fernseh-

162 Schebler, Gerhard: Im und wider das Museum führen. (unveröffentl. Skript) Hauptseminararbeit an der Ludwig- Maximilians-Universität, Fakultät Kunstpädagogik, München 2004, S. 19.

163 Auch im Besucherbuch finden sich derart negative Kommentare.

164 Kirmeier u.a. 2002, S. 234, Nr. 85 B. 
sprecherin einen Filmbericht über den Papstbesuch an, der über die Ankunft des Papstes, die Vertragsverhandlungen sowie das Festbankett informierte. In karikierender Weise agierten die Schauspieler in extrem übersteigerter Mimik und Gestik. Nach Ende des Filmberichts folgte die Wettervorhersage. Gezeigt wurde dieser Film auf einer Monitorwand mit je vier Bildschirmen in drei Reihen. Die Filmbilder liefen über die gesamten auf- und aneinandergereihten Monitore, so dass die Seitenränder der Bildschirme ein unterbrochenes Bild erzeugten.

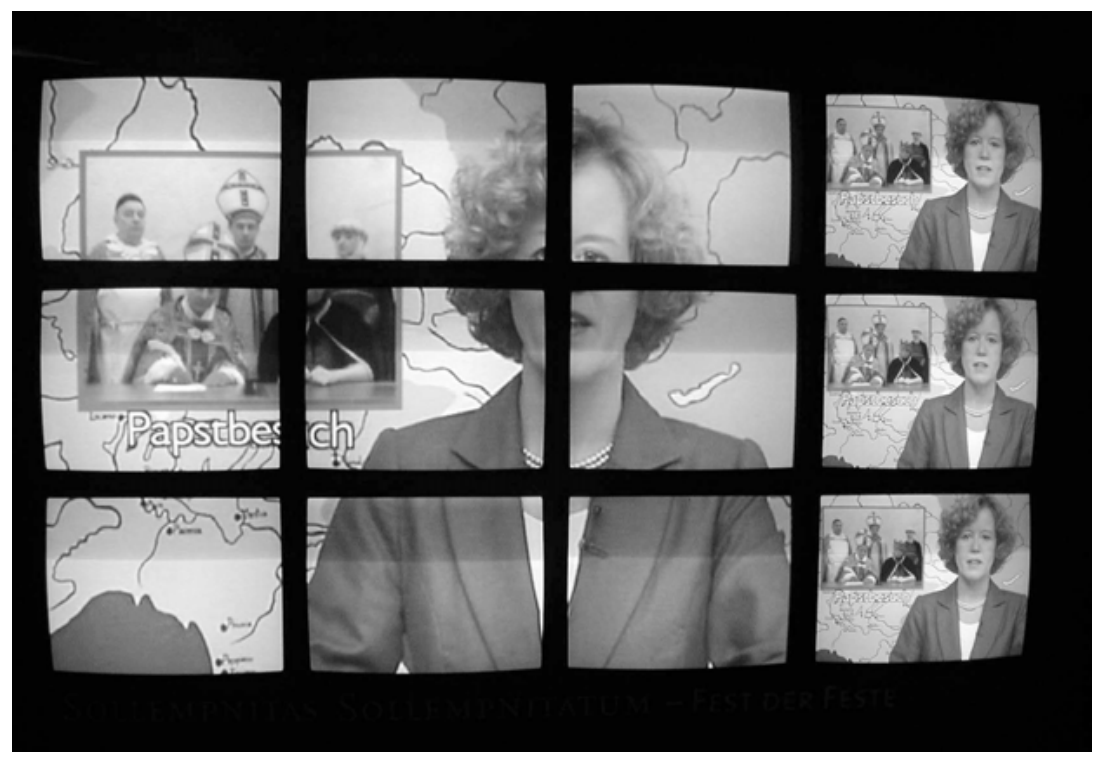

Abbildung 66: Filmsequenz, „Nachrichtensendung zum Papstbesuch in Bamberg “im Raum der „Friedenskuss“.

Durch diese Irritation sollte der Besucher erkennen, dass es sich hierbei um keine Dokumentation im traditionellen Sinne, sondern eine humorvolle Interpretation des historischen Berichts handelte. Die zugehörige archivalische Handschrift „Bericht des Diakons Bebo zum Papstbesuch in Bamberg" ${ }^{\text {"165 }}$ befand sich in einer Vitrine in der Mitte des Raumes. In diesem Widmungsbrief berichtet Bebo als Augenzeuge über den Besuch von Papst Benedikt VIII. in Bamberg. Dieser Raum erfüllte in der Ausstellungsdramaturgie ein Bindeglied zwischen dem Raum „Der Kaiser“

165 Ebd., S. 233, Nr. 85 A. 
und dem letzten Raum „Unterwegs im Reich“. Diese eher untergeordnete Funktion in der Ausstellungsdramaturgie stand im Widerspruch zur großen Aufmerksamkeit seitens der Besucher, die diese Medieninstallation erfuhr.

„Dies war wirklich nur als Persiflage oder ironischer Bruch zu den Objekten gedacht. Der Film zieht mehr Aufmerksamkeit auf sich als teilweise die hochwertigen Objekte.“166

Eine Verwechslung mit einer ernsthaften Dokumentation wurde sowohl durch die Brechung des Bildes mittels Anordnung der Monitore wie auch durch die karikierende Schauspielerei verhindert. Dennoch ist zu bedenken, was offensichtlich die Aufmerksamkeit der Besucher auf sich zieht. Es vollzog sich eine Bedeutungsverschiebung weg von den musealen Exponaten hin zu den leicht konsumierbaren, bewegten Bildern des Films. Die in der Vitrine liegenden Handschrift, in der Diakon Bebo über den Papstbesuch berichtet, erhielt meist lediglich flüchtige Blicke. Im Gegensatz dazu tritt dieser Film sowohl akustisch wie auch visuell dominant in den Vordergrund. Der humoristische Film bediente das Unterhaltungsbedürfnis der Besucher und sorgte für Auflockerung im Rundgang.

In den persönlichen Interviews der Besucherbefragung führte dieser Film zu extrem unterschiedlichen Bewertungen. Die historisch orientierten Menschen lehnten diese Form der Präsentation ganz klar ab. Die karikierende Darstellung wurde als überzeichnet und folglich wenig überzeugend empfunden. Der Kontrast zum restlichen Umfeld war zu groß.

„Dies lässt an nötiger Seriosität vermissen, um der Thematik gerecht zu werden." (Soldat, geb. 1952)

„Dieser Film ist zu karikierend und dem kirchlichen Thema nicht angemessen.“ (Hausfrau, geb. 1956)

„Der Fressfilm bemüht sich, die Begebenheit darzustellen, doch spricht dies nicht an." (Physikerin, geb. 1930)

Dies stand im Gegensatz zu dem Typus der allgemein visuell orientierten Menschen, denn diese betrachteten den Film als willkommene Ab-

166 Interview mit Herrn Dr. Christian Lankes, wissenschaftlicher Mitarbeiter beim Haus der Bayerischen Geschichte, am 6. Juli 2002. 
wechslung. Sie zeigten sich überrascht, solch ein Moment in einer historischen Ausstellung vorzufinden:

„[...] witzig, nicht nur ernst, sondern locker“ (Verkäuferin, geb. 1953)

,[...] eine originelle Umsetzung des historischen Themas“ (Hausfrau, geb. 1957)

\section{Raum „Unterwegs im Reich“, Inszenierung zum Thema Reisekönigtum} „Heuschreckenplage“ (siehe Abb. 67-71)

Eine ebenfalls kontrovers beurteilte Inszenierung befand sich im Raum „Unterwegs im Reich“. Eine sich über drei Kojen ausbreitende Inszenierung mit giftgrünen Plastikheuschrecken, die an Stoffbahnen hingen und sich am Boden verteilten, illustrierte eine Beschreibung aus der Chronik von Thietmar von Merseburg ${ }^{167}$, der 1002 von Verpflegungsproblemen in Paderborn berichtete und die unersättliche Habgier der Bayern kritisierte (siehe Abb. 69). Mit dieser Inszenierung wurde der Besuch des Herrschers mit seinem Gefolge von schätzungsweise 300 bis 1000 Menschen mit einer Heuschreckenplage verglichen. ${ }^{168}$

Ergänzt wurden die Heuschrecken mit einer Zeichnung auf der Stoffbahn, die den langen Tross der Gefolgschaft Heinrichs II. darstellte (siehe Abb. 67). In Anlehnung an die graphische Darstellung von Fahrplänen wurde der Terminkalender des Königs vom 25.12.1002 bis zum 25.12.1003 mit verschiedenen Stationen unter Angabe von Ort und Datum innerhalb eines Jahres aufgezeigt (siehe Abb. 68). Ebenfalls auf der Stoffbahn beschrieb ein Zitat aus den Quedlinburger Annalen, wie eine Seuche das kaiserliche Heer 1022 in Italien dezimierte (siehe Abb. 71). Ein weißer, stilisierter Thron in Form eines Sattels, auf einem Podest in der Mitte einer Koje platziert, symbolisierte das Reisekönigtum mit Heinrich II. als reisender Herrscher auf dem Pferd (siehe Abb. 70).

In den persönlichen Interviews zeigte sich auch hier, wie unterschiedlich das Urteil zu denselben Ensembles ausfallen kann. Neben absoluter Ablehnung und der Bewertung als eine Anbiederung an die Spaßgesellschaft ohne wissenschaftlichen Anspruch stand die Freude am

167 Ebd., S. 183, Nr. 56. Der wichtigste Chronist für die Zeit Heinrichs II. ist der dem Herrscher nahe stehende Thietmar, Bischof von Merseburg.

168 Dieser Vergleich mit einer Heuschreckenplage ist kein historisches Bild, sondern eine aktuelle Erfindung der Ausstellungsmacher. 
humorvollen Element und das Lob für eine gelungene Visualisierung und Erinnerungshilfe. ${ }^{169}$

Bei beiden Visualisierungen stellt sich die Frage, ob sie adäquate Formen für die Illustrierung historischer Sachverhalte darstellen können. Die Heuschrecken überraschten, ließen schmunzeln, bei manchen erzeugten sie vielleicht ein leichtes Schaudern, ohne jedoch ernsthaft zu irritieren, teils stießen sie auf Gleichgültigkeit oder auch Ablehnung. Ebenso zeigte sich beim Papstfilm unterschiedliche Akzeptanz durch das Publikum. Der Papstfilm kann als eine Antwort auf die Mediengesellschaft gewertet werden. Er bediente das Unterhaltungsbedürfnis und fand somit auch zahlreiche Befürworter unter den Besuchern. Würde sich die Ausstellung auf diese Form der Vermittlung beschränken, so wäre es gerechtfertigt, davon zu sprechen, dass der Bildungsanspruch zu Gunsten von populären Formen geopfert wurde.

Diese Bewertung würde jedoch der Ausstellung im Gesamten nicht gerecht werden. Für die Beurteilung dieser Frage ist auch ausschlaggebend, wie einzelne, eben auch diese populären Elemente in den Gesamtkontext eingebunden sind. Dies bedeutet, dass nicht nur die fachwissenschaftlichen Kriterien für eine Bewertung relevant sind, sondern auch gemäß eines kommunikativen Ansatzes besucherorientierte Anliegen einfließen sollten. ${ }^{170}$ Insbesondere Landesausstellungen werden für ein breites Publikum konzipiert. Aus diesem Grund ergibt sich die Notwendigkeit, im Konzept zu berücksichtigen, wie potentielle Besucher erreicht werden können. Ausstellungen unter dem hohen Anspruch der Wissenschaftlichkeit zu konzipieren und gleichzeitig den Interessen eines heterogenen Publikums gerecht zu werden, ist ein kaum lösbarer Anspruch, dennoch existiert dieses Anliegen.

Für die Heinrichsausstellung kann festgehalten werden, dass sie Elemente integrierte, wie sie sich auch bei kommerziellen Anbietern finden lassen. Sie setzte damit auf Methoden und Medien, die in erprobter Weise auf Breitenwirkung zielen. Diese Funktion erfüllte allem voran das

169 Angemerkt wurde jedoch, dass zur besseren Verständlichkeit der Heuschreckeninszenierung ein Hinweis auf diesen bildhaften Vergleich irgendwo hätte stehen sollen.

170 Kritisch angemerkt werden muss auch, dass bei manch negativen Kommentaren emotionale Befindlichkeiten in den Vordergrund treten und diese dann als Maßstab für die Beurteilung des Gesamten herangezogen werden. 
Mittelalterliche Gehöft. Es wurde auch im Hinblick auf das Erreichen der Zielgruppen der Nicht-Museumsbesucher konzipiert.

„Die Zielgruppe der Nicht-Museumsbesucher war auch der Anlass für das Gehöft auf dem Domplatz. Ich kann mir durchaus vorstellen, dass am Stammtisch über die Ausstellung geredet wird. Und für viele Bamberger, die normalerweise nicht dorthin gehen würden, ist dies der Anlass zu kommen. Daraus wird ein Gesprächsstoff. “171

In der Landesausstellung konnten zum Beispiel - wie dies auch beim Ritterturnier in Kaltenberg möglich war - Schafe gestreichelt werden. Im Unterschied jedoch befand sich in Kaltenberg der Streichelzoo bei einem Gastzelt, dessen Außenfassade als künstliche Burg aus Plastikplanen gestaltet war. Währenddessen erhob sich in Bamberg hinter dem Streichelzoo beim Mittelalterlichen Gehöft die Kulisse des Bamberger Doms.
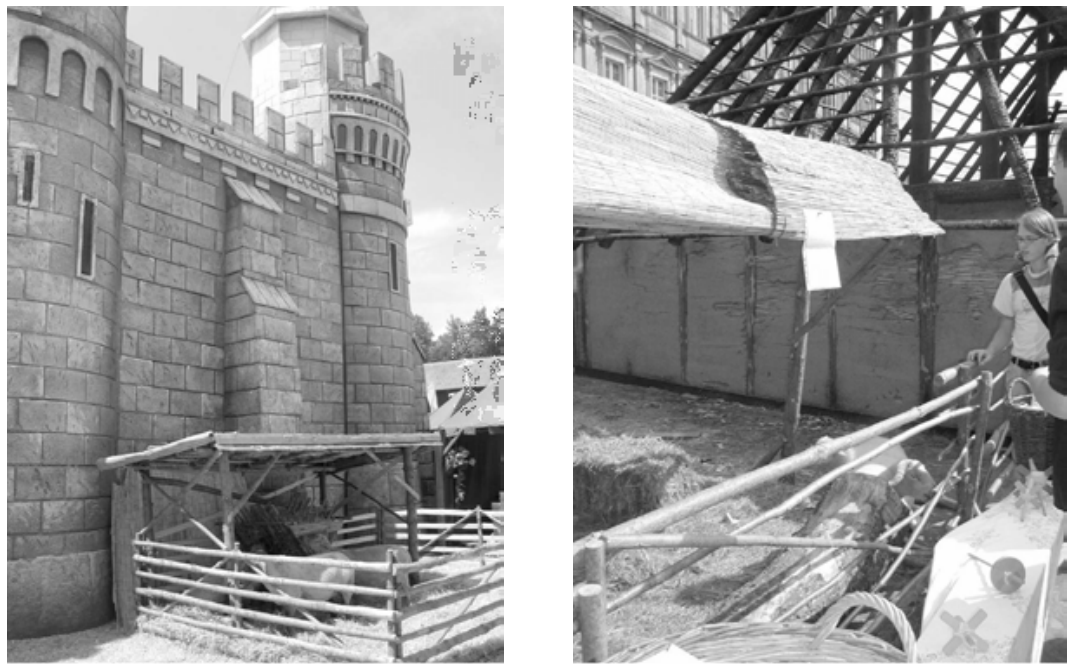

Abbildung 72/73: Streichelzoo mit Schafen sowohl beim Ritterturnier in Kaltenberg (links) als auch beim Mittelalterlichen Gehöft in Bamberg (rechts).

171 Interview mit Herrn Dr. Josef Kirmeier, Projektleitung der Landesausstellung „Kaiser Heinrich II. 1002-1024“ des Hauses der Bayerischen Geschichte, am 17. Oktober 2001. 
Auch das umfangreiche Begleitprogramm zur Landesausstellung mit Handwerksvorführungen erinnerte an das Angebot von kommerziell orientierten mittelalterlichen Märkten. ${ }^{172}$

Während jedoch die kommerziellen Anbieter ihr Angebot auf diese sinnliche Komponente zentrieren, erfüllte dies in der Landesausstellung eine hinführende Funktion mit dem Ziel, Neugier zu wecken und dazu zu bewegen, sich auf das weitere Angebot der Ausstellung einzulassen. Dem intensiven Studium und konzentrierten Betrachten der Exponate konnten sich die Besucher im Diözesanmuseum und der Staatsbibliothek widmen, ohne durch inszenatorische Einbauten abgelenkt zu werden.

Mit Inszenierungen findet somit auf ästhetischer Ebene eine Annäherung statt. Jedoch lassen sich auch hier bei genauerer Betrachtung der gestalterischen Umsetzung Unterschiede aufzeigen. Die Ziele der Inszenierungen in der Landesausstellung bestanden nicht darin, ein Ambiente „so authentisch wie nur möglich“"173 zur Schaffung ,einer Kontrastwelt mit Paradiescharakter“"174 zu kreieren. Die Rekonstruktion des mittelalterlichen Gehöfts basierte auf wissenschaftlichen Forschungen. Nach dem ursprünglichen Konzept hätte es zwar dort Schauwerkstätten mit Rekonstruktionen von Handwerksgeräten gegeben, doch wäre dies in einer musealen Präsentationsform erfolgt, ergänzt mit Objektbeschreibungen sowie Informationstafeln. Diese museale Präsentationsform im rekonstruierten Pfostenhaus wäre somit einem rein kommerziellen Anliegen, ein möglichst perfektes Ambiente zum Eintauchen in die Vergangenheit der mittelalterlichen Welt zu schaffen, hinderlich gewesen.

Weder mit der Heuschreckeninszenierung noch mit dem Papstfilm wurden klischeehafte Mittelaltervorstellungen bedient. Mit den unterschiedlichen Inszenierungen entstanden Raumbilder, die in ihrer Umsetzung Zuspruch oder Ablehnung fanden, jeweils abhängig von persönlichen Wertschätzungen. Die Raumbilder dienten der Illustrierung der Herrscherpersönlichkeit und des Umfelds von Heinrich II., und damit wurde dem Bildungsziel des Hauses der Bayerischen Geschichte entsprochen.

Kritisch angemerkt sei dennoch, dass eine Thematisierung der Konstrukthaftigkeit der Vergangenheitsbilder keinen Raum fand. In einer geschlossenen Erzählung wird der Parcours durch die Alte Hofhaltung mit den Schnitzfiguren aus dem 16. Jahrhundert geschlossen. Irritieren-

172 Beschreibung des Ritterturniers in Kaltenberg siehe Kapitel 5, S. 243.

173 Vgl. König 2004, S. 24. Siehe auch Kapitel 5, S. 249.

174 Vgl. Kagelmann 1998, S. 79. Siehe auch Kapitel 4, S. 244. 
de, kontroverse oder kritische Fragen in Hinblick auf den Heinrichskult in der Gegenwart blieben offen.

\subsection{Zusammenfassung}

Mit rund 206.000 Besuchern zählte diese Ausstellung im Hinblick auf die Besucherzahlen zu den erfolgreichsten Projekten des Hauses der Bayerischen Geschichte. (Haus der Bayerischen Geschichte 2003, S. 52). Das besucherorientierte Konzept versuchte, viele Ansprüche an einem Ausstellungsort zu vereinen. Sowohl der Fachwissenschaftler wie auch das Laienpublikum sollten angesprochen werden, wobei dem Letzteren ein höherer Stellenwert eingeräumt wurde. Die ideale Situation vor Ort in Bamberg ermöglichte es, an verschiedenen Orten unterschiedliche Präsentationskonzepte zu verwirklichen und diese miteinander zu vergleichen. Als deutliches Ergebnis der Untersuchung kann festgestellt werden, dass keinem Konzept der Vorzug gegeben werden kann.

Die Bewertung der unterschiedlichen Präsentationsformen durch die Besucher war von persönlichen Präferenzen abhängig. Dabei ist sehr bemerkenswert, dass völlig unterschiedliche Aspekte als positiv empfunden und auch extrem gegensätzlich beurteilt wurden. Dementsprechend kann die salomonische Lösung der Trennung zwischen Inszenierung und objektorientierter Präsentation als gute Methode gewertet werden, unterschiedliche Besuchergruppen zu erreichen und diese somit auch mit weiterführenden Aspekten zu konfrontieren. ${ }^{175}$ Die Befragung

175 Dieses Ergebnis bestätigt auch eine Karlsruher Untersuchung, die ebenfalls zwei Ausstellungen verglich, die sich unterschiedlicher Präsentationsmethoden bediente. Unter dem gemeinsamen Thema „Spätmittelalter am Oberrhein" gab das Badische Landesmuseum einen facettenreichen Einblick in das städtische Leben des späten Mittelalters und inszenierte die Exponate unter Einsatz von Innenarchitektur, Modellen und audiovisuellen Medien. Im Gegensatz dazu zeigte die Staatliche Kunsthalle die Blüte spätgotischen Kunstschaffens. Dort wurden die hochrangigen Werke in einer kunsthistorisch objektorientierten Präsentation gezeigt. In beiden Fällen bewertete das Publikum die Ausstellung im allgemeinen positiv, jedoch wurde keiner Präsentationsform eindeutig der Vorzug gegeben. Diplomatisch wurde relativiert, ,dass beide Ausstellungen auf ihre Art gut, aber doch zu unterschiedlich seien, als dass man sie miteinander vergleichen könne.“ Vgl. Klein, Hans-Joachim: Gemischtes Doppel. Evaluation der Ausstellungen Spätmittelalter am Oberrhein in der Staat- 
bestätigte, dass es nicht den typischen Museumsbesucher gibt. Es gibt sowohl die flanierenden Besucher, die den Unterhaltungswert der Ausstellung schätzen, genauso aber auch die spezifisch Interessierten, die weite Wege auf sich nehmen, angezogen vom historischen Thema der Ausstellung oder um beispielsweise herausragende Exponate zu sehen.

Auf die Frage, wie zukünftige Ausstellungen aussehen sollten, betonten die Besucher, dass keinesfalls auf Originalobjekte verzichtet werden könne, da diese für die Authentizität grundlegend seien. Das Erzählen der Geschichte müsse anhand von Objekten erfolgen. ${ }^{176}$ Das Präsentationskonzept der Alten Hofhaltung aber wurde trotz einiger Kritik größtenteils als Weg in die richtige Richtung bezeichnet.

Außerdem wurde durch die persönlichen Interviews bestätigt, dass Ausstellungsbesuche ganzheitliche Erlebnisse sind. In die Bewertung der Ausstellung flossen nicht nur Kommentare zu Inhalt und Gestaltung ein. Unabhängig von subjektiven Interessen stand die Befriedigung des Bedürfnisses nach einer angenehmen Atmosphäre in den Ausstellungsräumen an vorderster Stelle. Getrübt wurde jedoch bei vielen Befragten das positive Erlebnis durch die Enge und das schlechte Klima im Ausstellungsareal der Alten Hofhaltung. Das wunderbare Gesamtambiente um den Bamberger Dom sowie in der Alten Hofhaltung mit Biergarten und einem Angebot an mittelalterlichen Speisen trug dennoch zu einem schönen Gesamterlebnis bei. Auch das abwechslungsreiche Rahmenprogramm belebte den Ausstellungsort.

Überraschend war, dass bei einem Teil der Besucher ein hohes Maß an Sensibilität gegenüber Ausstellungsgestaltung existiert und erfahrene Ausstellungsbesucher eine Art persönliche Ausstellungskompetenz entwickeln. Dies bedeutet, dass sie ihre Aufnahmefähigkeiten gut einschätzen können. Sie wissen, dass mit dem Besuch einer Ausstellung letztlich nur ein facettenhafter Einblick möglich ist und Hintergründe nur über das weitere Studium von Büchern erarbeitet werden können. Folglich kritisieren sie nicht die Kürze der Texte, sondern konzentrieren sich auf Objekte und wissen gute Gestaltung zu schätzen.

lichen Kunsthalle und im Badischen Landesmuseum, beide Karlsruhe, Karlsruhe 2002, S. 105.

176 Der Wunsch nach Authentizität der ausgestellten Objekte zeigte sich auch bei dem Ausstellungsprojekt „Museum der Souvenirs der sechziger Jahre“ des Künstlers Guillaume Bijl. Siehe Kapitel 4, S. $222 \mathrm{f}$. 



\section{SCHLUSSBETRACHTUNG}

Events sind gegenwärtig Bestandteil der deutschen Museumslandschaft. So gewannen auch besucherorientierte Konzepte in den vergangenen Jahrzehnten zunehmend an Bedeutung. Die Präsentationskonzepte von kulturhistorischen Ausstellungen entwickelten sich weg von objektorientierten Präsentationen hin zu inszenierten Erlebnisorten. Diese Veränderungen bedingen negative wie auch positive Konsequenzen, vergleichbar den zwei Seiten einer Medaille.

Positiv an dieser Entwicklung ist, dass die potentiellen Besucher und die Kommunikation mit diesen an Bedeutung gewinnen. Dieser gesteigerte Stellenwert der Interessen und Bedürfnisse der Besucher fließt in die konzeptionellen Überlegungen von Ausstellungsgestaltungen ein und verändert die Präsentationsformen. Damit wird dem demokratischen Anliegen, nicht nur das interessierte Fachpublikum, sondern auch breite Bevölkerungsschichten zu erreichen, entsprochen. Die Annahme, dass die Exponate zu den Besuchern sprechen, funktioniert nur dann, wenn der Rezipient das nötige Hintergrundwissen zur Decodierung bereits besitzt. Die Betrachter brauchen jedoch die Vermittlung durch symbolische Zeichensysteme, wenn Informationen bildungsrelevant sein sollen. So wird in inszenierten Ausstellungen der Versuch unternommen, ein sinnliches Beziehungsgefüge zu schaffen, welches die Exponate in einen illustrierenden Kontext einbindet. Entgegen einem ,vernunftlosen Erschauern vor dem Original" ${ }^{\text {"1 }}$ kann sich vertiefendes Verstehen vollziehen, wenn sich die Erfahrung nicht auf reine Bewunderung der Exponate beschränkt, sondern Bezüge und Vernetzungen zu anderen Exponaten, Ereignissen oder Sachverhalten hergestellt werden.

Mit Blick auf die Entwicklung in amerikanischen Museen kann dies bedeuten, dass im Kanon der Hierarchie klassischer Aufgaben von $\mathrm{Mu}-$ seen, welcher das Sammeln, Bewahren, Erforschen und Vermitteln umfasst, die Besucher nicht nur eine gleichrangige Position erhalten, sondern diese sogar an der Spitze der Bedeutungspyramide stehen. Damit

1 Sauerländer, Willibald: Die Luft auf der Spitze des Pinsels. Kritische Spaziergänge durch Bildersäle. München 2002, S. 154. 
verbunden ist jedoch die Befürchtung, dass Ausstellungsräume zu Spaßtempeln mutieren und dies zu einer Disneysierung unter gleichzeitiger Aufgabe des Bildungsanspruches führt. Der Zwang zur Belebung der Museen durch ständig neue Erlebnisangebote stellt Museen vor mehrere Herausforderungen und wird auch von Museumsfachleuten immer wieder kritisch hinterfragt.

Tatsächlich kann festgestellt werden, dass sich manche Befürchtungen als berechtigt erweisen. So werden zum Beispiel Ressourcen in der fachlichen Sammlungsbetreuung zu Gunsten der Finanzierung von Marketing- und Öffentlichkeitsmaßnahmen gekürzt. Bereits vor knapp zwanzig Jahren wies Ekkehard auf die Problematik des Wetteiferns im Medium Großausstellung hin, welches in der Folge zu einem „Ausstellungskarussell der Superlative an Preziosen und Kosten" führte (Ekkehard 1986, S. 70). Der Wettbewerb innerhalb des Ausstellungsbetriebs von Museen um die Gunst der potentiellen Besucher wurde zudem durch das steigende Angebot von Themen- und Freizeitparks verschärft. Durch die Erlebnisorientierung der Museen veränderten sich auch die Erwartungen und Wahrnehmungsgewohnheiten der Besucher, indem diese in Museen nicht mehr allein einen Ort der Hochkultur, sondern zunehmend auch einen Ort der Unterhaltung sehen.

Dieser Entwicklung hin zu Erlebnisorientierung können sich die $\mathrm{Mu}-$ seen jedoch kaum entziehen, da Häuser, die keine aktuellen Anreize zum Besuch ihrer Ausstellung liefern, mit sinkenden Besucherzahlen konfrontiert sind (Graf 2000, S. 27). Auf diese Einnahmen sind die Ausstellungshäuser aber angewiesen, insbesondere auch im Hinblick auf Kürzungen staatlicher Zuschüsse. Im Zuge von Sparmaßnahmen öffentlicher Träger müssen bzw. sollten die Museen aus eigenen Reihen reagieren, wenn sie nicht wollen, dass ihnen Veränderungen von außen aufgezwungen werden. Dies mag als zu pragmatischer Ansatz kritisiert werden, doch im gegenwärtigen Prozess der Umstrukturierung bedeutet dies auch eine Gewährleistung von Qualität. ${ }^{2}$

2 So kann dies zum Beispiel bedeuten, dass als Direktor eines Hauses nicht mehr eine Person mit einem fachwissenschaftlichem Studium der Kunstoder Geschichtswissenschaft steht, sondern ein Betriebswirt. Ökonomische Überlegungen rangieren dann an erster Stelle, erst in zweiter Linie werden fachwissenschaftliche Belange berücksichtigt. 
„Wo die Häuser das Heft in der Hand halten, können sie den sich abzeichnenden Wandel gestalten - oder aber sich vom Sturmwind der Veränderung umpusten lassen. Sie haben die Wahl."

Die Museen sind gefordert, ihre alte Systematik zu überdenken und beweglich zu machen, nur dann können sie ihr schlummerndes Angebot an sinnlichen und anthropologischen Erfahrungen aktivieren. Dies schließt ein, sich aus dem Spezialistentum zu befreien, um im Medienzeitalter als Gegenstimme vernommen zu werden (Sauerländer 2002, S. 155). Diese aus pädagogischer Perspektive an sich positive Veränderung hin zu Besucherorientierung ist somit oft nicht nur auf Freiwilligkeit der Ausstellungshäuser zurückzuführen, sondern auch durch geringere öffentliche Gelder und der daraus resultierenden Notwendigkeit der Erwirtschaftung eigener Mittel bedingt. Umso wichtiger erscheint es, diesen Veränderungsprozess von Seiten der Museen aktiv und unter Berücksichtigung museumsspezifischer und bildungsrelevanter Ansprüche zu gestalten.

In diesem Spannungsfeld zwischen Kommerzialisierung und Besucherorientierung, in dem sich inszenierte Ausstellungen befinden, ist diese Studie angesiedelt. ${ }^{4}$ Ein zentraler Leitgedanke bestand darin, wo und wie sich die museumspädagogischen Belange innerhalb dieser Entwicklung von Ausstellungen positionieren können. Es wurden Formen besucherorientierter Konzepte vorgestellt und diskutiert. Im Vordergrund stand die Reflexion im Hinblick auf die gegenwärtige Ausstellungskultur. Das Ziel der Studie bestand nicht darin, ein Rezept für die ideale Gestaltung einer Ausstellung zu liefern, denn sowohl Ausstellungsorte, Exponate, Themen sind derart vielfältig, dass jede Form der Präsentation von traditioneller Objektorientierung bis hin zu raumgreifen-

3 Liebs, Holger: Die Tage der Ruhe sind gezählt. Im Trubel der Sparmaßnahmen: An den deutschen Museen zeichnet sich ein Generationswechsel ab. In: Süddeutsche Zeitung vom 05./06.01.05.

4 Der gegenwärtige Diskussionsbedarf zu diesem Thema zeigt sich auch an der Vielzahl von Tagungen und Fortbildungen, die aktuell von Bildungsinstitutionen angeboten wurden werden. Stellvertretend seien einige genannt: Die Tagung an der Universität in Hildesheim (11./12.02/05) stand unter dem Thema „Kulturvermittlung zwischen kultureller Bildung und Eventmarketing - eine Profession mit Zukunft?“ Das Symposium „Kulturtourismus - Kultur als Tourismus: Reisen mit dem feinen Unterschied" an der Bundesakademie für kulturelle Bildung Wolfenbüttel (16./17.02.05) thematisierte ebenfalls dieses Spannungsfeld. Der 3. Kulturpolitische Salon in Leipzig (13.01.04) stand unter dem Slogan „Zwang zum Event? Kulturpolitik und Erlebnisorientierung“. 
den Gesamtinszenierungen die jeweils adäquate Realisierung sein kann. Dies spricht für eine Vielfalt von Präsentationsformen in der Ausstellungslandschaft. Diese können sich sowohl auf formaler Ebene von rekonstruktiven bis abstrahierenden Raumbildern unterscheiden, wie auch auf inhaltlicher Ebene, indem sie sich variantenreicher Ausstellungsstrategien bedienen wie zum Beispiel narrativer, künstlerischer oder auch partizipativer Konzepte.

Die Studie argumentiert für besucherorientierte und ganzheitliche Ausstellungskonzepte. Nichtsdestotrotz gibt es Formen der Besucherorientierung, die nicht diesen Kriterien entsprechen und somit dem Bildungsanspruch von Museen nicht gerecht werden. Eine klare Absage soll jenen Konzepten erteilt werden, die, mit dem Ziel des Eintauchens in eine wie auch immer geartete Vergangenheit, zu einer nostalgischen Stilisierung der Vergangenheit führen. Das Phänomen der Musealisierung führt zu einer „,fetischierten Objektfixierung“, die nicht die Möglichkeiten der sinnlichen Bildung und Emanzipation weiterentwickelt, sondern in ein emotionalisiertes „mixtum nostalgium“ mündet (Korff 1990, S. 67). Ein wichtiges Kriterium der Abgrenzung kulturhistorischer Ausstellungen von kommerziellen Angeboten bildet die jeweilige Zielformulierung. Besteht das Ziel kommerzieller Anbieter meist darin, unter Einsatz quasi-authentischer historischer Facetten ein möglichst perfektes Vergangenheitsbild zu entwerfen, sollten museale Ausstellungen die Differenzen zwischen Vergangenheit und Gegenwart nicht einebnen, sondern die Konstrukthaftigkeit der historischen Imaginationen betonen und Irritationen im Fluss der Wahrnehmung erzeugen.

Der Auftrag musealer Ausstellungen im Hinblick auf den Bildungsanspruch liegt weniger in einer regulären, formalen Vermittlung von Wissen. Gefordert ist vielmehr eine Qualität der Präsentation, die zur schöpferischen Auseinandersetzung ermuntert. Als elementare Aufgabe musealer Ausstellungen wird formuliert, dass diese als Stätten der Differenzerfahrung und der Reflexion fungieren. Eine gesellschaftliche Funktion dieser Orte liegt auch darin, für kritische gesellschaftspolitische Fragen Sensibilität zu wecken. Über die Entwicklung von Verständnis und Wertschätzung der Vergangenheit hinaus soll die Kritikfähigkeit gegenüber der eigenen Epoche und deren gesellschaftlichen Äußerungen gefördert werden. Es geht darum, bewusst Fragen zu stellen, Sehgewohnheiten zu stören oder auch Fremdheitserfahrungen zu initiieren.

„Gerade weil das Museum kein Ort ausgedörrter Faktenwissenschaft ist und kein in sich abgeschlossenes, auf die Ewigkeit ausgerichtetes Haus, gerade 
deshalb ist es ja so wertvoll. Weil es keine Fix- und Fertig Rezepte verheißt, keine endgültigen Antworten parat hält, sondern immer wieder zu Fragen einlädt.“ (Rauterberg 2002, S. 40).

Ein weiteres Aufgabenfeld musealer Ausstellungen kann in der Sensibilisierung der Sinne mit dem Ziel des Sehenlernens liegen. Entgegen der Flüchtigkeit und Schnelllebigkeit der Bilder in der alltäglichen Umwelt, bilden Museen Orte der Aufmerksamkeit und Konzentration. Die spezifischen Erfahrungsqualitäten liegen in der historischen sowie ästhetischen Erfahrung. Obgleich diese - wie aufgezeigt - zu Wahrnehmungskonflikten führen können, kristallisierten sich Kriterien heraus, die für beide Erfahrungsformen relevant sind. Weder bei der ästhetischen noch bei der historischen Erfahrung geht es um Eindimensionalität. Beiden gemeinsam ist Sensibilisierung für die Vielschichtigkeit und Mannigfaltigkeit der Interpretationen von Historie, Artefakten wie auch gegenwärtigen Erscheinungen.

Im Hinblick auf die Position der Museumspädagogik sieht sich diese mit der Problematik konfrontiert, dass sie aufgrund der Finanznöte der Museen dazu aufgefordert ist, attraktive und auch populäre Veranstaltungen zu initiieren, und so das Bildungsanliegen leicht ins Hintertreffen geraten könnte. Sie kann dazu funktionalisiert werden, als Helferin zum Anlocken von Besuchern zu fungieren. Diese Herausforderung besteht und dieser gilt es sich zu stellen.

Im Speziellen wurde in der Studie die Frage thematisiert, wie sich die Museumspädagogik im Bereich der Ausstellungsgestaltung positionieren kann. ${ }^{5}$ Die Mitarbeit bei der Konzipierung von Ausstellungen zählt nach wie vor eher zu den Randbereichen im Aufgabenspektrum von Museumspädagogen. Festgehalten werden kann, dass die Mitwirkung bei

5 Inszenierte Ausstellungen wirken sich auch auf die Gestaltung des personellen pädagogischen Begleitprogramms aus. Anhand eines Praxisbeispiels zeigte Arndt auf, dass Inszenierungen und der Einsatz moderner Medien im Ausstellungsparcours nicht die personelle Vermittlung ersetzen können, sondern über die sinnlichen Reize hinaus eine reflektierende Vertiefung gewährleisten. Dabei betont sie, dass Multimedia-Angebote jedoch nicht als Gegner der pädagogischen Arbeit betrachtet, sondern integriert und auch thematisiert werden sollten. Vgl. Arnt, Sirka: „Heidi“ zwischen den Welten. Erfahrungen mit einer inszenierten Ausstellung zum Roman von Johanna Spyri im Alpinen Museum in München. (unveröffentl. Skript) Magisterarbeit an der LMU München, Fakultät Kunstpädagogik, München 2004, S. 80. 
Ausstellungsprojekten spezifische Kompetenzen erfordert, die sich einerseits mit den Aufgaben in der personellen Vermittlung überschneiden, darüber hinaus jedoch spezielle Ausstellungskompetenz notwendig ist. $\mathrm{Zu}$ dem breiten Spektrum an Fähigkeiten, welches sich mit dem Begriff Ausstellungskompetenz verbindet, gehört einerseits visuelles und räumliches Vorstellungsvermögen. Andererseits meint dies soziale Fähigkeiten im Rahmen der Mitarbeit innerhalb eines Ausstellungsteams.

In der Studie wurde versucht herauszuarbeiten, worin spezifische museumspädagogische Ausstellungskompetenzen liegen können. Ein Bereich liegt in der Kenntnis kommunikativer Strategien, wie sie unter den Begriffen Anschaulichkeit, Handlungsorientierung, Ganzheit und Differenzierung beschrieben wurden. Das Wissen um diese Strategien gilt genauso für alle anderen Mitwirkenden im Team, zählt jedoch nicht zu deren Kernbereich. Neben einem methodischen Know-how der Ausstellungsgestaltung besteht darüber hinaus ein inhaltlicher Anspruch. Inwieweit sich diese pädagogischen Aspekte im Ausstellungskonzept verwirklichen lassen, hängt grundlegend davon ab, ob die Ausstellungsleitung diesen aufgeschlossen gegenübersteht und dieses Anliegen mitträgt. Die tatsächliche Mitwirkung von Museumspädagogen pendelt zwischen zwei Extremen. Einerseits kann beobachtet werden, dass diesen die Leitung und somit auch die inhaltliche Konzepterstellung übertragen wird. Andererseits wird ihr lediglich eine Randfunktion zugebilligt: Sie darf ein fertiges Ausstellungskonzept mit einem museumspädagogischen Begleitprogramm ergänzen.

Ausstellungen bilden eine spezifische Form von Massenkommunikation. Insofern lassen sich theoretische Reflexionen auf dem Gebiet der Medienpädaogik auf die Museumspädagogik übertragen. Bauer sieht in der Medienpädagogik eine Mediationsagentur zwischen Medienökonomie und Medienkultur. ${ }^{6}$ Das pädagogische Interesse richtet sich an die Wertperspektiven gesellschaftlicher Kommunikation. In diesem Sinne ist Medienpädagogik eine Vermittlungsagentur zwischen Medienökonomie

6 Bauer weist auf die Problematik der Begriffswahl Medienpädagogik hin, die für mache signifikant wie auch unbehaglich klingt. Jedoch betont er, dass man dies nicht durch Termini wie zum Beispiel Medienkompetenz verschleiern sollte, da durch derartige Umschreibungen der herrschaftsverdächtige Tatzusammenhang von Medien und Pädagogik, mit dessen kritischen Implikationen man durchaus konfrontiert bleiben sollte, verdeckt werden würde. Vgl. Bauer, A. Thomas: Medienpädagogik als Mediationsagentur zwischen Medienökonomie und Medienkultur. In: Altmeppen, Klaus-Dieter: Medien und Ökonomie, Wiesbaden 2003, S. 123. 
und Medienkultur. Analog könnte man dies auf die Museumspädagogik übertragen: Museumspädagogik ist eine Vermittlungsagentur zwischen Ausstellungsökonomie und Ausstellungskultur. Sie positioniert sich auch dort, wenn es um ethische Werte geht und Fragen nach der Moral zu stellen sind.

Wenngleich nach dem ursprünglichen Konzept dieser Studie nicht angedacht, führte das Thema Inszenierung und Erlebnis bei einem historischen Blick auf die Ausstellungsgeschichte unweigerlich zu den Propagandaausstellungen der Nationalsozialisten. In Reaktion auf deren ideologischen Missbrauch von Ausstellungsinszenierungen waren die Nachkriegsjahre von reduzierten, entpolitisierten und nüchternen Ausstellungsgestaltungen geprägt. Nach über einem halben Jahrzehnt ist diese Zäsur überwunden, szenographische Konzepte unter Einsatz moderner Medien sind gegenwärtig. Gerade jedoch diese Gefahr des Missbrauchs des Mediums Ausstellung verweist auf einen Problemkreis, der auch momentan aktuell ist. Inszenierungen führen zu einer Emotionalisierung der Ausstellungsumwelt. Das in dieser Studie als positiv bewertete Ansprechen aller Sinne und einer ganzheitlichen Orientierung wird somit durch die Möglichkeit der ideologischen Vereinnahmung kontrastiert. Mit Inszenierungen lassen sich auf subtile Art und Weise gefärbte Interpretationen vermitteln, die sowohl politischen oder auch ökonomischen Interessen dienstbar gemacht werden und damit für manipulative Zwecke eingesetzt werden können. Dies führt zu dem Thema der Subjektivität bezüglich der Interpretation von Historie. Geschichte wird immer unter einer bestimmten Perspektive beleuchtet, die jeweils von den herrschenden gesellschaftlichen Systemen geprägt ist. Auch hier stellen diese unumgänglichen Zusammenhänge eine Herausforderung für die Ausstellungsmacher dar und wenden sich somit an deren Verantwortungsbewusstsein, in kritischer Reflexion über jeweilige Inhalte, Methoden und Medien zu entscheiden.

Mit dieser Studie wird für Ausstellungskonzepte plädiert, die keine eindimensionalen Geschichtsbilder produzieren, sondern in deren Vordergrund die Offenheit der Interpretation steht, die eher Irritationen bewirken sollen, als endgültige Wahrheiten festzuschreiben. Ausstellungsgestaltungen sollten die Imaginationskraft aktivieren, jedoch keine starren Bilder entwerfen, sondern Leerstellen zum Weiterdenken eröffnen. Gleichsam als Schlüssel weisen kulturhistorische Ausstellungen Wege in die Vergangenheit. Durch die Inszenierungen in Ausstellungsräumen werden Exponate und ihre mannigfaltigen Geschichten in der Gegenwart zur Aufführung gebracht. Der Gratwanderung zwischen Anregung der 
Vorstellungsfähigkeit und dem Festschreiben von Bildern und Interpretationen muss jedoch mit höchster Sensibilität begegnet werden. Diese Aufgabe gilt es, immer wieder neu und verantwortungsvoll auch insbesondere im Hinblick auf die Zugriffe ökonomischer Interessen zu lösen. 


\section{LITERATUR VERZEICHNIS}

Addyman, Peter/Gaynor, Anthony: The Jorvik Viking Center: An Experiment in Archaeological Site Interpretation. In: The International Journal of Museum Management and Curatorship. 3. (1984) S. 7-18.

Almasan, Anneliese/Borzyskowski, Ellen von/Schambach, Sigrid/Klein, Hans-Joachim: Neue Methoden der Ausstellungsplanung in Museen Abschlußbericht. Karlsruhe, 1993.

Alpers, Svetlana: The Museum as a Way of Seeing. In: Lavine, Steven D./ Karp, Ivan (Hrsg.): Exhibiting Cultures. Washington/London: Smithsonian Institution Press 1991, S. 25-32.

Althoff, Gerd (Hrsg.): Die Deutschen und ihr Mittelalter. Darmstadt: Wissenschaftliche Buchgesellschaft 1992.

Altmeppen, Klaus-Dieter/Karmasin, Matthias (Hrsg.): Medien und Ökonomie, Band 1/1: Grundlagen der Medienökonomie: Kommunikations- und Medienwissenschaft, Wirtschaftswissenschaft. Wiesbaden: Westdeutscher Verl. 2003.

Ames, Kenneth L./Franco, Barbara/Frye, Thomas L. (Hrsg.): Ideas and Images: Developing Interpretative History Exhibits. Walnut Creek/ London/New Delhi: AltaMira Press 1992.

Ammann, Jean-Christophe: Das Museum: Trainingslager für die Wahrnehmung oder Steinbruch für das Haus der eigenen Zukunft. In: Schneede Uwe M. (Hrsg.): Museum 2000 - Erlebnispark oder Bildungsstätte. Köln: DuMont 2000, S. 18-28.

Anderton, Frances/Chase, John: Las Vegas. Ein Führer zur zeitgenössischen Architektur. Köln: Könemann 1997.

Arndt, Sirka: ,Heidi` zwischen den Welten. Erfahrungen mit einer inszenierten Ausstellung zum Roman von Johanna Spyri im Alpinen Museum in München. (unveröffentl. Skript) Magisterarbeit an der LudwigMaximilians-Universität, Fakultät Kunstpädagogik, München 2004.

Assmann, Aleida: Erinnerungsräume - Formen und Wandlungen des kulturellen Gedächtnisses. München: Beck 1999.

Auer, Hermann (Hrsg.): Museologie: Neue Wege - Neue Ziele. Bericht über ein internationales Symposium, veranstaltet von den ICOM-National- 
komitees der Bundesrepublik Deutschland, Österreichs und der Schweiz. München/London/New York/Paris: Saur 1989.

Azara, Pedro/Harth, Carlos G.: Bühnen- und Ausstellungsarchitektur. Stuttgart/München: Deutsche Verlags Anstalt 2000.

Badisches Landesmuseum Karlsruhe (Hrsg.): Inszenierte Geschichte(n). Baden-Baden: Nomos 1999.

Badisches Landesmuseum Karlsruhe (Hrsg.): Spätmittelalter am Oberrhein. Alltag, Handwerk und Handel 1350-1525, Katalogband zur Ausstellung. Stuttgart: Thorbecke 2001.

Bann, Stephen: Das ironische Museum. In: Rüsen, Jörn u.a. (Hrsg.): Geschichte sehen. Pfaffenweiler: Centaurus 1988, S. 63-68.

Bann, Stephan: Die Kleidung Klios. Museale Darstellung von Geschichte im 19. Jahrhundert. In: Borsdorf, Ulrich u.a. (Hrsg.): Orte der Erinnerung. Frankfurt/New York: Campus 1999, S. 303-318.

Bartov, Omer/Brink, Cornelia/Hirschfeld, Gerhard u.a.: Bericht der Kommission zur Überprüfung der Ausstellung, Vernichtungskrieg. Verbrechen der Wehrmacht 1941 bis $1944^{`} .2000$.

Bätschmann, Oskar: Der Künstler als Erfahrungsgestalter. In: Stöhr, Jürgen (Hrsg.): Ästhetische Erfahrung heute. Köln: DuMont 1996, S. 248-281.

Bätschmann, Oskar: Ausstellungskünstler - Kult und Karriere im modernen Kunstsystem. Köln: DuMont 1997.

Bätz, Oliver/Gößwald, Udo (Hrsg.): Experiment Heimatmuseum - Zur Theorie und Praxis musealer Museumsarbeit. Berlin: Jonas 1988.

Bauer, Ingolf (Hrsg.): Das Bayerische Nationalmuseum. Der Neubau an der Prinzregentenstraße 1892 -1900. München: Hirmer 2000.

Bauer, Thomas A.: Medienpädagogik als Mediationsagentur zwischen Medienökonomie und Medienkultur. In: Altmeppen, Klaus-Dieter/Karmasin, Matthias (Hrsg.): Medien und Ökonomie. Wiesbaden: Westdeutscher Verl. 2003, S. 115-138.

Baumgärtel-Fleischmann, Renate: Ausgewählte Kunstwerke aus dem Diözesanmuseum Bamberg. Bamberg: Bayerische Verlagsanstalt 1992.

Baumuk, Bodo-Michael: Dauerausstellung und Wechselausstellung. Sieben Hügel. Bilder und Zeichen des 21. Jahrhunderts. In: Schwarz, Ulrich/ Teufel, Philipp (Hrsg.): Museografie und Ausstellungsgestaltung. Ludwigsburg: av-Edition 2001, S. 180-191.

Bayerische Staatskanzlei (Hrsg.): Das Haus der Bayerischen Geschichte. München 1965.

Bédarida, Marc: Euro Disney Park. In: $\mathrm{ARCH}^{+}-$Zeitschrift für Architektur und Städtebau. 114/115. (1992) S. 92-95. 
Bedno, Jane/Bedno, Ed: Museum Exhibitions: Past Imperfect, Future Tense. Thirty Years of Social, Economic and Technical Changes to the Art of Designing Museum Exhibitions. In: Museums News. 78. (1999) Heft 5. S. 38-61.

Beier, Rosemarie (Hrsg.): Geschichtskultur in der Zweiten Moderne. Frankfurt/New York: Campus 2000.

Belcher, Michael: Exhibitions in Museums. Washington D.C.: Smithsonian Institution Press 1991.

Belting, Hans: Bild-Anthropologie - Entwürfe für eine Bildwissenschaft. München: Fink 2001.

Bennett, Tony: Museums and the People. In: Lumley, Robert (Hrsg.): The Museum Time-Machine. London/New York: Routledge 1988, S. 63-85.

Bergmann, Klaus/Fröhlich, Klaus/Kuhn, Annette/Rüsen, Jörn/Schneider, Gerhard: Handbuch der Geschichtsdidaktik. (5. überarb. Aufl.) Seelze-Velber: Kallmeyer 1997.

Billmann, Hans-Joachim: Multimedia in Museen - Neue Formen der Präsentation - neue Aufgaben der Museumspädagogik. Bremen: engram AG 2000.

Blais, Andrée (Hrsg.): Text in the Exhibition Medium. Québec 1995.

Boehm, Gottfried: Bildsinn und Sinnesorgane. In: Stöhr, Jürgen (Hrsg.): Ästhetische Erfahrung heute. Köln: DuMont 1996, S. 148-165.

Bolz, Norbert: Inszenierte Welt. In: Fehr, Michael u.a. (Hrsg.): Platons Höhle - Das Museum und die elektronischen Medien. Köln: Wienand 1995, S. 159-166.

Boockmann, Hartmut: Geschichte im Museum? Zu den Problemen und Aufgaben eines Deutschen Historischen Museums. München: Deutscher Kunstverlag 1987.

Boockmann, Hartmut: Wege ins Mittelalter. Historische Aufsätze Hartmut Boockmann. Hrsg. von Dieter Neitzert u.a. München: Beck 2000.

Borchert, Jörn: Das familienfreundliche Museum - Gedanken auf dem Weg zu einer neuen Präsentationskultur. In: Schwarz, Ulrich/Teufel, Philipp (Hrsg.): Museografie und Ausstellungsgestaltung. Ludwigsburg: avEdition 2001, S. 114-129.

Bormann, Regina: Eventmaschinerie Erlebnispark - Systemintegration durch performative Institutionen. In: Gebhardt, Winfried u.a. (Hrsg.): Events Soziologie des Außergewöhnlichen. Leske + Budrich: Opladen 2000, S. 137-160.

Borsdorf, Ulrich: ,et in flumen Rura vadunt.' Das Mittelalter im Ruhrlandmuseum - Vergessene Zeiten? In: Seibt, Ferdinand u.a. (Hrsg.): Vergessene Zeiten. Mittelalter im Ruhrgebiet. Essen: Pomp 1990, S. 13-17. 
Borsdorf, Ulrich/Grütter, Heinrich Theodor: Überdachte Fragmentarik: Die Ausstellung, Vergessene Zeiten. Das Mittelalter im Ruhrgebiet‘. In: Fröhlich, Klaus (Hrsg.): Geschichtskultur. Pfaffenweiler: Centaurus 1992, S. 179-206.

Borsdorf, Ulrich/Grütter, Heinrich Theodor (Hrsg.): Orte der Erinnerung Denkmal, Gedenkstätte, Museum. Frankfurt/New York: Campus 1999.

Bosch-Schairer, Carmen: Besucherorientierung als Marketingstrategie amerikanischer Museen - ein Vorbild für deutsche Museen? (unveröffentl. Skript) Weinsberg 2004.

Boswell, David/Evans, Jessica (Hrsg.): Representing the Nation: A Reader. Histories, Heritage and Museums. London/New York: Routledge 1999.

Bracker, Jörg: Grenzen des historischen Museums? In: Museumskunde. 46. (1981) Heft 3. S. 132-140.

Braun, Christina von: Historische Imagination - Bild. (5. überarb. Aufl.) In: Bergmann, Klaus u.a. (Hrsg.): Handbuch der Geschichtsdidaktik. SeelzeVelber: Kallmeyer 1997, S. 67-71.

Braun, Andreas: Emotionale Besuchererlebnisse in Ausstellungen. In: Landesstelle für die nichtstaatl. Museen in Bayern (Hrsg.): Geöffnet! Das Museum für den Besucher. München 2000, S. 58-59.

Breithaupt, Julia/Joerißen, Peter: Museumspädagogen machen (andere?) Ausstellungen. Publikation im Anschluß an die Jahrestagung der Arbeitsgemeinschaft der deutsch-sprechenden Mitglieder der CECA im ICOM. Erlangen/Nürnberg 1986.

Bundesverband der deutschen Kinder- und Jugendmuseen e.V.: Didaktik im Kindermuseum. Wie kann der Anspruch, Kinder und Jugendliche im Kindermuseum partizipieren zu lassen, erfolgreich umgesetzt werden?. Fulda 2000.

Burandt, Walter: Die Alte Hofhaltung in Bamberg: Kaiser- und Bischofspfalz. Bamberg: Bayerische Verlagsanstalt 1999.

Cameron, Duncan F.: A Viewpoint: The Museum as a Communication System and Implications for Museum Education. In: Curator. 11. (1968) Heft 1. S. 33-40.

Carr, David: Balancing Act: Ethics, Mission \& the Public Trust. In: Museum News. 80. (2001) Heft 5. S. 29-81.

Cassels, Richard: Learning Styles. In: Durbin, Gail (Hrsg.): Developing Museum Exhibitions for Lifelong Learning. London: The Stationery Office 2001, S. 38-45.

Caulton, Tim: Hands-on Exhibitions - Managing Interactive Museums and Science Centers. London/New York: Routledge 1998. 
Chambers, Marlene: Critiquing Exhibition Criticism. In: Museum News. 78. (1999) Heft 5. S. 31-65.

Clifford, James: Museums as Contact Zones. In: Representing the Nation: A Reader (Hrsg.): London/New York: Routledge 1999, S. 435-457.

Cohn, Regina/Gößwald, Udo: Experiment Heimatmuseum - Zur Theorie und Praxis der Präsentation von Geschichte. In: Bätz, Oliver/Gößwald, Udo (Hrsg.): Experiment Heimatmuseum. Berlin: Jonas 1988, S. 92-99.

Commandeur, Beatrix/Dennert, Dorothee (Hrsg.): Event zieht - Inhalt bindet. Besucherorientierung von Museen auf neuen Wegen. Bielefeld: transcript 2004.

Communications Design Team, Royal Ontario Museum: Spatial considerations. In: Hooper-Greenhill, Eilean (Hrsg.): The Educational Role of the Museum. London/New York: Routledge 1994, S. 178-190.

Compania Media (Hrsg.): Handbuch Museumsberatung: Akteure - Kompetenzen - Leistungen. Bielefeld: transcript 2000.

Cornell, Joseph: Schizophrenic Agora - Mission, Market and the Multitasking Museum. In: Museum News. 78. (1999) Heft 6. S. 40-47.

Crane, Susan A. (Hrsg.): Museums and Memory. Stanford: Stanford University Press 2000.

Csikszentmihalye, Mihaly/Hermanson, Kim: Intrinsic Motivation in Museums: Why Does One Want to Learn? In: Falk, John H./Dierking, Lynn D. (Hrsg.): Public Institutions for Personal Learning: Establishing A Research Agenda. Washington D.C. 1995, S. 67-78.

Dahm, Volker: Projekt eines NS-Dokumentationszentrums in München, Gutachten des Instituts für Zeitgeschichte. München/Berlin, 2002.

Danzker, Jo-Annie Birnie (Hrsg.): Robert Wilson - Steel Velvet. München: Prestel 1997.

Dauschek, Anja: Museumsmanagement. Amerikanische Strategien in der deutschen Diskussion. Ehestorf: I \& P Druck und Verl. 2001.

Davidson, Betty/Heald, Candace Lee/Hein, George E.: Increased Exhibit Accessibility Through Multisensory Interaction. In: Hooper-Greenhill, Eilean (Hrsg.): The Educational Role of the Museum. London/New York: Routledge 1994, S. 223-241.

Davis, Jessica/Gardner, Howard: Open Windows, Open Doors. In: HooperGreenhill, Eilean (Hrsg.): The Educational Role of the Museum. London/New York: Routledge 1994, S. 99-104.

Dean, David: Museum Exhibition: Theory and Practice. London/New York: Routledge 1994.

Dech, Uwe C.: Sehenlernen im Museum - Ein Konzept zur Wahrnehmung und Präsentation von Exponaten. Bielefeld: transcript 2003. 
Deneke, Bernward: Realität und Konstruktion des Geschichtlichen. In: Korff, Gottfried/Roth, Martin (Hrsg.): Das historische Museum: Labor, Schaubühne, Identitätsfabrik. Frankfurt/New York: Campus 1990, S. 65-86.

Derks, Heidrun: Design oder Nicht-Sein? Bedeutung und Funktion, Möglichkeiten und Grenzen von Ausstellungsgestaltung im Museum. In: Mitteilungsblatt des Museumsverbands für Niedersachsen und Bremen. 55. (1998) S. 19-30.

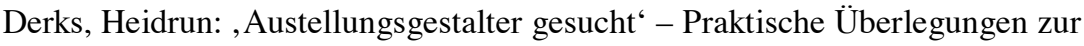
Kooperation von Museen und Gestaltern. In: Compania Media (Hrsg.): Handbuch Museumsberatung. Bielefeld: transcript 2000, S. 199-214.

Döry, Ludwig Baron: Mammute und ihre Kinder im Ausstellungswesen. In: Histor. Museum d. Stadt Frankfurt (Hrsg.): Die Zukunft beginnt in der Vergangenheit. Giessen: Anabas 1982, S. 20-37.

Dowidat, Stefanie: Ganz Ohr: Zur Raum- und anderer Akustik in musealen Ausstellungen. In: Standbein Spielbein, Museumspädagogik aktuell. 55. (1999) S. 24-25.

Dresch, Jutta: Das Badische Landesmuseum im wieder aufgebauten Karlsruher Schloss. In: Landesstelle für Museumsbetreuung Baden-Württemberg (Hrsg.): Neuordnungen: Südwestdeutsche Museen in der Nachkriegszeit. Tübingen: Silberburg 2002, S. 189-205.

Drescher, Bettina: Im Westen nichts Neues? Themenpark und Sieben Hügel. Präsentationsästhetiken im Vergleich. http://www.ulmer-verein.de/drescher.html. (letzter Zugriff: 03.07.01).

Dunlop, Beth: The Art of Disney Architecture. New York: Harry N. Abrams 1996.

Durbin, Gail (Hrsg.): Developing Museum Exhibitions for Lifelong Learning. (4. Aufl.) London: The Stationery Office 2001.

Eberhard, Kurt: Einführung in die Erkenntnis- und Wissenschaftstheorie. Geschichte und Praxis der konkurrierenden Erkenntniswege. Stuttgart/ Berlin/Köln: Kohlhammer 1999.

Edelmann, Walter: Lernpsychologie. Eine Einführung. Weinheim: Beltz 1994. Ehmer, Hermann, K. (Hrsg.): Visuelle Kommunikation. Beiträge zur Kritik der Bewußtseinsindustrie. Köln: DuMont 1971.

Engelke, Lutz: Die Zukunft hat keine Bilder. In: Museumskunde. 66. (2001) Heft 1. S. 37-42.

Ernst, Wolfgang: Museale Authentizität in einer Welt der virtuellen Kommunikation? In: Standbein Spielbein. (2002) Heft 63. S. 21-28.

Esch, Arnold: Beobachtungen zu Stand und Tendenzen der Mediävistik aus der Perspektive eines Auslandsinstituts. In: Oexle, Gerhard Otto (Hrsg.): 
Stand und Perspektiven der Mittelalterforschung am Ende des 20. Jahrhunderts. Göttingen: Wallstein 1996, S. 7-44.

Evans, Gary W.: Learning and the Physical Environment. In: Falk, John H./Dierking, Lynn D. (Hrsg.): Public Institutions for Personal Learning: Establishing a Research Agenda. Washington D.C. 1995, S. 119-126.

Falk, John H./Dierking, Lynn D.: The Museum Experience. Washington D.C.: Whalesback 1992.

Falk, John H./Dierking, Lynn D. (Hrsg.): Public Institutions for Personal Learning - Establishing a Research Agenda. Washington D.C. 1995.

Falk, John H./Dierking, Lynn D.: Learning from Museums - Visitor Experiences and the Making of Meaning. Walnut Creek/Lanhan/New York/ Oxford: AltaMira 2000.

Falk, John H./Dierking, Lynn D.: Recalling the Museum Experience. In: Hirsch, Joanne S./Silverman, Lois H. (Hrsg.): Transforming Practice. Washington D.C. 2000, S. 268-277.

Fast, Kirsten (Hrsg.): Handbuch der museumspädagogischen Ansätze. Opladen 1995

Fastert, Sabine: Die Entdeckung des Mittelalters: Geschichtsrezeption in der nazarenischen Malerei des frühen 19. Jahrhunderts. München/Berlin: Dt. Kunstverl. 2000

Fatzer, Gerhard: Ganzheitliches Lernen: Humanistische Pädagogik und Organisationsentwicklung; ein Handbuch für Lehrer, Pädagogen, Erwachsenenbildner und Organisationsberater. Paderborn: Junfermann 1987.

Fehr, Michael: Nicht mein Haus, nicht meine Geschichte. Ein Kommentar zum Haus der Geschichte in Bonn. ttp://www.keom.de/kuenstler/texte/ nicht_mein_haus.html. (letzter Zugriff: 16.07.04).

Fehr, Michael: Aufklärung oder Verklärung. In: Rüsen, Jörn u.a. (Hrsg.): Geschichte sehen. Pfaffenweiler: Centaurus 1988, S. 110-123.

Fehr, Michael (Hrsg.): Open Box - Künstlerische und wissenschaftliche Reflexionen des Museumsbegriffs. Köln: Wienand 1988.

Fehr, Michael/Grohé, Stefan (Hrsg.): Geschichte - Bild - Museum. Zur Darstellung von Geschichte im Museum. Köln: Wienand 1989.

Fehr, Michael: Müllhalde oder Museum: Endstationen in der Industriegesellschaft. In: Fehr, Michael/Grohé, Stefan (Hrsg.): Geschichte - Bild - Museum. Köln: Wienand 1989, S. 182-196.

Fehr, Michael: Historische Erfahrung als ästhetische Reflexion. http://www. keom.de/museumstheorie/collection.html. (letzter Zugriff: 31.10.2001).

Fehr, Michael/Krümmel, Clemens/Müller, Markus (Hrsg.): Platons Höhle Das Museum und die elektronischen Medien. Köln: Wienand 1995. 
Fehr, Michael: Das Museum als Ort der Beobachtung Zweiter Ordnung. Einige Überlegungen zur Zukunft des Museums. In: Beier, Rosemarie (Hrsg.): Geschichtskultur in der Zweiten Moderne. Frankfurt/New York: Campus 2000, S. 149-166.

Felfe, Robert/Janzing, Godehard: Zukunft ausstellen: Expo, Sieben Hügel und Millennium Dome. http://www.ulmer-verein.de/ausstellung3.htm. (letzter Zugriff: 03.07.01).

Fischer, Stefan: Gestern ist heute. Pyramiden, Minnesang, Feuersturm: Auch bei den Zeitschriften ist Geschichtliches plötzlich sehr gefragt. In: Süddeutsche Zeitung vom 27.08.03.

Fliedl, Gottfried (Hrsg.): Museum als soziales Gedächtnis? Kritische Beiträge zu Museumswissenschaft und Museumspädagogik. Klagenfurt 1988.

Fliedl, Gottfried/Muttenthaler, Roswitha/Posch, Herbert (Hrsg.): Erzählen, Erinnern, Veranschaulichen. Theoretisches zur Museums- und Ausstellungskommunikation. Wien 1992.

Fliedl, Gottfried/Muttenthaler, Roswitha/Posch, Herbert (Hrsg.): Museumsraum, Museumszeit - Zur Geschichte des Österreichischen Museums- und Ausstellungswesens. Wien: Picus 1992.

Fliedl, Gottfried (Hrsg.): Wie zu sehen ist: Essays zur Theorie des Ausstellens. Wien: Turia und Kant 1995.

Flügel, Christof: Schöne neue Welt? ,Neue Medien“ im Museum. In: Museum heute, Fakten - Tendenzen - Hilfen. (2002) Heft 23. S. 25-28.

Foerster, Cornelia: Zwischen malerischer Präsentation und historischer Dokumentation. Darbietungsformen in Geschichtsmuseen des 20. Jahrhunderts. In: Museumskunde. 60. (1995) S. 88-94.

Forsthuber, Sabine: Hans Tietzes kunstpädagogische Ausstellungen. In: Fliedl, Gottfried (Hrsg.): Museumsraum, Museumszeit. Wien: Picus 1992, S. 167-188.

Franzke, Jürgen: Sakral oder schockierend - Die Darstellung historischer Wirklichkeit im Museum. In: Rüsen, Jörn u.a. (Hrsg.): Geschichte sehen. Pfaffenweiler: Centaurus 1988, S. 69-81.

Frei, Alfred G.: Inszenierte Geschichte(n). Bilanz einer Landesausstellung. In: Badisches Landesmuseum Karlsruhe (Hrsg.): Inszenierte Geschichte(n). Baden-Baden: Nomos 1999, S. 169-197.

Freymann, Thelma von (Hrsg.): Am Beispiel erklärt - Aufgaben und Wege der Museumspädagogik. Hildesheim/Zürich/New York: Georg Olms 1988.

Fried, Johannes: Vom Zerfall der Geschichte zur Wiedervereinigung. Der Wandel der Interpretationsmuster. In: Oexle, Otto Gerhard (Hrsg.): Stand 
und Perspektiven der Mittelalterforschung am Ende des 20. Jahrhunderts. Göttingen: Wallstein 1996, S. 45-72.

Fried, Johannes: Otto der Große, sein Reich und Europa - Vergangenheitsbilder eines Jahrtausends. In: Puhle, Matthias (Hrsg.): Otto der Große, Magdeburg und Europa. Mainz: Philipp von Zabern 2001, S. 537-562.

Fried, Johannes: Die Aktualität des Mittelalters. Gegen die Überheblichkeit unserer Wissensgesellschaft. Stuttgart: Thorbecke 2002.

Fröhlich, Klaus (Hrsg.): Geschichtskultur. Pfaffenweiler: Centaurus 1992.

Fröhlich, Werner/Nöthen, Joachim: Besucherbefragung zur Landesausstellung ,Kaiser Heinrich II. 1002 - 1024‘, Ergebnisbericht. München, 2003.

Fröhling, Stefan/Reuß, Andreas: Brand auf dem Domplatz. Gefahr für die Landesausstellung. In: Bayerische Staatszeitung vom 28.06.02.

Früchtl, Josef/Zimmermann, Jörg (Hrsg.): Ästhetik der Inszenierung. Frankfurt am Main: Suhrkamp 2001.

Früchtl, Josef/Zimmermann, Jörg: Ästhetik der Inszenierung. Dimensionen eines gesellschaftlichen, individuellen und kulturellen Phänomens. In: Früchtl, Josef/Zimmermann, Jörg (Hrsg.): Ästhetik der Inszenierung. Frankfurt am Main: Suhrkamp 2001, S. 9-47.

Fuchs, Marga (Hrsg.): ,Ihr habt Euer Leben dem Führer geweiht!‘ Aspekte des Nationalsozialismus in Bamberg, Darstellungen und Quellen zur Geschichte Bambergs 2. Bamberg 1989.

Fuhrmann, Horst: Einladung ins Mittelalter. München: Beck 2000.

Füßmann, Klaus/Grütter, Heinrich Theodor/Rüsen, Jörn (Hrsg.): Historische Faszination - Geschichtskultur heute. Köln/Weimar/Wien: Böhlau 1994.

Füßmann, Klaus: Historische Formungen. Dimensionen der Geschichtsdarstellung. In: Füßmann, Klaus u.a. (Hrsg.): Historische Faszination. Köln/Weimar/Wien: Böhlau 1994, S. 27-44.

Gardner, Howard: Abschied vom IQ - Die Rahmen-Theorie der vielfachen Intelligenzen. Stuttgart: Klett-Cotta 1991.

Gebhardt, Winfried/Hitzler, Ronald/Pfadenhauer, Michaela (Hrsg.): Events Soziologie des Außergewöhnlichen. Opladen: Leske + Budrich 2000.

Gebhardt, Winfried: Feste, Feiern, Events - Zur Soziologie des Außergewöhnlichen. In: Gebhardt, Winfried u.a. (Hrsg.): Events - Soziologie des Außergewöhnlichen. Opladen: Leske+Budrich 2000, S. 17-32.

Gemmeke, Claudia/John, Hartmut/Krämer, Harald (Hrsg.): euphorie digital? Aspekte der Wissensvermittlung in Kunst, Kultur und Technologie. Bielefeld: transcript 2001.

Gersmann, Gudrun: Schöne Welt der bunten Bilder - Kritische Anmerkungen zur Geschichtsdarstellung in den Neuen Medien. In: Gemmeke, Clau- 
dia/John, Hartmut u.a. (Hrsg.): euphorie digital? Bielefeld: transcript 2001, S. 105-120.

Gesser, Susanne: Dokumentation zum 30. Jubiläum des Kindermuseums: Ein Museum für Kinder im Museum. Frankfurt am Main 2003 (= Kleine Schriften des Historischen Museums in Frankfurt/Main, Bd. 53).

Gillman, B. J.: Museum Fatigue. In: Scientific Monthly. (1916) Heft 11 S. 62-74.

Glaser, Hermann/Deneke, Bernward/Kastner, Karl G. (Hrsg.): Vorüberlegungen zum Konzept eines historischen Museums für Nürnbergs Industriekultur. Nürnberg: Medien und Kultur 1978.

Glaser, Hermann: Zukunft braucht Herkunft. Über die ästhetische Erziehung des Menschen und den gesellschaftlichen Sinngehalt des Musealen. In: Museumskunde. 67. (2002) Heft 2/02. S. 26-33.

Glass, Christian: Präsentationsformen in kulturhistorisch-volkskundlichen Museum. In: Zeitschrift für Volkskunde. 85. (1989) S. 33-47.

Glass, Christian: ,Aber es soll kein Museum werden. 'Die Häuser der Geschichte in Deutschland. In: Museumskunde. 66. (2001) Heft 1/01. S. 117122.

Godau, Sigrid: Inszenierung oder Rekonstruktion? Zur Darstellung von Geschichte im Museum. In: Fehr, Michael/Grohé, Stefan (Hrsg.): Geschichte - Bild - Museum. Köln: Wienand 1989, S. 199-211.

Gorbey, Ken: Das Jüdische Museum Berlin. Der Auftrag, das Publikum, das erzählerische Konzept. In: Museumskunde. 66. (2001) Heft 2/01. S. 73-75.

Gorgus, Nina: Der Zauberer der Vitrinen - Zur Museologie Georges Henri Rivières. Münster/New York/München/Berlin: Waxmann 1999.

Graf, Bernhard/Treinen, Heiner: Besucher im Technischen Museum. Berlin: Gebr. Mann 1983 (= Berliner Schriften zur Museumskunde, Bd. 4).

Graf, Bernhard: Besucherorientierte Ausstellungsplanung: Projekte, Konzeptionen, Ergebnisse. In: Haus der Bayerischen Geschichte (Hrsg.): Kolloquiumsbericht: Besucherforschung und Vermittlungsstrategien in historischen Ausstellungen. München 1991, S. 14-19.

Graf, Bernhard: Besucherorientierung als Leitziel der Museumsarbeit in der Bundesrepublik Deutschland. In: Landesstelle für die nichtstaatl. Museen in Bayern (Hrsg.): Geöffnet! Das Museum für den Besucher. Tagungsbericht zum 10. Bayerischen Museumstag in Landshut. München 2000, S. 21-29.

Grasskamp, Walter: Konsumglück - Die Ware Erlösung. München: Beck 2000. 
Grasskamp, Walter: Kunst als Ressource? Kulturelle Kompetenz als neues Leitbild. In: Politische Studien. 385. (2002) S. 43-56.

Grasso, Hank/Morrison, Howard: Collaboration: Towards a More Holistic Design Process. In: Hooper-Greenhill, Eilean (Hrsg.): The Educational Role of the Museum. London/New York: Routledge 1994, S. 172-177.

Greenhalgh, Paul: Education, Entertainment and Politics: Lessons from the Great International Exhibitions. In: Vergo, Peter (Hrsg.): The New Museology. London: Reaktion Books 1989, S. 74-98.

Grewcock, Duncan: Before, During and After: Front-end, Formative and Summative Evaluation. In: Lord, Barry/Lord, Gail Dexter (Hrsg.): The Manual of Museum Exhibitions. Walnut Creek/Lanhan/New York/Oxford: AltaMira Press 2002, S. 44-53.

Gribl, Albrecht A.: Der Besucher in der Ausstellung - ratlos? Zur Sprache heutiger Konzeption. In: Landesstelle für die nichtstaatl. Museen in Bayern (Hrsg.): Geöffnet! Das Museum für den Besucher. Tagungsbericht zum 10. Bayerischen Museumstag in Landshut. München 2000, S. 30-37.

Grimm, Ulrike: Das Badische Landesmuseum in Karlsruhe. Zur Geschichte seiner Sammlungen. Karlsruhe, 1993.

Grötsch, Kurt: Emotionales Management und emotionales Lernen in Erlebniswelten. In: Nahrstedt, Wolfgang u.a. (Hrsg.): Lernen in Erlebniswelten. Bielefeld: IFKA 2002, S. 42-61.

Grütter, Heinrich Theodor: Warum fasziniert die Vergangenheit? Perspektiven einer neuen Geschichtskultur. In: Füßmann, Klaus u.a. (Hrsg.): Historische Faszination. Köln/Weimar/Wien: Böhlau 1994, S. 45-57.

Grütter, Heinrich Theodor: Die Präsentation der Vergangenheit. Zur Darstellung von Geschichte in historischen Museen und Ausstellungen. In: Füßmann, Klaus u.a. (Hrsg.): Historische Faszination. Köln/Weimar/Wien: Böhlau 1994, S. 173-188.

Grütter, Heinrich Theodor: Geschichte im Museum. (5. überarb. Aufl.) In: Bergmann, Klaus u.a. (Hrsg.): Handbuch der Geschichtsdidaktik. SeelzeVelber: Kallmeyer 1997, S. 707-713.

Gudehus, Christian P.: Was bleibt, zählt. Kritische Überlegungen zum Jüdischen Museum Berlin. http://www.vl-museen.de/aus-rez/gudehus021.htm. (letzter Zugriff: 08.02.02).

Gudjons, Herbert: Pädagogisches Grundwissen. Bad Heilbrunn: Klinkhardt 1995.

Gudjons, Herbert: Handlungsorientiert lehren und lernen. (5. überarb. u. erw. Aufl.) Bad Heilbrunn: Klinkhardt 1997. 
Gunther, Charles F.: Museum-goers: life-styles and learning characteristics. In: Hooper-Greenhill, Eilean (Hrsg.): The Educational Role of the Museum. London/New York: Routledge 1994, S. 118-130.

Guthrie, Hammond M.: Educational Design in the Museum. In: Reinwardt Academy (Hrsg.): Exhibition Design as an Educational Tool. Amsterdam 1984, S. 11-36.

Haberstroh, Jochen: Gruppe Anthropomorpher Steinfiguren - Die Bamberger Götzen - ein Zeugnis vorchristlicher Vorstellungen. In: Kirmeier, Josef u.a. (Hrsg.): Kaiser Heinrich II. 1002-1024. Augsburg 2002, S. 127-130.

Hackelsberger, Christoph: Der Hofgarten - Besitz der Bürger. In: Süddeutsche Zeitung vom 08./09.12.84.

Hagedorn-Saupe, Monika/Noschka-Roos, Annette: Museumspädagogik in Zahlen, Erhebungsjahr 1993. Berlin 1994.

Hagstedt, Herbert/Staudte, Adelheid/Verplancke, Philip/Schreiber, Ursula: Kritische Anmerkungen zu Kinder- und Jugendmuseen. In: Die Grundschulzeitschrift/Themenheft: Kindermuseen. 11. (1997) Heft 101. S. 3034.

Halbertsma, Nico: Museumspädagogik zwischen allen Stühlen?!. In: Standbein Spielbein. (1998) Heft 50. S. 19-24.

Hallam, Elizabeth/Street, Brian V. (Hrsg.): Cultural Encounters: Representing Otherness. London/New York: Routledge 2000.

Hamburger Institut für Sozialforschung (Hrsg.): Verbrechen der Wehrmacht. Dimensionen des Vernichtungskrieges 1941-1944. Ausstellungskatalog. (2. überarb. Aufl.) Hamburg: Hamburger Edition 2002.

Häntzschel, Jörg: Im Namen des Geldes. Wie sich das Smithsonian in den Netzen seiner Sponsoren verfängt. In: Süddeutsche Zeitung vom 27.08.02.

Hardtwig, Wolfgang: Geschichtskultur und Wissenschaft. München: Deutscher Taschenbuch Verlag 1990.

Hartwig, Helmut: Spurensicherung zwischen historischer und ästhetischer Praxis. In: Bätz, Oliver/Gößwald, Udo (Hrsg.): Experiment Heimatmuseum. Berlin: Jonas 1988, S. 100-105.

Hasse, Claus-Peter: ,Einfach atemberaubend und beeindruckend“ - Zur Durchführung und Resonanz der 27. Ausstellung und Landesausstellung Sachsen-Anhalt Otto der Große, Magdeburg und Europa. In: Ministerium für Wirtschaft und Arbeit des Landes Sachsen-Anhalt, Kulturhistorisches Museum Magdeburg (Hrsg.): Otto der Große, Magdeburg und Europa. Magdeburg 2002, S. 14-28.

Hauenschild, Andrea: Neue Museologie. Anspruch und Wirklichkeit anhand vergleichender Fallstudien in Kanada, USA und Mexiko. Bremen: Selbstverlag des Museums 1988. 
Haus der Bayerischen Geschichte (Hrsg.): Kolloquiumsbericht: Besucherforschung und Vermittlungsstrategien in Historischen Ausstellungen. München 1991.

Haus der Bayerischen Geschichte: Landesausstellung Heinrich II., Bamberg, 8. Juli bis 20. Oktober 2002, Konzept, Stand: 12.02.01. (unveröffentl. Skript) Augsburg 2001.

Haus der Bayerischen Geschichte: Landesausstellung Heinrich II., Bamberg, 8. Juli bis 20. Oktober 2002, Konzept, Stand: 24.07.01. (unveröffentl. Skript) Augsburg 2001.

Haus der Bayerischen Geschichte (Hrsg.): Kaiser Heinrich II. - Eine Reise durch die Ausstellung. Begleitheft zur bayerischen Landesausstellung in Bamberg. Augsburg 2002.

Haus der Bayerischen Geschichte (Hrsg.): 20 Jahre Haus der Bayerischen Geschichte - 20 Jahre Geschichtsarbeit in Bayern. Augsburg 2003.

Haus der Bayerischen Geschichte (Hrsg.): Expertentagung ,Ausstellung und Tourismus ‘ vom 26.-27.02.03 in Kloster Banz. http://www.hdbg.de/basis/ 05_content_shop/content/6000_artikel_downloads/download-dateien/banz _protokoll.pdf. (letzter Zugriff: 31.01.05).

Haus der Geschichte der Bundesrepublik Deutschland (Hrsg.): Erlebnis Geschichte. Das Buch zur Ausstellung. (3., überarb. Aufl.) Bonn: Gustav Lübbe 2000.

Haus der Geschichte Baden-Württemberg, Stuttgart (Hrsg.): Landesgeschichten. Der deutsche Südwesten von 1790 bis heute. Das Buch zur Dauerausstellung. Stuttgart, 2002.

Hedge, Alan: Human Factor Considerations in the Design of Museums to Optimize their Impact on Learning. In: Falk, John H./Dierking, Lynn D. (Hrsg.): Public Institutions for Personal Learning: Establishing A Research Agenda. Washington D.C. 1995, S. 105-118.

Hein, George E.: The Constructivist Museum. In: Hooper-Greenhill, Eilean (Hrsg.): The Educational Role of the Museum. London/New York: Routledge 1994, S. 80-91.

Hein, George E.: Learning in the Museum. London/New York: Routledge 1998.

Hein, George E./Alexander, Mary: Museums - Places of Learning. Washington D.C. 1998.

Hein, Hilde S.: The Museum in Transition, a Philosophical Perspective. Washington/London: Smithsonian Institution Press 2000.

Heinisch, Severin: Objekt und Struktur - Über die Ausstellung als einen Ort der Sprache. In: Rüsen, Jörn u.a. (Hrsg.): Geschichte sehen. Pfaffenweiler: Centaurus 1988, S. 82-87. 
Heinje, Silvia: Ausstellen. Was sich herausstellt. In: Standbein Spielbein. (1989) Heft 25. S. 4-9.

Heinze, Sigrid/Ludwig, Andreas: Geschichtsvermittlung und Ausstellungsplanung in Heimatmuseen - eine empirische Studie in Berlin. Berlin 1992 (= Materialien aus dem Institut für Museumskunde, Bd. 35).

Heit, Alfred: ,Die ungestillte Sehnsucht “ - Versuch über ein Movens historischer Faszination in Umberto Ecos Roman ,Der Name der Rose'. In: Füßmann, Klaus u.a. (Hrsg.): Historische Faszination. Köln/Weimar/ Wien: Böhlau 1994, S. 113-128.

Held, Jutta: Konzeptionen historischer Museen. In: Kuhn, Annette/Schneider, Gerhard (Hrsg.): Geschichte lernen im Museum. Düsseldorf: Schwann 1978, S. 11-31.

Heller, Andreas: Inszenierte Authentizität? Die Grenzen von Design und Szenographie. In: Museumskunde. 66. (2001) Heft 1. S. 33-36.

Helzel, Frank: Ein König, ein Reichsführer und der Wilde Osten. Heinrich I. (919 - 936) in der nationalen Selbstwahrnehmung der Deutschen. Bielefeld: transcript 2004.

Henderson, Amy/Kaeppler, Adrienne L. (Hrsg.): Exhibiting Dilemmas. Issues of Representation at the Smithsonian. Washington D.C. 1997.

Henning, Lothar: Zur technischen und gestalterischen Realisation des DürerStudios. In: Kunstpädagogisches Zentrum im Germanischen Nationalmuseum (Hrsg.): Zum Beispiel Dürer-Studio. Ravensburg: Otto Maier 1972, S. 70-81.

Hense, Heidi: Das Museum als gesellschaftlicher Lernort, Aspekte einer pädagogischen Neubestimmung. Frankfurt: Brandes \& Apsel 1990.

Herbst, Wolfgang/Levykin K. G. (Hrsg.): Museologie - Theoretische Grundlagen und Methodik der Arbeit in den Geschichtsmuseen. Berlin: Deutscher Verlag der Wissenschaften 1988.

Herles, Diethard: Das Museum und die Dinge: Wissenschaft, Präsentation, Pädagogik. Frankfurt/New York: Campus 1996.

Hertlein, Margit: Mind-Mapping. Die kreative Arbeitstechnik. Hamburg: Rowohlt, 1997.

Heumann Gurian, Elaine: Noodling Around with Exhibition Opportunities. In: Lavine, Steven D./Karp, Ivan (Hrsg.): Exhibiting Cultures. Washington D.C./London: Smithsonian Institution Press 1991, S. 176-190.

Hinz, Berthold: Der ,Bamberger Reiter‘. In: Warnke, Martin (Hrsg.): Das Kunstwerk zwischen Wissenschaft und Weltanschauung. Gütersloh: Bertelsmann 1970, S. 26-47. 
Hirsch, Joanne S./Silverman, Lois S. (Hrsg.): Transforming Practice - Selections from the Journal of Museum Education, 1992-1999. Washington D.C. 2000.

Hirschmüller, Markus/Madundo, Peter/Schindele, Harald: Identität ist das Ziel. Die Orte sind herstellbar. In: StadtBauwelt. (1999) Heft 36. S. 20282031.

Historisches Museum der Stadt Frankfurt am Main (Hrsg.): Die Zukunft beginnt in der Vergangenheit - Museumsgeschichte und Geschichtsmuseum. Giessen: Anabas 1982.

Hjorth, Jan: Travelling exhibits: The Swedish experience. In: Miles, Roger/Zavala, Lauro (Hrsg.): Towards the Museum of the Future. London: Routledge 1994, S. 99-116.

Hochreiter, Walter: Vom Musentempel zum Lernort. Zur Sozialgeschichte deutscher Museen 1800 - 1914. Darmstadt: Wissenschaftliche Buchgesellschaft 1994.

Hoffmann, Gabriele: Für eine ,Kunst mit Folgen“. Der Künstler Hans Haacke im Gespräch. In: Neue Zürcher Zeitung vom 13.03.04.

Hoffmann, Detlef: ,Laßt Objekte sprechen!‘ Bemerkungen zu einem verhängnisvollen Irrtum. In: Spickernagel, Ellen/Walbe, Brigitte (Hrsg.): Das Museum - Lernort contra Musentempel. Düsseldorf: Anabas 1976, S. 101120.

Hoffmann, Detlef: Künstler und Wissenschaftler als Produzenten kulturhistorischer Ausstellungen? In: Rüsen, Jörn (Hrsg.): Geschichte sehen. Pfaffenweiler: Centaurus 1988, S. 137-144.

Hoffrichter, Horst: Kommentierende Bildbeschriftungen, didaktische Kabinette und präferierte Informationsbereiche in Kunstmuseen. In: Klein, Hans-Joachim (Hrsg.): Kunstrezeption - kühle Annäherung an ein heißes Thema. Karlsruhe 1992, S. 23-40.

Hooper-Greenhill, Eilean: Communication in Theory and Practice. In: Hooper-Greenhill, Eilean (Hrsg.): The Educational Role of the Museum. London/New York: Routledge 1994, S. 28-43.

Hooper-Greenhill, Eilean: Education, Communication and Interpretation: Towards a Critical Pedagogy in Museums. In: Hooper-Greenhill, Eilean (Hrsg.): The Educational Role of the Museum. London/New York: Routledge 1994, S. 3-27.

Hooper-Greenhill, Eilean: Learning from Learning Theory in Museums. In: Hooper-Greenhill, Eilean (Hrsg.): The Educational Role of the Museum. London/New York: Routledge 1994, S. 137-145.

Hooper-Greenhill, Eilean (Hrsg.): The Educational Role of the Museum. London/New York: Routledge 1994. 
Hooper-Greenhill, Eilean: Museums and the Shaping of Knowledge. London/New York: Routledge 1999.

Hooper-Greenhill, Eilean: Museums and the Interpretation of Visual Culture. London/New York: Routledge 2000.

Horta, Maria de Lourdes: Museum Language and Exhibitions' Speeches. In: Sofka, Vinos (Hrsg.): The Language of Exhibitions. Stockholm 1995, S. 55-60.

Hungerbühler Savary, Ruth: Das ganze Leben: Ein Erlebnis. In: archithese. 6. (1993) S. 8-13.

Husemann, Ralf: ,RAF war keine Art Bonnie and Clyde‘. Der Ausstellungsmacher Klaus Biesenbach verteidigt sein Projekt. In: Süddeutsche Zeitung vom 28.07.03.

Hutterer, Claudia: Über Begriffs- und Bedeutungsver(w)irrungen. Möglichkeiten, Aufgaben und konkrete Chancen der Kunst- und Kulturvermittlung im Rahmen des Festivals der Regionen. In: Blickpunkte. (1999) Heft 2. S. 24-29.

ICOM-Deutschland; ICOM-Österreich; ICOM-Schweiz: ICOM Ethische Richtlinien für Museen. Berlin/Wien/Zürich 2003.

Iglhaut, Stefan: Szenographie: Verschmelzung der Sparten und Disziplinen. In: Museumskunde. 66. (2001) Heft 1. S. 49-55.

Izard, Carrol E.: Die Emotionen des Menschen. Eine Einführung in die Grundlagen der Emotionspsychologie. Weinheim: Beltz 1994.

Jauß, Hans Robert: Kleine Apologie der ästhetischen Erfahrung. In: Stöhr, Jürgen (Hrsg.): Ästhetische Erfahrung heute. Köln: DuMont 1996, S. 15 41.

Jedermann, Katharina: Künstler als Ausstellungsgestalter. In: Bätz, Oliver/ Gößwald, Udo (Hrsg.): Experiment Heimatmuseum. Berlin: Jonas 1988, S. 82-91.

Jeffery, Kodi R.: Constructivism in Museums: How Museums Create Meaningful Learning. In: Hirsch, Joanne S./Silvermann, Lois H. (Hrsg.): Transforming Practice. Washington D.C 2000, S. 212-221.

Jeismann, Karl-Ernst: Geschichtsbewußtstein - Theorie. In: Bergmann, Klaus u.a. (Hrsg.): Handbuch der Geschichtsdidaktik. Seelze-Velber: Kallmeyer 1997, S. 42-44.

John, Hartmut: Spielen wir noch in der Champions-League? oder: Plädoyer für professionelle Ausstellungsplanung im Museum. In: Schwarz, Ulrich/ Teufel, Philipp (Hrsg.): Museografie und Ausstellungsgestaltung. Ludwigsburg: av-Edition 2001, S. 38-59. 
Jonge, Ad de: Ein Schatz an interessanten Daten. Die Suche von Prof. Jos. M.M. Hermans nach mittelalterlichen Handschriften. In: Deutsche Ausgabe der Groninger Museumskrant. (2001) Heft 1. S. 5-8.

Jordanova, Ludmilla: History, Otherness and Display. In: Hallam, Elizabeth/Street, Brian V. (Hrsg.): Cultural Encounters: Representing Otherness. London/New York: Routledge 2000, S. 245-259.

Jung, Sabine/Arbeitskreis selbständiger Kultur-Institute e.V.: Neue Wege der Museumspädagogik. Publikation zu einer internationalen Fachtagung im Museumszentrum Lorsch. Bonn, 2003.

Jussen, Bernhard (Hrsg.): Signal - Christian Boltanski. Göttingen: Wallstein 2004 (= Von der künstlerischen Produktion der Geschichte, Bd. 5).

Kagelmann, Jürgen H.: Erlebniswelten: Grundlegende Bemerkungen zum organisierten Vergnügen. In: Rieder, Max u.a. (Hrsg.): ErlebnisWelten. München/Wien: Profil 1998, S. 58-94.

Kaiser, Brigitte: Aktivitäten zur Belebung eines kleinen Stadtmuseums, das Beispiel Neuötting. In: Museum heute, Fakten - Tendenzen - Hilfen. (1999) Heft 18. S. 28-30.

Kaiser, Brigitte: Museumspädagogik und Ausstellungsarchitektur. Der Kinderpfad in der Landesausstellung ,Heinrich II. und seine Zeit' in Bamberg. In: Museum heute, Fakten - Tendenzen - Hilfen. (2002) Heft 24. S. 36-40.

Kamber, André (Hrsg.): Stichworte zu einem sentimentalen Lexikon um Daniel Spoerri und um ihn herum. München 1990.

Karp, Ivan/Lavine, Steven D. (Hrsg.): Exhibiting Cultures. The Poetics and Politics of Museum Display. Washington D.C./London: Smithsonian Institution Press 1991.

Kehr, Wolfgang: Zweimal ,Diablo“? Gewalt und Schrecken in der romanischen Portalplastik der Kathedrale Saint-Lazare in Autun (Burgund). In: Kirschenmann, Johannes (Hrsg.): Begegnungen zwischen Kunstwissenschaft und Kunstpädagogik. Weimar: Verl. und Datenbank für Geisteswiss. 1999, S. 37-54.

Keller, Hagen: Die Ottonen. München: Beck 2001.

Kelly, Judith: The Sciart Experiment. In: Museums Journal. 101. (2001) Heft 9. S. 30-33.

Kemp, Wolfgang: Brian O`Doherty: In der weißen Zelle - Inside the White Cube. Berlin: Merve 1996.

Kemper, Peter (Hrsg.): Der Trend zum Event. Frankfurt am Main: Suhrkamp 2001.

Kerner, Max: Das Mittelalter als ,Kindheit Europas'. Zu den Geschichtsromanen Umberto Ecos. In: Segl, Peter (Hrsg.): Mittelalter und Moderne. Ent- 
deckung und Rekonstruktion der mittelalterlichen Welt. Sigmaringen: Thorbecke 1997, S. 289-304.

Kindler, Gabriele (Hrsg.): MuseumsTheater: theatrale Inszenierungen in der Ausstellungspraxis. Bielefeld: transcript 2001.

Kindler, Gabriele/Liebelt, Udo: Bildung und Kommunikation. Museumspädagogik im Konzert der Museumsarbeit. In: Landesstelle für die nichtstaatl. Museen in Bayern (Hrsg.): Im Dialog - Museumspädagogik für alle Besucher, Tagungsdokumentation zum 11. Bayerischen Museumstag in Bayreuth. München 2002, S. 19-29.

Kirch, Raimund: Wie Bamberg zum Zentrum des Reiches wurde. In: Nürnberger Zeitung vom 09.07.02.

Kirmeier, Josef/Schneidmüller, Bernd/Weinfurter, Stefan/Brockhoff, Evamaria (Hrsg.): Kaiser Heinrich II. 1002-1024. Katalog zur Bayerischen Landesausstellung in Bamberg. Augsburg 2002.

Kirmeier, Josef: Landesausstellung Kaiser Heinrich II. - Ein Resümee. In: Haus der Bayerischen Geschichte (Hrsg.): Expertentagung ,Ausstellung und Tourismus' $26 .-27.02 .03$ in Kloster Banz. http://www.hdbg.de/basis/ 05_content_shop/content/6000_artikel_downloads/download-dateien/banz _protokoll.pdf. (letzter Zugriff: 31.01.05).

Kirschenmann, Johannes u.a. (Hrsg.): Ikonologie und Didaktik: Begegnungen zwischen Kunstwissenschaft und Kunstpädagogik. Weimar: Verl. und Datenbank für Geisteswiss. 1999.

Kissler, Alexander: Sodom und Andorra. Wie eine Fürther Ausstellung über das Bild vom Judentum unsere Erinnerungskultur verändern könnte. In: Süddeutsche Zeitung vom 09.04.02.

Kivelitz, Christoph: Die Propagandaausstellungen in europäischen Diktaturen. Konfrontation und Vergleich: Nationalsozialismus in Deutschland, Faschismus in Italien und die UdSSR der Stalinzeit. Bochum: Dr. Dieter Winkler, 1999.

Klein, Hans-Joachim/Bachmayer, Monika: Museum und Öffentlichkeit. Berlin: Gebr. Mann 1981.

Klein, Hans-Joachim: Der gläserne Besucher - Publikumsstrukturen einer Museumslandschaft. Berlin: Gebr. Mann 1990.

Klein, Hans-Joachim/Wüsthoff-Schäfer, Barbara: Inszenierung an Museen und ihre Wirkung auf Besucher. Berlin 1990.

Klein, Hans-Joachim (Hrsg.): Kunst-Rezeption - kühle Annäherung an ein heißes Thema. Karlsruhe 1992.

Klein, Hans-Joachim (Hrsg.): Front-End Evaluation - ein nichtssagender Name für eine vielsagende Methode. Karlsruhe 1993. 
Klein, Hans-Joachim (Hrsg.): Vom Präsentieren zum Vermitteln, Fachtagung am Grassi Museum in Leipzig im Mai 1993. Karlsruhe 1994.

Klein, Hans-Joachim (Hrsg.): Mediendämmerung - die unaufhaltsame Computerisierung der Museen. Karlsruhe 1995.

Klein, Hans-Joachim: Gemischtes Doppel - Evaluation der Ausstellungen Spätmittelalter am Oberrhein in der Staatlichen Kunsthalle und im Badischen Landesmuseum, beide in Karlsruhe. Karlsruhe 2002.

Klein, Norman M.: Der Raum summt wie ein glücklicher Wal. Scripting Las Vegas. In: StadtBauwelt. (1999) Heft 36. S. 2000-2005.

Klose, Dagmar: Geschichtsbewußtsein - Ontogenese. (5. überarb. Aufl.) In: Bergmann, Klaus u.a. (Hrsg.): Handbuch der Geschichtsdidaktik. SeelzeVelber: Kallmeyer 1997, S. 51-56.

Kloster Seeon (Hrsg.): Faszination Mittelalter, Otto der Große, Bayern und Europa. Seeon 2001.

Klot, Christina v.: Zurück ins Mittelalter: Wo die Guten siegen. Im Sommer ist die Hochsaison der Ritterspiele. Bis zu 50000 Fans suchen die Gemeinschaft tapferer Recken, holder Maiden und eifriger Handwerker. In: mobil. (2003) Heft 6. S. 72-75.

Knapp, Gottfried: Der Mann, von dem man nichts wusste. Wie die Bayerische Landesausstellung in Aschaffenburg ,Das Rätsel Grünewald‘ zu lösen versucht. In: Süddeutsche Zeitung vom 30.11.02.

Knez, Eugene I./Wright, Gilbert: The Museum as a Communications System: An Assessment of Cameron`s Viewpoint. In: Curator. 13. (1970) Heft 3. S. 204-212.

Knol, Egge/Hermans, Jos M.M./Driebergen, Matthijs (Hrsg.): Hel et Hemel. De Middeleeuwen in het Noorden. Groningen, 2001.

Koch, Michael: Das Museum als Gesamtkunstwerk. Gabriel von Seidls Neubau im Spiegel der Kritik. In: Bauer, Ingolf (Hrsg.): Das Bayerische Nationalmuseum. Der Neubau an der Prinzregentenstraße 1892-1900. München: Hirmer 2000, S. 209-232.

Kolsteren, Steven: Einblick in den Geist des Mittelalters. Die Mission von Peter Greenaway. In: Deutsche Ausgabe der Groninger Museumkrant. (2001) Heft 1. S. 2-3.

König, Gabriele: Kinder- und Jugendmuseen. Genese und Entwicklung einer Museumsgattung, Impulse für besucherorientierte Museumskonzepte. Opladen: Leske + Budrich 2002

König, Stefan/Ernszt, Peter: Das Kaltenberger Ritterturnier. München: Langen Müller 2004.

Konsten, Marie-Thérèse: ,Amsterdam'daki Anadolu - Anatolien in Amsterdam‘ Türken im Historischen Museum Amsterdam. In: Museumsblatt, 
Mitteilungen aus dem Museumswesen Baden-Württembergs. 21. (1997) S. 26-29.

Korff, Gottfried: Didaktik des Alltags - Hinweise zur Geschichte der Bildungskonzeption kulturhistorischer Museen. In: Kuhn, Annette/Schneider, Gerhard (Hrsg.): Geschichte lernen im Museum. Düsseldorf: Schwann 1978, S. 32-48.

Korff, Gottfried: Aporien der Musealisierung. Notizen zu einem Trend, der die Institution, nach der er benannt ist, hinter sich gelassen hat. In: Zacharias, Wolfgang (Hrsg.): Zeitphänomen Musealisierung. Essen: Klartext 1990, S. 57-71.

Korff, Gottfried/Roth, Martin (Hrsg.): Das historische Museum - Labor, Schaubühne, Identitätsfabrik. Frankfurt/New York: Campus 1990.

Korff, Gottfried: Bildwelt Ausstellung - Die Darstellung von Geschichte im Museum. In: Borsdorf, Ulrich (Hrsg.): Orte der Erinnerung. Frankfurt/New York: Campus 1999, S. 319-336.

Korff, Gottfried: Das Popularisierungsdilemma. In: Museumskunde. 66. (2001) Heft 1. S. 13-20.

Korff, Gottfried: Museumsdinge: Deponieren - Exponieren. Köln/Weimar/ Wien: Böhlau 2002.

Körner, Hans-Michael: Das Bayerische Nationalmuseum in München. In: Körner, Hans-Michael (Hrsg.): Museumskonzeptionen - Präsentationsformen und Lernmöglichkeiten. München 1999, S. 33-46.

Köster, Gabriele/Pöppelmann, Heike: Otto der Große, Magdeburg und Europa - Texte und Bilder einer Ausstellung. In: Ministerium für Wirtschaft und Arbeit des Landes Sachsen-Anhalt, Kulturhistorisches Museum Magdeburg (Hrsg.): Otto der Große, Magdeburg und Europa. Magdeburg 2002, S. 29-42.

Kotler, Neil/Kotler, Philip: Museum Strategy and Marketing: Designing Missions, Building Audiences, Generating Revenue and Resources. San Francisco: Jossey-Bass 1998.

Kotler, Neil: Marketing the Museum's Full Range of Assets. In: Museum News. 78. (1999) Heft 3. S. 30-61.

Kotteder, Franz: Ude kippt Nazi-Ausstellung. München unterm Hakenkreuz: Neue Abteilung im Stadtmuseum muss überarbeitet werden. In: Süddeutsche Zeitung vom 06.08.02.

Kramer, Dieter: Kulturgeschichtstheorie und kulturgeschichtlich-volkskundliche Museen und Sammlungen. In: Spickernagel, Ellen/Walbe, Brigitte (Hrsg.): Das Museum - Lernort contra Musentempel. Gießen: Anabas 1976, S. 21-31. 
Kramp, Mario (Hrsg.): Krönungen, Könige in Aachen - Geschichte und Mythos. Ausstellungskatalog in 2 Bänden. Mainz: Philipp von Zabern 2000.

Kranert, Hendrik: Schlossmuseum Quedlinburg: Verdrängtes kommt ans Licht. Schau nimmt sich erstmals des Heinrich-Kultes der Nazis an - Gemeinde musste ihre Stiftskirche überlassen. In: Mitteldeutsche Zeitung vom 03.04.04.

Kravagna, Christian: Das Museum als Arena. Institutionskritische Texte von KünstlerInnen. Köln: Walther König 2001.

Kreft, Michael: Europa-Park - von der Unternehmervision zum Marktführer. In: Steinecke, Albrecht (Hrsg.): Erlebnis- und Konsumwelten. München/Wien: Oldenbourg 2000, S. 133-144.

Kreye, Andrian: Geschmackssache. Beispiel USA: Mäzene fördern die Kultur - und gefährden sie. In: Süddeutsche Zeitung vom 25.08.03.

Krill, Hannes: Römer bereichern Rosenheim. Landesausstellung ein großer Erfolg mit 250000 Besuchern. In: Süddeutsche Zeitung vom 08.11.00.

Kriss-Rettenbeck, Lenz: Das Problem großer historischer Ausstellungen. In: Museumskunde. 45. (1980) Heft 3. S. 115-133.

Kroeber-Riel, Werner/Weinberg, Peter: Konsumentenverhalten. München: Vahlen 1999.

Kroos, Renate: Vom Umgang mit Reliquien. In: Legner, Anton (Hrsg.): Ornamenta Ecclesiae. Kunst und Künstler der Romanik. Köln 1985, S. 2549.

Krüger, Dieter: Beratung und visuelle Kommunikation - Spagat zwischen Informationsmenge und visueller Aufbereitung. In: Compania Media (Hrsg.): Handbuch Museumsberatung. Bielefeld: transcript 2000, S. 265270.

Kuhn, Annette/Schneider, Gerhard (Hrsg.): Geschichte lernen im Museum. Düsseldorf: Schwann 1978.

Kulik, Gary: Designing the Past: History-Museums Exhibitions from Peale to the Present. In: Leon, Warren u.a. (Hrsg.): History Museums in the United States. Illinois: Illini Books 1989, S. 3-37.

Kulturreferat der Landeshauptstadt München/Bayerische Landeszentrale für politische Bildungsarbeit (Hrsg.): Ein NS-Dokumentationszentrum für München. Ein Symposium in zwei Teilen 5.-7.12.2002, 16.-17.1.2003, Tagungsband. München: Vögel 2003.

Kunstpädagogisches Zentrum im Germanischen Nationalmuseum (Hrsg.): Zum Beispiel Dürer-Studio - Dokumentation und Kritik eines ausstellungsdidaktischen Experiments. Ravensburg: Otto Maier 1972.

Kunz-Ott, Hannelore (Hrsg.): Aspekte der Museumsarbeit in Bayern: Erfahrungen - Entwicklungen - Tendenzen. München: Weltkunst 1996. 
Landesstelle für die nichtstaatl. Museen in Bayern (Hrsg.): Geöffnet! Das Museum für den Besucher. 10. Bayerischer Museumstag in Landshut 7.-9. Juli 1999, Tagungsbericht. München 2000.

Landesstelle für die nichtstaatl. Museen in Bayern (Hrsg.): Museen in Bayern. Das bayerische Museumshandbuch. (3. überarb. Aufl.) München/Berlin: Deutscher Kunstverlag 2000.

Landesstelle für die nichtstaatl. Museen in Bayern (Hrsg.): Im Dialog. Museumspädagogik für alle Besucher. 11. Bayerischer Museumstag in Bayreuth 18.-20. Juli 2001, Tagungsdokumentation. München 2002.

Landesstelle für Museumsbetreuung Baden-Württemberg (Hrsg.): Neuordnungen: Südwestdeutsche Museen in der Nachkriegszeit. Tübingen: Silberburg 2002.

Landsmann, Hannah: ,Objekt versus Computer‘ Symposium zu einem unter Museumsfachleuten heiß diskutierten Thema. In: Newsletter Jüdisches Museum Wien. (2001) Heft 32. S. 6-8.

Landsmann, Hannah: Objekt versus Computer?! Sinn und Unsinn Neuer Medien im Museums- und Ausstellungswesen, 12. Juni 2001, Jüdisches Museum Wien, Protokoll des Symposiums. (unveröffentl. Skript) Wien 2001.

Langemeyer, Gerhard: Erfahrungen mit argumentierenden Ausstellungen im Landesmuseum Münster. In: Spickernagel, Ellen/Walbe, Brigitte (Hrsg.): Das Museum - Lernort contra Musentempel. Düsseldorf: Anabas 1976, S. 121-136.

Latimer, Sue: Artistic Licence. In: Museums Journal. 101. (2001) Heft 8. S. 29-31.

Lauer, Herbert: Landesausstellung ,Heinrich II. als Wirtschaftsfaktor/ Stellungnahme der Stadt Bamberg. In: Haus der Bayerischen Geschichte (Hrsg.): Expertentagung Ausstellung und Tourismus 26.-27.02.03 in Kloster Banz. http://www.hdbg.de/basis/05_content_shop/content/6000_ artikel_downloads/download-dateien/banz_protokoll.pdf. (letzter Zugriff: 31.01.05).

Leeuw, Ronald de: Neue Konzepte in Holland - Das Rijksmuseum in Amsterdam. In: Mai, Ekkehard (Hrsg.): Die Zukunft der Alten Meister. Köln/Weimar/Wien: Böhlau 2001, S. 73-88.

Legner, Anton (Hrsg.): Ornamenta Ecclesiae - Kunst und Künstler der Romanik. Katalog zur Ausstellung des Schnütgen-Museums in der JosefHauberich-Kunsthalle. Köln 1985.

Lehnerer, Thomas: Ästhetische Bildung. In: Staudte, Adelheid (Hrsg.): Ästhetisches Lernen auf neuen Wegen. Weinheim/Basel: Beltz 1993, S. 3843. 
Leon, Warren/Rosenzweig, Roy (Hrsg.): History Museums in the United States - A Critical Assessment. Illinois: Illini Books 1989.

Lichtwark, Alfred: Die Museen als Volksbildungsstätten. In: Die Museen als Volksbildungsstätten. Ergebnisse der 12. Konferenz der Centralstelle für Arbeiter- und Wohlfahrtseinrichtungen. Berlin 1904.

Liebertz, Charmaine: Kunstdidaktische Aspekte in der Museumspädagogik Entwicklung und Gegenwart. Weinheim 1988.

Liebs, Holger: Die Tage der Ruhe sind gezählt. Im Trubel der Sparmaßnahmen zeichnet sich ein Generationenwechsel ab. In: Süddeutsche Zeitung vom 05./06.01.05.

Liebs, Holger: Im Echoraum der Geschichte. Zum Streit um die RAFAusstellung: Warum die Kunst die Freiheit besitzt, unverdaute Historie ans Licht zu bringen. In: Süddeutsche Zeitung vom 21.08.03.

Lindner, Ulrike: Bericht zur Fachtagung des Bundesverbandes Museumspädagogik e.V. vom 04.-07.10.01 in Berlin: ,Zeitzeichen - Leitzeichen Kommunikation im Museum‘. In: Landesarbeitskreis Museumspädagogik Bayern e.V. 23. Mitgliederrundschreiben. (2001) S. 3-4.

Loibl, Richard: Ritterburg und Burgspektakel - Besucherorientierung im Oberhausmuseum Passau. In: Museum heute, Fakten - Tendenzen - Hilfen. (1999) Heft 17. S. 29-33.

Lord, Barry/Lord, Gail D. (Hrsg.): The Manual of Museum Exhibitions. Walnut Creek/Lanham/New York/Oxford: AltaMira Press 2002.

Lowenthal, David: ,History' und 'Heritage ' - widerstreitende und konvergente Formen der Vergangenheitsbetrachtung. In: Beier, Rosemarie (Hrsg.): Geschichtskultur in der Zweiten Moderne. Frankfurt/New York: Campus 2000, S. 71-94.

Lublar, Steven: Exhibiting Memories. In: Henderson, Amy/Kaeppler, Adrienne L. (Hrsg.): Exhibiting Dilemmas. Washington D.C. 1997, S. 15-27.

Lüdke, Dietmar/Jacob-Friesen, Holger (Hrsg.): Spätmittelalter am Oberrhein. Teil 1: Maler und Werkstätten 1450-1525. Ausstellungskatalog. Stuttgart: Thorbecke 2001.

Lumley, Robert (Hrsg.): The Museum Time-Machine - Putting Cultures on Display. London/New York: Routledge 1988.

Lüttichau, Mario-Andreas von: Rekonstruktion der Ausstellung ,Entartete Kunst‘. (5. überarb. Aufl.) In: Schuster, Peter-Klaus (Hrsg.): Die Kunststadt München 1937. Nationalsozialismus und ,Entartete Kunst‘. München: Prestel 1998, S. 120-259.

Lutum-Lenger, Paula: Die Gegenwärtigkeit der Geschichte. Eine Ausstellung zur südwestdeutschen Landesgeschichte seit 1790. In: Haus der Ge- 
schichte Baden-Württemberg, Stuttgart (Hrsg.): Landesgeschichten. Der deutsche Südwesten von 1790 bis heute. Stuttgart 2002, S. 10-21.

Lutz, Raphael: Geschichtswissenschaft im Zeichen der Extreme. Theorie, Methoden, Tendenzen von 1900 bis zur Gegenwart. München: Beck 2003.

Maar, Christa/Burda, Hubert: Iconic Turn. Die neue Macht der Bilder. Köln: DuMont 2004.

Macdonald, Sharon/Fyfe, Gordon (Hrsg.): Theorizing Museums. Oxford: Blackwell Publishers 1998.

Macdonald, Sharon/Silverstone, Roger: Rewriting the Museums' Fictions: Taxonomies, Stories and Readers. In: Boswell, David/Evans, Jessica (Hrsg.): Representing the Nation: A Reader. London/New York: Routledge 1999, S. 421-434.

Macdonald, Sharon J.: Nationale, postnationale, transkulturelle Identitäten und das Museum. In: Beier, Rosemarie (Hrsg.): Geschichtskultur in der Zweiten Moderne. Frankfurt/New York: Campus 2000, S. 123-148.

Mai, Ekkehard: Expositionen - Geschichte und Kritik des Ausstellungswesens. München/Berlin: Deutscher Kunstverlag 1986.

Mai, Ekkehard (Hrsg.): Die Zukunft der Alten Meister - Perspektiven und Konzepte für das Kunstmuseum von heute. Köln/Weimar/Wien: Böhlau 2001.

Majec, Gerhard: Großausstellungen: Ihre kulturpolitische Funktion - ihr Publikum. In: Fliedl, Gottfried (Hrsg.): Museum als soziales Gedächtnis? Klagenfurt 1988, S. 63-79.

Marks, Richard/Williamson, Paul (Hrsg.): Gothic, Art for England 14001547. Ausstellungskatalog. London: V\&A Publications 2003.

Marling, Karal A. (Hrsg.): Designing Disney`s Theme Park: The Architecture of Reassurance. Paris/New York: Flammarion 1997.

Maroević, Ivo: Introduction to Museology - the European Approach. München: Dr. Christian Müller-Straten 1998.

Maroević, Ivo: Museumsausstellung - Museologische Herausforderung. (unveröffentl. Skript) Zagreb, 2001.

Martin, Jean-Hubert/Til, Barbara/Zeisig, Andreas: Künstlermuseum Bogomir Ecker, Thomas Huber. Eine Neupräsentation der Sammlung des museum kunst palast. Düsseldorf, 2002.

Maset, Pierangelo: Ästhetische Bildung der Differenz, Kunst und Pädagogik im technischen Zeitalter. Stuttgart: Radius 1995.

Matelic, Candace T.: Forging a Balance - A Team Approach to Exhibit Development at the Museum of Florida History. In: Ames, Kenneth L. u.a. (Hrsg.): Ideas and Images. Walnut Creek/London/New Delhi: AltaMira Press 1992, S. 187-210. 
May, Margaret: Exhibitions Ideas: Integrating the Voices of Communities and Audiences. In: Lord, Barry/Lord, Gail D. (Hrsg.): The Manual of Museum Exhibitions. Walnut Creek/Lanham/New York/Oxford: AltaMira Press 2002, S. 32-38.

Mazzoni, Ira D.: Von Disney lernen? Zukunftsperspektiven für das Museum: Themenpark? Multi-Media-Salon? Kulturzentrum? In: Museumskunde. 63. (1998) Heft 2. S. 14-16.

McLean, Kathleen: Planning for People in Museum Exhibitions. Washington D.C., 1993.

Mclean, Kathleen: Museum Exhibitions and the Dynamics of Dialogue. In: Daedalus, Journal of the American Academy of Arts and Science. 128. (1999) Heft 3. S. 83-108.

Meeter, Han/Verhaar, Jan: Project Model Exhibitions. Amsterdam, 1989.

Meier, Thomas D./Reust, Hans R. (Hrsg.): Medium Museum - Kommunikation und Vermittlung für Kunst und Geschichte. Bern/Stuttgart/Wien: Haupt 2000 .

Meißner, Joachim: Indianer gegen Hunnen, Freizeitstämme auf dem Kriegspfad. In: Kemper, Peter (Hrsg.): Der Trend zum Event. Frankfurt am Main: Suhrkamp 2001, S. 110-117.

Mensch, Peter van: Towards a Methodology of Museology, PhD Thesis at the University of Zagreb. http://www.xs4all.nl/ rwa/contents.htm. (letzter Zugriff: 29.12.01).

Mensch, Peter van: Museum Buildings \& Urban Context (unveröffentl. Skript). Reinwardt Academy, Amsterdam 2000.

Mensch, Peter van: Characteristics of exhibitions. (unveröffentl. Skript). Reinwardt Academy, Amsterdam 2001.

Mikunda, Christian: Der verbotene Ort oder die inszenierte Verführung: Unwiderstehliches Marketing durch strategische Dramaturgie. Frankfurt/Wien: Carl Ueberreuter 2002.

Miles, Roger: The Design of Educational Exhibits. London 1982.

Miles, Roger/Zavala, Lauro (Hrsg.): Towards the Museums of the Future New European Perspectives. London/New York: Routledge 1994.

Ministerium für Wirtschaft und Arbeit des Landes Sachsen-Anhalt, Kulturhistorisches Museum Magdeburg (Hrsg.): Otto der Große, Magdeburg und Europa: Auf den Spuren Ottos des Großen in Sachsen Anhalt. Magdeburg 2002.

Mintz, Ann: That's Edutainment! When the Interests of Museums and the Entertainment Industry Converge. In: Museum News. 73. (1994) Heft 6. S. 32-35. 
Möller, Roland/Zeune, Joachim: Schloß Tratzberg. Renaissancejuwel im Inntal, Tirol. Innsbruck 2001.

Morasch, Ludwig: PlayCastle: Europas erstes Infotainment Center - eine entgrenzte Freizeitwelt. In: Steinecke, Albrecht (Hrsg.): Erlebnis- und Konsumwelten. München/Wien: Oldenbourg 2000, S. 224-237.

Mühldorfer-Vogt, Christian: ,Auf den Spuren der Ottonen“ - Konzeptionelle Überlegungen zu einem musealen Projekt. (unveröffentl. Skript) Quedlinburg 2004.

Müllenmeister, Horst: Geschichte und Tourismus. In: Füßmann, Klaus u.a. (Hrsg.): Historische Faszination. Geschichtskultur heute. Köln/Weimar/ Wien: Böhlau 1994, S. 249-265.

Müller, Lothar: Der strenge Gott der Didaktik. Original und Fälschung: Das Jüdische Museum in Berlin. In: Süddeutsche Zeitung vom 11.09.01.

Müller, Burkhard: Die Heimkehr des harmlosen Lindwurms. Bunte Fläche des Dazumal. Die Karlsruher Ausstellung über das Nibelungenlied bringt ihren Gegenstand zum Verschwinden. In: Süddeutsche Zeitung vom 28.01.04.

Munro, Patricia: Besucherorientierung als Katalysator für sinnvolle Veränderung. In: Compania Media (Hrsg.): Handbuch Museumsberatung. Bielefeld: transcript 2000, S. 137-148.

Museums-Pädagogisches Zentrum (Hrsg.): Berufsfeld Museumspädagogik im Wandel, Annäherungen - Herausforderungen - Visionen, Dokumentation einer museumspädagogischen Fachtagung vom 25. bis 28. April in München. München: Manz 1998.

N.N.: Bamberg hat gar nichts besseres passieren können. Landesausstellung Kaiser Heinrich II. endete mit Rekordergebnis. http://www.bamberg.de/ rathaus/journal/021101t1/htm. (letzter Zugriff: 30.11.04).

N.N.: Antibolschewistische Schau - Ihre künstlerische Gestaltung. In: Münch. Neueste Nachrichten vom 18.11.36.

N.N.: In dunklen Zeiten. Regensburger Ausstellung erhielt Demokratie-Preis. In: Passauer Neue Presse vom 30.12.03.

N.N.: The New EconoMoMA. In: Süddeutsche Zeitung vom 28.09.04.

Nahrstedt, Wolfgang/Brinkmann, Dieter/Theile, Heike/Röcken, Guido (Hrsg.): Lernen in Erlebniswelten - Perspektiven für Politik, Management und Wissenschaft. Bielefeld: IFKA 2002.

Nahrstedt, Wolfgang/Brinkmann, Dieter/Theile, Heike/Röcken, Guido (Hrsg.): Lernort Erlebniswelt - Neue Formen informeller Bildung in der Wissensgesellschaft. Bielefeld : IFKA 2002.

Newman, Andrew: Feelgood Factor. In: Museums Journal. 102/3. (2002) S. 28-31. 
Nicks, John: Curatorship in the Exhibition Planning Process. In: Lord, Barry/Lord, Gail D. (Hrsg.): The Manual of Museum Exhibitions. Walnut Creek/Lanham/New York/Oxford: AltaMira Press 2002, S. 345-347.

Niemetz, Dirk (Hrsg.): Aktuelle Probleme der Geschichtsdidaktik. Stuttgart: Metzler 1990.

Nishen, Dirk: The Story of Berlin. Geschichten einer Metropole. Berlin schaut in den Spiegel. Berlin: Druckhaus Mitte 1999.

Noschka-Roos, Annette: Bibliographie - Report 1993 zu Museologie, Museumspädagogik, Museumsdidaktik und Besucherforschung. Berlin 1993.

Noschka-Roos, Annette: Besucherforschung und Didaktik. Opladen: Leske und Budrich 1994.

Noschka-Roos, Annette: Referierende Bibliographie zur Besucherforschung. Berlin 1996.

Noschka-Roos, Annette (Hrsg.): Besucherforschung im Museum. Instrumentarien zur Verbesserung der Ausstellungskommunikation. München: Deutsches Museum 2003.

Nowak, Stefan/Teufel, Philipp: Die Kuh, der Gestalter, das Geld und ihre Liebhaber. Integrative Ausstellungsplanung am Beispiel des Geldmuseums Frankfurt. In: Schwarz, Ulrich/Teufel, Philipp (Hrsg.): Museografie und Ausstellungsplanung. Ludwigsburg: av-Edition 2001, S. 62-87.

Nuissl, Ekkehard/Paatsch, Ulrich/Schulze, Christa (Hrsg.): Bildung im Museum - Zum Bildungsauftrag von Museen und Kunstvereinen. Heidelberg: AfeB-Taschenbücher 1987.

Oexle, Otto Gerhard: Das entzweite Mittelalter. In: Althoff, Gerd (Hrsg.): Die Deutschen und ihr Mittelalter. Darmstadt: Wissenschaftliche Buchgesellschaft 1992, S. 7-28.

Oexle, Otto Gerhard: Geschichtswissenschaft im Zeichen des Historismus: Studien zur Problemgeschichte der Moderne. Göttingen: Vandenhoeck \& Ruprecht 1996.

Oexle, Otto Gerhard (Hrsg.): Stand und Perspektiven der Mittelalterforschung am Ende des 20. Jahrhunderts. Göttingen: Wallstein 1996.

Oexle, Otto Gerhard: Die Moderne und ihr Mittelalter - eine folgenreiche Problemgeschichte. In: Segl, Peter (Hrsg.): Mittelalter und Moderne. Entdeckung und Rekonstruktion der mittelalterlichen Welt. Sigmaringen: Thorbecke 1997, S. 307-364.

Oexle, Otto Gerhard: Memoria und Kulturelles Gedächtnis im Werk Christian Boltanskis. In: Bernhard, Jussen (Hrsg.): Signal - Christian Boltanski. Göttingen: Wallstein 2004, S. 83-101.

Oliveira, Nicolas de/Oxley, Nicola/Petry, Michael/Archer, Michael (Hrsg.): Installation Art. London: Thames \& Hudson 1996. 
Opaschowski, Horst W.: Kathedralen des 21. Jahrhunderts, Erlebniswelten im Zeitalter der Eventkultur. Hamburg: Germa Press 2000.

Opaschowski, Horst W.: Kathedralen und Ikonen des 21. Jahrhunderts: Zur Faszination von Erlebniswelten. In: Steinecke, Albrecht (Hrsg.): Erlebnisund Konsumwelten. München/Wien: Oldenbourg 2000, S. 44-54.

Paatsch, Ulrich (Hrsg.): Konzept Inszenierung: Inszenierte Ausstellungen ein neuer Zugang für Bildung im Museum? Ein Leitfaden. Heidelberg, 1990.

Paatsch, Ulrich: Neue Museologie, Nachbarschaftsmuseen, Ecomuseen. Theoretische Bezüge von integrativer Museumsarbeit in Regionalmuseen. (unveröffentl. Skript) Bundesakademie für Kulturelle Bildung, Wolfenbüttel 2002.

Padtberg, Carola: Terrormythos RAF. An der Ausstellung über die RoteArmee-Fraktion scheiden sich die Geister. http://zeus.zeit.de/text/2003/31/ raf-ausstellung. (letzter Zugriff: 13.08.04).

Pahs, Stephan: Warum der Holzschuh geröntgt werden musste - oder: Musealisierung eines Tagelöhnerhauses mit den Mitteln moderner Kunst. Das Projekt ,InnenLeben - Haus der Gefühle' im Westfälischen Freilichtmuseum Detmold. In: Museum heute, Fakten - Tendenzen - Hilfen. (2002) Heft 23. S. 53-57.

Parmentier, Michael: Zwischen Schule und Freizeitpark: Das Museum als Stätte der Selbstbildung. In: Standbein Spielbein. (1997) Heft 49. S. 12-17.

Parmentier, Michael: History is bunk. Gibt es eine Alternative zur Chronologie in historischen Museen. In: Standbein Spielbein. (2003) Heft 67. S. 4-8.

Pine, Joseph B./Gilmore, James H.: The Experience Economy. In: Museum News. 78. (1999) Heft 2. S. 45-48.

Pine, Joseph B./Gilmore, James H.: Erlebniskauf - Konsum als Ereignis, Business als Bühne, Arbeit als Theater. München: Econ 2000.

Pitman, Bonnie (Hrsg.): Presence of Mind: Museums and the Spirit of Learning. Washington D.C. 1999.

Plato, Alice von: Präsentierte Geschichte - Ausstellungskultur und Massenpublikum im Frankreich des 19. Jahrhunderts. Frankfurt/New York: Campus 2001.

Plessen, Marie-Louise von/Spoerri, Daniel: Entwurf zu einem Lexikon eines Musée Sentimental Cologne. Köln 1979.

Plessen, Marie-Louise von: Duell der Sinne und der Dinge - das Autorenmuseum. In: Korff, Gottfried/Roth, Martin (Hrsg.): Das historische Museum: Labor, Schaubühne, Identitätsfabrik. Frankfurt/New York: Campus 1990, S. 179-186. 
Prantl, Heribert: Das RAF-Tabu. In: Süddeutsche Zeitung vom 28.07.03.

Preiß, Achim (Hrsg.): Das Museum: die Entwicklung in den 80er Jahren. München: Klinkhardt \& Biermann 1990.

Preiß, Achim: Elfenbeinturm oder Massenmedium. In: Preiß, Achim (Hrsg.): Das Museum: Die Entwicklung in den 80er Jahren. München: Klinkhardt \& Biermann 1990, S. 261-278.

Puhle, Matthias (Hrsg.): Otto der Große, Magdeburg und Europa. Kurzführer zur Ausstellung im Kulturhistorischen Museum Magdeburg. Mainz : Philipp von Zabern 2001.

Puhle, Matthias (Hrsg.): Otto der Große, Magdeburg und Europa. Katalog zur Ausstellung im Kulturhistorischen Museum Magdeburg. Mainz: Philipp von Zabern 2001.

Puhle, Matthias: Historische Großausstellungen und ihre kulturpolitische Bedeutung. In: Ministerium für Wirtschaft und Arbeit des Landes SachsenAnhalt, Kulturhistorisches Museum Magdeburg (Hrsg.): Otto der Große, Magdeburg und Europa. Magdeburg 2002, S. 7-13.

Pürer, Heinz: Einführung in die Publizistikwissenschaft, Systematik, Fragestellungen, Theorieansätze, Forschungstechniken. München: Ölschläger 1990.

Putnam, James: Art and Artifact - The Museum as Medium. New York: Thames \& Hudson 2001.

Ranger, Kurt: Anschaulich ausstellen. Bilder erzählen Geschichte. In: Badisches Landesmuseum Karlsruhe (Hrsg.): Inszenierte Geschichte(n). Baden-Baden: Nomos 1999, S. 11-26.

Raphael, Freddy/Herberich-Marx, Geneviève: Das Museum als Provokation des Erinnerungsvermögens. In: Korff, Gottfried/Roth, Martin (Hrsg.): Das historische Museum: Labor, Schaubühne, Identitätsfabrik. Frankfurt/New York: Campus 1990, S. 146-163.

Rauterberg, Hanno: Musealisiert de Museen! Über den Wert und die Werte einer großen Institution. In: Museumskunde. 67. (2002) Heft 2/02. S. 3440.

Reichling, Norbert: Bericht über den Workshop: „Reliquien oder Relikte? Zwischen Bewahrpädagogik und NS-Devotionalienschau. Tagung in Düsseldorf vom 4.11.03-9.12.03. In: http://hsozkult.geschichte.hu-berlin.de/ tagungsberichte/id=368 (letzter Zugriff: 10.02.05).

Reinle, Dominik: ,Die Geschichte läuft weiter‘. Bonner Haus der Geschichte feiert zehnjähriges Bestehen. http://www.wdr.de/themen/kultur/1/haus_ der_geschichte/index.jhtml. (letzter Zugriff: 26.07.04).

Reinwardt Academy (Hrsg.): Exhibition Design as an Educational Tool. Amsterdam 1984. 
Reiter, Markus: Hunderttausend heulende Höllenhunde. Weh dem, der Symbole hört: Peter Greenaway inszeniert in Groningen eine laute und deutliche Mittelalterausstellung. In: Frankfurter Allgemeine Zeitung vom 18.05.01.

Rese, Bernd: Didaktik im Museum - Systematisierung und Neubestimmung. Bonn: Habelt 1995.

Reuter, Helga: Neue Kommunikationsmedien in Museen - Bereicherung oder Verarmung? In: Auer, Hermann (Hrsg.): Museologie: Neue Wege - Neue Ziele. München/London/New York/Paris: Saur 1989, S. 228-238.

Rieder, Max/Bachleitner, Reinhard/Kagelmann, H. Jürgen (Hrsg.): ErlebnisWelten: Zur Kommerzialisierung der Emotionen in touristischen Räumen und Landschaften. München/Wien: Profil 1998.

Roberts, Lisa C.: From Knowledge to Narrative: Educators and the Changing Museum. Washington D.C./London: Smithsonian Institution Press 1997.

Roberts, Lisa C.: Educators on Exhibit Teams: A New Role, a New Era. In: Hirsch, Joanne S./Silverman, Lois H. (Hrsg.): Transforming Practice. Washington D.C. 2000, S. 89-97.

Rohmeder, Jürgen: Das Dürer-Studio. Entstehung, Beschreibung, Betrieb und Echo. In: Kunstpädagogisches Zentrum im Germanischen Nationalmuseum (Hrsg.): Zum Beispiel Dürer-Studio. Ravensburg: Otto Maier 1972, S. 12-69.

Rohmeder, Jürgen: Methoden und Medien der Museumsarbeit - Pädagogische Betreuung der Einzelbesucher im Museum. Köln: DuMont 1977.

Rohr, Alheidis v.: Grenzen der Inszenierung im Museum. In: Museumskunde. 47. (1982) Heft 1. S. 72-82.

Rojek, Chris: Fatal Attractions. In: Boswell, David/Evans, Jessica (Hrsg.): Representing the Nation: A Reader. London/New York: Routledge 1999, S. 185-207.

Rösch, Stefan: Zerplatzte Träume, zerstörte Illusionen: Das Scheitern von Freizeitgroßprojekten. Eine Analyse von möglichen Fehlerquellen in der Projektentwicklung und im Betrieb von Freizeitgroßprojekten am Beispiel des PlayCastle in Seefeld/Tirol. In: Schmude, Jürgen (Hrsg.): Tegernseer Tourismus Tage 2002. Regensburg 2003, S. 125-133.

Roth, Martin: Heimatmuseum - Zur Geschichte einer deutschen Institution. Berlin: Gebr. Mann 1990.

Roth, Martin: Aktuelle Weichenstellung für das Museum von morgen. In: Landesstelle für die nichtstaatl. Museen in Bayern (Hrsg.): Geöffnet! Das Museum für den Besucher. Tagungsbericht zum 10. Bayerischen Museumstag in Landshut. München 2000, S. 17-20. 
Roth, Martin: Szenographie - Zur Entstehung von neuen Bildwelten im Themenpark der Expo 2000. In: Museumskunde. 66. (2001) Heft 1. S. 25-32.

Ruf, Reiner: Eine schwere Geburt - Schau für die Sinne - und keine historische Sinnstiftung. http://www.suedwest-aktiv.de. (letzter Zugriff: 13.12. 02).

Rumpf, Horst: Spielarten der Kulturaneignung. In: Staudte, Adelheid (Hrsg.): Ästhetisches Lernen auf neuen Wegen. Weinheim/Basel: Beltz 1993, S. 19-30.

Rumpf, Horst: Die Gebärde der Besichtigung. In: Fast, Kirsten (Hrsg.): Handbuch der museumspädagogischen Ansätze. Opladen: Leske+ Budrich 1995, S. 29-45.

Rüsen, Jörn: Kunst und Geschichte - Theoretische Überlegungen zur Präsentation menschlicher Vergangenheit. In: Spickernagel, Ellen/Walbe, Brigitte (Hrsg.): Das Museum - Lernort contra Musentempel. Gießen: Anabas 1976, S. 7-20.

Rüsen, Jörn: Für eine Didaktik historischer Museen. In: Rüsen, Jörn u.a. (Hrsg.): Geschichte sehen. Pfaffenweiler: Centaurus 1988, S. 9-20.

Rüsen, Jörn/Ernst, Wolfgang/Grütter, Heinrich Theodor (Hrsg.): Geschichte sehen - Beiträge zur Ästhetik historischer Museen. Pfaffenweiler: Centaurus 1988 .

Rüsen, Jörn: Die Rhetorik des Historischen. In: Fehr, Michael/Grohé, Stefan (Hrsg.): Geschichte - Bild - Museum. Köln: Wienand 1989, S. 113-126.

Rüsen, Jörn: Was ist Geschichtskultur? Überlegungen zu einer neuen Art über Geschichte nachzudenken. In: Füßmann, Klaus u.a. (Hrsg.): Historische Faszination. Köln/Weimar/Wien: Böhlau 1994, S. 3-26.

Rüsen, Jörn: Geschichtskultur. (5. überarb. Aufl.) In: Bergmann, Klaus u.a. (Hrsg.): Handbuch der Geschichtsdidaktik. Seelze-Velber: Kallmeyer 1997, S. 38-41.

Rüsen, Jörn: Historisches Erzählen. (5. überarb. Aufl.) In: Bergmann, Klaus u.a. (Hrsg.): Handbuch der Geschichtsdidaktik. Seelze-Velber: Kallmeyer 1997, S. 57-63.

Russell, Terry: The Enquiring Visitor: Usable Learning Theory for Museum Contexts. http://www.gem.org.uk/russell.html. (letzter Zugriff: 02.07.01).

Sachs-Hombach, Klaus/Rehkämper, Klaus (Hrsg.): Bild - Bildwahrnehmung - Bildverarbeitung. Interdisziplinäre Beiträge zur Bildwissenschaft. Wiesbaden: DUV 1998.

Sangl, Sigrid: ,... die Wände geblümelt im Sinne der Zeit ...' Die Innendekoration des Bayerischen Nationalmuseums und die Rolle von Rudolf Seitz. In: Bauer, Ingolf (Hrsg.): Das Bayerische Nationalmuseum. Der Neubau 
an der Prinzregentenstraße 1892-1900. München: Hirmer 2000, S. 101128.

Sauerländer, Willibald: Die Luft auf der Spitze des Pinsels. Kritische Spaziergänge durch Bildersäle. München: Hanser 2002.

Sauerländer, Willibald: Laut, farbig und nicht ohne Witz. Eine theatralische Inszenierung des Mittelalters: die große ,Gothic'-Ausstellung. In: Süddeutsche Zeitung vom 01.12.03.

Sauter, Beatrix: Museum und Bildung: eine historisch-systematische Untersuchung zu Formen der Überlieferung und der Identitätsfindung. Baltmannsweiler: Schneider Hohengehren 1994.

Schäfer, Hermann: Zwischen Disneyland und Musentempel: Zeitgeschichte im Museum. In: Museumskunde. 60. (1995) Heft 1. S. 27-32.

Schäfer, Hermann: Erlebnis Geschichte - Eine neue Ausstellung für neue Besucher. In: Haus der Geschichte der Bundesrepublik Deutschland (Hrsg.): Erlebnis Geschichte. Das Buch zur Ausstellung. Bonn: Gustav Lübbe 2000, S. 8-19.

Schaffner, Ingrid/Winzen, Matthias (Hrsg.): Deep Storage. Arsenale der Erinnerung. Sammeln, Speichern, Archivieren in der Kunst. Ausstellungskatalog. München/New York: Prestel 1997.

Schäfke, Werner: Geschichte ist nicht ausstellbar. In: Preiß, Achim (Hrsg.): Das Museum: Die Entwicklung in den 80er Jahren. München: Klinkhardt \& Biermann 1990, S. 279-298.

Schärer, Martin R.: Die ausgestellte Ausstellung - ein museologisches Experiment. In: Museumskunde. 57. (1992) Heft 1. S. 43-50.

Schebler, Gerhard: Im und wider das Museum führen. (unveröffentl. Skript) Hauptseminararbeit an der Ludwig-Maximilians-Universität, Fakultät Kunstpädagogik, München 2004.

Scherrieb, Heinz Rico: Bildung als Edutainment - globaler Trend für Freizeit und Erlebniswelten. In: Nahrstedt, Wolfgang u.a. (Hrsg.): Lernen in Erlebniswelten. Bielefeld: IFKA 2002, S. 31-38.

Schmidt, Rudolf: Das Zusammenspiel von Kognition und Emotion in der ästhetischen Erziehung. (3. unveränd. Aufl.) In: Matthies, Klaus u.a. (Hrsg.): Ästhetische Erziehung in der Grundschule. Hemsbach: Beltz 1994, S. 1-4.

Schmieglitz-Otten Juliane: Das Museum als erlebnispädagogischer Lernort. Lüneburg: Neubauer 1991.

Schmitz, Thorsten: Tabu-Bruch: Ausstellung israelischer Soldaten. http: //www.nahost-politik.de/israel/armee/ausstellung.htm (letzter Zugriff: 29. 09.04).

Schmude, Jürgen (Hrsg.): Tegernseer Tourismus Tage 2002, Proceedings. Regensburg 2003. 
Schneede, Uwe M. (Hrsg.): Museum 2000 - Erlebnispark oder Bildungsstätte. Köln: DuMont 2000.

Schneider, Jens: Des Königs nackte Bretter. Die Ausstellung ,Auf den Spuren der Ottonen` im Quedlinburger Schlosskeller. In: Süddeutsche Zeitung vom 04.05.04.

Schneider, Gerhard: Geschichtsbild. (5. überarb. Aufl.) In: Bergmann, Klaus u.a. (Hrsg.): Handbuch der Geschichtsdidaktik. Seelze-Velber: Kallmeyer 1997, S. S.290-292.

Schneidmüller, Bernd/Weinfurter, Stefan (Hrsg.): Mittelalter Forschungen 1. Sigmaringen 1997.

Schneidmüller, Bernd/Weinfurter, Stefan: Bayerns Triumph - Europas Glanz/Zierde, Kaiser Heinrich II. und sein Reich. Ausstellung des Hauses der Bayerischen Geschichte 2002 in Bamberg, wissenschaftliches Ausstellungskonzept. (unveröffentl. Skript) 1999.

Schober, Anna: Montierte Geschichten - Programmatisch inszenierte historische Ausstellungen. Wien: Dachs 1994.

Schober, Anna: Ein Stück Nicht-Zeit in der Zeit - Historische Ausstellungen als Foren von Öffentlichkeit. http://www.eforum-zeitgeschichte.at/2_01a2. html. (letzter Zugriff: 07.02.02).

Scholze, Jana: Medium Ausstellung. Lektüren musealer Gestaltung in Oxford, Leipzig, Amsterdam und Berlin. Bielefeld: transcript 2004.

Schörken, Rolf: Geschichte erzählen heute. In: Niemetz, Gerold (Hrsg.): Aktuelle Probleme der Geschichtsdidaktik. Stuttgart: Metzler 1990, S. 137157.

Schörken, Rolf: Historische Imagination und Geschichtsdidaktik. Paderborn/ München/Wien/Zürich: Schöningh 1994.

Schörken, Rolf: Historische Imagination - Wort. (5. überarb. Aufl.) In: Bergmann, Klaus u.a. (Hrsg.): Handbuch der Geschichtsdidaktik. SeelzeVelber: Kallmeyer 1997, S. 64-66.

Schostak, Renate: Wie ein Bayer von Deutschland Besitz ergriff. In: Frankfurter Allgemeine Zeitung vom 23.07.02.

Schouten, Frans: Visitor Perception: The Right Approach. In: Reinwardt Academy (Hrsg.): Exhibition Design as an Educational Tool. Amsterdam 1984, S. 37-46.

Schouten, Frans: The Paradox of the Map - Semiotics and Museum Education. In: Museum and Curatorship. 11. (1992) S. 285-289.

Schreiber, Waltraud (Hrsg.): Erste Begegnung mit Geschichte: Grundlagen historischen Lernens. Neuried: Ars Una 1999.

Schuck-Wersig, Petra: Die Lust am Schauen oder müssen Museen langweilig sein? Plädoyer für eine neue Sehkultur. Berlin: Gebr. Mann 1986. 
Schuck-Wersig, Petra/Wersig, Gernot: Museen und Marketing in Europa Großstädtische Museen zwischen Administration und Verwaltung. Berlin 1992.

Schuck-Wersig, Petra/Schneider, Martina/Wersig, Gernot: Wirksamkeit öffentlichkeitsbezogener Maßnahmen für Museen und kulturelle Ausstellungen. (3. erw. Aufl.) Berlin 1993.

Schuck-Wersig, Petra/Wersig, Gernot: Multimedia-Anwendungen in Museen. Berlin 1998.

Schuck-Wersig, Petra/Wersig, Gernot: Museumsmarketing in den USA Neue Tendenzen und Erscheinungsformen. Opladen: Leske und Budrich 1999.

Schuhmacher, Doris: Ästhetische Bildung und Hochschulausbildung nach der Moderne. Alphabetisierung - Nivellierung - Differenzierung. In: Essener Unikate. (1997) Heft 9. S. 65-73.

Schuler, Thomas: Drei Betriebe unter einem Dach. Plädoyer für eine neue Organisationsstruktur für Museen. In: Treff, Hans-Albert (Hrsg.): Museen unter Rentabilitätsdruck. Engpässe - Sackgassen - Auswege. München 1998, S. 107-122.

Schulz, Wolfgang: Unterrichtsplanung. München/Wien/Baltimore: Urban \& Schwarzenberg 1980.

Schulze, Gerhard: Die Erlebnisgesellschaft - Kultursoziologie der Gegenwart. (8. Aufl.) Frankfurt am Main/New York: Campus 2000.

Schurr, Eva: Historische Haltestellen. Auf den Spuren Kaiser Heinrichs II. und Kunigundes im Stadtraum Bamberg. Faltblatt zu den „Historischen Haltestellen“, 2002.

Schuster, Peter-Klaus: Auf der Suche nach dem verlorenen Paradies. Runge Marc - Beuys. In: Vitali, Christoph (Hrsg.): Ernste Spiele. Der Geist der Romantik in der deutschen Kunst 1790 - 1990. Stuttgart: Oktagon 1995, S. 47-67.

Schuster, Peter-Klaus (Hrsg.): Die Kunststadt München 1937 - Nationalsozialismus und Entartete Kunst. (5. überarb. Aufl.) München: Prestel 1998.

Schwarz, Ulrich: Entstehungsphasen einer Ausstellung. In: Schwarz, U1rich/Teufel, Philipp (Hrsg.): Museografie und Ausstellungsgestaltung. Ludwigsburg: av-Edition 2001, S. 16-37.

Schwarz, Ulrich/Teufel, Philipp (Hrsg.): Museografie und Ausstellungsgestaltung. Ludwigsburg: av-Edition 2001.

Screven, Chandler G.: Computer im Ausstellungswesen. In: Klein, HansJoachim (Hrsg.): Mediendämmerung - die unaufhaltsame Computerisierung der Museen. Karlsruhe 1995, S. 9-22. 
Scrive, Martine: Zur Konzeption wissenschaftlicher Ausstellungen. In: Schwarz, Ulrich/Teufel, Philipp (Hrsg.): Museografie und Ausstellungsgestaltung. Ludwigsburg: av-Edition 2001, S. 146-165.

Seel, Martin: Die Kunst der Entzweiung. Zum Begriff der ästhetischen Rationalität. Frankfurt am Main: Suhrkamp 1997.

Seel, Martin: Inszenieren als Erscheinenlassen. Thesen über die Reichweite eines Begriffs. In: Früchtl, Josef/Zimmermann, Jörg (Hrsg.): Ästhetik der Inszenierung. Frankfurt am Main: Suhrkamp 2001, S. 48-62.

Segl, Peter: Mittelalter und Moderne. Entdeckung und Rekonstruktion der mittelalterlichen Welt. Kongreßakten des 6. Symposiums des Mediävistenverbandes in Bayreuth 1995. Sigmaringen: Thorbecke 1997.

Seibt, Gustav: Das Reich vor der Nation, Magdeburgs große Ausstellung über Kaiser Otto den Großen. In: Die Zeit vom 30.08.01.

Seibt, Ferdinand/Gleba, Gudrun/Grütter, Heinrich Theodor u.a. (Hrsg.): Vergessene Zeiten. Mittelalter im Ruhrgebiet. Katalog zur Ausstellung im Ruhrlandmuseum Essen. Essen: Pomp 1990.

Seibt, Gustav: Das Reich vor der Nation, Magdeburgs große Ausstellung über Kaiser Otto den Großen. : In: Die Zeit vom 30.07.2001.

Serrell, Beverly: Exhibit Labels: An Interpretative Approach. Oxford: AltaMira Press 1996.

Shanks, Michael/Tilley, Christopher: Re-Constructing Archaeology. Cambridge 1987.

Sheehan, James J.: Geschichte der deutschen Kunstmuseen. Von der fürstlichen Wunderkammer zur modernen Sammlung. München: Beck 2002.

Siebert, Horst: Pädagogischer Konstruktivismus. Eine Bilanz der Konstruktivismusdiskussion für die Bildungspraxis. Neuwied/Kriftel: Luchterhand 1999.

Siebert, Horst: Der Konstruktivismus als pädagogische Weltanschauung Entwurf einer konstruktivistischen Didaktik. Frankfurt/Main: VAS 2002.

Silverman, Lois H.: Making Meaning Together: Lessons from the Field of American History. In: Hirsch, Joanne S./Silverman, Lois H. (Hrsg.): Transforming Practice. Washington D.C. 2000, S. 230-239.

Sofka, Vinos (Hrsg.): The Language of Exhibitions. Stockholm 1995.

Sonnenberger, Franz: Das Museums als historisches Theater. In: Kindler, Gabriele (Hrsg.): MuseumsTheater. Bielefeld: transcript 2001, S. 65-74.

Soren, Barbara: Qualitative and Quantitative Audience Research. In: Lord, Barry/Lord, Gail D. (Hrsg.): The Manual of Museum Exhibitions. Walnut Creek/Lanham/New York/Oxford: AltaMira Press 2002, S. 58-66.

Sorensen, Colin: Theme Parks and Time Machines. In: Vergo, Peter (Hrsg.): The New Museology. London: Reaktion Books 1989, S. 60-73. 
Sousa, Jean L. (Hrsg.): Telling Images - Stories in Art. Chicago 1997.

Spalding, Julian: The Poetic Museum: Reviving Historic Collections. München/London/New York: Prestel 2002.

Spencer Hugh A. D.: Interpretative Planning. In: Lord, Barry/Lord, Gail D. (Hrsg.): The Manual of Museum Exhibitions. Walnut Creek/Lanham/New York/Oxford: AltaMira Press 2002, S. 373-386.

Spickernagel, Ellen/Walbe, Brigitte (Hrsg.): Das Museum - Lernort contra Musentempel. Gießen: Anabas 1976.

Spoerri, Daniel: Einleitung. In: Plessen, Marie-Louise von/Spoerri, Daniel (Hrsg.): Entwurf zu einem Lexikon eines Musée Sentimental Cologne. Köln 1979, S. 8-10.

Städtische Galerie Nordhorn (Hrsg.): Museum für die Souvenirs der sechziger Jahre, 40 historische Objekte präsentiert von Guillaume Bijl. Nordhorn 2001.

Standop, Jutta: Emotionen und ihr Einfluss auf das kognitive Lernen. In: Nahrstedt, Wolfgang (Hrsg.): Lernen in Erlebniswelten. Bielefeld: IFKA 2002, S. 75-80.

Staniszewski, Mary Anne: The Power of Display - A History of Exhibition Installations at the Museum of Modern Art. Cambridge/London: MIT Press 1998.

Staudte, Adelheid (Hrsg.): Ästhetisches Lernen auf neuen Wegen. Weinheim/Basel: Beltz 1993.

Staudte, Adelheid: Im Spiel zwischen Sinnlichkeit und Vernunft. Die ästhetische Dimension des Lernens. In: Staudte, Adelheid (Hrsg.): Ästhetisches Lernen auf neuen Wegen. Weinheim/Basel: Beltz 1993, S. 7-18.

Steen, Jürgen: Didaktische Aspekte einer Theorie des Historischen Museums. In: Kuhn, Annette/Schneider, Gerhard (Hrsg.): Geschichte lernen im Museum. Düsseldorf: Schwann 1978, S. 49-81.

Steen, Jürgen: Ausstellung und Text. In: Fliedl, Gottfried u.a. (Hrsg.): Wie zu sehen ist. Wien: Turia und Kant 1995, S. 46-62.

Steen, Jürgen: Kategorien der Darstellung von Geschichte im Museum. In: Museumskunde. 60. (1995) Heft 1. S. 23-26.

Steinecke, Albrecht (Hrsg.): Erlebnis- und Konsumwelten. München/Wien: Oldenbourg 2000.

Steinecke, Albrecht: Tourismus und neue Konsumkultur: Orientierungen Schauplätze - Werthaltungen. In: Steinecke, Albrecht (Hrsg.): Erlebnisund Konsumwelten. München/Wien: Oldenbourg 2000, S. 11-27.

Steiner, Otto: Wie viel Geld kann man mit einem Museum verdienen? In: Treff, Hans-Albert (Hrsg.): Museen unter Rentabilitätsdruck. Engpässe Sackgassen - Auswege. München 1998, S. 203-213. 
Stephan, Ralph/Theune-Großkopf, Barbara: Das Berufsbild der Museumspädagogik. Positionspapier des Vereins für Museumspädagogik BadenWürttemberg. In: Standbein Spielbein. (2003) Heft 66. S. 60-61.

Stierle, Karlheinz: Ästhetische Rationalität. München: Fink 1996.

Stiftung Jüdisches Museum Berlin (Hrsg.): Geschichten einer Ausstellung. Zwei Jahrtausende deutsch-jüdische Geschichte. Oldenburg, 2001.

Stiller, Jürgen: Formen und Wirkungen handlungsorientierter Informationsvermittlung in der Museumspädagogik. Exemplarisch untersucht an der didaktischen Aufbereitung und dem Besucherverhalten in einer Abteilung des Museums für Kunst und Kulturgeschichte in Dortmund. Dortmund 1993.

Stoeber, Michael: Guillaume Bijl, Städt. Galerie Nordhorn 12.1.-18.3.2001. In: Kunstforum. (2001) Heft 154. S. 400-401.

Stöhr, Jürgen (Hrsg.): Ästhetische Erfahrung heute. Köln: DuMont 1993.

Sturm, Eva: Konservierte Welt - Museum und Musealisierung. Berlin: Reimer 1991.

Suckale-Redlefsen, Gude: Prachtvolle Bücher zur Zierde der Kirchen. In: Kirmeier, Josef u.a. (Hrsg.): Kaiser Heinrich II. 1002 - 1024. Augsburg 2002, S. 78-92.

Tenzer, Eva: Der tote Mönch in der Tüte. Die Klischees werden per Computer faszinierend bedient - Peter Greenaway inszeniert im Groninger Museum ,Hölle und Himmel'. In: Süddeutsche Zeitung vom 26./27.05.01.

Teufel, Philipp: Museografie, Ausstellungsgestaltung und Szenografie. Vom Begriffswirrwarr zur Vielsprachigkeit der Disziplinen. In: Schwarz, Ulrich/Teufel, Philipp (Hrsg.): Museografie und Ausstellungsgestaltung. Ludwigsburg: av-Edition 2001, S. 10-15.

Thierig, Mil: Kinderleicht lernen - Multimedia als Herausforderung. In: Gemmeke, Claudia/John, Hartmut (Hrsg.): euphorie digital? Bielefeld: transcript 2001, S. 229-239.

Till, Karen E.: Verortung des Museums. Ein geo-ethnographischer Ansatz zum Verständnis der sozialen Erinnerung. In: Beier, Rosemarie (Hrsg.): Geschichtskultur in der Zweiten Moderne. Frankfurt/New York: Campus 2000, S. 183-206.

Till, Wolfgang: Das Stadtmuseum im Netzwerk der Münchner Erinnerungskultur. In: Kulturreferat der Landeshauptstadt München u.a. (Hrsg.): Ein NS-Dokumentationszentrum für München. München: Vögel 2003, S. 273 280.

Treff, Hans-Albert (Hrsg.): Museen unter Rentabilitätsdruck, Engpässe Sackgassen - Auswege, Bericht über ein internationales Symposium vom 29. bis 31. Mai 1997 am Bodensee, veranstaltet von den ICOM- 
Nationalkomitees Deutschland, Österreich und der Schweiz. München 1998.

Treinen, Heiner: Was sucht der Besucher im Museum? In: Fliedl, Gottfried (Hrsg.): Museum als soziales Gedächtnis? Klagenfurt 1988, S. 24-41.

Treinen, Heiner: Besucherforschung und Vermittlungsstrategien in kulturhistorischen Ausstellungen. In: Haus der Bayerischen Geschichte (Hrsg.): Kolloquiumsbericht: Besucherforschung und Vermittlungsstrategien in historischen Ausstellungen. München 1991, S. 11-13.

Treml, Manfred: „Ausgestellte Geschichte“ Überlegungen zur Didaktik in kulturhistorischen Ausstellungen und Museen. In: Jung, Sabine/Arbeitskreis selbständiger Kultur-Institute e.V. (Hrsg.): Neue Wege der Museumspädagogik. Bonn, 2003.

Truettner, William H.: For Museum Audiences: The Morning of a New Day? In: Henderson, Amy/Kaeppler, Adrienne L. (Hrsg.): Exhibiting Dilemmas. Washington D.C. 1997, S. 28-46.

Tucker, Marcia: Museums Experiment with New Exhibition Strategies. http://www.nytimes.com/yr/mo/day/artleisure/museums-exhibit-strategies. html (letzter Zugriff: 01.11.99).

Ullrich, Volker: Fragwürdiger Augenzeuge. Die neue Wehrmachtsausstellung ist eröffnet - ein Gespräch mit der Historikerin Ulrike Jureit, Sprecherin des Ausstellungsteams. In: Die Zeit vom 29.11.01.

Ullrich, Volker: Von strenger Sachlichkeit. Die neue Wehrmachtsausstellung zeigt ein noch dunkleres Bild des NS-Militärs als die alte. In: Die Zeit vom 29.11.01.

Urban, Andreas: Von der Gesinnungsbildung zur Erlebnisorientierung - Geschichtsvermittlung in einem kommunalen historischen Museum im 20. Jahrhundert. Schwalbach/Ts.: Wochenschau 1999.

Verein Festival der Regionen (Hrsg.): Festival der Regionen 1999 - Randzonen, Katalog. Linz: Gutenberg 2000.

Vergo, Peter (Hrsg.): The New Museology. London: Reaktion Books 1989.

Vergo, Peter: The Rhetoric of Display. In: Miles, Roger/Zavala, Lauro (Hrsg.): Towards the Museum of the Future. London/New York: Routledge 1994, S. 149-159.

Verplancke, Philip: Kindermuseen: Ausstellungen als Lern- und Aktionsräume. In: Die Grundschulzeitschrift/Themenheft Kindermuseen. 11. (1997) Heft 101. S. 8-15.

Vieregg, Hildegard: Vorgeschichte der Museumspädagogik dargestellt an der Entwicklung in den Städten Berlin, Dresden, München, Hamburg bis zum Beginn der Weimarer Republik. Münster/Hamburg 1991. 
Vieregg, Hildegard: Kein Museum in Disneyland: Vom großen Unterschied zwischen klassischen Museen und der Musealisierung der Umwelt. In: Vieregg, Hildegard u.a. (Hrsg.): Museumspädagogik in neuer Sicht - Erwachsenenbildung im Museum. Baltmannsweiler: Schneider Hohengehren 1994, S. 295-305.

Vieregg, Hildegard/Schmeer-Sturm, Marie-Louise/Thinesse-Demel, Jutta/ Ulbricht, Kurt (Hrsg.): Museumspädagogik in neuer Sicht - Erwachsenenbildung im Museum, Band 1: Grundlagen - Museumstypen - Museologie. Baltmannsweiler: Schneider Hohengehren 1994.

Vitali, Christoph (Hrsg.): Ernste Spiele. Der Geist der Romantik in der deutschen Kunst 1790 - 1990. Katalog zur Ausstellung im Haus der Kunst. Stuttgart: Oktagon 1995.

Vitali, Christoph: Mein ideales Museum. In: Schneede Uwe M. (Hrsg.): Museum 2000 - Erlebnispark oder Bildungsstätte. Köln: DuMont 2000, S. 102-111.

Vogel, Klaus: Tagungsreferat bei der Fortbildungsveranstaltung des Sächsischen Museumsbundes ,Professionelle Ausstellungsgestaltung' am 27. Oktober 1997 in Leipzig, Alte Börse. In: Information des Sächsischen Museumsbundes e.V. 15. (1997) S. 61-68.

Vogt, Arnold: Museale Vermittlung und Museumspädagogik. In: Klein, HansJoachim (Hrsg.): Vom Präsentieren zum Vermitteln. Karlsruhe 1994, S. 53-68.

Vollhardt, Ulla-Britta: Geschichtspolitik in Bayern. Das Haus der Bayerischen Geschichte zwischen Privatisierung und Institutionalisierung. München: Herbert Utz 2003.

Waidacher, Friedrich: Handbuch der Allgemeinen Museologie. (3. unveränd. Aufl.) Wien/Köln/Weimar: Böhlau 1999.

Waidacher, Friedrich: Museum lernen: Lange Geschichte einer Verweigerung oder warum Museen manchmal so gründlich daneben stehen. http:// www.vl-museen.de/m-online/99/99-2.pdf. (letzter Zugriff: 02.02.05).

Waidacher, Friedrich: Ausstellungen besprechen. http://www.vlmuseen.de/m-online/00/00-2.pdf. (letzter Zugriff: 02.02.05).

Waldemer, Georg: Auf zwei Stellen hinterm Komma? Besucherforschung zwischen Demographie und Kundenzufriedenheit. In: Landesstelle für die nichtstaatl. Museen in Bayern (Hrsg.): Geöffnet! Das Museum für den Besucher, Tagungsbericht zum 10. Bayerischen Museumstag in Landshut. München 2000, S. 38-46.

Wallace, Mike: Mickey Mouse History and Other Essays on American Memory. Philadelphia: Temple University Press 1996. 
Wamser, Ludwig (Hrsg.): Die Römer zwischen Alpen und Nordmeer. Zivilisatorisches Erbe einer europäischen Militärmacht. Mainz: Philipp von Zabern 2000 .

Warne, Martin (Hrsg.): Das Kunstwerk zwischen Wissenschaft und Weltanschauung. Gütersloh: Bertelsmann 1970.

Wechsler, Ulrich: Erst laufen, dann Rad fahren. Nicht die Nutzung der Medien macht den Grad unserer Bildung aus, sondern der Grad unserer Bildung bestimmt, wie sinnvoll die Nutzung der Medien ist. In: Süddeutsche Zeitung vom 06./07.04.02.

Wefing, Heinrich: Wo die Fülle den Mangel nicht verhüllen kann. Die Dauerausstellung im Jüdischen Museum Berlin. In: Museumskunde. 66. (2001) Heft 2/01. S. 76-78.

Weil, Stephen E.: Rethinking the Museums and other Meditations. Washington D.C./London: Smithsonian Institution Press 1990.

Weinfurter, Stefan: Mittelalterliche Geschichte. In: Schreiber, Waltraud (Hrsg.): Erste Begegnungen mit Geschichte. Grundlagen Historischen Lernens. Neuried: Ars Una 1999, S. 741-750.

Weinfurter, Stefan: Heinrich II. (1002-1024) - Herrscher am Ende der Zeiten. Regensburg: Friedrich Pustet 2000.

Weinzinger, Birgit/Lichtenberger, Eva: Megaflop Erlebniswelt. http://www. landtag.noe.gruene.at/pr2000/301100erlebniswelt.html. (letzter Zugriff: 11.09.01).

Welsch, Judith: Die Ausstellung ,Ornamenta Ecclesiae ‘ zum Jahr der romanischen Kirchen aus museumspädagogischer Sicht. (unveröffentl. Skript) Schriftliche Hausarbeit zur 1. Staatsprüfung für das Lehramt für die Sekundarstufe I. Bonn, 1985.

Welsch, Wolfgang: Ästhetisches Denken. Stuttgart: Reclam 1993.

Welsch, Wolfgang: Grenzgänge der Ästhetik. Stuttgart: Reclam 1996.

Wemhoff, Matthias (Hrsg.): Kunigunde - empfange die Krone. Katalog zur Ausstellung im Museum in der Kaiserpfalz. Paderborn: Bonifatius 2002.

Werner, Frank R. (Hrsg.): Hans Dieter Schaal. In-Between. Ausstellungsarchitektur. Stuttgart/London: Edition Axel Menges 1999.

Werner, Frank R.: Raum-Zeiten und Zeit-Räume: Ephemere Architektur im Spiegel der Geschichte. In: Werner, Frank R. (Hrsg.): Hans Dieter Schaal. In-Between. Ausstellungsarchitektur. Stuttgart/London: Edition Axel Menges 1999, S. 13-35.

Weschenfelder, Klaus/Zacharias, Wolfgang: Handbuch Museumspädagogik. Orientierungen und Methoden für die Praxis. Düsseldorf: Schwann 1981. Wieczorek, Alfried/Kretzschmar, Ulrike: Exposé zum Ausstellungsprojekt ,Europas Mitte um 1000‘. Stand: 11.05.99. Mannheim 1999. 
Wiesinger, Udo B.: Museum der industriellen Arbeitswelt in Steyr. In: Fliedl, Gottfried (Hrsg.): Museum als soziales Gedächtnis? Klagenfurt 1988, S. 80-91.

Wißner, Bernd: Das groß Buch vom LEGOLAND Deutschland. Augsburg 2002.

Wohlfromm, Anja: Museum als Medium - Neue Medien in Museen, Überlegungen zu Strategien kultureller Repräsentation und ihre Beeinflussung durch digitale Medien. Köln: Herbert von Halem 2002.

Wüst, Rainer: Mittendrin im mittelalterlichen Markt zu Kaltenberg. Altes Handwerk, sinnenfrohes Spektakulum, kulinarische Köstlichkeiten und köstliches Kaltenberger Bier. In: Begleitprogramm Kaltenberger Ritterturnier 2003. St. Ottilien 2003, S. 18-22.

Zacharias, Wolfgang (Hrsg.): Zeitphänomen Musealisierung - Das Verschwinden der Gegenwart und die Konstruktion der Erinnerung. Essen: Klartext 1990.

Zacharias, Wolfgang: Ausstellungen machen: Rückblicke, Aktualitäten, Ausblicke. In: Standbein Spielbein/Themenheft: Ausstellungen für Kinder. (1998) Heft 52. S. 2-6.

Zehetmair, Hans: Rede des Bayerischen Staatsministers für Wissenschaft, Forschung und Kunst, Hans Zehetmair, anlässlich der Eröffnung der Bayerischen Landesausstellung 2002 ,Kaiser Heinrich II. am 8. Juli 2002 (Skript für die Presse). Bamberg 2002.

Zekri, Sonja: Die RAF-Geschichte wird zum Ready-made. Über Nutzen und Risiko gefährlicher Bilder: Ein Gespräch mit dem Medientheoretiker Boris Groys über die umstrittene Ausstellung in Berlin. In: Süddeutsche Zeitung vom 28.07.03.

Zekri, Sonja: Unter des SA-Lederhose wird gejodelt. Düsteres Menetekel oder blinkende Puppenstube: München streitet um eine Ausstellung zur NSGeschichte im Stadtmuseum. In: Süddeutsche Zeitung vom 09.08.02.

Zekri, Sonja: München - Hauptstadt der Verdrängung. In: Museumskunde. 68. (2003) Heft 1/03. S. 59-63.

Zekri, Sonja: Angst vor der Bildermaschine. Zum Streit um die Berliner RAFAusstellung. Wie die Kunst in den Verdacht moralischer Verantwortungslosigkeit gerückt wird. In: Süddeutsche Zeitung vom 25.07.03.

Zekri, Sonja: Verstehen Sie Spaßkultur? In: Süddeutsche Zeitung vom 18.11.03. 



\section{INTERNETQUELLEN}

www.agil-online.de (letzter Zugriff: 15.10.04)

www.bamberg.de/rathaus/journal/021101t1/htm (letzter Zugriff: 30.11.04)

www.bundesakademie.de (letzter Zugriff: 10.02.05)

www.fdr.at/index.html (letzter Zugriff: 20.08.04)

www.hdbg.de (letzter Zugriff: 15.02.05)

www.heinrichII.de (letzter Zugriff: 15.02.05)

www.hsozkult.geschichte.hu-berlin.de/tagungsberichte (letzter Zugriff: 15.02.

$05)$

www.iconic-turn.de (letzter Zugriff: 04.01.05)

www.isb.bayern.de/bf.isbl/lps/gym.html (letzter Zugriff: 21.11.02)

www.isb.bayern.de/rs/Lehrplan (letzter Zugriff: 21.11.02)

www.jmberlin.de (letzter Zugriff: 27.07.04)

www.judentum.net/kultur/adam-2.htm (letzter Zugriff: 12.01.05)

www.karfunkel.de (letzter Zugriff: 26.10.04)

www.km.bayern.de/index2.html. (letzter Zugriff: 21.11.02).

www.kunstkammer.at/index1.htm (letzter Zugriff: 10.02.05)

www.legoland.de (letzter Zugriff: 08.11.04)

www.museum-kunst-palast.de/dt/sites/s2s2.asp (letzter Zugriff: 10.02.05).

www.nahost-politik.de/israel/armee/ausstellung.htm (letzter Zugriff: 10.02.05)

www.peter-greenaway.de (letzter Zugriff: 10.02.05).

www.riksutstallningar.se (letzter Zugriff: 16.01.06)

www.ritterturnier.de (letzter Zugriff: 20.10.04)

www.roemer-ausstellung.de (letzter Zugriff: 10.02.05)

www.schloss-thurn.de (letzter Zugriff: 12.02.05)

www.schloss-tratzberg.at (letzter Zugriff: 27.11.04)

www.si.edu (letzter Zugriff: 10.02.05)

www.sim-sozialforschung.de (letzter Zugriff: 06.12.04)

www.vl-museen.de/aus-rez/ (letzter Zugriff: 08.01.06)

www.vl-museen.de/musgesch.htm (letzter Zugriff: 25.08.04) 



\section{INTERVIEWLEITFRAGEN FÜR DIE BESUCHER-}

BEFRAGUNG IN DER LANDESAUSSTELLUNG „KAISER HeINRICH II. 1002-1024“

\section{Fragenblock I - Fragen zum Gesamteindruck}

- Was blieb Ihnen am besten von der gesamten Ausstellung in Erinnerung?

- Was störte Sie an der Ausstellung und warum?

- Was blieb positiv in Erinnerung und warum?

Fragenblock II - Fragen zu didaktischen Elementen

Thema: Information/Texte in der Ausstellung

- Was halten Sie davon, Texte hinter kleinen Türen zu verstecken?

- Halten Sie die Präsentation von Texten mittels Computer für eine gute Methode?

- Wie ist Ihre Meinung zum Audioguide?

Thema: Wahrnehmen mit allen Sinnen

- Haben Sie die Elemente zum Anfassen in der Ausstellung wahrgenommen?

- Haben Sie diese selbst ausprobiert?

- Wie ist Ihre Meinung hierzu?

Fragenblock III - Fragen zu Inszenierungseinheiten in der Alten Hofhaltung (pro Raum ein Photo vorlegen)

Raum: „Der neue König - Triumphat Baioaria - Bayern triumphiert“

- Können Sie beschreiben, was dieser Raum darstellen sollte?

- An welche Gegenstände oder Gruppierungen können Sie sich erinnern? 
Raum: „Der Kaiser - Decus Europae - Zierde Europas “

- Was sollte dieser Raum darstellen?

- Welche Assoziationen weckte bei Ihnen die Gestaltung mit den Stäben und den beleuchteten Sternmotiven?

- Was, glauben Sie, wollten die Gestalter damit ausdrücken?

- Wie ist Ihre Meinung zu dieser Form der Präsentation?

Raum: „Unterwegs im Reich“

Box: Inszenierung „Treue Weggefährten Heinrichs II.“

- Halten Sie die künstlerische Interpretation für eine gute Möglichkeit, bei Mangel an Archivalien die Vergangenheit erfahrbar zu machen?

- Sollte dies künftig noch öfters eingesetzt werden?

\section{Fragenblock IV - Gesamtbewertung}

- In der Ausstellung wurden verschiedene Methoden der Ausstellungsgestaltung umgesetzt. Welchen Ausstellungsbereich bevorzugen Sie persönlich und warum?

- Welche Art von Ausstellungen wünschen Sie sich in der Zukunft?

- Soziodemographische Angaben: Alter, Bildungsabschluss und Beruf 


\section{ABbILDUNGSVERZEICHNIS}

Abb. 1. Blick in den Kirchensaal des Bayerischen Nationalmuseums im Jahr 1900 (In: Bauer 2000, Tafel 16)

Abb. 2. Inszenierung „Baden 1849 - Herrschaft des Volkes - Nach der Flucht des Großherzogs: Kurze Zeit der Demokratie“ (Foto: Th. Goldschmidt)

Abb. 3. Blick in einen Raum des Themenhotels „Ritterburg - Castillo Alcazar" (Foto: Europa-Park Rust)

Abb. 4. Inszenierung „Die Metropole der 20er Jahre bei Nacht“ in der Ausstellung „Berlin - Berlin“ (Foto: Reinhard Görner)

Abb. 5. Blick in eine Vitrine in der Ausstellung „Chiffren der Erinnerung“ (Foto: Brigitte Kaiser)

Abb. 6. Sichtachse „Konzentrationslager Dachau“ in der Ausstellung „Chiffren der Erinnerung“ (Foto: Brigitte Kaiser).

Abb. 7. Inszenierung zum Bundestag (Foto: Hermann Reichenwallner)

Abb. 8. Inszenierung „Raum der verrinnenden Zeit“ (Foto: Landschaftsverband Westfalen-Lippe/Galle)

Abb. 9. Objektwand in der Ausstellung „Amsterdam'daki Anadolu Anatolien in Amsterdam“ (In: Konsten 1997, S. 27)

Abb. 10. Blick in die Abteilung „Die revolutionäre Kampfzeit der Weimarer Republik“ (In: Kivelitz 1999, S. 549)

Abb. 11. Inszenierung „Eisernes Kreuz“ (Foto: Noel Matoff)

Abb. 12. Blick auf Lesekabinen (Foto: Stadtarchiv München)

Abb. 13. Installationsansicht zur Ausstellung „Museum für die Souvenirs der sechziger Jahr" (Foto: Städtische Galerie Nordhorn)

Abb. 14. Eingangsinszenierung ,Römische Legionäre im Alpenvorland bei Oberammergau 15 v.Chr.“ (Foto: Archäologische Staatssammlung, M. Eberlein)

Abb. 15. Inszenierung des imperialen Rom in Caesar's Palace in Las Vegas (In: Klein 1999, S. 2003)

Abb. 16. Der „Bamberger Reiter“ (Foto: Achim Hubel)

Abb. 17. Mittelalterlicher Markt beim Kaltenberger Ritterturnier (Foto: Brigitte Kaiser)

Abb. 18. Buchmalerin auf dem mittelalterlichen Markt beim Kaltenberger Ritterturnier (Foto: Brigitte Kaiser)

Abb. 19. Eingang zum Erlebnispark Schloss Thurn (Foto: Brigitte Kaiser) 
Abb. 20. Eingangsbereich von LEGOLAND Deutschland (Foto: Brigitte Kaiser)

Abb. 21. Blick auf „Knigths’ Kingdom“ (Foto: Brigitte Kaiser)

Abb. 22. Abteilung „Geschichte und Propaganda“ in der Ausstellung „Auf den Spuren der Ottonen“ (Foto: Signa-Design)

Abb. 23. Das Zimmer von François I. in der Sammlung des Hôtel de Cluny (In: Plato 2001, S. 71)

Abb. 24. Blick in die Fuggerstube im Schloss Tratzberg (In: Zeune/Möller 2001, S. 49)

Abb. 25. Mittelaltersaal im Erdgeschoss des Badischen Landesmuseums in Karlsruhe (In: Grimm 1993, S. 186)

Abb. 26. Blick in die Ausstellung „Ornamenta Ecclesiae“ in der Kunsthalle Köln (Foto: Judith Welsch)

Abb. 27. Bereich Heiligenverehrung, Ausstellung ,Vergessene Zeiten Mittelalter im Ruhrgebiet“ (Foto: Ruhrlandmuseum Essen)

Abb. 28. Blick in den „Raum der Toten“, Ausstellung „Hell \& Heaven“ (Foto: Uwe Hemmen)

Abb. 29. Totenschädel aufgereiht auf Tischen im „Raum der Toten“, Ausstellung „Hell \& Heaven“ (Foto: Uwe Hemmen).

Abb. 30. Station Nr. 4 ,Kunigundenschale“ im Rahmen der Kunstinstallation „Historische Haltestellen“ (Foto: Joachim Grau)

Abb. 31. Raumskizze der Gruppe Gut, Raum „Der Kaiser“ (Graphik: Gruppe Gut)

Abb. 32. Überblick zum Ausstellungsgelände (Graphik: http://www.heinrichII.de, überarbeitet von Brigitte Kaiser)

Abb. 33. Mittelalterliches Gehöft auf dem Domplatz in Bamberg (Foto: Brigitte Kaiser)

Abb. 34. Grundriss Staatsbibliothek (Graphik: http://www.heinrichII.de, überarbeitet von Brigitte Kaiser)

Abb. 35. Grundriss Diözesanmuseum (Graphik: http://www.heinrichII.de, überarbeitet von Brigitte Kaiser)

Abb. 36. Diözesanmuseum/Raum ,Goldener Schmuck“ (Foto: Christiane Kappes)

Abb. 37. Diözesanmuseum/Raum „Die Kaisermäntel“ (Foto: Christiane Kappes)

Abb. 38. Grundriss Alte Hofhaltung (Graphik: http://www.heinrichII.de, überarbeitet von Brigitte Kaiser)

Abb. 39. Kinderpfad mit insgesamt acht Stationen im Ausstellungsgelände (Foto: Christiane Kappes)

Abb. 40. Station Nr. 7 des Kinderpfades im Diözesanmuseum (Foto: Christiane Kappes)

Abb. 41./ Orientierungshilfen im Ausstellungsgelände

42. (Fotos: Brigitte Kaiser) 
Abb. 43. PC-Informationssystem mit Leuchtgraphik (Foto: Brigitte Kaiser)

Abb. 44. Versteckte Informationsebene (Foto: Christiane Kappes)

Abb. 45. Objektbeschriftung mit Leuchtgraphik (Foto: Christiane Kappes)

Abb. 46. Objektbeschriftung mit Plexiglas (Foto: Brigitte Kaiser)

Abb. 47. Eingangsinszenierung in der Alten Hofhaltung (Foto: Christiane Kappes)

Abb. 48. Gruppe Anthropomorpher Steinfiguren (Foto: Historisches Museum Bamberg)

Abb. 49. Raum „Unterwegs im Reich“/“Erinnerungen“ (Foto: Christiane Kappes)

Abb. 50. Koje „Der Sarkophagtrog“ (Foto: Christiane Kappes)

Abb. 51. Stilisierte Kasel mit Klappen zum Öffnen (Foto: Brigitte Kaiser)

Abb. 52. Informationstext hinter den Klappen (Foto: Brigitte Kaiser)

Abb. 53. Hands-On Angebote zum Thema „Handelswege und Handelswaren" (Foto: Brigitte Kaiser)

Abb. 54. Vitrine mit Nasalhelm und Schwert (Foto: Brigitte Kaiser)

Abb. 55. Hands-On Angebote zum Thema „Reiterkrieger“ (Foto: Brigitte Kaiser)

Abb. 56. Blick in den Raum „Der Kaiser“ (Foto: Christiane Kappes)

Abb. 57. Sternenmantel Kaiser Heinrichs II. (Foto: Diözesanmuseum Bamberg)

Abb. 58. Blick in den Raum „Der neue König“ (Foto: Christiane Kappes)

Abb. 59. Exponat „Nachbildung der Heiligen Lanze“ (Foto: Christiane Kappes)

Abb. 60. Durchgangsraum „Legenden“ (Foto: Brigitte Kaiser)

Abb. 61. Vitrinenwand im Raum „Die Heinriche“ (Foto: Christiane Kappes)

Abb. 62. Münzen hinter Gucklöchern (Foto: Christiane Kappes)

Abb. 63. Münze aus der Heinrichszeit (Foto: Christiane Kappes)

Abb. 64. Inszenierung „Treue Weggefährten Heinrichs II.“ (Foto: Christiane Kappes)

Abb. 65. Treue Weggefährten Heinrichs II.“ von Rosemarie Zacher (Foto: Claudia Rehm)

Abb. 66. Filmsequenz „Nachrichtensendung zum Papstbesuch in Bamberg“ (Foto: Brigitte Kaiser)

Abb. 67.- Inszenierung „Heuschreckenplage“ zum Thema Reisekönigtum

71. (Fotos: Christiane Kappes)

Abb. 72. Streichelzoo beim Ritterturnier in Kaltenberg (Foto: Brigitte Kaiser)

Abb. 73. Streichelzoo beim Mittelalterlichen Gehöft in Bamberg (Foto: Brigitte Kaiser) 



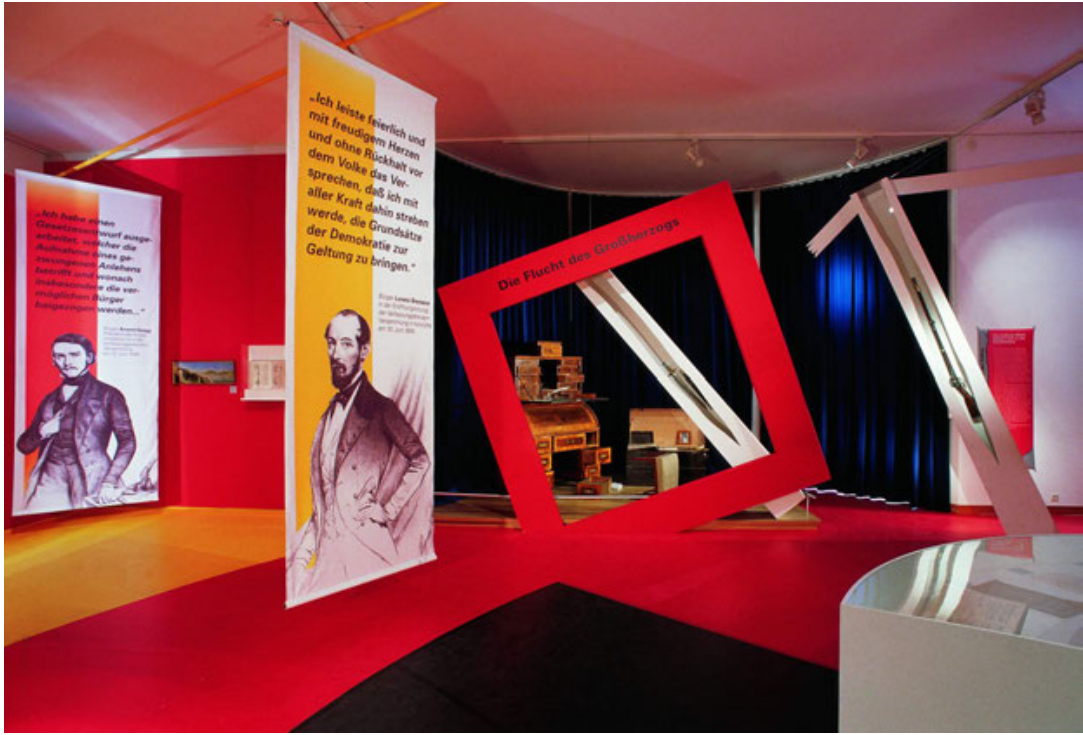

Abbildung 2: Inszenierung „Baden 1849 - Herrschaft des Volkes Nach der Flucht des Großherzogs: Kurze Zeit der Demokratie“.

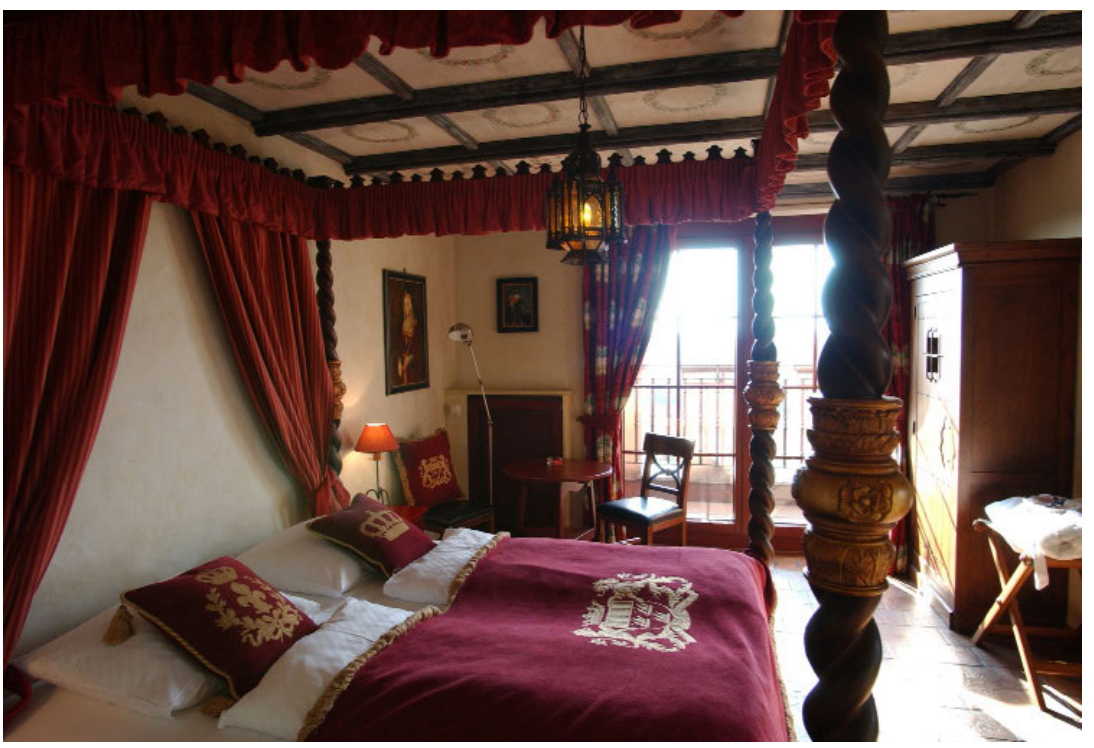

Abbildung 3: Blick in einen Raum des Themenhotels „, Ritterburg Castillo Alcazar" im Europapark Rust. 


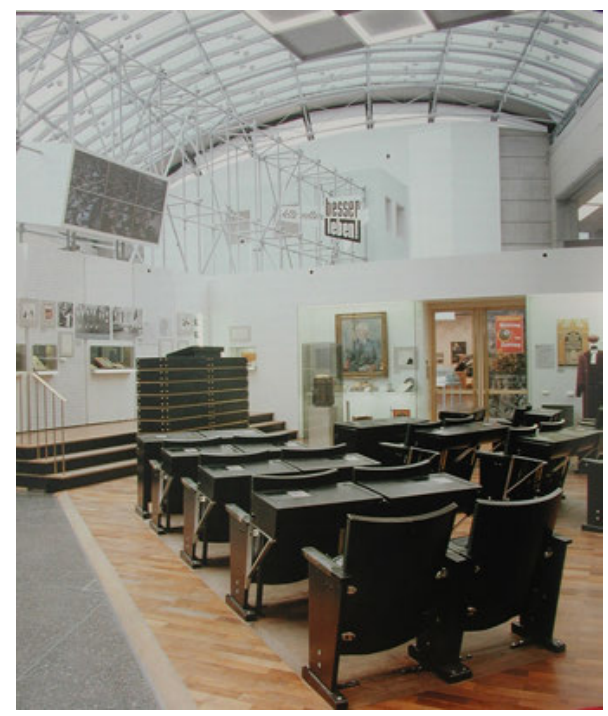

Abbildung 7: Inszenierung zum Bundestag mit Bundestagsgestühl, Monitor mit Bundestagsdebatten, Exponate zu Bundespräsident Heuss, Bundesrat und Bundesregierung und Bundesverfassungsgericht.

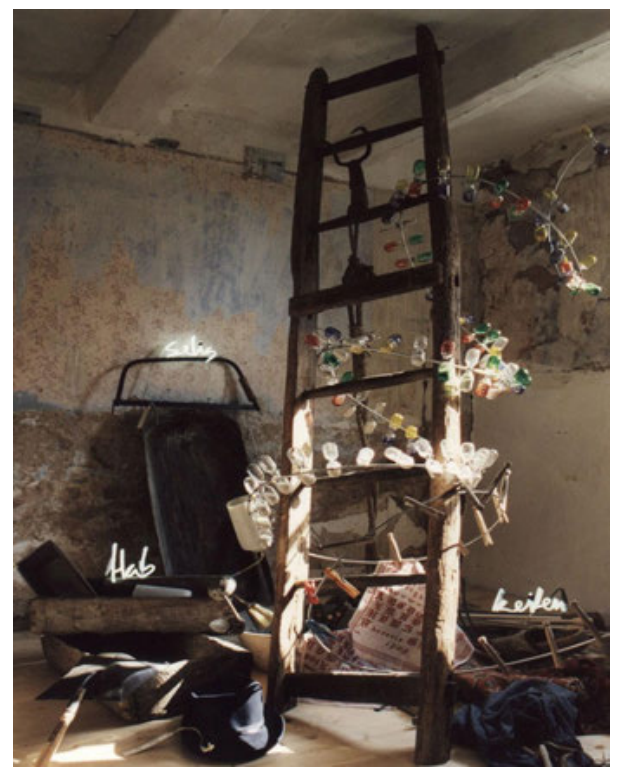

Abbildung 8: Inszenierungseinheit "Raum der verrinnenden Zeit im Rahmen des Kunstprojekts "Innenleben - Haus der Gefühle". 


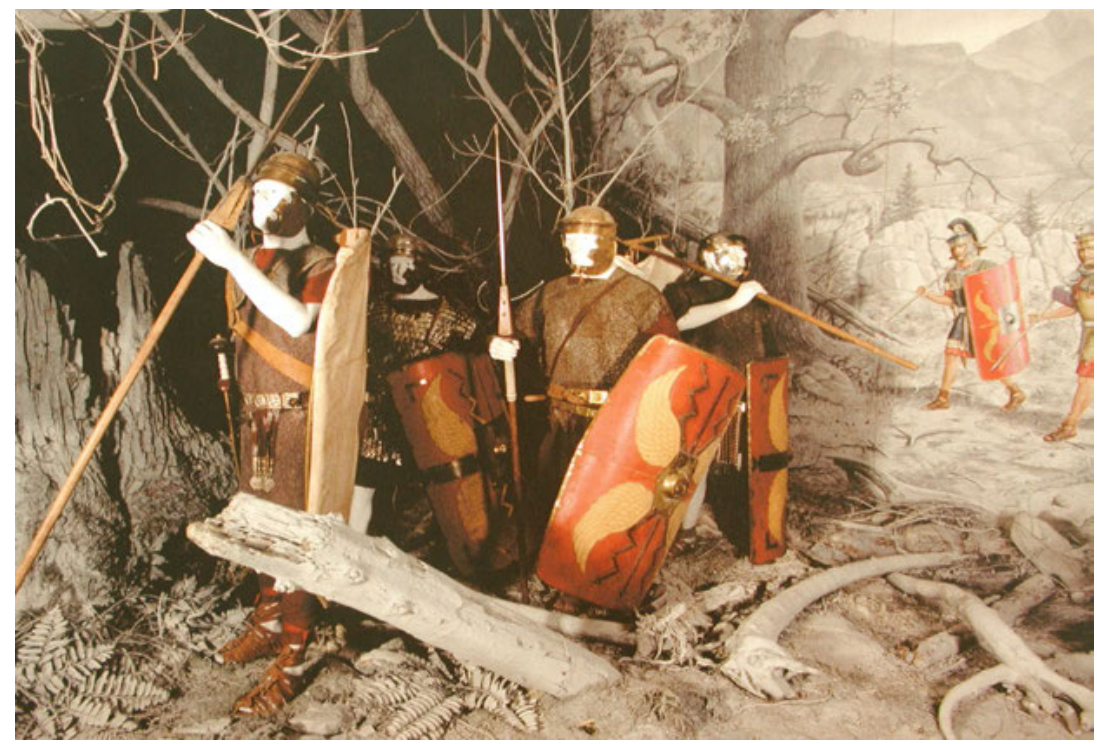

Abbildung 14: Eingangsinszenierung „Römische Legionäre im Alpenvorland bei Oberammergau 15 v. Chr.".

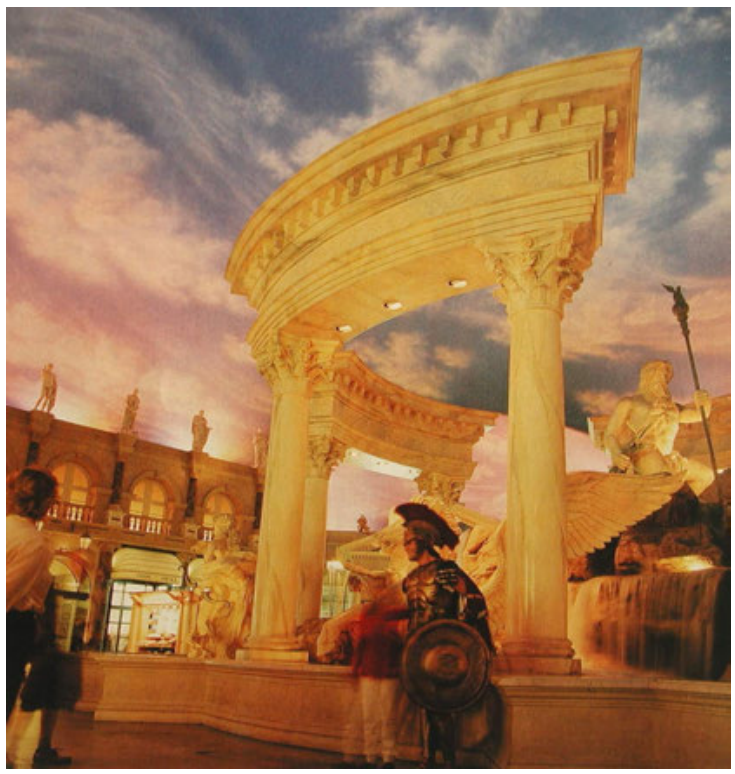

Abbildung 15: Inszenierung des imperialen Rom in Caesar's Palace in Las Vegas. 


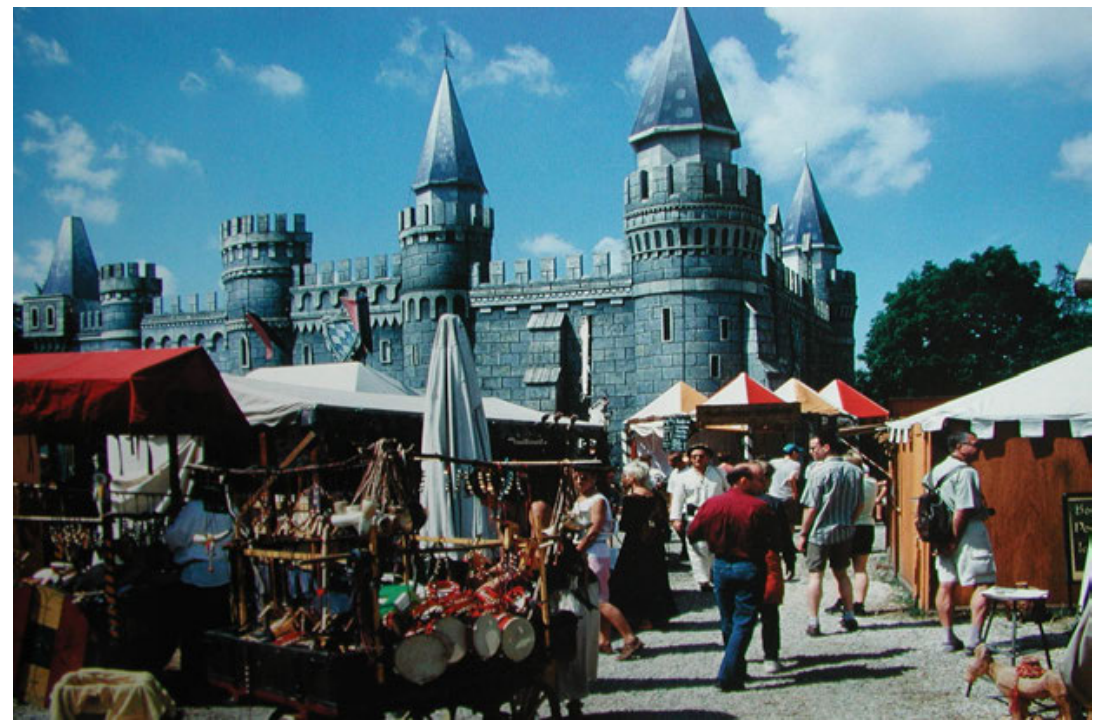

Abbildung 17: Der mittelalterliche Markt beim Kaltenberger Ritterturnier.

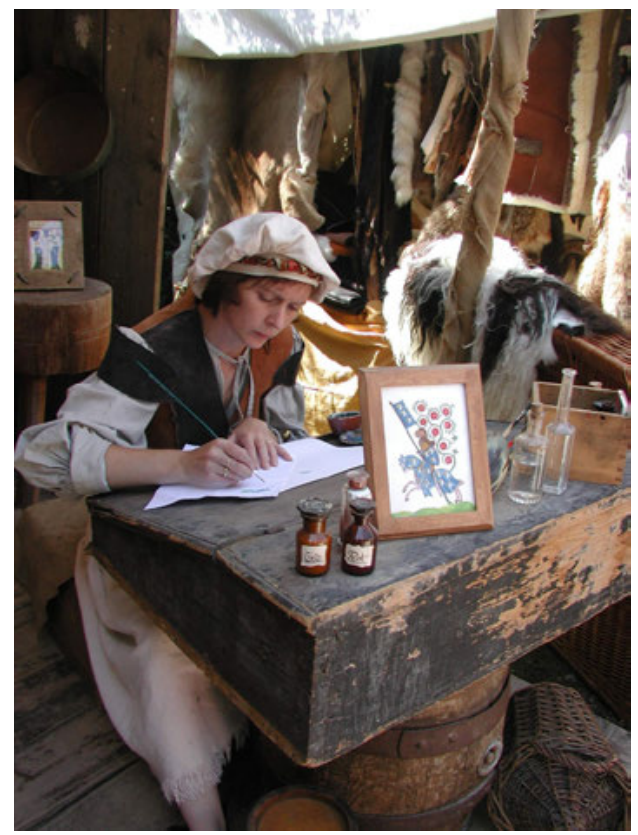

Abbildung 18: Buchmalerin auf dem mittelalterlichen Markt beim Kaltenberger Ritterturnier. 


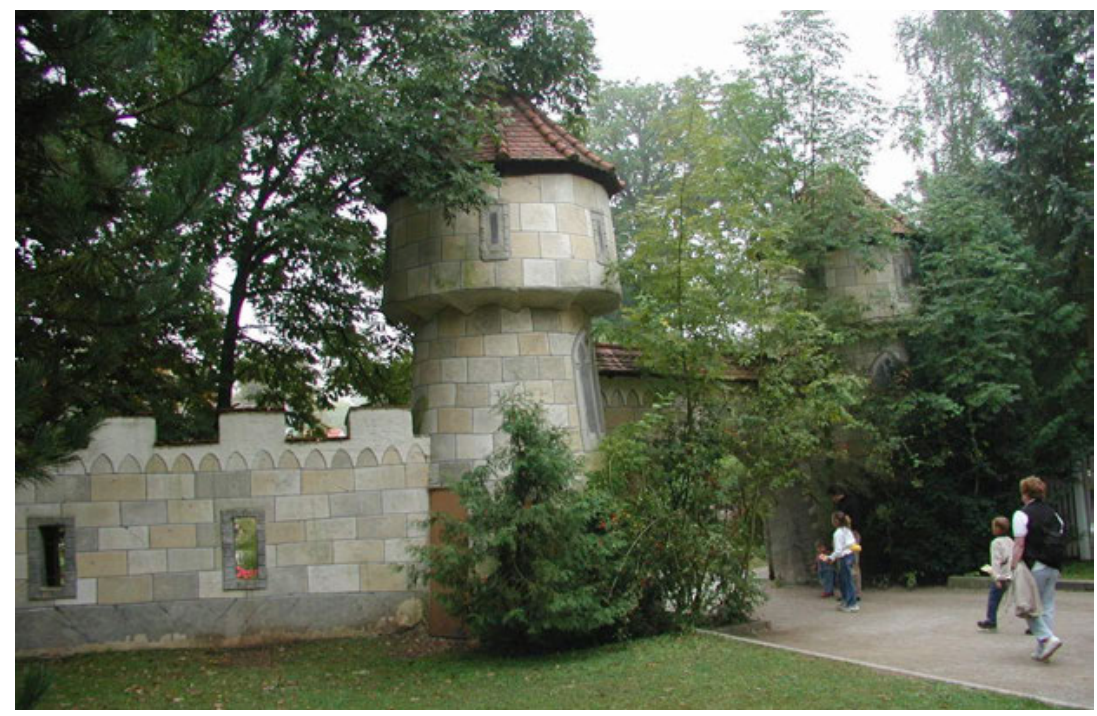

Abbildung 19: Eingang zum Erlebnispark Schloss Thurn.

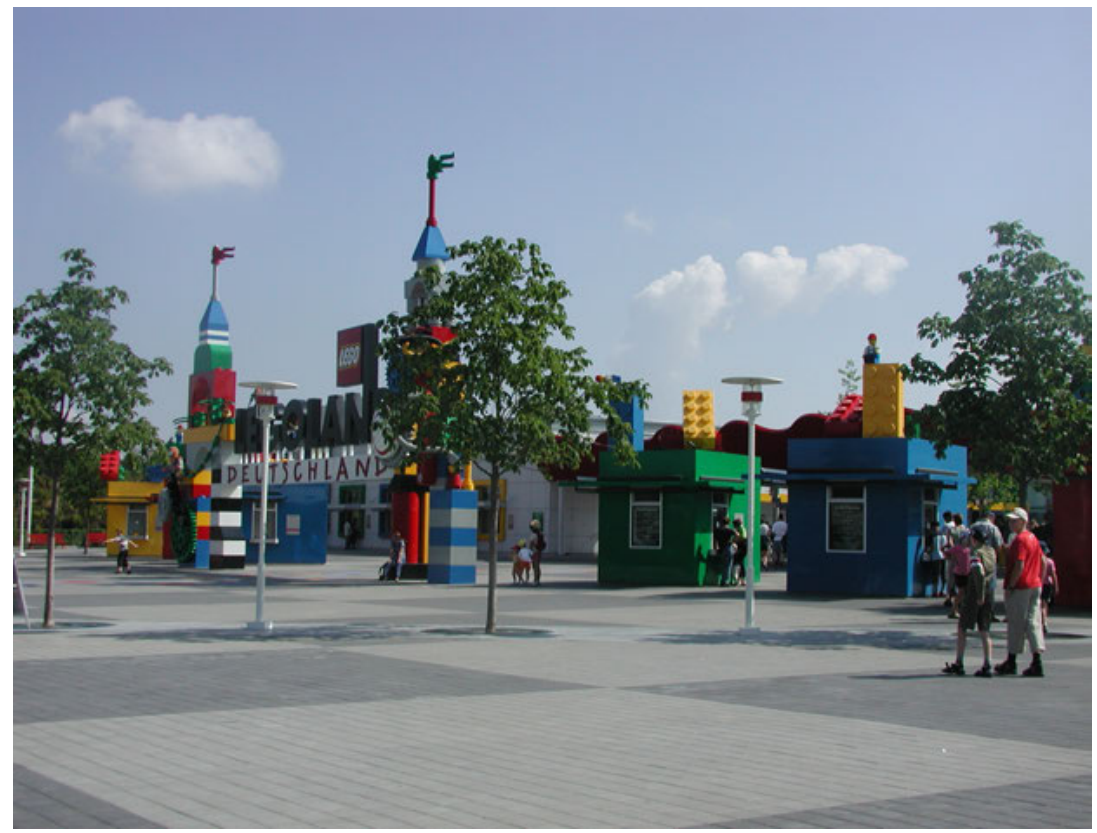

Abbildung 20: Eingangsbereich von LEGOLAND Deutschland. 


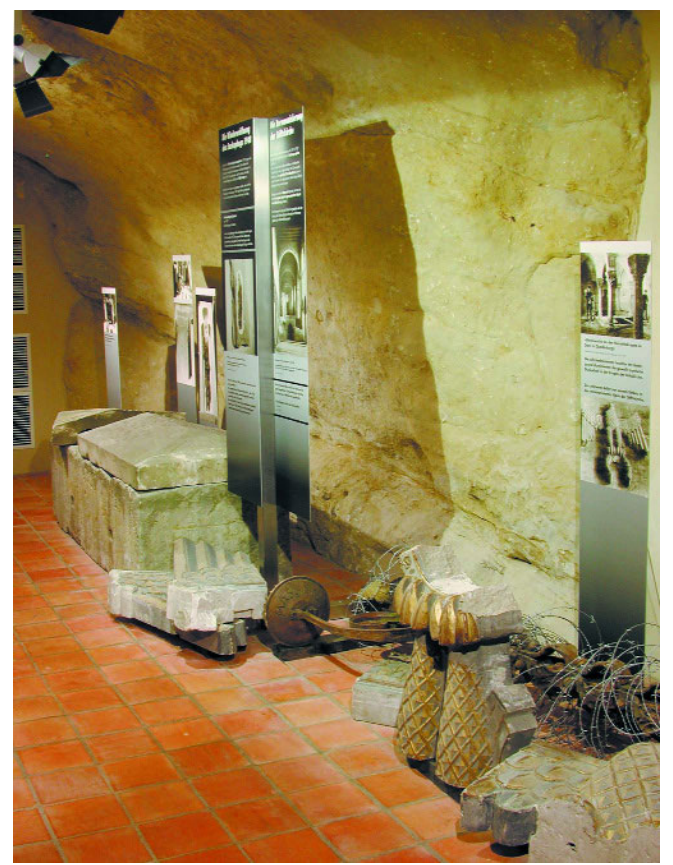

Abbildung 22: Abteilung ,, Geschichte und Propaganda “ in der Ausstellung „Auf den Spuren der Ottonen“.

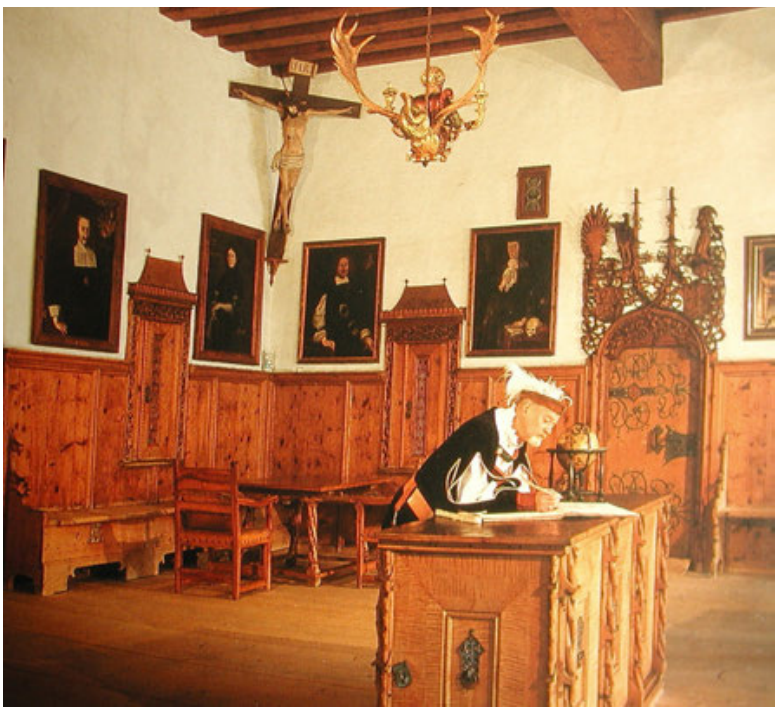

Abbildung 24: Blick in die Fuggerstube im Schloss Tratzberg. 


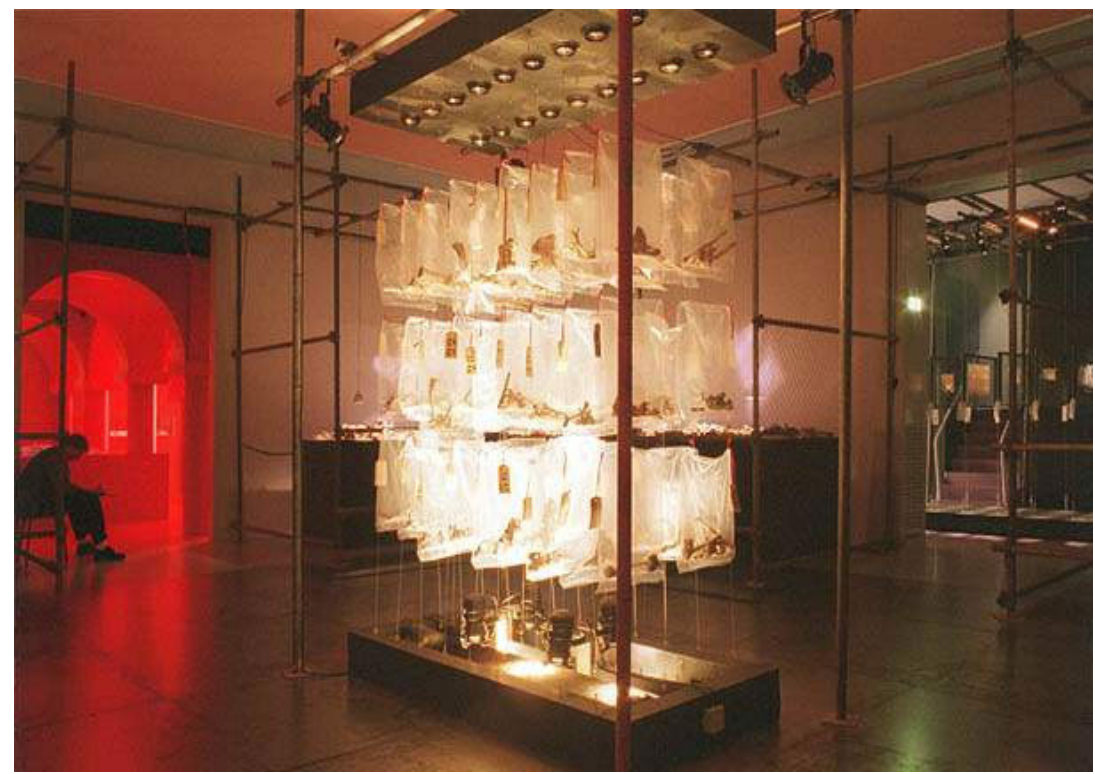

Abbildung 28: Blick in den „Raum der Toten “ in der Ausstellung ,Hell \& Heaven“.

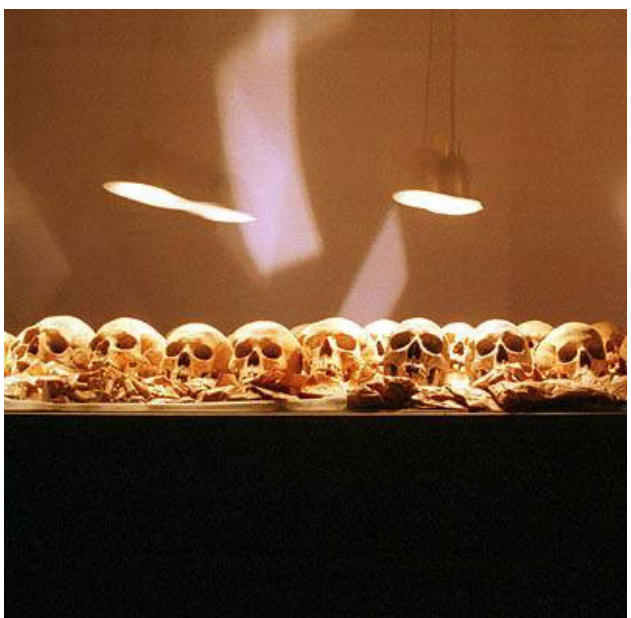

Abbildung 29: Totenschädel von 400 Mönchen aus dem niederländischen Kloster Aduard aufgereiht auf Tischen im „, Raum der Toten“ in der Ausstellung ,Hell \& Heaven“. 


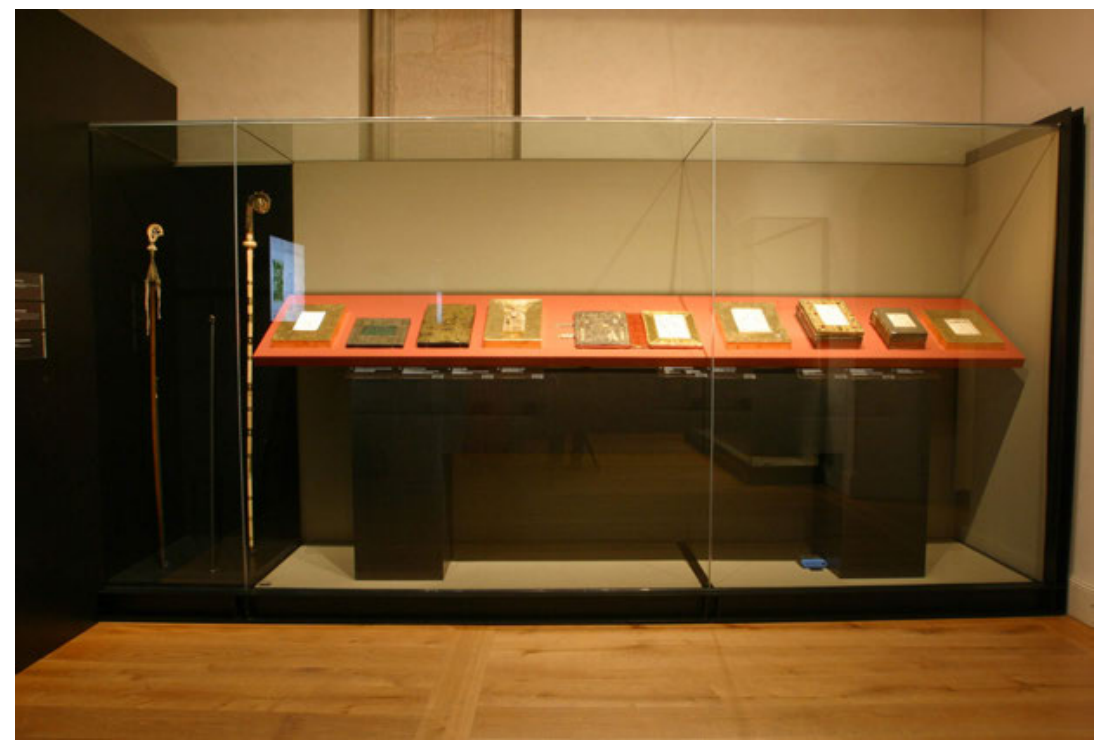

Abbildung 36: Diözesanmuseum/Raum „,Goldener Schmuck“.

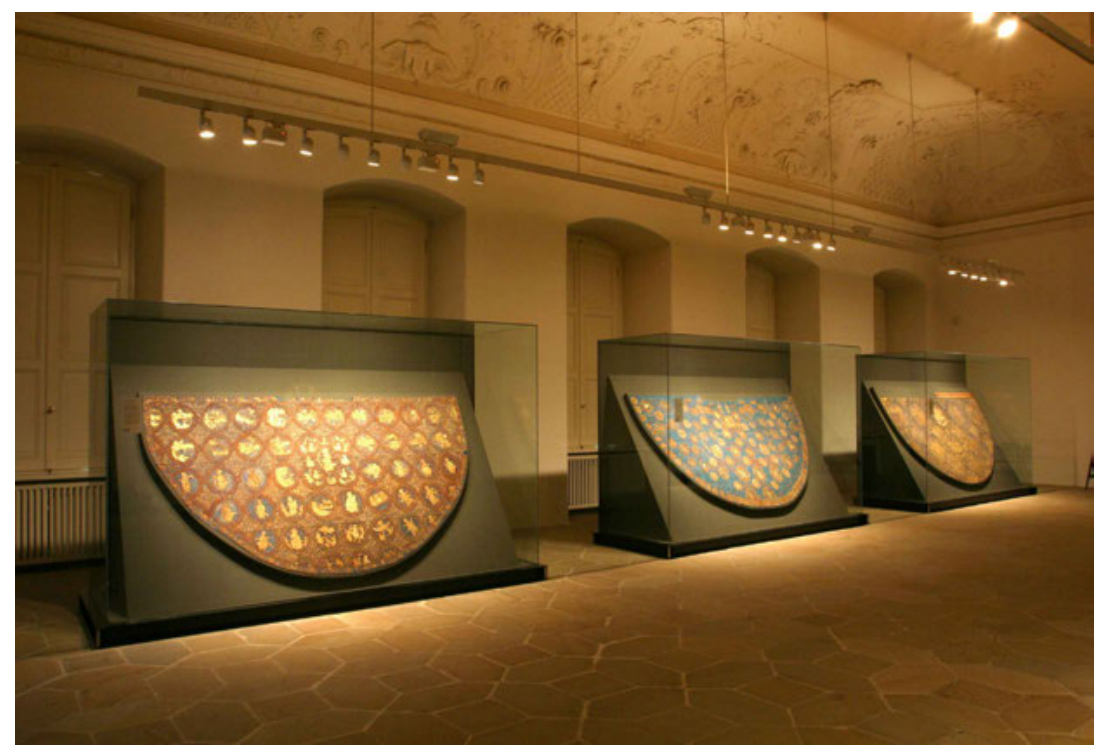

Abbildung 37: Diözesanmuseum/Raum „Die Kaisermäntel“. 


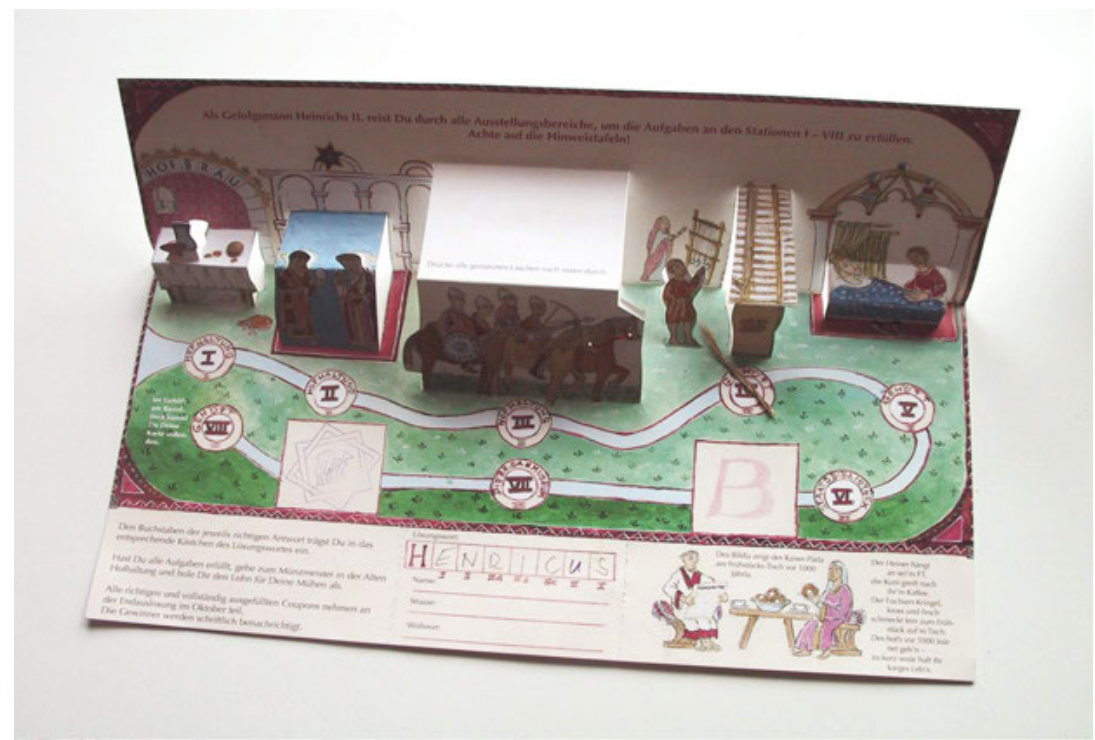

Abbildung 39: Kinderpfad mit insgesamt acht Stationen im Ausstellungsgelände.

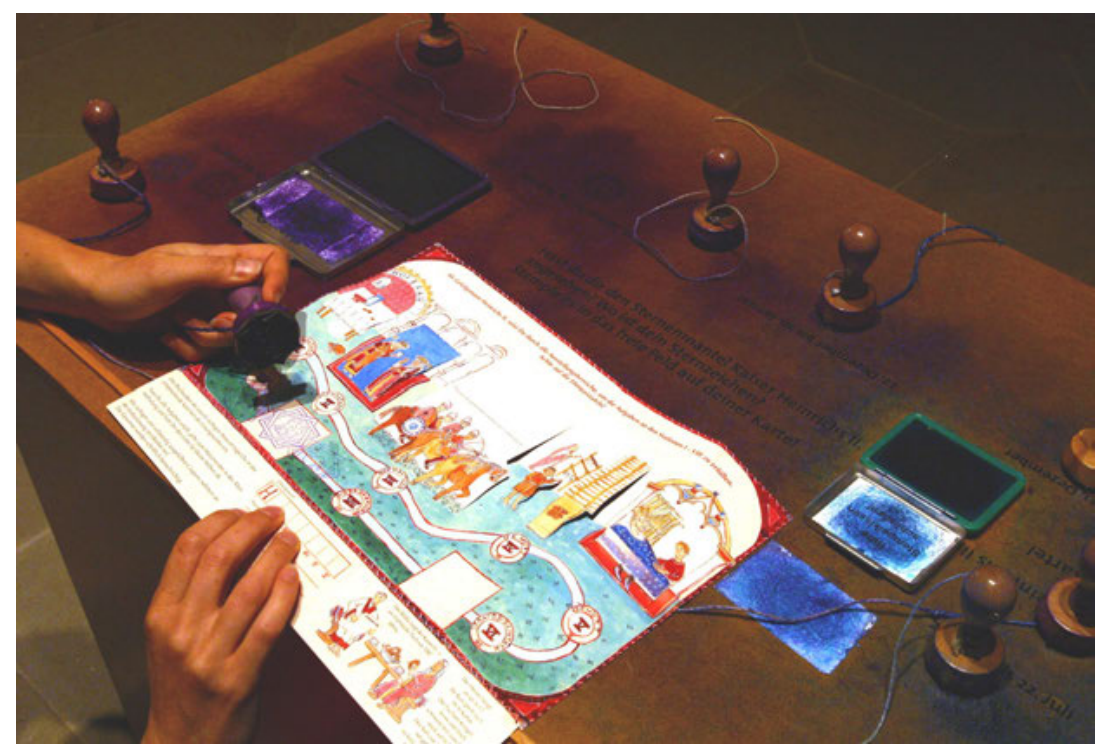

Abbildung 40: Station Nr. 7 des Kinderpfads im Diözesanmuseum: Stempeln des eigenen Sternzeichens. 


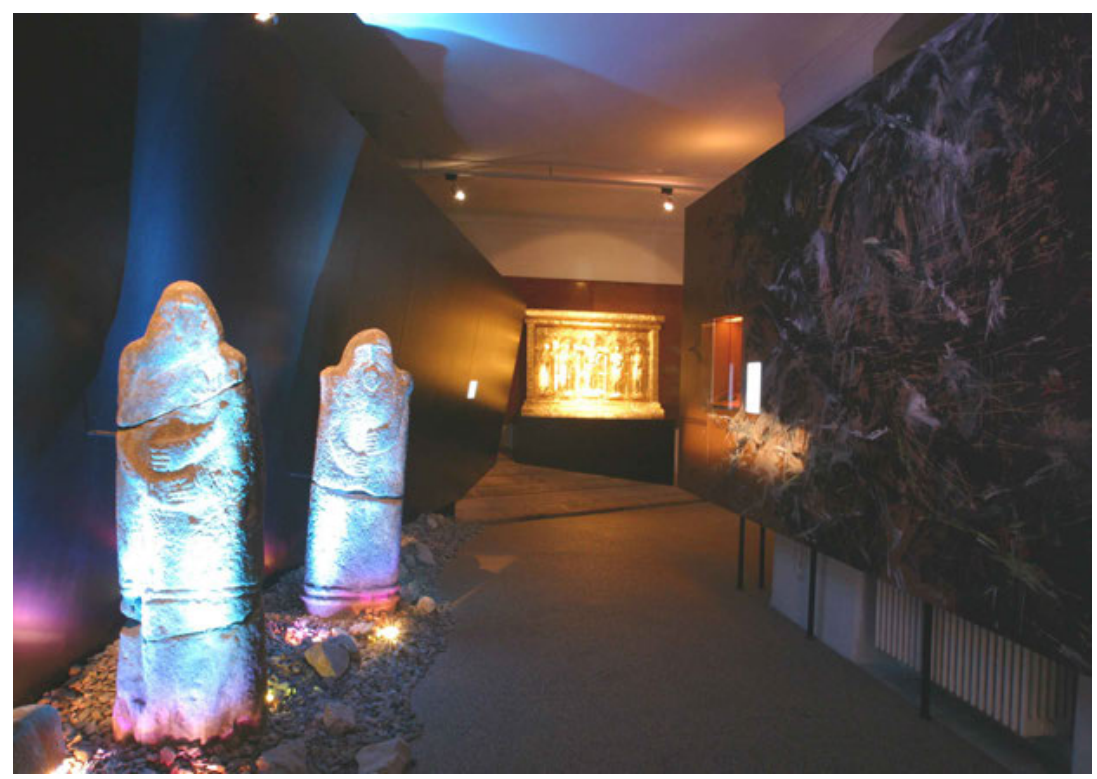

Abbildung 47: Eingangsinszenierung in der Alten Hofhaltung.

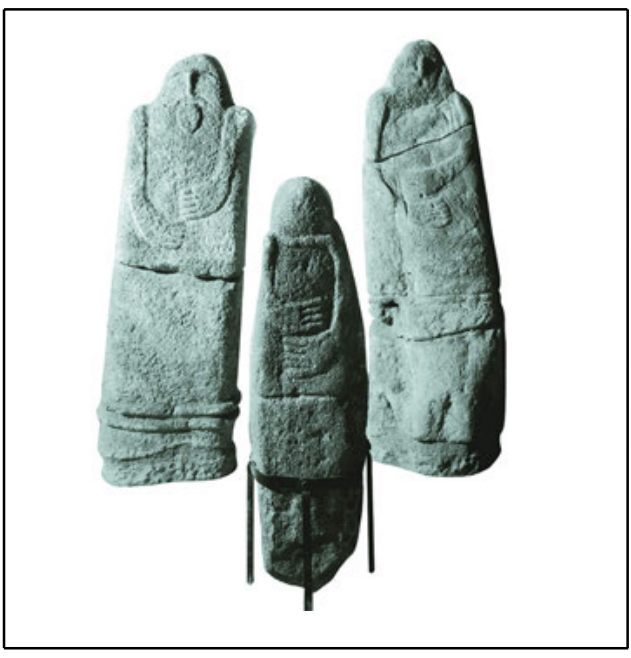

Abbildung 48: Gruppe Anthropomorpher Steinfiguren. 


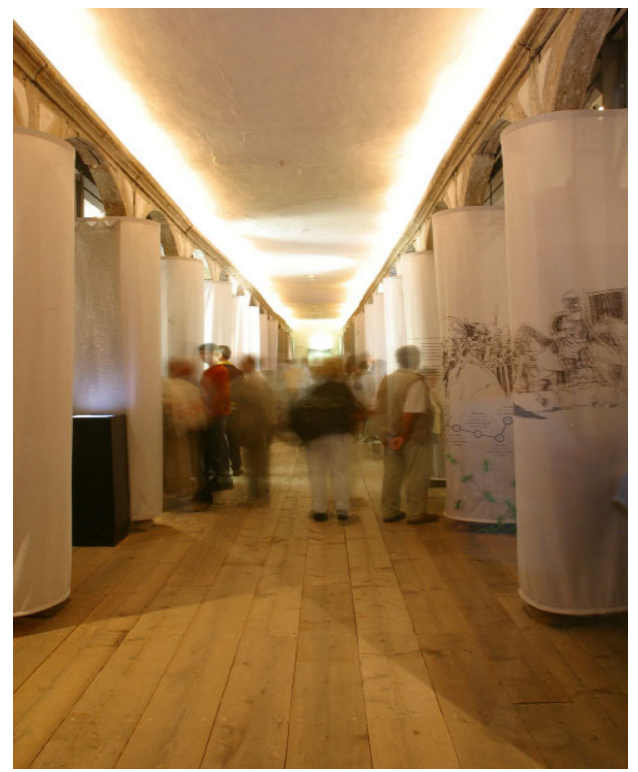

Abbildung 49: Gesamtansicht des letzten Raums im Ausstellungsrundgang durch die Alte Hofhaltung mit dem Thema „Unterwegs im Reich" und ,Erinnerungen“.

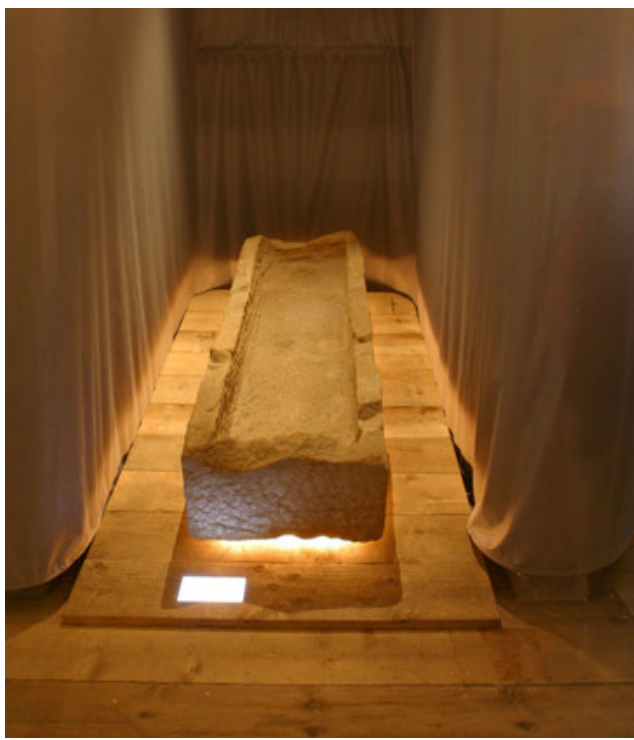

Abbildung 50: Koje: „,Der Sarkophagtrog aus dem Bamberger Dom “. 


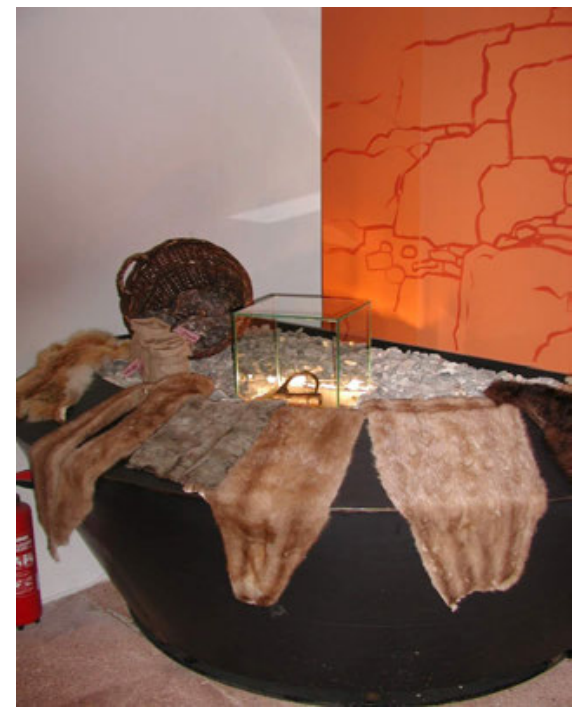

Abbildung 53: Hands-On Angebote zum Thema „Handelswege und Handelswaren “ im Raum „Die Heinriche“.
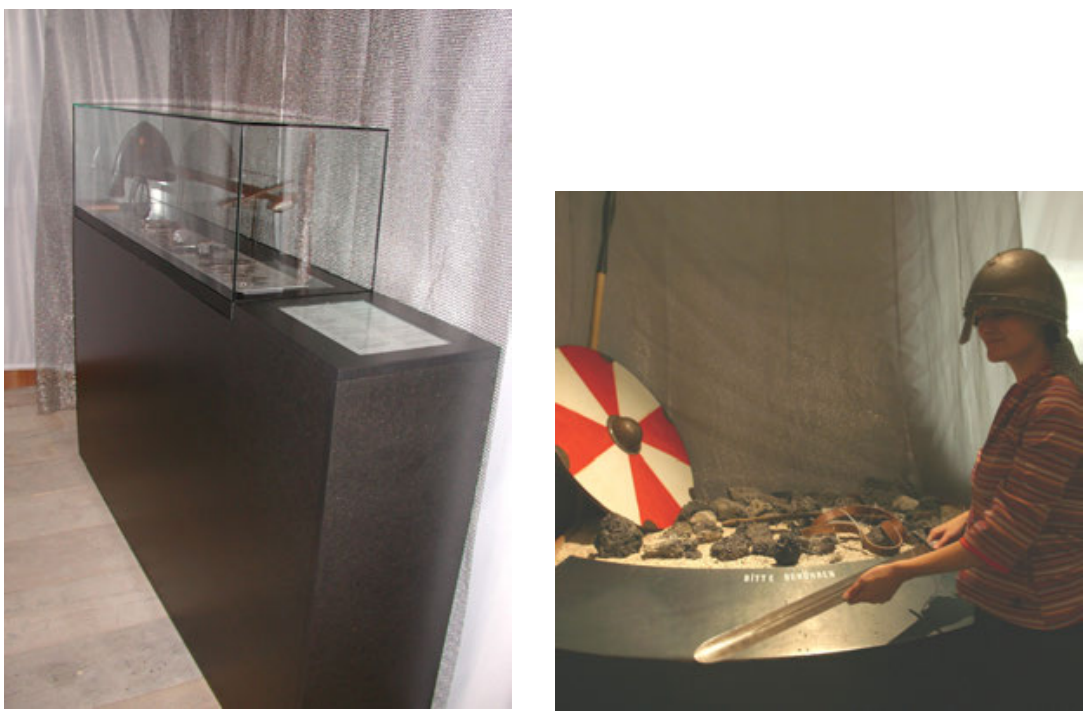

Abbildung 54/55: Hands-On Angebote zum Thema „Reiterkrieger“ im Raum „Unterwegs im Reich“: Eine Koje zeigt neben weiteren Originalen einen Nasalhelm (11./Anfang 12. Jh.) und ein Schwert (frühes 11. Jh.) in einer Vitrine. Die benachbarte Koje bietet einen Nasalhelm zum Aufsetzen und ein Schwert zum Anfassen. 


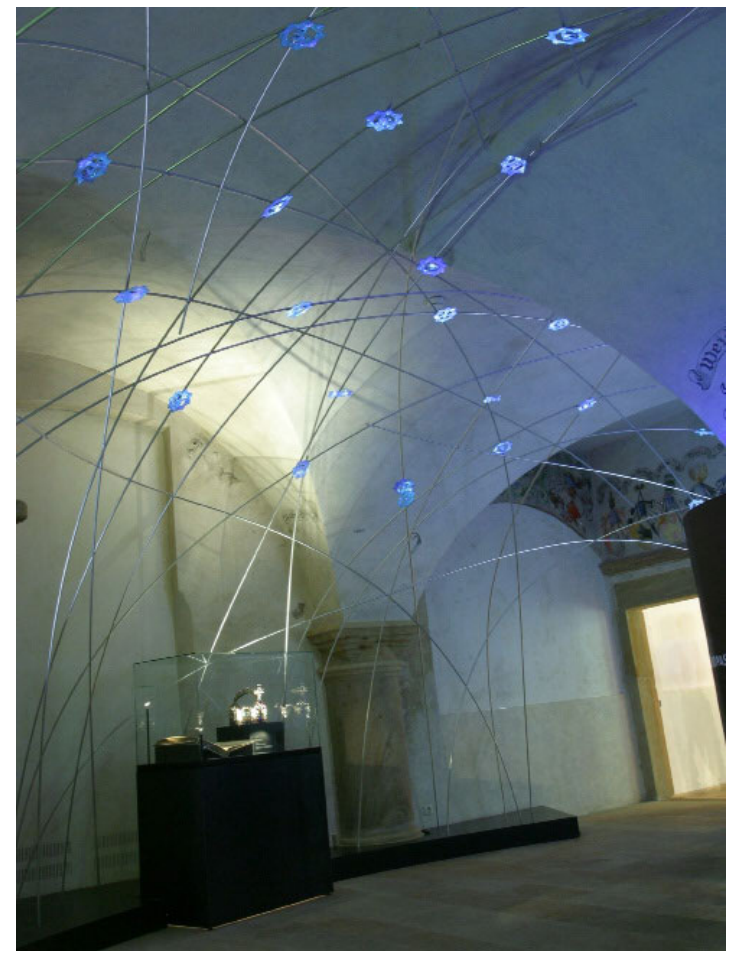

Abbildung 56: Blick in den Raum „Der Kaiser": Kuppel mit Sternmotiven aus dem ,,Sternenmantel Kaiser Heinrichs II. “.

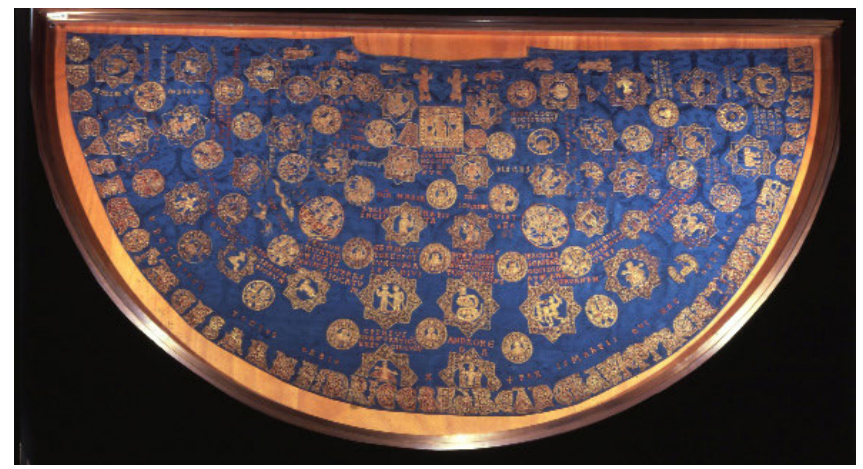

Abbildung 57: ,,Sternenmantel Kaiser Heinrichs II.“ 


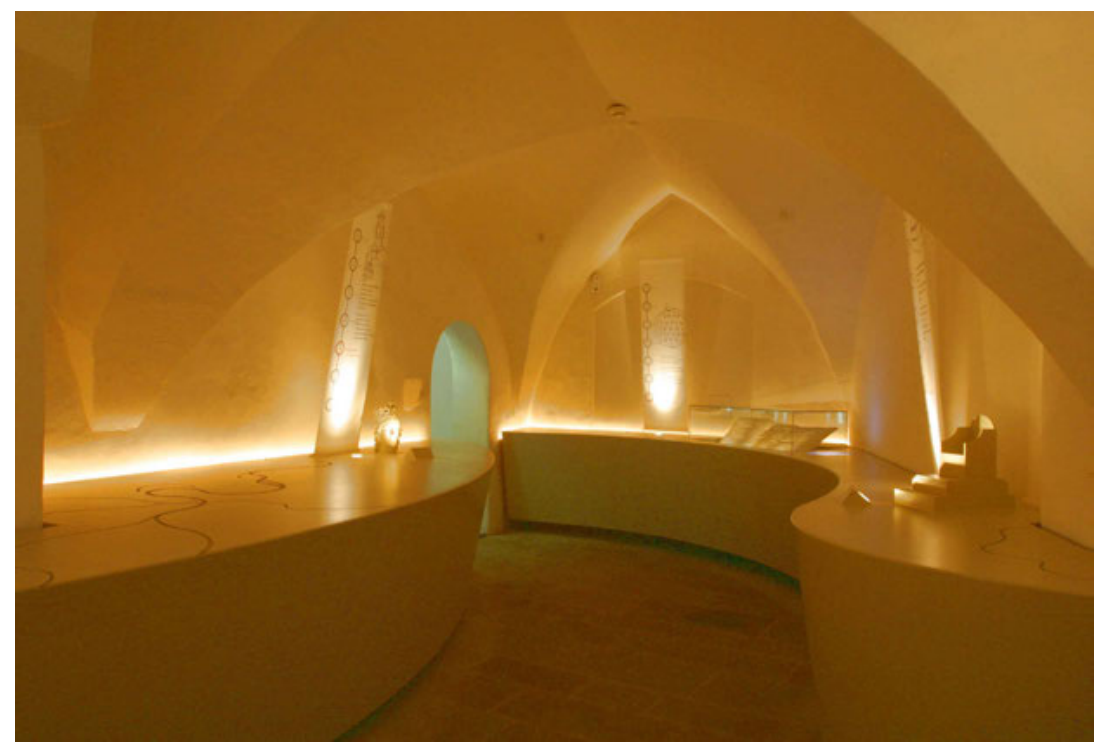

Abbildung 58: Blick in den Raum „Der neue König“ mit sieben Stationen zum Königsumritt.

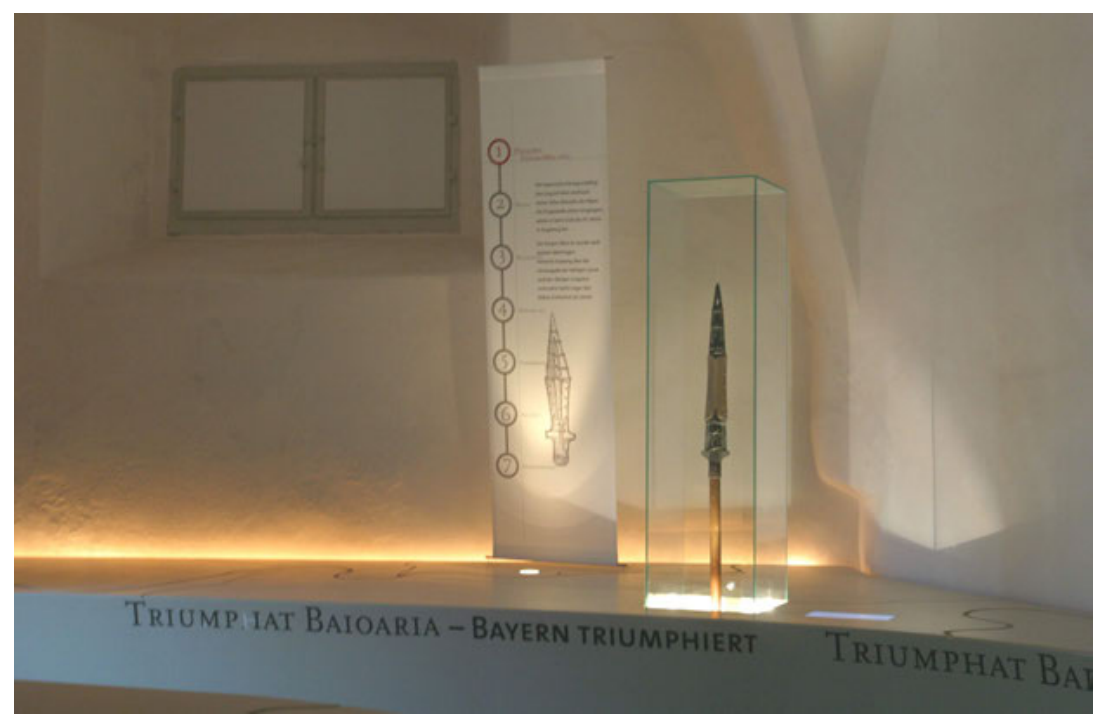

Abbildung 59: Blick auf die Station Nr. 1 in Polling mit dem Exponat "Nachbildung der Heiligen Lanze“, darunter befindet sich an der Vitrine der Titel ,"Triumphat Baioaria - Bayern triumphiert". 


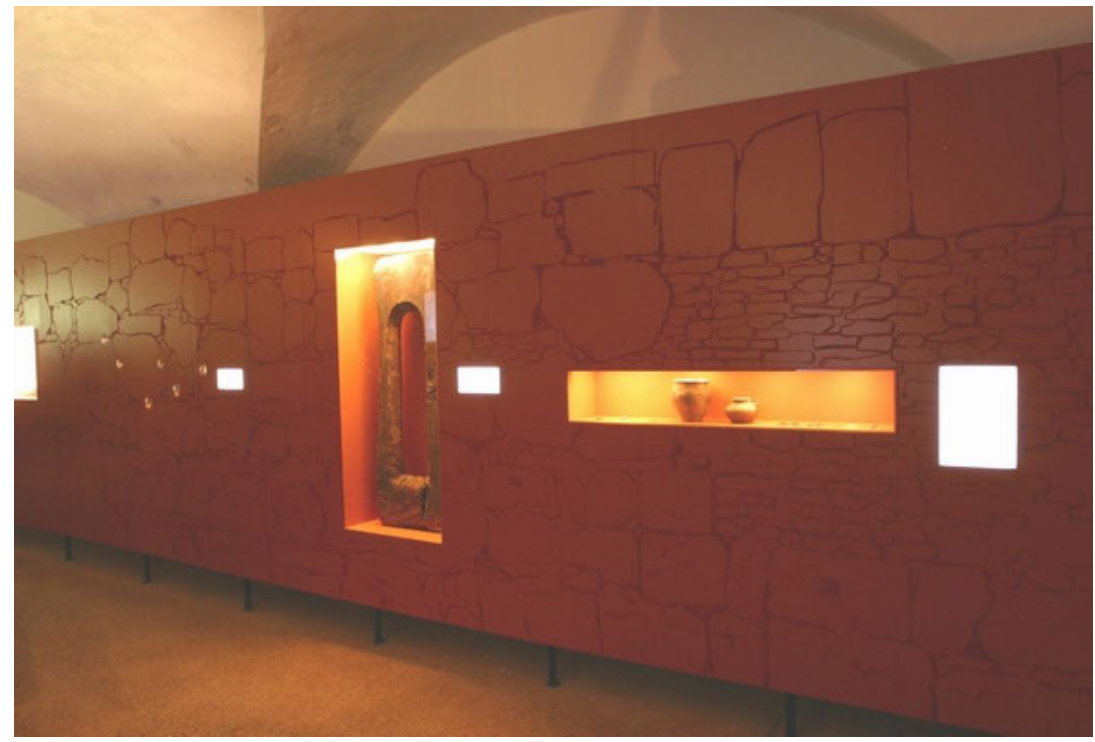

Abbildung 61: Vitrinenwand im Raum „Die Heinriche“, großformatige Exponate im Wechsel mit Kleinfunden.
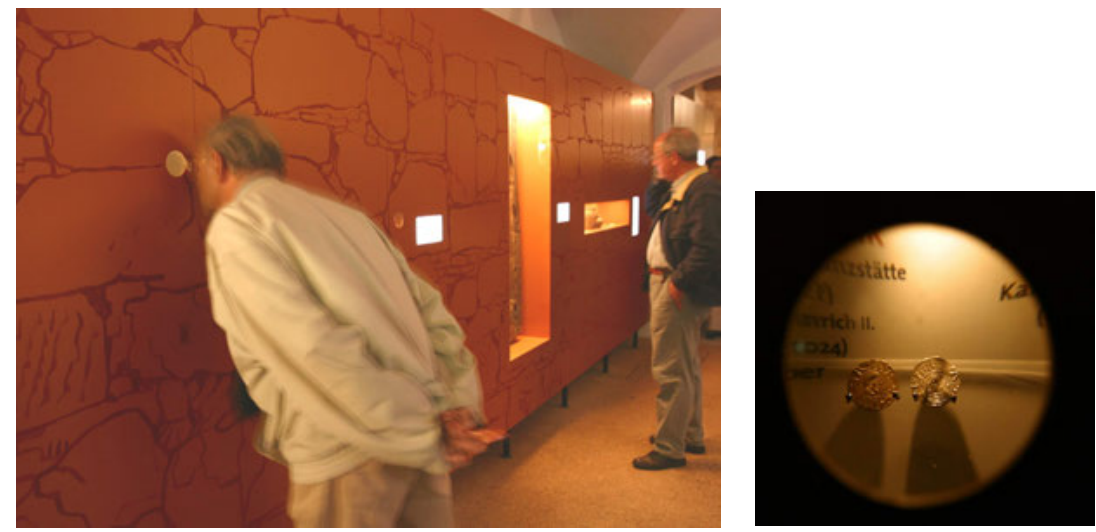

Abbildung 62/63: Münzen aus der Zeit Heinrichs II. hinter Gucklöchern motivieren zum genauen Hinsehen. 

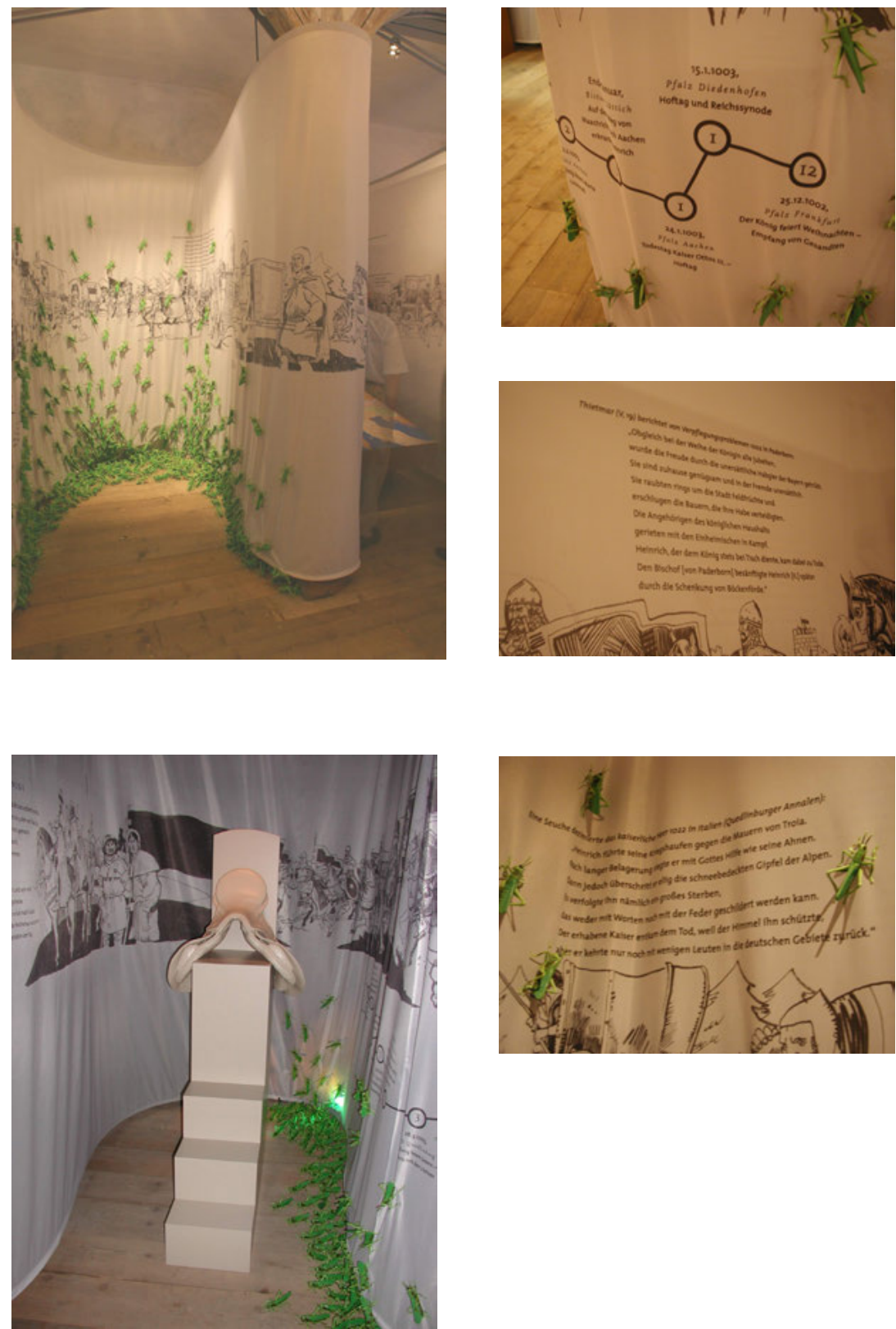

Abbildung 67-71: Inszenierung zum Reisekönigtum

„Heuschreckenplage“ im Raum „Unterwegs im Reich“. 


\section{Weitere Titel dieser Reihe}

Beat Raeber,

Christoph Kehl (Hg.)

Zwischen Null und Eins

Ein Handbuch zur

digitalen Kunst

Juni 2006, ca. 170 Seiten,

kart., ca. $18,80 €$,

ISBN: 3-89942-439-5

Stiftung Niedersachsen (Hg.)

"älter - bunter - weniger"

Die demographische Heraus-

forderung an die Kultur

April 2006, ca. 250 Seiten,

kart., $24,80 €$,

ISBN: 3-89942-505-7

Oliver Scheytt

Kulturstaat Deutschland

Ein kulturpolitisches Plädoyer

April 2006, ca. 200 Seiten,

kart., ca. $21,80 €$,

ISBN: 3-89942-400-X

Sonja Vandenrath

Private Förderung zeitgenössischer Literatur

Eine Bestandsaufnahme

März 2006, ca. 250 Seiten,

kart., ca. $25,80 €$,

ISBN: 3-89942-417-4

Brigitte Kaiser

Inszenierung und Erlebnis

in kulturhistorischen

Ausstellungen

Museale Kommunikation in

kunstpädagogischer

Perspektive

Februar 2006, 448 Seiten,

kart., 32,80 €,

ISBN: $3-89942-452-2$
Lutz Hieber, Stephan Moebius, Karl-Siegbert Rehberg (Hg.)

Kunst im Kulturkampf

Zur Kritik der deutschen

Museumskultur

2005, 210 Seiten,

kart., zahlr. Abb., 24,80 €,

ISBN: 3-89942-372-O

Birgit Mandel (Hg.)

Kulturvermittlung zwischen kultureller Bildung und Kulturmarketing

Eine Profession mit Zukunft

2005, 270 Seiten,

kart., $19,80 €$,

ISBN: 3-89942-399-2

Sabiene Autsch,

Michael Grisko,

Peter Seibert (Hg.)

Atelier und Dichterzimmer in neuen Medienwelten

Zur aktuellen Situation von

Künstler- und Literaturhäusern

2005, 264 Seiten,

kart., 27,80 €,

ISBN: 3-89942-314-3

Udo Liebelt,

Folker Metzger (Hg.)

Vom Geist der Dinge

Das Museum als Forum für

Ethik und Religion

2005, 196 Seiten,

kart., $22,80 €$,

ISBN: 3-89942-398-4

Leseproben und weitere Informationen finden Sie unter: www.transcript-verlag.de 


\section{Weitere Titel dieser Reihe}

Hartmut John,

Ira Mazzoni (Hg.)

Industrie- und Technik-

museen im Wandel

Perspektiven und

Standortbestimmungen

2005, 302 Seiten,

kart., $27,80 €$,

ISBN: 3-89942-268-6

Franziska Puhan-Schulz

Museen und Stadtimage-

bildung

Amsterdam - Frankfurt/Main -

Prag. Ein Vergleich

2005, 342 Seiten,

kart., zahlr. Abb., 27,80 €,

ISBN: 3-89942-360-7

Tiziana Caianiello

Der "Lichtraum (Hommage à Fontana) « und das "Creamcheese« im museum

kunst palast

Zur Musealisierung der

Düsseldorfer Kunstszene der

196oer Jahre

2005, 262 Seiten,

kart., zahlr. Abb., 26,80 €,

ISBN: 3-89942-255-4

Kathrein Weinhold

Selbstmanagement im

Kunstbetrieb

Handbuch für Kunstschaffende

2005, 320 Seiten,

kart., $25,80 €$,

ISBN: 3-89942-144-2
Beatrix Commandeur,

Dorothee Dennert (Hg.)

Event zieht - Inhalt bindet

Besucherorientierung von

Museen auf neuen Wegen

2004, 196 Seiten,

kart., $22,80 €$,

ISBN: 3-89942-253-8

Peter J. Bräunlein (Hg.)

Religion und Museum

Zur visuellen Repräsentation von Religion/en im

öffentlichen Raum

2004, 248 Seiten,

kart., zahlr. Abb., 23,80 €,

ISBN: 3-89942-225-2

Uwe Christian Dech

Aufmerksames Sehen

Konzept einer Audioführung zu ausgewählten Exponaten

2004, 164 Seiten,

kart., zahlr. Abb., 19,80€,

ISBN: 3-89942-226-O

Hartmut John,

Jutta Thinesse-Demel (Hg.)

Lernort Museum -

neu verortet!

Ressourcen für soziale

Integration und individuelle

Entwicklung.

Ein europäisches

Praxishandbuch

2004, 202 Seiten,

kart., $23,80 €$,

ISBN: 3-89942-155-8

Leseproben und weitere Informationen finden Sie unter: www.transcript-verlag.de 